\title{
Seismic II Over I Drop Test Program Results and Interpretation
}

Brian Thomas

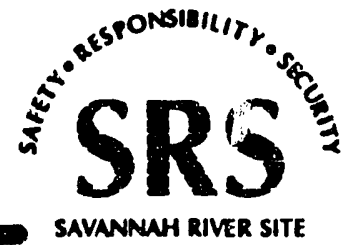

Prepared for the U. S. Department of Energy under Gontract No PE-AC09-89SR18035 
WSRC-TR-93-0094

Revision 0

\section{Seismic II Over I Drop Test Program Results and Interpretation}

Brian Thomas

Westinghouse Savannah River Company

Savannah River Site

Aiken, SC 29808 
WSRC-TR-93-0094

Revision 0

Publication Date: March 1993

\section{Seismic II Over I Drop Test Program Results and Interpretation ${ }^{(\mathrm{U})}$}

Brian Thomas

Approved by:

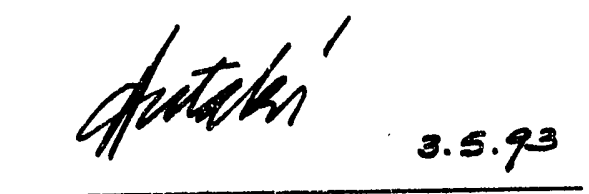

G. A. Antaki

Manager, Systems Structural Analysis

Systems Engineering/Structural Mechanics

Westinghouse Savannah River Company

Savannah River Site

Aiken, SC 29808
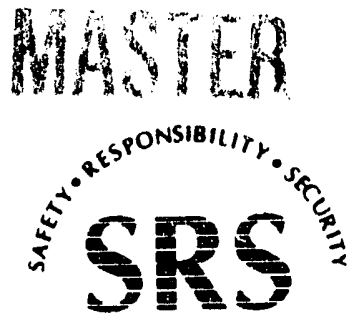

SAVANNAIIRIVER SITE

Prepared for the U. S. Department of Energy under contract No. DE-AC09-89SR18035 


\section{Disclaimer}

This report was prepared as an account of work sponsored by an agency of the United States Government. Neither the United States Government nor any agency thereof, nor any of their employees, makes any warranty, express or implied, or assumes any legal liability or responsibility for the accuracy, completeness, or usefulness of any information, apparatus, product, or process disclosed, or represents that its use would not infringe privately owned rights. Reference herein to any specific commercial product, process, or service by trade name, trademark, manufacturer, or otherwise does not necessarily constitute or imply its endorsement, recommendation, or favoring by the United States Government or any agency thereof. The views and opinions of authors expressed herein do not necessarily state or reflect those of the United States Government or any agency thereof.

Published in cooperation with WSRC Management Information Services Section, Publications Group.

Technical Editor: Amy Phillips 


\begin{abstract}
The consequences of non-seismically qualified (Category II) objects falling and striking essential seismically qualified (Category I) objects has always been a significant, yet analytically difficult problem, particularly in evaluating the potential damage to equipment that may result from earthquakes. Analytical solutions for impact problems are conservative and available for mostly simple configurations. In a nuclear facility, the "sources" and "targets" requiring evaluation are frequently irregular in shape and configuration, making calculations and computer modeling difficult. Few industry or regulatory rules are available on this topic even though it is a source of considerable construction upgrade
\end{abstract} costs.

A drop test program was recently conducted to develop a more accurate understanding of the consequences of seismic interactions. The resulting data can be used as a means to improve the judgment of seismic qualification engineers performing interaction evaluations and to develop realistic design criteria for seismic interactions. Impact tests on various combinations of sources and targets commonly found in one Savannah River Site (SRS) nuclear facility were performed by dropping the sources from various heights onto the targets.

This report summarizes results of the Drop Test Program. Force and acceleration time history data are presented as well as general observations on the overall ruggedness of various targets when subjected to impacts from different types of sources. 


\section{CONTENTS}

\begin{tabular}{|c|c|c|}
\hline Section & Title & \\
\hline & Abstract & \\
\hline 1.0 & Introduction a & Objectives \\
\hline 2.0 & Test Developi & It Considerations \\
\hline & 2.1 & Test Personnel Responsibilities \\
\hline & 2.2 & Selection of Source and Target Combinations \\
\hline & 2.3 & Test Configuration Considerations \\
\hline & 2.4 & Environmental Considerations \\
\hline & 2.5 & Target/Source Combinations for Testing \\
\hline 3.0 & Test Articles & Fixtures \\
\hline 4.0 & Safety Provis & \\
\hline 5.0 & Test Data \& I & umentation \\
\hline & 5.1 & Pre-Test Phase Data \\
\hline & 5.2 & Test Phase Data \\
\hline & 5.3 & Post-Test Data \\
\hline & 5.4 & Discussion of Test Results \\
\hline 6.0 & Conclusions & $\cdot$ \\
\hline 7.0 & Summary & \\
\hline 8.0 & References & \\
\hline
\end{tabular}

\section{List of Figures}

Figure

1

2

3

4
Title

Page

Drop Test Set-Up for Configurations 1, 2, 3, and 5

Target Construction for Configuration $3 \quad 8$

Drop Test Set-Up for Configuration 6

Drop Test Set-Up for Configuration 7 


\section{CONTENTS}

\section{List of Attachments}

\section{Attachment}

1

2

3

4

5

6

7

8

9

10

11

\section{Title}

EES Final Report on the Seismic II/I Drop Test Program

Physical Properties of Targets and Sources

EES Task Quality Assurance Plan for II/I

Drop Test Program

EES Task Technical Plan for II/I Drop Test Program

EES Field Procedure No. FP-351:

"Cabinet Drop Tests-Camera Only"

EES Fielcl Procedure No. FP-370:

"Supported Beam Drop Tests"

EES Field Procedure No. FP-380:

"Aircraft Cable Drop Tests"

EES Field Procedure No. FP-379:

"Instrumented Cabinet Drop Tests"

Photographs of Selected Sources and Targets

EES Test Data Sheets

EES Test Plots 


\subsection{Introduction and Objectives}

The consequences of seismic Category II objects ("sources") falling and interacting with seismic Category I objects ("targets") during an earthquake has always been an analytically difficult problem. These interactions are often referred to as II/I interactions. The wide variety of equipment source and target combinations that exist in any facility adds to this challenge. In addition, the analytical complexities introduced by various structural characteristics, geometric configurations, and impact loads makes it very difficult to predict equipment failure because of II/I interactions by analytical means.

The criteria that govern the evaluation of target and source interactions are based on engineering judgment concerning failure modes that must be both credible and significant.1.2 In an effort to optimize the evaluation of seismic II/I interactions, the Structural Mechanics Section (SM) developed the II/I Drop Test Program. The Equipment Engineering Section (EES) was responsible for all testrelated activities described in Section 2.1.

The main objective of the II/I Drop Test Program was to document, both qualitatively and quantitatively, the significant effects of sources striking targets for the most common target and source combinations found in the reactor areas at the Savannah River Site (SRS). Qualitative results include recorded high-speed photography, still photographs of the impacted area,, and individual test documentation. Quantitative results include force time history plots at the target support points and acceleration time history plots near the impacted area for selected target source combinations. The information obtained from this test program will be used in future evaluations of equipment and in the design of new protective barriers at the Savannah River Site.

\subsection{Test Development}

The development of this test program considered the most commonly occurring types of sources and targets found in the reactor areas at SRS. The ones selected could feasibly be evaluated in a drop test environment under laboratory conditions. The following considerations were addressed in the test program:

$\begin{array}{ll}\text { - } & \text { Test personnel responsibilities } \\ \text { - } & \text { Sources, targets, and combinations selection } \\ \text { - } & \text { Test configurations } \\ \text { - } & \text { Drop heights and drop mode selection } \\ \text { 2.1 } & \text { Test Personnel Responsibilities }\end{array}$

The Equipment Engineering Section (EES) of the Equipment and Materials Technology Department of the
Savannah River Technology Center was responsible for the following activities:

\section{- Design and fabrication of test fixtures \\ - $\quad$ Set-up and operation of the drop test site with quick-release mechanism and target area suitable for impact drop testing of the items described in Section 2.5 \\ - Coordination of video activities with EES video laboratory \\ - Procurement and calibration of load cells and other data acquisition items required for recording drop test energy data. (Refer to Section 5.1 for more information on accelerometers.) \\ - $\quad$ Preparation of a laboratory test plan that met approved SRS quality assurance procedures \\ - Issuance of a final report that included force and acceleration time history plots for each post-test condition of all sources and targets}

The EES organization was selected to perform the drop tests because of its experience in test programs, onsite location, and ability to assist with acquiring and transporting equipment items to be tested. The results are presented in Attachment 1. The location of the Drop Test Program was the Engineering Assistance Building 723-A, located in the lower 700 Area at SRS. Sort yards at SRS had an adequate supply of the test articles that are common in the reactor areas making the test articles more readily accessible and easier to transport to the 700 Arca.

\subsection{Selection of Source and Target Combinations}

Combinations of sources and targets to be tested were selected based primarily on two sources of information:

The main source of information was the Reactor Seismic Improvement Project (S-4605) scoping walkdown data for all L-Reactor systems inspected by the Systems Structural Analysis Group to develop a project conceptual design report (CDR) in the fall of 1991. The scoping effort identified potential II/I interaction hazards. Similar conditions are assumed to exist in $\mathrm{K}$ Reactor.

Another source of information was the field walkdown data for $\mathrm{I} / \mathrm{I}$ interaction hazards for the following Reactor Restart Projects in L Reactor: S430), S43(24, S4306, S4309, and S4315. 
In all cases, the II/I interaction hazard observations were the result of evaluations of credible sources for their ability to withstand a design basis earthquake (DBE). It should be noted that some potential II/I sources were judged to be too complex and costly to evaluate in this report (e.g., un-reinforced block walls) and are outside the scope of this program.

A detailed list of target and source combinations that were tested can be found in Section 2.5. The intention of the test program was that each configuration to be tested should simulate the actual field condition as closely as possible. The test results can then be used to evaluate the significance of these potential credible failure modes.

\subsection{Test Configuration Considerations}

The list of targets and sources in Section 2.5 contains specific requirements based on observations obtained from field walkdowns.

Drop height was based primarily on the fact that, for the reactor areas at SRS, the majority of the II/I interaction hazards occur at levels of the building where the maximum floor to ceiling distance is $20 \mathrm{ft}$ or less. In general, the drop height for a conduit or light fixture falling on a floor-mounted electrical cabinet will not normally exceed $10 \mathrm{ft}$. For each configuration tested, drop tests were performed from various heights (example $-1 \mathrm{ft}$, $5 \mathrm{ft}, 15 \mathrm{ft}$ ) to demonstrate the effects of increasing impact loads on the target. Some source/target combinations were tested twice under the same conditions as a check for consistency.

The orientation of the source striking the target and the point of impact along the length of the target was occasionally varied. It was of interest to sce how a change in either of these parameters affected the magnitude of the impact loads. The decision of what angle of impact to use in the test is based on a judgment. However, the intent is not to test every condition that can theoretically occur, but rather to test conditions that are likely to occur during an carthquake.

Some targets such as pipe sections have two supports at a certain span length spacing. The support span length for these targets was limited to approximaicly $7 \mathrm{ft}$ because of the physical limitations of the test facility.

This limitation may require that this data be extrapolated to be able to compare it with longer spans sometimes found in the field.

\subsection{Environmental Considerations}

The objects included in this test program, with the exceptions of the ceiling panels and wallboard, were all constructed of steel. The temperature range that they would normally experience in the field is relatively small, from $40^{\circ} \mathrm{F}$ to about $120^{\circ} \mathrm{F}$. In this temperature range, steel properties remain fairly constant and were therefore not a consideration. The tests were performed at ambient conditions.

Significant irradiation results in increased yield stresses but reduced ductility. ${ }^{3}$ Most of the II/I interaction hazards identified from recent field walkdowns were not in high radiation areas. For the purposes of this project, the effects of irradiation were judged to be negligible.

Humidity is not considered to have any adverse effect on steel other than rust, which may result from extended periods of exposure. Since evaluation walkdowns include a separate assessment of material condition caused by external corrosion, rust is not a consideration for this test program.

The test facility is subject to controlled temperature conditions and was considered to be adequate in all respects for this test program. Many of the objects tested in this program had been previously used in the reactor areas. Some of the objects exhibited signs of wear. The wear was actually judged to be desirable because it more closely simulated actual field conditions.

\subsection{Target and Source Combinations for Testing}

The following information was intended to define specific target and source combinations along with any other details required for the Drop Test Program. High-speed and still photographs were recorded to help characterize the consequences of the impacts sustained. The configuration numbers listed below were not intended to prioritize the tests.

A review of the attached test data sheets for each of the targets reveals that not all of the sources were dropped from the entire range of heights listed for that particular target. In fact, for some targets tested, one or more of the sources may not have been dropped at all. As testing progressed, decisions were made as to which drops would be of most value to the overall test program. Refer to Attachment 2 for detailed information regarding target and source physical properties:

\section{TARGET:}

Conduit, 3/4-inch diameter, simply supported with an approximate span of 7 it (Sec Figure 1.)

\section{SOURCES:}

a. $2 \mathrm{ft} \times 3 \mathrm{ft}$ piece of $1 / 4$-inch wallboard

b. light fixtures (fluorescent \& incandescent)

c. ceiling pancl

d. 3/4-inch diameter concluit

TYPE OF DROP:

Free fall from heights between 1 it and $15 \mathrm{ft}$ 
INSTRUMENTATION:

Load cells at target support points

2. TARGET:

Conduit, 2-inch diameter, same configuration as Item 1 above

SOURCES:

a. 6-inch diameter pipe

b. fluorescent light fixture

c. duct

\section{TYPE OF DROP:}

Free fall from heights between $1 \mathrm{ft}$ and $15 \mathrm{ft}$

INSTRUMENTATION:

Same as Item 1

3. TARGET:

Two pieces of T.S. $5 \times 5 \times 3 / 8$ joined together side by side that use the same configuration as Item 1 except that span is $4 \mathrm{ft}$ (See Figure 2.)

\section{SOURCES:}

a. 6-inch diameter pipe (drop heights from 1 inch to 12 inches only)

b. duct

c. $2 \mathrm{ft} \times 3 \mathrm{ft}$ piece of $1 / 4$-inch wallboard

d. 3/4-inch diameter conduit

e. light fixtures (fluorescent \& incandescent)

\section{TYPE OF DROP:}

Free fall from heights between $1 \mathrm{ft}$ and $15 \mathrm{ft}$

INSTRUMENTATION:

Same as Item 1

4. TARGET:

Electrical equipment cabinet 26 inches $\times 30$ inches $\times 7 \mathrm{ft} 6$ inches. Relay(s) mounted in cabinet and monitored for chatter.

SOURCES:

a. $2 \mathrm{ft} \times 4 \mathrm{ft}$ ceiling tile

b. $2 \mathrm{ft} \times 3 \mathrm{ft}$ piece of 1/4-inch wallboard

c. 3/4-inch diameter conduit

d. light fixtures (fluorescent \& incandescent)

TYPE OF DROP:

Same as Item 1 except that maximum drop height is $8 \mathrm{ft}$

\section{INSTRUMENTATION:}

Accelerometer mounted near relay as well as electrical monitoring devices that can check for relay chatter.

\section{TARGET:}

Duct, 24 inches $\times 24$ inches $\times 8 \mathrm{ft}$ long, same configuration as Item 1

\section{SOURCES:}

a. cable tray

b. duct

c. pipe, 6-inch diameter

d. conduit, 2 -inch diameter

TYPE OF DROP:

Same as Item 1 except that maximum drop height is $12 \mathrm{ft}$

INSTRUMENTATION:

Same as Item 1

6. TARGET:

Aircraft cable as shown in Figure 3

SOURCES:

a. cable tray

b. duct

c. 6-inch diameter pipe

d. 2-inch diameter conduit

TYPE OF DROP:

Same as Item 1 except the maximum drop height is $8 \mathrm{ft}$

INSTRUMENTATION:

Same as Item 1

7. TARGET:

Emergency lighting battery pack enclosure as shown in Figure 4

SOURCES:

a. light fixtures, fluorescent and incandescent

b. ceiling panel, $2 \mathrm{ft} \times 4 \mathrm{ft}$

c. conduit, 3/4-inch diameter

d. $2 \mathrm{ft} \times 3 \mathrm{ft}$ piece of $1 / 4$-inch wallboard

TYPE OF DROP:

Same as Item 1 except that maximum drop height is $12 \mathrm{ft}$

INSTRUMENTATION:

Electrical monitoring devices that can check for relay chatter

8. TARGET:

Electrical cabinets attached to floor mounted unistrut frame

SOURCES:

a. light fixtures, fluorescent and incandescent

b. 3/4-inch diameter conduit 
TYPE OF DROP

Same as Item 1 except that maximum drop height is $20 \mathrm{ft}$

\section{INSTRUMENTATION}

None

\subsection{Test Articles and Fixtures}

Test fixtures were designed and fabricated as required. Shop fabrication drawings of all test fixtures are maintained in EES Job Folder No. 22116.

A crane used to lift the sources, along with a holding and release mechanism, was supplied by EES as part of the test equipment. The high bay area located in Building 723 . $A$ is outfitted with a steel pad (approximately $4 \mathrm{ft} \times 4 \mathrm{ft}$ ) in the floor at the impact location.

All articles used in the test program, with the exception of the electrical cabinet of Configuration No. 4 , were to be disposed of as salvage material at the conclusion of the test.

\subsection{Safety Provisions}

All safety-related activities associated with the Drop Test Program were conducted under the control of the EES Group. Examples of activities in the safety category are definition of exclusion area boundaries, erection of protective barriers, and definition of minimum number of personnel required in the vicinity of the drop tests.

\subsection{Test Data and Instrumentation}

The requirements described in the following pre-test, test, and post-test data sections conform to the EES- approved task quality assurance plan (Attachment 3) and task technical plan (Attachment 4). In addition, each of the eight configurations listed in Section 2.5 belongs to one of four different EES field procedures (Attachments 5 through 8 ) that were created for this test program. Each procedure outlines in detail the requirements and procedures associated with its particular category of drop test.

\subsection{Pre-Test Phase Data}

The instrumentation required for each of the test configurations has been summarized in Section 2.5. Load cells, when specified, were located at the target support points. The accelerometers used in Configuration No. 4 were located on the target near the location of the electrical relays. For the purposes of this test, the accelerometer readings were for information only, thereby negating the need for re-calibration. The calibration of all load cells was in accordance with Savannah River Technology Center (SR'TC) quality assurance procedures.
Other activities included in the pre-test data phase included recording weights, dimensions, and physical characteristics of both target and source. Photographs of these assemblies were also obtained. Refer to Attachment 9 for photographs of selected sources and targets and Attachment 2 for detailed physical information of items tested. In addition, information such as vendor data, shop fabrication drawings, and memos have been maintained in the II/I Drop Test File in the custody of the Systems Structural Analysis Group (Structural Mechanics Section).

Photographic equipment was positioned under direction of the EES test representative to capture the impact area. Although every attempt was made to capture all tests on film, some of the tests were not filmed because of operational problems with the video equipment.

\subsection{Test Phase Data}

The following types of data were obtained during the tests:

$\begin{array}{ll}\text { - } & \text { acceleration data } \\ \text { - } & \text { load data } \\ \text { - } & \text { visual data } \\ \text { general observations }\end{array}$

The accelerometers specified in Configuration No. 4 were placed on the target between the two relays to gather vertical acceleration time history data.

Load cells, when used, were positioned at target support points and used to gather force time history data for vertical loads.

Visual data was from high-speed photography, which showed the last few feet of the fall of the source, the impact, and the rebound of the source after impact. General observations were noted or sketched to document unique circumstances or results assnciated with a particular test.

\subsection{Post-Test Data}

Included in the post-test data were examinations and measurements describing the final condition and configuration of both source and target. Examples of things that were noted were broken welds, local deformations, and joint or connection failures. These observations were documented on the test data sheets (Attachment 10). Still photographs were also selectively laken.

The acceleration and force time history information was processed on EES-supplied data acquisition equipment to produce a hard copy record to use in post-test evaluations. These information sources can be found in the Altachment 11. 
The high-speed photography data was transferred to standard video tape i? ?uipment (i.e., 30 "frames" per second) to provide a slow-motion picture of the impact of the source and target. This vas done for most of the source and target combinations tested. The resulting video tapes have been stored in the Seismic II over I Crop Test project file.

\subsection{Discussion of Test Results}

This section discusses the test results and provides guidance on how to interpret the data sheets shown in Attachment 10 and plots contained in : ittachment 11 .

To fully understand of the test results, read the EES final test report (Attachment 1). This report not only provides the point of view of the Equipment Engineering Section, but also contains useful information concerning any anomalies observed during the course of testing. Some, but not all, of these anomalies are also mentioned on individua! test data sheets. For example, one important topic mentioned is negative readings (loads) on some plots. Because some of the amplifiers were not reset following some tests, the subsequent testing did not always start with a reading of zero. For these tests, the peak load should be taken as the maximum load shown on the plot plus the starting negative value.

The individual test data sheets of Attachment 10 are taken from one of four field procedures issued by the EES Group. The list at the front of Attachment 10 identifies the procedure number, source, target, and drop height for each test case. The four EES field procedures (sce Attachments 5 through 8 ) provide detailed information on test set-ups, data acquisition equipment, and test procedures. Additional detailed information regarding physical characteristics of the sources and targets is contained in Altachment 2.

To aid in the test data interpretation, it is suggested that the data sheets and plots be reviewed in conjunction with the slo": motion video. Much can be learned from this method of review. It should be noted that the "High Speed Video Start \& Stop Position" listed on the data sheets is the reading of the count meter on the video machine if the machine has been re-zeroed before advancing the tape. The "Time" block on the data sheets refers to real time. It corresponds to the time listed on the border of the screen on the actual slow motion video.

One of the most important observations obtained from the test program is that the orientation of the source as it strikes the target largely determines the magnitude of forces at the target support points. If the source was skewed just slightly as it struck the target, the resulting forces were significantly reduced. As expected, glancing blows produced smaller loads. Energy appeared to have been uset up by rotation of the source and flexing of the source at time of impact. Even under controlled test conditions, it was difficult to obtain a truly solid impact.
This leads one to consider feasible angles of impact when reviewing potential concerns in the field. In many cases, only a glancing blow would be possible because of obstructions from other objects. The obstructions should result in significantly lower impact loads.

Because of equipment difficulties, a few of the plots contained in Attachment 11 are believed to be inaccurate. Notes were made on the data sheets whenever a problem with the data acquisition equipment was encountered. This is an indication that the corresponding plot may be incorrect.

The "Target Damage" and "Source Damage" blocks on the data sheets will sometimes report "NONE" when the accompanying video does, in fact, show damage. This report of "NONE" should be taken to mean "no additional damage" because some of the sources and targets were used multiple times. The sources may have sustained damage from a previous test but no new damage from the test in question. This method of testing can lead to some inaccuracies because permanent deformation from a previous test can lead to strain hardening and stress redistribution that can affect the results of subsequent tests. For the purposes of this test program, these inaccuracies could be tolerated because the objective was to find general trends in data and not exact plots that could be reproduced exactly by analytical methods

\section{General Trends}

As expected, the stiffness of the targets and sources had a tremendous effect on the magnitude of the peak impact loads. Although it is intuitive to most engineers that two rigid objects impacting each other will have much higher loads than two flexible objects impacting each other, the plots and accompanying video footage of many of the drops assist in "calibrating" the engineer's judgment as to how dramatic the differences can be.

In general, objects tested (both targets and sources) werc more rugged than one would have intuitively reasoned before seeing the objects tested. This impression may be due in part to the fact that most engineering reviews of systems and components are done primarily by using elastic analysis methods. Engineers are familiar with the low allowable limits that accompany these types of methods. The ability of an object to deform plastically and redistribute stresses truly elevates its ultimate capacity. This fact was brought out clearly in these tests.

\section{Specific Trends Listed by Target}

\section{Small Electrical Cabinets (Tests IA through 7A)}

- Cabinet outer case was extremely durable when imp-ated by small to medium-sized objec!s. (It was hard to put even a small dent in the sabinet.) 
- It appeared as though only sensitive relays in a cabinet such as the ones tested would be a concern.

- The disconnect switches mounted in the cabinet were not energized during the tests.

Continuity and megger checks were performed after the tests. The disconnect switches housed inside appeared fine.

\section{Emergency Light Battery Pack (Tests 8A through 17A)}

- The metal enclosure, although only 18-gage construction, held up surprisingly well. It offered good overall protection to the batteries and electrical components inside.

- The Potter \& Brumfield relay mounted in the cabinet never malfunctioned. It did become loose in Test 11A, but this was the fourth impact to the cabinet without rechecking the relay's installation. On subsequent more severe tests, the relay remained tight. For this reason, it was concluded that the relay was probably loose at the beginning of the tests. It would appear to be a good idea, however, to periodically check the tightness of the relays in existing installations to ensure that they have not loosened up for any reason.

3/4-Inch IMC Conduit (Tests 1 through 8 and Tests 22 through 24)

- As expected, the conduit formed a plastic hinge at the point of impact when struck by objects of even moderate kinetic energy. It was concluded that sources larger than the conduit should probably only be allowed to strike the conduit if dropped from only a short distance, say of $1 \mathrm{ft}$ or less.

- One interesting observation regarding this small conduit was that even when the conduit was deformed substantially because of fairly large impacts, a collapse of the conduit wall was never observed. Although the conduits were cmpty during testing, it is believed that the samples tested would have remained functional

\section{2-Inch IMC Conduit (Tests 9 through 14)}

- The larger conduit performed in a manner similar to the 3/4-inch conduit except that it was obviously much stronger. Again, the conduit wall never collapsed from any impacts in the test program. Even the 6-inch pipe and heavy duct left only a slight dent in the conduit wall, and that was after striking the conduit hard enough to deform it several inches at mid-span.

\section{HVF. $=$ Duct (Tests 15 through 21)}

- Local collapse of the duct at the point of impact and at the support points effectively absorbed much of the energy im 'arted from the source.

- The "pocket lock" joint, which was intentionally fabricated at the mid-span of the duct, was shown to be rugged. This type of joint is one commonly used at SRS. Howeve: it was noted that when the joint started to open up (after several impacts from heavy objects), it took little additional impact load for the joint to completely fail. It was concluded that a field walkdown of HVAC ducts should verify that the joints are in good shape (i.e., tight joints).

\section{Barricade Assembly (Tests 25 through 54)}

- $\quad$ This stiff, tube steel structure recorded peak support loads that were of high magnitude but of very short duration. Although this condition was anticipated, the design of this type of protective barricr is usually unduly conservative because of the specified design loads. This represents an area for additional study. One approach would be to design the barrier with lower stiffness properties so that it can use strain energy as a means to absorb the impact energy.

\section{Aircraft Cable (Tests 55 through 77)}

- The cable, in general, worked well for two main reasons. First, it seemed to absorb energy well and kept peak loads to a minimum when struck by various objects. Secondly, it appeared to be durable and resistant to cutting from sharp edges.

- The safety cable appears to have good potential in future safety upgrades because it is cheap and often the easiest thing to install when faced with space limitations in the field.

Electrical Equipment Cabinet With Relays (Tests 78 through 105)

- The so-called "Bad Actor" relay was a poor performer. Even small impacts to the cabinet resulted in significant chatter of the relay.

- On the ocher hand, the seismically rugged Potter \& Brumfield relay perfomed nawlessly. Heavy impacts to the cabinet 
(often exceeding $10 \mathrm{~g}$ 's) did not cause the relay chatter even slightly. The cabinet itself also held up well, sustaining only minor dents to the top after sustaining almest 30 impacts from various sources.

- The exceptional performance of the Potter \& Brumfield relay has resulted in consideration of future relay tests on other "seismically rugged" relays. If additional tests to other seismically rugged relays yield similar results, the traditional practice of precluding all potential impacts may be relaxed to allow cabinet interactions from small objects such as ceiling tile, light fixtures. or sprinkler heads.

\subsection{Conclusions}

The detailed account of specific test results and trends given in Section 5.4 serves to guide the reader through an interpretation of the test results. When the data sheets in Attaciment 10 and plots in Attachment 11 are used in conjunction with the available slow motion video tapes, insight is gained of the consequences of seismically induced interaction hazards.

The integration of the data in this report into seismic interaction criteria has not yet been completed. The test data are currently being studied further and will form the basis for future seismic interaction evaluation criteria at Savannah River Site.

\subsection{Summary}

By developing the experience data of these and other impact effects, the test program results will help to enhance the basis for engineering judgment with regard to seismic interaction hazards commonly found in SRS facilities. This will help the seismic qualification engineers to focus upgrade considerations only on interaction hazards that are both credible and significant.

In addition, existing seismic interaction evaluation criteria will be updated to include improved methods for estimating impact effects.

These two areas of improvement represent a potential to achieve significant cost savings by reducing the evaluation time needed to perform the reviews. Mr importantly, the number of support upgrades needed to prevent or lessen the effects of seismically induced impacts should be reduced.

A video has been produced to summarize this test program and it can be obtained through the WSRC Systems Structural Analysis Group at SRS.

\subsection{References}

1. SRS Procedure SEP-6, "Procedure for the Seismic Evaluation of SRS Reactor Systems Using Experience Data".

2. SKS Standard T-020-R, "Evaluation of Seismic Spatial Interactions from Non-Seismic Category Structures, Systems and Components".

3. "Response of Metals to High Velocity Deformation", Metallurgical Society Confarences, Volume 9, Interscience Publishers, Inc., New York, New York (1961), p.51. 


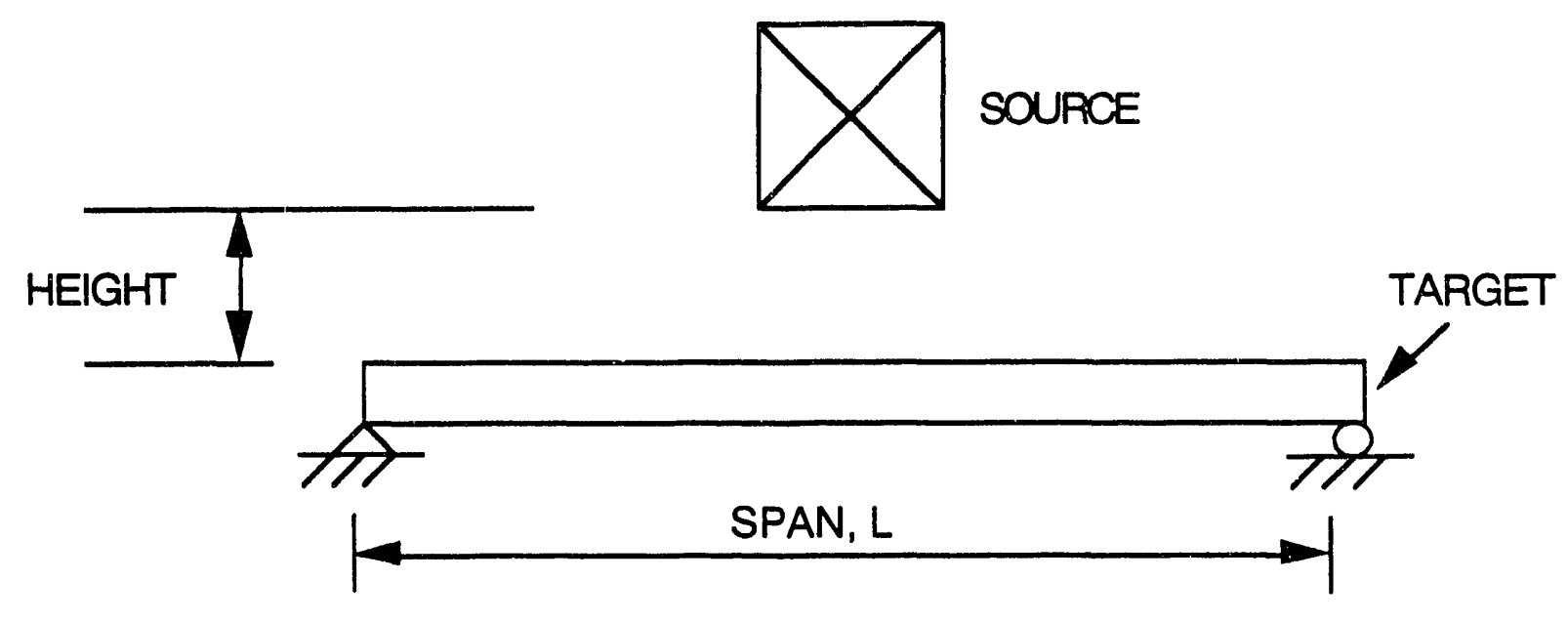

FIGURE 1.

Drop Test Set-Up for Configurations 1, 2, 3 \&5

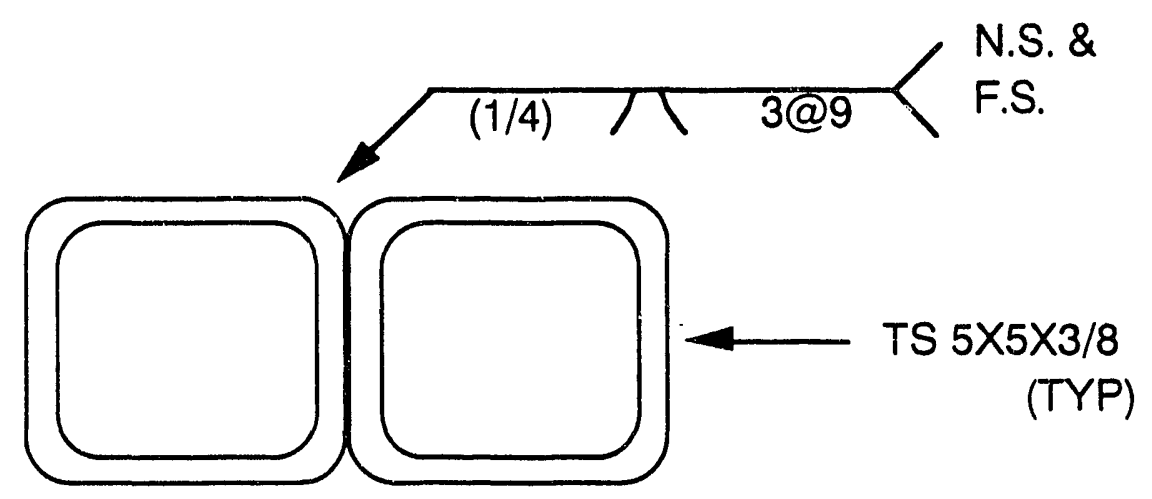

FIGURE 2.

Target Construction for Configuration 3 


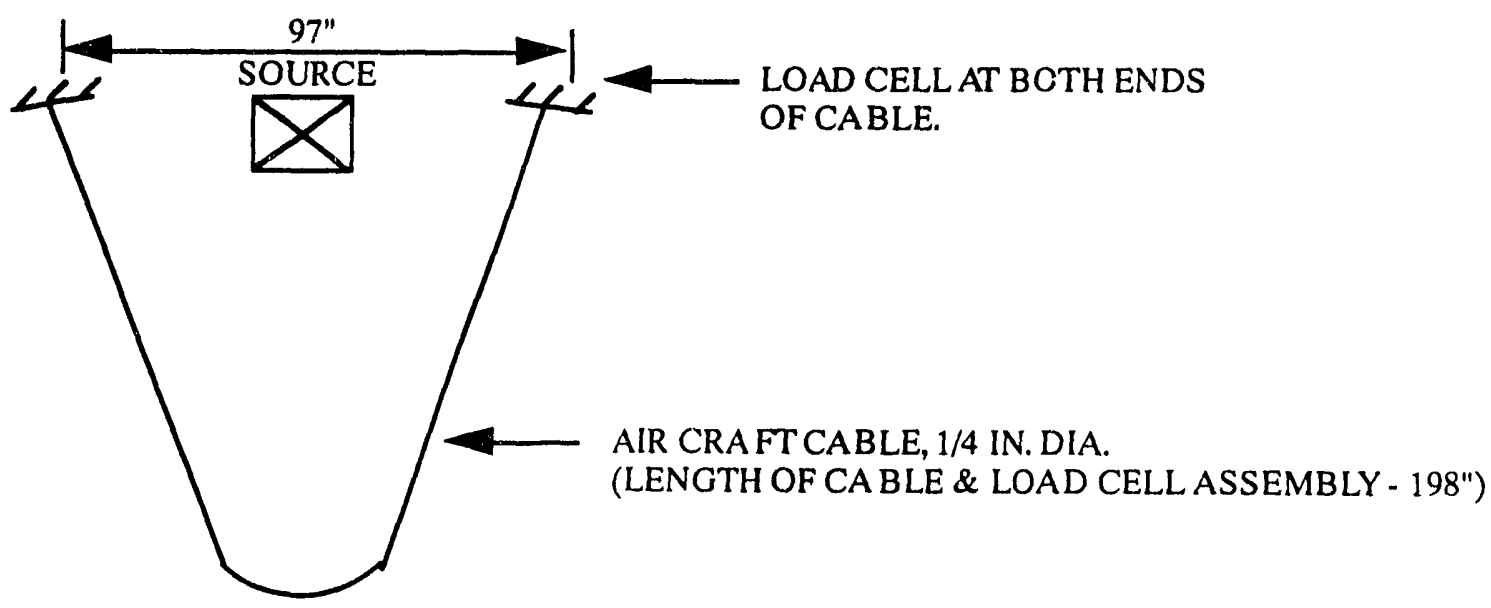

FIGURE 3.

Drop Test Set-Up for Configuration 6

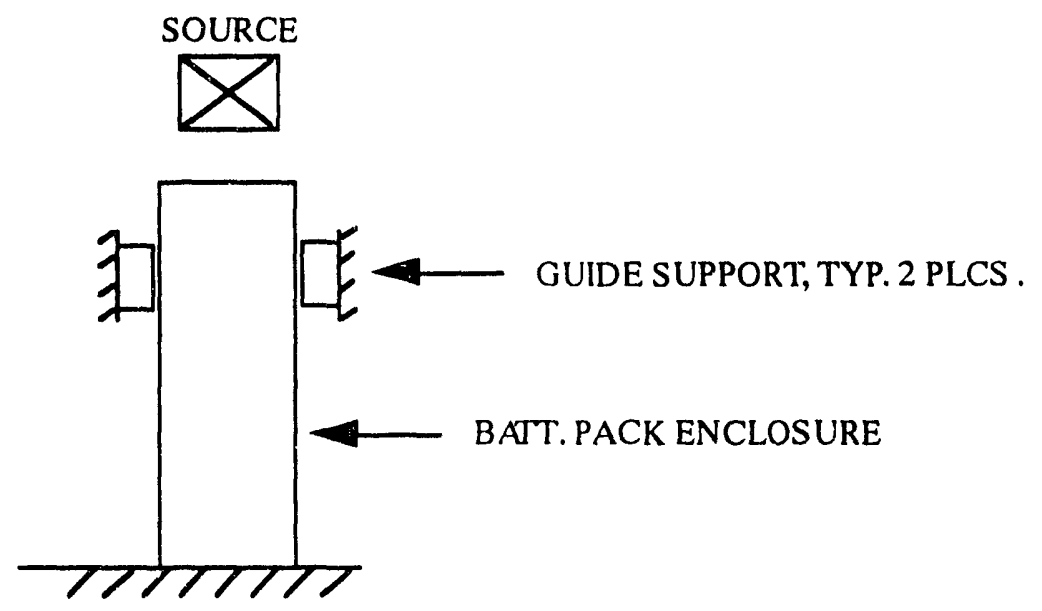

FIGURE 4.

Drop Test Set-Up for Configration 7 
Attachment 1. EES Final Report on Seismic II/I Drop Test Program (1 of 10)

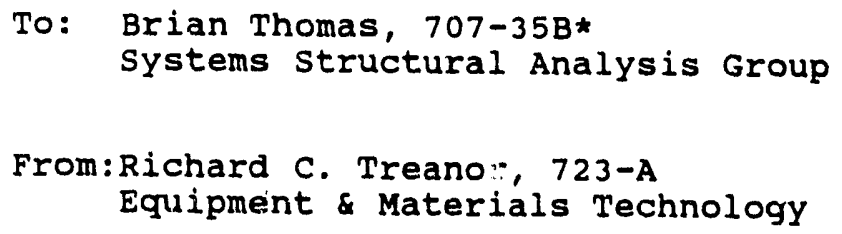

December 1, 1992

\title{
Seismic II/I Drop Test Program: Final Report
}

\begin{abstract}
Attached please $f$ ind the final report that documents the seismic II/I Drop Test program which was conducted by E\&MT for the systems structural Analysis Group. This report brings to a close, the testing that was conducted over the past several months. I hope that your expectations of the testing have been fulfilled. We enjoyed doing the work and have gained valuable knowledge in the area of seismic testing. I will be closing out the job folder over the next several weeks. If for any reason you have a question or problem, do not hesitate to contact us.
\end{abstract}

CC: Tom J. French, 730-A

Don Pak, 723-A

Mark T. Ferencz, 723-A

Kevin M. Rehberger, 723-A

EES DCC, *

* with Data Sheets

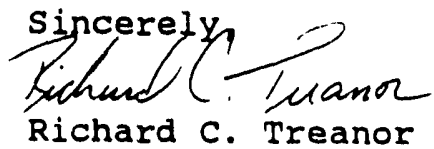


Attachment 1. EES Final Report on Seismic II/I Drop Test Program (2 of 10)

\section{BEIBMIC II/I DROP TEST PROGRAM}

\section{FINAL REPORT}

\section{CONDUCTED}

BY

\section{EQOIPMENT \& MATERIALB TECHNOLOGY}

ROR

SYSTEMS STRUCTURAL ANALYBIB GROOP 
Attachment 1. EES Final Report on Seismic II/I Drop Test Program (3 of 10)

Gavannah River Technology Center Beismic II/I Drop Test Report $12 / 1 / 92$

Page 2

\section{INTRODUCTION}

The Systems Structural Analysis Group requested Equipment \& Materials Technology to conduct several drop tests to help quantify the impact characteristics of seismic category II commodities that may fall and strike seismic category I commodities during a seismic event. A seismic category I item can be defined as a structure, system, or component (SSC) which must continue to perform its required function during and after a seismic event. A seismic category II item is synonymous with "non-seismic" Cat I items. The cat I \& II drop items can be located in the Reactor areas of the Savannah River site. The drop test program has been termed the seismic II/I Drop Test Program and will be referred to as such throughout the documentation.

The Sejsmir. II/I Drop Test Program was broken up into four distinct phases of testing. Each of those phases will be discussed in detail later in this report. The intent of this report and the data acquired from testing is to help the systems structural Analysis Group better understand the physical interactions that can occur during a seismic event. The ability to quantify loads for certain impacts is vastly improved through physical testing than any theoretical or mathematical simulation. However, when dealing with such a broad scope of testing, it is impossible to mock-up or simulate every situation that may occur during a seismic event. Therefore, it was decided to use commonly found items from the Reactor areas of Category II/I ratings that had a potential to be a source or target.

The seismic category II commodities were that were dropped were " :erred to as the "source". Various sources used were lighr fixtures, cable trays, ducts, wallboard sections, ceiling panels, etc. Seismic category I commodities were referred to as the "target" and were the object the "source" was impacting when dropped. Various targets were conduit, duct, barricade, etc. The sources were dropped from various heights and these heights were concurrent with a probable height as found in the field. For example, a light fixture was not dropped any higher than 20 feet because that is not a probable scenario as found in the field. Many of the drops and elevations were based on the results of a prior test.

The results of the data were not intended to qualify certain equipment. The data shall provide a baseline for comparison of seismic II/I impacts in order to gather valuable information that can be used to increase SRS 
Attachment 1. EES Final Report on Seismic II/I Drop Test Program (4 of 10)

Gavannah River Technology Center seismic II/I Drop Test Report $12 / 1 / 92$

Rage 3

engineers' awareness in evaluating seismic interaction hazards. No drop tests of this type have ever been performed in the past.

\section{TEST EOUIPYENT E PACIIITY}

\section{EES 723-A High Bay}

All drops were conducted in the 723-A High Bay facility. The High Bay of $723-\mathrm{A}$ is a Drop Testing Facility which uses a $6.25^{\prime \prime}$ thick armor plate steel slab approximately $5 \times 5$ feet square imbedded in reinforced concrete as the base of the drop pad. A Bux-Shrader CE-7R electromagnet with 1200 lbs capacity gave the ability to drop an object upon command.

\section{KISTLER Piezoelectric Load cells}

The load cells were selected for their accuracy, reliability, and their ability to measure dynamic loads. The load cells use highly accurate quartz disks which, when loaded, produce an electrical charge. This electrical charge output is directly proportional to the force imposed. The charge is collected by an electrode in the load cell and is fed to a plug on the outer housing of the load cell. From the plug, a cable feeds the electrical charge to an amplifier that converts the electrostatic charge to a proportional voltage.

Four different models of load cells were used in the testing. Three of the load cells were the single component type which only measure a compressive force. Load cell models 9001, 9021A, and 9041A were selected for the ranges of loads that were expected to be measured; their ranges were $0-1,650 \mathrm{lbs}, 0-7,850 \mathrm{lbs}$, and $0-20,200 \mathrm{lbs}$ respectively. A larger range results in a decrease of accuracy in the lower ranges of the scale. For example, if a load of 200 lbs was measured by the Model $9041 \mathrm{~A}$ load cell which has $a+/-1$ if linearity associated with its full range scale, the $9041 \mathrm{~A}$ accuracy range is $+/-202$ lbs which makes it impractical in measuring the low end forces.

\section{KISTLER 5004 Dual Mode Charge Amplifier}

This device converts the electrostatic charge generated by the load cell into a proportional voltage. The amplifier has twelve ranges and is calibrated in mechanical units per volt with adjustment for the load cell sensitivity. LEDs
I 
Attachment 1. EES Final Report on Seismic I1/I Drop Test Program (5 of 10)

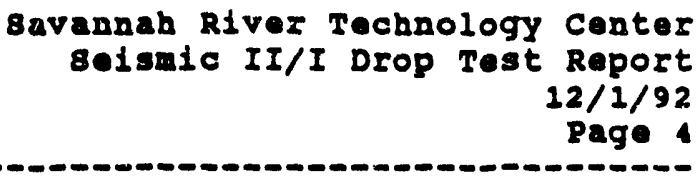

are used to display an overload condition of the amplifier and the proper operation mode.

\section{Kodak Extapro 1000 Motion Analyzer}

This motion analyzer (more frequently referred to as a high speed camera) was used to capture the interactions of the source and target in slow-motion. The high-speed camera was hooked directly to a standard VCR for immediate transfer of the video image from the high-speed video tape to a standard 3/4" video format.

\section{wilcoxin Accelerometer}

The accelerometer used in the Instrumented Cabinet Drop Tests (FP-379) measured the $G$ forces applied to the cabinet when impacted by various objects. This accelerometer was of the piezoelectric type. The accelerometer had a measuring sensitivity of $94.88 \mathrm{mv} / \mathrm{g}$. In conjunction with the accelerometer, a Wilcoxin Research Model PR 710 amplifier was used to amplify the output signal.

\section{Sony/Tektronix RTD 710A D uitizer}

The Digitizer was used to sample and store the output voltages from the 5004 Amplifier, accelerometers, and relays. The Digitizer converted the analog voltage signal and stored to a digitized form of that processed signal. The Digitizer had the ability to sample at the rate of 100 ns. The Digitizer also had an oscilloscope that allowed instant viewing of the output signal.

\section{PHABEs of TESTINC}

The Seismic II/I Drop Test Program was broken up into four phases. The following are a brief description of the phases of testing.

Drops were chosen as a result of several walkdowns in the Reactor areas. From these walkdowns, several potential scenarios were developed as potential seismic hazards. The most commonly occurring source and target combinations were used in the test program. The four categories consisted of: 
Attachment 1. EES Final Report on Seismic II/I Drop Test Program (6 of 10)

Gavannah River Technology Center Beiamic II/I Drop Test Report $12 / 1 / 92$

Page 5

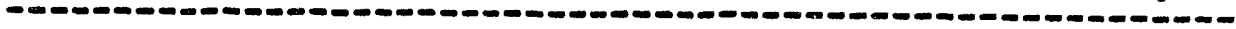

PFAsE 1 Cabinot Drop roata (EEB-Field Procodure: Fp-351) These tests were designed to help determine fallure modes during a seismic event that may occur to an Emergency Lighting Battery Pack and Electrical Cabinet attached to a unistrut frame. These tests were documented using the high speed camera.

PHABE 2 8upported Bean Drop Tests (EE8-Field Procedure: FP-370) These tests were used to measure the reaction forces on a simple supported beam. Four different objects were used as a simple supported beam: $3 / 4 "$ and 2 "electrical conduits, 24" $\times 24$ " $\times 22$ gage duct, and a barricade type assembly. These objects were set up in a simple supported beam configuration with load cells at each end of the beam.

PHA8E 3 Aircraft Cable Drop Tests (EE8-Field Procedure: PP-380) These tests were performed to measure the reaction forces that may occur on cable supports when various objects are dropped onto a span of the cable. A $1 / 4$ " aircraft cable was spanned across the I beam supports of the High Bay, and various objects were dropped on it. The tension was measured in the line by using

compression/tensile load cells.

\section{PHASE 4 Instrumented Cabinet Drop Tests (EEs-pield} Procedure: FP-379) This test was designed to determine the effects that seismic events may have on relays mounted in equipment cabinets. The tests specifically looked at the effects on Westinghouse and Potter Brumfield relays.

For more details on each of the four test phases listed above, refer to the respective EES Field Procedure.

\section{TEST RESULTS:}

Test results have been documented in the form of individual data sheets for each and every drop test performed. Plots of forces, acceleration, and relay voltages, all with respect to time, have also been documented for the appropriate test cases. The 3/4" video tape recordings have been linked to the individual tests by listing the tape recordings start and stop times on each test data sheet. In addition to the data acquisition and high speed video, still photographs were taken to document the test equipment, test set-ups, and drop objects.

In some of the tests, we experienced high frequency noise in the output voltage response. We believe this is due to the cables, typical coaxial cables have capacitances 
Attachment 1. EES Final Report on Seismic II/I Drop Test Program (7 of 10)

Bavannah River Technology Center seismic II/I Drop Test Report $12 / 1 / 92$

Page 6

of 20 to $30 \mathrm{pF} / \mathrm{ft}$. The cables capacitance coupled with the capacitance of the load cell, sets up a paralleling capacitance to the charge amplifier input. This paralleling capacitance can cause noise in the output signal. An increase in amplifier gain and the added length of cable will increase the noise as well. There is nothing wrong with the data; noise, unless completely filtered out, is common in any electrical output signal. An example of this can be seen in Test $\# 76$ and Test \#77. The noise is the same in both graphs, however the noise is more apparent in Test \#77 because of the scaling on the graphs.

Some data was missed because the time response of the data acquisition system was set on a short trigger delay. The trigger delay was set up for a quick responding spike from the load cells, and in the aircraft cable test, the response from the load cells came much later than the initial impact. This was due to the stretching of the cable. When the cable was initially impacted the trigger responded, thereby missing the desired spike.

Some graphs appear to indicate negative loading, but this is a result of built-up charge from previous drops. The amplifier has a switch that clears all charge from the system, however before some tests the amplifier was not reset or re-zeroed. This data is still good because the loads are all relative to the initial load. An example of this can be seen in Test \#17. The initial load should be zeroed at approx. -250 lbs. and the peak load is approx. 1250 lbs.

In other tests, the graph has flat sections. This was caused by exceeding the capacity of the load cell. The load cells have a given overload and for any loads greater than the upper limit the output remains constant. This can be seen in Test \#21; Ch. 1 was overloaded and the plot flattened out at 1,650 lbs. This load is the upper limit of the load cell which was used for this particular test.

\section{RECOYPENDATIONB:}

Several lessons were learned from the project that would be beneficial to any subsequent testing. The first and foremost would be the implementation of a Data Acquisition Software system such as Labview. A Software data acquisition sy! tem was to be used for this particular project, however due to time constraints, all of the bugs were not worked out of the system in time for its use in the project. By using data acquisition software, there would be no need for the large RTD Digitizing system. The output of the measuring devices could have been fed directly to the 
Attachment 1. EES Final Report on Seismic II/I Drop Test Program (8 of 10)

$$
\begin{array}{r}
\text { Bavannah RIVer Technology Center } \\
\text { 8eismio II/I Drop Test Report } \\
12 / 1 / 92 \\
\text { Pago } 7
\end{array}
$$

computer software program. The program has the ability to sample the outputs, digitize the analog signals, store the data, and manipulate the data into various forms such as graphs, spreadsheets, etc.

The RTD Digitizer is an excellent piece of equipment that can be hooked up and ready at a moments notice, as was the case in these tests. A drawback to the digitizer is the fact that it can only store one event. In addition, in order to store the event permanently, the information must be downloaded to a computer and then processed with some other software application that can handle the information.

In order to get more accurate data, the tests parameters should be more closely controlled. This can be done by narrowing the scope of each test and concentrating on a particular interest to gain from the testing. In addition, more time should be given up front to define specific goals for each set of data. This will allow for better preparation of the testing.

\section{Decumentation:}

All pertinent information and data can be located in the EES Job Folder \#22116. The Job Folder is located in EES DDC in 730-A.

\section{Disposition of comments}

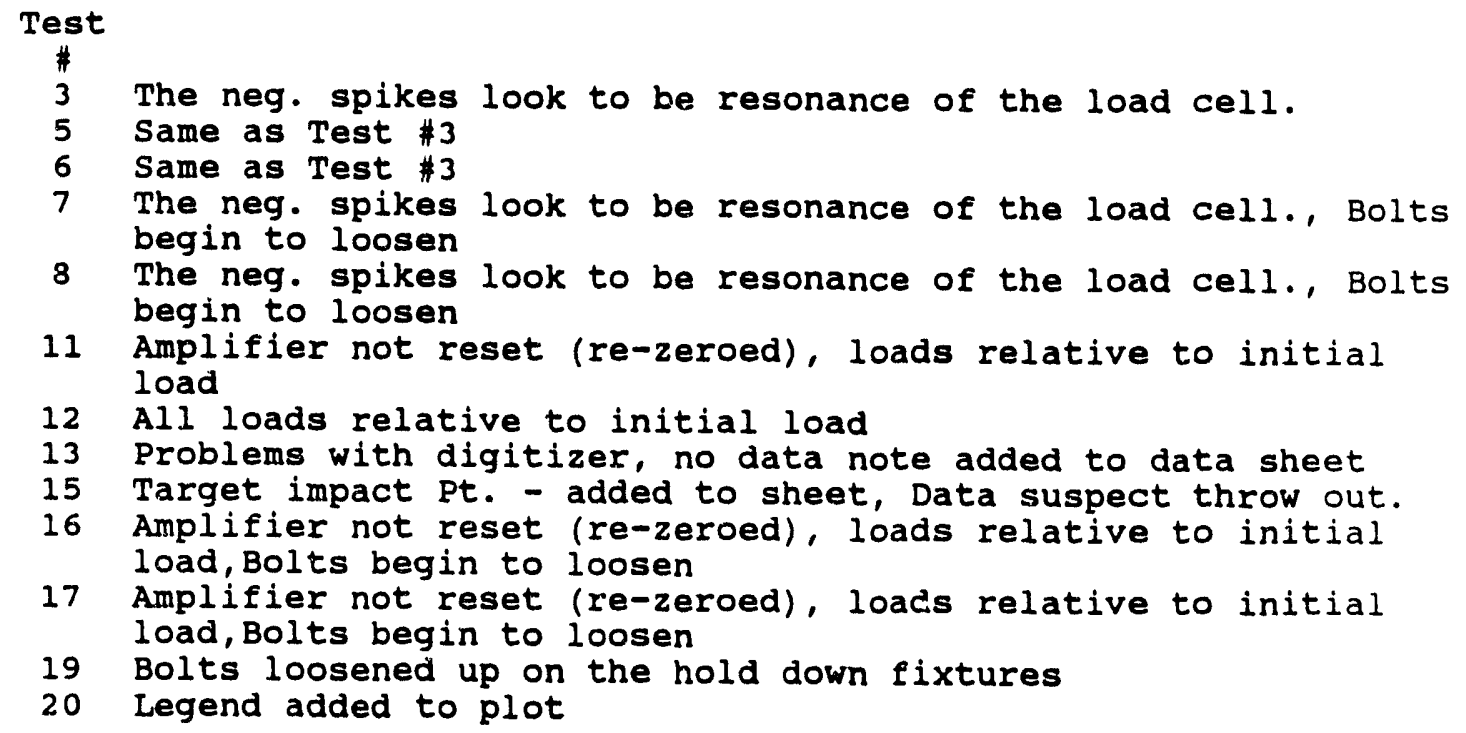


Attachment 1. EES Final Report on Seismic II/I Drop Test Program (9 of 10)

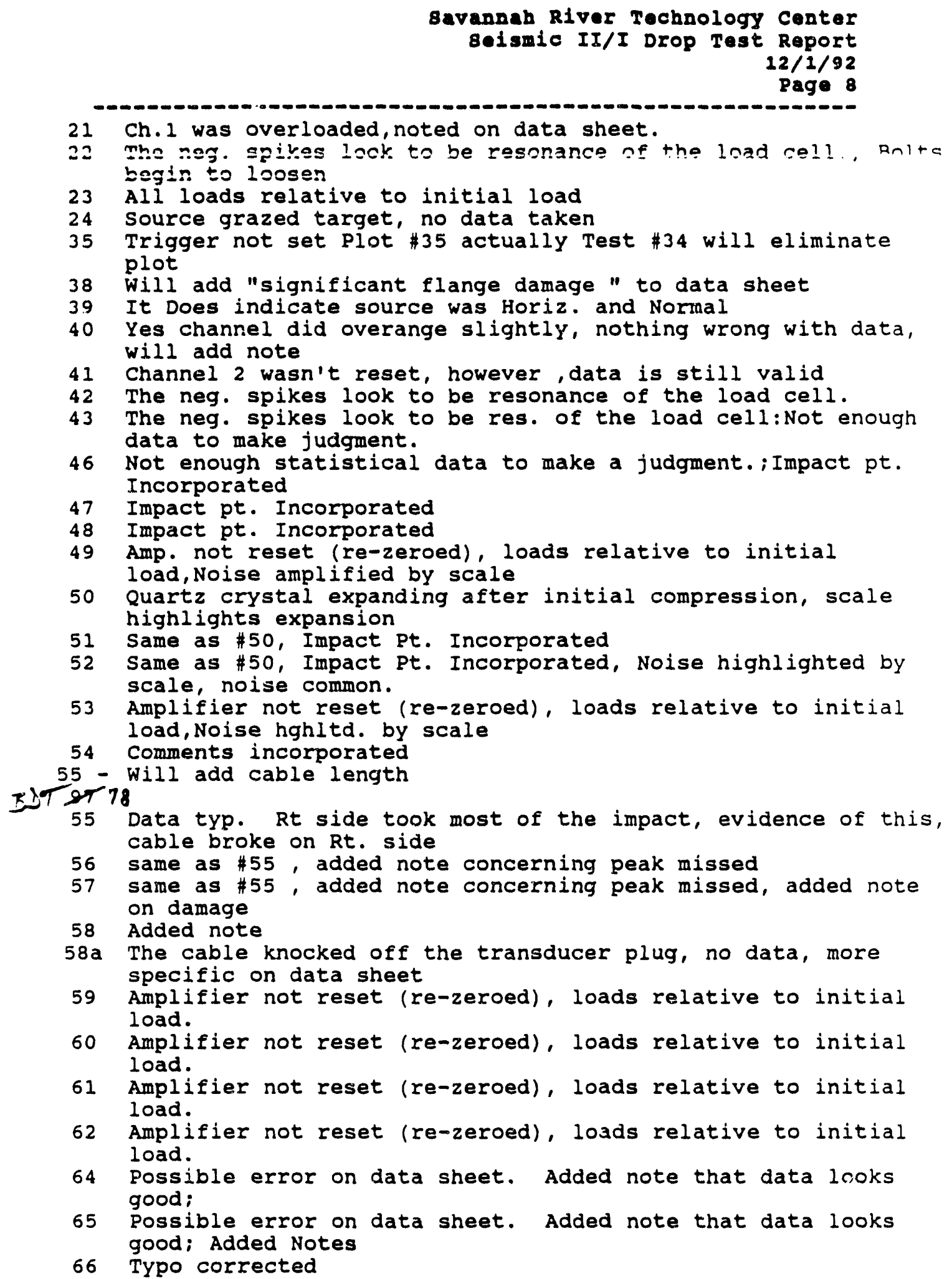


Attachment 1. EES Final Report on Seismic II/I Drop Test Program (10 of 10)

\section{Savannab River Teahnology Center seismic II/I Drop Test Report $12 / 1 / 92$ Page 9}

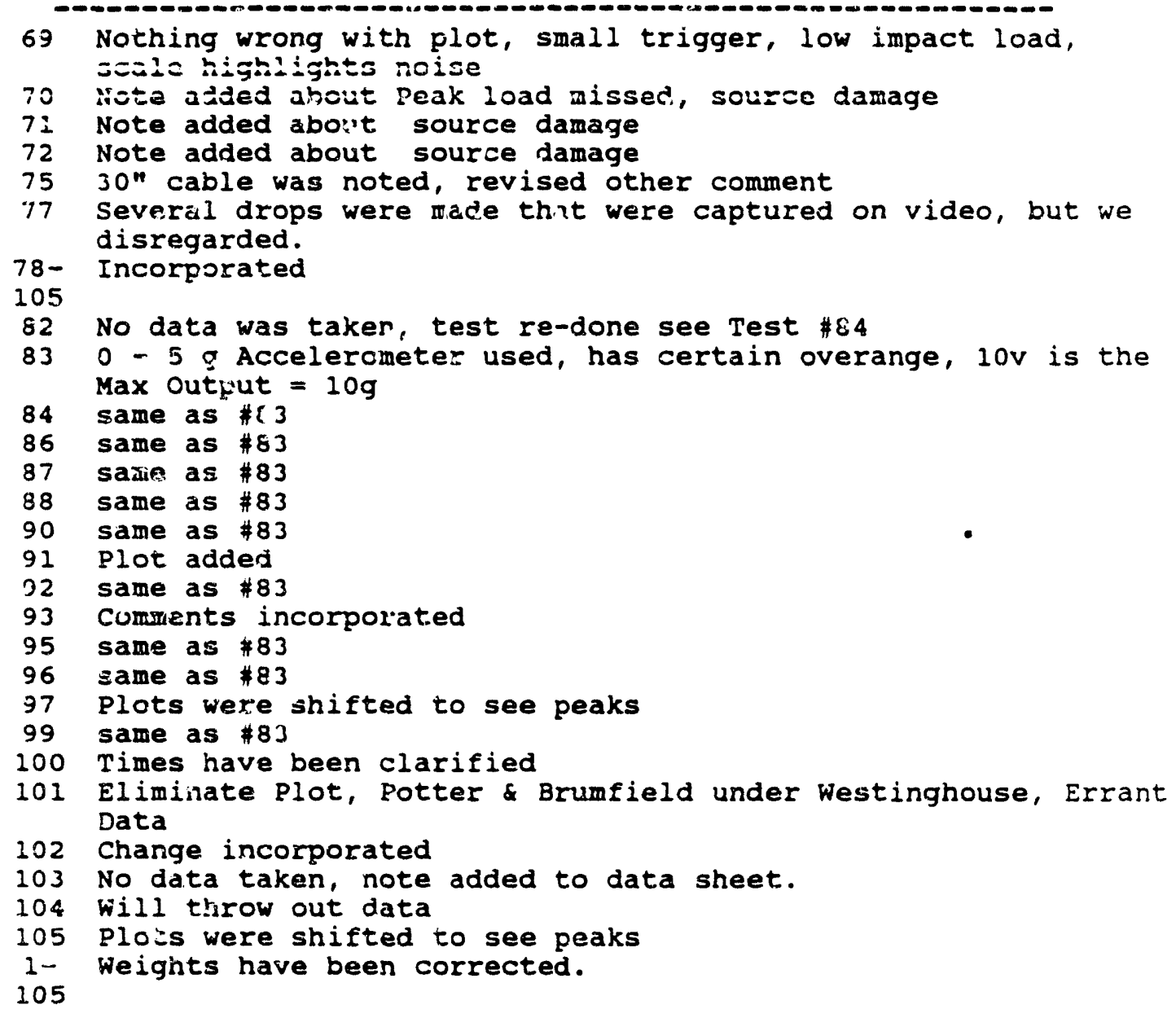


Attachment 2. Physical Properties of Targets and Sources (1 of 3)

\section{Iargets}

1. 3/4-inch IMC Conduit (intermediate metallic conduit)

- Outside diameter $=1.029$ in.; thickness $=.075$ in.

- $\mathrm{I}=.026$ in. $^{2}: \mathrm{S}=.050 \mathrm{in}^{\mathrm{I}}$

- Pin-to-pin length $=82$ in.

- Weight $=.82 \mathrm{lbs} / \mathrm{ft}$

2. 2-inch IMC Conduit

- Outside diameter $=2.36 \mathrm{in}$.; thickness $=.095 \mathrm{in}$.

- $I=.434$ in. $2: S=.368$ in. 1

- Pin-to-pin length $=82$ in.

- Weight $=2.42 \mathrm{lbs} / \mathrm{ft}$

3. Barricade Assembly

- Two pieces of tube steel 5 in. $\times 5$ in. $\times 3 / 8$ in. welded together (Sce Figure 2 of test report for construction.)

- $I=45.6$ in. $^{2} S=18.22$ in. $^{1}$ (combined properties)

- Pin-to-pin length $=48$ in.

- Weight $=44.74 \mathrm{lb} s \mathrm{ft}$ (combined weight)

4. Electrical Equipment ('abinet

- Overall dimensions $=24$ in. wide $\times 25-1 / 2$ in. deep $\times 70$ in. high

- Door opening $=19$ in. $\lambda .61-1 / 2$ in.

- Top and sides $=.048$ in. $t$. ick

- Door $=040$ in. thick

- Internal reinforcing members $=.075$ in. thick Vertical members $=.075$ in, thick Horizontal members $=.050$ in. thick

- Relay mounting plate - 1/4-inch thick aluminum

- "Bad Actor" relay - Westinghouse-type SG Relay

- Seismically rugged relay Potter \& Brumfield. Model KRPAllAG

5. HVAC Duct

- Total length of target assembly $=94$ in. (two 47-inch pieces connected with a "Pocket-Lock" joint)

- Pin-to-pin length $=82$ in.

- Dimensions $=24$ in. $\times 24$ in. with 1 in. flanges

- Duct thickness $=0.025$ in. (25-gage)

- Flange height $=1$ in.

- Weight $=86 \mathrm{lbs}$

6. Aircraft Cable

- 1/4-inch diameter gal vanized stcel aircraft cable, $7 \times 7$ strand

- For details on U-bolt clips, eye nuts, etc. as well as geometry of test set-up, refer to Figure 3 of test report and to EES Dwg. No. EES-22-116-R1-012. 


\section{Attachment 2. Physical Properties of Targets and Sources (2 of 3 )}

7. Emergency Lighting Battery Pack Enclosure

- Manufacturer: Manville/Holophane

- Model No: M-19

- Dimensions: 13 in. high $\times 15$ in. wide $\times 3-1 / 2$ in. deep

- Weight: 42 lbs (complete assembly including batteries)

- Cabinet gage: \#18 (.0478 in.)

- Type of electrical relay: Potter \& Brumfield, model KUMP-11D18, plug-in type

8. Small Electrical Cabinets

- Two small cabinets mounted at the top and in the middle of the floor mounted unistrut frame were the ones that were impacted by the different sources.

- The cabinet dimensions: $10-1 / 4$ in. $\times 5-1 / 4$ in. $\times 19-1 / 4$ in. and 7-1/2 in. $\times 4$ in. $\times 14-1 / 2$ in.

- Both cabinets were Square D brand, 16-gage, with disconnect switches mounted inside

1. Incandescent Light Fixture

\section{Sources}

- Weight of assembly is listed on the individual data sheets. The weight range is from 4 lbs to 6.8 lbs.

- Diameter of shade $=15-3 / 4$ in.

2. Fluorescent Light Fixtures

- Various designs tested

- Weight of fixture is listed on the individual data sheets, ranging from $15 \mathrm{lbs}$ to $29-1 / 2 \mathrm{lbs}$.

3. 2-inch IMC Conduit

- Overall length $=94$ in

- Weight= approximately $19-1 / 4 \mathrm{lbs}$

- Refer to Target No. 2 for section properties.

4. $3 / 4$ in. Heavy Wall Conduit

- Outside diameter $=1.05 \mathrm{in}$. thickness $=.113 \mathrm{in}$.

- $\mathrm{I}=.037$ in. $^{2}, \mathrm{~S}=.0706$ in. ${ }^{1}$

- Length $=6 \mathrm{ft}$

- Weight $=6.8 \mathrm{lbs}$

5. Cable Tray Filled with Wire

- Dimensions: 18 in. $\times 3$ in. $\times 65$ in.

- Weight $=101 \mathrm{lbs}$

6. Duct, Light Weight

- $W t=43 \mathrm{lbs}$.

- Length $=47$ in.

- See Target No. 5 for additional properties.

7. Duct, Heavy

- $\mathrm{Wt}=96 \mathrm{lbs}$.

- Overall dimensions: 18 in. $\times 30$ in. $\times 48$ in. long with flanges of $1-1 / 2$ in. $\times 1-1 / 2$ in. $\times 1 / 8$-inch thick angle iron

- Thicknesi $=.0635$ in. (16-gage) 
Seismic II Over I Drop Test Program

Results and is plementation

Attachment 2. Physical Properties of Targets and Sources (3 of 3 )

8. Ceiling Panels

- $2 \mathrm{ft} \times 4 \mathrm{ft}$ for use in standard drop ceiling

- Weight $=2 \mathrm{lbs}$

9. Transite Wallboard, Cement - Fiberglass (used as replacement for cement-asbestos)

- Overall dimensions $=2 \mathrm{ft} \times 3 \mathrm{ft} \times 1 / 4$-inch thick

- Weight = $11 \mathrm{lbs}$

10. 6-inch Diameter Pipe

- Outside diameter $=6.625$ in.: thickness $=.280 \mathrm{in}$.

- $\mathrm{I}=28.14$ in. ${ }^{2} ; \mathrm{S}=8.50$ in. 1

- Length $=4 \mathrm{ft} 0$ in.

- Weight $=76 \mathrm{lbs}$

11. "Solid Object" Used in Test \#93

- $\mathrm{Wt}=336 \mathrm{gm}$.

- Diameter $=2$ in.

- Length $=2-7 / 16$ in.

- Material = aluminum 
Attachment 3. EES Task Quality Assurance Plan for II/I Drop Test Program (1 of 8)

\author{
TASR QUALITY ASSURANCE PLAN:
}

DROP TEST: A METHOD FOR DETERMINING DESIGN LOADS FOR II/I INTERACTION EFFECTS.

Document No.:22116-TQAP

Rev.: 0 IDENTIFICATION

Effective Date: $5-5-92$

EES Job No.:22116
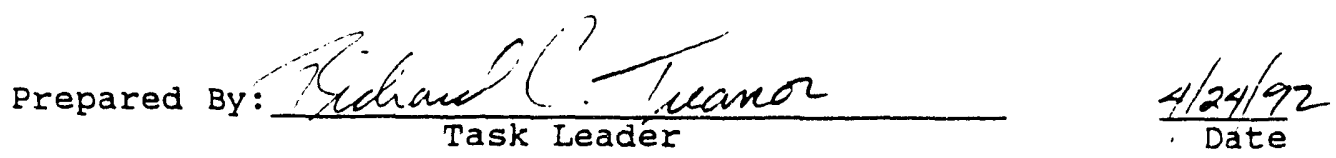

Approved By:<smiles>[Te][Te]1=CC=C1</smiles>
EES Level 5 Manager

$$
\frac{-}{\text { Date }}
$$

Reviewed

By:

ist

Cognizant Qualicy Function

$\frac{-F / 3 c / s z}{\text { Date }}$

Approved BY:

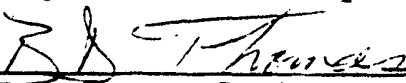

$\frac{5 / 4 / 7 \div 2}{\text { Date }}$ 
Attachment 3. EES Tas! Quality Assurance Plan for II/I Drop Test Program (2 of 8)

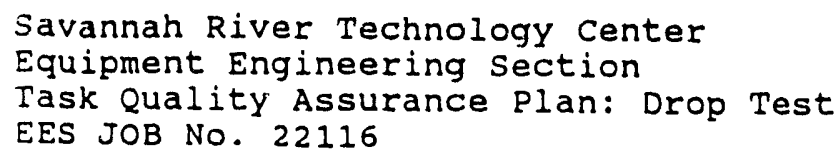

\section{DESCRIPTION OF REVISIONS}

REVISION
DATE

SECTION

22116-TQAP
DESCRIPIION

Original Issue 
Attachment 3. EES Task Quality Assurance Plan for II/I Drop Test Program (3 of 8)

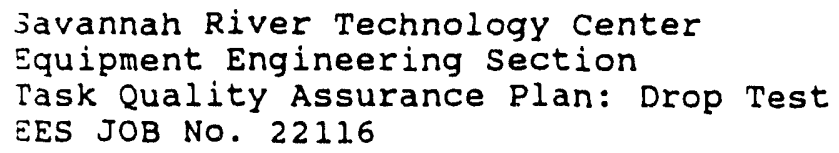

Revision 0

DOC. NO. 22116 -TQAP

Page 30 f 8

\section{TABLE OF CONTENTS}

1. PURPose............................ 4

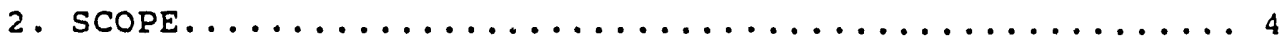

3. TERMS/DEFINITIONS ....................... 4

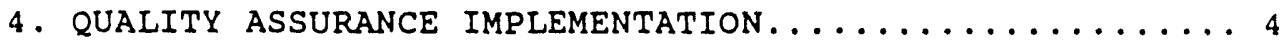

4.1. ORGANIZATION ................... 4

4.2. QUALITY ASSURANCE PROGRAM............ 4

4.3. DESIGN CONTROL.................. 4

4.4. PROCUREMENT DOCUMENT CONTROL.......... 5

4.5. INSTRUCTION, PROCEDURES, AND DRAWINGS.... 5

4.6. DOCUMENT CONTROL................ 5

4.7. PURCHASED ITEMS AND SERVICES ......... 6

4.8. IDENTIFICATION AND CONTROL OF ITEMS...... 6

4.9. CONTROL OF SPECIAL PROCESSES.......... 6

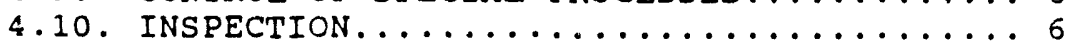

4.11 . TEST CONTROL. .................. 6

4.12. CONTROL OF MEASURING AND TEST EQUIPMENT.. 6

4.13. HANDIING, STORAGE, AND SHIPPING........ 6

4.14. INSPECTION, TEST, AND OPERATION STATUS... 7

4.15. CONTROL OF NON-CONFORMING ITEMS .......7 7

4.16. CORRECTIVE ACTION SYSTEM............ 7

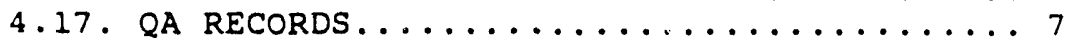

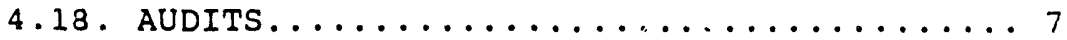

4.19. QUALITY IMPROVEMENT.............. 7

4.20. SOFTWARE QUALITY PROGRAM............. 8

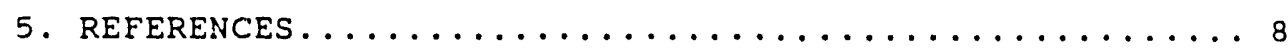


Attachment 3. EES Task Quality Assurance Plan for II/I Drop Test Program (4 of 8)

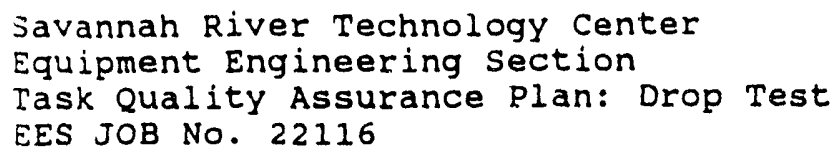

1. PURPOSE

1.1 The systems Structural Analysis group has requested Equipment Engineering Section (EES) to conduct several "drop" tests. The tests are being performed to help quantify impact loads of seismic category II commodities which could fall and impact seismic category I components in the reactor areas during a seismic event.

2.1 This Task Quality Assurance Plan(TQAP) establishes the responsibilities and levels of control for $Q A$ related activities associated with the Drop Tests.

2. SCOPE

2.1 This TQAP is applicable, upon approval, towards the accomplishment of the Drop Test.

3. TERMS/DEFINITIONS
3.1 TTP- Task Technical Plan
3.2 TQAP- Task Quality Assurance Plan
3.3 Task Leader - A cognizant Equipment Engineering Section (EES) engineer designated as such at the initiation of the corresponding task.

\section{QUALITY ASSURANCE IMPLEMENTATION}

\subsection{ORGANIZATION}
4.1.1. EES is the design agency for this activity and is organized in accordance with EES 1Q28-5001

\subsection{QUALITy Assurance pRogram}
4.2 .1 .
This project will be classified as Production Support per EES 1Q28-5003-2.

\subsection{DESIGN CONTROL}


Attachment 3. EES Task Quality Assurance Plan for II/I Drop Test Program (5 of 8)

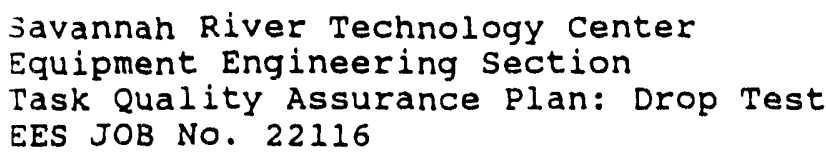

Revision 0

DOC. NO. 22116-TQAP

Page 5 of 8

4.4. PROCUREMENT DOCUMENT CONTROL

4.4.1. Purchase orders will be administered through the current site system and handled in accordance with EES 10285004 procurement Document Control.

$4 \cdot 4 \cdot 2$

Copies of all purchase requisitions, purchase specifications or special documents generated to acquire parts or outside services, except stores orders will be kept in the job folder.

\subsection{INSTRUCTION, PROCEDURES, AND DRAWINGS}

4.5 .1

As applicable, instruction and drawings will be controlled in accordance with EES Instruction, Procedures and Drawings, EES 1Q28-5005 and $1228-5003-3$.
4.5 .2 .
Development drawings are adequate documentation for fabrication and assembly of the Drop Test fixture.

4.6. DOCUMENT CONTROL 
Attuchment 3. EES Task Quality Assurance Plan for II/I Drop Test Program (6 of 8 )

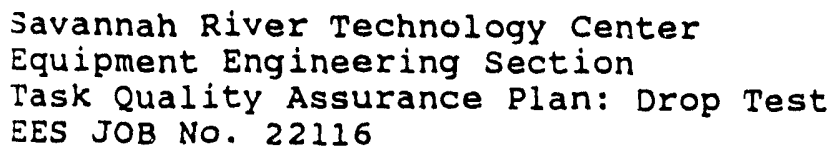

Revision 0

DOC. NO. $22116-\mathrm{TQAP}$

page $60 \mathrm{f} 8$
4.6.1.
All data obtained from tcsta, test procedures and analysis will be kept in the EES job folder.
4.6 .2 .
Contro? of Task Documents shall b! in accordance with EES procedure 1026-5006.
$4 \cdot 6 \cdot 3$. Test Procedures and Task Plans will be
reviewed and approved by the Customer.

\subsection{PURCHASED ITEMS AND SERVICES}
4.7 .1 .
Purchase items arid services shall be in accordance with EES Procedure 1Q28- 5004 "Procurement Document Control"

4.8. IDENTIFICATION AND CONTROI OF ITEMS

$4 \cdot 8 \cdot 1$

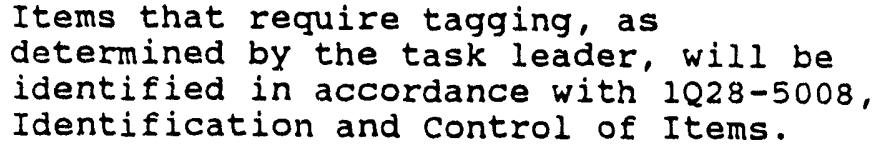

4.9. CONTROL OF SPECIAL PROCESSES

4.9.1. No special processes are required for this task.

\subsection{INSPECTION}
4.10.1. Inspections of the Test equipment, when specified, will be identified in the EES Test or Operating procedures in accordance with 1Q28-5010.

\subsection{TEST CONTROL}
4.11.1. Tests will be conducted and documented in accordance with EES 1228-5011, Test control.

\subsection{CONTROL OF MEASU..ING AND TEST EQUIPMENT}


Attachment 3. EES Task Quality Assurance Plan for II/I Drop Test Program (7 of 8 )

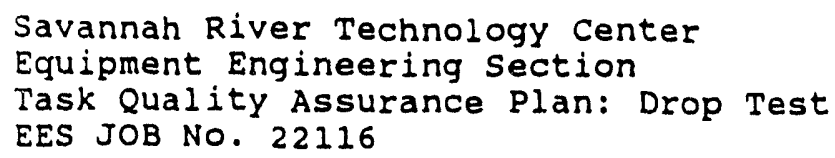

Revision 0

DOC. NO. 22116-TQAP

Page 70 f 8

\subsubsection{Control of MTE equipment shall be in accordance to EES 1Q28-5012-1 and 105012-2.}

\subsection{HANDLING, STORAGE, AND SHIPPING}

4.13.1. Special handling, storage, or shipping instructions will be in accordance with EES 1Q28-5013, Packaging, Handling, Shipping, and storage.

4.14. INSPECTION, TEST, AND OPERATION STATUS

4.14.1. The status of inspections, tests, and operation of the Test will be identified, when deemed necessary, by any person on the project team with agreement from the Task Leader and accordance with EES 1028-5014, Inspection, Test and operating status.

\subsection{CONTROL OF NON-CONFORMING ITEMS}

4.15.1. Control of all non-conforming items \& activities shall be in accordance with EES 1Q28-5015, Control of Nonconforming Items and Activities unless pre-authorized reword is provided.

4.15.2. Non-Conformance Reports (NCR's) Shall not be generated for the failure of drop items, during Normal Test Conditions.

\subsection{CORRECTIVE ACTION SYSTEM}

4.16.1. If a significant condition adverse to quality should be identified during this task, EES responsibilities will be per EES procedure 1228-5016.

\subsection{QA RECORDS}
4.17 .1 .
Task records ie. TTP, TQAP, Final Repert, etc. will be maintained in accordance with EES procedure 1Q28-5017. 
Attachment 3. EES Task Quality Assurance Plan for II/I Drop Test Program (8 of 8 )

Savannah River Technology Center

Equipment Engineering Section

Task Quality Assurance Plan: Drop Test

EES JOB NO. 22116
Revision 0

DOC. NO. 22116-TQAP

Page 8 of 8

1.18. AUDITS
4.18.1. If surveillances or an audit is conducted on the task, EES
responsibilities will be per EES
procedure 1Q28-5018.

4.19. QUALITY IMPROVEMENT

4.19.1. Not applicable

4.20. SOFTWARE QUALITY PROGRAM

4.20.1 Not applicable

\subsection{REFERENCES}

5.1 WSRC QA Manual 1Q

5.21028 Manual, EES Training \& Quality Assurance Procedures

5.3 TTP-22116, Drop Test Task Technical Plan 
Attachment 4. EES Task Technical Plan for II/I Drop Test Program (1 of 6)

\section{TASR TECKNICAL PLAN:}

DROP TEST: A METHOD FOR DETERMINING DESIGN
LOADS FOR II/I INTERACTION EFFECTS.

\section{CONTEOLLED IDENTIFICATION}

Document No.:22116-TTP

Rev.: 0

Effective Date: $5-5.92$

EES Job No.:22116
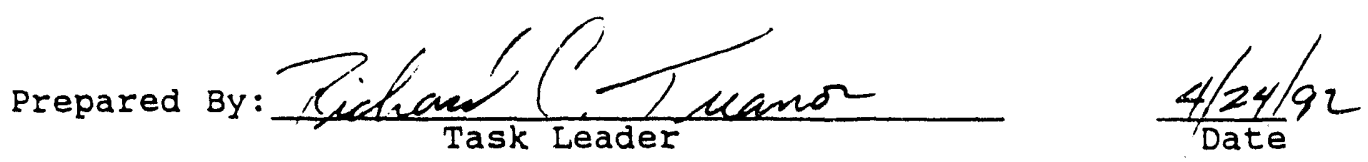

Approved

By:

Pript

EES Level 5 Manager

Reviewed By: $\bar{i}(\dot{t})$ Therte

Cognizant Quality Function

$\frac{- \text { Date }}{\text { Date }}$

Approved

By:

$\rightarrow x$

$\frac{i / 3 c / \% 2}{\text { Date }}$

$\frac{5 / 4 / 72}{\text { Date }}$ 
Attachment 4. EES Task Technical Plan for II/I Drop Test Program (2 of 6)

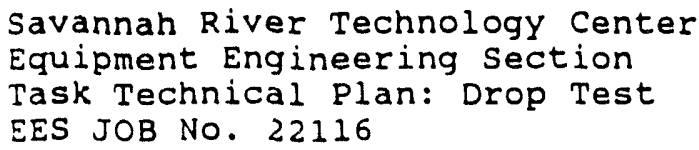

DESCRIPTION OF REVISIONS

\section{REVISION}

0

\section{DATE}

SECTION

22116-TTP
DESCRIPTION

Original Issue 
Attachment 4. EES Task Technical Plan for ll/I Drop Test Program (3 of 6)

Savannah River Technology Center

Equipment Engineering Section

Revision 0

Task Technical Plan: Drop Test

DOC. No. 22116-TTP

EES JOB No. 22116

Page 3 of 6

TABLE G CONTENTS

1. PURPOSE........................... 4

2. $\operatorname{SCOPE} \ldots \ldots \ldots \ldots \ldots \ldots \ldots \ldots \ldots \ldots \ldots \ldots \ldots \ldots$

3. TERMS,DEFINITIONS .................... 4

4. FUNCTIONAL PEREORMANCE REQUIREMENTS........... 4

5. ACCEPTANCE REQUIREMENTS ............... 5

6. APPLICABLE CODES AND STANDARDS ............ 5

7. REVIEWS .........................

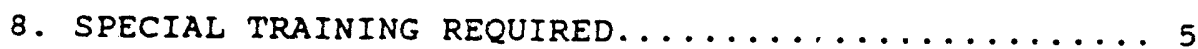

9. DELIVERABLES/DESIGN OUTPUTS.............. 5

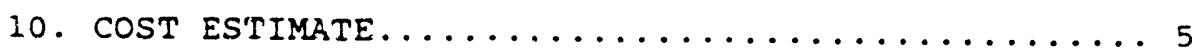

11. REFERENCES ..................... 
Attachment 4. EES Task Technical Plan for II/I Drop Test Program $(4$ of 6$)$

Savannah River Technology Center

Equipment Engineering Section

Task Technical plan: Drop Test

EES JOB NO. 22116
Revision 0

Doc. No. $22116-$ TTP

Page 4 of 6

\title{
1. PURPOSE
}

1.1 Systems Structural Analysis group has requested Equipment Engineering Section (EES) to conduct "drop" tests. The tests are being performed to lelp quantify impact loads of seismic category II rommodities which could fall and impact seismic category I components in the reactor areas during a seismic event.

1.2 This Task Technical Plan(TTP) identifies objectives, the scope of work, and other technical components of the Drop Tests.

\section{SCOPE}

2.1 This TTP is applicable, upon approval, towards the accomplishment of the Drop Test.

\section{TERMS/DEFINITIONS}

\author{
3.1 TTP- Technical Task Plan \\ 3.2 TQAP- Technical Quality Assurance Plan \\ 3.3 Task Leader - A cognizant Equipment Engineering \\ Section (EES) engineer designated at the \\ initiation of the corresponding rask.
}

\section{FUNCTIONAL PERFORMANCE REQUIREMENTS}

4.1 The objective of this task is to perform drop tests under specified test configurations as outline in the Basic Data Report [11.1], and the Reactor Seismic Improvement Project 54605 [11.4]. The specific test configurations may change throughout the test, therefore they will be documented and placed in the Job folder as the test progresses.

These requirements include:

4.1.1 Provide Facility in which Test is to be Conducted. 
Attachment 4. EES Task Technical Plan for II/I Drop Test Program (5 of 6)

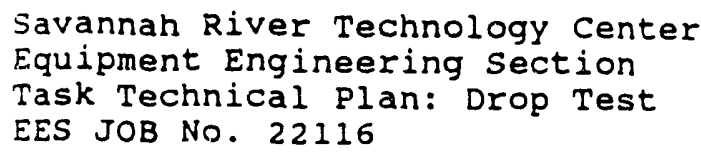

Revision 0

DOC. NO. $22116-$ TTP

Page 5 of 6

4.1.2 Design and Fabricate Equipment requiron for holding and dropping of apparatus.

4.1.3 Coordinate all video applications of test as required by the customer.

4.1.4 Procure and coordinate calibration of load cells, accelerometers, and other data acquisition equipment required for the tests.

4.1.5 Prepare all Test set-ups, and Test procedures required to carry-out the tests.

4.1.6 Issuance of a final report as outlined in the basic data documents $[11.1],[11.4] . \star$ If accelerometers can be obtained for the tests, they will be used and the data will be for Information only, due to SRS calibration requirements.

\section{ACCEPTANCE REQUIREMENTS}

5.1 The customer shall be responsible for determining the acceptability of the Test Data. Due to the fact that the natue of the test is mainly Research and Development, there is no defined quantitative acceptance criteria.

\section{APPLICABLE CODES AND STANDARDS}

6.1 Specific codes/standards shall be identified in design/development documents, procurement specifications, purchase requisitions, drawings, etc. as required.

\section{REVIEW}

7.1 The Peer Review Process as outlined in 1Q28-5003-2 will be used for verification of design and the results obtained in this task.

\section{SPECIAL TRAINING REQUIRED}


Attachment 4. EES Task Technical Plan for II/I Drop Test Program (6 of 6)

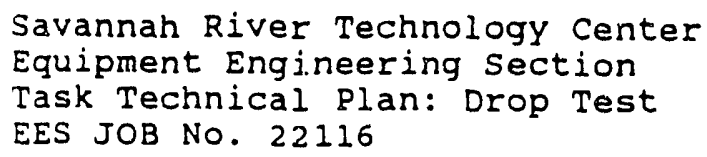

Revision 0

Doc. No. 22116 -TTP

Page 6 of 6

\subsection{Not Applicable}

9. DELIVERABLES/DESIGN OUTPUTS

9.1 The final deliverable from EES, will be a complete test package/report. This package will include the Test procedure, Test data, and Video Footage. EES will not quantify the data as it would relate to seismic quantities in the field.

10. COST ESTIMATE

10.1 A cost estimate has been prepared and can be found in the Job Folder

\section{REFERENCES}

11.1 G.A. Antaki to EES "Basic Data Report", EPD-SE91-0509:68 12/10/91

11.2 WSRC QA Manual 1Q

11.3 1228 Manual, EES QA and Training Procedures

11.4 Reactor Seismic Improvement Project $\$ 4605$ II/I Drop Test Plan 
Attachment 5. EES Field Procedure No. FP-351: "Cahinet Drop Tests-Camera Only" (1 of 12)

\section{SEISMIC II/I DRCP TEST PROGRAM! \\ CABINET DROP TESTS - CAMERA ONLY \\ EES FIELD PROCEDURE: FP-351, REV O}

Job Number: 22116

$5 / 13 / 92$

Equipment Enginee:ing Section

CONTROLLED

IDENTIFECTICN

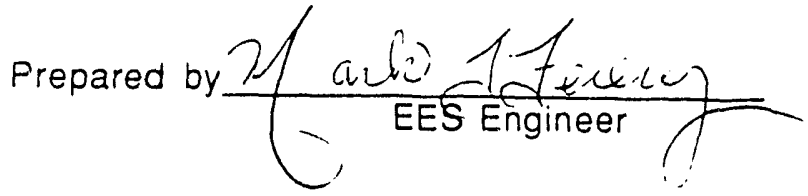

Date $5-13-42$

Aoproved by

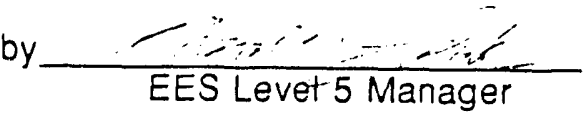

Date

Approved by $\frac{\text { Cognizant Quality Function }}{\text { Con }}$

Date _.

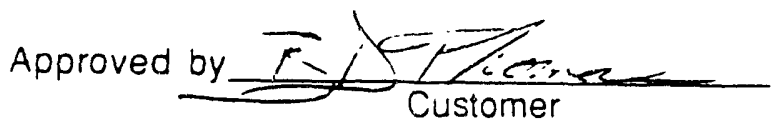

Date $5-13 \%$ 
Aftachment 5. EES Field Procedure No. FP.3E1: "Cabinct Drop Tests-Camera Only" (2 of' 12)

Savannah River Technology Center

Equipment Engineering

Seismic II/I Drop Test Program

Cabinet Droo Tests - Camera Only

REVISION HISTORY LOG

Revision

0
Date

$5 / 13 / 92$
EES-FP-351, Rev. 0

Date Approved: 5/13/92, Category 2

Page 2 of 12

Description of Change

Original Issue 
Attachment 5. EES Field Procedure No. FP-351: "Cabinet Drop Tests-Camera Only" (3 of 12)

\begin{tabular}{l} 
Savannah River Technology Center $\begin{array}{r}\text { EES-FP-351, Rev. } 0 \\
\text { Equipment Engineering }\end{array}$ Date Approved: $5 / 13 / 92$, Category 2 \\
Seismic IIII Drop Test Program \\
CabinetDrop Tests-Came 3 of 12 \\
\hline
\end{tabular}

TABLE OF CONTENTS

\begin{tabular}{|c|c|c|}
\hline & \multicolumn{2}{|r|}{ PURPOSE } \\
\hline & \multicolumn{2}{|r|}{ SCOPE } \\
\hline & \multicolumn{2}{|c|}{ TERMS/DEFINITIONS ..... } \\
\hline & \multicolumn{2}{|c|}{ RESPONSIBILITIES...... } \\
\hline & \multicolumn{2}{|r|}{ PROCEDURE } \\
\hline & 5.1 & \\
\hline & 2 & Requi \\
\hline & 5.3 & Accepta \\
\hline & 5.4 & st Procedure ................ \\
\hline & 5.5 & Electrical Cabinets Attached To Unistrut Frame Assembly \\
\hline & \multicolumn{2}{|r|}{ 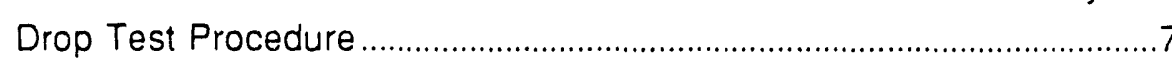 } \\
\hline & \multicolumn{2}{|r|}{ RECORDS } \\
\hline & \multicolumn{2}{|r|}{ REFERENCES } \\
\hline & \multicolumn{2}{|r|}{ ATTACHMENTS } \\
\hline
\end{tabular}


Attachment 5. EES Field Procedure No. FP-351: "( abinet Drop Tests-( amera Only" (t of 12)

Savannah River Technology Center

Equipment Engineering

Seismic II/I Drop Test Program

Cabinet Drop Tests - Camera Only
EES-FP-351, Rev. 0

Date Approved: $5 / 13 / 92$, Category 2

Page $4 \quad 12$

\subsection{PURPOSE}

1.1 The Systems Structural Analysis group has requested Equipment Engineering to conduct several drop tests to help quantify/qualify the impact characteristics of seismic category 11 commodities that may fall and strike seismic category I commodities during a seismic event.

1.2 Four sets of tests have been requested (see Attachment 1):

- Supported beam tests where load cells are to be utilized to gather load data during the drops.

- Aircraft cable tests where load cells are utilized to gain reaction force data on cable supports.

- Cabinet drop tests to view failure modes that may occur 10 battery packs and cabinets attached to unistrut frames during seismic events.

- Instrumented cabinet drop tests to determine effects of seismic events on relays mounted in equipment cabinets. Relays will be monitored using data acquisition, and an accelerometer will be used to assist in corresponding impact loads to relay data.

1.3 The function of all of these tests is to look for trends in data in order to provide a baseline for comparison of seismic $1 \mathrm{l} / \mathrm{l}$ impacts and in order to gather valuable information that can be used to increase SRS engineers' experise in evaluating seismic interaction hazards.

1.4 This procedure applies to only the cabinet drop tests.

\subsection{SCOPE}

2.1 This is a one time procedure, and only applies to activities conducted in the Equipment Engineering Section (EES) in support of the Seismic II/I Drop Tesi Program.

2.2 Drop testing will take place in the 723-A High-Bay Area.

2.3 All data generated by this test are intended to determ ne impact characteristics.

2.4 The test systems pertaining to tiis program are classified Production Support (PS), and the program is classified as a Task Activity.

\subsection{TERMSIDEFINITIONS}


Altachment 5. EES Field Procedure No. FP-351: "Cabinet Dron Tests-Camera Only" (5 of 12 )

Savannah River Technology Center Equipment Engineering Seismic II// Drop Test Program Cabinet Droe Tests - Camera Only
EES-FP-351, Rev. 0 Date Approved: $5 / 13 / 92$, Category 2

\subsection{EES - Equipment Engineering Section}

3.2 Seismic Category 1 Commodities - a structure, system or component (SSC) which must continue to perform its required function during or atter a seismic event.

3.3 Seismic Category 11 Commodities - synonymous with "non-seismic category I" commodities.

\subsection{RESPONSIBILITIES}

4.1 The EES Mechanical Engineers shall be responsible for:

4.1.1 Assisting EES personnel in the execution of this procedure.

4.1.2 Assisting in the coordination, scheduling and controlling activities associated with this procedure.

4.1.3 Assisting in data acquisition.

4.1.4 Instructing personnel in the use of this procedure.

4.2 Personnel performing this test shall have received instruction from an EES Mechanical Engineer prior to testing and shall be responsible for adherence to procedure requirements.

\subsection{PROCEDURE}

5.1 Safety

5.1.1 All applicable EES, SRTC, and SRS Safety Rules will be followed.

5.2 Required Equipment

5.2.1 Drop Mechanism, Bux-shrader CE-7R.

5.2.2 Emergency lighting battery pack with relay, 1 each.

5.2.3 Electrical cabinets attached to unistrut frame assembly, 1 each

5.2.4 Ceiling panel, approximately 10 each.

$5.2 .53 / 4$ conduit, $6 \mathrm{H}$ long, approximately 10 each.

5.2.6 Fivorescent light fixture, approximately 10 each. 
Altachument 5. EES Fleld Procedure No. FP-351: "Cabinet Drop Tests-Camera Only" (6 of 12)

Savannah River Technology Center

Equipment Engineering

Seismic II/I Drop Test Program

Cabinet Droo Tests - Camera Only
EES-FP-351, Rev. 0

Date Approved: $5 / 13 / 92$, Category 2

Page 6 of 12

5.2.7 Incandescent light fixture, approximately 10 each.

5.2.8 $2^{\prime} \times 2^{\prime} \times 1 / 4^{\prime \prime}$ wallboard, approxirnately 10 each.

5.2.9 $20^{\prime}$ tape measure.

5.2.10 Any other drop item that is specified by customer.

5.2.11 Drop Test Adapter, EES-22116-R4-001, 1 Al adapter for light objects (<10 lbs) and 1 SST adapter for heavier objects.

5.3 Acceptance Criteria and Test Requirements

5.3.1 Because this is a Research \& Development type task activity, acceptance criteria is not required for this test. The collection of data to determine the impact characteristics of seismic $11 / /$ interactions is the objective of this test.

5.3.2 Damage to any of the drop commodities that is a result of a direct testing activity (i.e. dronping the items) shall no* require a Noncontormance Repc (NCR).

5.4 Emergency Lighting Battery Pack Drop Test Procedure

5.4.1 Place emergency lighting battery pack in center of drop frad on zero level of high bay. You may want to support battery pack by placing a heavy object on either side of the cabinet to keep it from tipping over during a drop.

5.4.2 Attach the drop release mechanism (Bux-shrader CE-7R) to the High Bay crane. Operate the drop release mechanism according to EES Drop Test procedure L9.2. 3602 Rev. 0.

5.4.3 Complete top section of Test Data Sheet, Attachment 2.

5.4.4 Verify that battery pack is operational and record on Attachment 2.

5.4.5 Verify that relay in battery pack is powered or is not powered as per customers instructions and record on Attachment 2.

5.4.6 Attach Drop Test Adapter (Al adapter for light objects, $<10$ Ibs. and 1 SST adapter for heavier obiects) to droD obiect. 
Attachment 5. EES Field Procedure No, FP-351: "Cabinet Drop Tests-Camera Only" (7 of 12)

Savannah River Technology Center Equipment Engineering

Seismic :1// Drop Test Proc $n$

Cabinet Drop Tests - Camera Only
EES-FP.351, Rev. 0

Date Approved: 5/13/92, Category 2

Page 7 of 12

5.4.7 Use crane and drop release mechanism to lift object to preferred height and location using tape measure. May want to use plumb tob to align object over desired target. NOTE: If source object can be safely raised and dropped by hand, the drop mechanism does not have to be used. The item must be light enough to hold in the air with one hand, and the dropping of the item must not pose any threat to personnel.

5.4.8 (Set-up high speed video if customer desires. Record start position of video tape on Attachment 2.)

5.4.9 Clear personnel, except for crane and drop mechanism operators, from high bay.

5.4.10 Countdown from 5 to alert personnel. (At count of 1 highspeed video will be taken if customer desires.) At count of 0 release object to be dropped using drop mechanism.

5.4.11 (If video taken, after source impacts battery pack and all action ceases stop video and record stop position of video tape on Attachment 2.)

5.4.12 Verify that battery pack is operational and record on Attachment 2.

5.4.13 Record damage to target and source on Attachment 2. Note if emergency lights illuminated, dimmed or turned off, as the case may be.

5.4.14 Repeat 5.4.3 to 5.4.12 as desired.

5.4.15 Return High bay area to original condition.

5.5 Electrical Cabinets Attached To Unistrut Frame Assembly Drop Test Procedure

5.5.1 Place electrical cabinets attached to unistrut frame assembly in center of drop $p$ ad on zero level of high bay.

5.5.2 Attach the drop release mechanism (Bux-shrader CE-7R) to the High Bay crane. Operate the drop release mechanism according to EES Drop Test procedure L9.23602 Rev. 0.

5.5.3 Complete top section of Test Data Sheet, Attachment 2. 
Altachment 5. EES Field Procedure No. FP-351: "Cabinet Drop 'Tests-Camera Only" (8 of' 12)

Savannah River Technology Center Equipment Engineering Seismic II/I Drop Test Program Cabinet Droo Tests. Camera Only
EES-FP-351, Rev. 0

Date Approved: $5 / 13 / 92$, Category 2

Page 8 of 12

5.5.4 Attach Drop Test Adaj: : (Al adapter for light objects, $<10$ Ibs, and 1 SST adapter for heavier objects) to drop object.

5.5.5 Use crane and drop release mechanism to lift object to preferred height and location using tape measure. May want to use plumb bob to align object over desired target. NOTE: If source object can be safely raised and dropped by hand, the drop mechanism does nut have to be used. The item must be light enough to hold in the air with one hand, and the dropping of the item must not pose any threat to personnel.

5.5.6 (Set-up high speed vifeo if customer desires. Record start position of video tape on Attachment 2.)

5.5.7 Clear personnel, except for crane and irop mechanism operators, from high bay.

5.5.8 Countdown from 5 to alen personnal. (At count of 1 highspeed video will be taken if customer desires.) At count of 0 release object to be dropped using drop mechanism.

5.5.9 If video taken, after source impacts cabinet and all action ceases stop video and record stop position of video tape on Attachment 2.)

5.5.10 Record damage to target and source on Attachment 2.

5.5.11 Repeat 5.5.3 to 5.5.9 as desired.

5.5.12 Return High bay area to original condition.

\subsection{RECORDS}

6.1 The completed copy of this procedure shall be maintained in accordance with EES procedure 1028-5017.

6.2 All pertinent procedures, reports and data relating to these test activities will be maintained in Job Folder 22116.

6.3 A final consolidated report that incorporates all of the drop tests will be written to document the findings of the tests and will be distributed to EES Document Control and to the customer.

\subsection{REFERENCES}

\subsection{EES Drop Procedure L9.2-3602 Rev. 0}


Attachment 5. EES Field Procedure No, FP.351: "Cahinet Drop Tests-Camera Only" (9 of 12)

Savannah River Technology Center Equipment Er.gineering EES.FP.351, Rev. 0 Seismic II/I Drop Test Program Date Approved: $5 / 13 / 92$, Category 2

Cabinet Droo Tests - Camera Only Page 9 of 12

$7.2 \quad$ 1228-Manua!, EES Training and L.4 Procedure Manua!.

\subsection{ATTACHMENTS}

8.1 Attachment 1, Scope of Seismic II/I Drop Tests

8.2 Attachment 2, Test Data Sheet 
Altachment 5. EES Field Procedure No, FP.351: "Cabinet Drop 'Tests-Camera (Only" (10) of' 12)

Savannah River Technology Center

Equipment Engineering

Seismic II/I Drop Test Program

Cabinet Droo Tests - Camera Only
EES.FP.351, Rev. 0

Date Approved: 5/13/92. Category 2

Page 10 of 12

\section{S.1 nttachment !}

\section{SCOPE OF SEISMIC II/ DROP TESTS}

1. Simoly Supported (pinned) Beam Configuration - Load Cells at Supports

Purpose: To gain reaction force data and to view failure modes, if any. The primary function of all of these tests is to look for trends in data.

Consideration: if theta small Fx\&Fy negligible, pin supports to eliminate problem.

Target: $3 / 4$ " conduit $(27 / 32$ IC, $11 / 8$ OD), $10 \mathrm{ft}$.

Sources: fluorescent light fixture

ceiling panel

$3 / 4$ conduit, $6 \mathrm{tt}$.

incandescent light fixture

$2^{\prime} \times 2^{\prime} \times 1 / 4^{\prime \prime}$ wallboard

$\left[\right.$ op H: 1 to $15^{\prime}$

Target: $\quad 2^{\prime \prime}$ conduit (2 1/8 ID, 25/16), $10 \mathrm{H}^{1}$

Sources: fluorescent light fixture

$3 / 4$ conduit, $6 \mathrm{ft}$.

duct (30 x 18:, 1/8 thick), $4 \mathrm{ft}$.

$6 "$ pipe $(6 \mathrm{ID}, 65 / 8 \mathrm{OD}, 18.97 \mathrm{lb} / \mathrm{tt}), 6 \mathrm{Ht}$

Drop H: 1 to $15^{\prime}$

Target: two $5 \times 5 \times 3 / 8$ tube welded side to side, $4 \mathrm{ft}$. $^{2}$

Sources: fluorescent light fixture-

$3 / 4$ conduit, $6 \mathrm{ft}$.

duct $(30 \times 18:, 1 / 8$ thick $), 4 \mathrm{ft}$.

6" pipe, $6 \mathrm{Ht}$

equipment cabinet, $24 \times 24 \times 10 "$

$2^{\prime} \times 2^{\prime} \times 1 / 4$ " wallboard

Drop $\mathrm{H}: 1$ to $15^{\prime}$ (for $6^{\prime \prime}$ pipe start at .5", 1", 2", 3", etc... until function realized)

Target: duct ( $30 \times 18:, 1 / 8$ thick), $12 \mathrm{ft}$.

Sources: duct $(30 \times 18:, 1 / 8$ thick $), 4 \mathrm{tt}$.

$6 "$ pipe, $6 \mathrm{ft}$

2 " conduit, $6 \mathrm{Ht}$

Drop H: 1 to $12^{\prime}$

11. Aircratt Cable Droo - Load Cells at each end ${ }^{3}$

Purpose: To gain reaction force data and to view failure modes, if any. The primary function of all of these tests is to look for trends in data.

\footnotetext{
'Priority Test: concentrate on this beam test

2priority Test: should be conducted atter \#1 priority test.

3 Priority Test: should be conducted atter $\$ 2$ priority test.
} 
Attachment 5. EES Field Procedure No. FP-351: "Cabinet Drop Tests-Car:atra Only" (11 of 12)

Savannan River Technology Center

Equipment Engineering

Seismic II// Drop Test Program

Cabinet Drop Tests - Camera Only
EES.FP-351, Rev. 0

Date Approved: $5 / 13 / 92$, Category 2

Page 11 of 12

Consideration: pivot source at one end and let it fall.

Target: aircratt cable, 1/4" dia., galvanized, $7 \times 7$ strand core, MMC \#3450T(cr 7) 32

Sources: duct ( $30 \times 18:, 1 / 8$ thick), $4 \mathrm{H}$. $2^{n}$ conduit, $6 \mathrm{th}$.

Drop H: 1 to $4^{\prime}$

III. Cabinet Drops ${ }^{4}$

Purpose: to view failure modes that may occur to battery packs and cabinets at: ached to unistrut frames during seismic events.

Target: emergency lighting battery pack

Sources: fluorescent light fixture ceiling panel $3 / 4$ conduit, 6 it. incandescent light fixture

Drop H: 1 to $12^{\prime}$

Target: electrical cabinet attached to unistrut frame

Sources: fluorescent light fixture $3 / 4$ conduit, $6 \mathrm{ft}$. incandescent light fixture $2^{\prime} \times 2^{\prime} \times 1 / 4^{\prime \prime}$ wallboard

Drop H: 1 to $15^{\prime}$

IV Instrumented Cabinet Droos

Purpose: 10 determine effects of seismic events on relays mounted in equiprient cabinets. Relays will be monitored using data acquisition, and an accelerometer will be used to assist in corresponding impact loads to relay data.

Target: $\quad 26^{\prime \prime} \times 30^{\prime \prime} \times 7^{\prime}-6^{\prime \prime}$ equipment cabinet

Sources: fituorescent light fixture ceiling Danel $3 / 4$ conduit, $6 \mathrm{ft}$. incandescent light fixture $2^{\prime} \times 2^{\prime} \times 1 / 4^{\prime \prime}$ wallboard

Drop H: 1 to $12^{\prime}$

Anority Tests snould be rondurted first 
Attachment 5. EES Field Procedure No. FP-351: "Cabinet Drop Tests-Camera Only" (12 of" 12)

Savannah River Technology Center Equipmient Engineering Seismic II/I Drop Test Program Cabinet Croo Tests - Camera Only
EES-FP-351, Rev. 0 Date Approved: 5/13/92, Category 2 Page 12 of 12

\subsection{Attachment 2}

\section{IEST DATA SHEET}

PRE-TEST

PREPARED BY: DATE: TIME $(X X: X X):$

BRIEF DESCRIPTION OF TEST:

IF BATTERY PACK IS TARGET, IS IT OPERATIONAL? (Y/N)

DROP TARGET: DROF SOURCE \& ID:

SOURCE \& ADAPTER $W^{+}($LBS $)$: TARGET WT + (LBS):

DROP HEIGHT: SPAN OF TARGET:

IMPACT PT. ON TARGET: SOURCE ORIENTATION:

IF RELAY USED, RELAY ENERGIZED DURING DROP? (Y/N) ********************POST-TEST

BRIEF DESCRIPTION OF DAMAGE TO TARGET:

IF BATTERY PACK IS TARGET, IS IT OPERATIONAL? (Y/N)

BRIEF DESL.RIPTION OF DAMAGE TO SOURCE:

PHOTOGRAPHS TAKEN (Y/N), ROLL AND \#:

VIDEO TAKEN (Y/N), START AND STOP POS.:

COMMENTS

ACCEPTED BY: DATE:

'Approximate weight using M\&TE category 3 equipment. 
Attachment 6. EES Procedure No. FP-370: "Supported Beam Drop Tests" (1 of 18)

\section{SEISMIC II/I DROP TEST PROGRAM}

\section{SUPPORTED BEAM DROP TESTS}

EES FIELD PROCEDURE: FP-370

Job Number: 22116

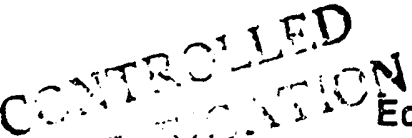

$8 / 5 / 92$

C.. Equipment Engineering Section

ID:
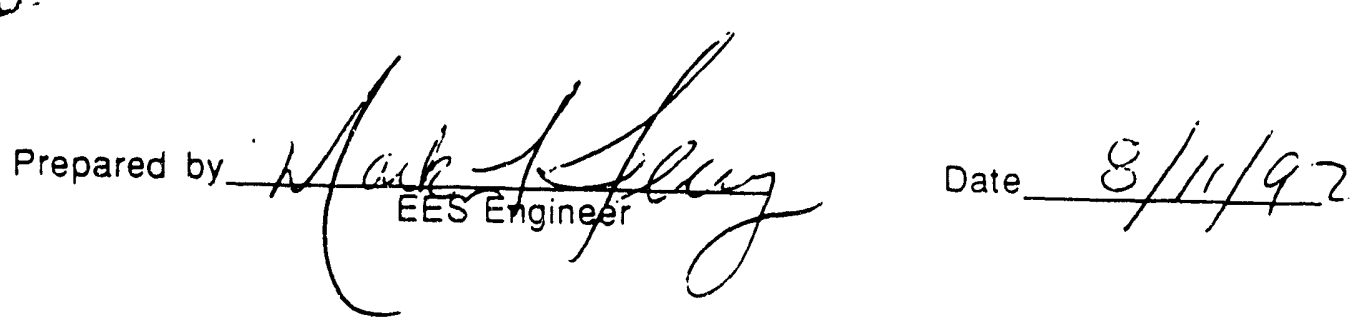

Approved by

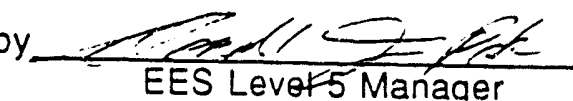

Approved by $\frac{\text { Cognizant Quality Function }}{\text { Con }}$

Date $5 / 1 / 9=$

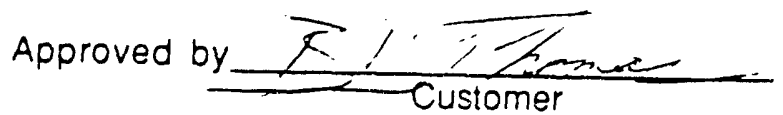

Date $\% 111 \%=$

Reviewed by $\frac{T \sum T Q S \text { anh }}{\text { EES Electrical Engineer }}$

Date $8 / 11 / 92$ 
Attachment 6. EES Procedure No. FP-370: "Supported Beam Drop Tests" (2 of 18)

Savannah River Technology Center

Equipment Engineering

Seismic I//I Drop Test Program

Supported Beam Drop Tests

\section{REV!S!OM H!STOPY LOG}

\section{Revision}

0
Date

$8 / 5 / 92$

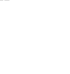

EES-FP-370, Rev. 0

Date Approved: 8/14/92, Category 2

Page 2 of 18 
Attachment 6. EES Procedure No. FP-370: "Supported Beam Drop Tests" (3 of 18)

Savannah River Technology Center Equipment Engineering Seismic II/I Drop Test Program Supported Beam Drop Tests
EES-FP-370, Rev. 0 Date Approved: $8 / 14 / 92$, Category 2

\section{TABLE OF CONTENTS}

1.0 PURPOSE

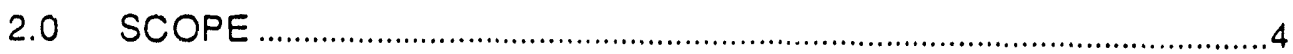

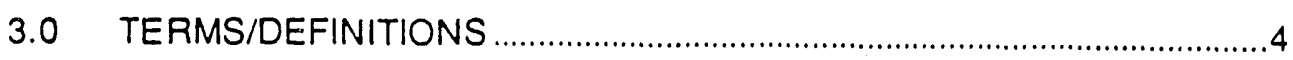

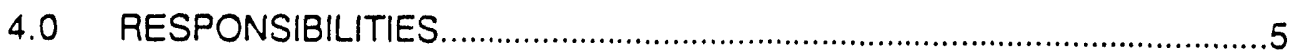

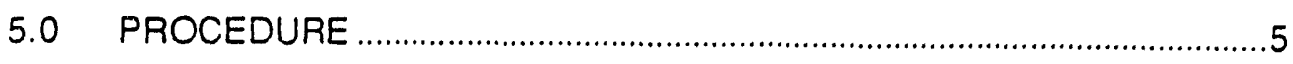

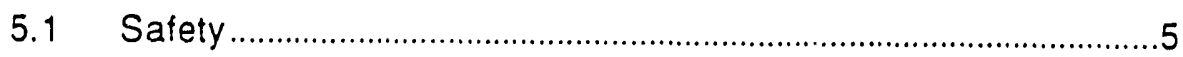

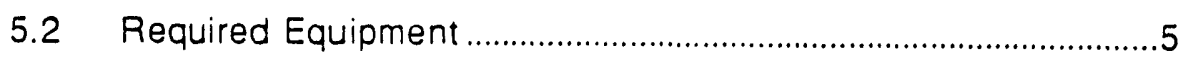

5.3 Acceptance Criteria and Test Requirements ..................................7

5.4 LABVIEW/Macintosh Calibration Procedure .................................8

5.5 Drop Test Procedure .................................................................... 8

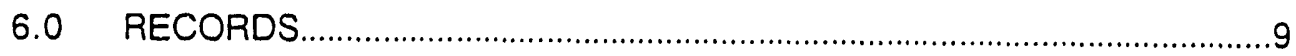

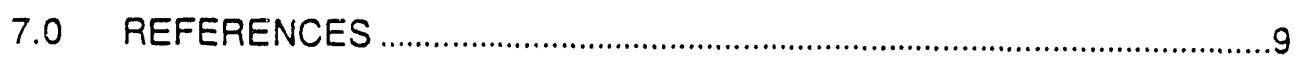

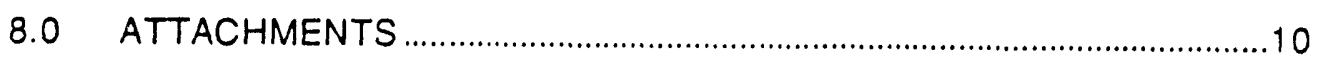


Attachment 6. EES Procedure No. FP-370: "Supported Beam Drop Tests" (4 of 18)

Savannah River Technology Center Equipment Engineering Seismic II/I Drop Test Program Supported Beam Drop Tests
EES.FP-370, Rev. $C$ Date Approved: 8/14/92, Category 2 Page 4 of 18

\subsection{PUP?OSE}

1.1 The Systems Structural Analysis group has requested Equipment Engineering to conduct several drop tests to help quantify/qualify the impact characteristics of seismic category 11 commodities that may fall and strike seismic category I commodities during a seismic event.

1.2 Four sets of tests have been requested (see Attachment 1):

- Supported beam tests where load cells are to be utilized to gather load data during the drops.

- Aircraft cable tests where load cells are utilized to gain reaction force data on cable supports.

- Cabinet drop tests to view failure modes that may occur to battery packs and cabinets attached to unistrut frames during seismic events.

- Instrumented cabinet drop tests to determine effects of seismic events on relays mounted in equipment cabinets. Relays will be monitored using data acquisition, and an accelerometer will be used to assist in corresponding impact loads to relay data.

1.3 The function of all of these tests is to look for trends in data in order to provide a baseline for comparison of seismic $1 / 1 /$ impacts and in order to gather valuable information that can be used to increase SRS engineers' expertise in evaluating seismic interaction hazards.

\subsection{This procedure applies to only the supported beam tests.}

\subsection{SCOPE}

2.1 This is a one time procedure, and only applies to activities conducted in the Equipment Engineering Section (EES) in support of the Seismic II/I Drop Test Program.

2.2 Drop testing will take place in the 723-A High-Bay Area.

2.3 All data generated by this test are intended to determine impact characteristics.

2.4 The test systems pertaining to this program are classified Production Support (PS), and the program is classified as a Task Activity.

\subsection{TERMSIDEFINITIONS}


Attachment 6. EES Procedure No. FP.370: "Supported Beam Drop Tests" (5 of' 18)

Savannah River Technology Center Equipment Engineering Seismic II/I Drop Test Program Supperted Beam Drop Tests
EES.FP.370, ReV. 0 Date Approved: $8 / 14 / 92$, Category 2 Page 5 of 18

3.1 EES - Equidment Enaineering Section

3.2 Seismic Category. 1 Commodities - a structure, system or component (SSC) which must continue to perform its required function during or after a seismic event.

3.3 Seismic Category II Commodities - synonymous with "non-seismic category I" commodities.

\subsection{RESPONSIBILITIES}

4.1 The EES Mechanical Engineers shall be responsible for:

4.1.1 Assisting EES personnel in the execution of this procedure.

4.1.2 Assisting in the coordination, scheduling and controlling activities associated with this procedure.

4.1.3 Assisting in data acquisition.

4.1.4 Instructing personnel in the use of this procedure.

4.1.5 Writing and issuing test report.

4.2 Personnel performing this test shall have received instruction from an EES Mechanical Engineer prior to testing and shall be responsible for adherence to procedure requirements.

4.3 Systems Structural Analysis group is responsible for the evaluation of the test data.

\subsection{PROCEDURE}

\subsection{Safety}

5.1.1 All applicable EES, SRTC, and SRS Safety Rules will be followed.

\subsection{Required Equipment}

\subsubsection{Drop Mechanism, Bux-shrader CE-7R.}

5.2.2 3/4" schedule 40 conduit 94" long modified per EES22116-R4-009 rev B, 6 each.

5.2.3 2" schedule 10 conduit 94" long modified per EES-22116R4-009 rev B, 2 each. 
Attachment 6. EES Procedure No. FP-370: "Supported Beam Drop Tests" (6 of' 18)

Savannah River Technology Center Equipment Engineering Seismic II// Drop Test Program Supported Beam Drop Tesis
EES.FP-370, Rev. 0

Date Approved: $8 / 14 / 92$, Category 2

Page 6 of 18

5.2.4 55" long barricade assembly, two $5^{\prime \prime} \times 5^{\prime \prime} \times 3 / 8$ " tube welded side by side as per EES-22116-R4-009 rev $B, 1$ each.

5.2.5 8' long duct assembly, two 48 " $\times 24 " \times 24 " \times 22$ gage sections fastened together, 2 each.

5.2.6 3/4" conduit, 6' long, approximately 10 each.

5.2.7 $2^{\prime} \times 4^{\prime}$ Ceiling panel, approximately 10 each.

5.2.8 $22^{\prime} \times 3^{\prime}$ transite waliboard, approximately 10 each.

5.2.9 6" pipe, 4' long (6" ID, 6-5/8" OD), 2 each.

5.2.10 Fluorescent light fixture, approximately 10 each.

5.2.11 Incandescent light fixture, approximately 10 each.

5.2.12 One $4^{\prime}$ section of $48^{\prime \prime} \times 30^{\prime \prime} \times 18^{\prime \prime} \times 1 / 8^{\prime \prime}$ thick duct, 2 each.

5.2.13 One 4' section of $48^{\prime \prime} \times 24^{\prime \prime} \times 24^{\prime \prime} \times 22$ gage, 2 each.

5.2.14 Small equipment cabinet, $24^{\prime \prime} \times 24^{\prime \prime} \times 10^{\prime \prime}, 1$ each.

5.2.15 Any other drop item that is specified by customer.

5.2.16 $20^{\prime}$ tape measure.

5.2.17 Drop Test Adapters, EES-22116-R4-001 rev A, 1 Al adapter for light objects (<10 lbs) and 1 SST adapter for heavier objects.

5.2.18 $1650 \mathrm{lb}$ load washer, Kistler 9001, M\&TE Category 1 (M\&TE \#/Expiration date to be specified on data sheets), 3 each.

5.2.19 7850 ib load washer, Kistler 9021A, M\&TE Category 1 (M\&TE \#/Expiration date to be specified on data sheets), 3 each.

5.2.20 $20200 \mathrm{lb}$ load washer, Kistler 9041A, M\&TE Category 1 (M\&TE \#/Expiration date to be specified on data sheets), 3 each. 
Attachment 6. EES Procedure No. FP.370: "Supported Beam Drop 'Tests" (7 of 18)

Savannah River Technology Center

Equipment Engineering

Seismic II/I Drop Test Program

Supported Beam Drop Tests
EES.FP. 370, Rev. 0

Date Approved: $8 / 14 / 92$, Category 2

Page 7 of 18

5.2.21 Charge amplifiers, Kistler 5004, (Identification \# to be specilled on data sheets. No M\&lt \# is required because the load cells were calibrated with a specific charge amplifier.), 3 each.

5.2:22 Charge attenuator, Kistler 5361A, (Identification \# to be specified on data sheets. No M\&TE \# is required because the load cells were calibrated with a specific charge attenuator.), to be used if needed, 3 each.

5.2.23 Cable, Kistler type 1631, 3 each.

5.2.24 Macintosh computer equipped with National Instruments Labview software, NB-MIO-16H-9 \& NB-DMA-8-G boards, RTSI cable and CB-50 l/O connector block.

5.2.25 Voltage source, M\&TE category 1 (M\&TE \# to be specified on data sheets), 1 each.

5.2.26 Multimeter, M\&TE category 1 (M\&TE \# to be specified on data sheets), 1 each.

5.2.27 High speed camera equipment.

5.5.28 Still Camera equipment.

5.2.29 Test set-up as outlined in Attachments 2, 3 and 4

5.2.30 NOTE: In the event that EES drawings are changed after or during testing, it is noted that the test fixtures and equipment shall be documented in the latest revision of the drawings. Because these drawings shall be located in the job folder along with the completed procedure, it will not be necessary to revise this procedure to document the changes in the drawings.

\subsection{Acceptance Criteria and Test Requirements}

5.3.1 Because this is a Research \& Development type task activity, acceptance criteria is not required for this test. The collection of data to determine the impact characteristics of seismic $1 / / \mathrm{l}$ is the objective of this test.

5.3.2 Damage to any of the drop commodities that is a result of a direct testing activity (i.e. dropping the items) shall not require a Nonconformance Report (NCR). 
Attachment 6. EES Procedure No. FP..370: "Supported B(am Drop Tests" (8 of' 18)

Savannah River Technology Center Equipment Engineering Seismic II// Drop Test Program Supported Beam Drop Tests
EES-FP-370, Rev. 0

Date Approved: $8 / 14 / 92$, Category 2 Page 8 of 18

\section{4}

I ARVIFW/Marintnah C.alihratinn Prncediıre

5.4.1 Calibration checks to be conducted before and after test.

5.4.2 Program Labview to acquire and report voltage directly if data acquisition program does not report raw voltage.

5.4.3 Complete top portion of Calibration Sheet, Attachment 6.

5.4.5 Connect voltage source output to appropriate channels on connector block and record voltage read off monitor on Attachment 6 for each channel checked (see table on Attachment 6 for required voltages). Simultaneously record voltage from source using multimeter to provide an additional check. IIf voltage is within $\pm 2 \mathrm{mV}$ of input voltage, it is acceptable.]

5.4.6 Record use of all M\&TE category 1 equipment on L.og Sheets, Attachment 7.

5.4.7 Calibration check complete.

5.5 Drop Test Procedure

5.5.1 Ser-up test as illustrated in Attachment 2, 3 or 4 using conduit, duct target or barricade assembly as described in Attachment 1. Pick appropriate load cell for items being dropped.

5.5.2 Attach the drop release mechanism (Bux-shrader CE-7R) to the High Bay crane. Operate the drop release mechanism according to EES Drop Test procedure L9.2-3602 Rev. 1.

5.5.3 Complete Pre test section of Test Data Sheet, Attachment 5.

5.5.4 Connect load washers to amplifiers. Use Attenuator if needed. Record use of M\&TE category 1 load washers, attenuators and amplifiers on Log Sheet. Attachment 7. NOTE: Load washers may need to be changed at this point when advancing to next test.

5.5.5 Connect amplifiers to appropriate connector block terminals.

5.5.6 Create time history file that will be used to acquire data.

5.5.7 Complete Data Acquisition section of Attachment 5. 
Attachment 6. EES Procedure No. FP.370: "Supported Beam Drop Tests" (9 of 18)

Savannah River Technology Center

Equipment Engineering

Seismic II// Drop Test Program

Supoented Beam Drop Tests
EES-FP. 370, Rev. 0

Date Approved: $8 / 14 / 92$, Category 2

Page 9 of 18

5.5.8 Attach Drod Test Adapter (Al adapter for light objects. $<10$ Ibs, and 1 SST adapter for heavier objects) to drop object.

5.5.9 Use crane and drop release mechanism to lift object to preferred height and location using tape measure. May want to use plumb bob to align object over desired target. Reference EES Drop Test procedure L9.2-3602 Rev. 1.

5.5.10 Set-up Labview software to acquire data.

5.5.11 (Set-up high speed video if customer desires. Record start position of video on tape on Attachment 5.)

5.5.12 Countdown from 5 to alert personnel. At count of 1 Acquisitioner must start acquiring data. (At count of 0 highspeed video will be taken if customer desires.) At count of 0 release object to be dropped using drop mechanism.

5.5.13 Approximately 2 seconds after mechanism hits target stop (video and) data acquisition. (If video taken, record stop position of video on tape on Attachment 5.)

5.5.14 Complete Post Test section of Attachment 5.

5.5.15 Repeat 5.5 .3 to 5.5 .14 as desired.

5.5.16 Perform housekeeping and return High bay area to original condition.

\subsection{RECORDS}

6.1 The completed copy of this procedure shall be maintained in accordance with EES procedure 1Q28-5017.

6.2 A copy of the M\&TE user logs will be forwarded to the appropriate M\&TE custodians.

6.3 All pertinent procedures, reports and data relating to these test activities will be maintained in Job Folder 22116.

6.4 A final consolidated report that incorporates all of the drop tests will be written by EES to document the findings of the tests and will be distributed to EES Document Control and to the customer.

\subsection{REFERENCES}


Altachment 6. EES Procedure No. FP-370: "Supported Beam Drop Tests" (10 of 18)

Savannah River Technology Center Equipment Engineering Seismic II/I Drop Test Program Supported Beam Drop Tests

7.1 EES Drop Procedure 1-9.2-3602 Rev. 1

7.2 1Q28-Manual, EES Training and QA Procedure Manual.

\subsection{ATTACHMENTS}

8.1 Attachment 1. Scope of Seismic II/I Drop Tests

8.2 Attachment 2, Conduit Drop Test Set Up

8.3 Attachment 3, Duct Drop Test Set Up

8.4 Attachment 4, Barricade Drop Test Set Up

8.5 Attachment 5, Test Data Sheet

8.6 Attachment 6, Calibration Sheet

8.7 Attachment 7, M\&TE Category 1 Log Sheet
EES.FP.370, Rev. 0 Page 10 of 18 
Attachment 6. EES Procedure No. FP-370): "Supported Beam Drop Tests" (11 of 18)

Savannah River Technology Center

Equipment Engineering

Seismic II/I Drop Test Program

Supported Beam Drop Tests
EES-FP-370, Rev. 0 Date Approved: $8 / 14 / 92$, Category 2

Page 11 of 18

\subsection{Attachment 1}

\section{SCOPE OF SEISMIC II/I DROP TESTS}

1. Simply Supported (oinned) Beam Configuration - Lead Cells at Supperts

Purpose: To gain reaction force data and to view failure modes, if any. The primary function of all of these tests is to look for trends in data.

Consideration: if theta small Fx\&Fy negligible, pin supports to eliminate problem.

Target: $3 / 4 "$ conduit (27/32 ID, 1 1/8 OD), $10 \mathrm{ft}$.

Sources: fluorescent light fixture

ceiling panel

$3 / 4$ conduit, $6 \mathrm{H}$.

incandescent light fixture

wallboard

Drop H: 1 to $15^{\prime}$

Target: $\quad 2 "$ conduit $(21 / 810,25 / 16), 10 \mathrm{ft}^{\prime}$

Sources: fluorescent light fixture

$3 / 4$ conduit, $6 \mathrm{H}$.

duct ( $30 \times 18:, 1 / 8$ thick), $4 \mathrm{ft}$.

duct (24" $\times 24^{\prime \prime} \times 22$ gage), $4 \mathrm{ft}$.

6" pipe (6 ID, 6 5/8 OD, $18.97 \mathrm{lb} / \mathrm{ft}), 4 \mathrm{ft}$

Drop H: 1 to $15^{\prime}$

Target: barricade assembly, two $5 \times 5 \times 3 / 8$ tube welded side to side, $4 \mathrm{ft}{ }^{2}$

Sources: fluorescent light fixture

$3 / 4$ conduit, $6 \mathrm{ft}$.

duct $(30 \times 18: 1 / 8$ thick), $4 \mathrm{ft}$.

duct $\left(24^{\prime \prime} \times 24^{\prime \prime} \times 22\right.$ gage $), 4 \mathrm{ft}$.

6 " pipe, $4 \mathrm{ft}$

equipment cabinet, $24 \times 24 \times 10^{\prime \prime}$

wallboard

Drop $\mathrm{H}$ : 1 to $15^{\prime}$ (for 6" pipe start at . 5", 1", 2", 3", etc... until function realized)

Target: duct assembly, two $4 \mathrm{ft}$ duct sections $(24 " \times 24 " \times 22$ gage) fastened Together

Sources: duct ( $30 \times 18:, 1 / 8$ thick), $4 \mathrm{tt}$.

duct $(24 " \times 24 " \times 22$ gage $), 4 \mathrm{ft}$.

$6^{\prime \prime}$ pipe, $4 \mathrm{Ht}$

2" conduit, $6 \mathrm{H}$

Drop H: 1 to $12^{\prime}$

\footnotetext{
'Priority Test: concentrate on this beam test

2 Priority Test: should be conducted after $\# 1$ priority test
} 
Altachment 6. EES Procedure No. FP.370: "Supported Beam Drop Tess" (12 of 18)

Savannah River Technology Center

Equipment Engineering

Seismic II// Drop Test Program

Supoorted Beam Droo Tesis

II Aircratt Cahlo nron. Lead Colls at each ond ${ }^{3}$

Purpose: To gain reaction force data and to view failure modes, if any. The primary function of all of these tests is to look for trends in data.

Consideration: pivot source at one end and let it fall.

Target: aircraft cable, 1/4" dia., galvanized, $7 \times 7$ strand core, MMC \#3450T(or 7) 32

Sources: duct ( $30 \times 18:, 1 / 8$ thick), $4 \mathrm{tt}$.

duct $\left(24^{\prime \prime} \times 24^{\prime \prime} \times 22\right.$ gage $), 4 \mathrm{ft}$.

2 " conduit, $6 \mathrm{ft}$.

Drop H: 1 to $4^{\prime}$

III. Cabinet Droos ${ }^{4}$

Purpose: to view failure modes that may occur to battery packs and cabinets attached to unistrut frames during seismic events.

Target: emergency lighting battery pack

Sources: fluorescent light fixture ceiling panel $3 / 4$ conduit, $6 \mathrm{tt}$. incandescent light fixture

Drop H: 1 10 12'

Target: electrical cabinet attached to unistrut frame

Sources: fluorescent light fixture $3 / 4$ conduit, $6 \mathrm{tt}$. incandescent light fixture wallboard

Drop H: $11015^{\prime}$

IV. Instrumented Cabinet Droos

Purpose: to determine effects of seismic events on relays mounted in equipment cabinets. Relays will be monitored using data acquisition, and an accelerometer will be used to assist in corresponding impact loads to relay data.

Target: $\quad 26^{\prime \prime} \times 30^{\prime \prime} \times 7^{\prime}-6^{\prime \prime}$ equipment cabinet

Sources: fluorescent light fixture

ceiling panel

$3 / 4$ conduit, $6 \mathrm{tt}$.

incandescent light fixture wallboard

Drop H: 1 to $12^{\prime}$
EES.FP-370, Rev. 0

Page 12 of 18 
Attachment 6. EES Procedure No. FP.370): "Supported Beam Drop Tes(s" (13 of 18)

Savanriah River Technology Cenier

Equipment Engineering

Seismic 11// Drop Test Program

Supoorted Beam Droo Tesis
EES-FP.370, Rev 0

Date Approved: $8 / 14 / 92$, Category 2

Page 13 of 18

\subsection{Attachment 2}

CONDUIT DROP TEST SET UP

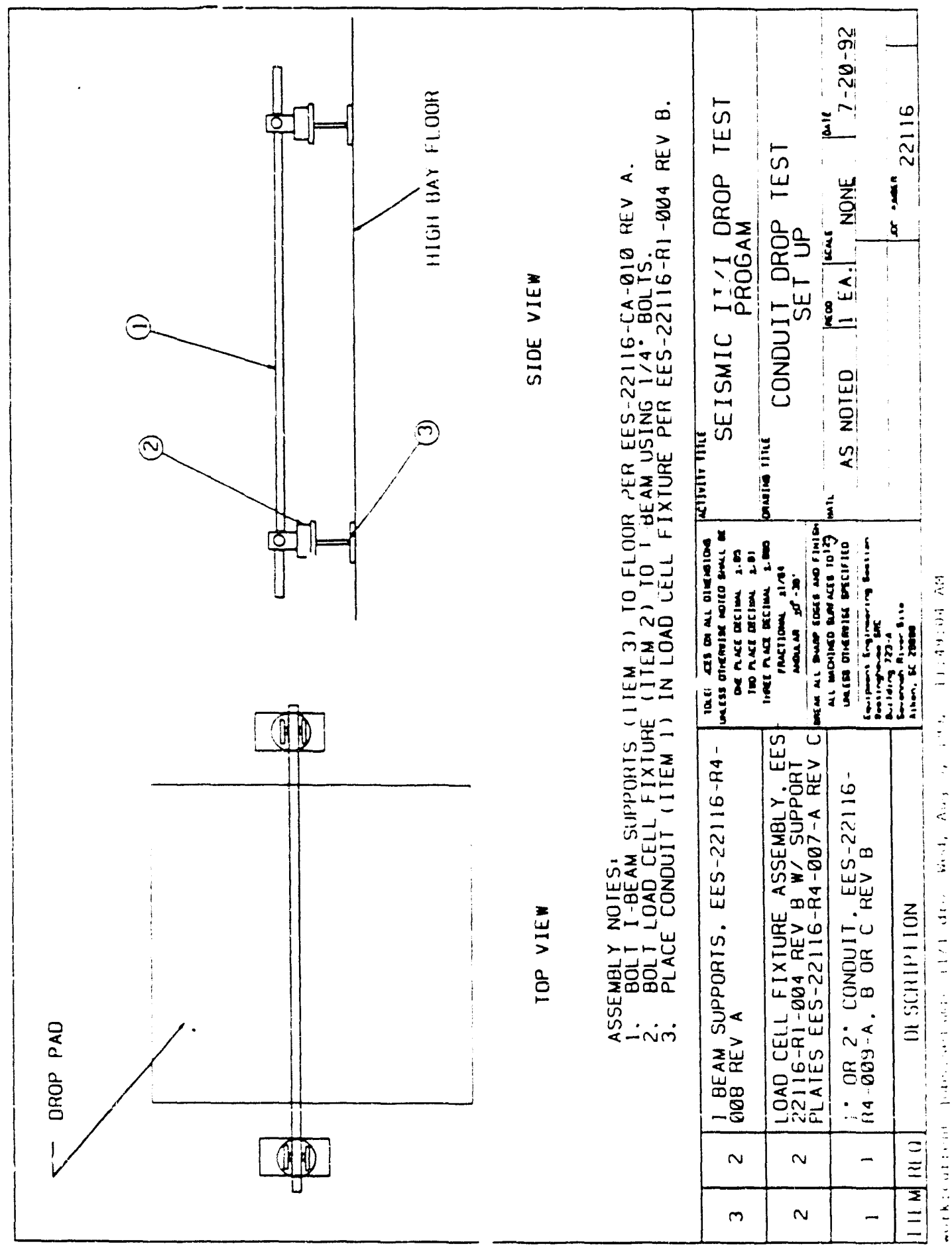


Attachment 6. EES Procedure No. FP.370: "Supported Beam Drop Tests" (14 of 18)

Savannah River Technology Center Equipment Engineering Seismic II/I Drop Test Program Supported Beam Droo Tests
EES.FP.370, Rev. 0 Date Approved: 8/14/92, Category 2

Page 14 of 18

0.3 Aitachitienti 3

DUCT DROP TEST SET UP
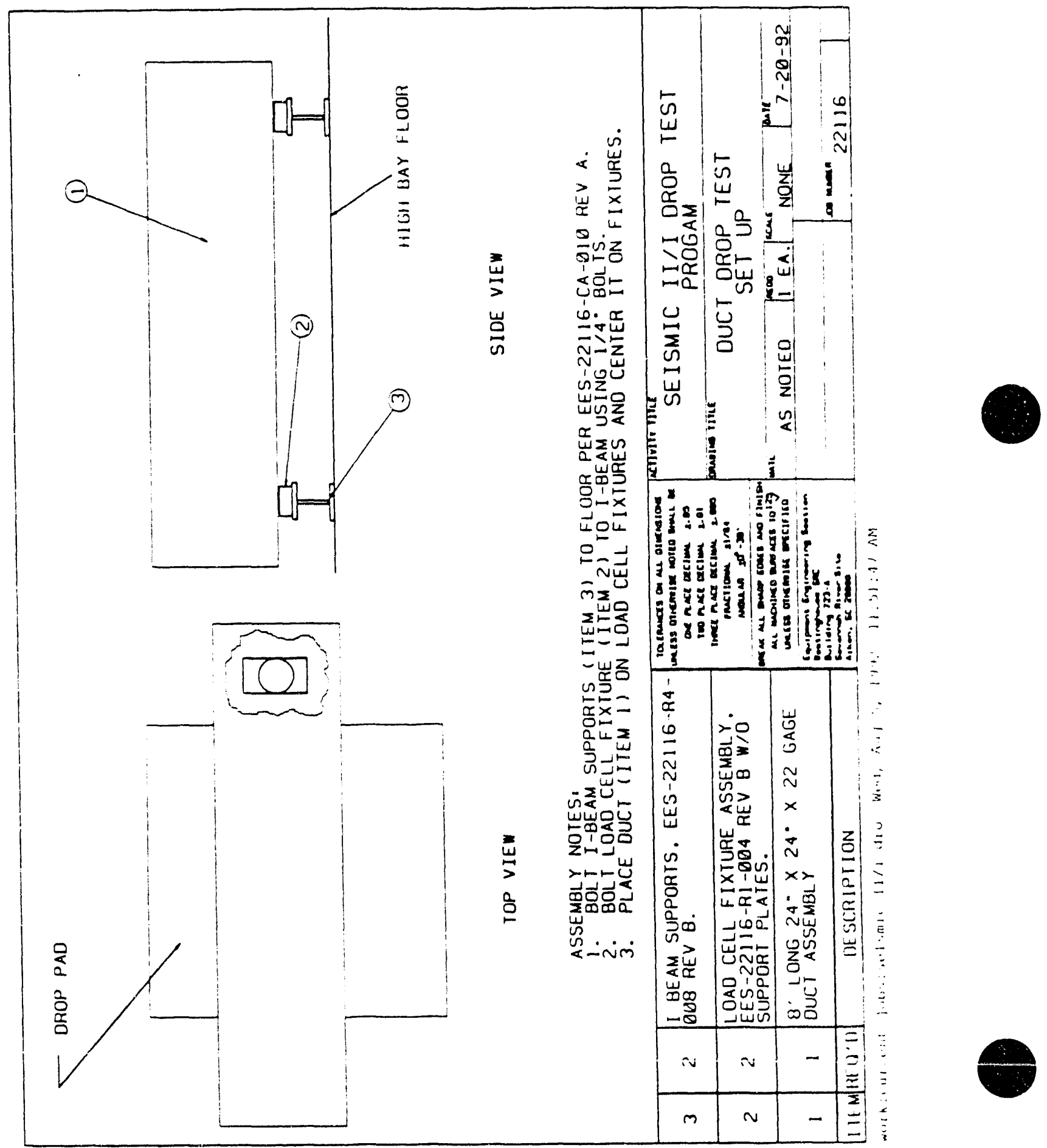
Attachment 6. EES Procedure No. FP.370: "Supported Beam Drop Tests" (15 of 18)

Savannah River Technology Center Equipment Engineering Seismic II/I Drop Test Program Supoorted Beam Drop Tests
EES.FP. 370 , Rev. 0 Date Approved: $8 / 14 / 92$ Category 2 Page 15 of 18

8.4 Attachment 4

\section{BARRICADE DROP TEST SET UP}

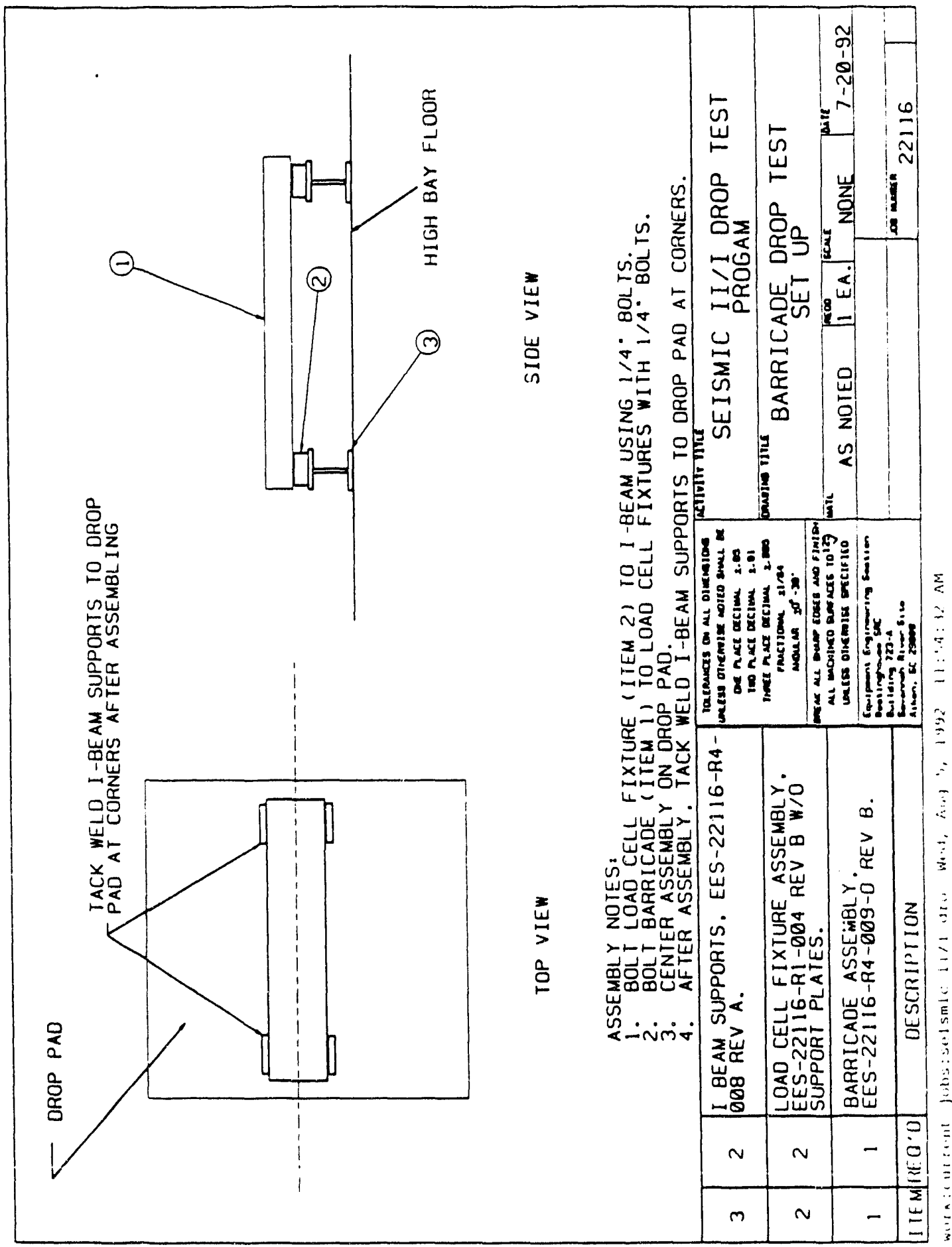


Attachment 6. EES Procedure No. FP-370: "Supported Beam Drop Tests" (16 of 18)

Savannah River Technology Center

Equipment Engineering

Seismic II// Drop Test Program

Supported Beam Drop Tests
EES-FP-370, ReV. 0

Date Approved: $8 / 14 / 92$, Category 2

Page 16 of 18

\subsection{ATTACHMEIVT 5 \\ IEST DATA SHEET \\ PRE TEST}

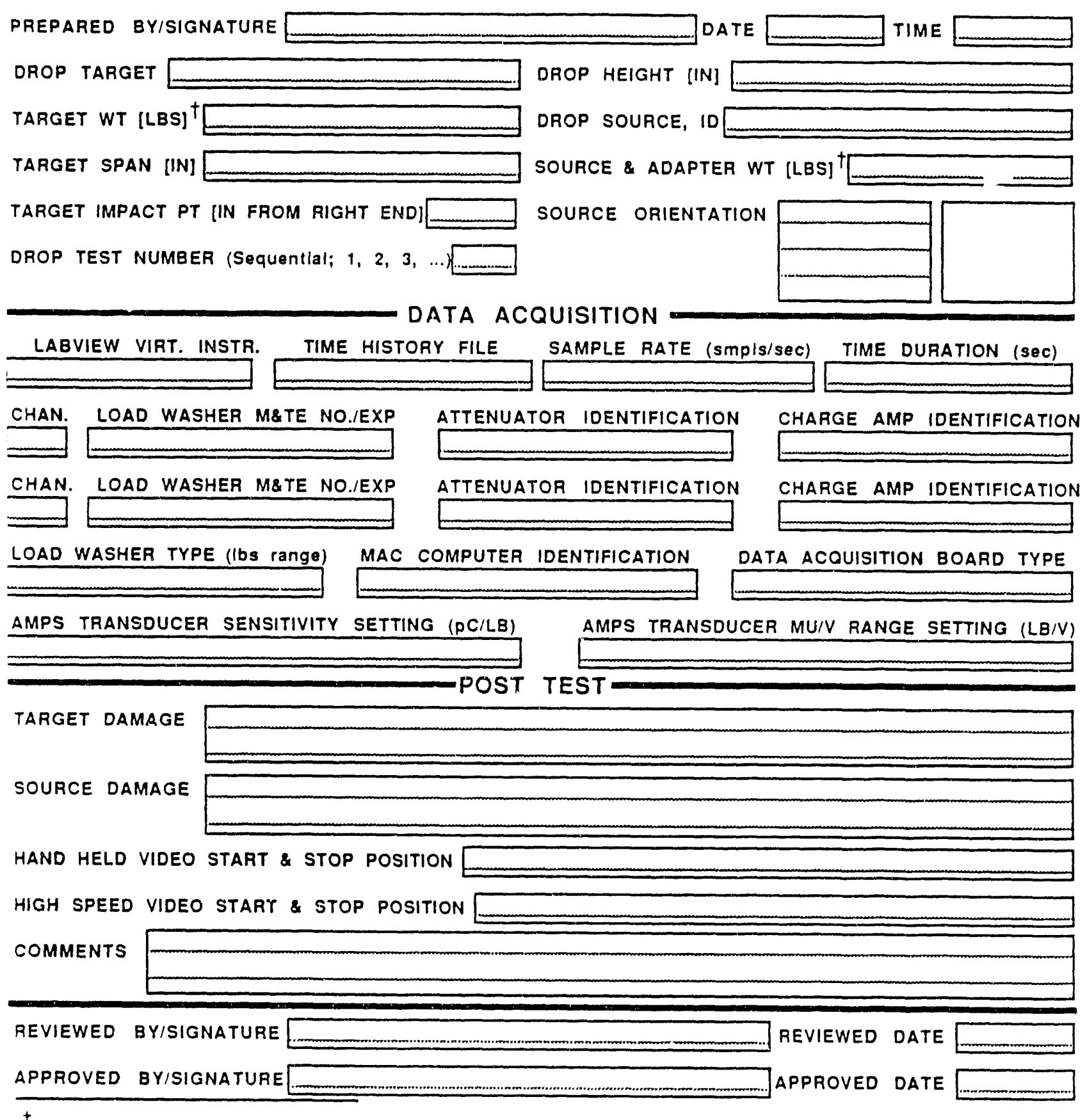

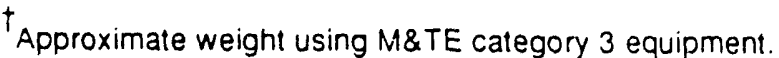


Attachment 6. EES Procedure No. FP-370: "Supported Beam Drop Tests" (17 of 18)

Savannah River Technology Center Equipment Engineering Seismic II/I Drop Test Program Supported Beam Drop Tests
EES-FP-370, Rev. 0 Date Approved: 8/14/92, Category 2

\subsection{Attachment 6}

\section{CALIBRATION SHEET}

PREPARED BY: DATE: TIME (XX:XX):

ITEM TO BE CALIBRATED/CHANNEL(s):

VOLTAGE SOURCE USED (M\&TE \#, EXPIR):

MULTIMETER USED (M\&TE \#, EXPIR):

Note: Attach copy of program (if different than data acquisition program) used to calibrate system to data sheet.

\begin{tabular}{|c|c|c|c|c|}
\hline $\begin{array}{c}\text { INPUT } \\
(V)\end{array}$ & $\begin{array}{c}\text { MULTIMETER } \\
\text { READING }(V)\end{array}$ & $\begin{array}{l}\text { CHANNEL \#: } \\
\text { READING }(V)\end{array}$ & $\begin{array}{l}\text { CHANNEL \#: } \\
\text { READING }(V)\end{array}$ & $\begin{array}{c}\text { CHANNEL \#: } \\
\text { REAOING }(V)\end{array}$ \\
\hline 010 & & & & \\
\hline 5 & & & & \\
\hline 10 & & & & \\
\hline
\end{tabular}

REVIEWED BY:

DATE:

ACCEPTED BY:

DATE: 
Attachment 6. EES Procedure No. FP.370: "Supported Beam Drop Tests" (18 of i8)

Savannah River Technology Center Equipment Engineering

Seismic II/I Drop Test Program

Supported Beam Drop Tests
EES-FP-370, Rev. 0

- Date Approved: 8/14/92, Category 2

Page 18 of 18

\section{7 Átachment 7}

\section{M\&TE CATEGORY 1 LOG SHEET}

M\&TE DEVICE:

M\&TE NO.: Calibration Expiration Date: _____

\begin{tabular}{|c|c|c|}
\hline DATE & USER'S SIGNATURE & $\begin{array}{l}\text { UNIQUE ID OF ITEM TESTED, } \\
\text { ACCEPTED OR VERIFIED }\end{array}$ \\
\hline & & \\
\hline & & \\
\hline & & \\
\hline & & \\
\hline & & \\
\hline & & \\
\hline & & \\
\hline & & \\
\hline & & \\
\hline & & \\
\hline & & \\
\hline & & \\
\hline & & \\
\hline & & \\
\hline & & \\
\hline & & \\
\hline
\end{tabular}

Authenticated By: 
Attachment 7. EES Field Procedure No. FP-380: "Aircraft Cable Drop Tests" (1 of 14)

\section{SFISMIC, II/I DROP TEST PROGRAM \\ AIRCRAFT CABLE DROP TESTS \\ EES FIELD PROCEDURE: FP-380}

Job Number: 22116

9/9/92

CONTROLLED

Equipment Engineering Section

IDENTIFICATION

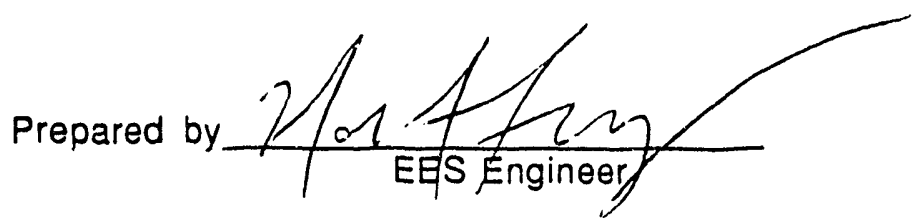

Date $i / 10 / 92$
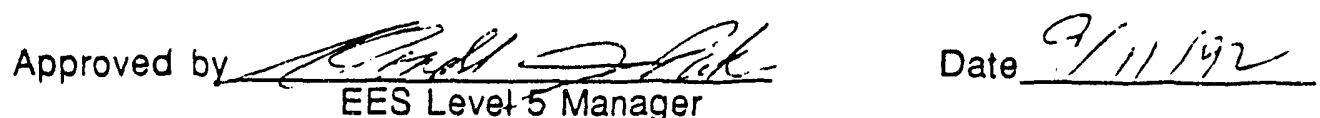

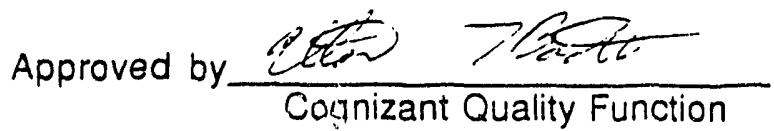

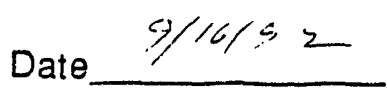

Approved by $\vec{F}, ;=$

Date $4 / 2192$

Reviewed by $\frac{T R T \text { Talank }}{\text { EES Electrical Engineer }}$

Date $9 / 16 / 92$
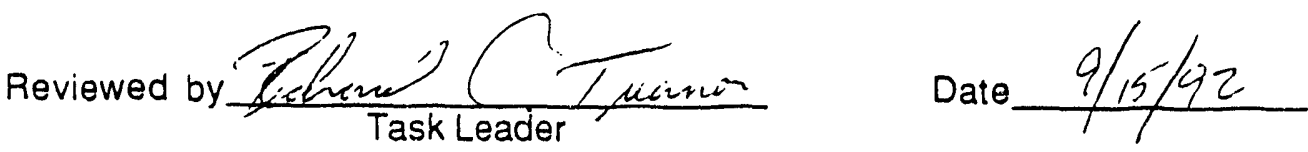
Attuchment 7. EES Field Procedure No. FP-381): "Aircraft Cable Drop Tests" (2 of 14)

Savannah River Technology Center

Equipment Engineering

Seismic II/I Drop Test Program

Aircraft Cable Drop Tests

\section{PEv!s!on! ب!story LOG}

$\begin{array}{lll}\text { Revision } & \text { Date } & \text { Descriotion of Change } \\ 0 & 9 / 9 / 92 & \text { Original issue }\end{array}$

EES-FP.380, Rev. 0

Date Approved: 9/16/92, Category 2

Page 2 of 14
$9 / 9 / 92$
Original issue 
Attachment 7. EES Field Procedure No. FP-380: "Aircraft Cable Drop Tests" (3 of 14)

Savannah River Technology Center Equipment Engineering

Seismic II/I Drop Test Program

Aircratt Cable Droo Tests

\section{TÁELE ÓF COUNTEIVTS}

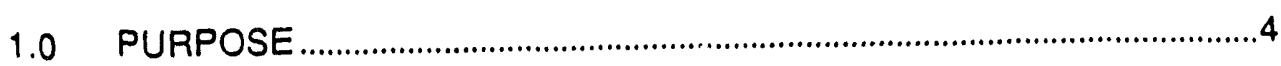

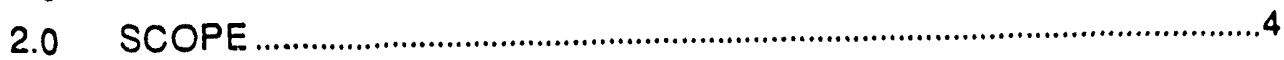

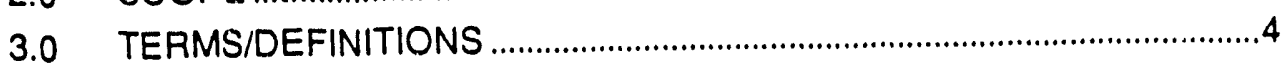

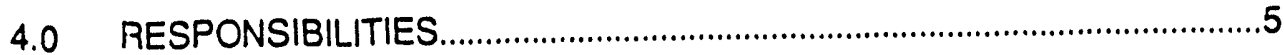

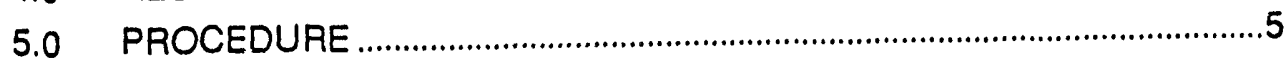

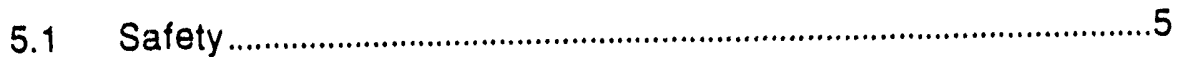

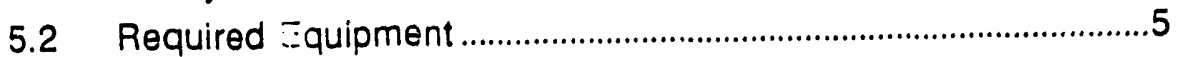

5.3 Acceptance Criteria and Test Requirements................................7

5.4 RTD 710 Calibration Check Procedure ..........................................7

5.5 Drop Test Prcsedure ...................................................................

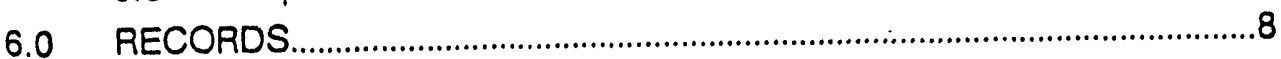

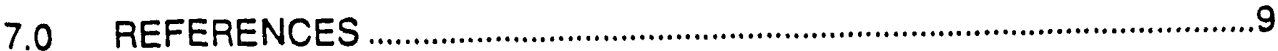

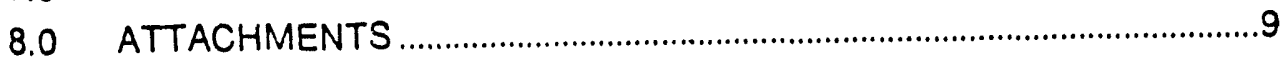


Attachment 7. EES Field Procedure No. FP-380): "Aircraft Cable Drop Tests" ( $\downarrow$ of 14$)$

Savannah River Technology Center Equipm.nt Engineering

Seismic II/I Drop Test Program Aircratt Cable Droo Tests
EES-FP-380, Rev. 0

Date Approved: 9/16/92, Category 2

Page 4 of 14

\section{i.}

1.1 The Systems Structural Analysis group has requested Equipment Engineering to conduct several drop tests to help quantify/qualify the impact characteristics of seismic category II commodities that may fall and strike seismic category I commodities during a seismic event.

1.2 Four sets of tests have been requested (see Attachment 1):

- Supported beam tests where load cells are to be utilized to gather load data during the drops.

- Aircraft cable tests where load cells are utilized to gain reaction force data on cable supports.

- Cabinet drop tests to view failure modes that may occur to battery packs and cabinets attached to unistrut frames during seismic events.

- Instrumented cabinet drop tests to determine effects of seismic events on relays mounted in equipment cabinets. Relays will be monitored using data acquisition, and an accelerometer will be used to assist in corresponding impact loads to relay data.

1.3 The function of all of these tests is to look for trends in data in order to provide a baseline for comparison of seismic $11 / 1$ impacts and in order to gather valuable information that can be used to increase SRS engineers' expertise in evaluating seismic interaction hazards.

1.4 This procedure applies to only the aircraft cable tests.

\subsection{SCOPE}

2.1 This is a one time procedure, and only applies to activities conducted in the Equipment Engineering Section (EES) in support of the Seismic II/I Drop Test Program.

2.2 Drop testing will take place in the 723-A High-Bay Area.

2.3 All data generated by this test are intended to determine impact characteristics.

2.4 The test systems pertaining to this program are classified as Production Support (PS), and the program is classified as a Task Activity.

\subsection{TERMS/DEFINITIONS}


Attachment 7. EES Field Procedure No. FP.380: "Aircraft Cable Drop Tests" (5 of 14)

Savannah River Technology Center Equipment Engineering Seismic II/I Drop Test Program Aircratt Cable Drop Tests
EES-FP-380, Rev. 0 Date Approved: 9/16/92, Category 2

Page 5 of 14

3.1 EES Equipmant Engineoring Section

3.2 Seismic Category I Commodities - a structure, system or component (SSC) which must continue to perform its required function during or after a seismic event.

3.3 Seismic Category II Commodities - synonymous with "non-seismic category I" commodities.

\subsection{RESPONSIBILITIES}

4.1 The EES Mechanical Engineers shall be responsible for:

4.1.1 Assisting EES personnel in the execution of this procedure.

4.1.2 Assisting in the coordination, scheduling and controlling activities associated with this procedure.

4.1.3 Assisting in data acquisition.

4.1.4 Instructing personnel in the use of this procedure.

4.1.5 Writing and issuing test report.

4.2 Person conducting test (preparing data sheets) is responsible for completing a M\&TE Category 1 Log Sheet (Attachment 4) for each piece of category 1 equipment used and is responsible for duplicating each log sheet and forwarding it to the appropriate M\&TE custodian.

4.3 Personnel performing this test shall have received instruction from an EES Mechanical Engineer prior to testing and shall be responsible for adherence to procedure requirements.

4.4 Systems Structural Analysis group is responsible for the evaluation of the test data.

\subsection{PROCEDURE}

\subsection{Safety}

5.1.1 All applicable EES, SRTC, and SRS Safety Rules will be followed.

5.2 Required Equipment

5.2.1 Drop Mechanism, Bux-shrader CE-7R. 
Attachment 7. EES Field Procedure No. FP-380: "Aircraft Cable Drop Tests" (6 of 14)

Savannah River Technology Center Equipment Engineering Seismic II/I Drop Test Program Aircratt Cable Drop Tests
EES-FP-380, Rev. 0

Date Approved: $9 / 16 / 92$, Category 2 Page 6 of 14

5.2.2 $2^{\prime \prime}$ schedule 10 conduit, 6 H. long, 1 each.

5.2.3 4' long duct assembly, one $48^{\prime \prime} \times 30^{\prime \prime} \times 18^{\prime \prime} \times 1 / 8^{\prime \prime}$ thick section, 1 each.

5.2.4 4' long duct assembly, one $48^{\prime \prime} \times 24^{\prime \prime} \times 24^{\prime \prime} \times 22$ gage section, 1 each.

5.2.5 Any other drop item that is specified by customer.

5.2.6 20' tape measure.

5.2.7 Drop Test Adapters, EES-22116-R4-001 rev A, 1 Al adapter for light objects (<10 lbs) and 1 SST adapter for heavier objects.

5.2.8 $4000 \mathrm{lb}$ load cell, Kistler 9332A, M\&TE Category 1 (M\&TE \#/Expiration date to be specified on data sheets), 2 each.

5.2.9 Charge amplifiers, Kistler 5004, (Identification \# to be specified on data sheets. No M\&TE \# is required because the load cells were calibrated with a specific charge amplifier.), 2 each.

5.2.10 Cable, Kistler type 1631, 3 each.

5.2.11 Macintosh computer equipped with National Instruments Labview software, NB-M1O-16H-9 \& NB-DMA-8-G boards, RTSI cable.

5.2.12 Pulse/Function Generator, M\&TE Category 1, (M\&TE \#/Expiration date to be specified on data sheets), 1 each.

5.2.13 High speed camera equipment.

5.2.14 Still Camera equipment.

5.2.15 Sony/Tektronix RTD 710A Digitizer, (ID of item to be specified on data sheets), 1 each.

5.2.16 Test set-up as per EES-22116-R1-012 rev $B$.

5.2.17 NOTE: In the event that EES drawings are changed after or during testing, the latest revision of the drawing will be noted on data sheet in the comments section. 
Attachment 7. EES Ficld Procedure No. FP-380: "Aircraft Cable Drop Tests" (7 of 14)

Savannah River Technology Center Equipment Engineering Seismic II/I Drop Test Program Aircratt Cable Droo Tests
EES.FP. 380 , Rev, 0

Date Approved: 9/16/92, Category 2 Page 7 of 14

\subsection{Accoptanco Crito!la and Tes! Requiroments}

5.3.1 There is no acceptance criteria for this task because the purpose of this test is to gather test data to determine the impact characteristics of seismic II/I objects.

5.3.2 Damage to any of the drop commodities that is a result of a direct testing activity (i.e. dropping the items) shall not require a Nonconformance Report (NCR).

\subsection{RTD 710 Calibration Check Procedure}

5.4.1 Calibration checks to be conducted before and after test.

5.4.2 Complete top portion of Calibration Sheet (Attachment 3) and set RTD settings to those specified on Attachment 3.

5.4.3 Connect pulse/function generator output to appropriate channels on RTD. Set generator to sine or square wave with peaks at \pm 10 VDC, \pm 5 VDC $\pm 100 \mathrm{mVDC}$ and 0 VDC with a period of your choice as shown on Attachment 3 . Record peak voltages and period off RTD on Attachment 3 for each channel. Document generator and RTD settings on Attachment 3.

5.4.4 Record use of all M\&TE category 1 equipment on Log Sheets, Attachment 4.

5.4.5 Calibration check complete.

5.5 Drop Test Procedure

5.5.1 Set-up test as illustrated in EES-22116-R1-012 rev B.

5.5.2 Attach the drop release mechanism (Bux-shrader CE-7R) to the High Bay crane. Operate the drop release mechanism according to EES Drop Test procedure L9.2-3602 Rev. 1.

5.5.3 Complete Pre test section of Test Data Sheet, Attachment 2.

5.5.4 Connect load cell to amplifiers. Record use of M\&TE category 1 load cell and amplifiers on Log Sheet. Attachment 4.

5.5.5 Conne'ct amplifiers to channels 1 \& 2 on RTD.

5.5.6 Compl'ste Data Acquisition section of Attachment 2. 
Attachment 7. EES Field Procedure No. FP-380: "Aircraft Cable Drop Tests" (8 of' 1f)

Savannah River Technology Center Equipment Engineering

Seismic II/I Drop Test Program

Aircraft Cable Droo Tests
EES.FP-380, Rev. 0

Date Approved: 9/16/92, Category 2

Page 8 of 14

5.5.7 Attach Diop Test Adapter (A.! adaptor for light objocts, <10 Ibs, and 1 SST adapter for heavier objects) to drop object.

5.5.8 Use crane and drop release mechanism to lift object to preferred height and location using tape measure. May want to use plumb bob to align object over desired target. Reference EES Drop Test procedure L9.2-3602 Rev. 1.

\subsubsection{Set-up RTD to acquire data.}

5.5.10 (Set-up high speed video if customer desires. Record start position of video on tape on Attachment 2.)

5.5.11 Countdown from 3 to alert personnel. (At count of 0 highspeed video will be taken if customer desires.) At count of 0 release object to be dropped using drop mechanism.

5.5.12 (If video taken, stop video when desire and record stop position of video on tape on Attachment 2.)

\subsubsection{Complete Post Test section of Attachment 2.}

5.5.14 Use Mac computer with Labview and GPIB cable to transfer data from RTD to disk for future manipulations. Plot data using plotter and RTD if desired.

\subsubsection{Repeat 5.5.3 to 5.5.14 as desired.}

5.5.16 Perform housekeeping and return High bay area to original condition.

\subsection{RECORDS}

6.1 The completed copy of this procedure shall be maintained in accordance with EES procedure 1028-5017.

6.2 A copy of the M\&TE user logs will be forwarded to the appropriate M\&TE custodians.

6.3 All pertinent procedures, reports and data relating to these test activities will be maintained in Job Folder 22116.

6.4 A final consolidated report that incorporates all of the drop tests will be written by EES to document the findings of the tests and will be distributed to EES Document Control and to the customer. 
Atlachment 7. EES Field Procedure No. FP-380: "Aircraft Cable Drop Tests" (9 of 14)

Savannah River Technology Center Equipment Engineering Seismic II// Drop Test Program Aircraft Cable Droo Tests

\section{2 모드드모!!도}

7.1 EES Drop Procedure L9.2-3602 Rev. 1

7.2 Q28-Manual, EES Training and QA Procedure Manual.

\subsection{ATTACHMENTS}
8.1 Attachment 1, Scope of Seismic II/I Drop Tests
8.2 Attachment 2, Test Data Sheet
8.3 Aitachment 3, Calibration Sheet
8.4 Attachment 4, M\&TE. Category 1 Log Sheet

EES-FP.380, Rev. 0 Date Approved: 9/16/92, Category 2

Page 9 of 14 
Attachment 7. EES Field Procedure No. FP-380: "Aircraft Cable Drop Tests" (10 of 14)

Savannah River Technology Center Equipment Engineering Seismic 11/I Drop Test Program Aircraft Cable Droo Tests
EES-FP. 380 , Rev 0

Date Approved: $9 / 16 / 92$, Category 2

Page 10 of 14

\subsection{Attachment 1}

\section{SCOPE OF SEISMIC IIII DROP TESTS}

L. Simoly Supported (oinned) Beam Configuration - Lead Cells at Supoorts

Purpose: To ga i, reaction force data and to view failure modes, if any. The primary function of all of these tests is to look for trends in data.

Consideration: if theta small Fx\&Fy negligible, pin supports to eliminate problem.

Target: $3 / 4^{\prime \prime}$ conduit (27/32 ID, $11 / 8$ OD), $10 \mathrm{ft}$.

Sources: fluorescent light fixture

ceiling panel

$3 / 4$ conduit, $6 \mathrm{tt}$.

incandescent light fixture wallboard

Drop H: 1 to $15^{\prime}$

Target: $2^{\prime \prime}$ conduit $\left(21 / 8\right.$ ID, 25/16), $10 \mathrm{ft}^{1}$

Sources: fluorescent light fixture

$3 / 4$ conduit, $6 \mathrm{ft}$.

duct ( $30 \times 18:, 1 / 8$ thick), $4 \mathrm{H}$.

duct (24" $\times 24^{\prime \prime} \times 22$ gage), $4 \mathrm{tt}$.

Drop $\mathrm{H}: \quad 1$ to $15^{\prime}$

6" pipe (6 ID, $65 / 8$ OD, $18.97 \mathrm{lb} / \mathrm{tt}), 4 \mathrm{ft}$

Target: barricade assembly, two $5 \times 5 \times 3 / 8$ tube welded sida to side, $4 \mathrm{ft}^{2}$

Sources: fluorescent light fixture

$3 / 4$ conduit, 6 th.

duct ( $30 \times 18:, 1 / 8$ thick), 4 tt.

duct $\left(24^{\prime \prime} \times 24^{\prime \prime} \times 22\right.$ gage $), 4 \mathrm{ft}$.

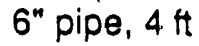

equipment cabinet, $24 \times 24 \times 10^{n}$

wallboard

Drop H: 1 to $15^{\prime}$ (for $6^{\prime \prime}$ pipe start at .5", $1^{n}, 2^{n}, 3^{n}$, etc... until function realized)

Target: duct assembly, two 4 ft duct sections $\left(24^{\prime \prime} \times 24^{\prime \prime} \times 22\right.$ gage) fastened together

Sources: duct ( $30 \times 18:, 1 / 8$ thick), 4 ft.

duct $\left(24^{\prime \prime} \times 24^{\prime \prime} \times 22\right.$ gage $), 4 \mathrm{ft}$.

$6^{\prime \prime}$ pipe, $4 \mathrm{tt}$

$2^{\prime \prime}$ conduit, $6 \mathrm{ft}$

Drop $H: \quad 1$ to $12^{\prime}$

'Priority Test: concentrate on this beam test

2Priority Test: should be conducted after \#1 priority test. 
Attachment 7. EES Field Procedure No. FP-380): "Aircraft Cable Drop Tests" (11 of 14)

Savannah River Technology Center Equipment Engineering

Seismic II/I Drop Test Program Aircraft Cable Drop Tests

11. Aircratt Cable Drno - Load Cells at each end ${ }^{3}$

Purpose: To gain reaction force data and to view failure modes, if any. The primary function of all of these tests is to look for trends in data.

Consideration: pivot source at one end and let it fall.

Target: aircraft cable, 1/4" dia., galvanized, $7 \times 7$ strand core, MMC \#3450T(or 7) 32

Sources: duct ( $30 \times 18:, 1 / 8$ thick), $4 \mathrm{ft}$ duct $\left(24^{\prime \prime} \times 24^{n} \times 22\right.$ gage $), 4 \mathrm{ft}$. $2^{n}$ conduit, $6 \mathrm{ft}$.

Drop H: 1 to $4^{\prime}$

lii. Cabinet Drops ${ }^{4}$

Purpose: to view failure modes that may occur to battery packs and cabinets attached to unistrut frames during seismic events.

Target: emergency lighting battery pack

Sources: fluorescent light fixture ceiling panel $3 / 4$ conduit, $6 \mathrm{ft}$. incandescent light fixture

Drop H: 1 to $12^{\prime}$

Target: electrical cabinet attached to unistrut frame

Sources: fluorescent light fixture $3 / 4$ conduit, $6 \mathrm{ft}$. incandescent light fixture wallboard

Drop H: 1 to $15^{\prime}$

IV. Instrumented Cabinet Drops

Purpose: to determine effects of seismic events on relays mounted in equipment cabinets. Relays will be monitored using data acquisition, and an accelerometer will be used to assist in corresponding impact loads to relay data.

Target: $\quad 26^{\prime \prime} \times 30^{\prime \prime} \times 7^{\prime}-6^{\prime \prime}$ equipment cabinet

Sources: fluorescent light fixture

ceiling panel

$3 / 4$ conduit, $6 \mathrm{ft}$.

incandescent light fixture wallboard

Drop H: 1 to 12

3 Priority Test: should be conducted after \#2 priority test.

${ }^{4}$ Priority Tests: should be conducted first. 
Attachment 7. EES Field Procedure No. FP-380: "Aircraft Cable Drop Tests" (12 of 14)

Savannah River Technology Center

Equipment Engineering

Seismic II// Drop Test Program

Aircraft Cable Drop Tests
EES-FP-380, Rev. 0

Date Approved: 9/16/92, Category 2

Page 12 of 14

\subsection{ATTACHMENT 2 \\ TEST DATA SHEET}

PRE TEST

prepared by/signatuae

DROP HEIGHT [IN] (Measured from top of cable support)

SHORTEST POSSIBLE DIST [IN] BETWEEN

CABLE SUPPORTS [IN] (EES-22116-R1-012)

DROP SOURCE, 10

LENGTH OF CABLE/LOAD CELL

ASSEMBLY (IN)

SOURCE \& ADAPTER WT [LBS]

DROP TEST NUMBER (Sequential; $1,2,3, \ldots$

DATA ACQUISITION

CHANNEL 1 \& CHANNEL 1 \& TRIGGER SOURCE ORIENTATION
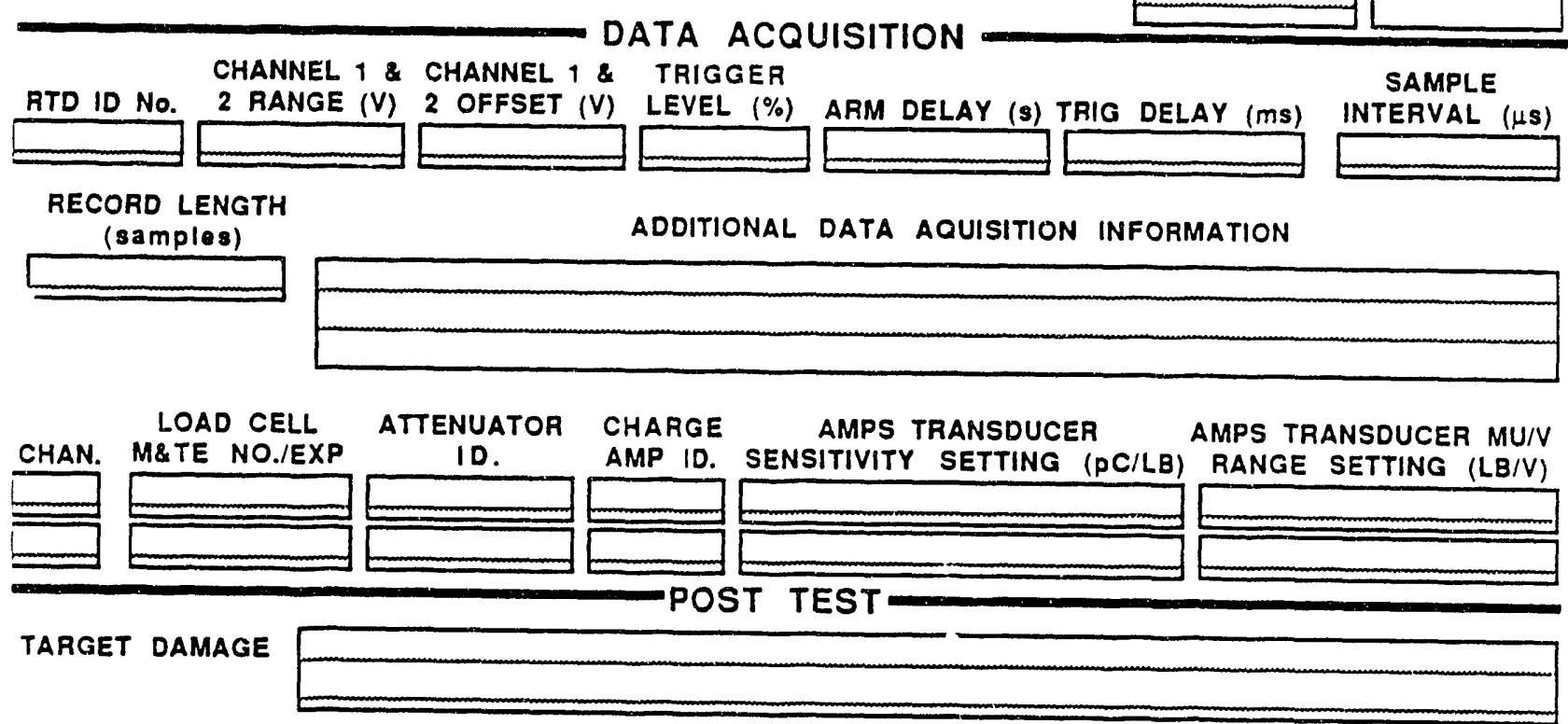

SOURCE DAMAGE

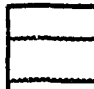

HAND HELD VIDEO START \& STOP POSITION

HIGH SPEED VIDEO START \& STOP POSITION

COMMENTS
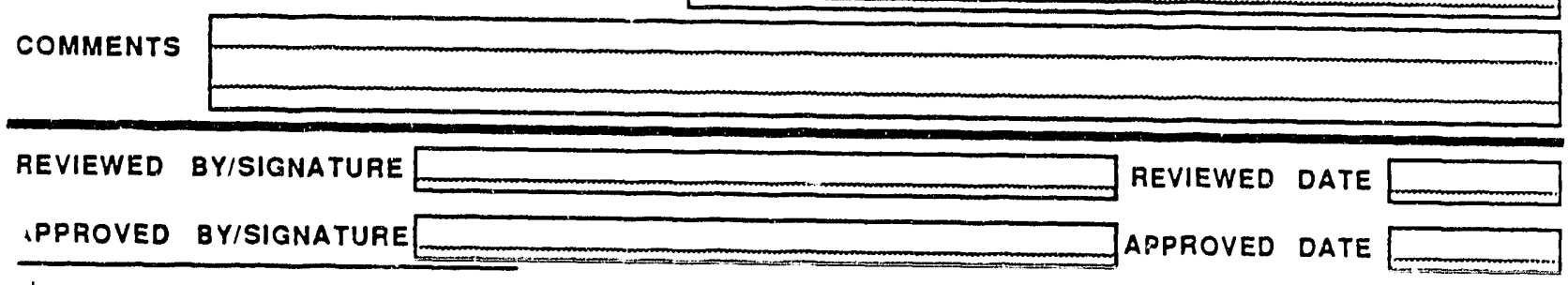

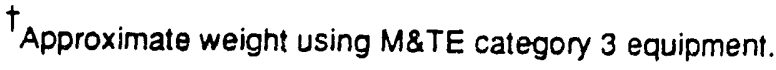


Attachment 7. EES Ficld Procedure Pio. FP-380: "Aircraft Cable Drop Tests" (13 of 14)

Savannah River Technology Center Equipment Engineering Seismic II// Drop Test Program Aircraft Cable Drop Tests
EES-FP-380, Rev. 0 Date Approved: 9/16/92, Category 2 Page 13 of 14

\subsection{Attachment 3}

\section{CALIBRATION SHEEI}

PREPARED BY:

DATE: TIME (XX:XX):

ITEM TO BE CALIBRATED/CHANNEL(s):

PULSE FUNCTION GENERATOR USED (M\&TE \#, EXPIR):

RTD SETTINGS

Channel 1 range:

$\checkmark$ Channel 2 range:

Channel 1 ofiset:

Channel 2 offset:

$\frac{V}{V}$

Trigger level:

Trigger delay:

Record length:

Arm delay:

ms Sample interval:

Any other documented settings:

\section{PULSE/FUNCTION GENERATOR SETTINGS}

Duty cycle:

Wave type:

Any other documented settings:

\begin{tabular}{|c|c|c|c|c|c|}
\hline \multicolumn{2}{|c|}{ PULSE FUNCTION GENERATOR } & \multicolumn{2}{|c|}{ CHANNEL 1} & \multicolumn{2}{|c|}{ CHANNEL 2} \\
\hline $\begin{array}{c}\text { INPUT } \\
\text { (V) }\end{array}$ & $\begin{array}{l}\text { PERIOD } \\
\text { (s) } \\
\end{array}$ & $\begin{array}{c}\text { RTD PERIOD } \\
\text { (s) }\end{array}$ & $\begin{array}{c}\text { RTD PEAK } \\
\text { READING (V) }\end{array}$ & $\begin{array}{c}\text { RTD PERIOD } \\
\text { (S) }\end{array}$ & $\begin{array}{c}\text { RTD PEAK } \\
\text { READING (V) }\end{array}$ \\
\hline \multicolumn{6}{|l|}{0} \\
\hline \multicolumn{6}{|l|}{0.10} \\
\hline \multicolumn{6}{|l|}{5} \\
\hline 10 & & & & & \\
\hline
\end{tabular}

REVIEWED BY:

DATE:

ACCEPTED BY:

DATE: 
Attachment 7. EES Field Procedure No. FP.380: "Aircraft Cable Drop Tests" (14 of 14)

Savannah River Technology Center Equipment Engineering Seismic II/I Drop Test Program Aircraft Cable Drop Tests

\subsection{Attachment 4}

\section{M\&IE CATEGORY 1 LOG SHEET}

M\&TE DEVICE:

M\&TE NO.: Calibration Expiration Date:

\begin{tabular}{|c|c|c|}
\hline DATE & USER'S SIGNATURE & $\begin{array}{c}\text { UNIQUE ID OF ITEM TESTED, } \\
\text { ACCEPTED OR VERIFIED }\end{array}$ \\
\hline
\end{tabular}

Authenticated By:
EES-FP-380, Rev. 0 Date Approved: 9/16/92, Category 2

\begin{tabular}{|l|l|l|}
\hline & & \\
\hline & & \\
\hline & & \\
\hline & & \\
\hline & & \\
\hline & & \\
\hline & & \\
\hline & & \\
\hline & & \\
\hline
\end{tabular}


Seismic II Over I Drop Test Program

Results and Interpretation

WSRC.TR-93-0094

Attachment 8. EES Field Procedure No. FP-379: "Instrumented Cabinet Drop Tests" (1 of 18)

SEISMIC. II! DROP TEST PROGRAM!

INSTRUMENTED CABINET DROP TESTS

BES FIELD PROCEDURE: FP-379

Job Number: 22116

Date Drafted: $9 / 21 / 92$

Effective Date: $9 / 24 / 92$

Equipment Engineering Section CONTROLLED IDENTIFICATION
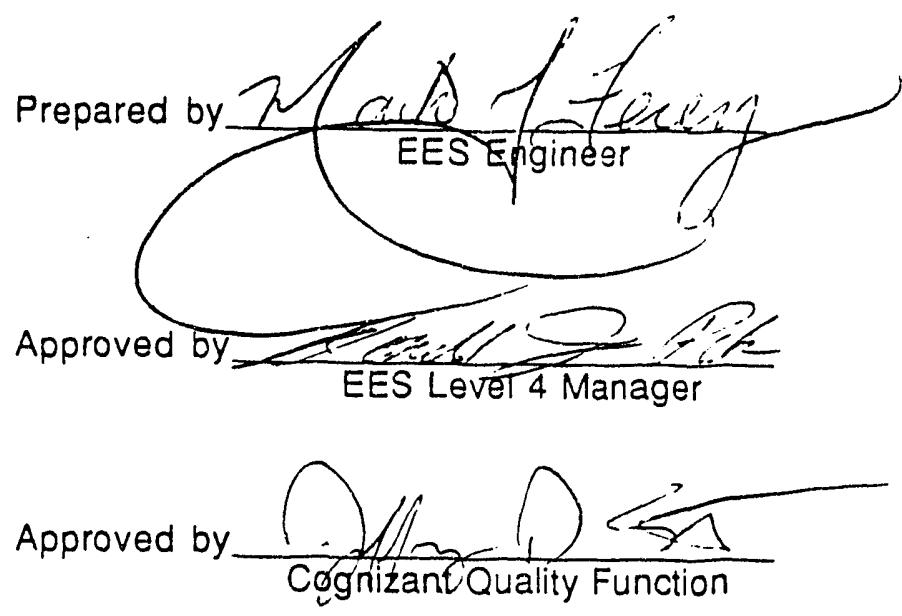

Approved by

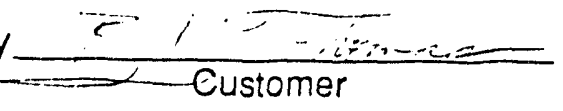

Reviewed by elan \&. dm an

EES Electrical Engineer

Reviewed by

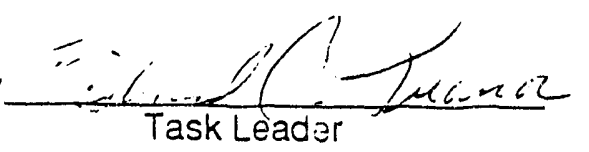

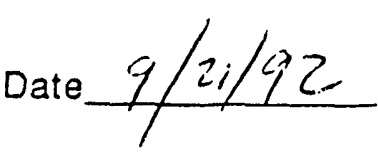

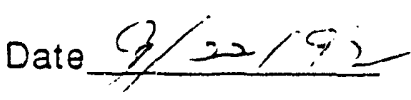

Date $9 / 23 / 6,2$

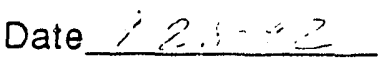

Date $9 / 22 / 42$

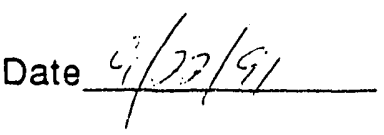

$93 \times(1212 . \mathrm{MWO}$ 
Attachment 8. EES Field Procedure No. FP.379: "Instrumented Cabinet Drop Tests" (2 of 18)

Savannah River Technology Center Equipment Engineering Seismic II/I Drop Test Program Instrumented Cabinet Drop Tests

REVISION HISTORY LOG

\section{Revision}

0
Date

9/21/92
EES-FP-379, Rev. 0 Effective Date: $9 / 24 / 92$, Category 2 Page 2 of 18

$9 / 21 / 92$

\section{Description of Change}

Original Issue 
Attachment 8. EES Field Procedure No. FP-379: "Instrumented Cabinet Drop Tests" (3 of 18)

Savannah River Technology Center Equipment Engineering Seismic II/I Drop Test Program Instrumented Cabinet Drop Tests

TABLE OF CONTENTS

10 PURPOSE

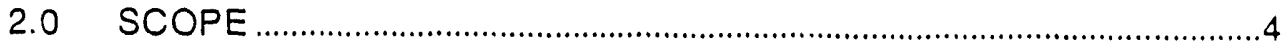

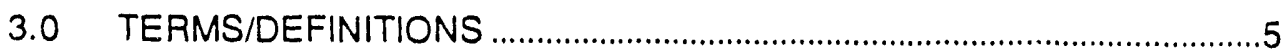

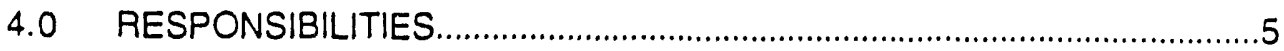

5.0 PROCEDURE

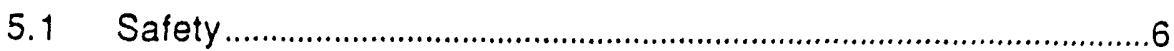

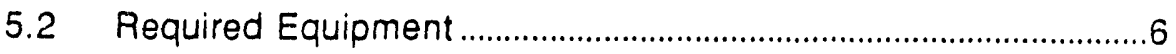

5.3 Acceptance Criteria and Test Requirements..................................7

5.4 RTD 710 Calibration Check Procedure ...........................................7

5.5 Drop Test Procedure ....................................................................

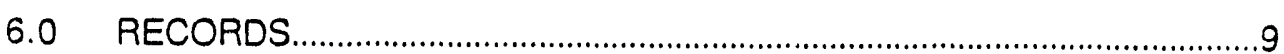

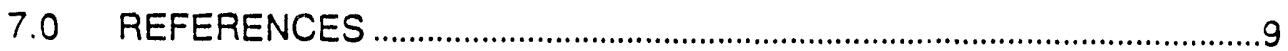

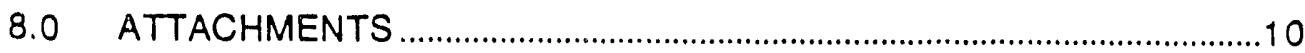


Attachment 8. EES Field Procedure No. FP-379: "Instrumented Cabinet Drop Tests" (4 of 18)

Savannah River Technology Center Equipment Engineering

Seismic II/I Drop Test Program Instrumented Cabinet Drop Tests
EES-FP-379, ReV. 0

Effective Dat?: $9 / 24 / 92$, Category 2

Page 4 of 18

\subsection{RURPOUSE}

1.1 The Systems Structural Analysis group has requested Equipment Engineering to conduct several drop tests to help quantify/qualify the impact characteristics of seismic category 11 commodities that may fall and strike seismic category I commodities during a seismic event.

1.2 Four sets of tests have been requested (see Attachment 1):

- Supported beam tests where load cells are to be utilized to gather load data during the drops.

- Aircraft cable tests where load cells are utilized to gain reaction force data on cable supports.

- Cabinet drop tests to view failure modes that may occur to battery packs and cabinets attached to unistrut frames during seismic events.

- Instrumented cabinet drop tests to determine effects of seismic events on relays mounted in equipment cabinets. Relays will be monitored using data acquisition, and an accelerometer will be used to assist in corresponding impact loads to relay data.

1.3 The function of all of these tests is to look for trends in data in order to provide a baseline for comparison of seismic $1 / / 1$ impacts and in order to gather valuable information that can be used to increase SRS engineers' expertise in evaluating seismic interaction hazards.

1.4 This procedure applies to only the instrumented cabinet drop tests.

\subsection{SCOPE}

2.1 This is a one time procedure, and only applies to activities conducted in the Equipment Engineering Section (EES) in support of the Seismic II/I Drop Test Program.

2.2 Drop testing will take place in the 723-A High-Bay Area.

2.3 All data generated by this test are intended to determine impact characteristics.

2.4 The test systems pertaining to this program are classified as Production Support (PS), and the program is classified as a Task Activity. 
Attachment 8. EES Ficld Procedure No. FP.379: "Instrumented Cabinet Drop Tests" (5 of" 18)

Savannah River Technology Center Equipment Engineering

Seismic II/I Drop Test Program Instrumented Cabinet Drop Tests
EES-FP-379, Rev. 0

Effective Date: $9 / 24 / 92$, Category 2

Page 5 of 18

2.5 A scoping activity to determine the effects of Westinghouse and Potter Brumfield relays lightly impacting a table while relays were in de-energized state was conducted on 9/10/92 by Ted Talarek and Mark Ferencz of E\&MT. The results indicated that the normally closed contacts open when the relays are lightly impacted. Therefore, it is not the intention of this test to determine the impact characteristics of the relay's normally closed contacts while the relays are de-energized. However, provisions have been made in this procedure to accommodate the above test as a test OPTION (see Attachments 2 and 3).

\subsection{TERMS/DEFINITIONS}

3.1 EES - Equipment Engineering Section

3.2 Seismic Category 1 Commodities - a structure, system or component (SSC) which must continue to perform its required function during or after a seismic event.

3.3 Seismic Category II Commodities - synonymous with "non-seismic category I" commodities.

\subsection{RESPONSIBILITIES}

4.1 The EES Mechanical Engineers shall be responsible for:

4.1.1 Assisting EES personnel in the execution of this procedure.

4.1.2 Assisting in the coordination, scheduling and controlling activities associated with this procedure.

4.1.3 Assisting in data acquisition.

4.1.4 Instructing personnel in the use or this procedure.

4.1.5 Writing and issuing test report.

4.2 Person conducting test (preparing data sheets) is responsible for completing a M\&TE Category 1 Log Sheet (Attachment 6) for each piece of category 1 equipment used and is responsible for duplicating each log sheet and forwarding it to the appropriate M\&TE custodian.

4.3 Personnel performing this test shall have received instruction from an EES Mechanical Engineer prior to testing and shall be responsible for adherence to procedure requirements. 
Attachment 8. EES Field Procedure No. FP-379: "Instrumented Cabinet Drop Tests" (6 of' 18)

Savannah River Technology Center Equipment Engineering Seismic 11/I Drop Test Program Instrumented Cabinet Drop Tests
EES-FP.379, Rev. 0

Effective Date: $9 / 24 / 92$, Category 2

Page 6 of 18

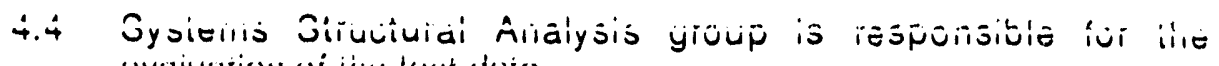
evaluation vi iile lest data.

\subsection{PROCEDURE}

\subsection{Safety}

5.1.1 All applicable EES, SRTC, and SRS Safety Rules will be followed.

\subsection{Required Equipment}

\subsubsection{Drop Mechanism, Bux-shrader CE-7R.}

5.2.2 3/4" conduit, 6' long, approximately 5 each.

5.2.3 2' $\times 4^{\prime}$ ' Ceiling panel, approximately 5 each.

5.2.4 2' $\times 3^{\prime}$ transite wallboard, approximately 5 each.

5.2.5 Fluorescent light fixture, approximately 5 each.

5.2.6 Incandescent light fixture, approximately 5 each.

5.2.7 Any other drop item that is specified by customer.

\subsubsection{0' tape measure.}

5.2.9 Drop Test Adapters, EES-22116-R4-001 rev A, 1 Al adapter for light objects (<10 lbs) and 1 SST adapter for heavier objects.

5.2.10 Macintosh computer equipped with National Instruments Labview software, NB-MIO-16H-9 \& NB-DMA-8-G boards, RTSI cable.

5.2.11 Multimeter, M\&TE category 1 (M\&TE \# to be specified on data sheets), 1 each.

5.2.12 10 VDC power supply, M\&TE category 2 (M\&TE \# to be specified on data sheets), 1 each.

5.2.13 125 VDC power supply, M\&TE category 2 (M\&TE \# to be specified on data sheets), 1 each.

5.2.14 600 ohm resistor $\pm 10 \%, 2$ each. 
Attachment 8. EES Field Procedure No. FP-379: "Instrumented Cahinet Drop Tests" (7 of 18)

Savannah River Technology Center

Equipment Engineering

Seismic $11 / 1$ Drop Test Program Instrumented Cabinet Drop Tests
EES.FP-379, Rev. 0

Effective Date: $9 / 24 / 92$, Category 2

Page 7 of 18

5.2.15 A C oord with switch box, 1 oash.

5.2.16 Accelerometer, Wilcoxon Research Model 793R, M\&TE category 1 (M\&TE \# to be specified on data sheets), 1 each.

5.2.17 Amplifier for accelerometer, Wilcoxon Research Model PR710, M\&TE category 1 (M\&TE \# to be specified on data sheets), 1 each.

5.2.18 Sony/Tektronix RTD 710A Digitizer, (ID of item to be specified on data sheets), 2 each.

5.2.19 Pulse/Function Generator, M\&TE Category 1, (M\&TE \#/Expiration date to be specified on data sheets), 1 each.

5.2.20 $6 \mathrm{ft}$ equipment cabinet with mounting plate, EES-22116R1-013 rev $A$.

5.2.21 AMF Potter \& Brumfield Relay, model KRPA11AG, 1 each.

5.2.22 Westinghouse Relay, type SG, style 1342925A, 1 each.

5.2.23 High speed camera equipment.

5.2.24 Still Camera equipment.

5.2.25 NOTE: In the event that EES drawings are changed after or during testing, the latest revision of the drawing will be noted on data sheet in the comments section.

\subsection{Acceptance Criteria and Test Requirements}

5.3.1 There is no acceptance criteria for this task because the purpose of this test is to gather test data to determine the impact characteristics of seismic II/I objects.

5.3.2 Damage to any of the drop commodities that is a result of a direct testing activity (i.e. dropping the items) shall not require a Nonconformance Report (NCR).

5.4 RTD 710 Calibration Check Procedure

5.4.1 Calibration checks to be conducted before and after test.

5.4.2 Complete top portion of Calibration Sheet (Attachment 5) and set RTD settings to those specified on Attachment 5 . 
Attachment 8. EES Field Procedure No. FP.379: "Instrumented Cabinct Drop Tests" (8 of 18)

Savannah River Technology Center

Equipment Engineering

Seismic II/I Drop Test Program

Instrumented Cabinet Drop Tests
EES.FP.379, Rev. 0

Effective Date: $9 / 24 / 92$, Category 2

Page 8 of 18

5.4.3 Connied puiseifunction generalur uulpul io apprupriale channels on RTD. Set generator to sine or square wave with peaks at \pm 10 VDC, \pm 5 VDC, $\pm 100 \mathrm{mVDC}$ and 0 VDC with a period of your choice as shown on Attachment 5. Record peak voltages and period off RTD on Attachment 5 for each channel. Document generator and RTD settings on Attachment 5.

5.4.4 Record use of all M\&TE category 1 equipment on Log Sheets, Attachment 6 .

\subsubsection{Calibration check complete.}

\subsection{Drop Test Procedure}

5.5.1 Set-up equipment as illustrated in Attachment 2 (or Attachment 3 as an OPTION).

5.5.2 Attach the drop release mechanism (Bux-shrader CE-7R) to the High Bay crane. Operate the drop release mechanism according to EES Drop Test procedure L9.23602 Rev. 1.

5.5.3 Complete Pre test section of Test Data Sheet, Attachment 4. If wish to change position of mounting plate or use optional equipment set up (Attachment 3), do it now.

5.5.4 Adjust 10 VDC power supply used for monitoring chatter to provide a $6 \pm .1$ VDC output to relay input terminals. Verify voltage with M\&TE category 1 multimeter and record on data sheet (Attachment 4). Log use of M\&TE category 1 multimeter on Attachment 6.

5.5.5 If energizing Westinghouse relay, adjust 125 VDC power supply used to energize relay coil to provide a $125 \mathrm{VDC}$ output to relay coil terminals. Verify voltage with M\&TE category 1 multimeter and record on data sheet (Attachment 4). Log use of M\&TE category 1 multimeter on Attachment 6.

5.5.6 If energizing Potter \& Brumfield relay, plug $A C$ cord into wall outlet and switch power box on.

5.5.7 Complete Data Acquisition section of Attachment 4. 
Attachment 8. EES Field Procedure No. FP.379: "Instrumented Cabinet Drop Tests" (9 of 18)

\begin{tabular}{lr} 
Savannah River Technology Center & $\begin{array}{r}\text { EES-FP-379, Rev. } 0 \\
\text { Equipment Engineering }\end{array}$ \\
Seismic II// Drop Test Program & Effective Date: $9 / 24 / 92$, Category 2 \\
Instrumented Cabinet Drop Tests & Page 9 of 18 \\
\hline
\end{tabular}

5.5.8 Attach Drop Test Adapter (A) adapter for liaht objects. $<10$ Ibs. and 1 SST adapter for heavier objects! to drop obiect.

5.5.9 Use crane and drop release mechanism to lift object to preferred height and location using tape measure. May want to use plumb bob to align object over desired target. Reference EES Drop Test procedure L9.2-3602 Rev. 1.

5.5.10 Set-up RTD to acquire data.

5.5.11 (Set-up high speed video if customer desires. Record start position of video on tape on Attachment 4.)

5.5.12 Countdown from 3 to alert personnel. (At count of 0 highspeed video will be taken if customer desires.) At count of 0 release object to be dropped using drop mechanism.

5.5.13 (If video taken, stop video when desire and record stop position of video on tape on Attachment 4.)

\subsubsection{Complete Post Test section of Attachment 4.}

5.5.15 Use Mac computer with Labview and GPIB cable to transfer data from RTDs to disk for future manipulations. Plot data using plotter and RTD if desired.

\subsubsection{Repeat 5.5 .3 to 5.5.15 as desired.}

5.5.17 Perform housekeeping and return High bay area to original condition.

\subsection{RECORDS}

6.1 The completed copy of this procedure shall be maintained in accordance with EES procedure 1Q28-5017.

6.2 A copy of the M\&TE user logs will be forwarded to the appropriate M\&TE custodians.

6.3 All pertinent procedures, reports and data relating to these test activities will be maintained in Job Folder 22116.

6.4 A final consolidated report that incorporates all of the drop tests will be written by EES to document the findings of the tests and will be distributed to EES Document Control and to the customer.

\subsection{REFERENCES}


Attachment 8. EES Field Procedure No. FP-379: "Instrumented Cabinet Drop Tests" (10 of 18)

\begin{tabular}{lr} 
Savannah River Technology Center & EES-FP-379, Rev. 0 \\
Equipment Engineering & Effective Date: $9 / 24 / 92$, Category 2 \\
Seismic II/I Drop Test Program & Page 10 of 18 \\
Instrumented Cabinet Drop Tests & \\
\hline
\end{tabular}

\subsection{EES Drop Procedure L9.2-3002 Rev. 1}

7.2 1Q28-Manual, EES Training and QA Procedure Manual.

\subsection{ATTACHMENTS}
8.1 Attachment 1, Scope of Seismic II/I Drop Tests
8.2 Attachment 2, Instrumented Cabinet Drop Test Set Up
8.3 Attachment 3, Instrumented Cabinet Drop Test Set Up Option
8.4 Attachment 4, Test Data Sheet
8.5 Attachment 5, Calibration Sheet
8.6 Attachment 6, M\&TE Category 1 Log Sheet 
Attachment 8. EES Field Procedure No. FP-379: "Instrumented Cabinet Drop Tests" (11 of 18)

Savannah River Technology Center Equipment Engineering Seismic II/I Drop Test Program Instrumented Cabinet Drop Tests
EES-FP.379, Rev. 0

Effective Date: $9 / 24 / 92$, Category 2

\section{Q.1 Attushment :}

\section{SCOPE OF SEISMIC II/I DROP TESTS}

L Simply Supported (oinned) Beam Configuration - Load Cells at Supports

Purpose: To gain reaction force data and to view failure modes, if any. The primary function of all of these tests is to look for trends in data.

Consideration: if theta small Fx\&Fy negligible, pin supports to eliminate problem.

Target: $\quad 3 / 4 "$ conduit (27/32 ID, $11 / 8$ OD), $10 \mathrm{ft}$.

Sources: fluorescent light fixture

ceiling panel

$3 / 4$ conduit, $6 \mathrm{ft}$.

incandescent light fixture

wallboard

Drop H: 1 to $15^{\prime}$

Target: $\quad 2^{n}$ conduit (2 1/8 ID, 2 5/16), $10 \mathrm{Ht}^{1}$

Sources: fluorescent light fixture

$3 / 4$ conduit, $6 \mathrm{ft}$.

duct ( $30 \times 18:, 1 / 8$ thick), $4 \mathrm{ft}$.

duct $(24 " \times 24 " \times 22$ gage), $4 \mathrm{ft}$.

$6 "$ pipe $(6 \mathrm{ID}, 65 / 8$ OD, $18.97 \mathrm{lb} / \mathrm{ft}), 4 \mathrm{ft}$

Drop H: 1 to $15^{\prime}$

Target: barricade assembly, two $5 \times 5 \times 3 / 8$ tube welded side to side, $4 \mathrm{ft}^{2}$

Sources: fluorescent light fixture

$3 / 4$ conduit, $6 \mathrm{ft}$.

duct ( $30 \times 18:, 1 / 8$ thick), $4 \mathrm{ft}$.

duct $\left(24 " \times 24^{\prime \prime} \times 22\right.$ gage $), 4 \mathrm{ft}$.

6" pipe, $4 \mathrm{ft}$

equipment cabinet, $24 \times 24 \times 10 "$

wallboard

Drop $\mathrm{H}$ : 1 to $15^{\prime}$ (for 6" pipe start at .5", 1", 2", 3", etc... until function realized)

Target: duct assembly, two $4 \mathrm{ft}$ duct sections $\left(24^{\prime \prime} \times 24^{\prime \prime} \times 22\right.$ gage) fastened together

Sources: duct ( $30 \times 18:, 1 / 8$ thick), $4 \mathrm{ft}$.

duct $\left(24^{\prime \prime} \times 24^{\prime \prime} \times 22\right.$ gage $), 4 \mathrm{ft}$.

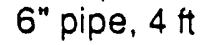

2" conduit, $6 \mathrm{ft}$

Drop H: 1 to $12^{\prime}$

\footnotetext{
'Priority Test: concentrate on this beam test

2Priority Test: should be conducted after \#1 priority test.
} 
Attachment 8. EES Field Procedure No. FP-379: "Instrumented Cabinet Drop Tests" (12 of 18)

Savannah River Technology Center Equipment Engineering Seismic II/I Drop Test Program Instrumented Cabinet Drop Tests

II Airrraft rahle Mrnn - I nad relle at each end ${ }^{3}$

Purpose: To gain reaction force data and to view failure modes, if any. Tho primary function of all of these tests is to look for trends in data.

Consideration: pivot source at one end and let it fall.

Target: aircraft cable, 1/4" dia., galvanized, $7 \times 7$ strand core, MMC \#3450T(or 7) 32

Sources: duct ( $30 \times 18:, 1 / 8$ thick), $4 \mathrm{ft}$. duct $\left(24^{\prime \prime} \times 24^{\prime \prime} \times 22\right.$ gage), $4 \mathrm{ft}$. $2^{\prime \prime}$ conduit, $6 \mathrm{ft}$.

Drop H: 1 to 4'

\section{Cabinet Drops ${ }^{4}$}

Purpose: to view failure modes that may occur to battery packs and cabinets attached to unistrut frames during seismic events.

Target: emergency lighting battery pack

Sources: fluorescent light fixture ceiling panel

$3 / 4$ conduit, $6 \mathrm{ft}$. incandescent light fixture

Drop H: 1 to $12^{\prime}$

Target: electrical cabinet attached to unistrut frame

Sources: fluorescent light fixture

$3 / 4$ conduit, $6 \mathrm{ft}$. incandescent light fixture wallboard

Drop H: 1 to 15

\section{Instrumented Cabinet Drops}

Purpose: to determine effects of seismic events on relays mounted in equipment cabinets. Relays will be monitored using data acquisition, and an accelerometer will be used to assist in corresponding impact loads to relay data.

Target: $\quad 26^{\prime \prime} \times 30^{\prime \prime} \times 7^{\prime}-6^{\prime \prime}$ equipment cabinet

Sources: fluorescent light fixture

ceiling panel

$3 / 4$ conduit, $6 \mathrm{ft}$.

incandescent light fixture wallboard

Drop H: 1 to 12

\footnotetext{
3 riority Test: should be conducted after \#2 priority test.

iPriority Tests: should be conducted first.
} 
Attachment 8. EES Field Procedure No. FP-379: "Instrumented Cabinet Drop Tests" (13 of 18)

Savannah River Technology Center Equipment Engineering Seismic II/I Drop Test Program Instrumented Cabinet Drop Tests
EES-FP-379, Rev. 0

Effective Date: $9 / 24 / 92$, Category 2

Page 13 of 18

\subsection{Attachment 2}

INSTRUMENTED CABINET DROP TEST SET UP
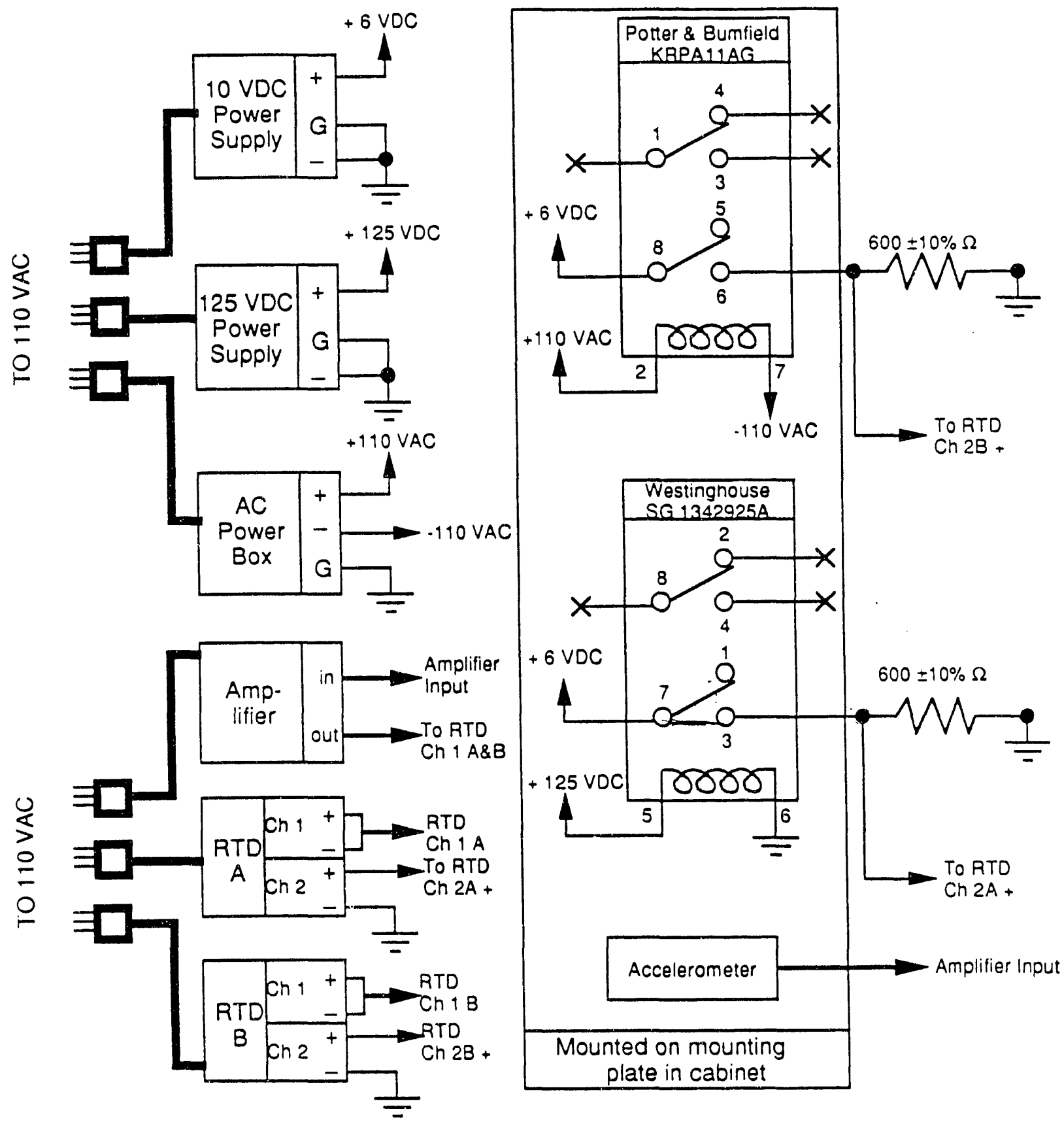
Att:chment 8. EES Field Procedure No. FP-379: "Instrumented Cabinet Drop Tests" (14 of 18)

Savannah River Technology Center Equipment Engineering

Seismic IV/I Drop Test Program

Instrumented Cabinet Droo Tests
EES-FP-379, Rev. 0

Effective Date: $9 / 24 / 92$, Category 2

Page 14 of 18

\subsection{Attachment 3}

\section{INSTRUMENTED CABINET DROP TEST SET UP OPTION}
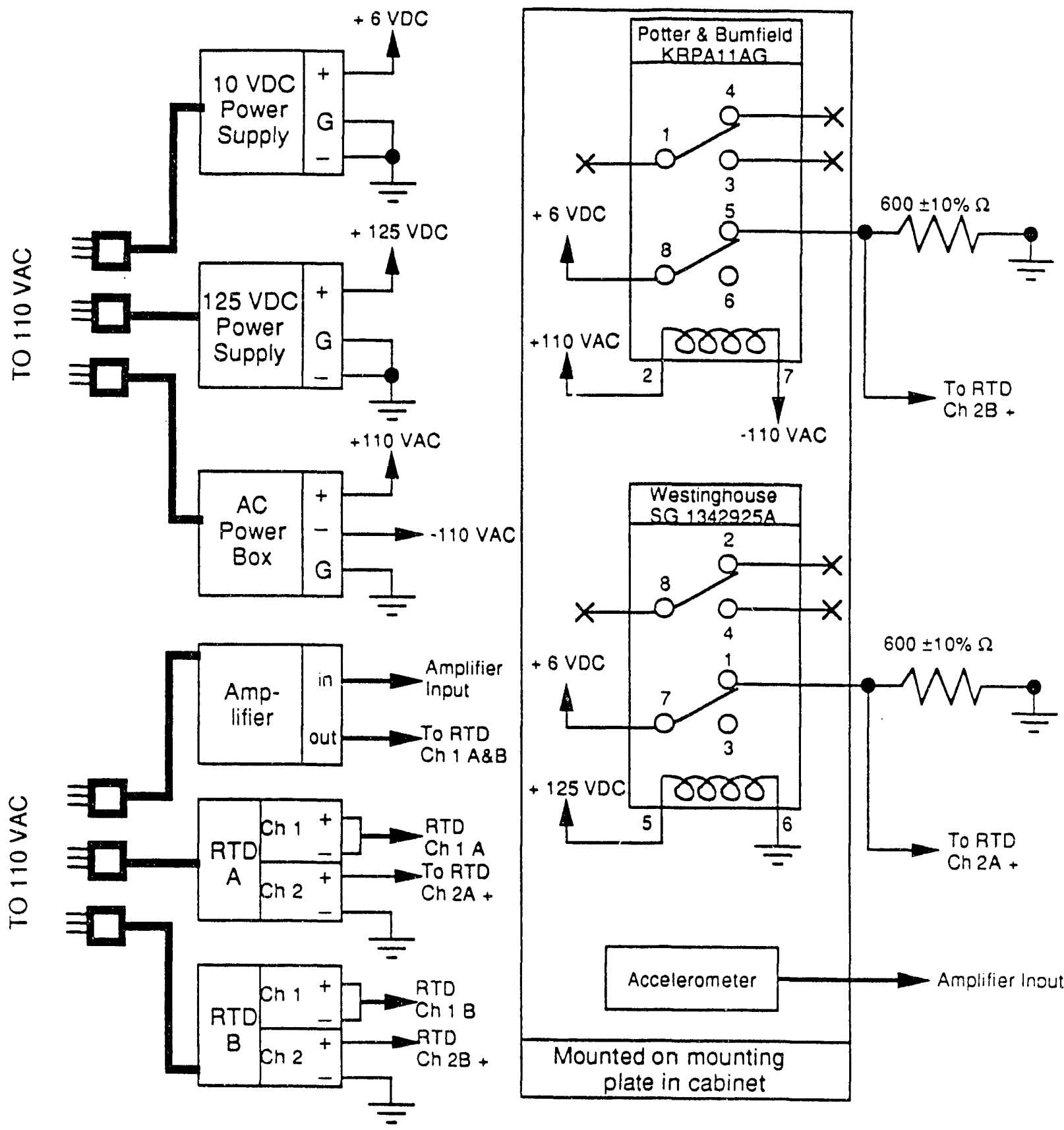
Attachment 8. EES Field Procedure No. FP.379: "Instrumented Cabinet Drop Tests" (15 of 18)

Savannah River Technology Center

Equipment Engineering

Seismic II/I Drop Test Program

Instrumented Cabinet Drop Tests
EES-FP-379, Rev. 0

Date Approved: 9/24/92, Category 2

Page 15 of 18

\subsection{ATTACHMENT 4 \\ TEST DATA SHEET}

(PAGE 1 OF 2)
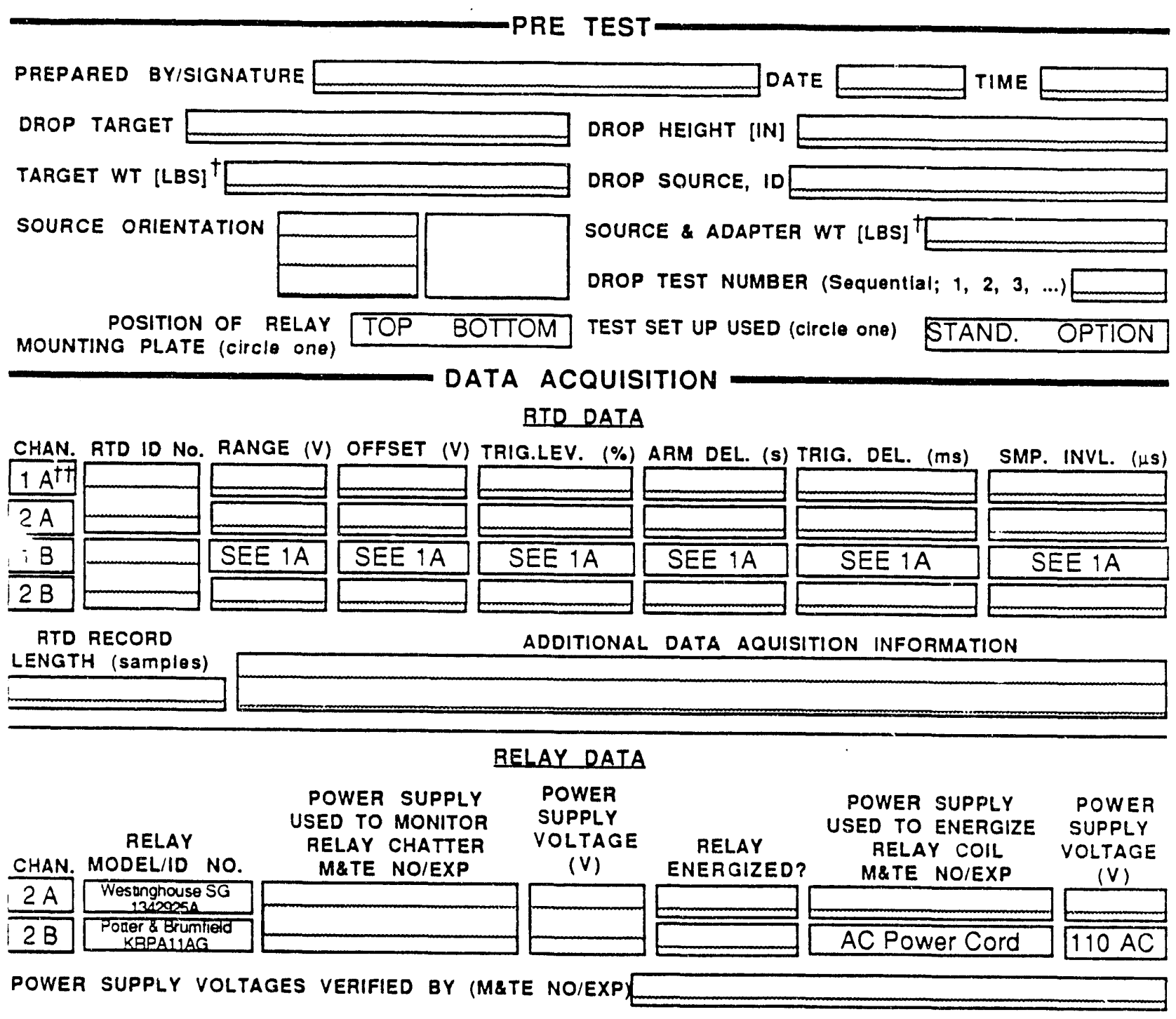

\section{ACCELEROMETER DATA}

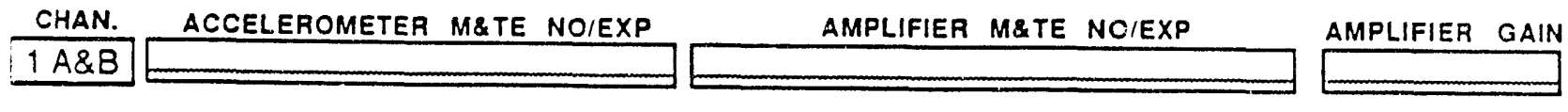

Approximate weight using M\&TE category 3 equipment.

t†

Numbers 1 \& 2 correspond to channels on each RTD ( 1 will be used by accelerometer, 2 will be used by rnlays.).
Letters A \& B correspond to different RTD ID numbers. 
Attachment 8. EES Field Procedure No. FP-379: "Instrumented Cabinet Drop Tests" (16 of 18)

Savannah River Technology Center Equipment Engineering Seismic II/I Drop Test Program Instrumented Cabinet Drop Tests
EES-FP-379, Rev. 0 Date Approved: $9 / 24 / 92$, Category 2

Page 16 of 18

\subsection{ATTACHMENT 4 TEST DATA SHEET (PAGE 2 OF 2)}

\section{POST TEST}

TARGET DAMAGE

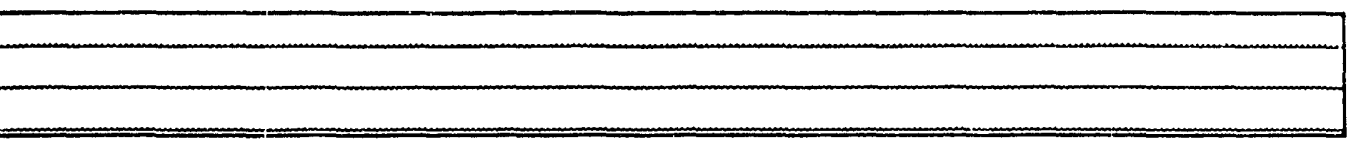

SOURCE DAMAGE

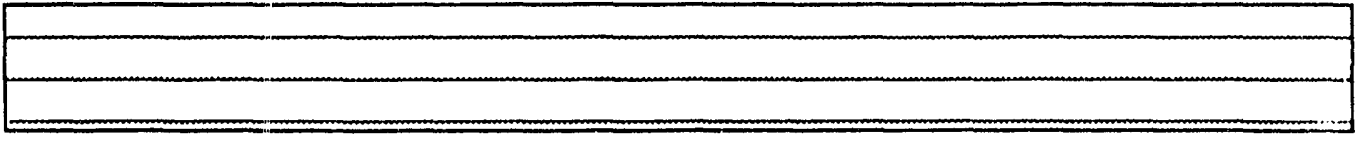

RELAY CHATTER IDENTIFIED ON POTTER \& BRUMFIELD RELAY (YIN)

IF YES, DURATION OF CHATTER [mS]

RELAY CHATTER IDENTIFIED ON WESTINGHOUSE RELAY (Y/N) IF YES, DURATION OF CHATTER [ms]

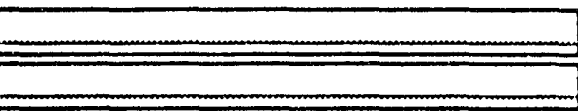

HAND HELD VIDEO START \& STOP POSITION

HIGH SPEED VIDEO START \& STOP POSITION

COMMENTS

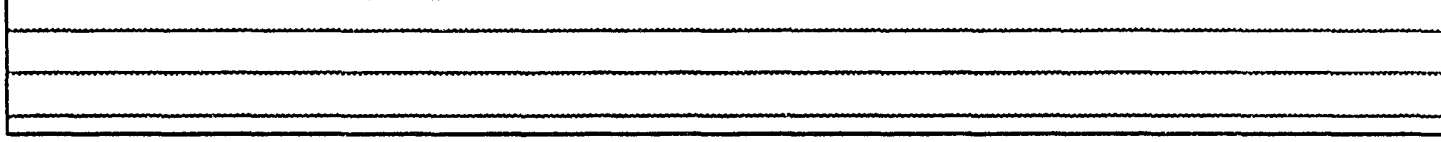

REVIEWED BYISIGNATURE

REVIEWED DATE

APPROVED BYISIGNATURE

APPROVED DATE

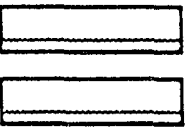


Attachment 8. EES Field Procedure No. FP-379: "Instrumented Cabinet Drop Tests" (17 of 18)

Savannah River Technology Center Equipment Engineering

Seismic II/I Drop Test Program Instrumented Cabinet Drop Tests
EES-FP-379, Rev. 0 Effective Date: 9/24/92, Category 2

Page 17 of 18

\subsection{Attachment 5}

\section{CALIBRATION SHEEI}

PREPARED BY:

DATE: TIME (XX:XX):

ITEM TO BE CALIBRATED/CHANNEL(s):

PULSE FUNCTION GENERATOR USED (CAT 1 M\&TE \#, EXPIR):

RTD SETTINGS

Channel 1 range:

Channel 1 offset:

Channel 2 range:

Channel 2 offset:

V

Trigger level:

Trigger delay:

Record length:

sec Arm delay:

ms Sample interval: counts

Any other documented settings:

\section{PULSE /FUNCTION GENERATOR SETTINGS}

Duty cycle:

Wave type:

Any other documented settings:

\begin{tabular}{|c|c|c|c|c|c|}
\hline \multicolumn{2}{|c|}{ PULSE FUNCTION GENERATOR } & \multicolumn{2}{|c|}{ CHANNEL 1} & \multicolumn{2}{|c|}{ CHANNEL 2} \\
\hline $\begin{array}{l}\text { INPUT } \\
\text { (V) }\end{array}$ & $\begin{array}{c}\text { PERIOD } \\
(s)\end{array}$ & $\begin{array}{c}\text { RTD PERIOD } \\
\text { (s) }\end{array}$ & $\begin{array}{c}\text { RTD PEAK } \\
\text { READING (V) }\end{array}$ & $\begin{array}{c}\text { RTD PERIOD } \\
(\mathrm{s})\end{array}$ & $\begin{array}{c}\text { RTD PEAK } \\
\text { READING (V) }\end{array}$ \\
\hline 0 & & & . & & \\
\hline 0.10 & & & & & \\
\hline 5 & & & & & \\
\hline 10 & & & & & \\
\hline
\end{tabular}

REVIEWED BY:

DATE:

ACCEPTED BY:

DATE: 
Attachment 8. EES Field Procedure No. FP-379: "Instrumented Cahinet Drop Tests" (18 of 18)

Savannah River Technology Center Equipment Engineering Seismic II/I Drop Test Program Instrumented Cabinet Droe Tests
EES-FP-379, Rev. 0 Effective Date: 9/24/92, Category 2 Page 18 of 18

\subsection{Attachment 6}

\section{M\&TE CATEGORY 1 LOG SHEET}

M\&TE DEVICE:

M\&TE NO.: Calibration Expiration Date: _____

\begin{tabular}{|l|l|l|}
\hline DATE & USER'S SIGNATURE & $\begin{array}{c}\text { UNIQUE ID OF ITEM TESTED, } \\
\text { ACCEPTED OR VERIFIED }\end{array}$ \\
\hline & & \\
\hline & & \\
\hline & & \\
\hline & & \\
\hline & & \\
\hline & & \\
\hline & & \\
\hline & & \\
\hline
\end{tabular}

Authenticated By: 


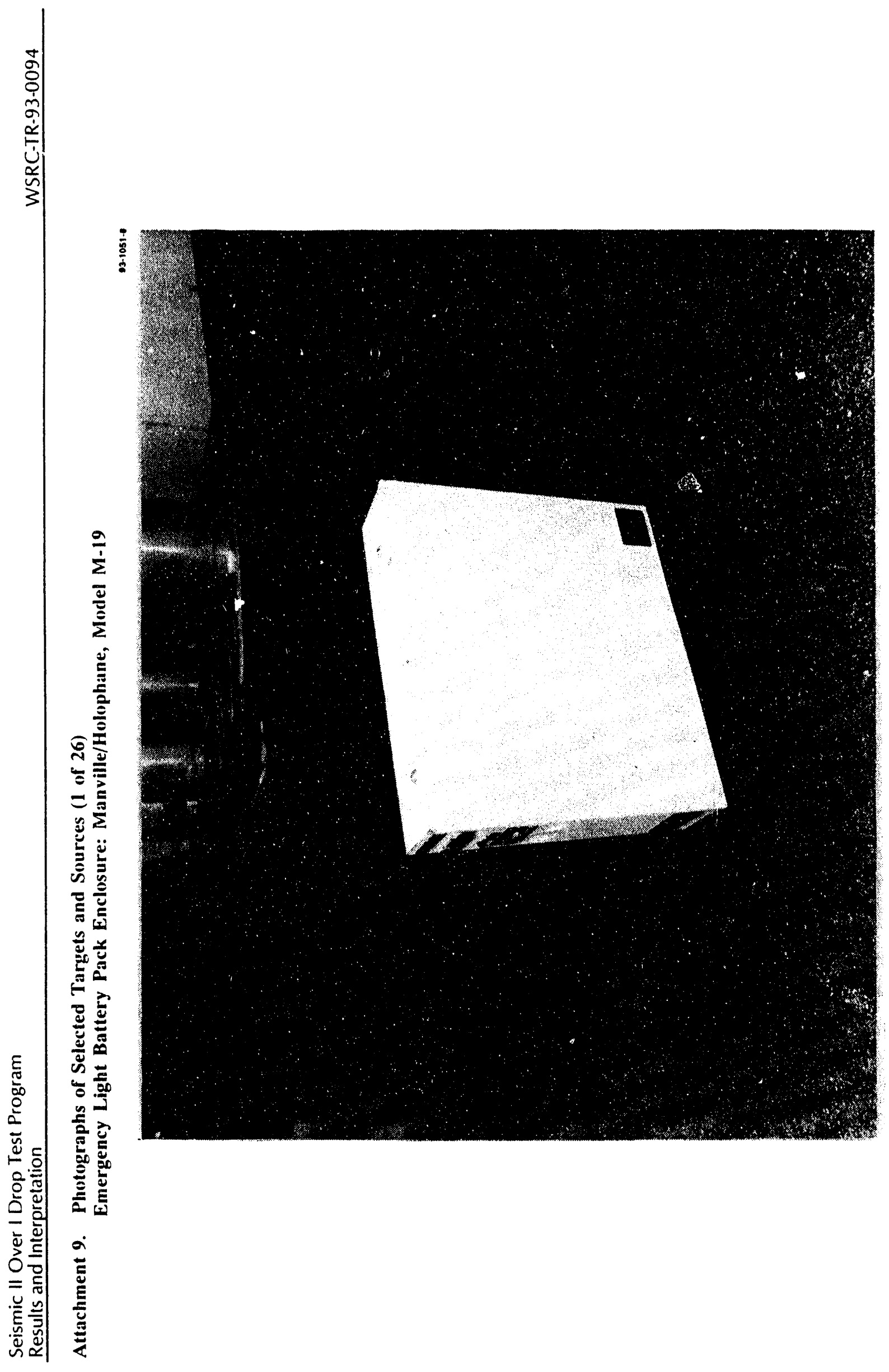




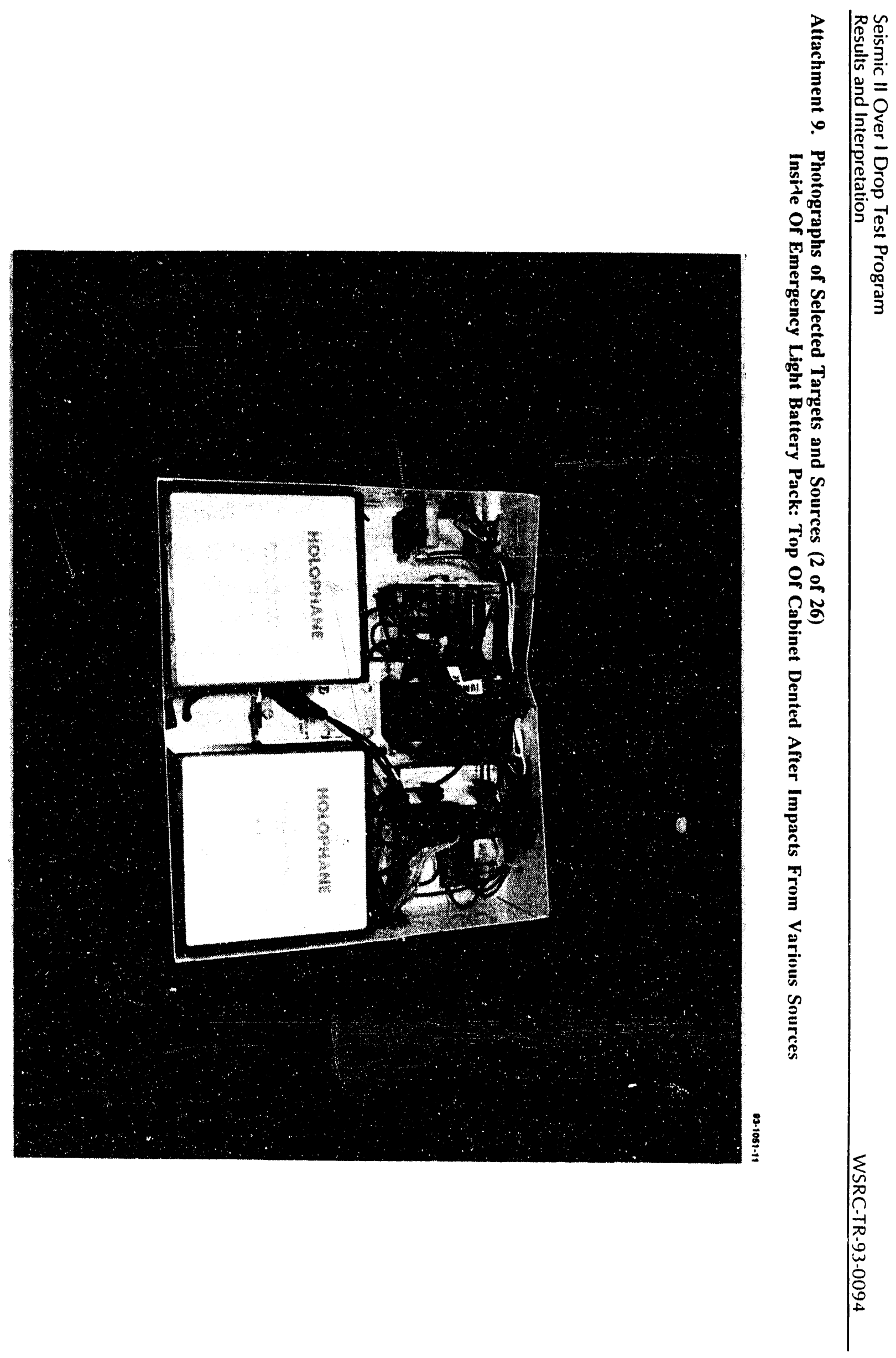




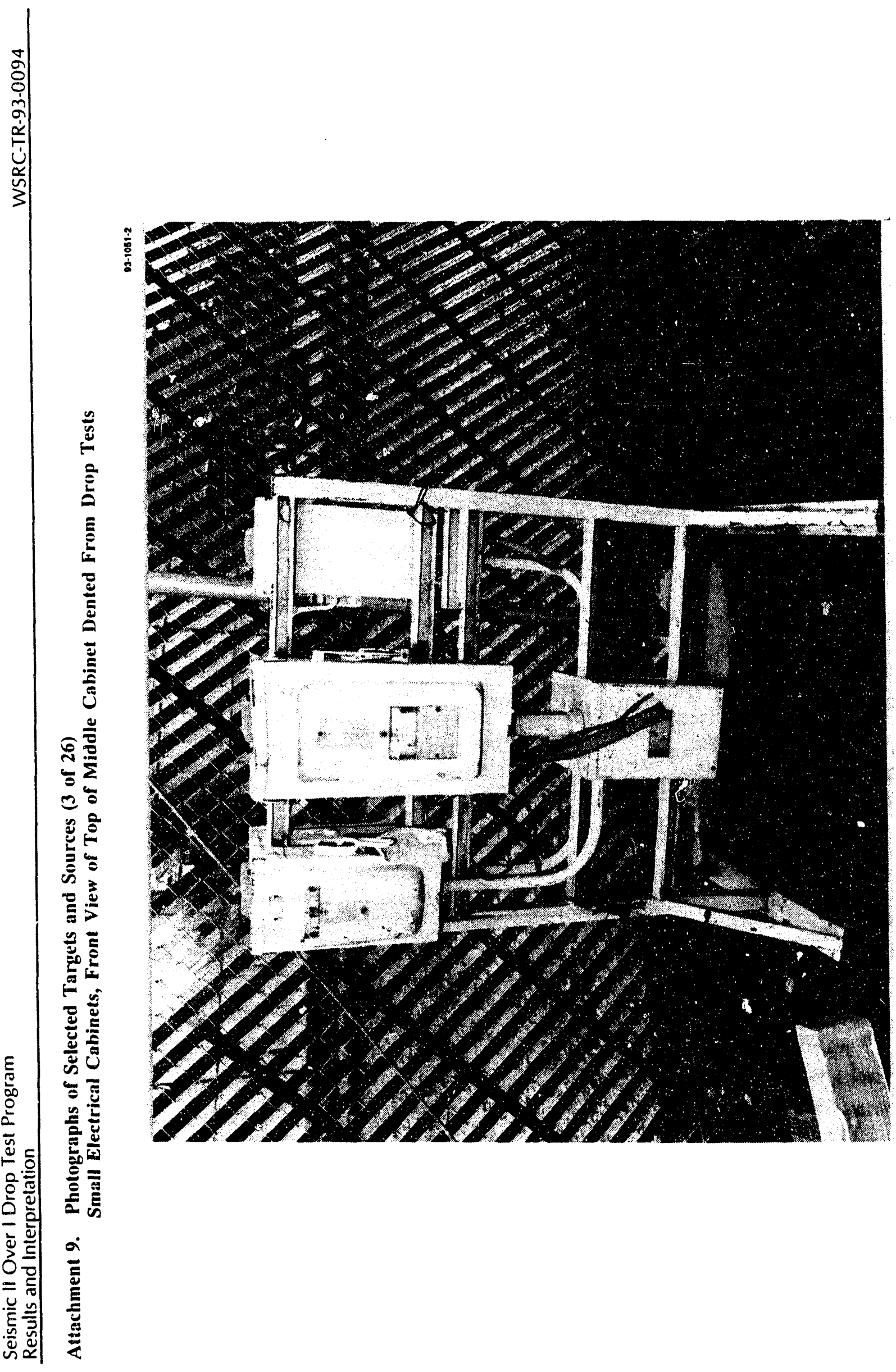




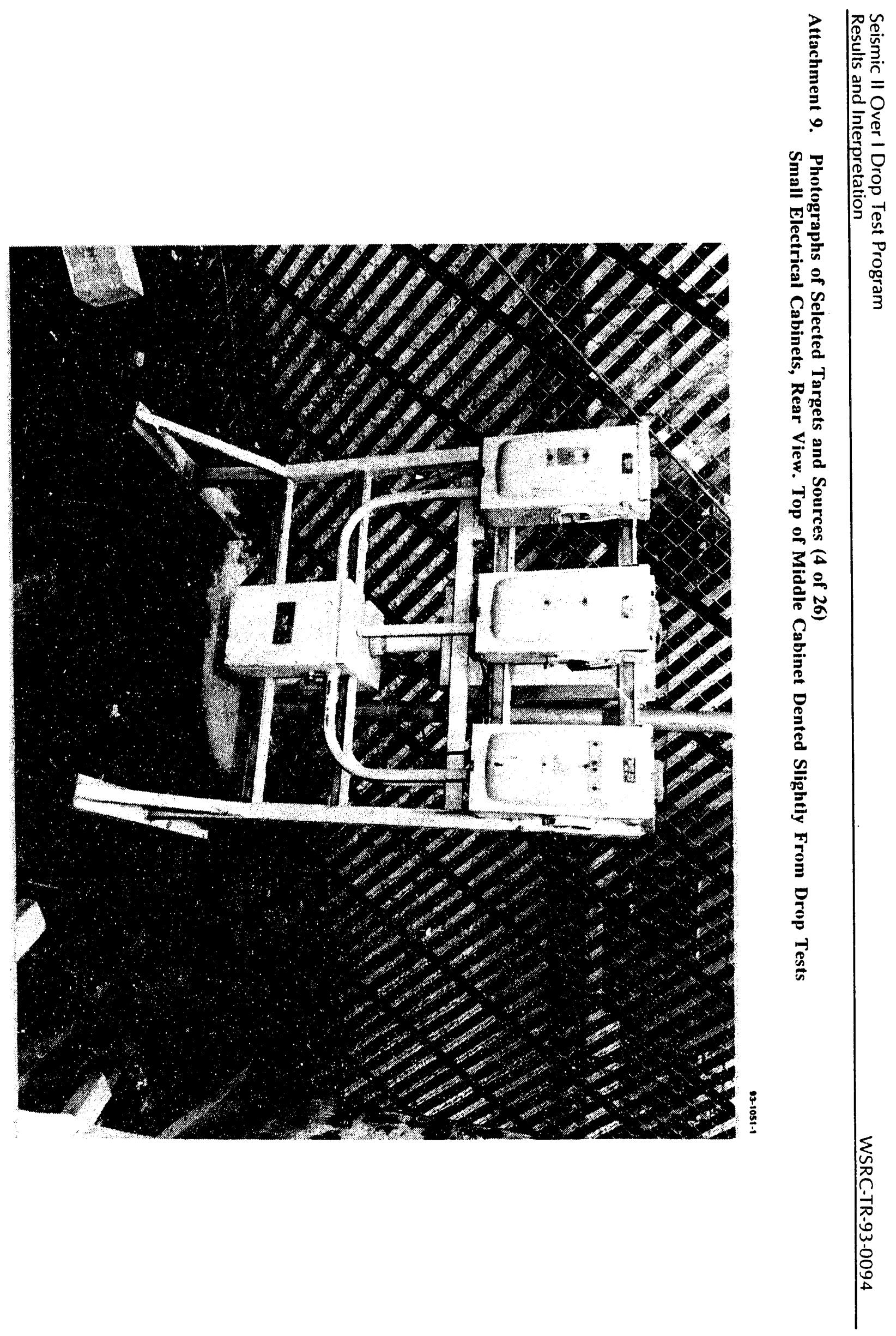




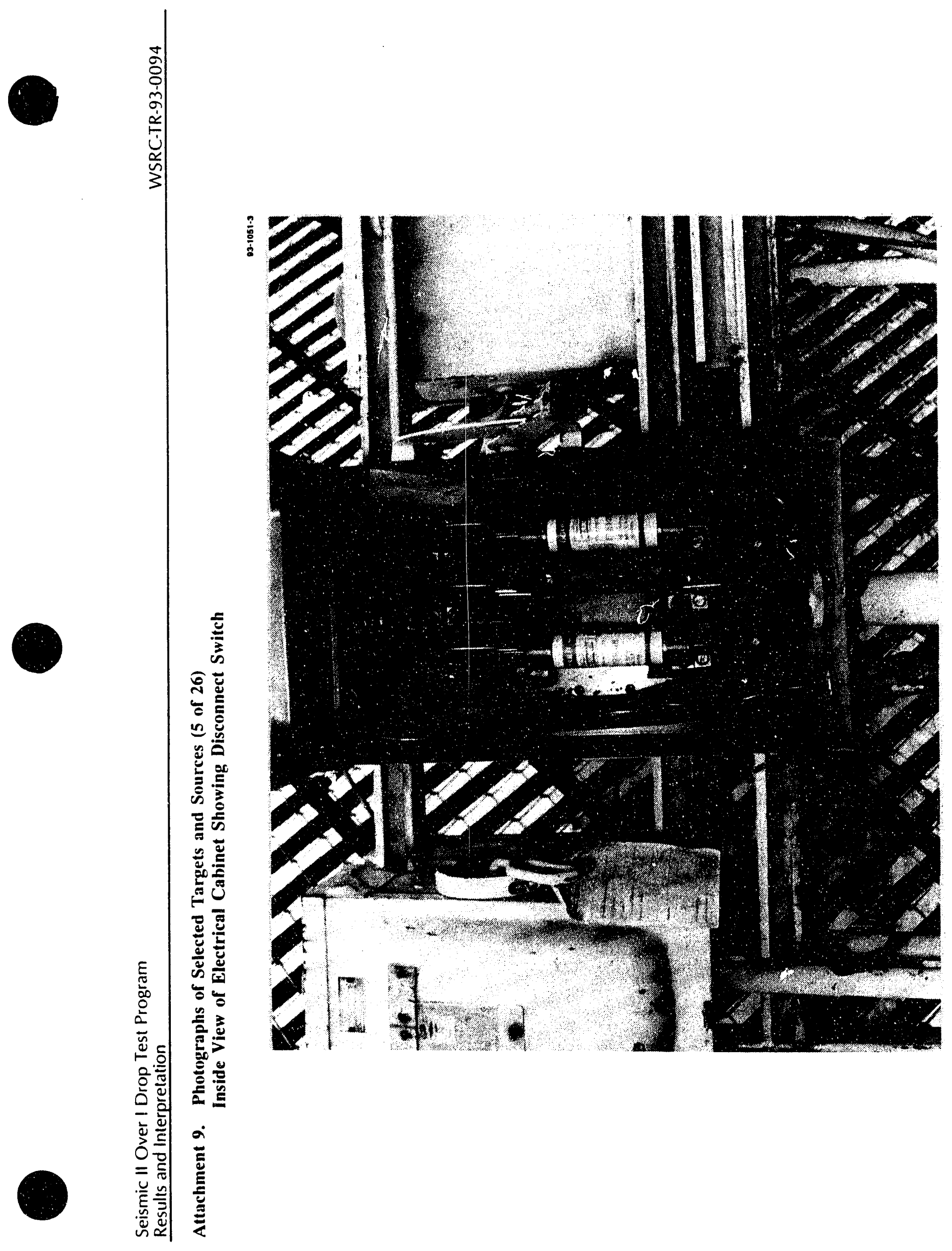









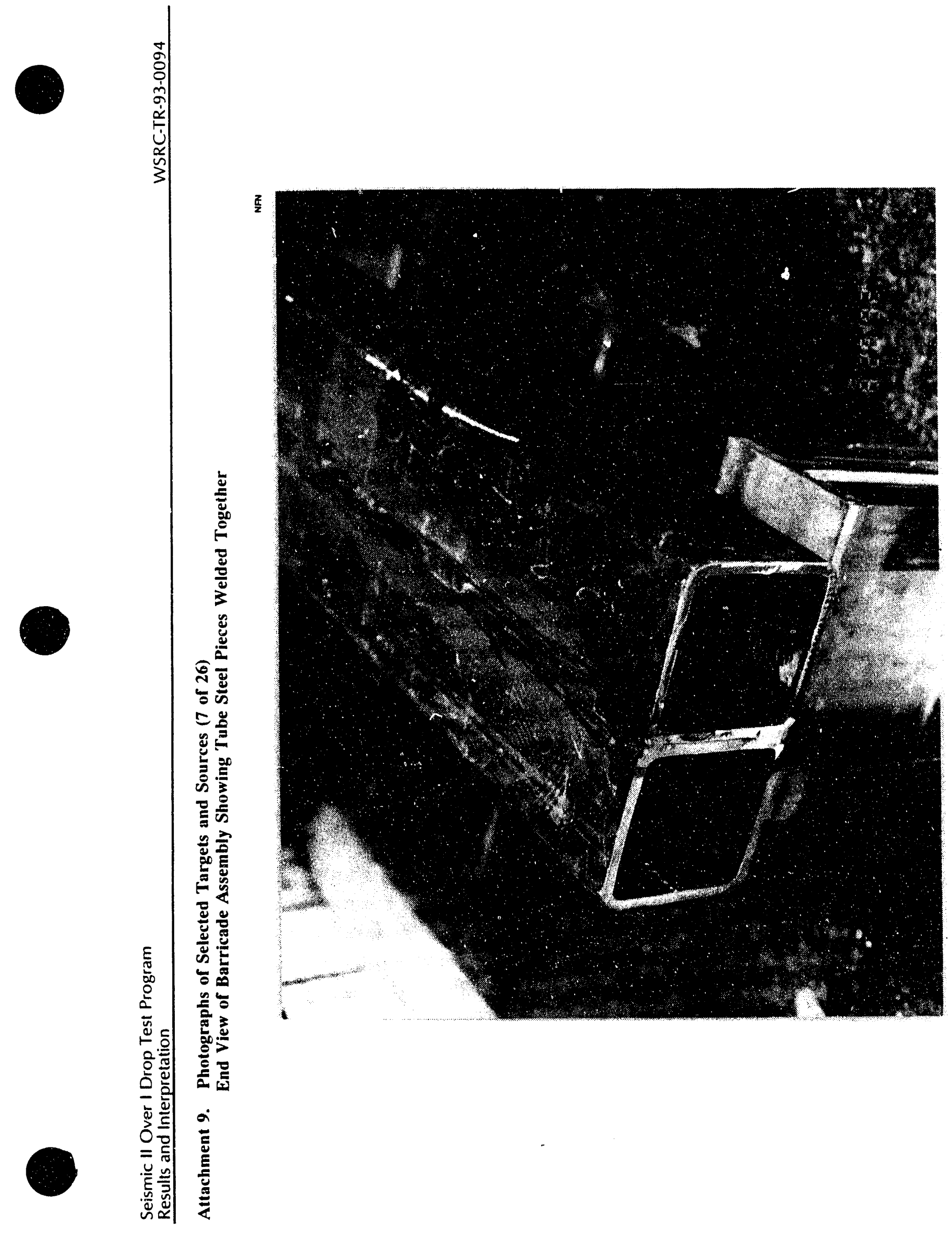



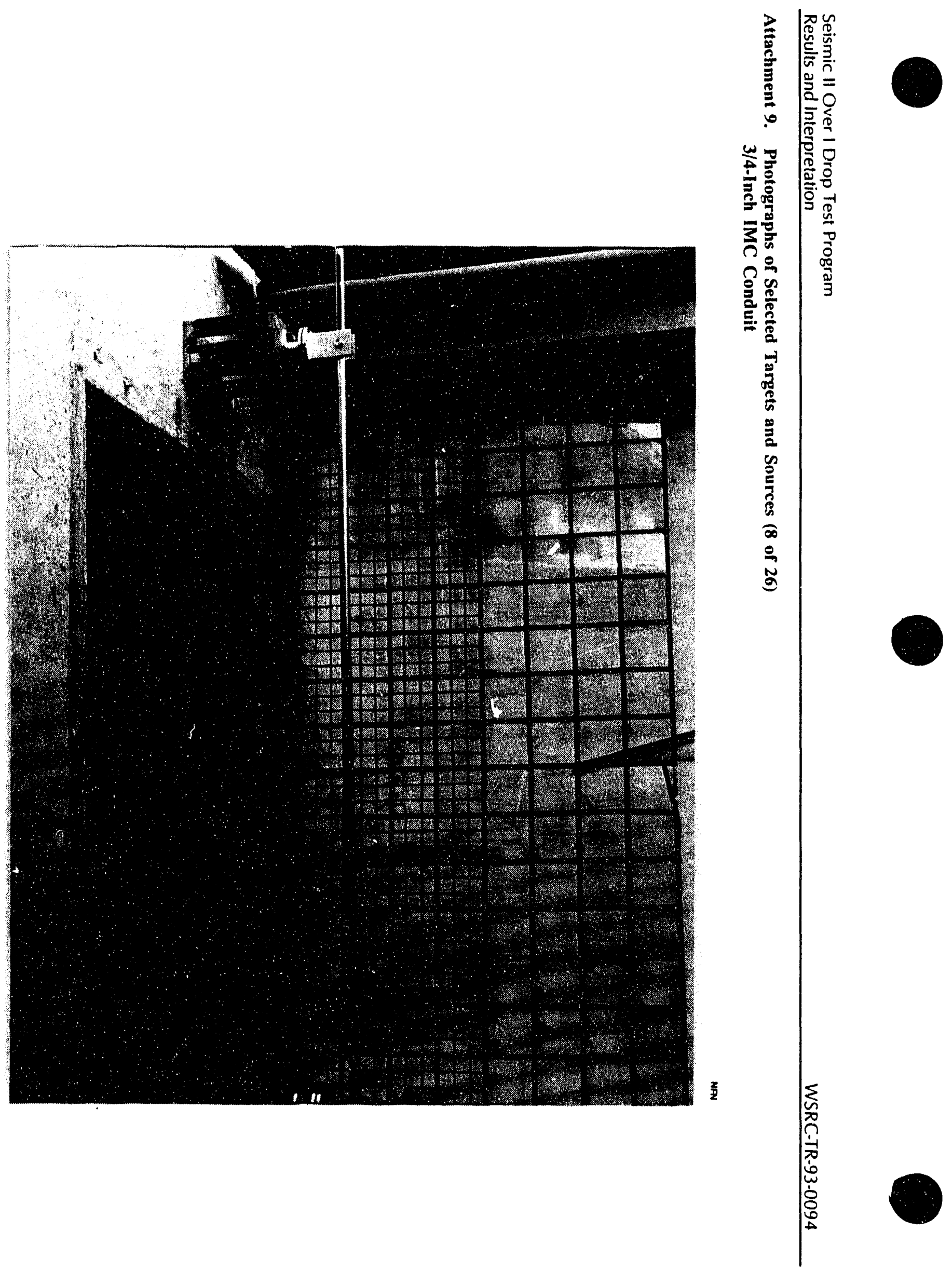


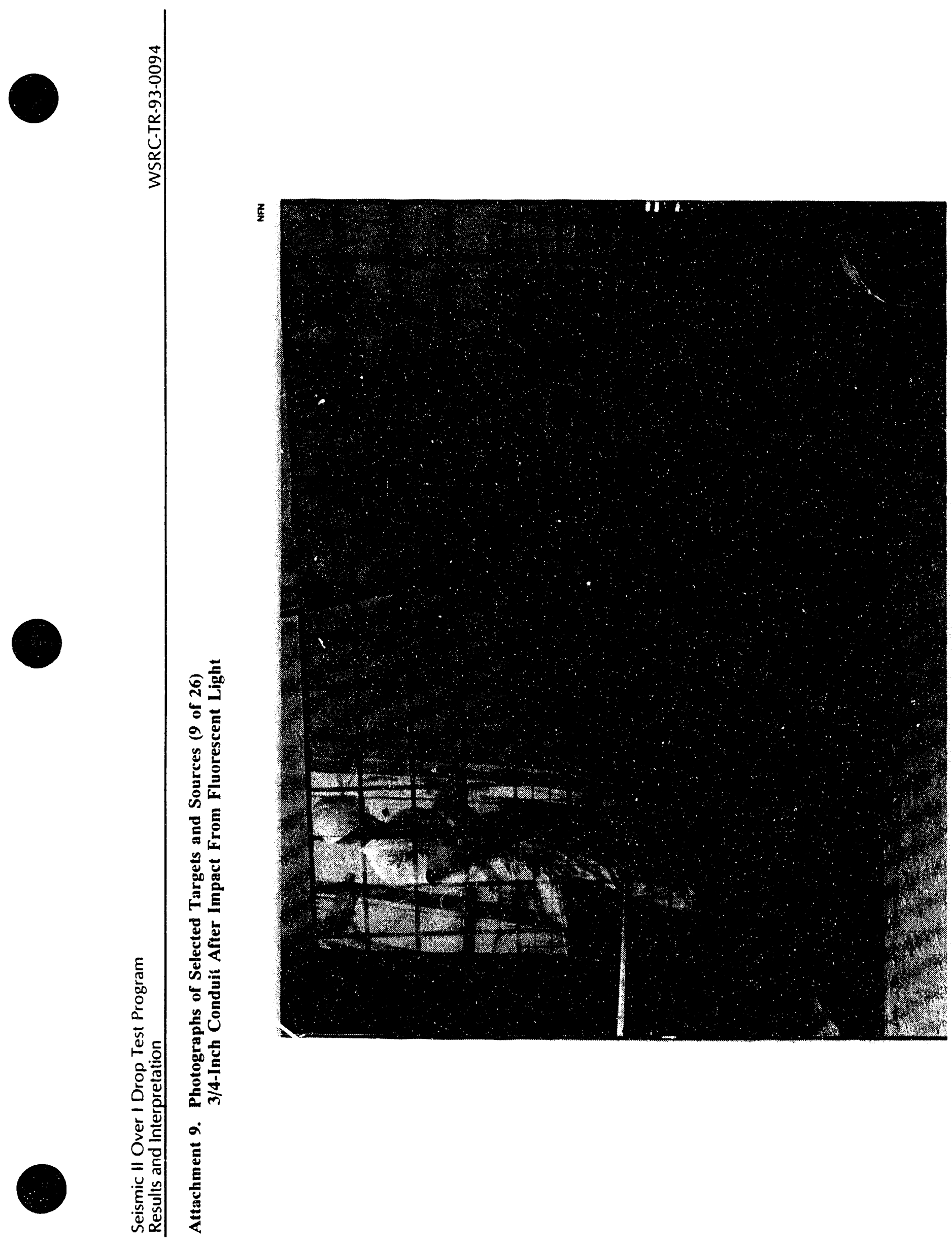




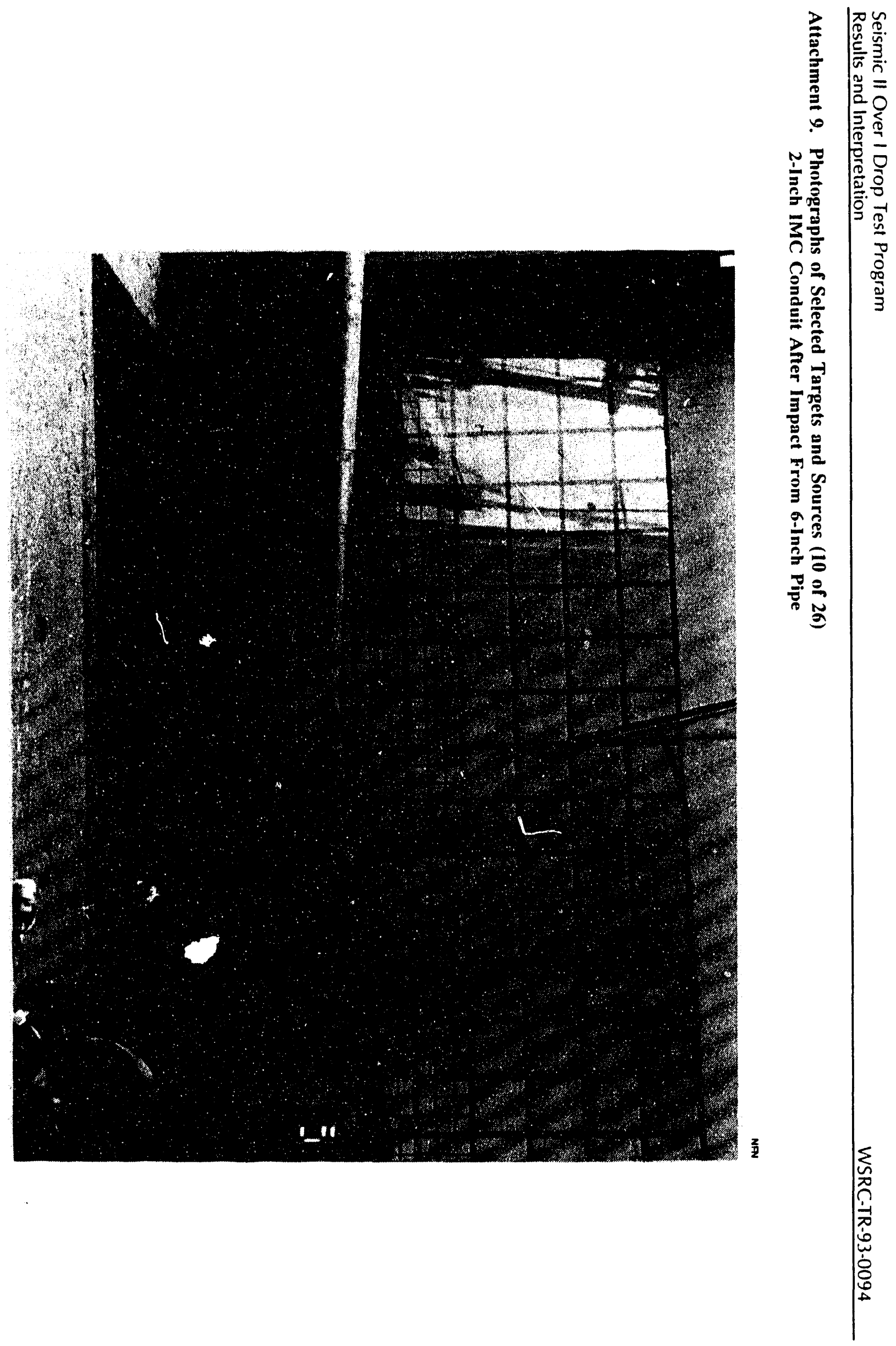




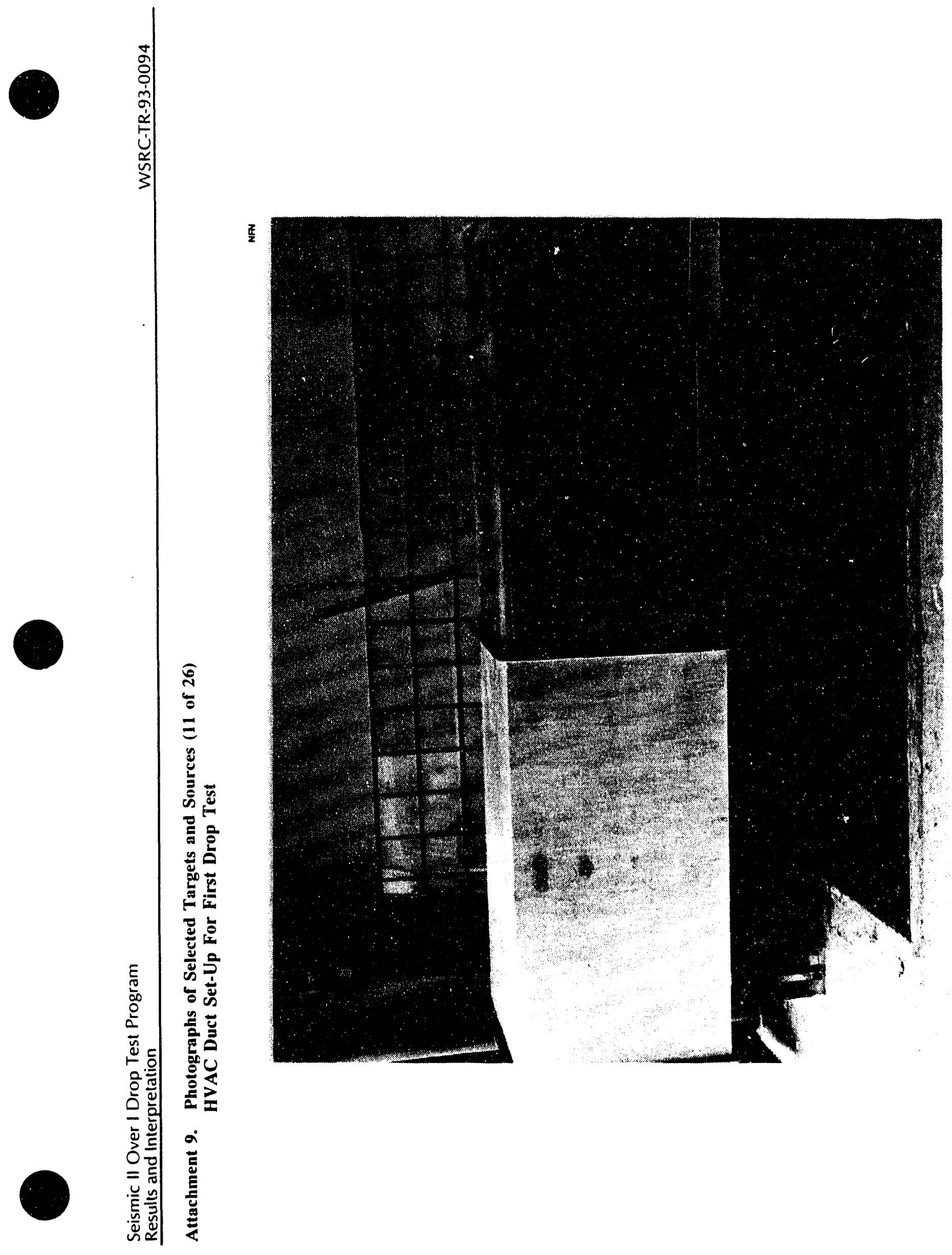



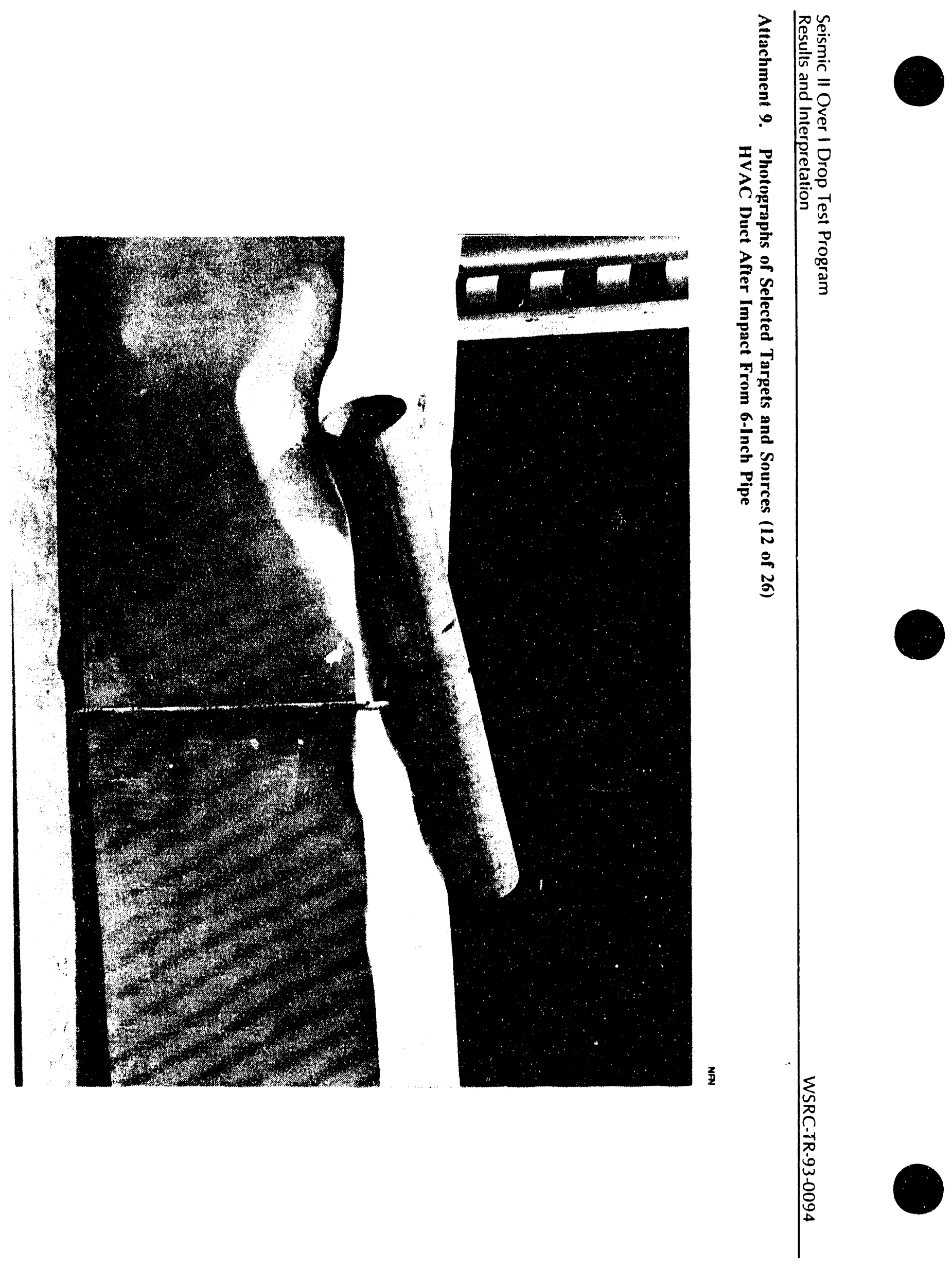


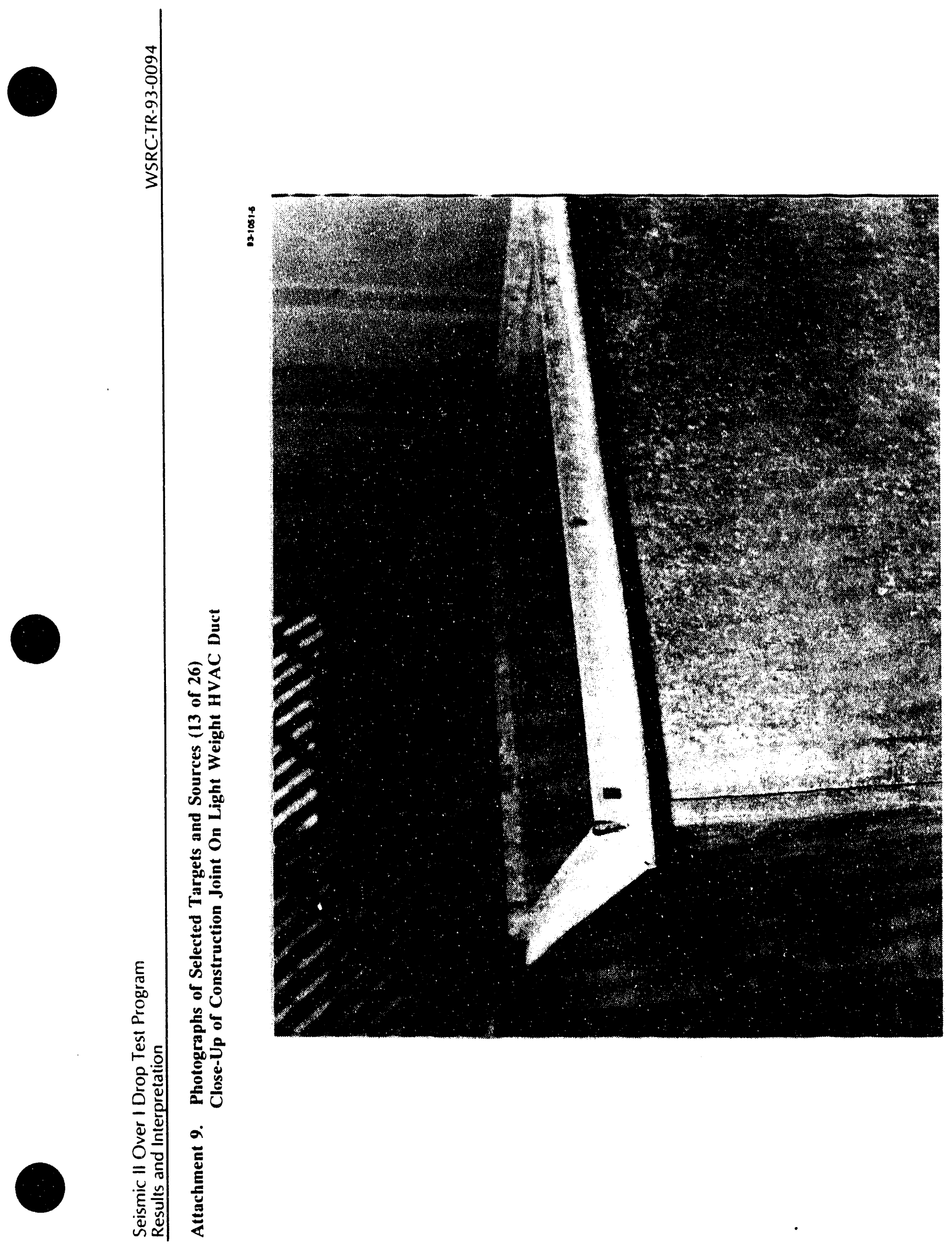




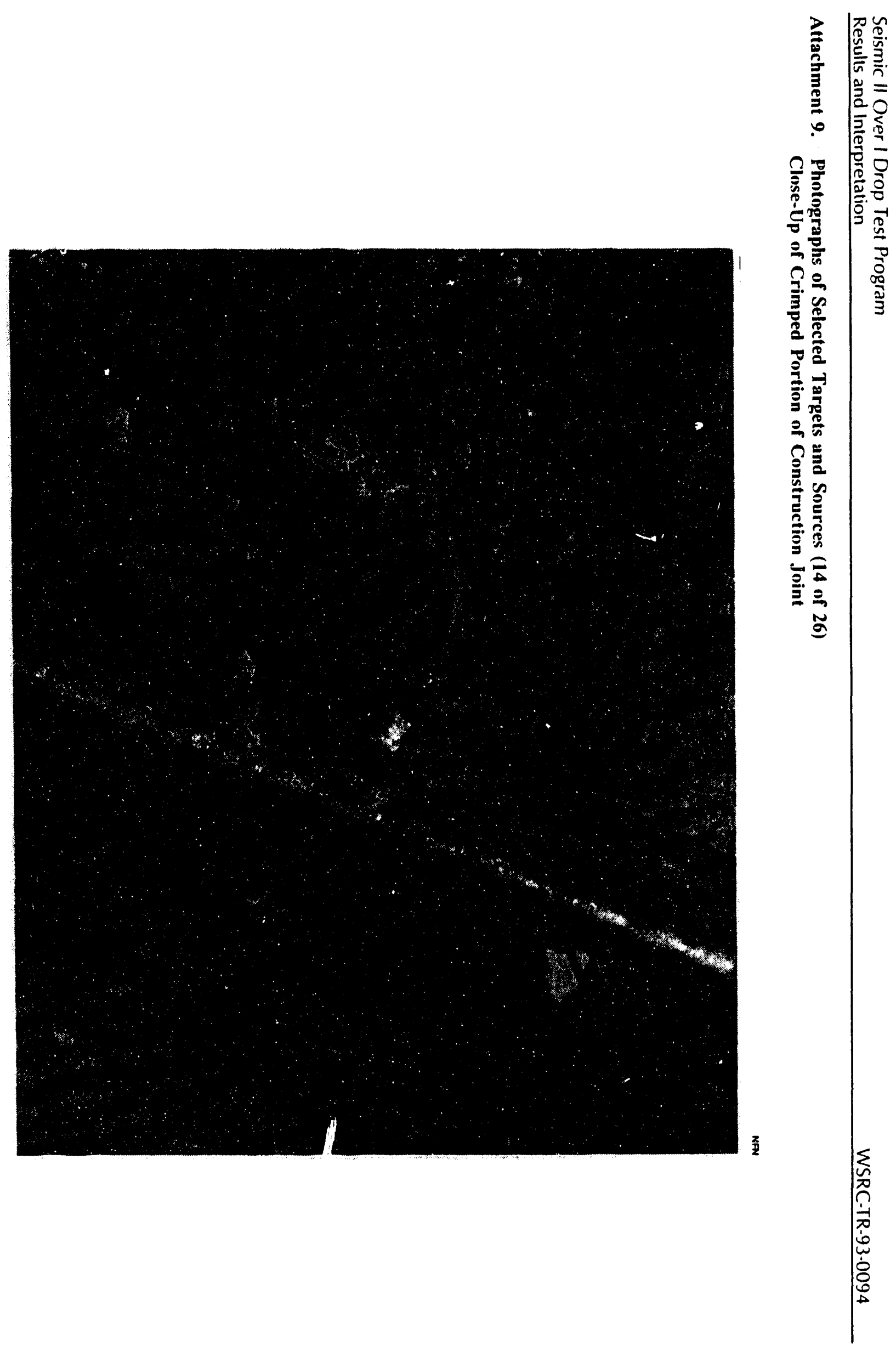




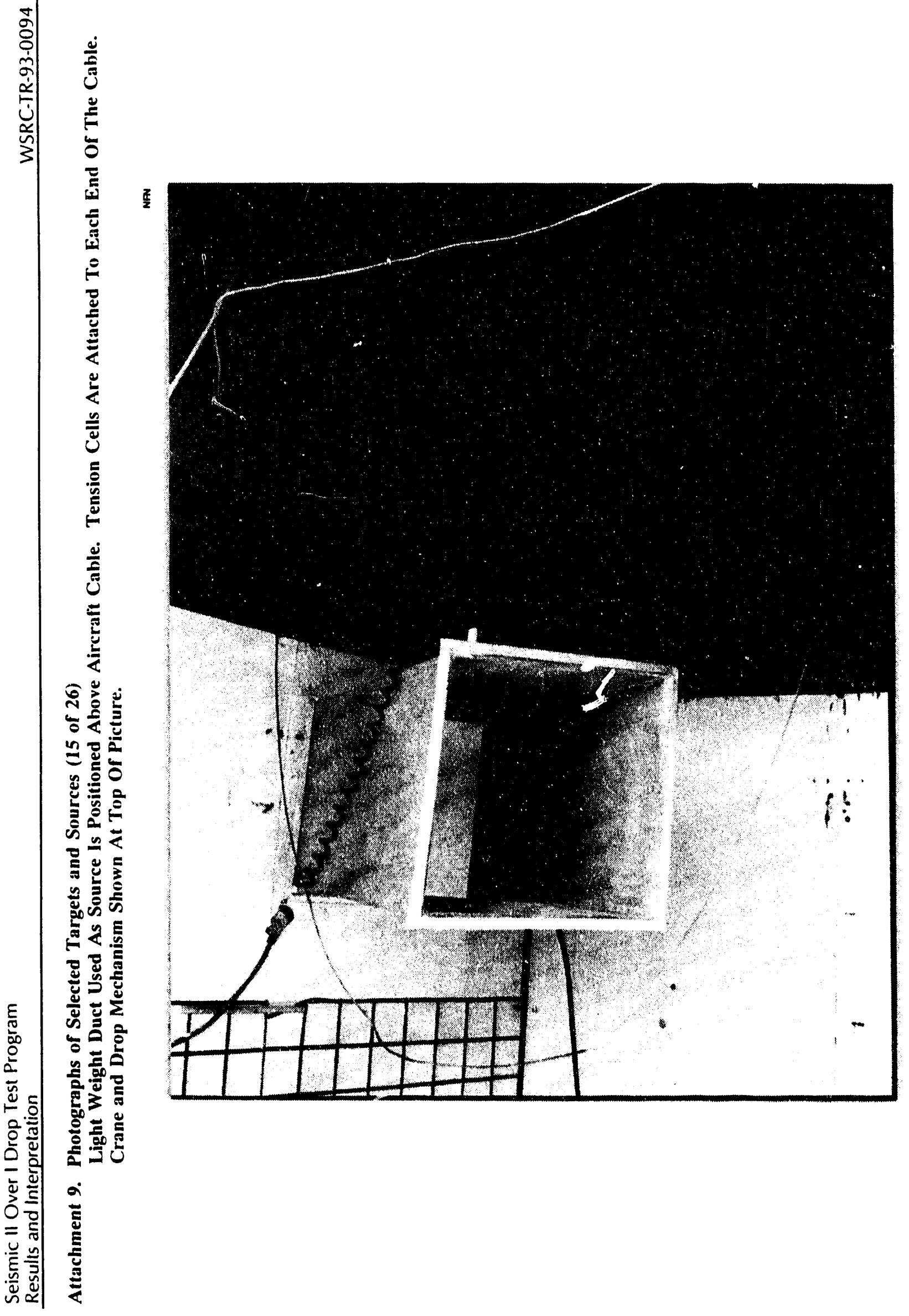




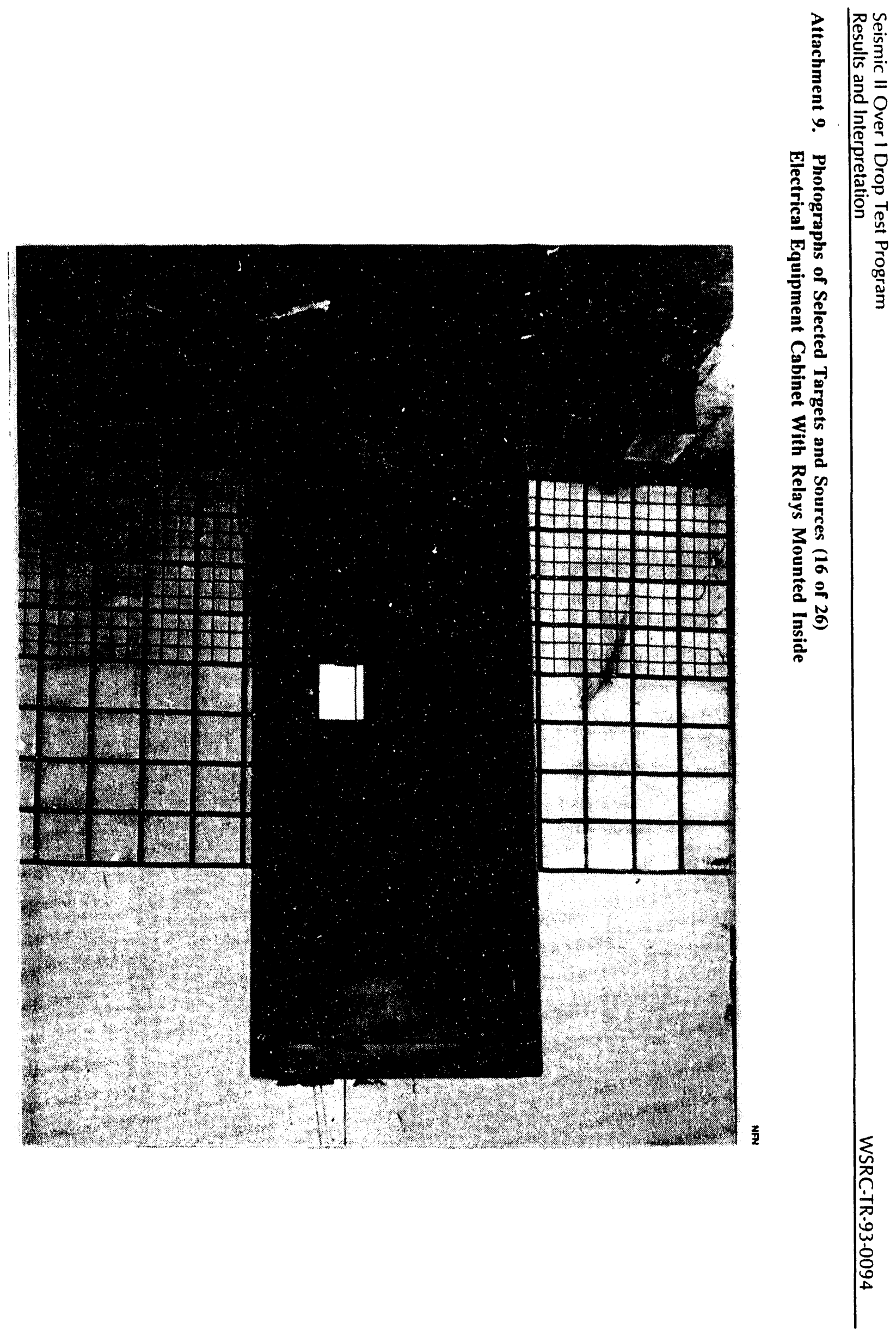




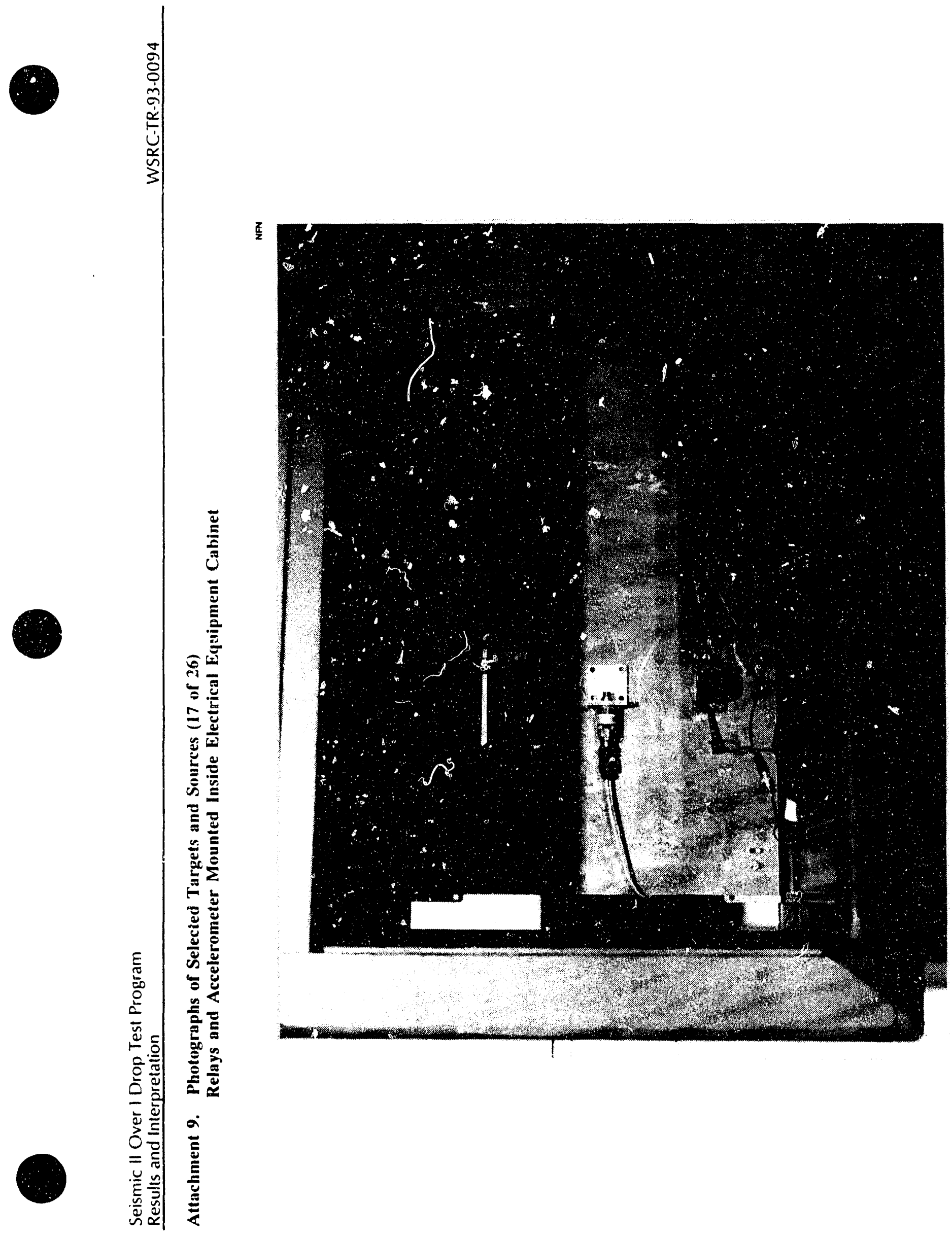






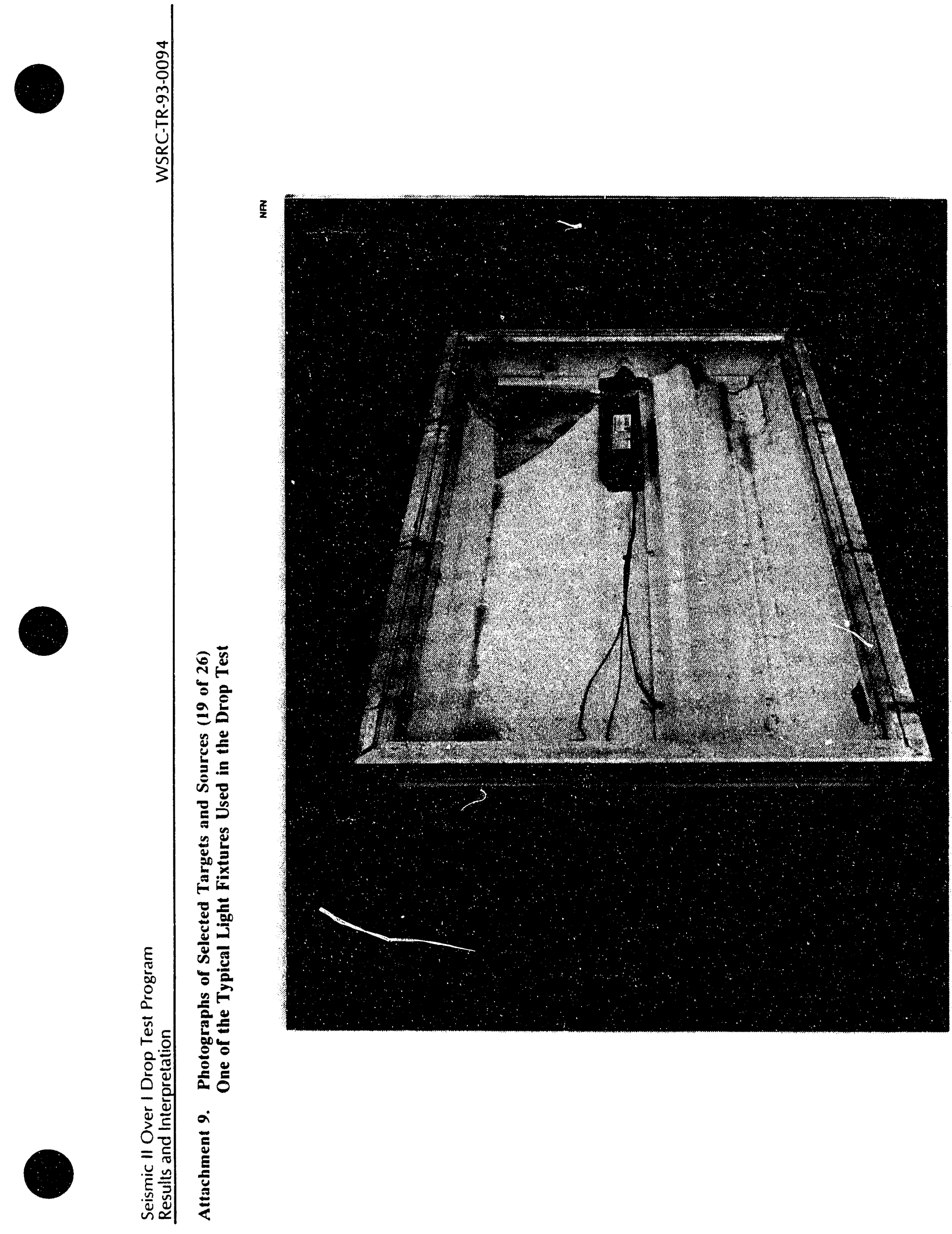




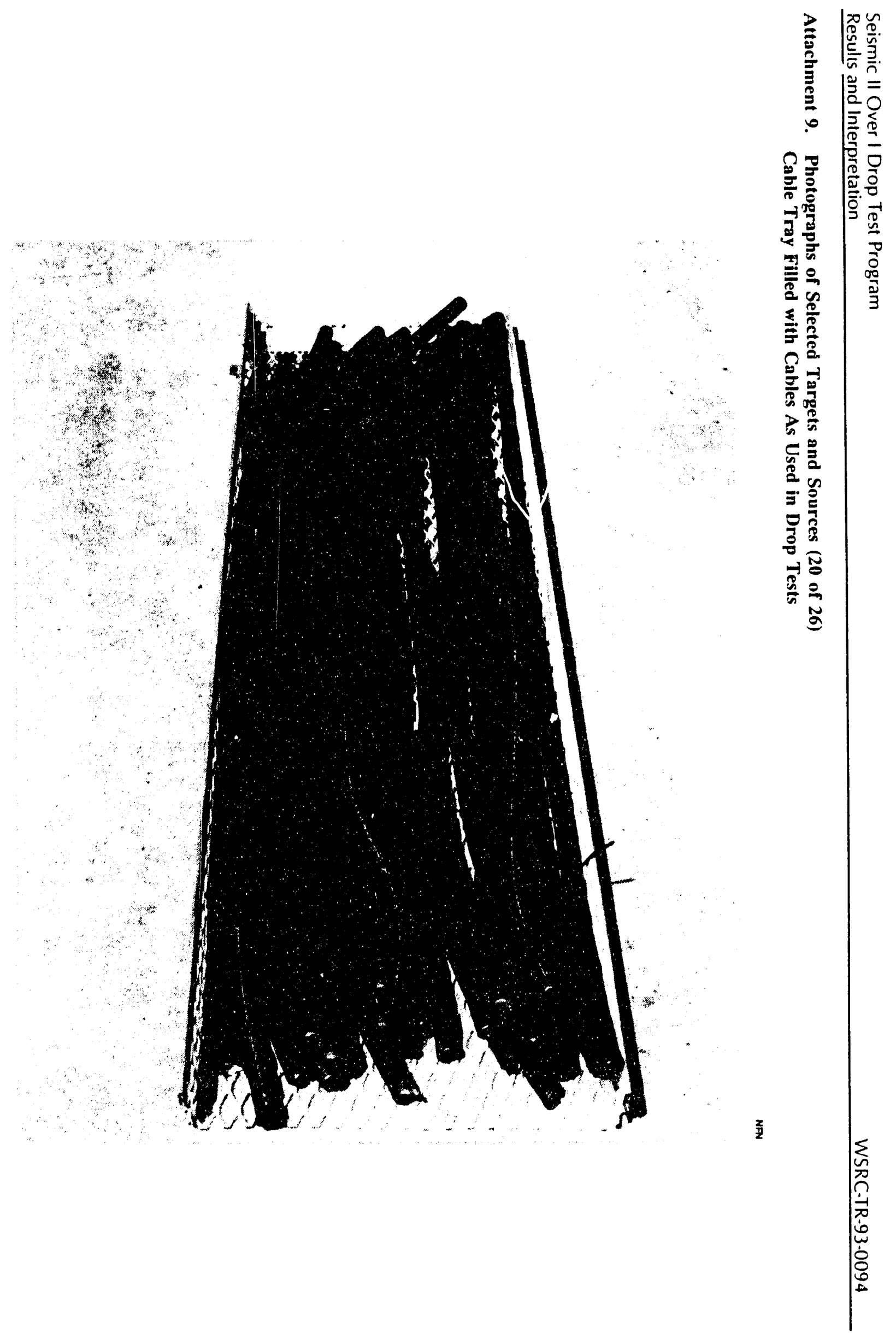




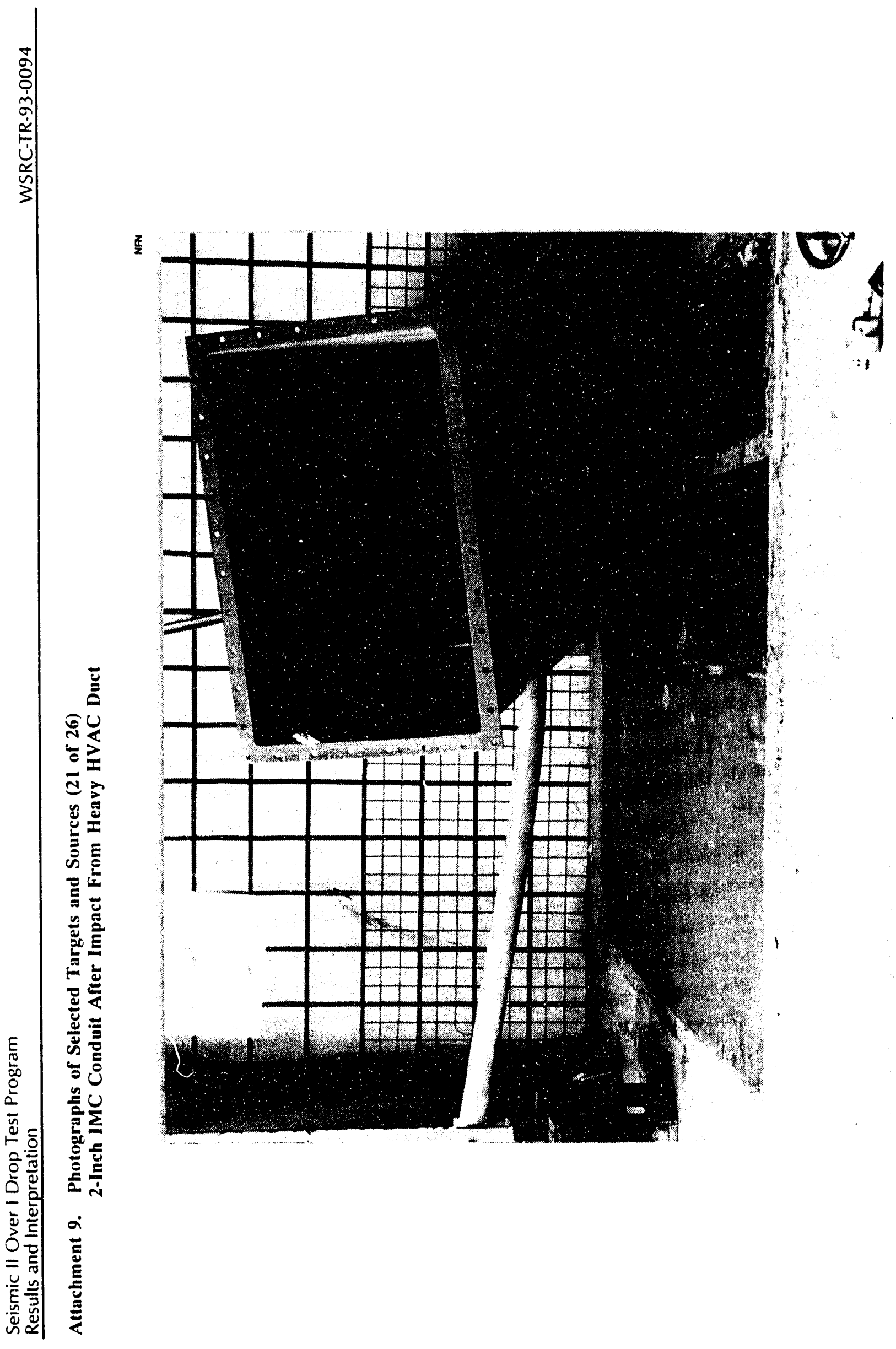




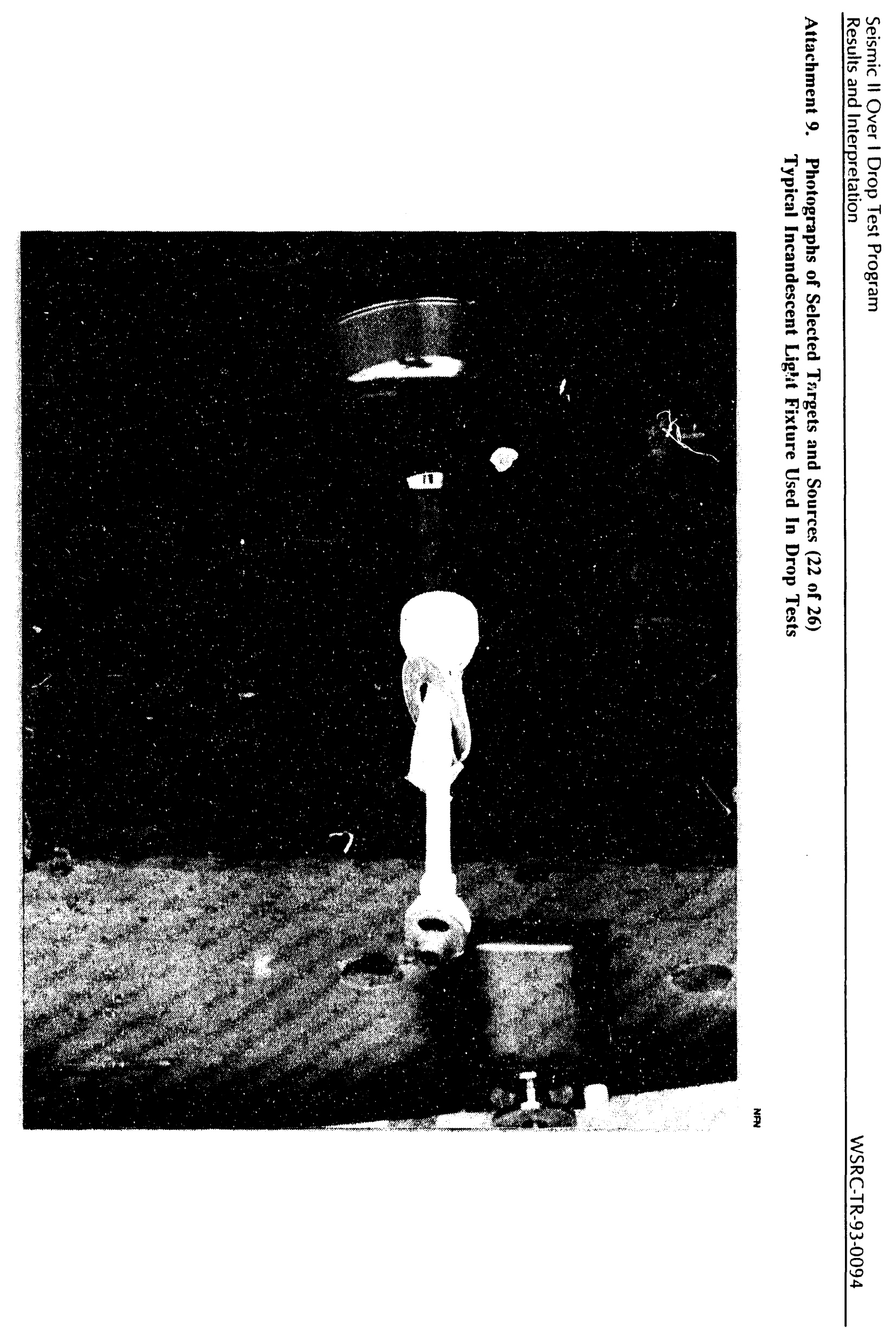




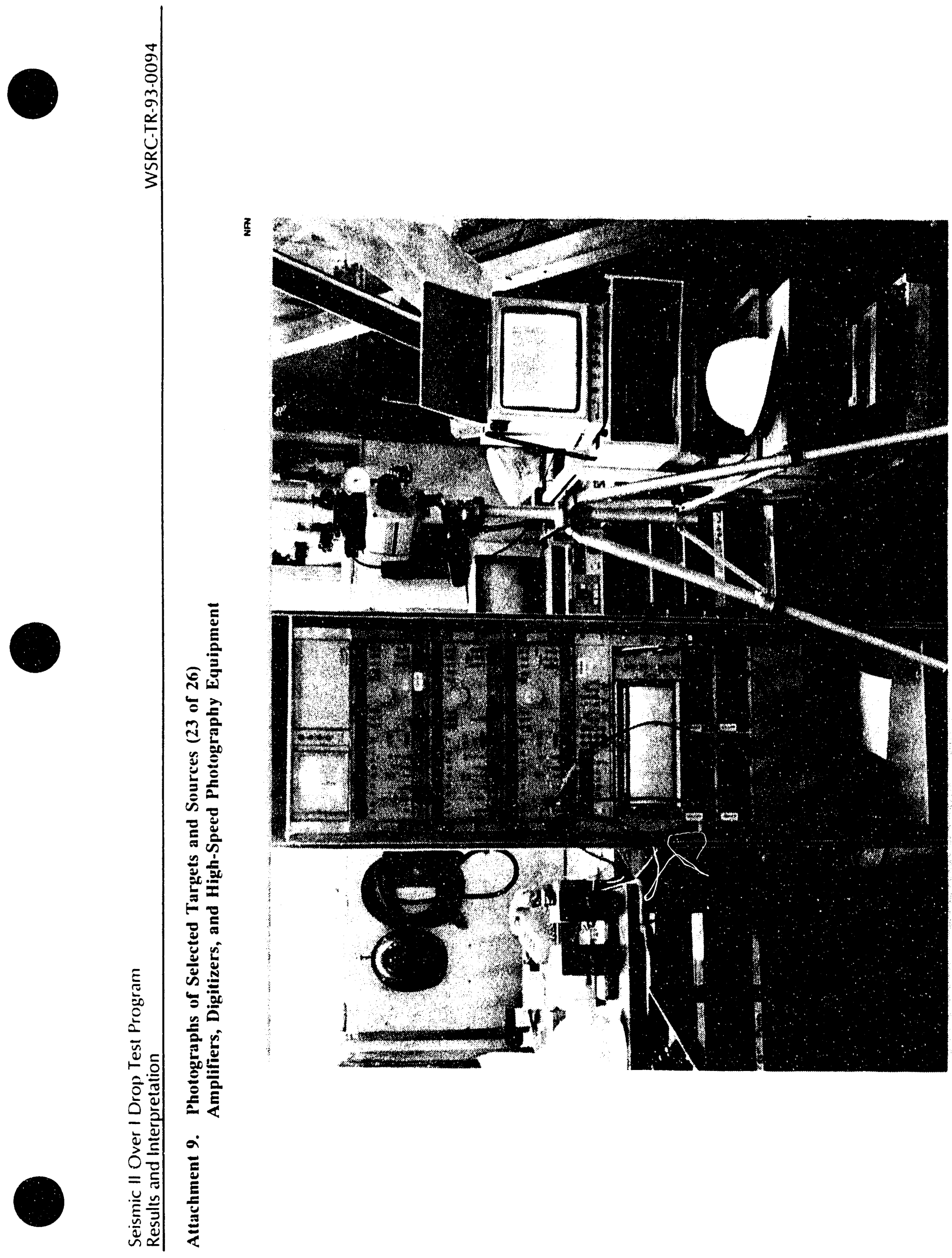




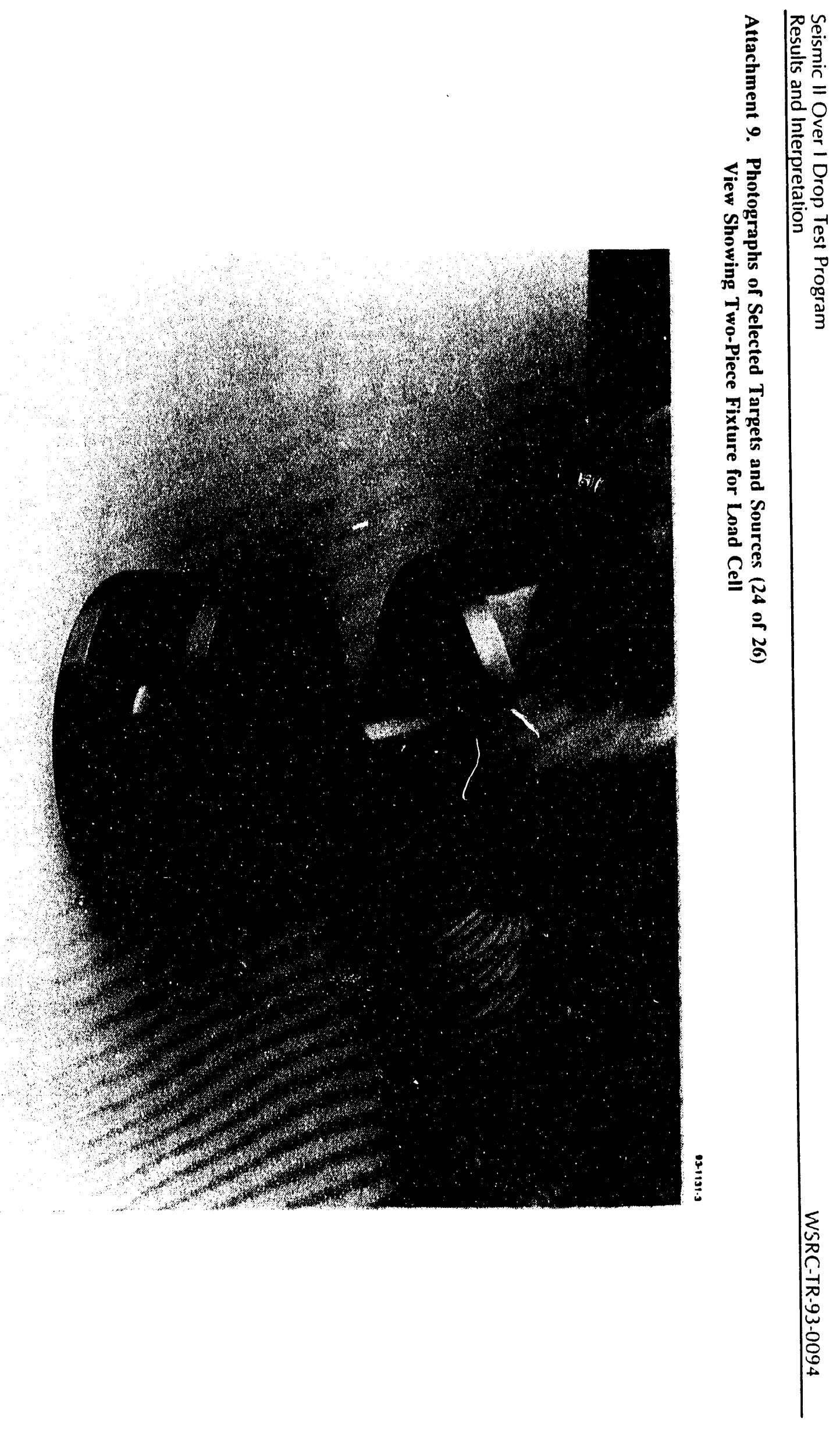




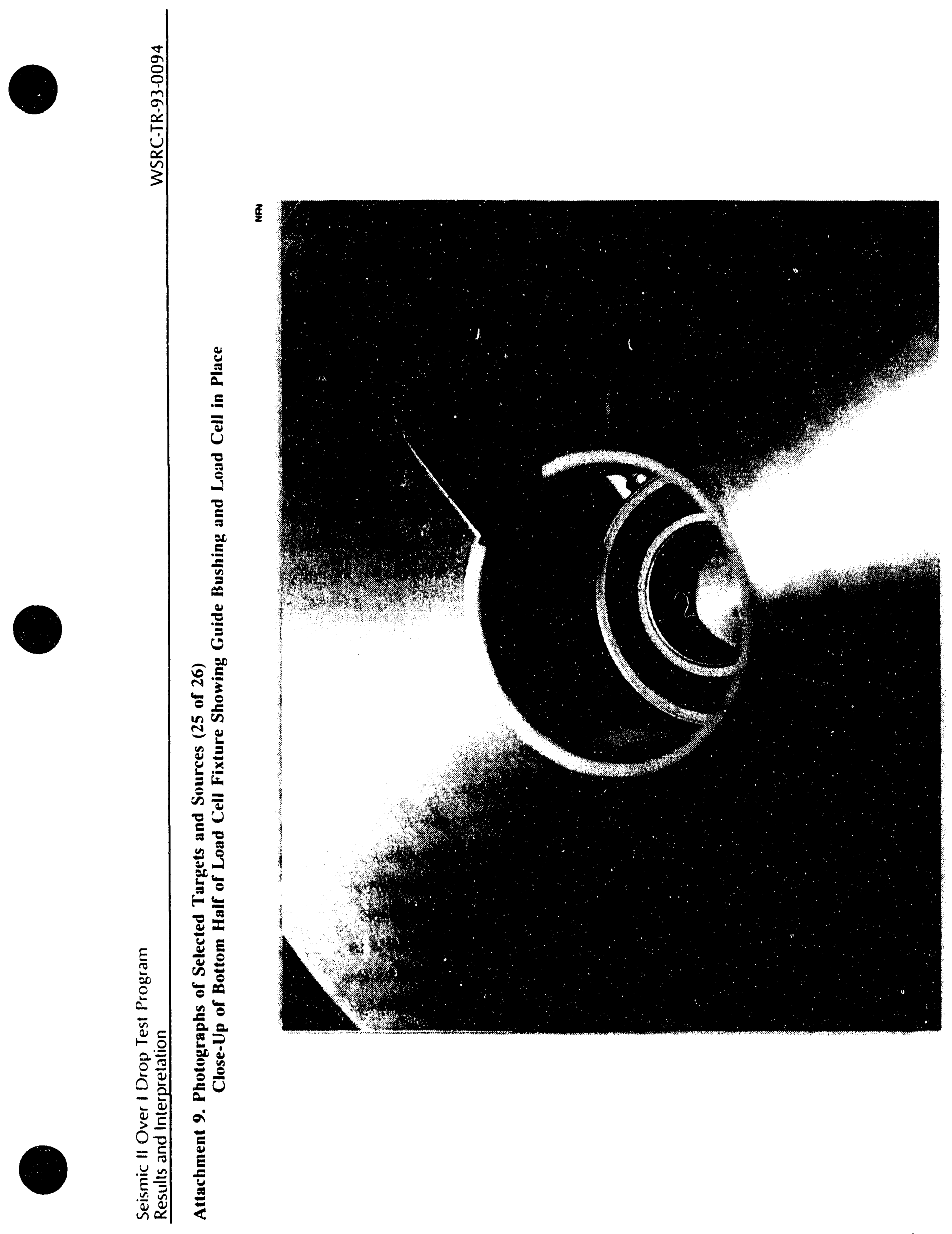




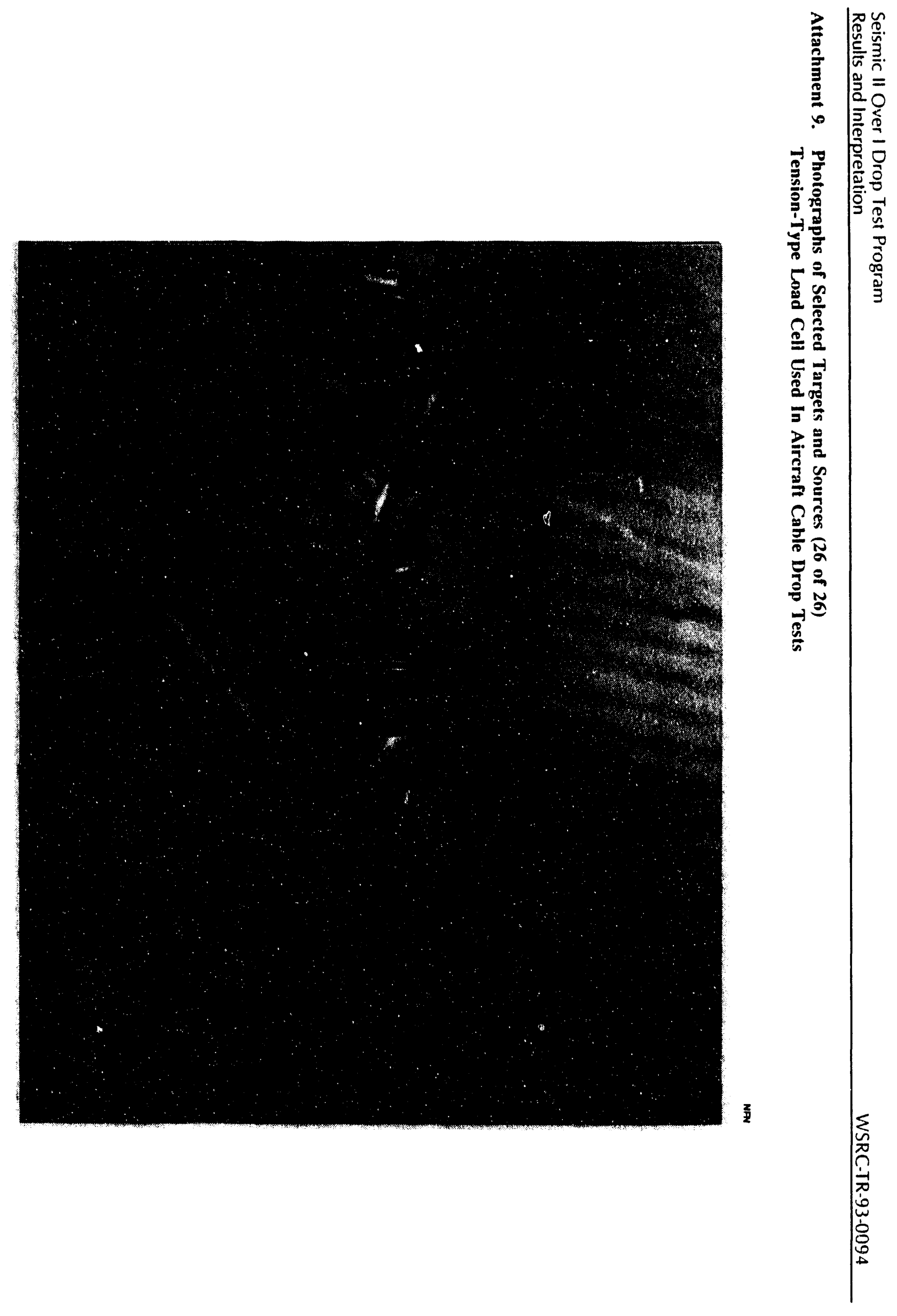


Attachment 10. Test Data Sheets (1 of 155)

\begin{tabular}{|c|c|c|c|c|}
\hline $\begin{array}{c}\text { DROP TEST } \\
\text { No. }\end{array}$ & $\begin{array}{c}\text { EES FIELD } \\
\text { PROCEDURE NO. }\end{array}$ & TARGET & SOURCE & $\begin{array}{c}\text { DROP } \\
\text { HEIGHT }\end{array}$ \\
\hline $1 \mathrm{~A}$ & FP-351 & $\begin{array}{c}\text { Small Electrical } \\
\text { Cabinets on Unistrut } \\
\text { Frame }\end{array}$ & $\begin{array}{c}\text { Incandescent Light } \\
\text { Fixture }\end{array}$ & $72 \mathrm{in.}$ \\
\hline $2 A$ & FP.351 & $"$ & $"$ & $240 \mathrm{in.}$ \\
\hline $3 A$ & FP.351 & $"$ & $\begin{array}{l}\text { Fluorescent Light } \\
\text { Fixture }\end{array}$ & $120 \mathrm{in.}$ \\
\hline $4 A$ & FP-351 & $"$ & $"$ & $240 \mathrm{in.}$ \\
\hline $5 \mathrm{~A}$ & FP. 351 & $"$ & $"$ & $240 \mathrm{in.}$ \\
\hline $6 \mathrm{~A}$ & FP.351 & $"$ & $\begin{array}{l}\text { (7) } 6 \mathrm{ft} \text { Picces of } \\
3 / 4 \text {-in. Conduit }\end{array}$ & $120 \mathrm{in.}$ \\
\hline $7 \mathrm{~A}$ & FP. 351 & $"$ & $"$ & $240 \mathrm{in.}$ \\
\hline $8 \mathrm{~A}$ & FP.351 & $\begin{array}{c}\text { Emergency Lt. Battery } \\
\text { Pack }\end{array}$ & $\begin{array}{l}\text { Incandescent Light } \\
\text { Fixture }\end{array}$ & $24 \mathrm{in}$. \\
\hline 9) $\mathrm{A}$ & FP-351 & $"$ & $"$ & 90 in. \\
\hline $10 \mathrm{~A}$ & FP.351 & $"$ & $"$ & 144 in. \\
\hline $11 A$ & FP. 351 & $"$ & $\begin{array}{l}2 \mathrm{ft} \times 3 \mathrm{ft} \text { Picec of } \\
\text { Transite Wallboard }\end{array}$ & $96 \mathrm{in.}$ \\
\hline $12 \mathrm{~A}$ & FP-351 & $"$ & $\begin{array}{c}2 \mathrm{ft} \times \underset{f}{\mathrm{ft} \text { Ceiling }} \\
\text { Panel }\end{array}$ & $72 \mathrm{in.}$ \\
\hline $13 A$ & FP-351 & $"$ & $\begin{array}{l}\text { 3/4-in. Conduit, } 6 \mathrm{ft} \\
\text { Long }\end{array}$ & $24 \mathrm{in.}$ \\
\hline $14 \mathrm{~A}$ & FP-351 & $"$ & $"$ & $48 \mathrm{in.}$ \\
\hline $15 A$ & FP.351 & $"$ & $\begin{array}{c}\text { Fluorescent Light } \\
\text { Fixture }\end{array}$ & 48 in. \\
\hline $16 \mathrm{~A}$ & FP.351 & $"$ & $"$ & $96 \mathrm{in.}$ \\
\hline $17 \mathrm{~A}$ & FP-351 & $"$ & $\begin{array}{l}2 \mathrm{ft} \times 3 \mathrm{ft} \text { Piece of } \\
\text { Transite Wallhoard }\end{array}$ & $1+4 \mathrm{in}$. \\
\hline 1 & (:P-370) & $\begin{array}{l}\text { 3/4-in. Conduit, } 82 \text { in. } \\
\text { Span }\end{array}$ & $\begin{array}{c}\text { Fluorescent Light } \\
\text { Fixture }\end{array}$ & $24 \mathrm{in}$. \\
\hline 2 & FP.37() & $"$ & $\begin{array}{c}\text { Incindescent light } \\
\text { Fixlure }\end{array}$ & $120 \mathrm{in.}$ \\
\hline
\end{tabular}


Attachment 10. Test Data Sheets (2 of 155)

\begin{tabular}{|c|c|c|c|c|}
\hline $\begin{array}{c}\text { DROP TEST } \\
\text { NO. } \\
\end{array}$ & $\begin{array}{c}\text { EES FIELD } \\
\text { PROCEDURE NO. }\end{array}$ & TARGET & $\overline{\text { SOURCE }}$ & $\begin{array}{c}\text { DROP } \\
\text { HEIGIIT }\end{array}$ \\
\hline 3 & FP. -370 & $\begin{array}{l}\text { 3/4-in. Conduit, } 82 \text { in. } \\
\text { Span }\end{array}$ & $\begin{array}{l}\text { Incandescent Light } \\
\text { Fixture }\end{array}$ & $180 \mathrm{in.}$ \\
\hline 4 & FP-370 & $"$ & $\begin{array}{l}\text { 3/4-in. Conduit, } 6 \mathrm{ft} \\
\text { Long }\end{array}$ & $60 \mathrm{in.}$ \\
\hline 5 & FP. 370 & $"$ & $"$ & $60 \mathrm{in.}$ \\
\hline 6 & FP. -370 & $"$ & $"$ & $120 \mathrm{in.}$ \\
\hline 7 & FP.370 & $"$ & $"$ & $180)$ in. \\
\hline 8 & FP.370 & $"$ & Wallboard & $60 \mathrm{in.}$ \\
\hline ) & FP-370 & $\begin{array}{c}\text { 2-in. Conduit, } 82 \text {-in. } \\
\text { Spain }\end{array}$ & 6-in. Pipe, 4 ft Long & $2+\mathrm{in}$. \\
\hline 10 & FP-370 & & $"$ & 6() $\mathrm{in.}$ \\
\hline 11 & FP-370 & $"$ & $\begin{array}{c}\text { Fluorescent Light } \\
\text { Fixture }\end{array}$ & $60 \mathrm{in.}$ \\
\hline 12 & FP-370 & $"$ & $"$ & $120 \mathrm{in.}$ \\
\hline 13 & FP-370) & $"$ & Heavy Du.t & $60 \mathrm{in.}$ \\
\hline 14 & FP-370) & $"$ & $"$ & $1211 \mathrm{in.}$ \\
\hline 15 & FP-370) & $\begin{array}{l}\text { HVAC Duct, } \text { S2-in. }_{\text {Spant }} \\
\text { S }\end{array}$ & Cable Tray & $12 \mathrm{in.}$ \\
\hline 16 & $\mathrm{FP}-370$ & $"$ & $"$ & $36 \mathrm{in.}$ \\
\hline 17 & FP-370 & $"$ & $"$ & $36 \mathrm{in.}$ \\
\hline 18 & FP-370 & $"$ & Heavy Duct & $12 \mathrm{in.}$ \\
\hline 19 & FP. 370 & $"$ & $\begin{array}{l}\text { 2-in. Conduit, } 194 \mathrm{in.} \\
\text { Long. }\end{array}$ & $60 \mathrm{in.}$ \\
\hline 20 & $F P-370$ & $"$ & " & $150 \mathrm{in.}$ \\
\hline 21 & FP-370 & $"$ & 6-in. Pipe, + ft Long. & $150 \mathrm{in.}$ \\
\hline 22 & FP. -370 & $\begin{array}{l}3 / 4 \text {-in. Conduit, 82-in. } \\
\text { Span }\end{array}$ & $\begin{array}{l}\text { 3/4-in. Conduit, } 6 \mathrm{ft} \\
\text { l.ong. }\end{array}$ & $60 \mathrm{in.}$ \\
\hline 23 & FP-370) & $"$ & $"$ & $120 \mathrm{in.}$ \\
\hline 24 & $F P-370$ & $"$ & $"$ & $120 \mathrm{in.}$ \\
\hline
\end{tabular}


Attachment 10. Test Duta Sheets (3 of 155 )

\begin{tabular}{|c|c|c|c|c|}
\hline $\begin{array}{l}\text { DROP TEST } \\
\text { NO. }\end{array}$ & $\begin{array}{c}\text { EES FIELD } \\
\text { PROCEDURE NO. }\end{array}$ & TARGET & SOURCE & $\begin{array}{c}\text { DROP } \\
\text { HEIGHT }\end{array}$ \\
\hline 25 & $F P \cdot 370$ & $\begin{array}{c}\text { Barricade Assembly, } \\
\text { 48-in. Span }\end{array}$ & $\begin{array}{c}\text { Incandescent Light } \\
\text { Fixture }\end{array}$ & $120 \mathrm{in}$. \\
\hline 26 & FP-370 & $"$ & 6-in. Pipe, 4 it Long. & $1.05 \mathrm{in.}$ \\
\hline 27 & $\mathrm{FP} \cdot 370$ & $"$ & $"$ & 4 in. \\
\hline 28 & FP.370 & $"$ & $"$ & 8 in. \\
\hline 29 & FP.370 & $"$ & $"$ & $12 \mathrm{in.}$ \\
\hline 30 & FP.370 & $"$ & $"$ & $8 \mathrm{in.}$ \\
\hline 31 & $F P-370$ & $"$ & $"$ & $10 \mathrm{in.}$ \\
\hline 32 & $F P \cdot 370$ & $"$ & $"$ & $10 \mathrm{in.}$ \\
\hline 33 & $F P \cdot 370$ & $"$ & $"$ & $10 \mathrm{in.}$ \\
\hline 34 & $F P-37()$ & $"$ & Heavy Duct & $24 \mathrm{in}$ \\
\hline 35 & $F P-370$ & $"$ & $"$ & $48 \mathrm{in}$. \\
\hline 36 & $1 \times P-370$ & $"$ & $"$ & $48 \mathrm{in}$. \\
\hline 37 & $F P-370$ & $"$ & $"$ & $72 \mathrm{in.}$ \\
\hline 38 & $F P \cdot 370$ & " & $"$ & 96 in. \\
\hline 39 & FP. 370 & $"$ & $"$ & $120 \mathrm{in.}$ \\
\hline 40 & FP-370 & $"$ & $"$ & $48 \mathrm{in.}$ \\
\hline+1 & PP.370 & $"$ & $"$ & $2+\mathrm{in}$. \\
\hline+2 & $(1 P \cdot 371)$ & $"$ & $"$ & $2+\mathrm{in}$. \\
\hline+3 & $19 P-370$ & $"$ & $"$ & $2+\mathrm{in}$ \\
\hline 44 & $1 \cdot P \cdot 370$ & $"$ & $"$ & It in. \\
\hline+5 & $1: 1 \cdot-370$ & " & $"$ & $36 \mathrm{in.}$ \\
\hline 46 & PP-370 & $"$ & $\begin{array}{l}\text { Fluorescent Light } \\
\text { Fixture }\end{array}$ & $72 \mathrm{in.}$ \\
\hline
\end{tabular}


Altachment 10. Test Data Sheets ( 4 of 155 )

\begin{tabular}{|c|c|c|c|c|}
\hline $\begin{array}{l}\text { DROP TEST } \\
\text { NO. }\end{array}$ & $\begin{array}{c}\text { EES FIELD } \\
\text { PROCEDURE NO. }\end{array}$ & TARGET & SOURCE & $\begin{array}{c}\text { DROP } \\
\text { HEIGHT }\end{array}$ \\
\hline+7 & $F P-370$ & $\begin{array}{c}\text { Banricade Assembly, } \\
\text { tí in. Span }\end{array}$ & $\begin{array}{l}\text { Fluorescent light } \\
\text { Fixture }\end{array}$ & $120 \mathrm{in}$. \\
\hline 48 & PP-370 & $"$ & $"$ & $180 \mathrm{in.}$ \\
\hline 49 & FP. .370 & $"$ & Wallboard & $60 \mathrm{in.}$ \\
\hline 50 & $1: 1 \cdot 370$ & $"$ & $"$ & $6(1) \mathrm{in.}$ \\
\hline 51 & {$[P-371)$} & $"$ & $"$ & $120 \mathrm{in.}$. \\
\hline 52 & FP -370 & $"$ & 3/4-in. Conduit, 6 it & $60 \mathrm{in.}$ \\
\hline 53 & FP. .370 & $"$ & (1) & $96 \mathrm{in.}$ \\
\hline 54 & FP-371) & $"$ & $"$ & $1211 \mathrm{in}$. \\
\hline 5.5 & $P P-380$ & dircrant cable & Light IVoight Duct & $24 \mathrm{in.}$ \\
\hline 56 & $F P .3 S(1)$ & $"$ & $"$ & 46 in. \\
\hline 57 & $P P-3811$ & $"$ & $"$ & $4 s^{\prime}$ ill. \\
\hline 58 & $19 P \cdot 380$ & $"$ & $"$ & 60 in. \\
\hline 50 & $F P-3 S()$ & $"$ & $"$ & $o() \mathrm{in.}$ \\
\hline 60 & $P P-3 S()$ & $"$ & $"$ & tis in. \\
\hline 61 & $(\therefore P \cdot 3 N()$ & $"$ & $"$ & $0(1)$ in. \\
\hline 62 & $\mid P P-38()$ & $"$ & $"$ & $4 s^{\prime} \mathrm{in}$. \\
\hline 6.3 & $P P-3 S(1)$ & $"$ & 6-ill. Pipe, + $1 \mathrm{l}$ I.ung & $2+\mathrm{in}$. \\
\hline 6.4 & $(P P \cdot 3 S()$ & $"$ & $"$ & $36 \mathrm{in.}$ \\
\hline 6.5 & {$[P-380$} & $"$ & $"$ & $36 \mathrm{in.}$ \\
\hline 60 & {$[P \cdot .31)$} & $"$ & $"$ & tis in. \\
\hline 67 & FP.3S() & $"$ & $"$ & $45 \mathrm{ins}$ \\
\hline $6 k$ & 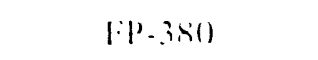 & $"$ & " & fis in. \\
\hline (1) & $\mid[p-3 s(1)$ & “ & (ahle lraly. & $2+1 \mathrm{in.}$ \\
\hline 70 & fP.is( & $"$ & $"$ & $36 \mathrm{in}$. \\
\hline 71 & $(1 P \cdot-3 \times()$ & $"$ & $"$ & It in. \\
\hline
\end{tabular}


Attachment 10. Test Data Sheets (5 of 155)

\begin{tabular}{|c|c|c|c|c|}
\hline $\begin{array}{l}\text { DROP TEST } \\
\text { NO. }\end{array}$ & $\begin{array}{c}\text { EES FIELD } \\
\text { PROCEDURE NO. }\end{array}$ & TARGET & SOURCE & $\begin{array}{c}\text { DROP } \\
\text { HEIGHT } \\
\end{array}$ \\
\hline 72 & FP-380 & Aircraft Cable & Cable Tray & $36 \mathrm{in.}$ \\
\hline 73 & FP. 380 & $"$ & $\begin{array}{l}\text { 2-in. Conduit, } 94 \text { in. } \\
\text { Long }\end{array}$ & $36 \mathrm{in.}$ \\
\hline 74 & $F P \cdot 380$ & $"$ & , & $48 \mathrm{in.}$ \\
\hline 75 & FP-380 & $"$ & $"$ & $72 \mathrm{in.}$ \\
\hline 76 & FP -380 & $"$ & $"$ & $72 \mathrm{in.}$ \\
\hline 77 & 10380 & $"$ & $"$ & 96 in. \\
\hline 78 & FP. 379 & $\begin{array}{l}\text { Electrical Equip. } \\
\text { Cabinet w/Relays }\end{array}$ & $2 \mathrm{ft} \times 4 \mathrm{ft}$ Cciling Tile & $24 \mathrm{in.}$ \\
\hline 79 & FP.379 & $"$ & $"$ & $48 \mathrm{in.}$ \\
\hline 80 & $F P-379$ & $"$ & $"$ & $72 \mathrm{in.}$ \\
\hline 81. & FP-379 & $"$ & ivallboard & $24 \mathrm{in.}$ \\
\hline 82 & F.P.379 & $"$ & $"$ & $48 \mathrm{in}$. \\
\hline 83 & FP-379 & $"$ & $"$ & $72 \mathrm{in.}$ \\
\hline 84 & FP.379 & " & $"$ & $48 \mathrm{i}$. \\
\hline 85 & {$[\cdot P-379$} & $"$ & Fluorescent Lt. Fixture & $24 \mathrm{in.}$ \\
\hline 86 & $F P-370$ & $"$ & $"$ & $48 \mathrm{in}$. \\
\hline 87 & FP-379) & $"$ & $"$ & $72 \mathrm{in.}$ \\
\hline 88 & FP. -379 & $"$ & $"$ & $96 \mathrm{in.}$ \\
\hline 89 & $P P-379$ & $"$ & $\begin{array}{l}\text { Incandescent LI. } \\
\text { Fixture }\end{array}$ & $24 \mathrm{in.}$ \\
\hline 90 & FP. 379 & $"$ & $"$ & $48 \mathrm{in.}$ \\
\hline 41 & FP-379 & $"$ & $"$ & $72 \mathrm{in.}$ \\
\hline 92 & FP.379 & $"$ & $"$ & $96 \mathrm{in.}$ \\
\hline
\end{tabular}


Attachment 10. Test Data Sheets (6 of 155)

\begin{tabular}{|c|c|c|c|c|}
\hline $\begin{array}{c}\text { DROP TEST } \\
\text { No. } \\
\end{array}$ & $\begin{array}{c}\text { EES FIELD } \\
\text { PROCEDURE NO. }\end{array}$ & TARGET & SOURCE & $\begin{array}{c}\text { DROP } \\
\text { HEIGHT } \\
\end{array}$ \\
\hline 93 & FP-379 & $\begin{array}{c}\text { Electrical Equipment } \\
\text { Cabinet w/Relays }\end{array}$ & $\begin{array}{c}\text { Solid Object (Sprinkler } \\
\text { Head) }\end{array}$ & $170 \mathrm{in.}$ \\
\hline 94 & FP-379 & $"$ & $\begin{array}{l}\text { 3/4-in. Conduit, } 6 \mathrm{ft} \\
\text { Long }\end{array}$ & $24 \mathrm{in.}$ \\
\hline 95 & FP-379 & $"$ & " & $48 \mathrm{in.}$ \\
\hline 96 & FP.379 & $"$ & $"$ & 48 in. \\
\hline 97 & FP-379 & $"$ & $2 \mathrm{ft} \times 4 \mathrm{ft}$ Ceiling Tilc & $96 \mathrm{in.}$ \\
\hline 95 & FP-379 & $"$ & $"$ & 48 in. \\
\hline 99 & FP-379 & $"$ & $"$ & - \\
\hline 10() & FP-379 & $"$ & Wallboard & $12 \mathrm{in.}$ \\
\hline 101 & FP-379 & $"$ & Fluorescent Lt. Fixture & $96 \mathrm{in.}$ \\
\hline 102 & FP-379 & $"$ & $"$ & $48 \mathrm{in.}$ \\
\hline 103 & FP-379 & $"$ & $\begin{array}{c}\text { Incandescent Lt. } \\
\text { Fixture }\end{array}$ & $24 \mathrm{in.}$ \\
\hline 104 & FP-379 & $"$ & $\cdots$ & - \\
\hline 105 & FP. 379 & $"$ & $\begin{array}{c}\text { Inciandescent Lt. } \\
\text { Fixture }\end{array}$ & $72 \mathrm{in.}$ \\
\hline
\end{tabular}


WSRC-TR-93-0094

Attachment 10. Test Data Sheets (7 of 155)

Savannah River Technology Center

Equipment Engineering

EES-FP-351, Rev. 0

Seismic IVI Drop Test Program

Cabinet Drop Tests - Camera Only

Date Approved: 5/13/92, Category 2

Page 12 of 12

\section{Q.2 ATTA.CHMAENT 2}

IEST DATA SHEET

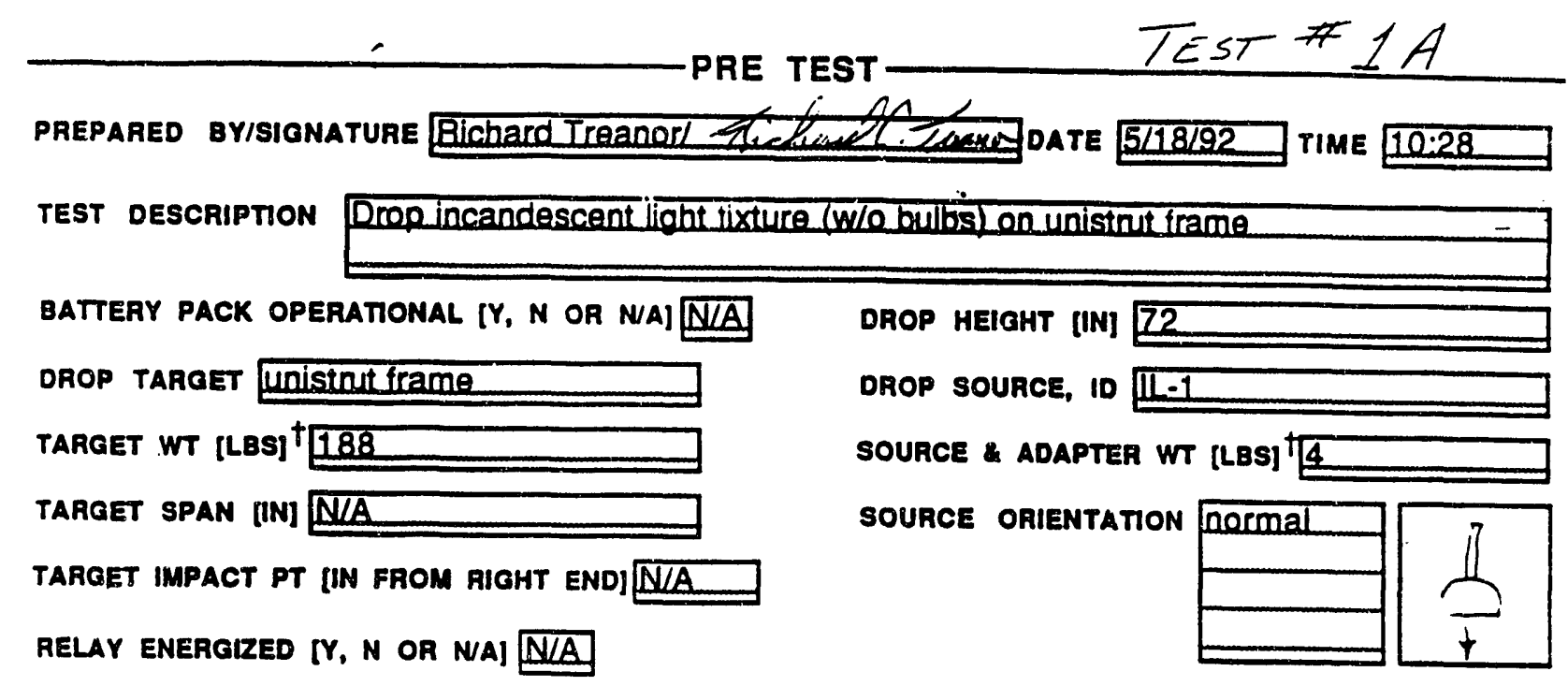

POST TEST

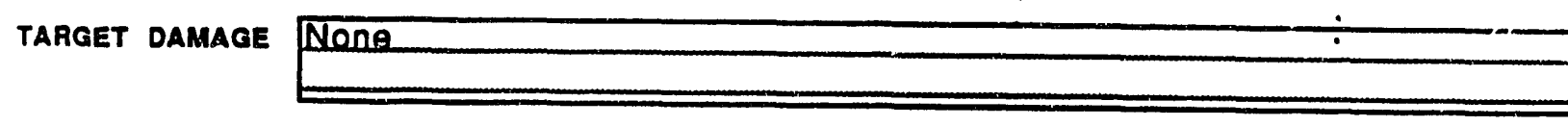

source dAMAGe Deated on liaht bowl circumference. Ne sionificant damage.

BATTERY PACK OPERATIONAL $[Y, N$ OR NA] N/A

HAND HELD VIDEO START \& STOP POSITION NIA

HIGH SPEED VIDEO START STOP POSITION $00: 00-00: 43$

COMMENTS

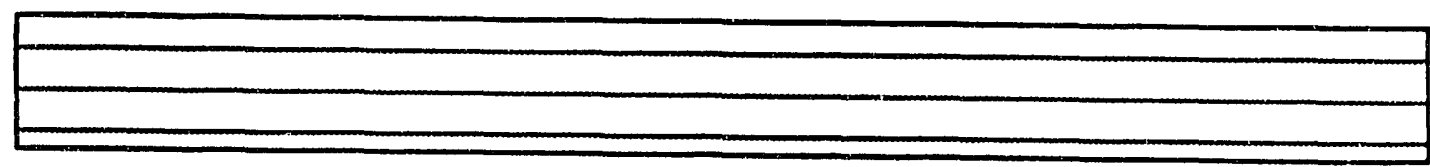

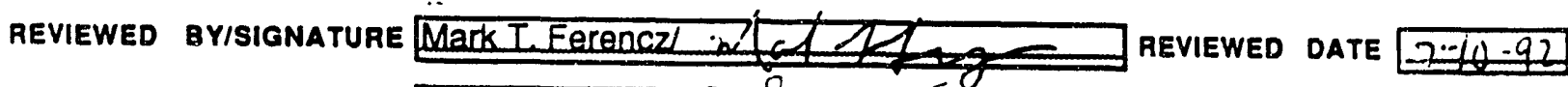
APPROVED BYISIGNATURE Brian Thomas/ 14 14-42

$\dagger_{\text {Approximate weight using M\&TE category } 3 \text { equipment. }}$ 
WSRC-TR-93-0094

Attachment 10. Test Data Sheets (8 of 155)

Savannah River Tochnology Center Equipment Engineering. Seismic IVI Drop Test Program Cabinet Drop Tests - Camera Only

EES-FP-351, Rev. 0 Date Approved: 5/13/92, Category 2

Page 12 of 12

\section{2 ÄTTACHLAENT 2}

\section{IEST DATA SHEET}

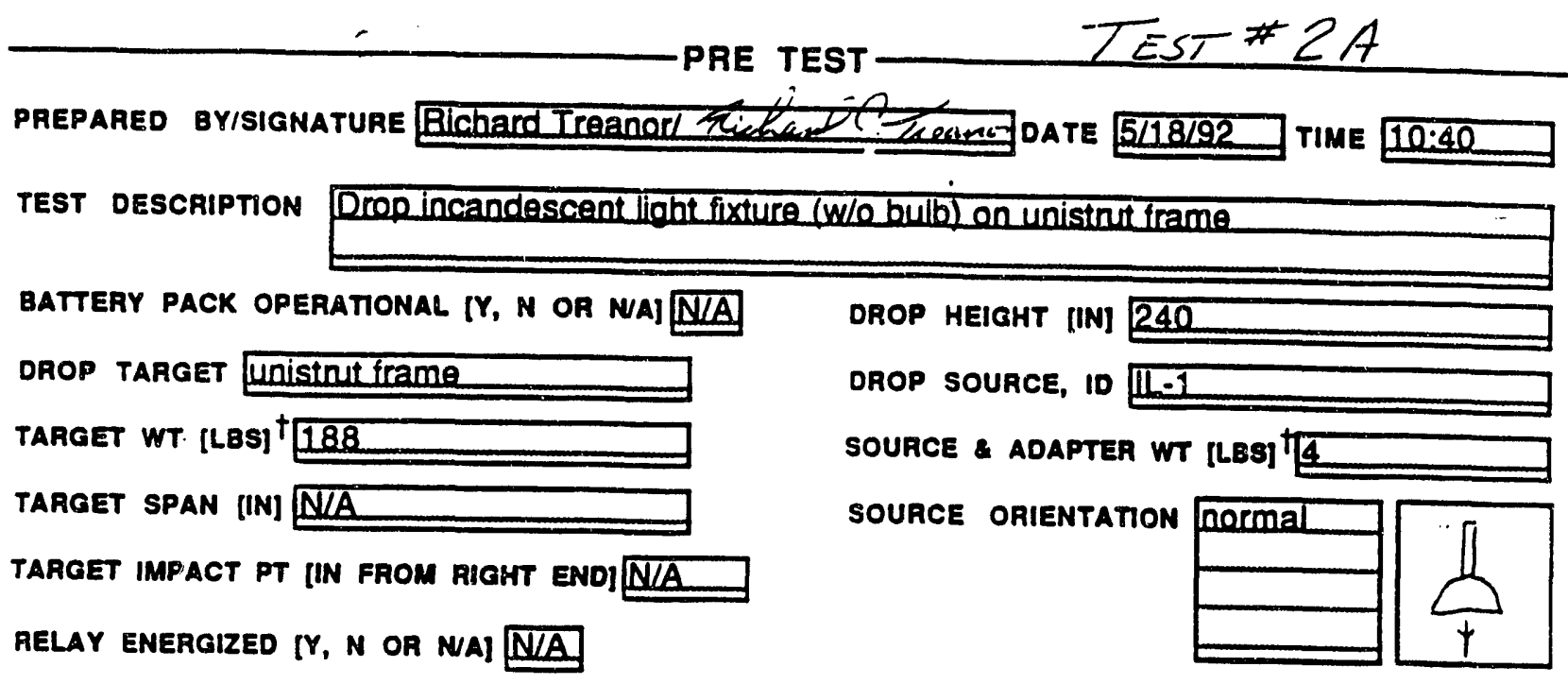

POST TEST
TARGET dAMAgE Scratchedunistnit frama_;

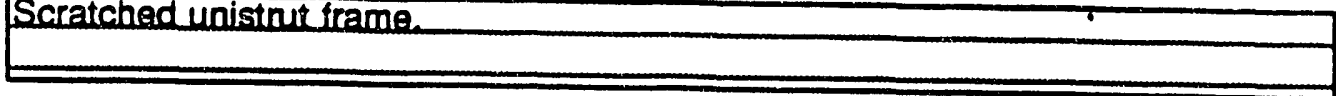
SOURCE DAMAGE Bowldisconnected from stem. Brokeceramicaconnection_connecting stem and bowh. 3/8n dent on bowl.

BATTERY PACK OPERATIONAL [Y, $N$ OR MA] NIA

HAND HELD VIDEO START \& STOP POSTION N/A

HIGH SPEED VIDEO START \& STOP POSITION 00:43-01:26
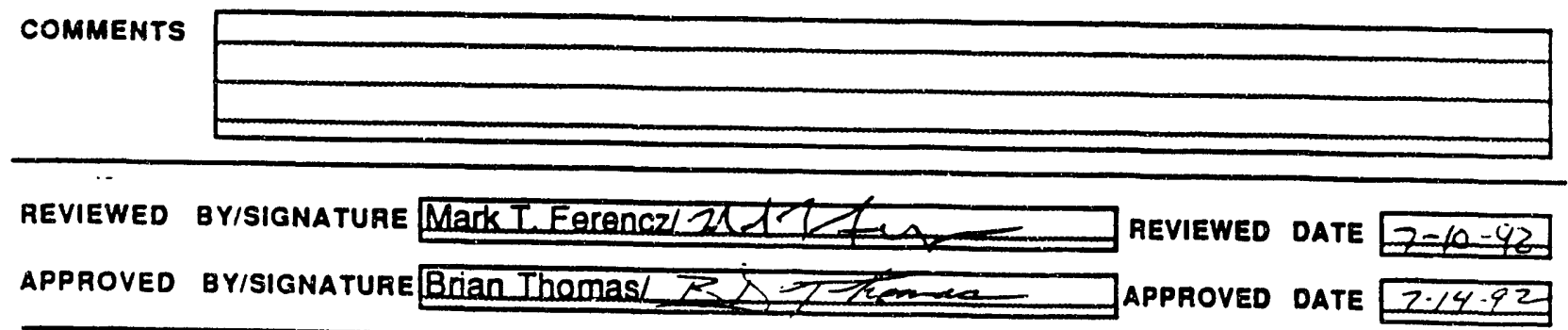

$\dagger_{\text {Approximate weight using M\&TE category } 3 \text { equipment. }}$ 
IVSRC-TR-93-0094

Attachment 10. Test Data Sheets (9 of 155 )

Savannah River Technology Center

Equipment Engineering

EES-FP-351, Rev. 0

Seismic IVI Drop Test Program

Cabinet Drop Tests - Camera Only

Date Approved: 5/13/92, Category 2

Page 12 of 12

\section{O.2 MTTMCHAinETivT 2}

IEST DATA SHEEI

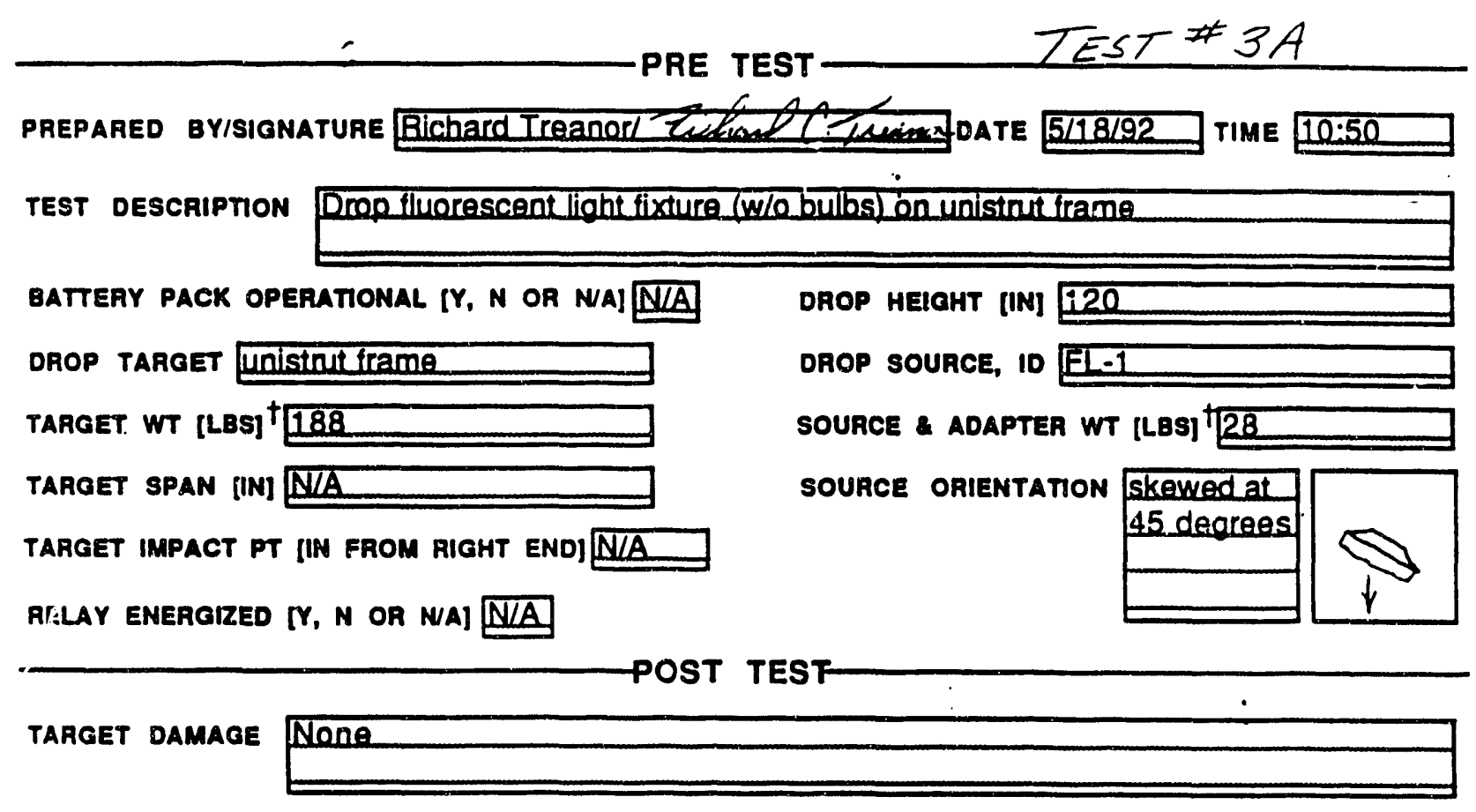

SOURCE DAMAGE Wightcaved in at one side (approx.2" degp) Plastic light cover shattered.

BATTERY PACK OPERATIONAL [Y, N OR NA] N/A

HAND HELD VIDEO START \& STOP POSITION 00:00-01:06

HIGH SPEED VIDEO START \& STOP POSITION 01:26-02:44

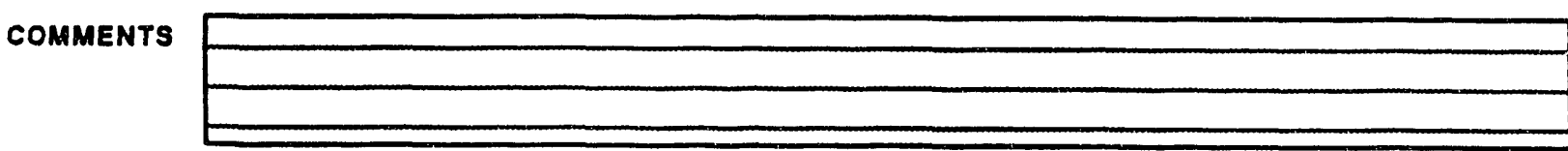

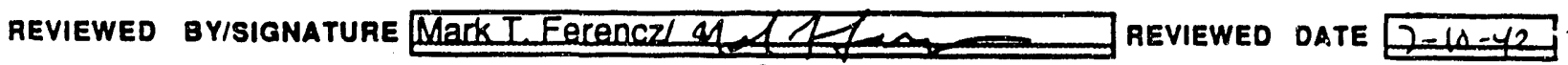

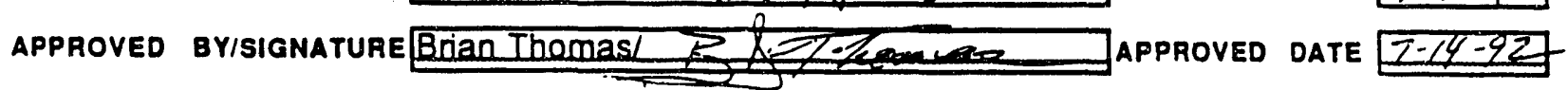

$\dagger_{\text {Approximate weight using M\&TE category } 3 \text { equipment. }}$ 
WSRC-TR-93-009

Attachment 10. Test Data Sheets (10 of 155)

Savannah River Techinology Center

Equipment Engineering

EES-FP-351, Rev. 0

Seismic IVI Drop Test Program

Cabinet Drop Tests - Camera Only

Date Approved: 5/13/92, Category 2

Page 12 of 12

\section{O.2 AंTIACHMENT Z}

IEST DATA SHEET

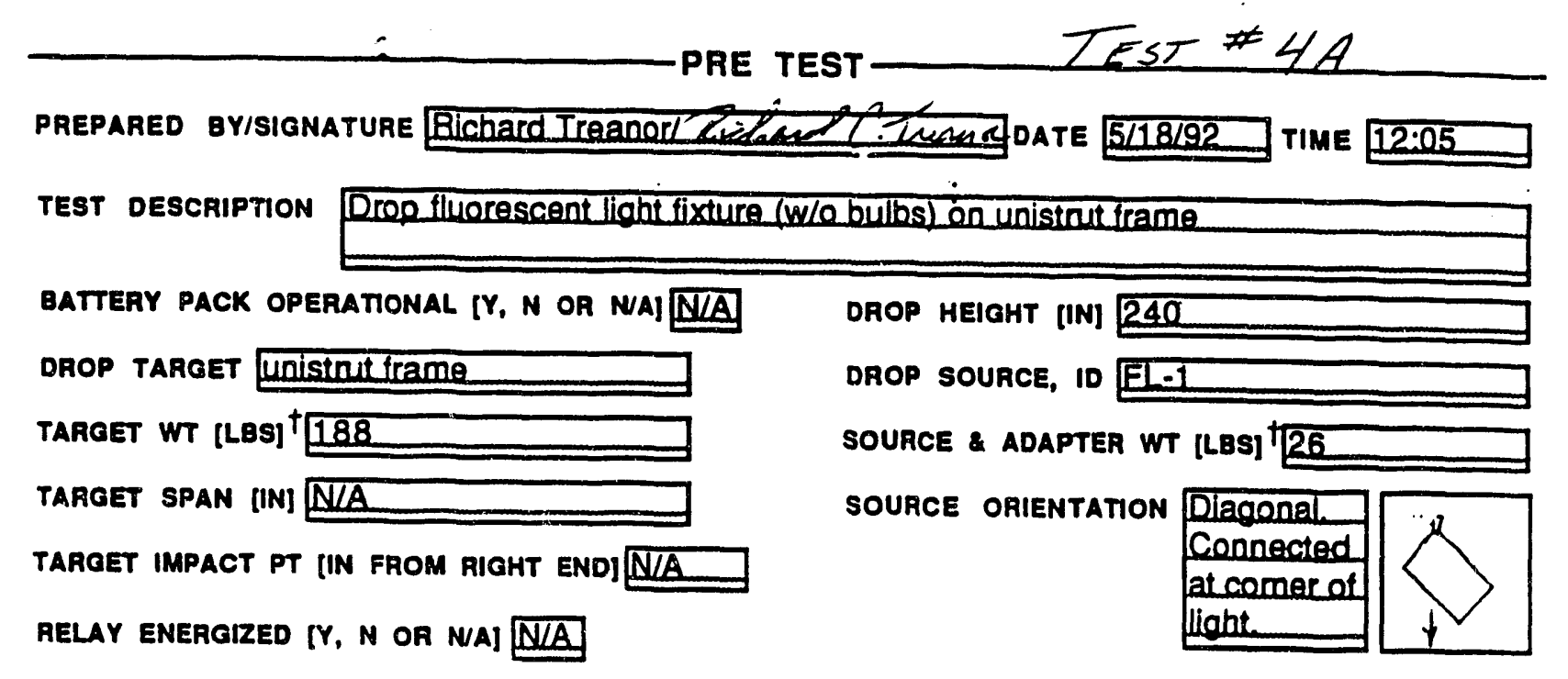

POST TEST

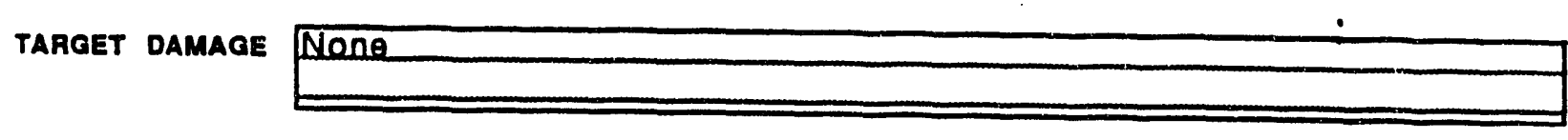

SOURCE DAMAOE Dentedside of lioht.

BATTERY PACK OPERATIONAL [Y, $N$ OR NA] N/A

HAND HELD VIDEO START STOP POSITION 01:06-01:55

HIGH SPEED VIDEO START \& STOP POSINON $02: 44-03: 27$

COMMENTs Source alanced taraet Not direct hit.

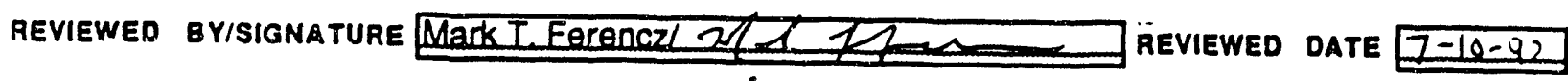
APPROVED BYISIGNATURE Brian Thomas

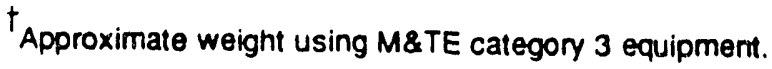


WSRC-TR-93-0094

Attachment 10. Test Data Sheets (11 of 155)

Savannah River Technology Center Equipment Engineering

Seismic IVI Drop Test Program

EES-FP-351, Rev. 0

Cabinet Drop Tests - Camera Only

\section{Date Approved: 5/13/92, Category 2}

Page 12 of 12

\subsection{ATTACHMENT 2}

\section{IEST DATA SHEET}

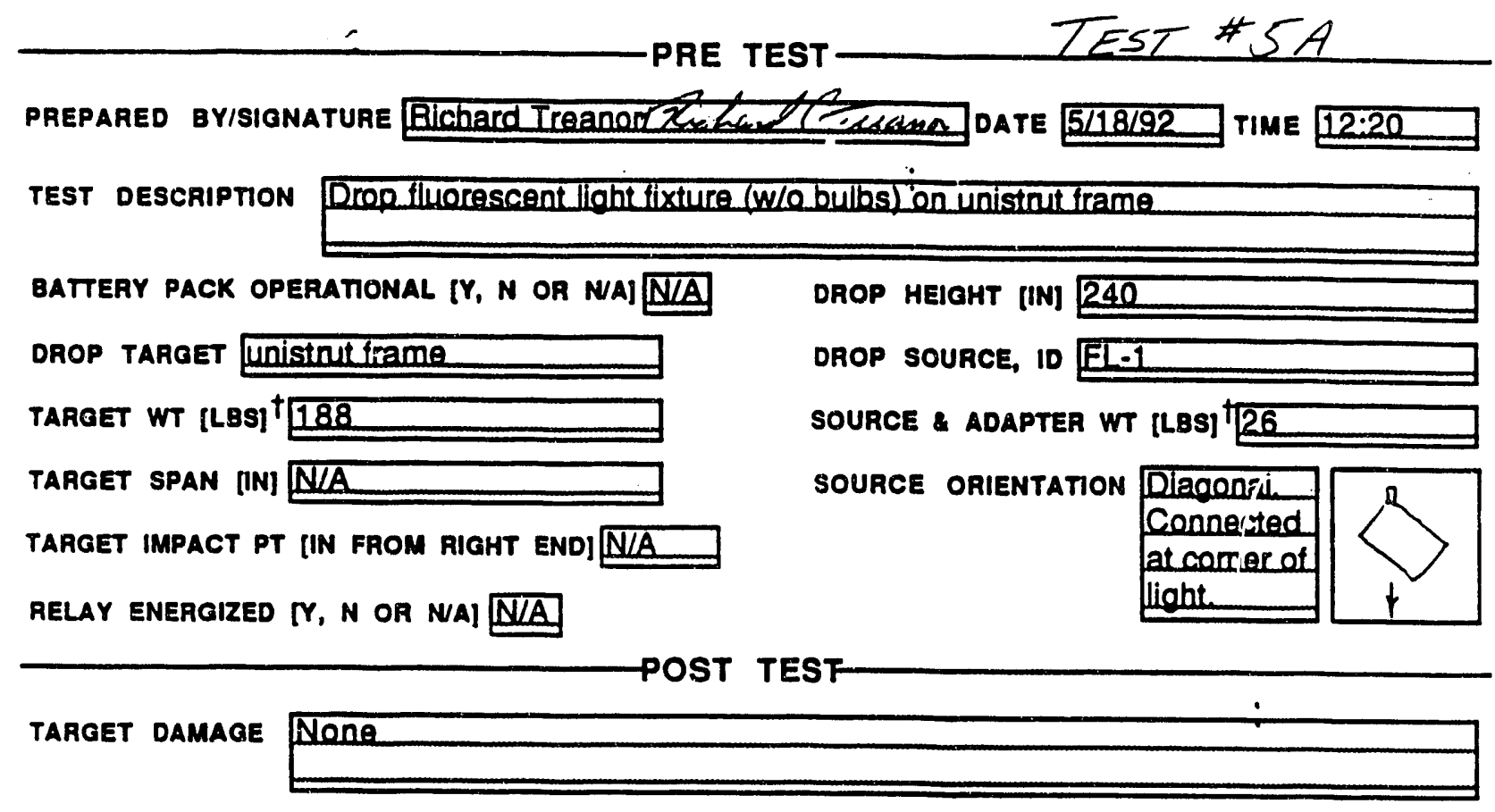

SOURCE DAMAGE lightplastic cover frame was broken off of liaht.

BATTERY PACK OPERATIONAL [Y, N OR N/A] N/A

HAND HELD VIOEO START \& STOP POSITION N/A

HIGH SPEED VIDEO START \& STOP POSITION 03:27-03:50

COMMENTS Source alanced target. Not direct hit.

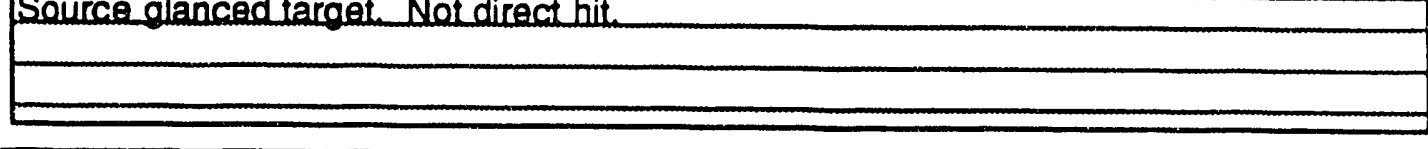

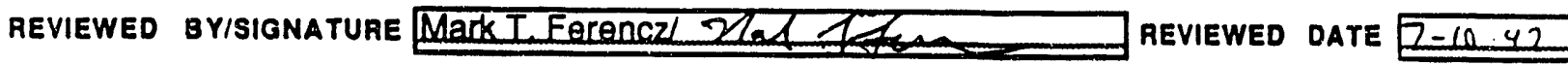
APPROVED BYISIGNATURE Brian Thomasl

${ }^{\dagger}$ Approximate weight using M\&TE category 3 equipment. 
IVSRC-TR-93-0094

Attachment 10. Test Data Sheets (12 of 155 )

Savannah River Technology Center

Equipment Engineering

EES-FP-351, Rev. 0

Seismic IVI Drop Test Program

Cabinet Drop Tests - Camera Only

\section{Q.2 ATTACHAMENT 2}

\section{IEST DATA SHEET}

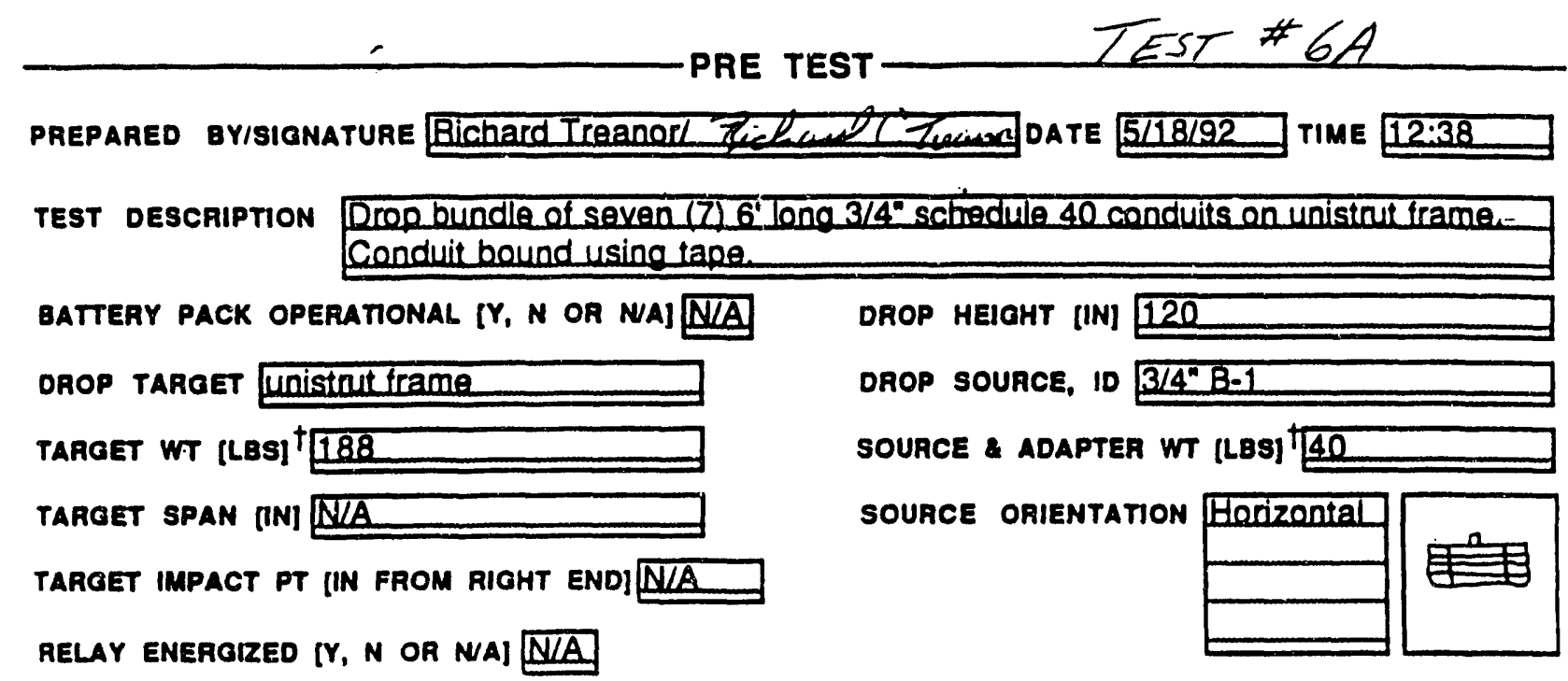

POST TEST

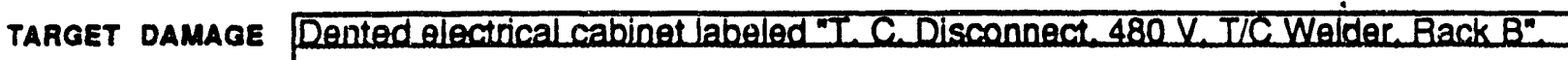

SOURCe damage Dented several conduits approx.1/4" deep at midspan.

BATTERY PACK OPERATIONAL $[Y, N$ OR NA] N/A

HAND HELD VIDEO START \& STOP POSITION NIA

HIGH SPEED VIDEO START \& STOP POSITION $03: 50-04: 25$

COMMENTS

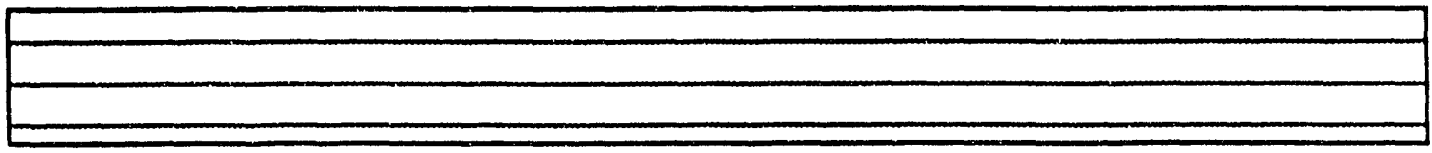

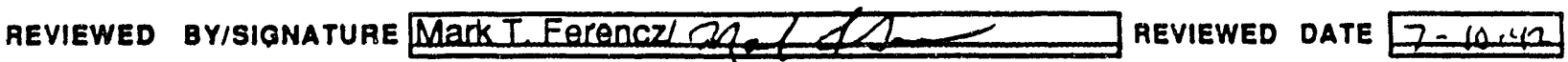
APPROVED Byisionature Brian Themasl

$\dagger_{\text {Approximate weight using M\&TE category } 3 \text { equipment. }}$ 
WSRC-TR-93-0094

Attachment 10. Test Data Sheets (13 of 155)

Savannah River Technology Center

Equipment Engineering

EES-FP-351, Rev. 0

Seismic IVI Drop Test Program

Date Approved: 5/13/92, Category 2

Cabinet Drop Tests - Camera Only

Page 12 of 12

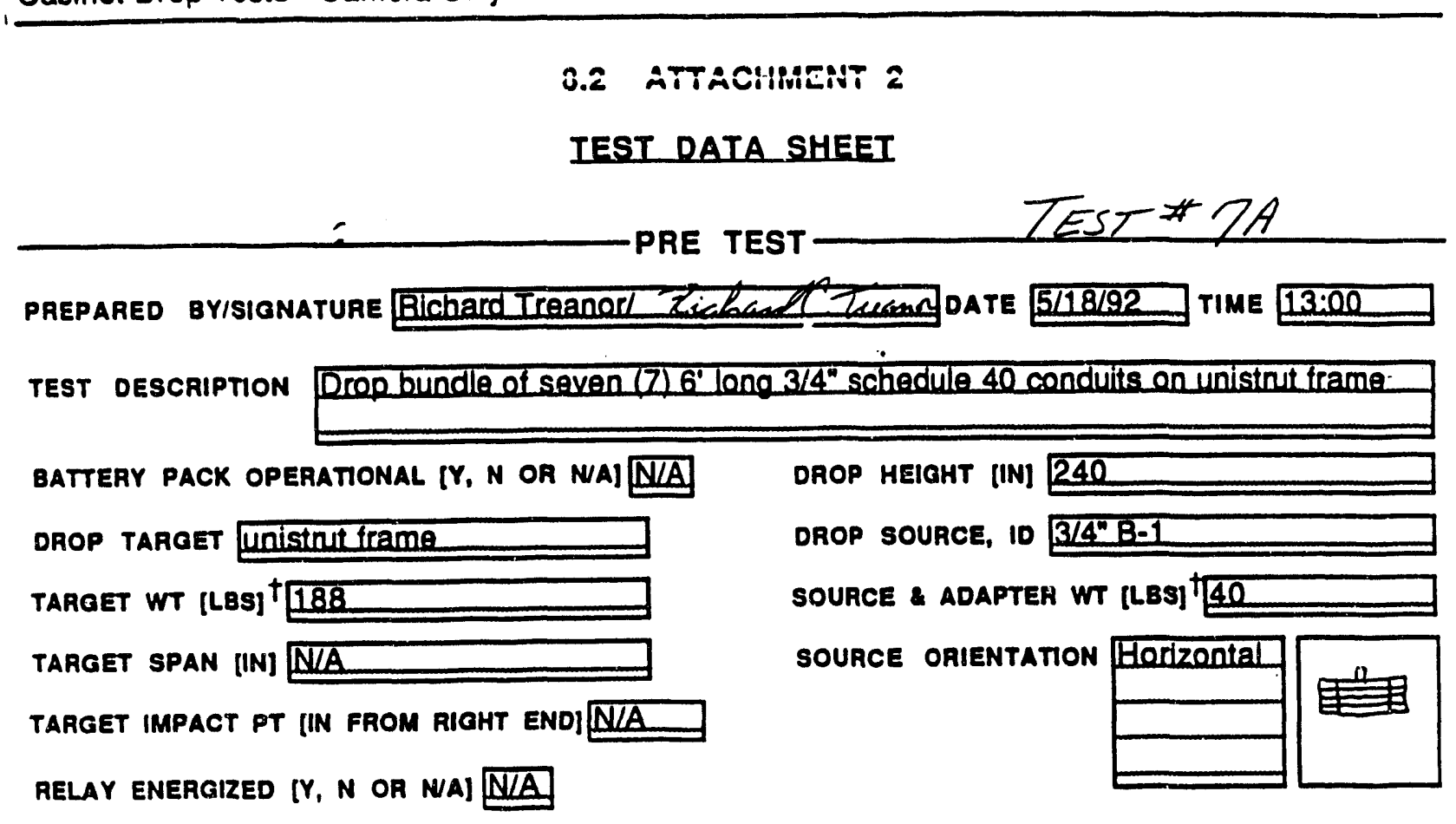

POST TEST

TARGET DAMAGE Brokedoors on "I.C. Disconnect.480V J/C Welder Back B" and Wolding Dise Switch No. 1480 V"boxes.

SOURCE DAMAGE Bentconduit approx.3" detormation-measuredatmidspan.Galvanized surface fllaked oft at impact points.

BATTERY PACK OPERATIONAL $[Y, N$ OR NA] N/A

HANO HELD VIDEO START \& STOP POSITION N/A

HIGH SPEED VIDEO START \& STOP POSITION $04 \overline{25-05 ; 33}$

COMMENTS

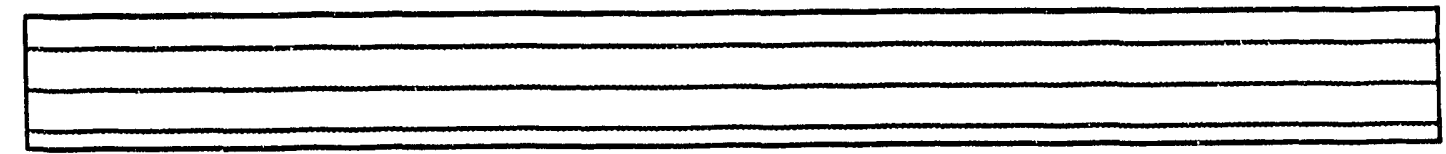

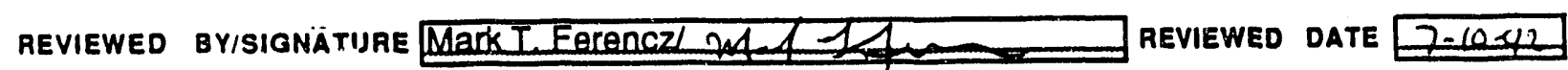

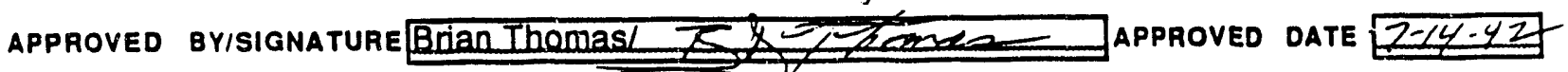

${ }^{\dagger}{ }_{\text {Approximate weight using M\&TE category } 3 \text { equipment. }}$ 
IVSRC-TR-93-0094

Attachment 10. Test Data Slects (14 of 155)

Savannah River Technology Center Equipment Engineering

Seismic IVI Drop Test Program

EES-FP.351, Rev. 0

Cabinet Drop Tests - Camera Only

\section{O.2 ATTACHiMENT a}

\section{IEST DATA SHEEI}

\section{Date Approved: 5/13/92, Category 2}

Page 12 of 12

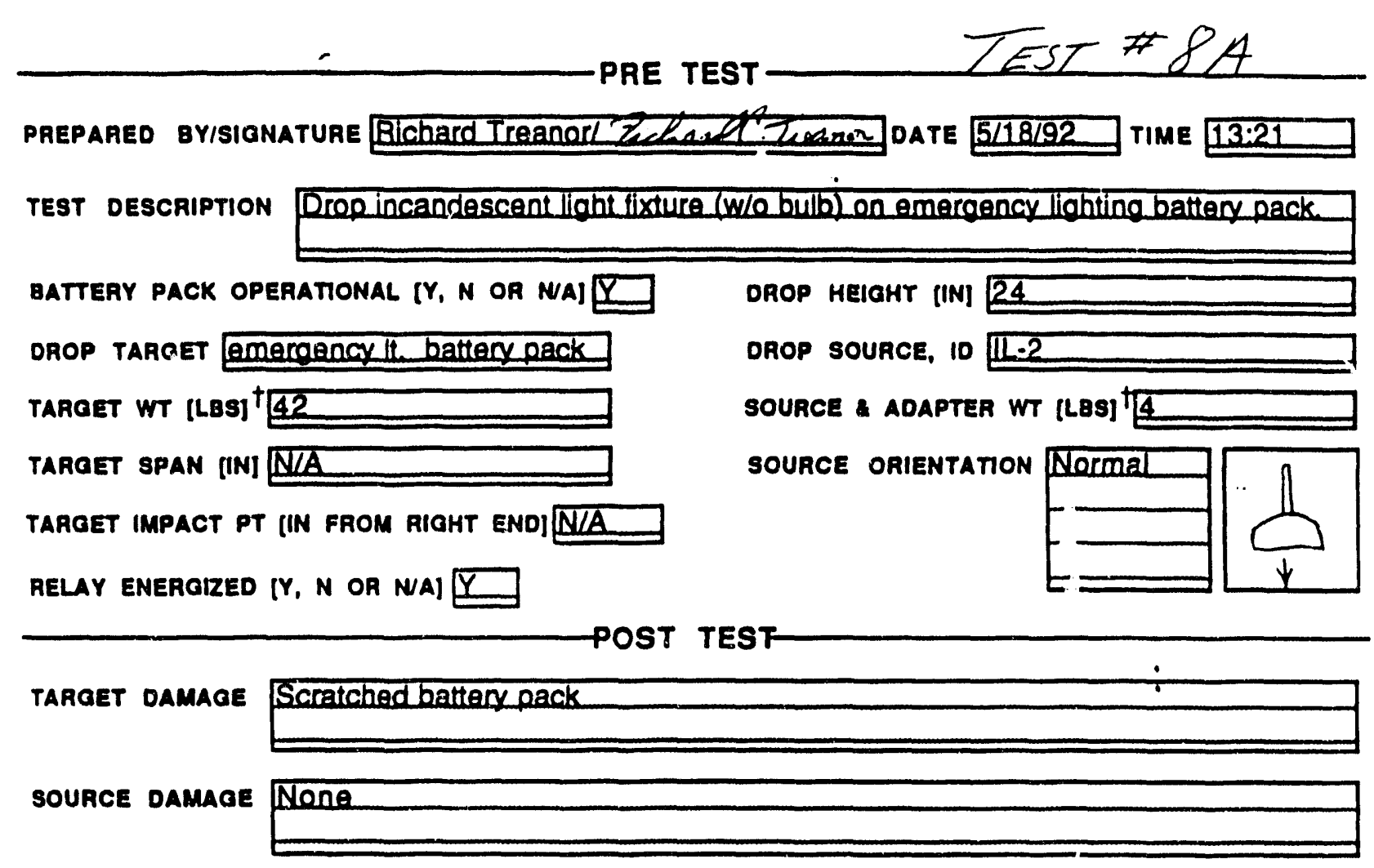

BATTERY PACK OPERATIONAL [Y, N OR NA]Y

HAND HELD VIDEO START \& STOP POSITION NIA

HIGH SPEED VIDEO START \& STOP POSITION $05: 33-06: 19$

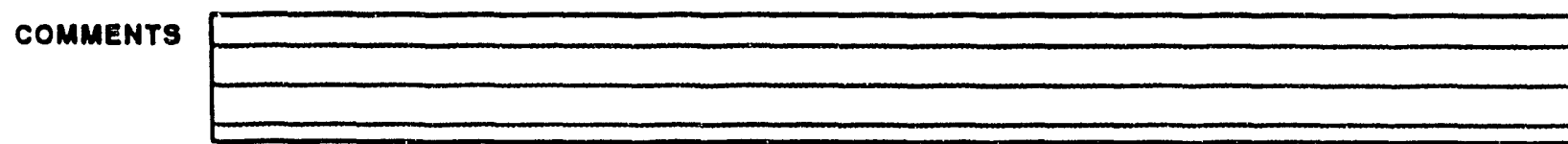

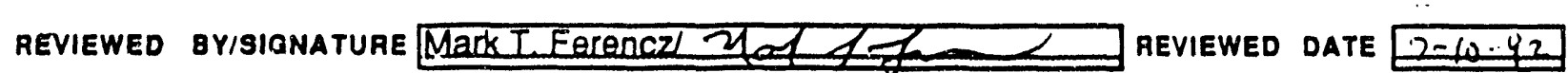
APPROVED ByISIGNATURE Brian Thomasl 2 d

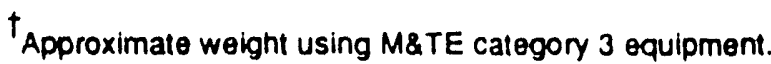


WSRC-TR-93-0094

Attachment 10. Test Data Sheets (15 of 155)

Savannah River Technology Center

Equipment Engineering

EES-FP-351, ReV. 0

Seismic IVI Drop Test Program

Cabinet Drop Tests - Camera Only

Date Approved: 5/13/92, Category 2

Page 12 of 12

\subsection{ATTACHASENT 2}

\section{IEST DATA SHEET}

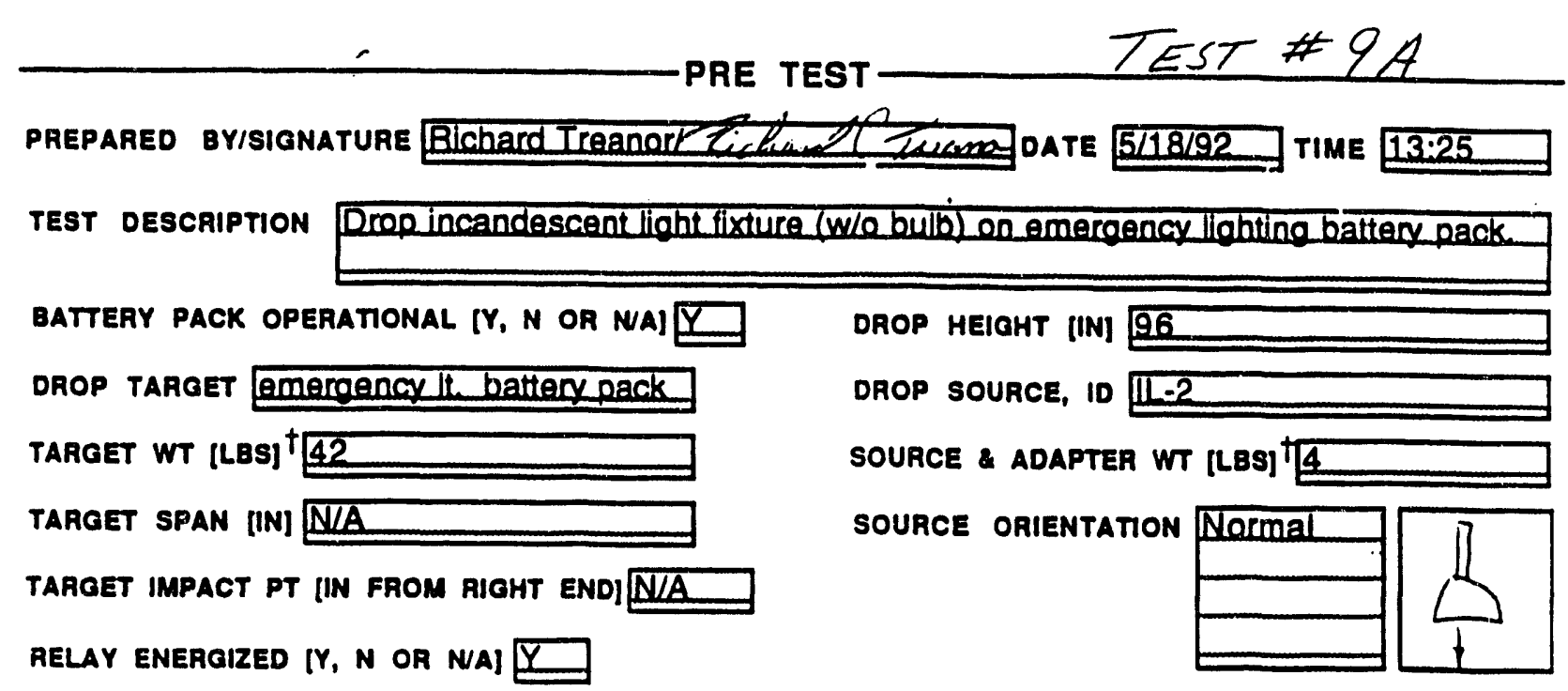

POST TESF

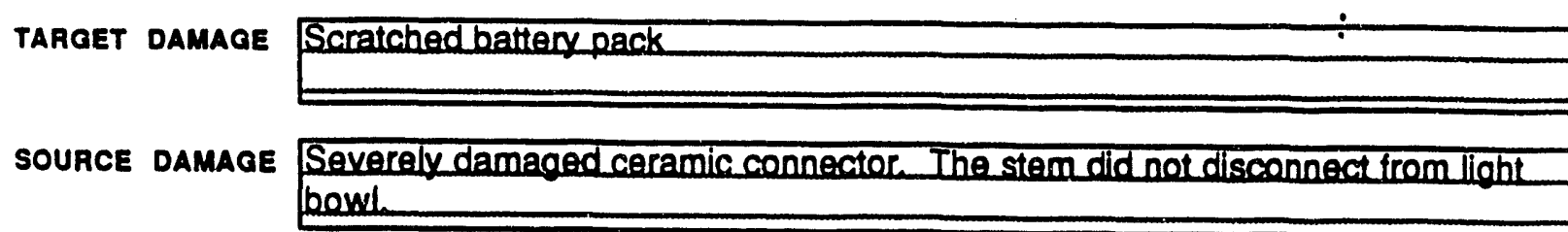

BATTERY PACK OPERATIONAL $[Y, N$ OR NA] $Y$

HAND HELD VIDEO START \& STOP POSIMON NIA

HIGH SPEED VIDEO START \& STOP POSITION $06: 19-06: 54$

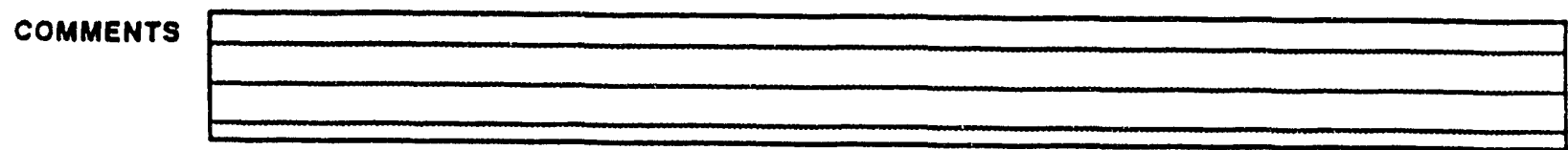

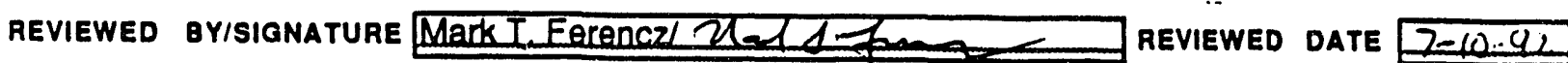
APPROVED BYISIGNATURE Brian Thomasl ZAPPROVED DATE Z- Z4-Z2

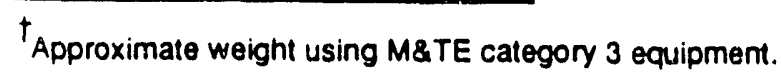


IVSRC-TR-93-0094

Aftachment 10. Test Data Sheets (16 of 155)

Savannah. River Technology Center Equipment Engineering

EES-FP-351, Rev. 0

Seismic IVI Drop Test Program

Cabinet Drop Tests - Camera Only

Date Approved: $5 / 13 / 92$, Category 2

Page 12 of 12

\subsection{ATTACHAHEMT 2}

\section{IEST DATA SHEET}

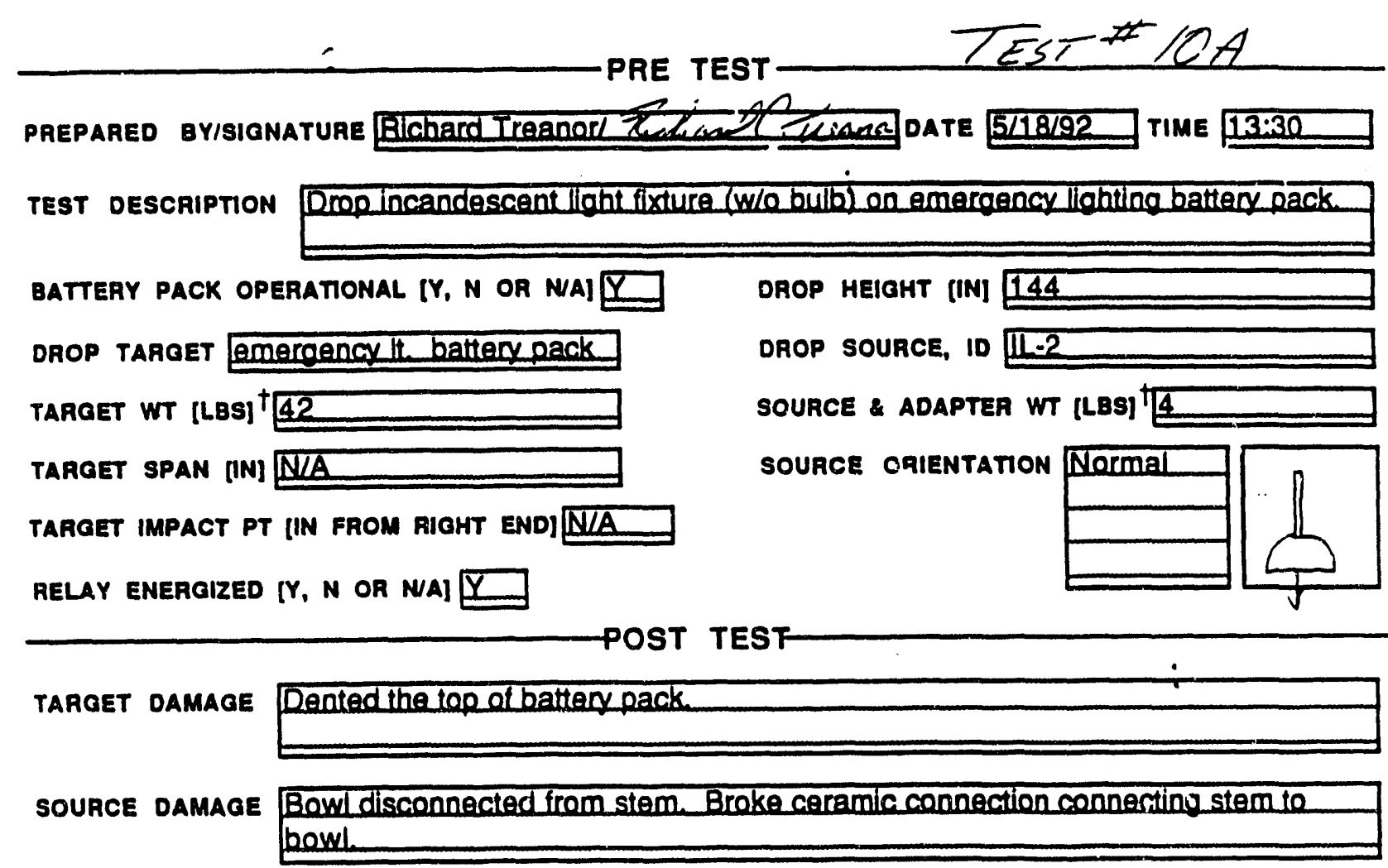

BATTERY PACK OPERATIONAL $[Y, N$ OR NAI $Y$

HAND HELD VIDEO START \& STOP POSITION NIA

HIGH SPEED VIDEO START \& STOP POSITION 06:54-07:19

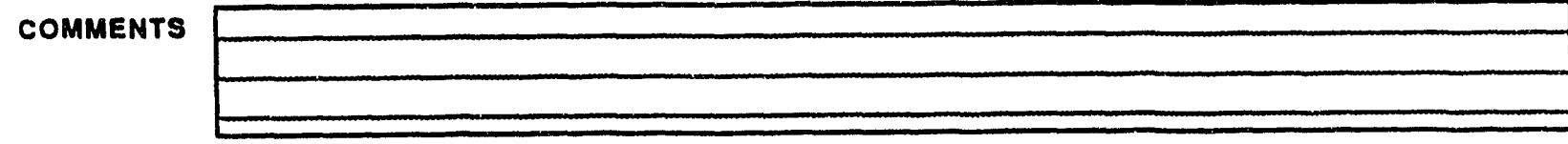

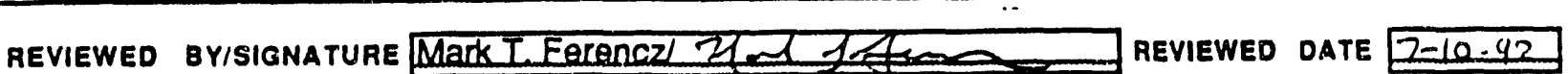
APPROVEC BYISIGNATURE Brian Themasl 2 APPROVED DATE $2-14-2$

$\dagger_{\text {Approximate weight using M\&TE category } 3 \text { equipment. }}$ 
WSRC-TR-93-0094

Attachment 10. Test Data Sheets (17 of 155)

Savannah River Technology Center

Equipment Engineering

EES-FP-351, Rev. 0

Seismic IVI Drop Test Program

Cabinet Drop Tests - Camera Only

\subsection{ATTACHMENT 2}

\section{IEST DATA SHEEI}

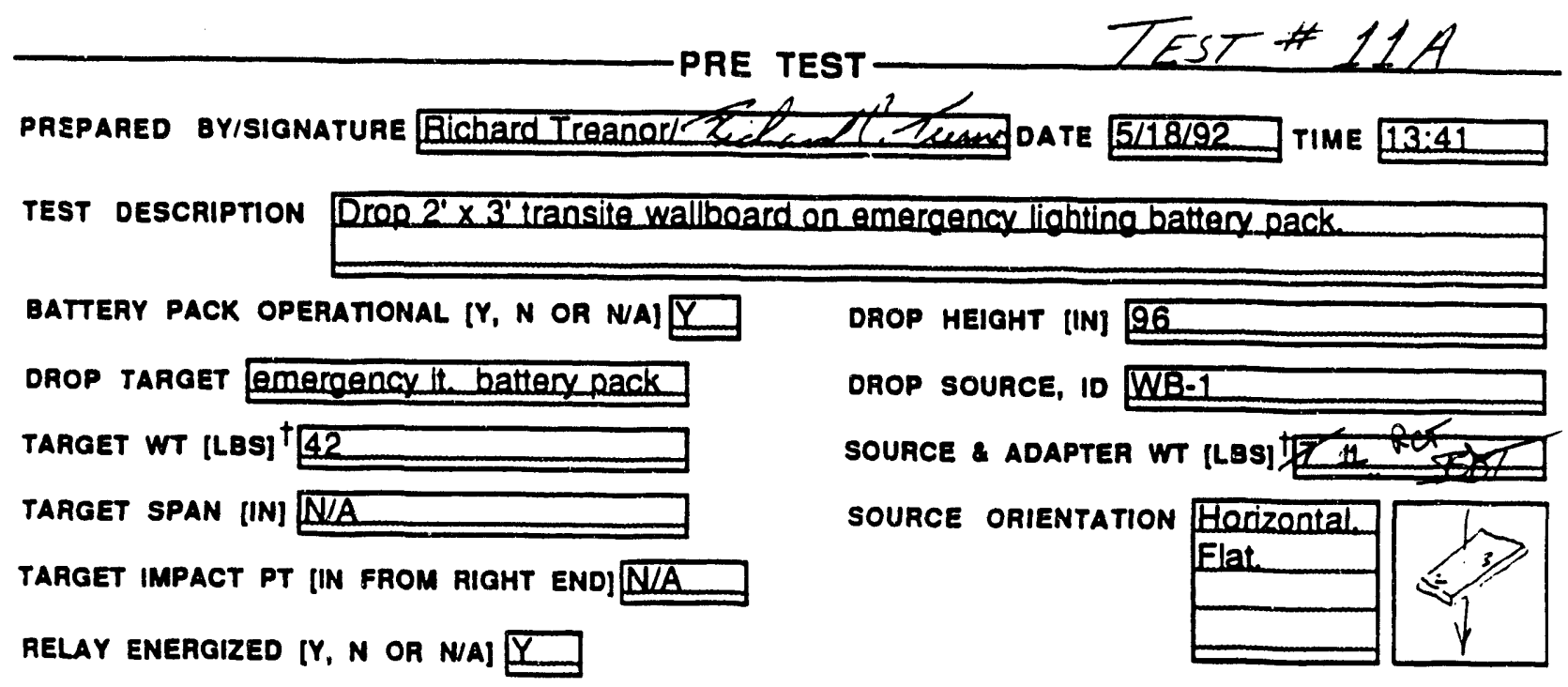

POST TEST

TARGET DAMAGE Relay came partially out of socket

SOURCE DAMAGE Transite wall board broke inte pieces.

BATTEFY PACK OPERATIONAL $[Y, N$ OR N/N

HAND HELD VIDEO START \& STOP POSITION NIA

HIGH SPEED VIDEO STAAT \& STOP POSITION 07:19-07:42

COMMENTS Belay was not checked prior to test therafore it is possible that the prior tests may have contributed to the dislodoing of the relay. The relay was replaced mere securely by slightly bending the connections before olacing inte sacket for next test.

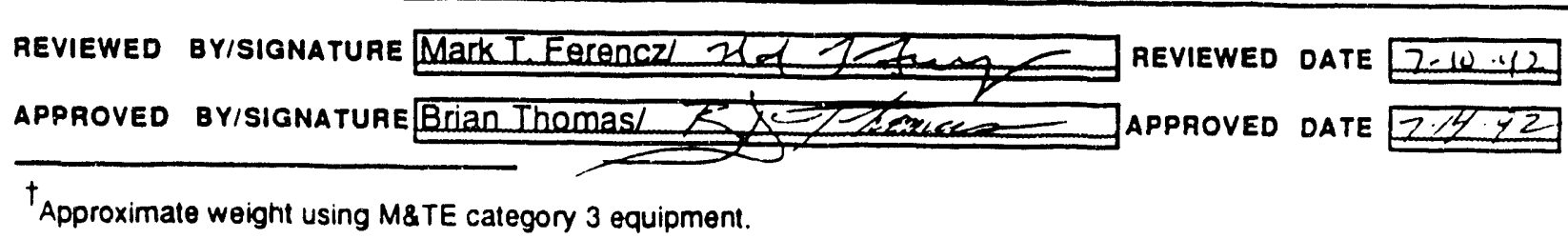


IVSRC-TR-93-0094

Attachment 10. Test Data Sheets (18 of 155 )

Savannah River Technology Center

Equipment Engineering

EES-FP-351, Rev. 0

Seismic IVI Drop Test Program

Cabinet Drop Tests - Camera Only

\section{O.2 ATTACHAMETHT 2}

IEST DATA SHEEI

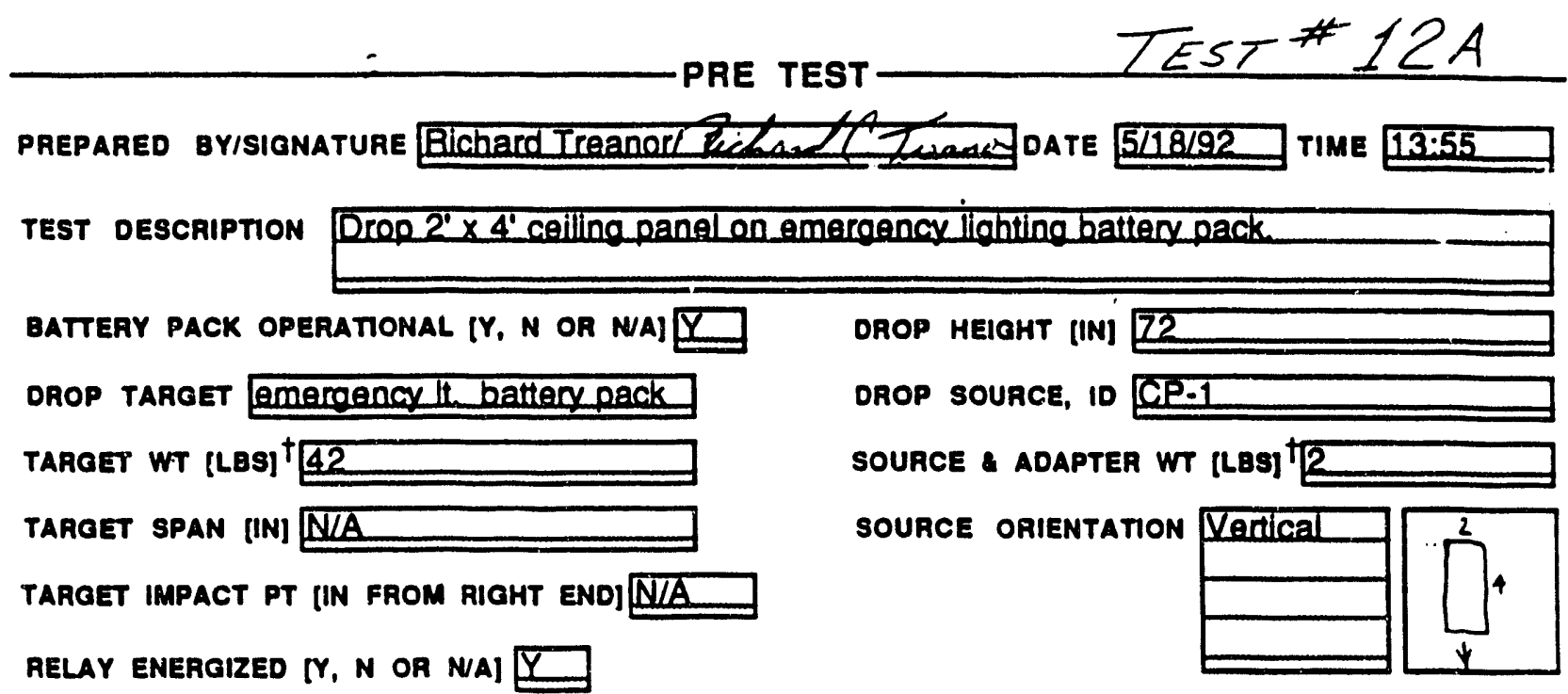

POST TEST

TARGET DAMAGE None

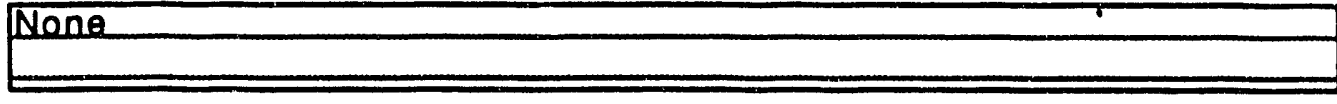

SOUACE DAMAGE Ceiling panel_cushed locally enly at impactarea.

BATTERY PACK OPERATIONAL $[Y, N$ OR NA] $Y$

HANO HELD VIDEO STAAT \& STOP POSITON NIA

HIGH SPEED VIDEO START \& STOP POSITION 07:42-08:22

comments Belay checked -. itwas seated properdy.

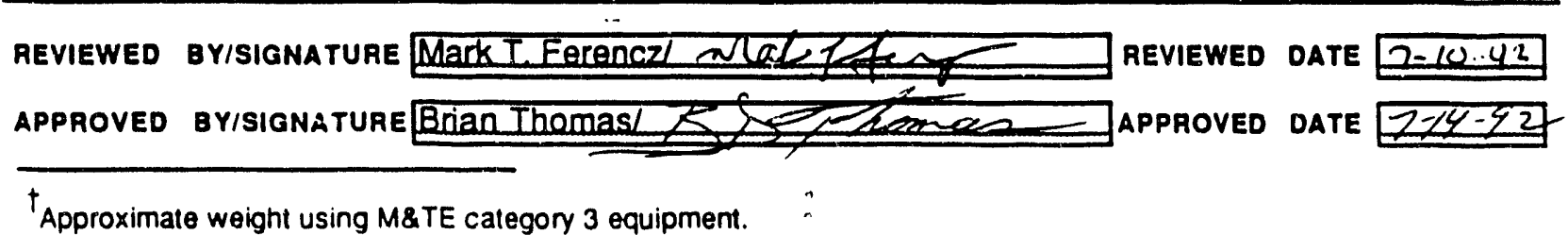


WSRC-TR-93-0094

Attachment 10. Test Data Sheets (19 of 155)

Savannah River Technology Center

Equipment Eingineering

EES-FP-351, Rev. 0

Seismic IVI Drop Test Program

Cabinet Drop Tests - Camera Only

\section{Date Approved: 5/13/92, Category 2}

Page 12 of 12

\section{Q.2 ATT ACHMENT 2}

\section{IEST DATA SHEET}

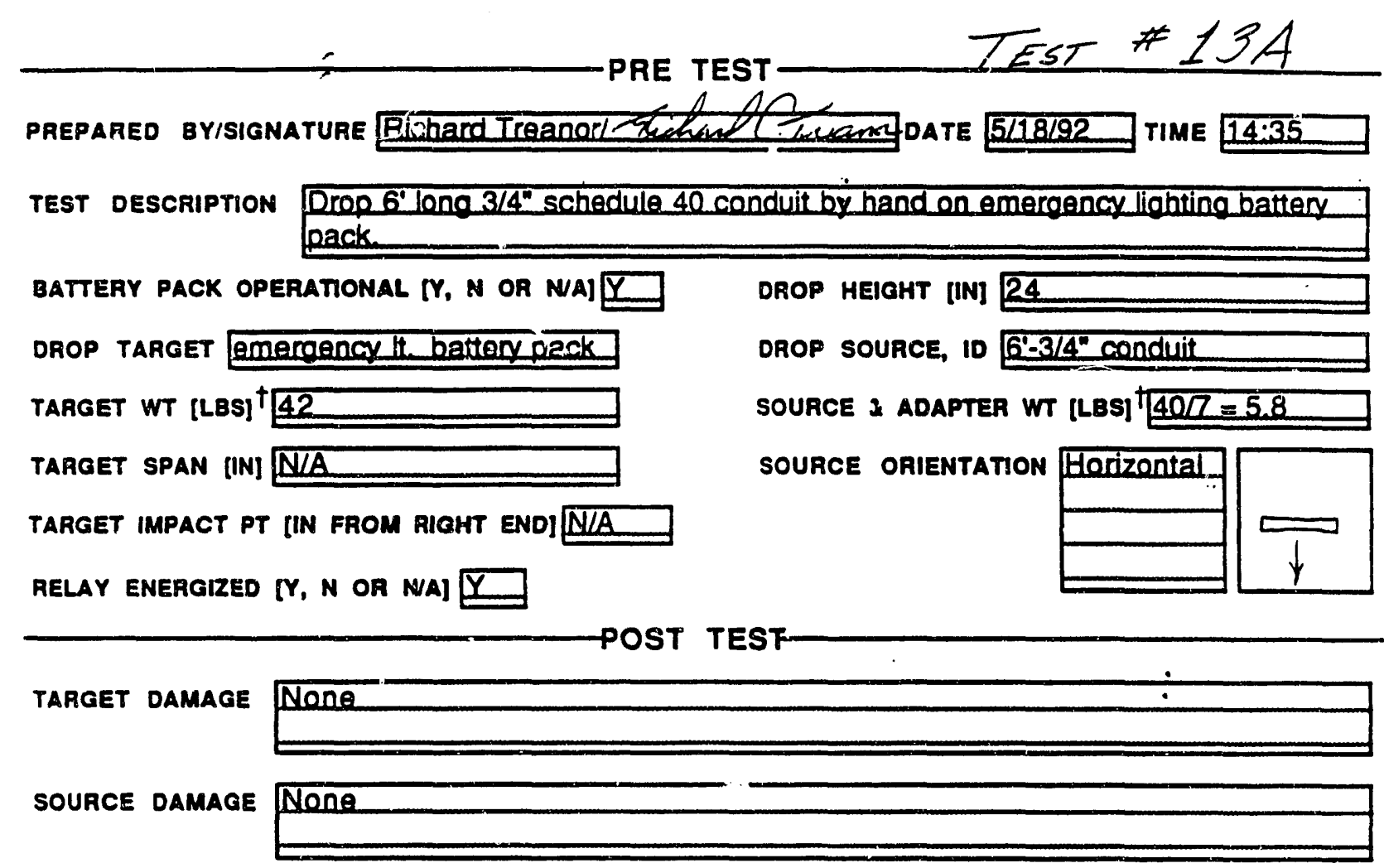

BATTERY PACK OPERATIONAL $[Y, N$ OR N/A] $Y$

HAND HELD VIDEO START \& STOP POSITON NIA

HIGH SPEED VINEO START \& STOP POSITION N/A

COMMENTs Belay checked-it was seated properly.

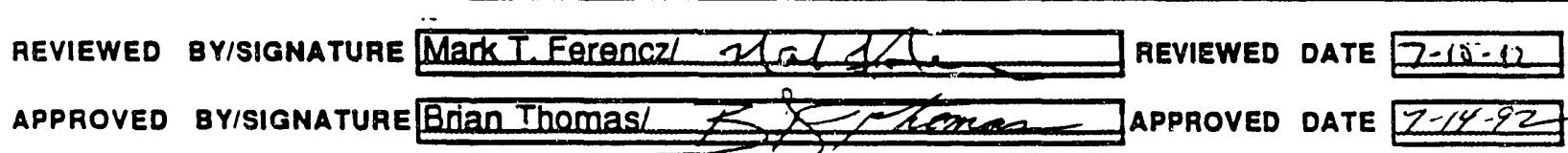

${ }^{\dagger}$ Approximate weight using M\&TE category 3 equipment. 
IVSRC-TR-93-0094

Attachment 10. Test Data Sheets (20 of 155)

Savannah River Technology Lan:or

Equipment Engineering.

EES-FP-351, Rev. 0

Seismic IVI Drop Test Program

Cabinet Drop Tests - Camera Only

\subsection{ATTACHMENT 2}

\section{TEST DATA SHEEI}

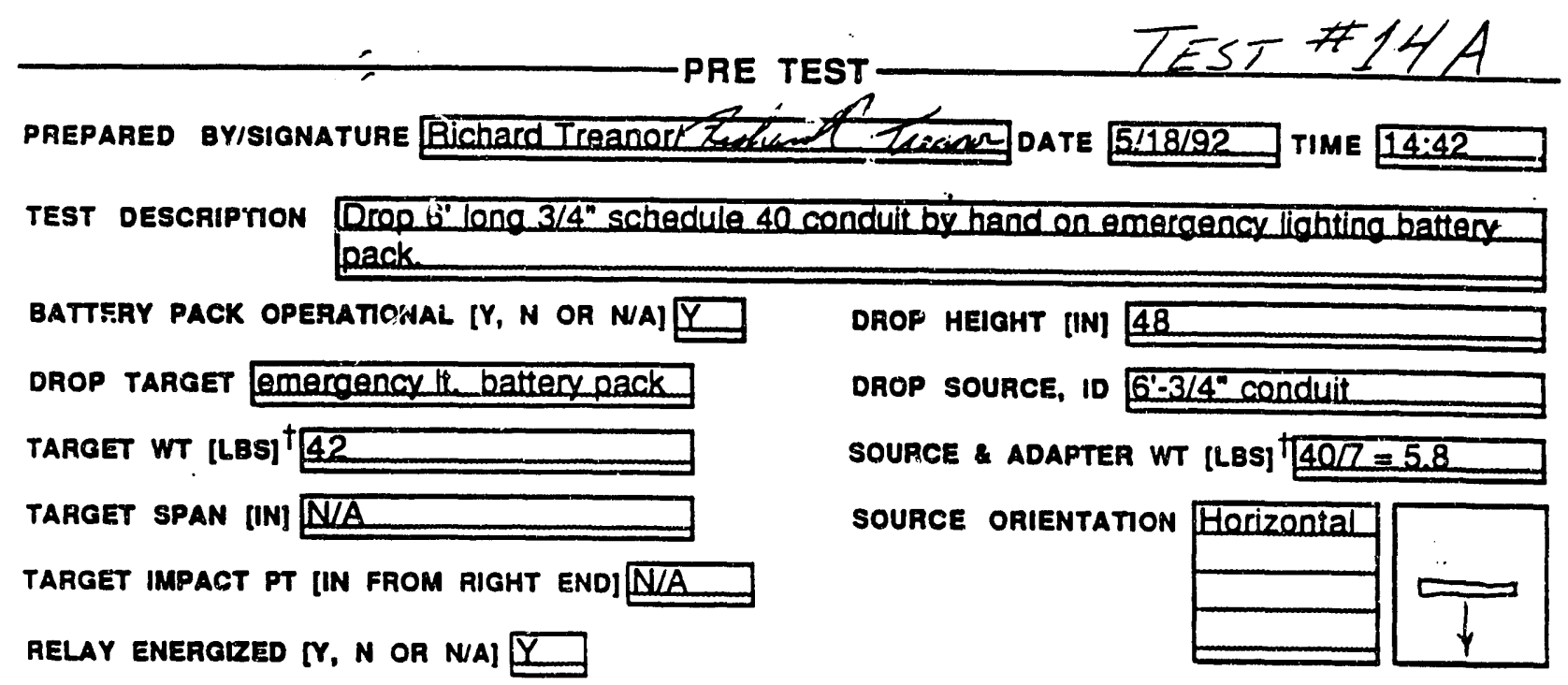

POST TEST

TARGET DAMAGE NONA

SOURCE DAMAGE NORE

BATTERY PACK OPERATIONAL $[Y, N$ OR NA] $Y$

HAND HELD VIDEO STAAT \& STOP POSITION NIA

HIGH SPEED VIDEO START \& STOP POSITION N/A

coMMENTs Belay checked -. itwas seated properly.

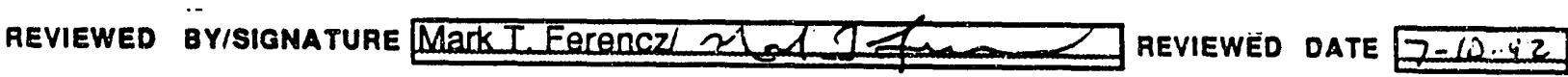

APPROVED BYISIGNATURE Brian Thomas/ DaPpRoved Date $2-492$

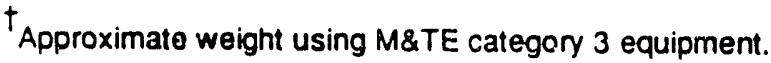


WSRC-TR-93-0094

Attachment 10. Test Data Sheets (21 of 155)

Savannah River Technology Center

Equipment Engineering.

Seismic IVI Drop Test Program

Cabinet Drop Tests - Camera Only

EES-FP-351, Rev. 0

Date Approved: 5/13/92, Category 2

Page 12 of 12

\subsection{ATTACHMENT ?}

\section{IEST DATA SHEET}

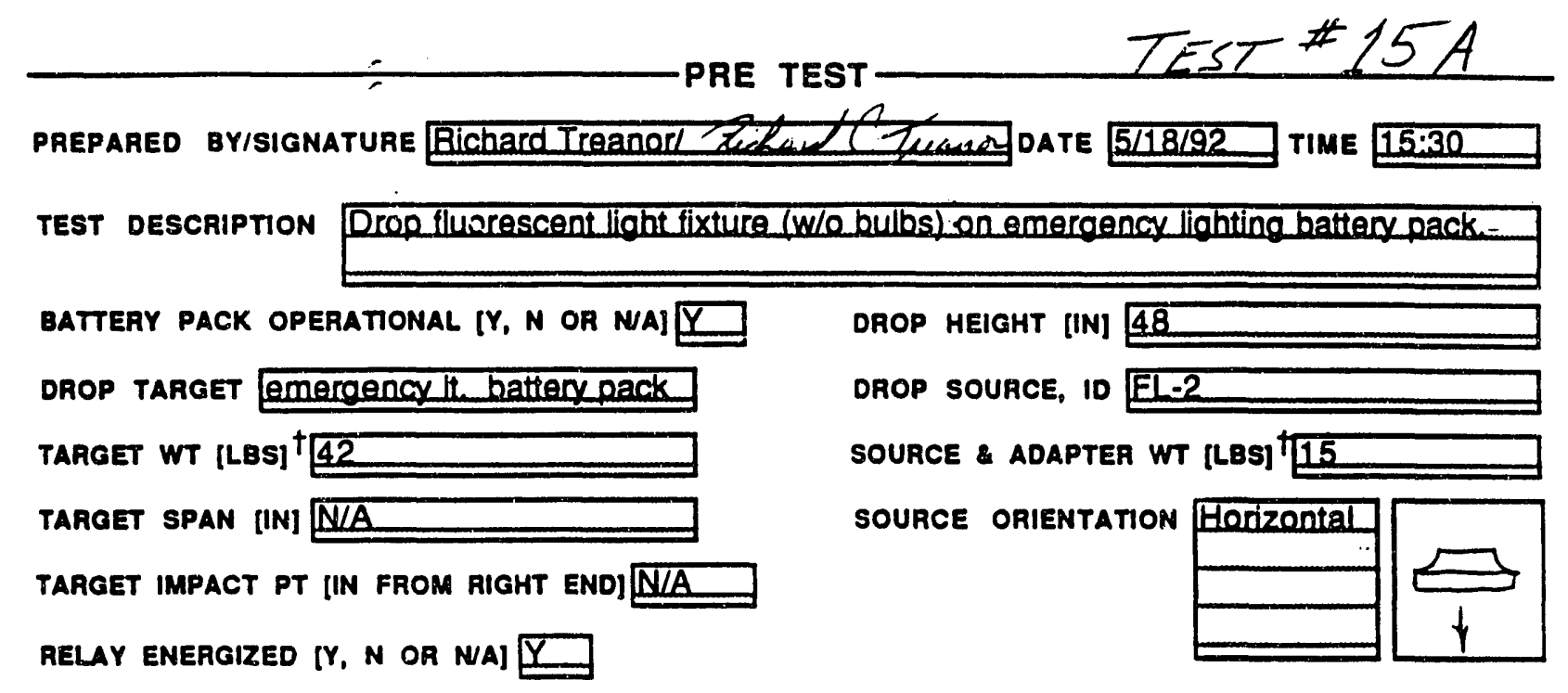

TARGET DAMAGE

None

source damage Dentedinside of liaht fixture.

BATTERY PACK OPERATIONAL [Y, $N$ OR N/A] $Y$

HAND HELD VIDEO START \& STOP POSITON N/A

HIGH SPEEO VIDEO START STOP POSITION $08: 24-08: 54$

comments Relaychecked - it was seated properly.
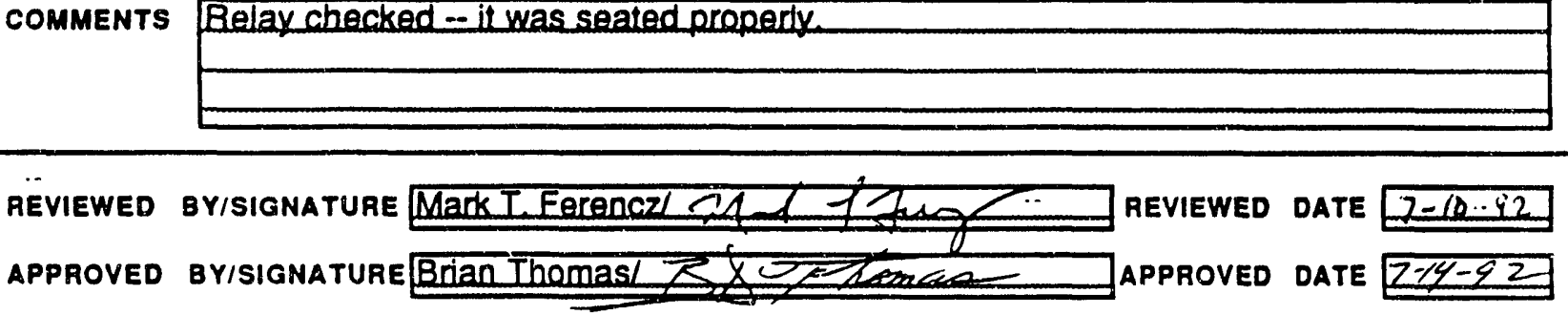

$\dagger_{\text {Approximate weight using M\&TE category } 3 \text { equipment. }}$ 
WSRC-TR-93-0094

Attachment 10. Test Data Sheets (22 of 155)

Savannah River Technology Cènter Equipment Engineering

\subsection{ATTACHMENT 2}

IEST DATA SHEEI

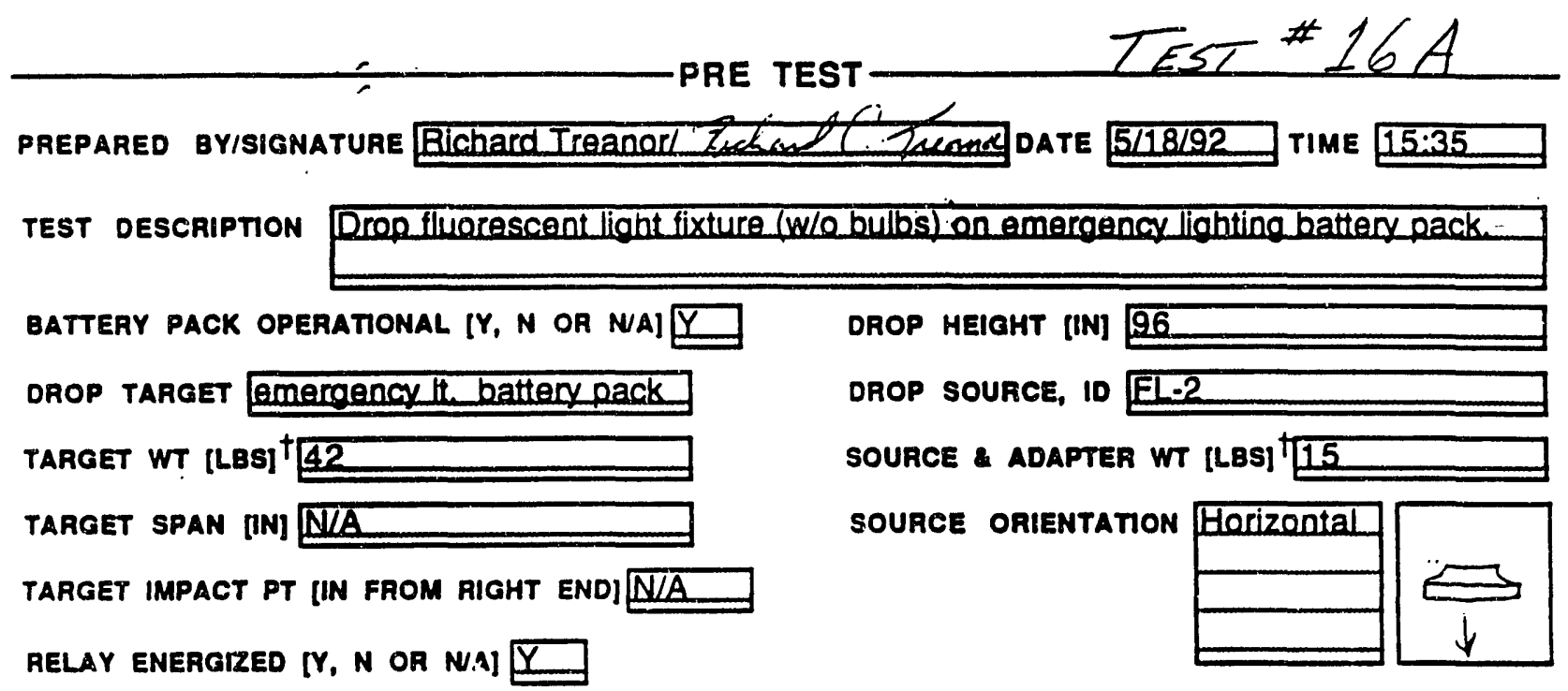

POST TEST

TARGET DAMAGE

\section{None}

SOURCE dAMAGE Lioht fixture was severely damaged

BATTERY PACK OPERATIONAL $[Y, N$ OR NA] $Y$

HAND HELD VIDEO START \& STOP POSITION N/A

HIGH SPEED VIDEO START \& STOP POSITION $08: 54-09: 38$

comMENTs Belay checked-itwas_seated properix

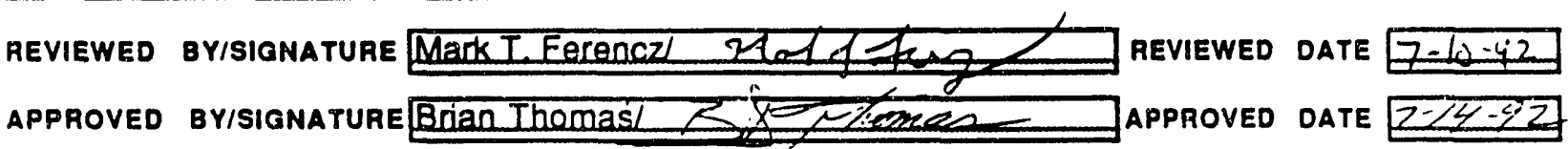

${ }^{\dagger}$ Approximate weight using M\&TE category 3 equipment. 
WSRC-TR-93-0094

Attachment 10. Test Data Sheets (23 of 155)

Savannah River Technology Center

EES-FP-351, Rev. 0

Equipment Engineering

Seismic IVI Drop Test Program

Cabinet Drop Tests - Camera Only

\subsection{ATTACHMENT 2}

\section{IEST DATA SHEET}

\section{PRE TEST}

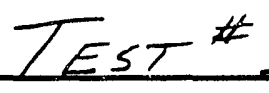

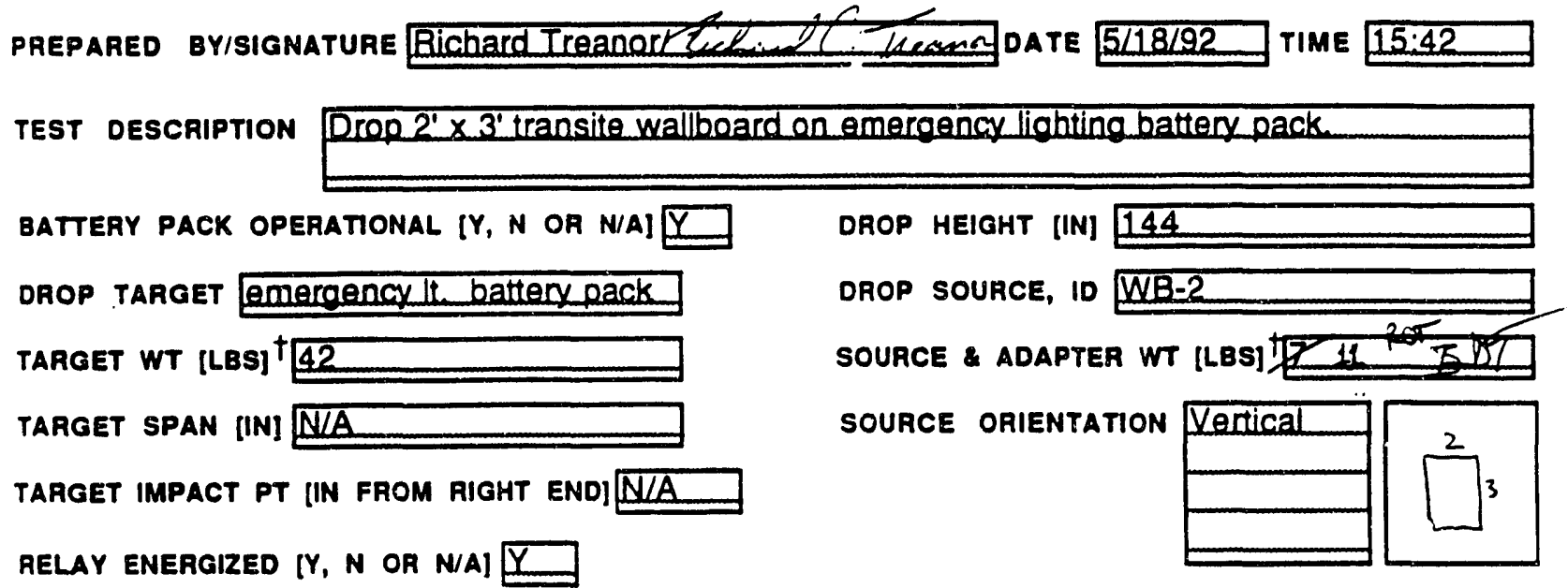

TARGET DAMAGE Dented top of battery pack. Pulled the front cover mounting screw from cabinet

SOURCE DAMAGE Broke small piece of wallboard at impact point.

BATTERY PACK OPERATIONAL $[Y, N$ OR N/A] $Y$

HAND HELD VIDEO START \& STOP POSITION N/A

HIGH SPEED VIDEO START \& STOP POSITION 09:38-10:25

COMMENTS Relay checked --it was seated properly.

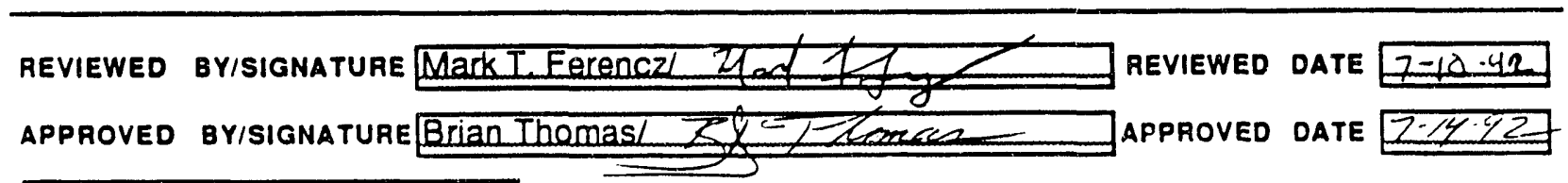

$\dagger_{\text {Approximate woight using M\&TE category } 3 \text { equipment. }}$ 
WSRC-TR-93-0094

Attachment 10. Test Data Sheets (24 of 155)

Savannah River Technology Center

EES-FP-370, Rev. 1

Equipment Engineering

Seismic II/I Drop Test Program

Date Approved: 8/28/92, Category 2

Supported Beam Drop Tests

Page 16 of 18

\subsection{ATTACHMENT 5}

IESI UAIA STIEET

PRE TEST

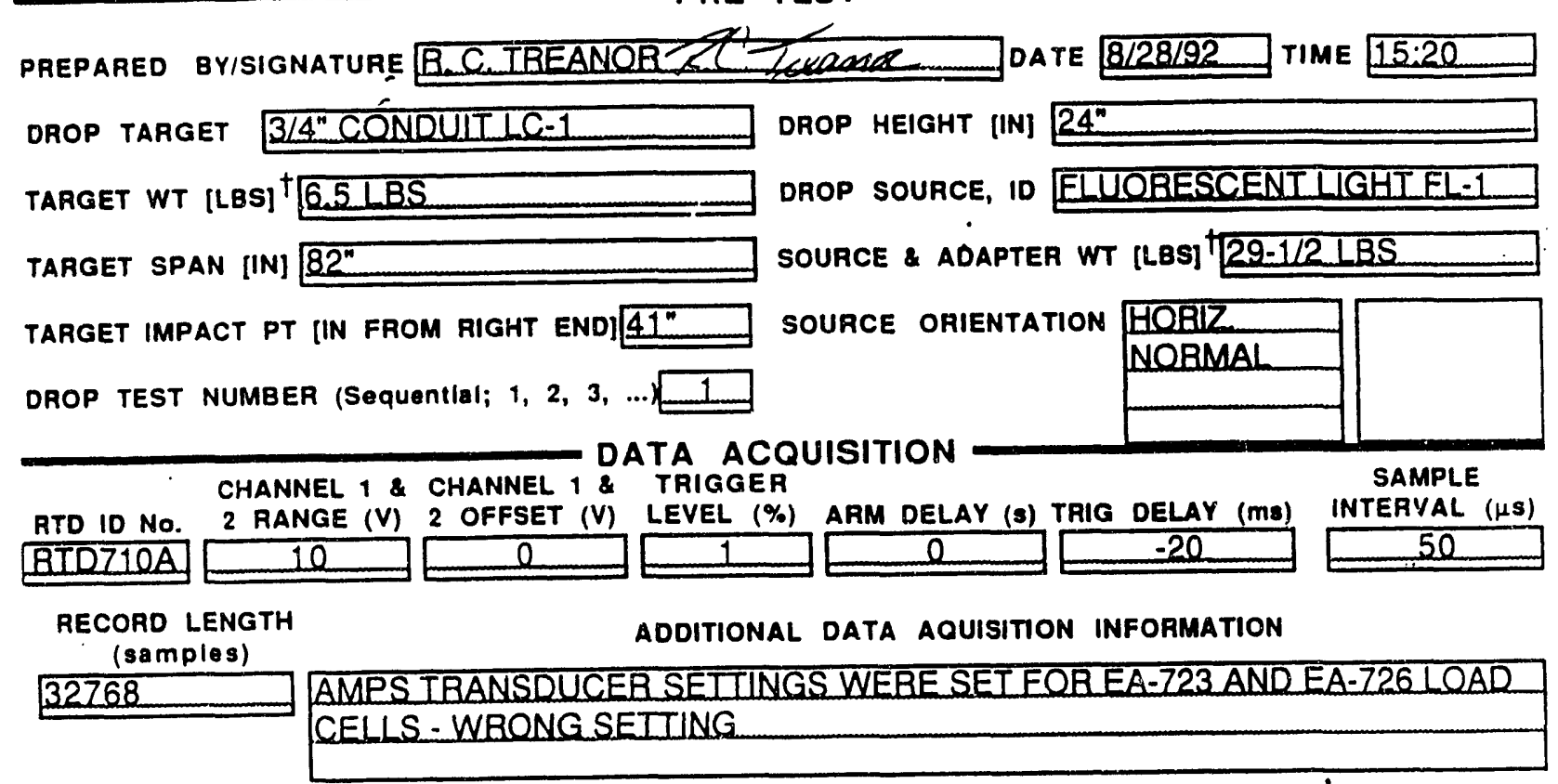

LOAD WASHER ATTENUATOR CHARGE
CHAN. M\&TE NO./EXP
I0.

TARGET DAMAGE BENTCONDUIT2" @MIDSPAN

SOURCE DAMAGE NODAMAGE

HAND HELD VIDEO START \& STOP POSITION NLA

HIGH SPEED VIDEO START \& STOP POSITION 10:16-12:08

COMMENTS SENSITIVITY WAS SEI WRONG SO THERE WAS NO TBIGGEB ANDNO DATAWAS IAKEN : SOURCE IMPACTED TABGET 3 TIMES FOLLOWING INUTLALINTEBACTION

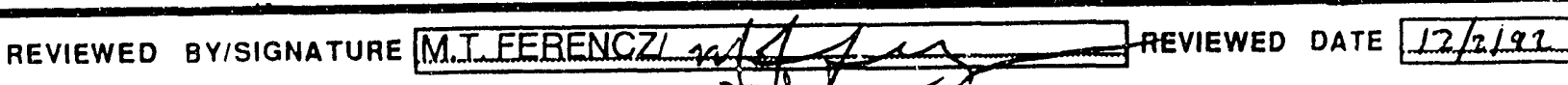

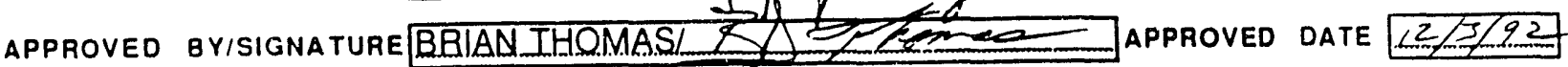

${ }^{\dagger}$ Approximate weight using M\&TE category 3 equipment. 
WSRC-TR-93-0094

Attachment 10. Test Data Sheets (25 of 155)

Savannah River Technology Center

Equipment Engineering

Seismic II// Drop Test Program

EES-FP-370, Rev. 1

Supported Beam Drop Tests

Date Approved: $8 / 28 / 92$, Category 2

Page 16 of 18

\subsection{ATTACHMENT 5}

\section{IEST EATA GIIEET}

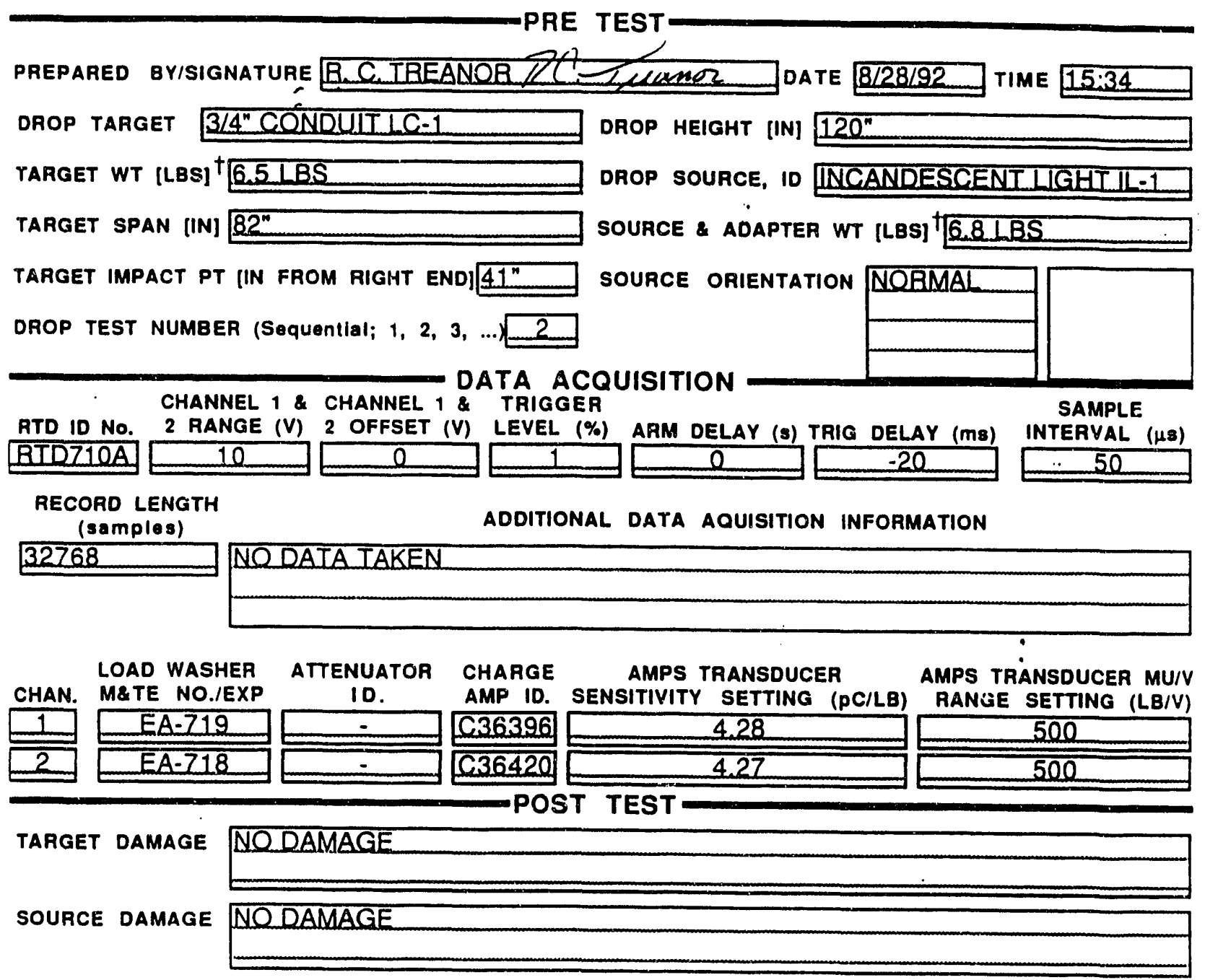

HANO HELD VIDEO START \& STOP POSITION NLA

HIGH SPEED VIDEO START \& STOP POSITION $12: 08-13: 4 \Omega$

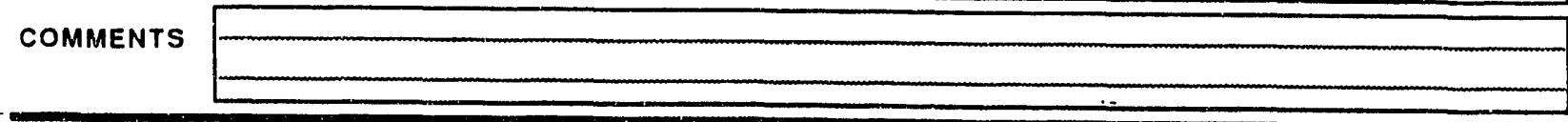

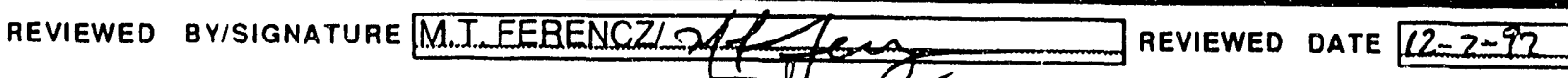
APPROVED BYISIGNATURE BRIAN IHOMASI $/$ APPROVED DATE $12 / 3 / 2$

${ }^{\dagger}$ Approximate weight using M\&TE category 3 equipment. 
IVSRC-TR-93-0094

Attachment 10. Test Data Sheets (26 of 155)

Savannah River Technology Center

Equipment Engineering

Seismic II/I Drop Test Program

Supported Beam Drop Tests

EES-FP-370, Rev. 1

Date Approved: 8/28/92, Category 2

Page 16 of 18

\subsection{ATTACHMENT 5 \\ IEST UATA SHIEET}

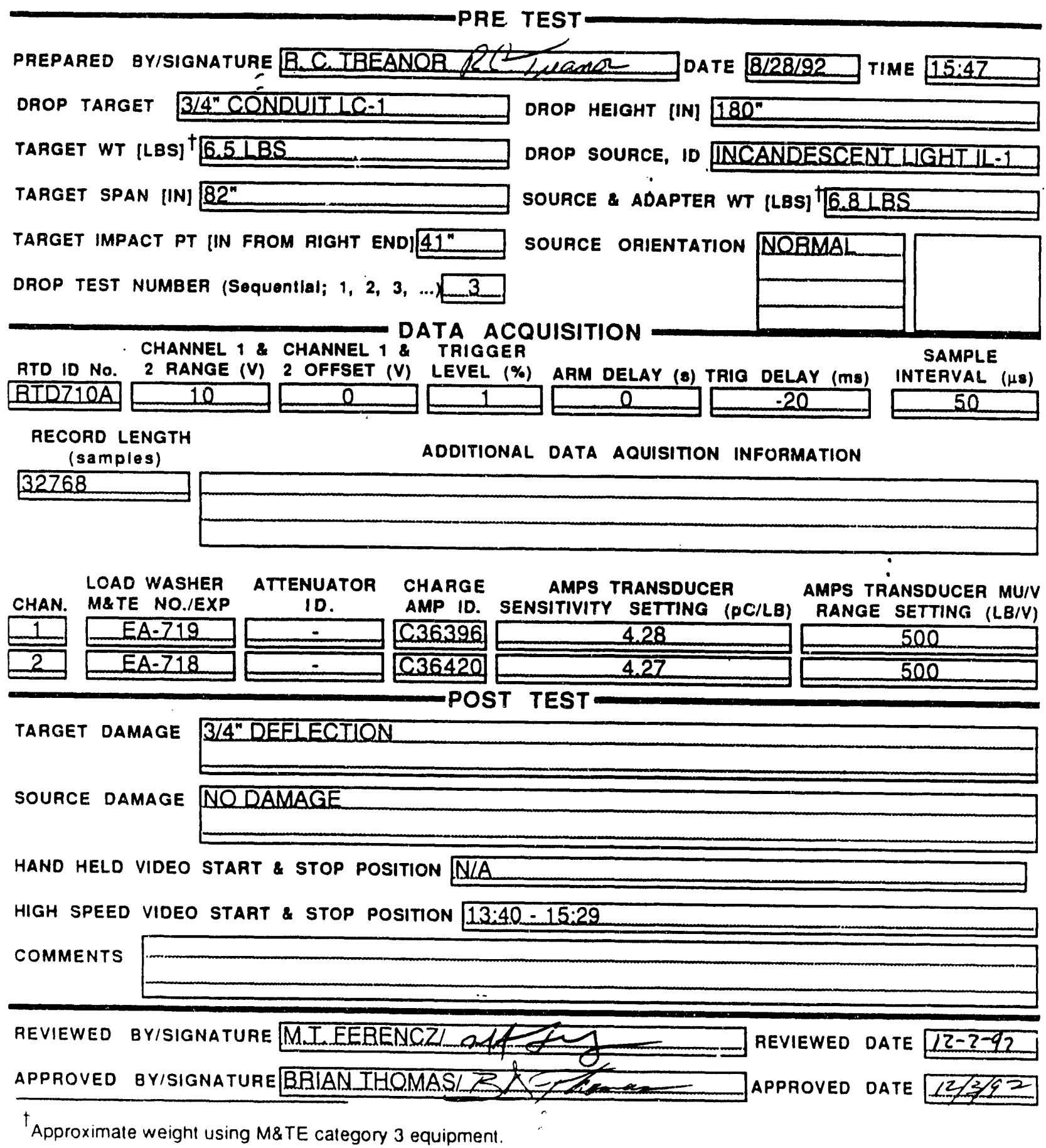


WSRC-TR-93-0094

Attachment 10. Test Data Sheets (27 of 155 )

Savannah River Technology Center

Equipment Engineering

EES-FP-370, Rev. 1

Seismic II/I Drop Test Program

Supported Beam Drop Tests

Date Approved: $8 / 28 / 92$, Category 2

Page 16 of 18

\subsection{ATTACHMENT 5 \\ IESI UATA STIEET}

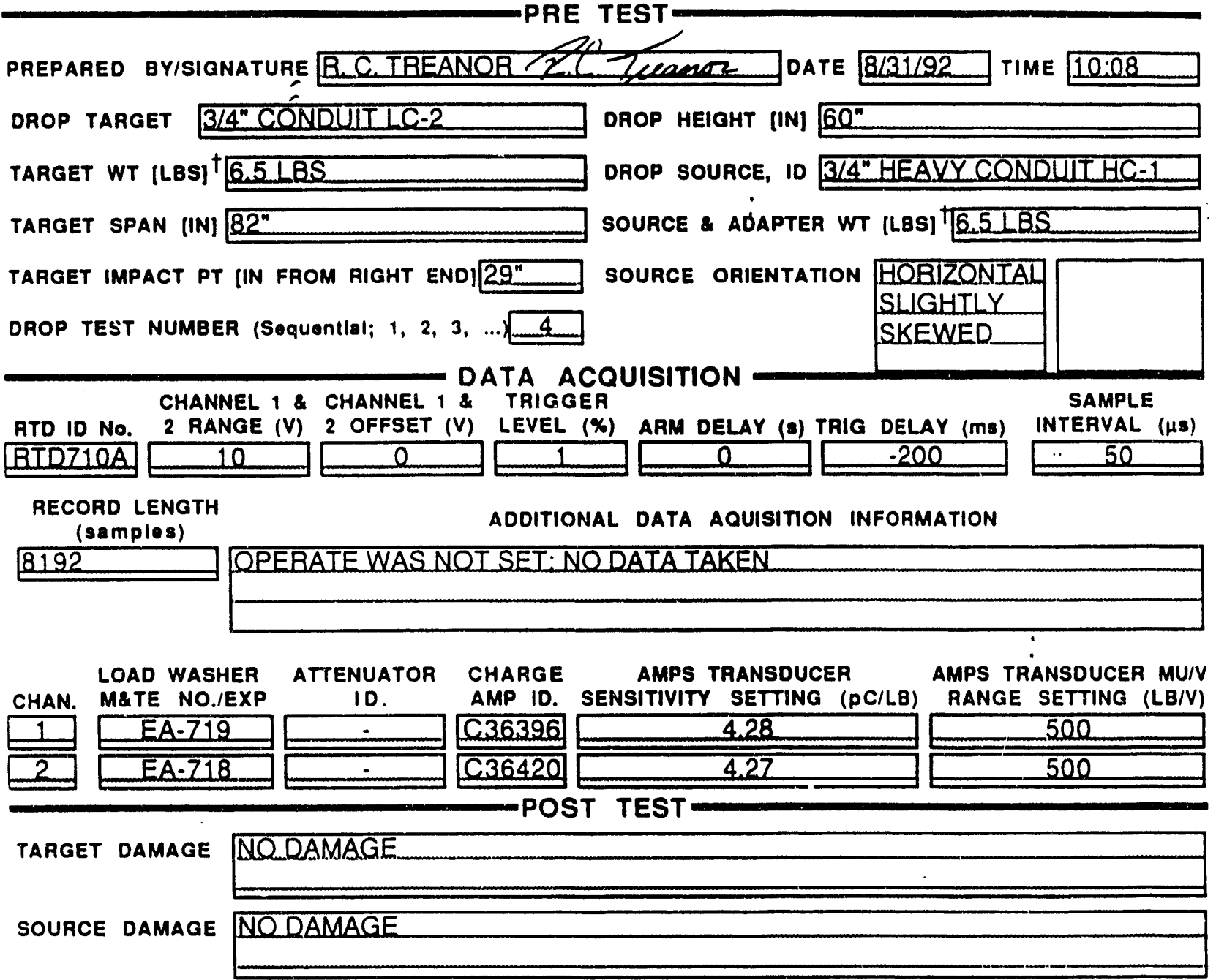

HAND HELD VIDEO START \& STOP POSITION NLA

HIGH SPEED VIDEO START \& STOP POSITION $15: 29-16: 44$

COMMENTS

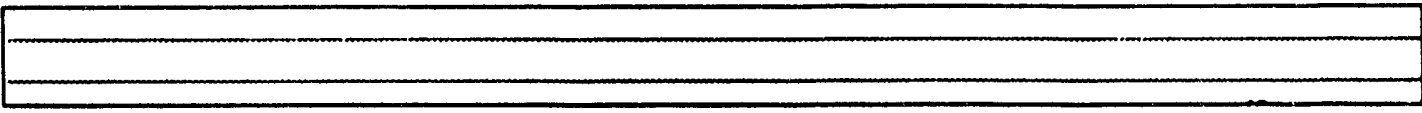

REVIEWEd ByISIGNATURE M.T.EERENCZ/21 ReVIEWED DATE 12-2-92 APPROVED BYISIGNATURE BRIAN_THOMASL

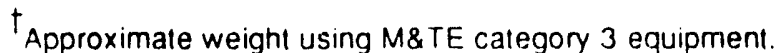


IVSRC.TR.93-0094

Attachment 10. Test Data Sheets (28 of 155 )

Savannah River Technology Center

Equipment Engineering

Seismic II// Drop Test Program

Supported Beam Drop Tests

EES-FP.370, Rev. 1

Date Approved: $8 / 28 / 92$, Category 2

Page 16 of 18

\subsection{ATTACHMENT 5 IESI UAIA SHEET}

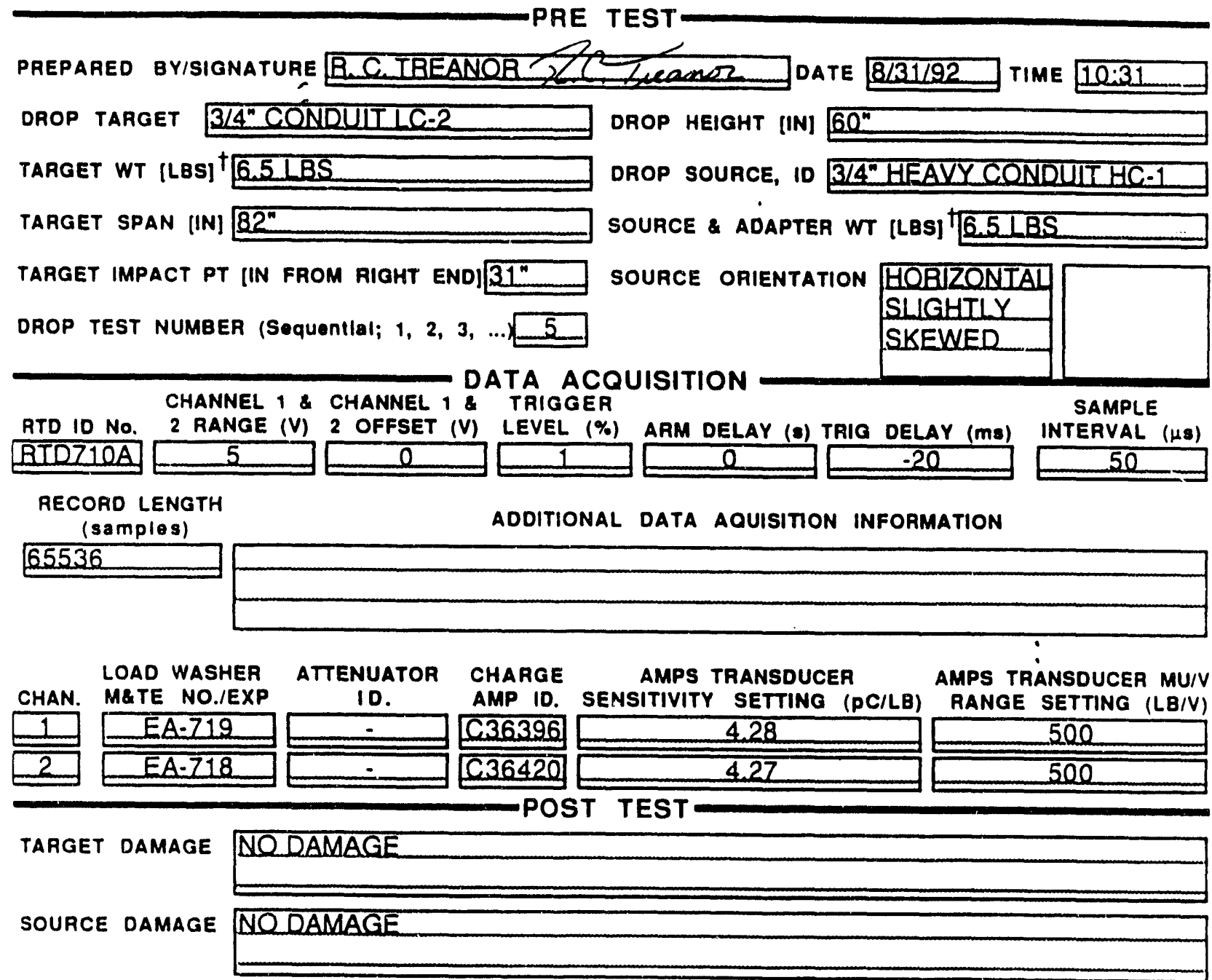

HAND HELD VIDEO START \& STOP POSITION NLA

HIGH SPEED VIDEO START \& STOP POSITION $1.6: 44-17: 20$

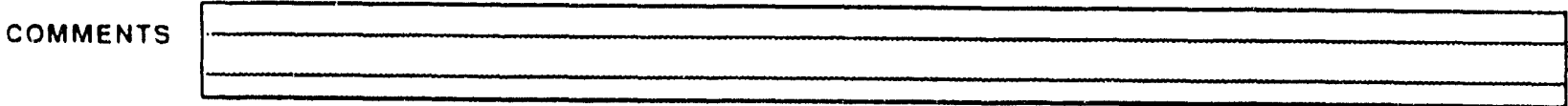

REVIEWED BYISIGNATURE M.T.EERENCZI 21 ReVIEWED DATE 12-2-92 APPROVED BYISIGNATURE BRIANIHOMASL Z LAPPOVED DATE 21392

${ }^{\dagger}$ Approximate weight using M\&TE category 3 equipment 
WSRC-TR-93-0094

Attachment 10. Test Data Sheets (29 of 155)

Savannah River Technology Center Equipment Engineering

Seismic IV/I Drop Test Program

Supported Beam Drop Tests

EES-FP-370, Rev. 1

Date Approved: 8/28/92, Category 2

Page 16 of 18

\subsection{ATTACHMENT 5 \\ IESI UAIA STIEEI}

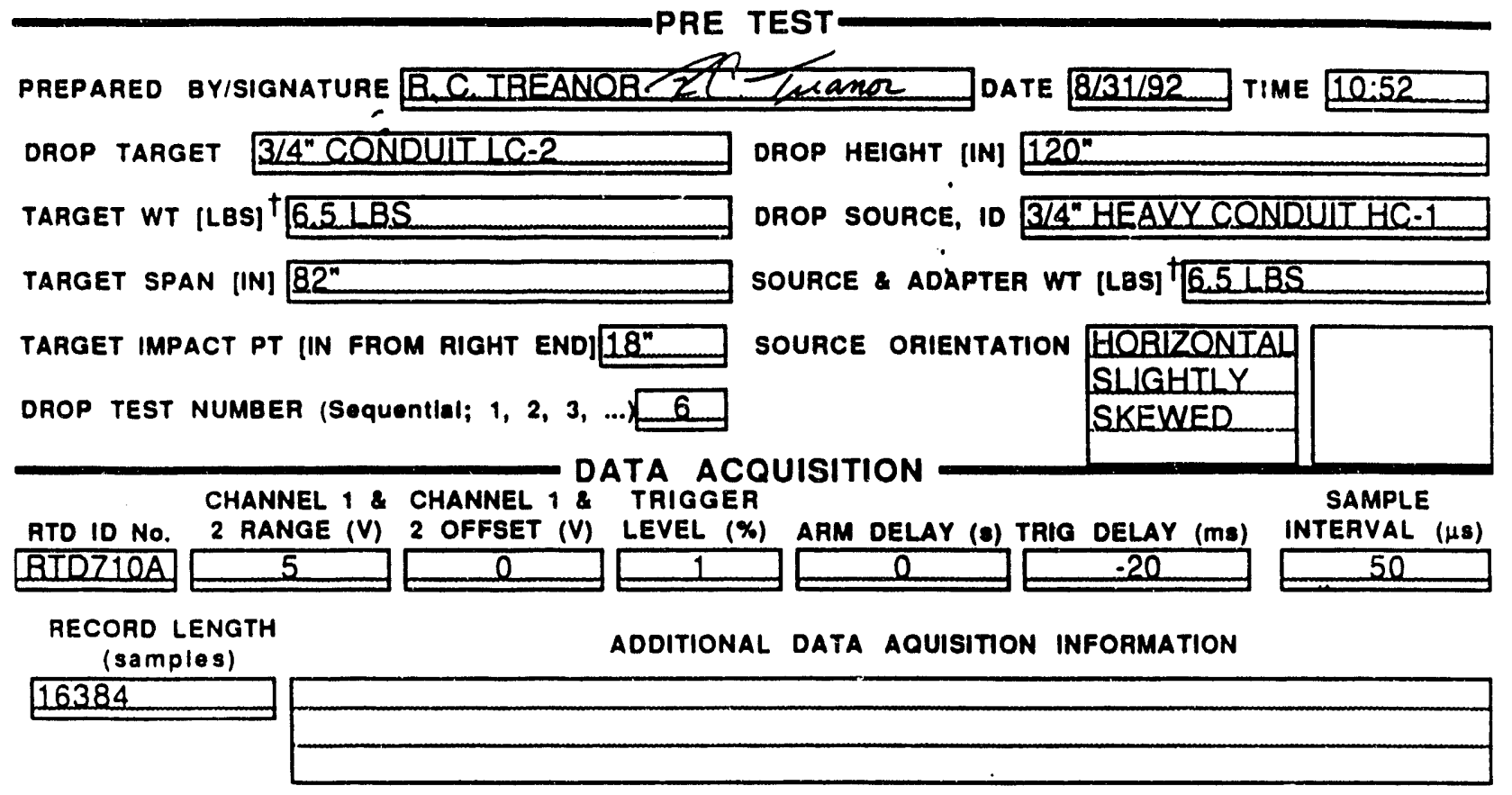

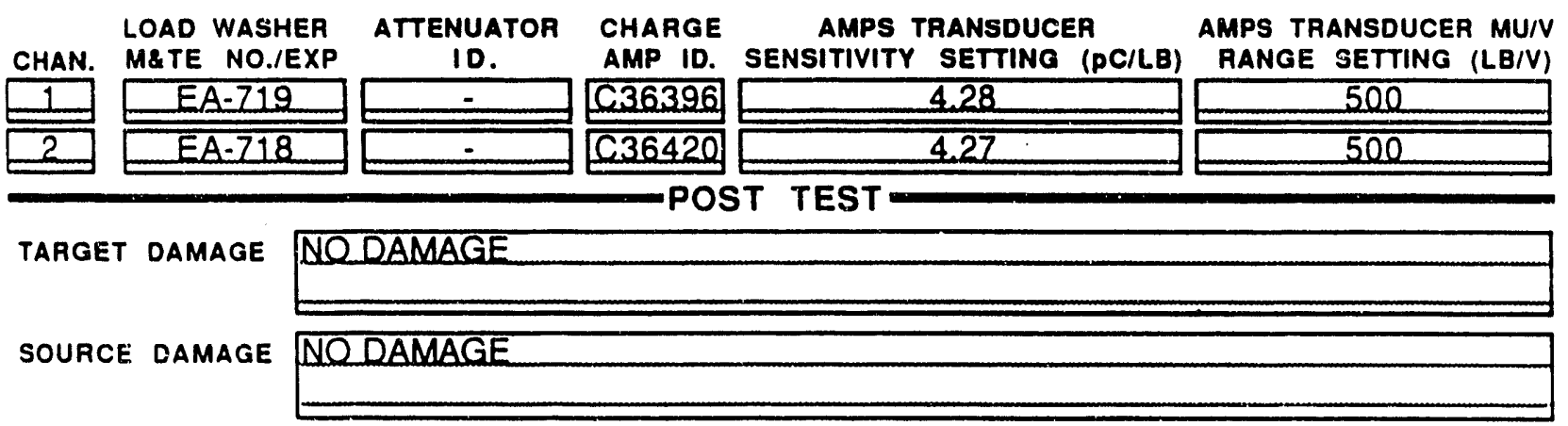

HAND HELD VIDEO START STOP POSITION DLA

HIGH SPEED VIDEO START \& STOP POSITION $17: 20-18: 40$

COMMENTS SOURCEIMEACIED TARGET TWLCE AETER THEINITIALIMPACI

REVIEWED BYISIGNATURE MII.FEBENCZI Y REVIEWED date $12-2-\pi$ APPROVED BYISIGNATURE BRIAN THOMASL \&

${ }^{\dagger}$ Approximale weight using M\&TE category 3 equipment. 
WSRC-TR-93-0094

Attuchment 10. Test Data Sheets (30 of 155)

Savannah River Technology Center

Equipment Engineering

Seismic II/I Drop Test Program

EES-FP.370, Rev. 1

Supported Beam Drop Tests

Date Approved: 8/28/92. Category 2

Page 16 of 18

\subsection{ATTACHMENT 5 \\ IEST UATAA SHEET}

PRE TEST

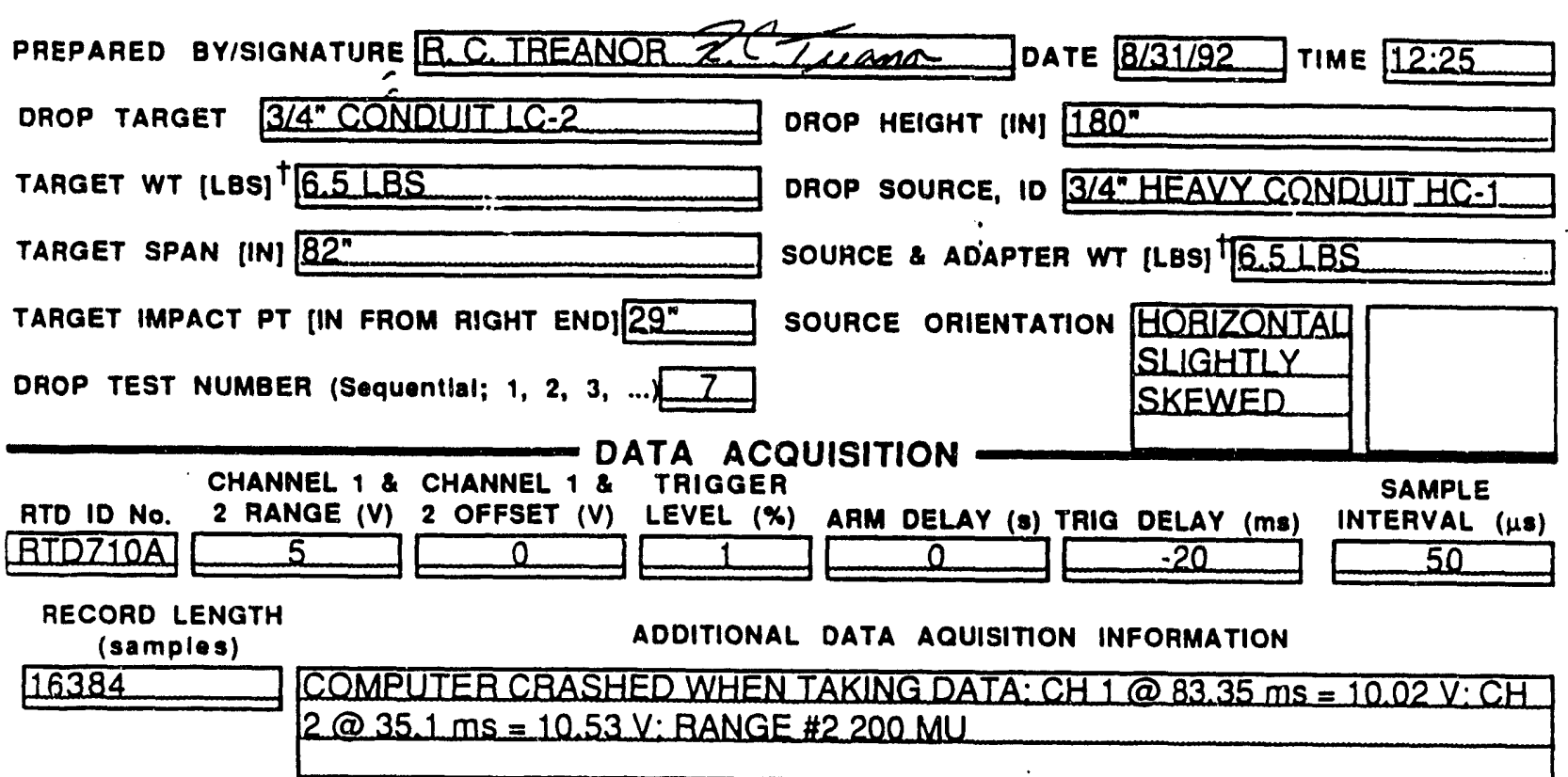

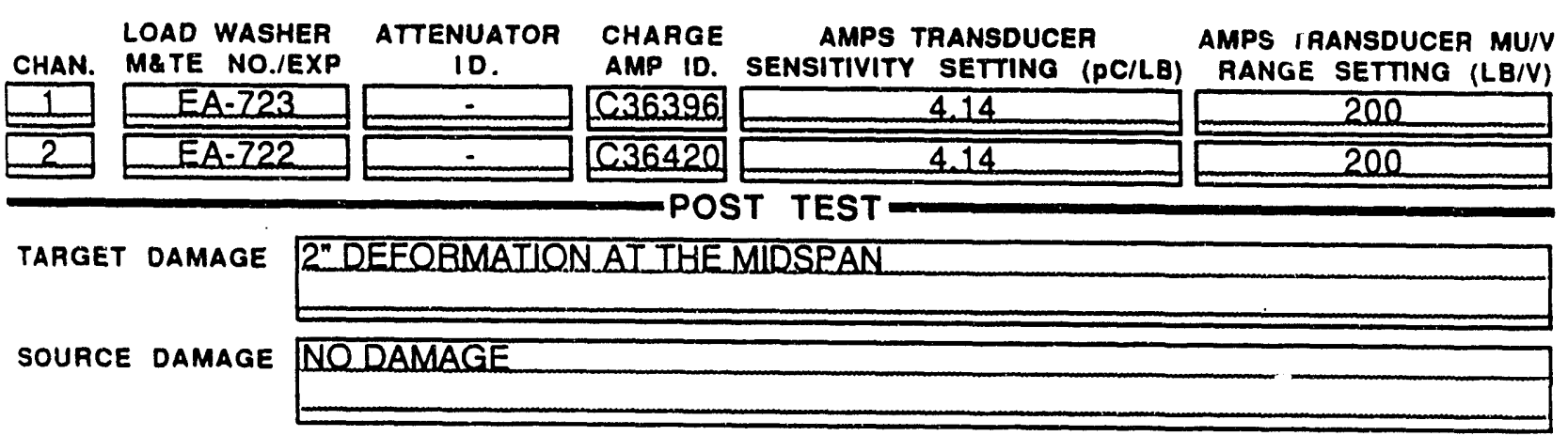

HAND HELD VIDEO START \& STOP POSITION NIA

HIGH SPEED VIDEO START \& STOP POSITION $18: 40-19: 46$

COMMENTS MAYHAVE OVERLOADED CELL'S_PEAK VOLIAGE

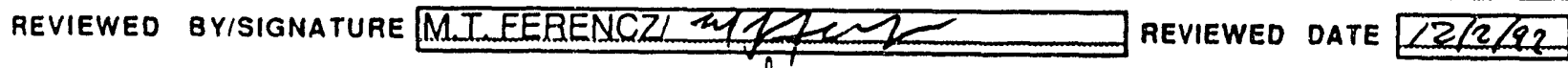

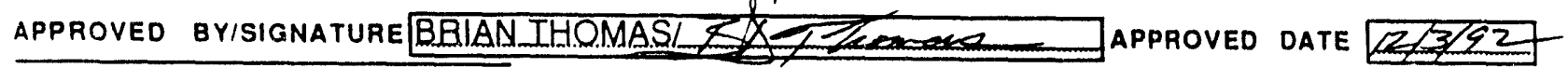

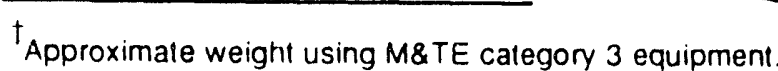


WSRC-TR-93-0094

Attachment 10. Test Data Shects (31 of 155)

Savannah River Technology Center

Equipment Engineering

Seismic II/I Drop Test Program

EES-FP-370, Rev. 1

Supported Beam Drop Tests

\section{Date Approved: 8/28/92, Category 2}

Page 16 of 18

\subsection{ATTACHMENT 5 \\ IEST DATA SHEET}

-PRE TEST

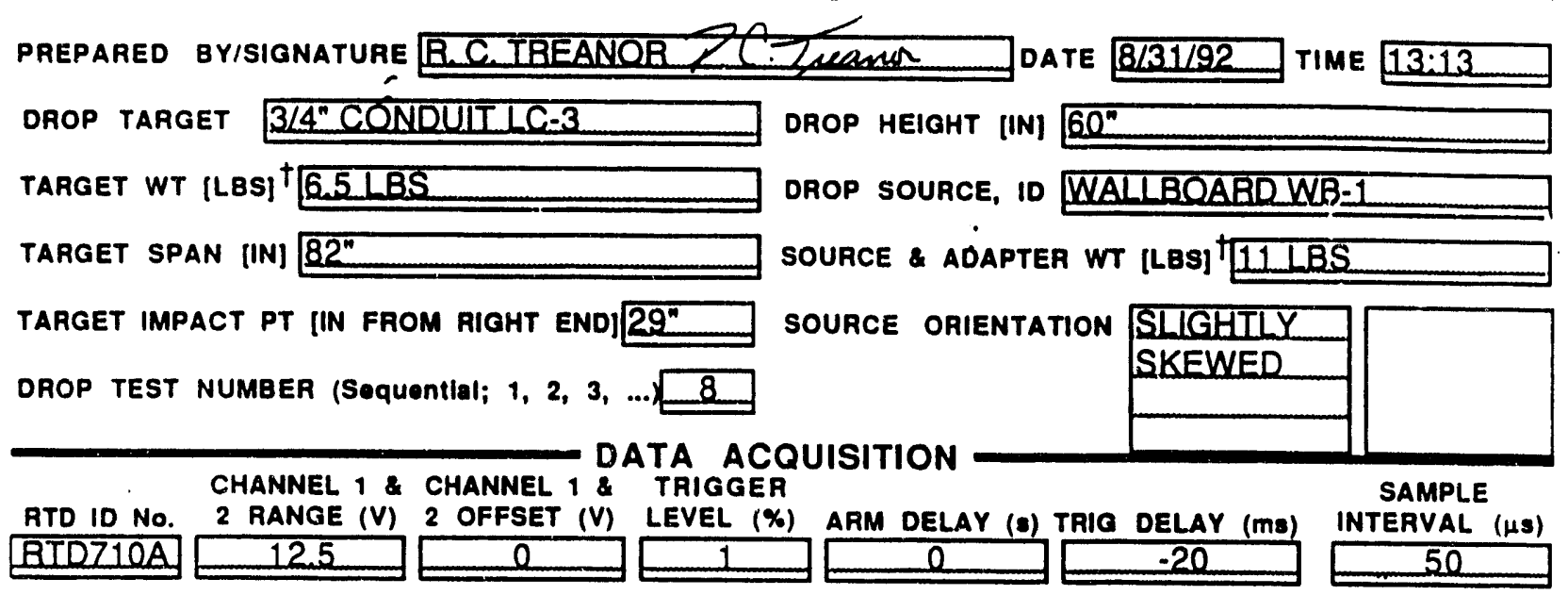

RECORD LENGTH

(samples)

ADDITIONAL DATA AQUISITION INFORMATION

$16384 \quad \mathrm{CH} 1 @-55.6 \mathrm{~ms}: V=-840 \mathrm{~V}$

CH2@-54.8ms: $V=-1.030 V$

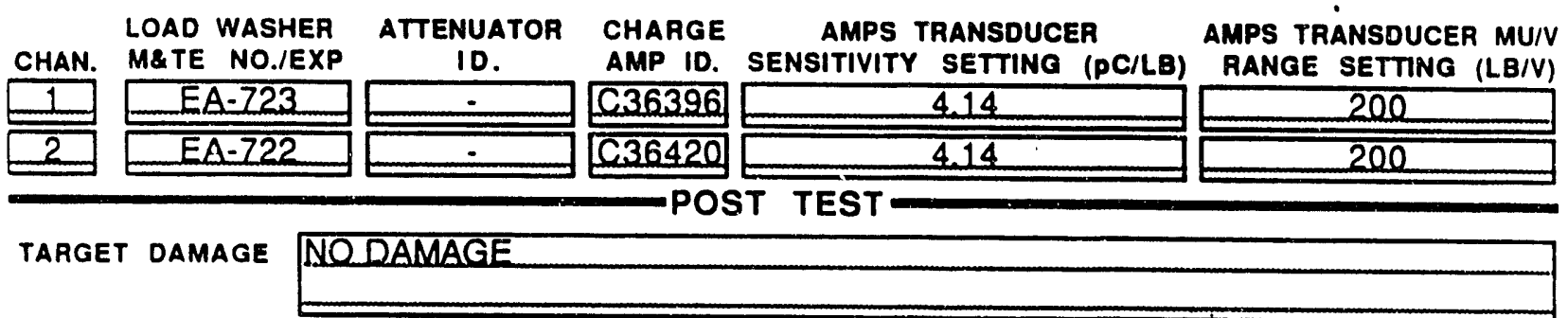

SOURCE DAMAGE BROKEINTR SEVERALPIECES

HAND HELD VIOEO START \& STOP POSITION N/A

HIGH SPEED VIDEO START \& STOP POSITION $1.2446-20: 21$

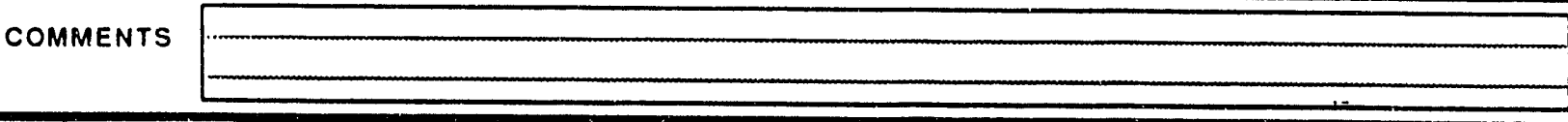

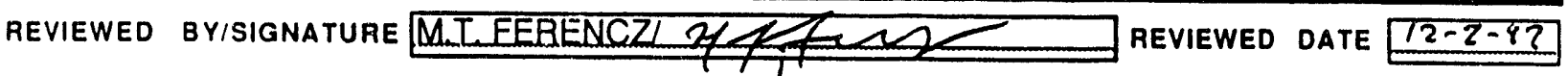

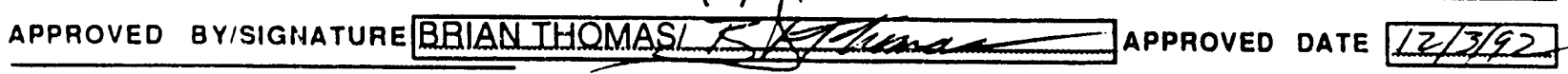

${ }^{\dagger}$ Approximate weight using M\&TE category 3 equipment. 
IVSRC.TR-93-0094

Allachment 10. Test Data Sheets (32 of 155)

Savannah River Technology Center

Equipment Engineering

Seismic IV/I Drop Test Program

Supported Beam Drop Tests

EES-FP-370, Rev. 1 Date Approved: 8/28/92, Category 2

Page 16 of 18

\subsection{ATTACHMENT 5 \\ TEET OATA SHEET}

PRE TEST

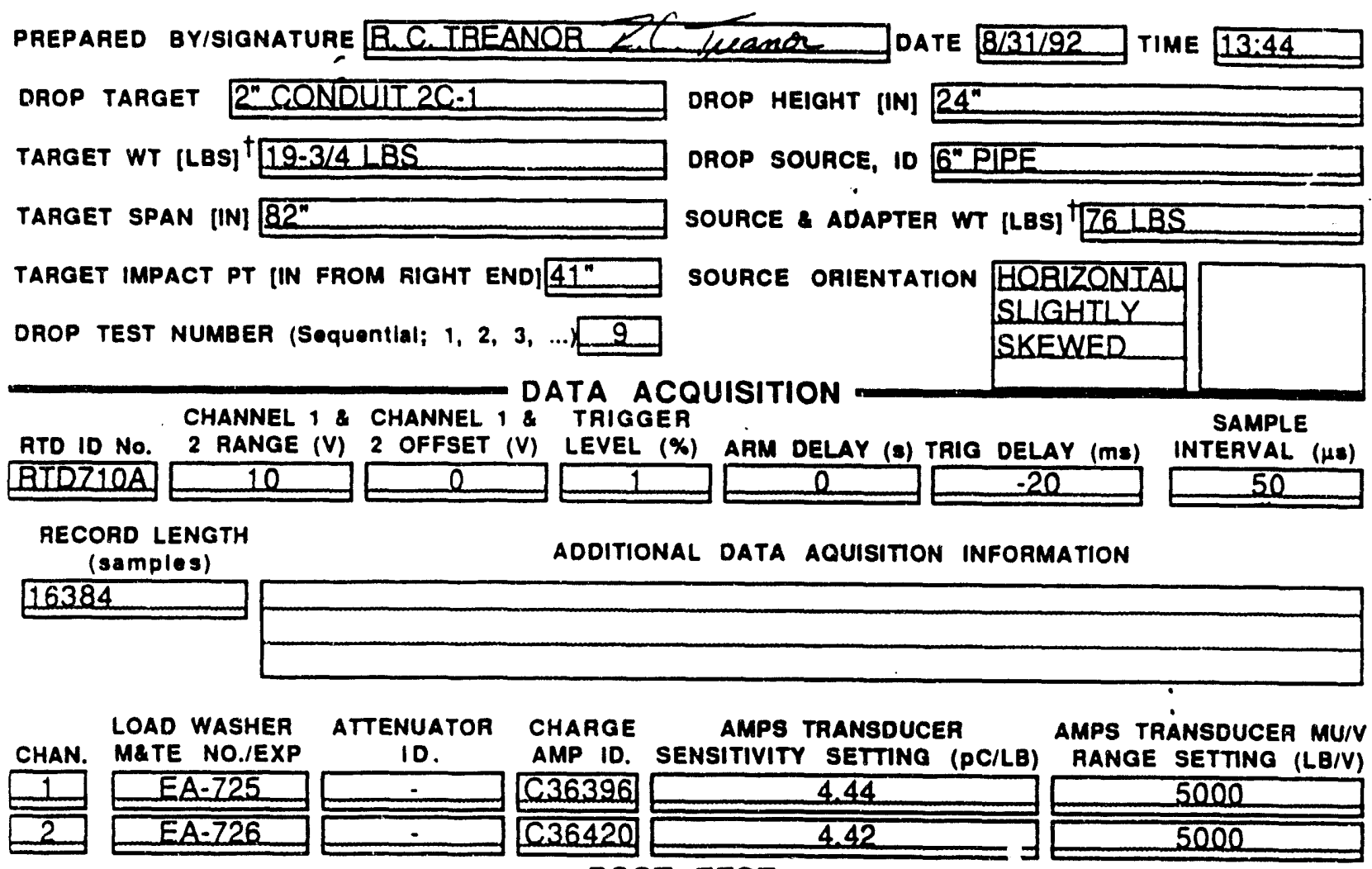

POST TEST

TARGET DAMAGE 3/4" DEEORMATION AT THEMIDSPAN

SCURCE DAMAGE NODAMAGE

HAND HELD VIDEO START \& STOP POSITION NLA

HIGH SPEED VIDEO START \& STOP POSITION $20.21 \cdot 21: 20$

COMMENTS

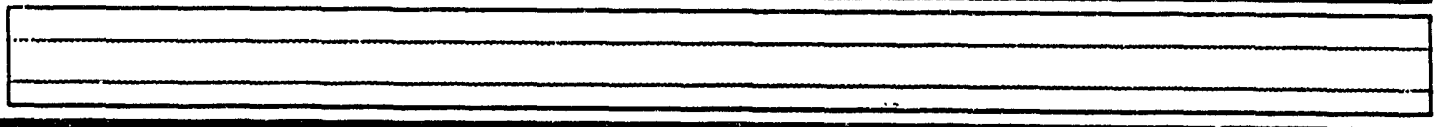

REVIEWED BYISIGNATURE MT.FEBENCZI y4 REVIEWED DATE $12-2$-gz APPROVED BYISIGNATURE BRIAN IHOMASL

${ }^{\dagger}$ Approxımate weight using M\&TE category 3 equipment. 
WSRC-TR-93-0094

Attachment 10. Test Data Sheets (33 of 155)

Savannah River Technology Center

Equipment Engineering

EES-FP-370, Rev. 1

Seismic II/I Drop Test Program

Date Approved: $8 / 28 / 92$, Category 2

Supported Beam Drop Tests

Page 16 of 18

\subsection{ATTACHMENT 5 \\ IEST UATA STHEET}

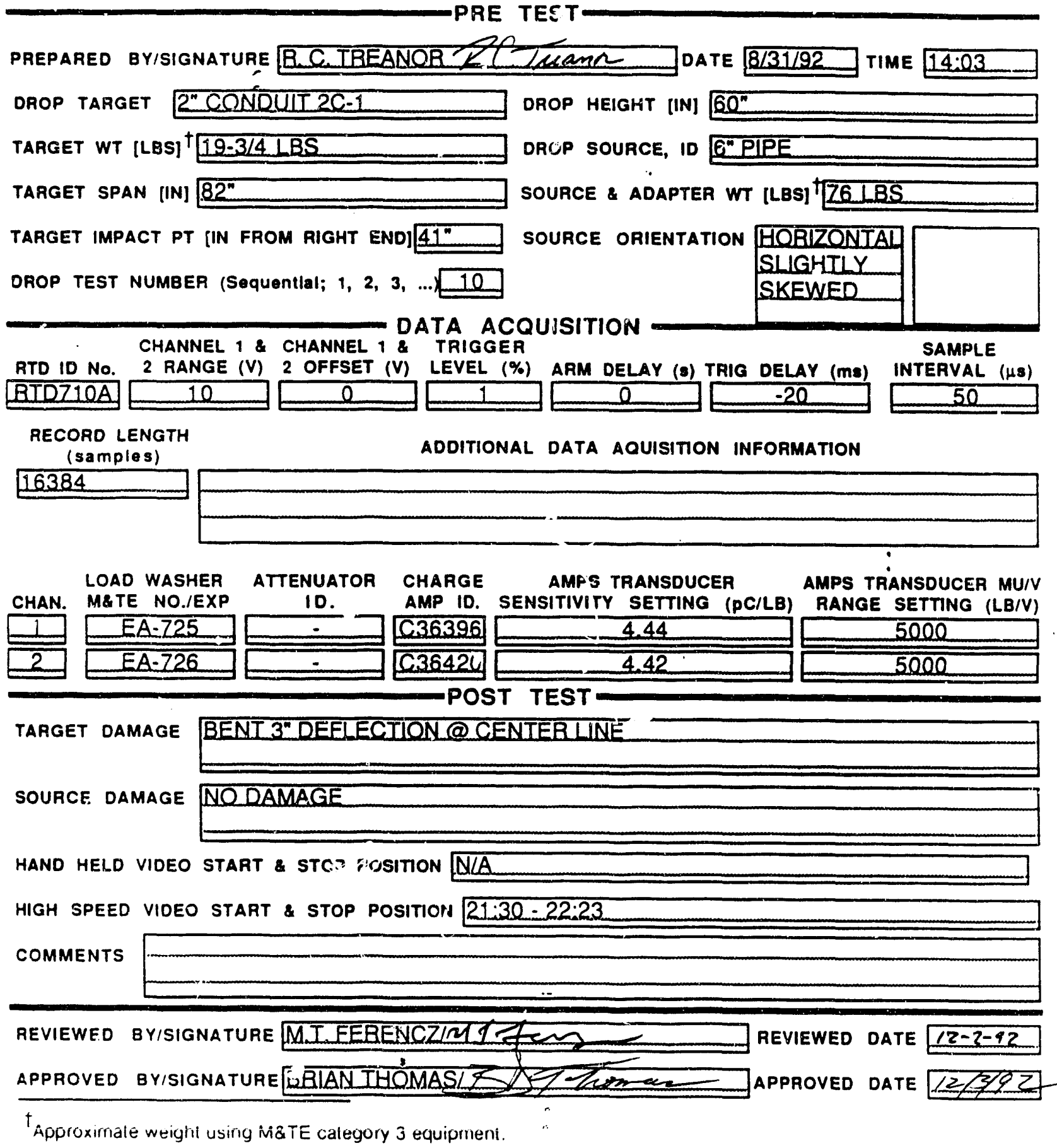


WSRC-TR-93-0094

Attachment 10. Test Data Sheets (34 of 155)

Savannah River Technology Center Equipment Engineering Seismic IVI Drop Test Program Supported Beam Drop Tests
EES-FP-370, Rev. 1

Date Approved: 8/28/92, Category 2

Page 16 of 18

\subsection{ATTACHMENT 5 \\ IEST UATA SHTEEI}

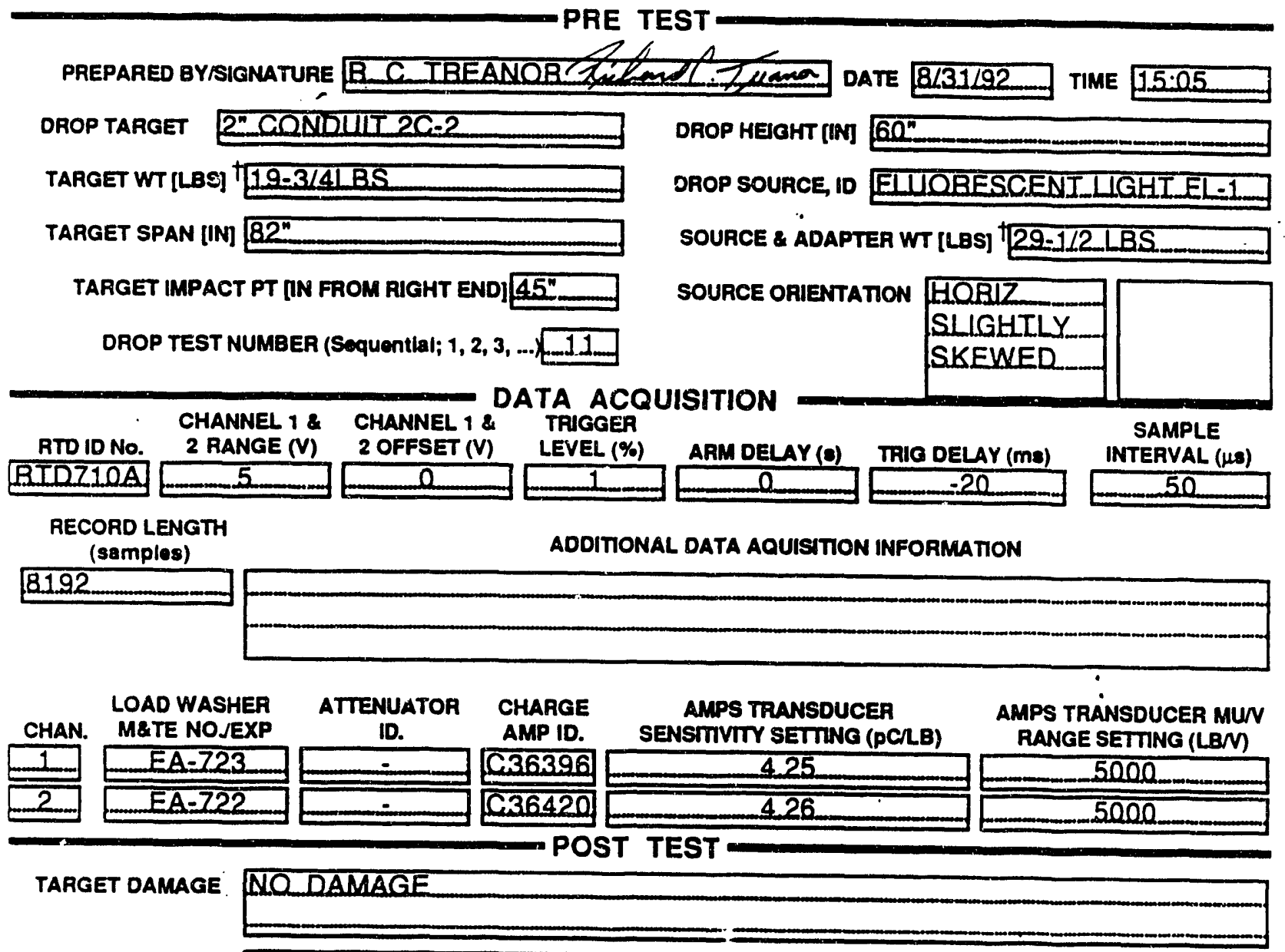

SOURCE DAMAGE DISMANTIED ERAME I REASSEMBLED

HAND HELD VIDEO START \& STOP POSITON NLA

HIGH SPEED VIDEO START \& STOP POSITION 22:23:22:38

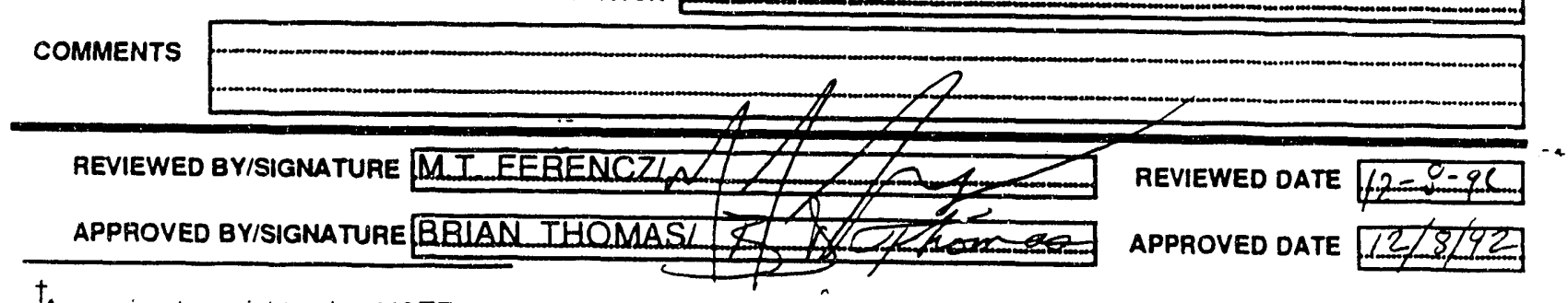

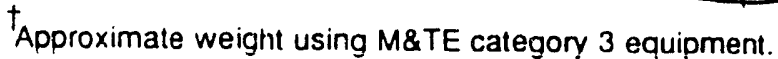


WSRC-TR-93-0094

Attachment 10. Test Data Sheets (35 of 155)

Savannah River Technology Center

Equipment Engineering

Seismic II/I Drop Test Program

Supported Beam Drop Tests

EES-FP-370, Rev, 1

Date Approved: $8 / 28 / 92$, Category 2

Page 16 of 18

\subsection{ATTACHMENT 5 \\ TEST DATA GIIEET}

PRE TEST

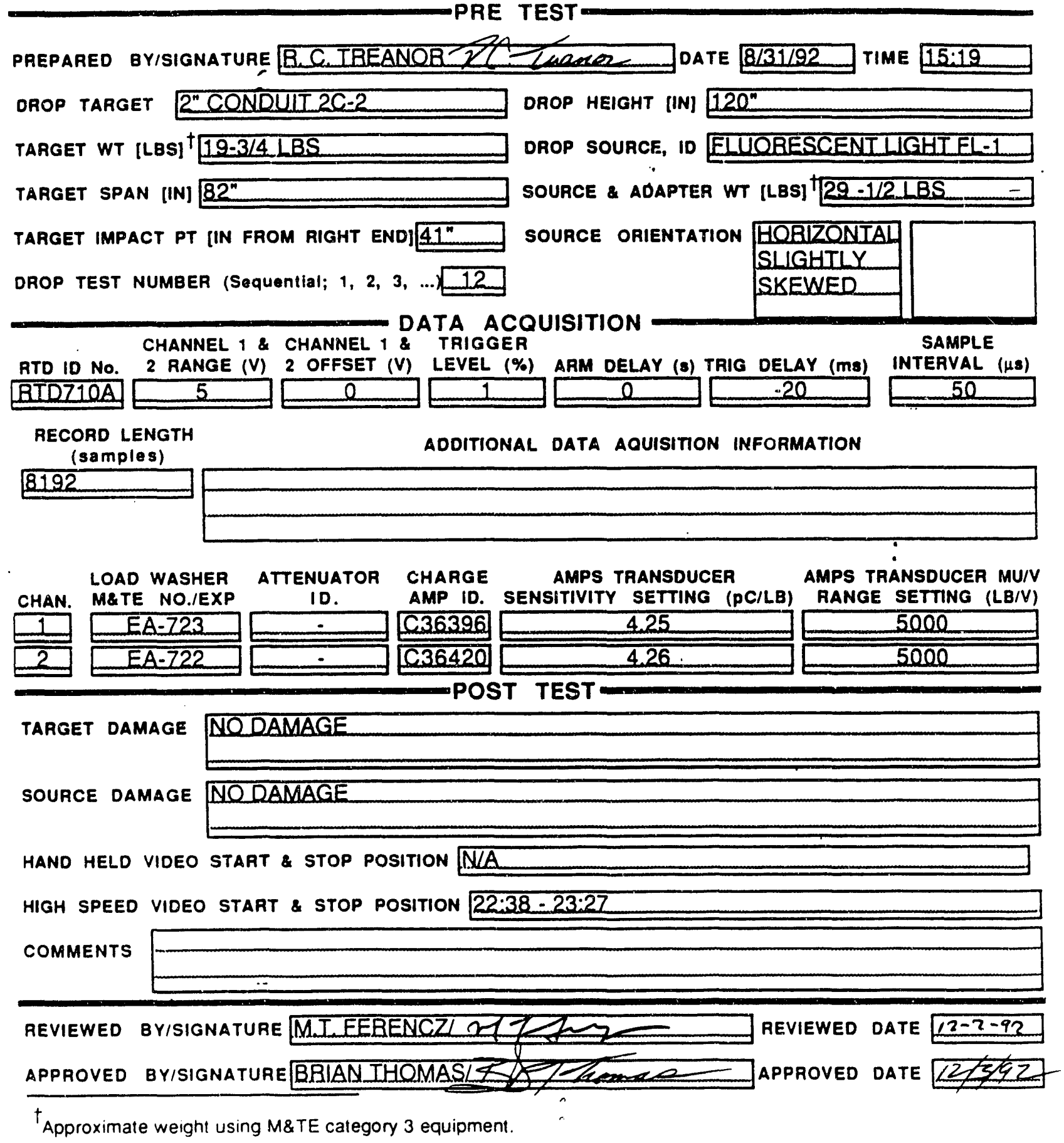


IVSRC-TR-93-0094

Attachment 10. Test Data Sheets (36 of 155)

Savannah River Technology Center

Equipment Engineering

Seismic II// Drop Test Program

Supported Beam Drop Tests
EES-FP-370, Rev. 1

Date Approved: $8 / 28 / 92$, Category 2

Page 16 of 18

\subsection{ATTACHMENT 5 \\ TEST DATA SHEET}

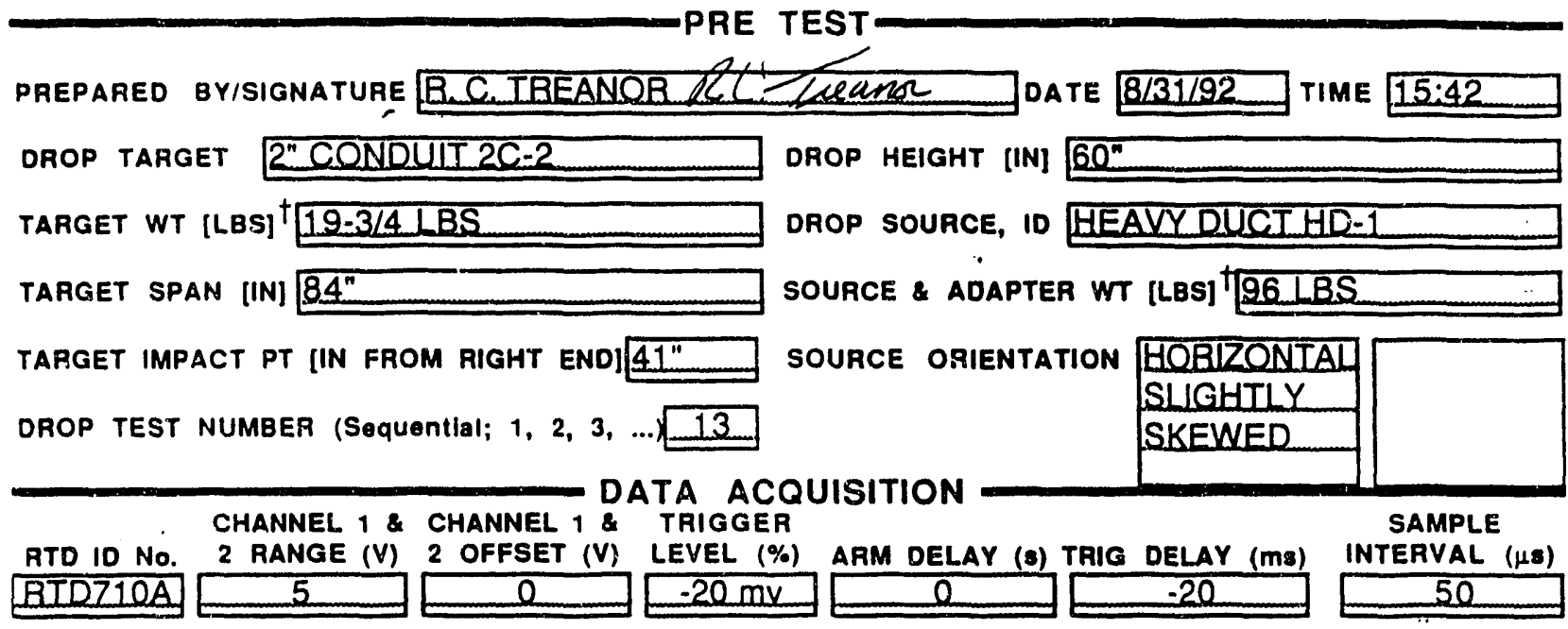

RECORD LENGTH

(samples)

ADDITIONAL OATA AQUISITION INFORMATION

8192 PROBLEMS WITH DIGITIZER:NO DATA TAKEN

\begin{tabular}{l} 
LOAD WASHER ATTENUATOR CHARGE \\
CHAN. M\&TE NO./EXP \\
\hline 1 \\
\hline IDA.723 \\
\hline AA-722
\end{tabular}

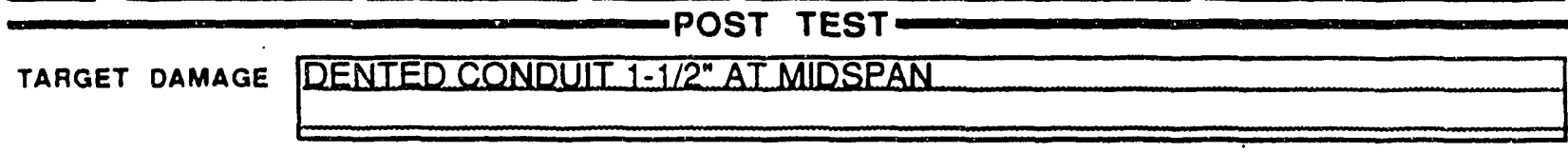

SOURCE DAMAGE NODAMAGE

HAND HELD VIDEO START \& STOP POSITION NLA

HIGH SPEED VIDEO START \& STOP POSITION $23: 27-23: 59$

COMMENTS

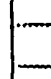

REVIEWED ByISIGNATURE M.T.FEBENCZIM 1 REVIEWED DATE $12-2-q 1$ APPROVED BYISIGNATURE BRIANIHOMAS/ ISAPPROVED DATE IZ/3/EZ

${ }^{\dagger}$ Approximate weight using M\&TE category 3 equipment. 
WSRC-TR-93-0094

Attachment 10. Test Data Sheets (37 of 155 )

Savannah River Technology Center

Equipment Engineering

Seismic II/I Drop Test Program

EES-FP-370, Rev. 1

Supported Beam Drop Tests

Date Approved: $8 / 28 / 92$, Category 2

Supported Beam Drop Tests

\subsection{ATTACHMENT 5 \\ TEST UATA GREET}
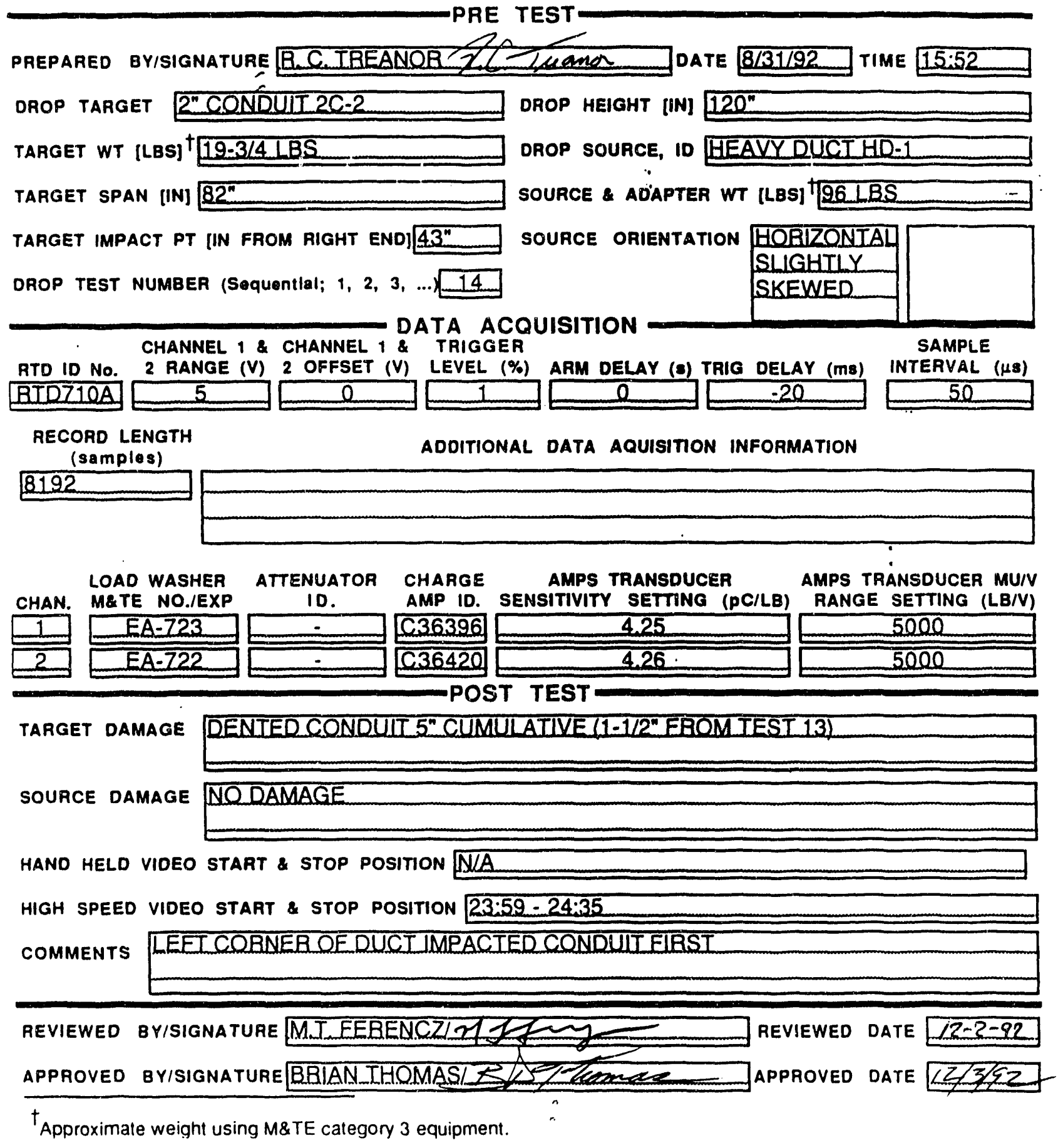
WSRC-TR-93-0094

Attachment 10. Test Data Sheets (38 of 155)

Savannah River Technology Center

Equipment Engineering

EES-FP-370, Rev. 1

Seismic II/I Drop Test Program

Date Approved: $8 / 28 / 92$, Category 2

Supported Beam Drop Tests

Page 16 of 18

\subsection{ATTACHMENT 5 \\ IEST SATA GIIEET}

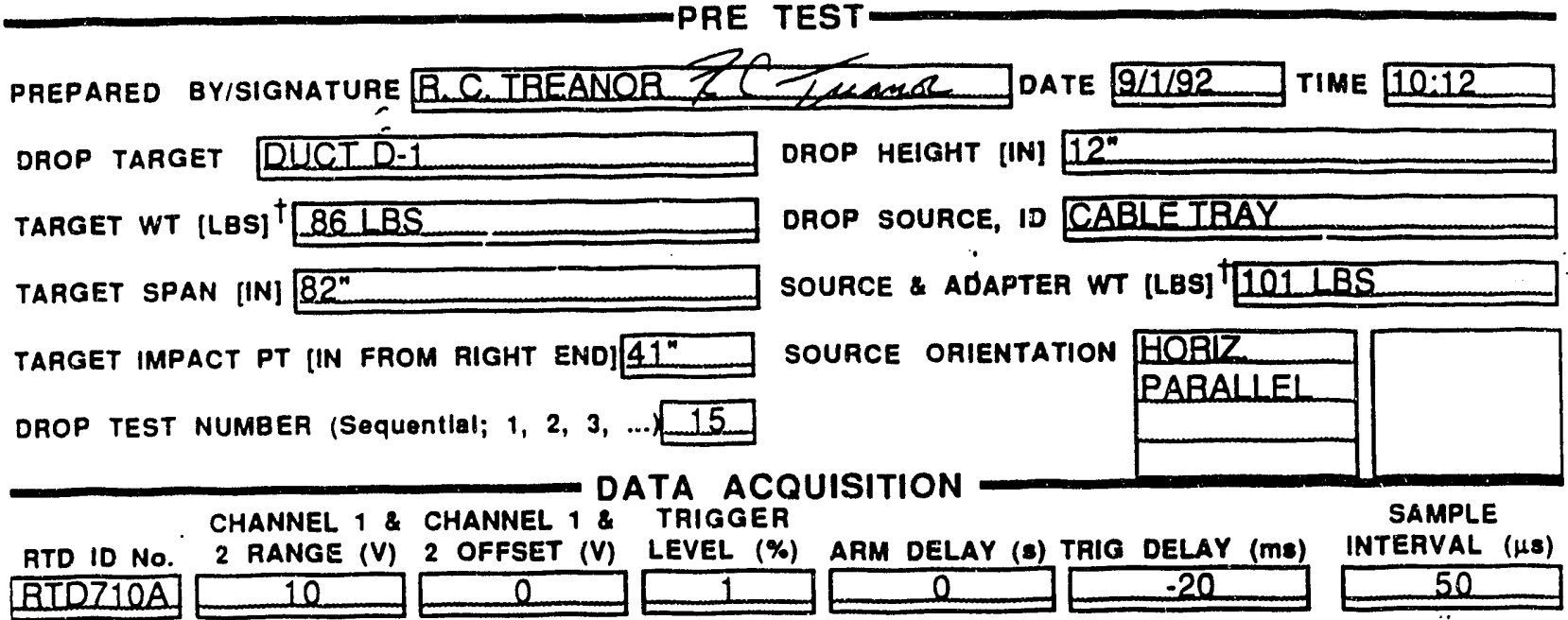

RECORD LENGTH

(samples)

8192 UNEXPLAINABLEERRANT DATA.DISREGARD DATA
ADOITIONAL DATA AQUISITION INFORMATION

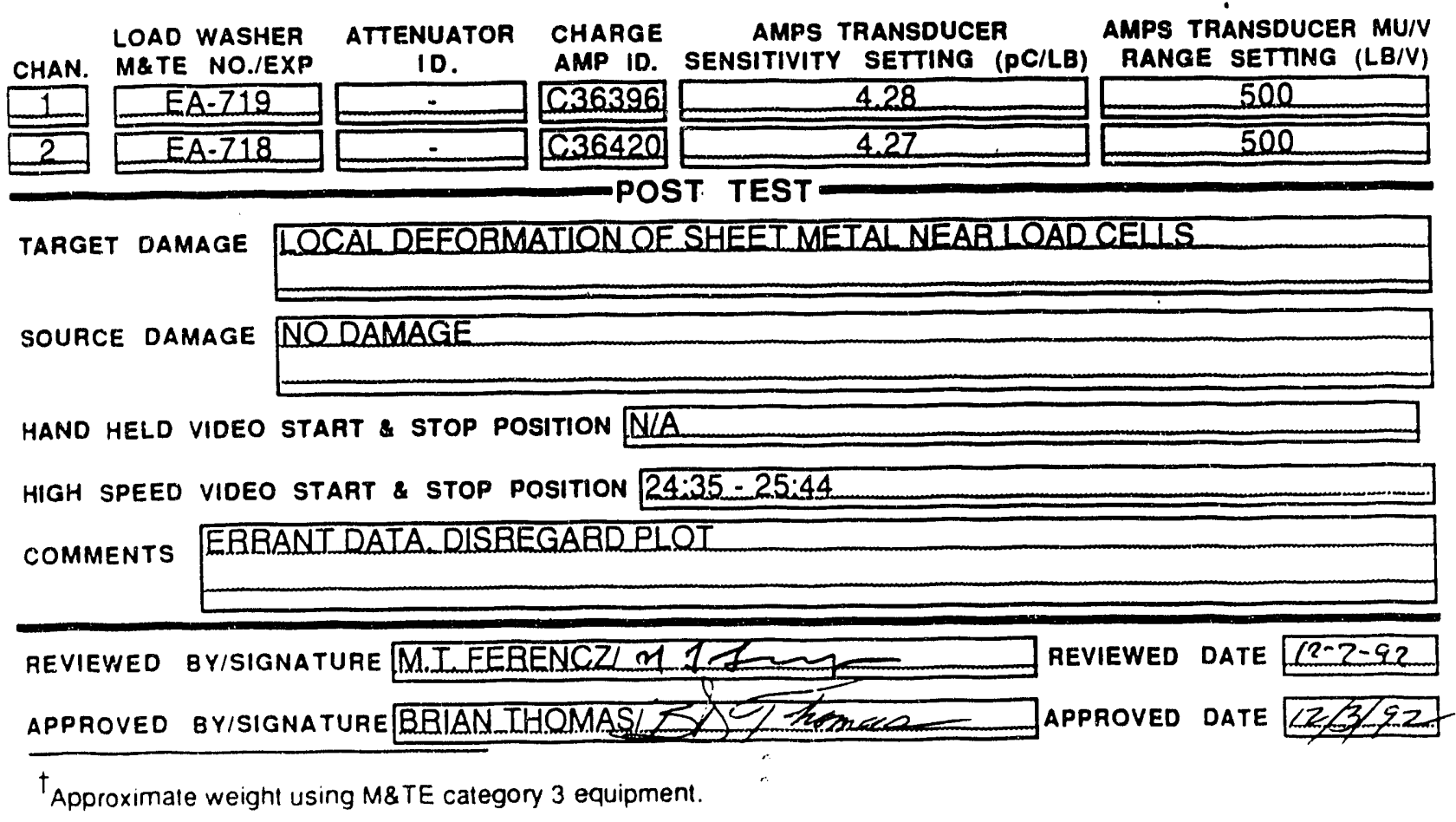


WSRC-TR-93-0094

Attachment 10. Test Data Sheets (39 of 155)

Savannah River Technology Center Equipment Engineering

EES-FP-370, Rev. 1 Seismic II/I Drop Test Program Supported Beam Drop Tests

\subsection{ATTACHMENT 5}

IEST DATA SHEIET

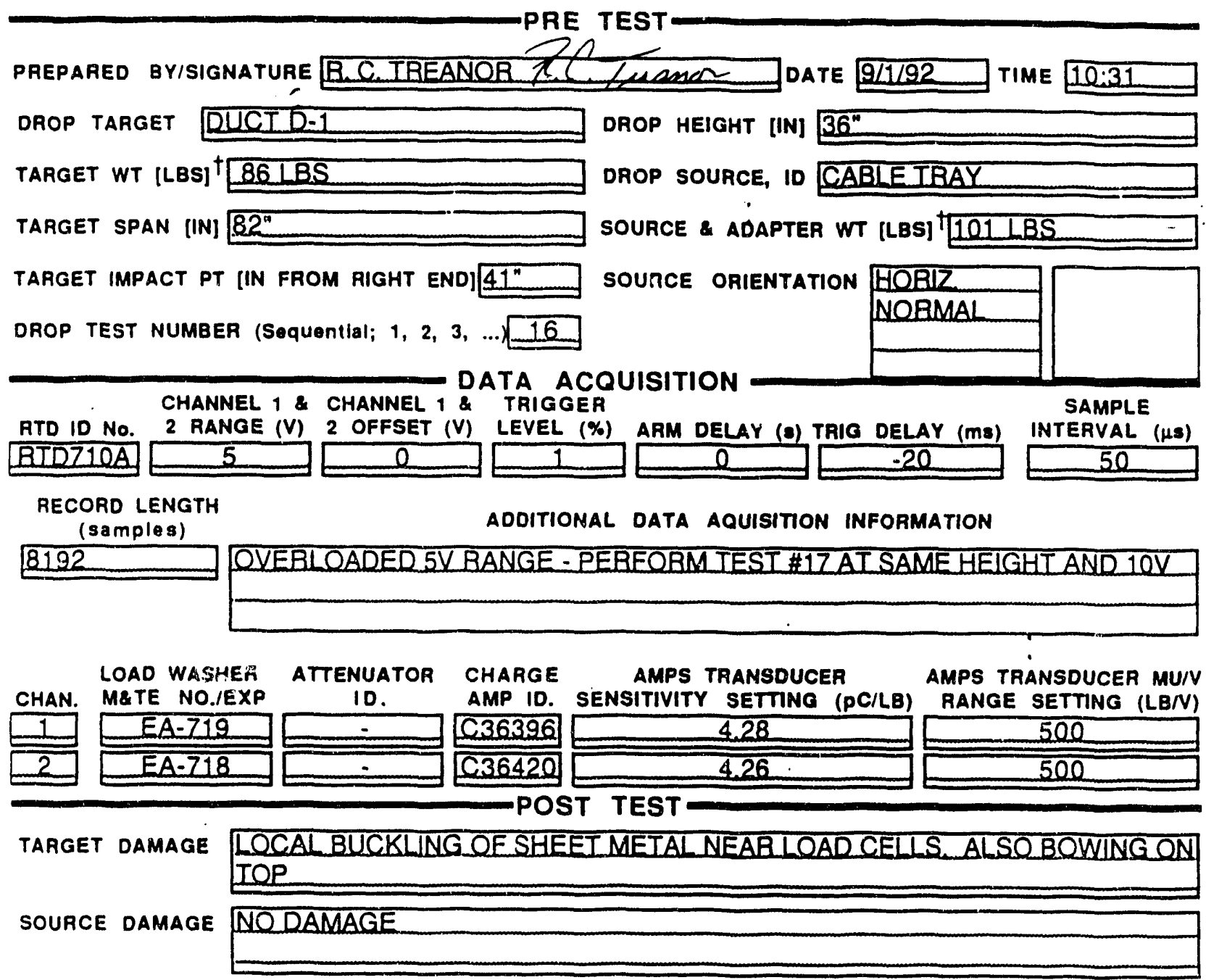

HAND HELD VIDEO START \& STOP POSITION NIA

HIGH SPEED VIDEO START \& STOP POSITION $25: 44-26: 32$

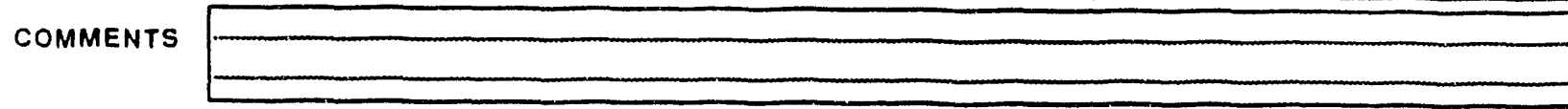

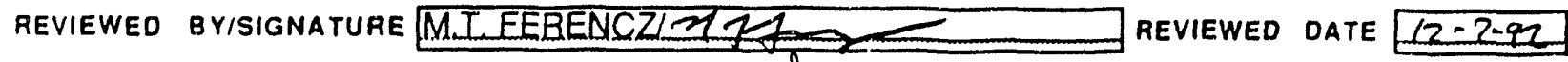
APPROVED BYISIGNATURE BRIANIHOMAS/ ${ }^{\dagger}$ Approximate weight using M\&TE category 3 equipment. 
WSRC-TR-93-0094

Attachment 10. Test Data Shcets (40 of 155)

Savannah River Technology Center

EES-FP-370, Rev. 1

Equipment Engineering

Seismic II/I Drop Test Program

Supported Beam Drop Tests

Date Approved: $8 / 28 / 92$, Category 2

Page 16 of 18

\subsection{ATTACHMENT 5}

IEST DATA SRIEET

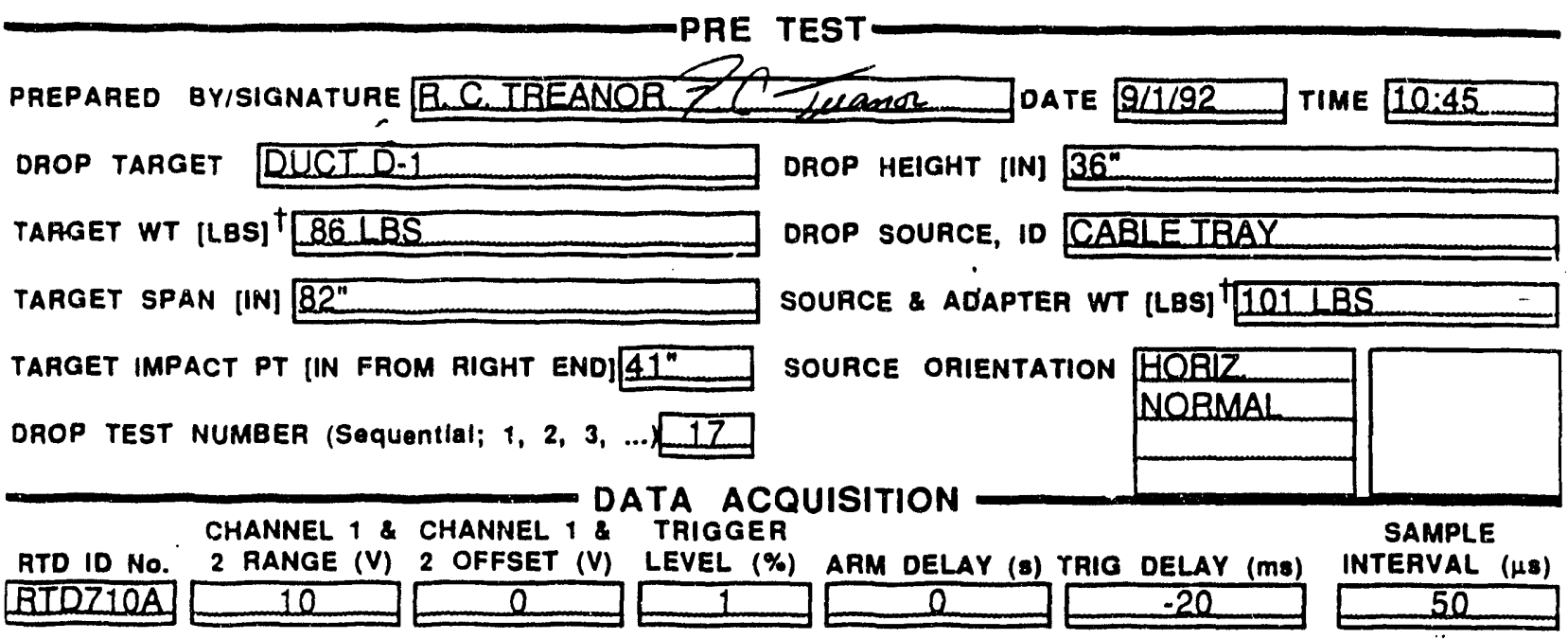

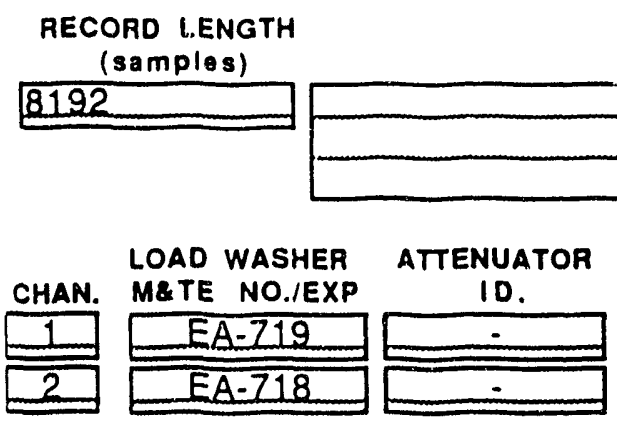

ADDITIONAL DATA AQUISITION INFORMATION
CHARGE AMPS TRANSDUCER

AMP 1D. SENSITIVITY SETTING (PC/LB)

C36396

C36420

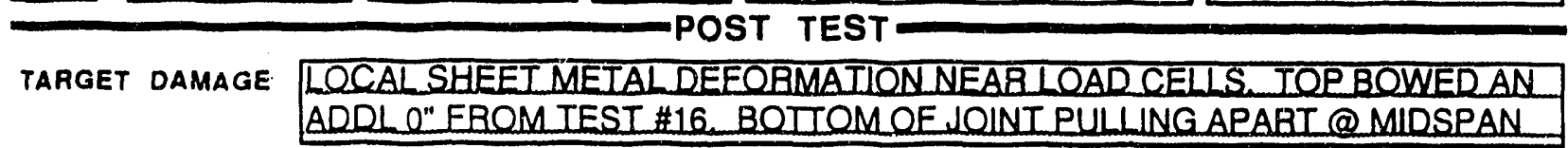

SOURCE DAMAGE NODAMAGE

HAND HELD VIDEO START \& STOP POSITION NIA

HIGH SPEED VIDEO START \& STOP POSITION $26: 32-26: 47$

COMMENTS

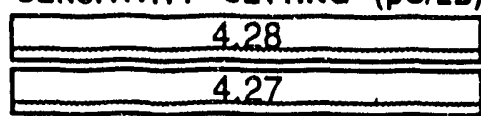
RANGE SETTING (LB/V) 
WSRC-TR-93-0094

Attachment 10. Test Duta Slicets ( +1 of 155 )

Savannah River Technology Center

Equipment Engineering

Seismic II// Drop Test Program

Supported Beam Drop Tests

EES-FP-370, Rev. 1

Date Approved: $8 / 28 / 92$, Category 2

Page 16 of 18

\subsection{ATTACHMENT 5 \\ IEST DATA SHEET}

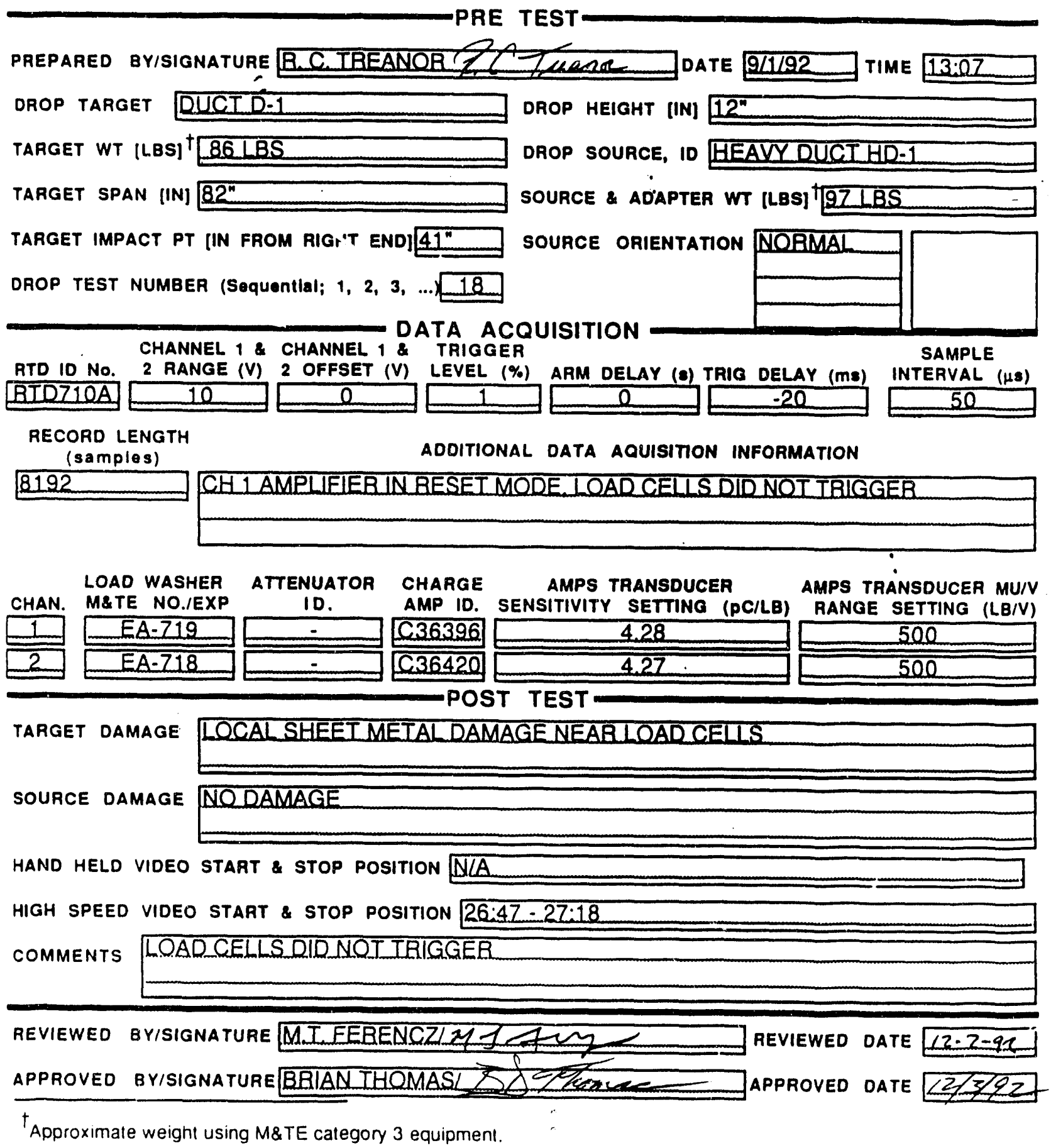


IVSRC-TR-93-0094

Attachment 10. Test Data Sheets ( 42 of 155$)$

Savannah River Technology Center Equipment Engineering

Seismic II// Drop Test Program

Supported Beam Drop Tests
EES-FP-370, Rev. 1

Date Approved: 8/28/92, Category 2

Page 16 of 18

\subsection{ATTACHMENT 5 \\ IEST CATA GHEET}

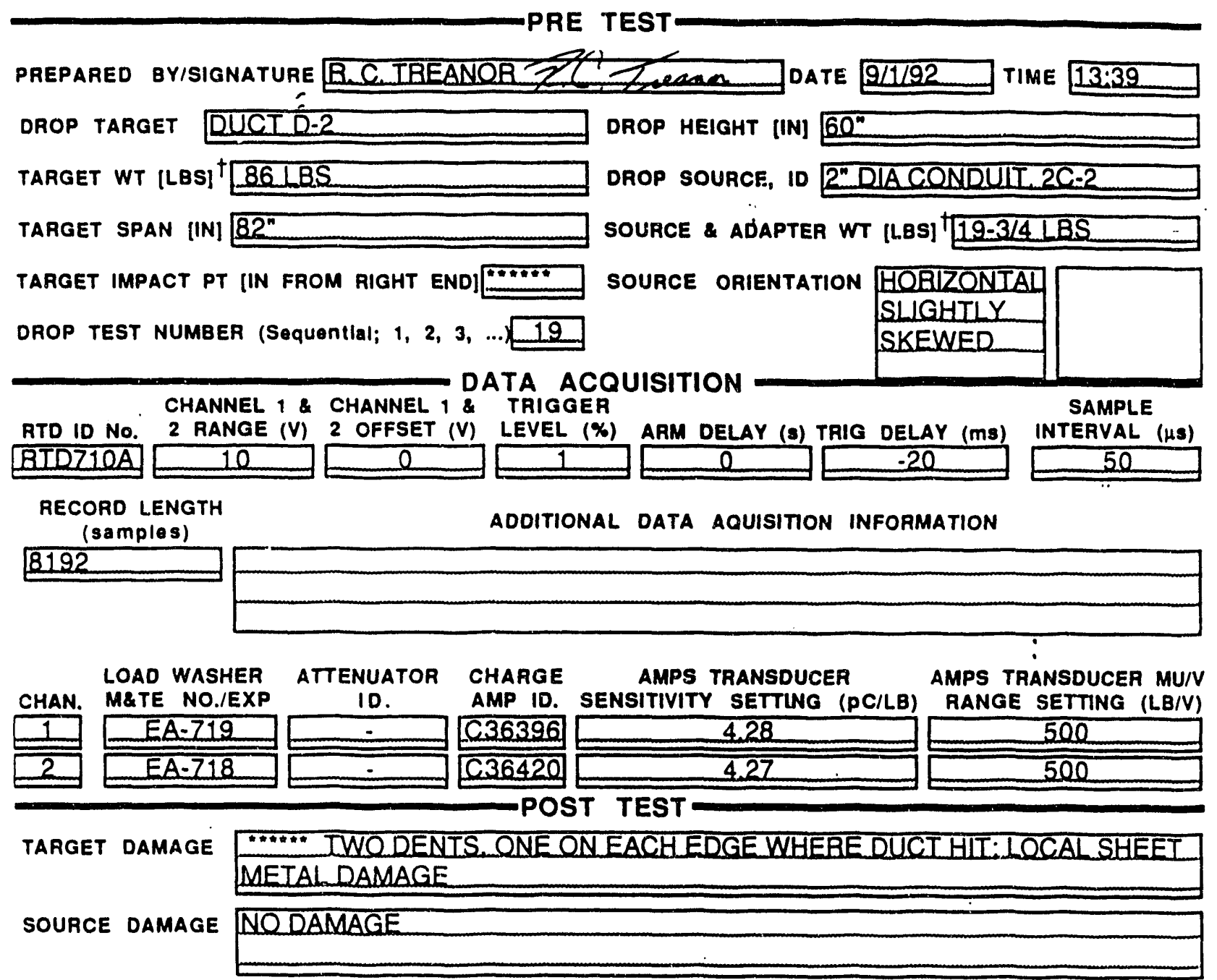

HAND HELD VIDEO START \& STOP POSITION WLA

HIGH SPEED VIDEO START \& STOP POSITION $27: 18-27: 27$

COMMENTS

REVIEWED BYISIGNATURE MT.FERENCZIYI I

APPROVED BYISIGNATURE BRIAN IHOMAS/ $5 / 2$ Zhen -

${ }^{\dagger}$ Approximate weight using M\&TE category 3 equipment. 
WSRC.TR-93-0094

Attachment 10. Test Data Sheets (43 of 155)

Savannah River Technology Center Equipment Engineering

Seismic IV/ Drop Test Program

Supported Beam Drop Tests
EES-FP-370, Rev. 1

Date Approved: 8/28/92, Category 2

Page 16 of 18

\footnotetext{
8.5 ATTACHMENT 5

IEST DATA S'TEEI

PRE TEST
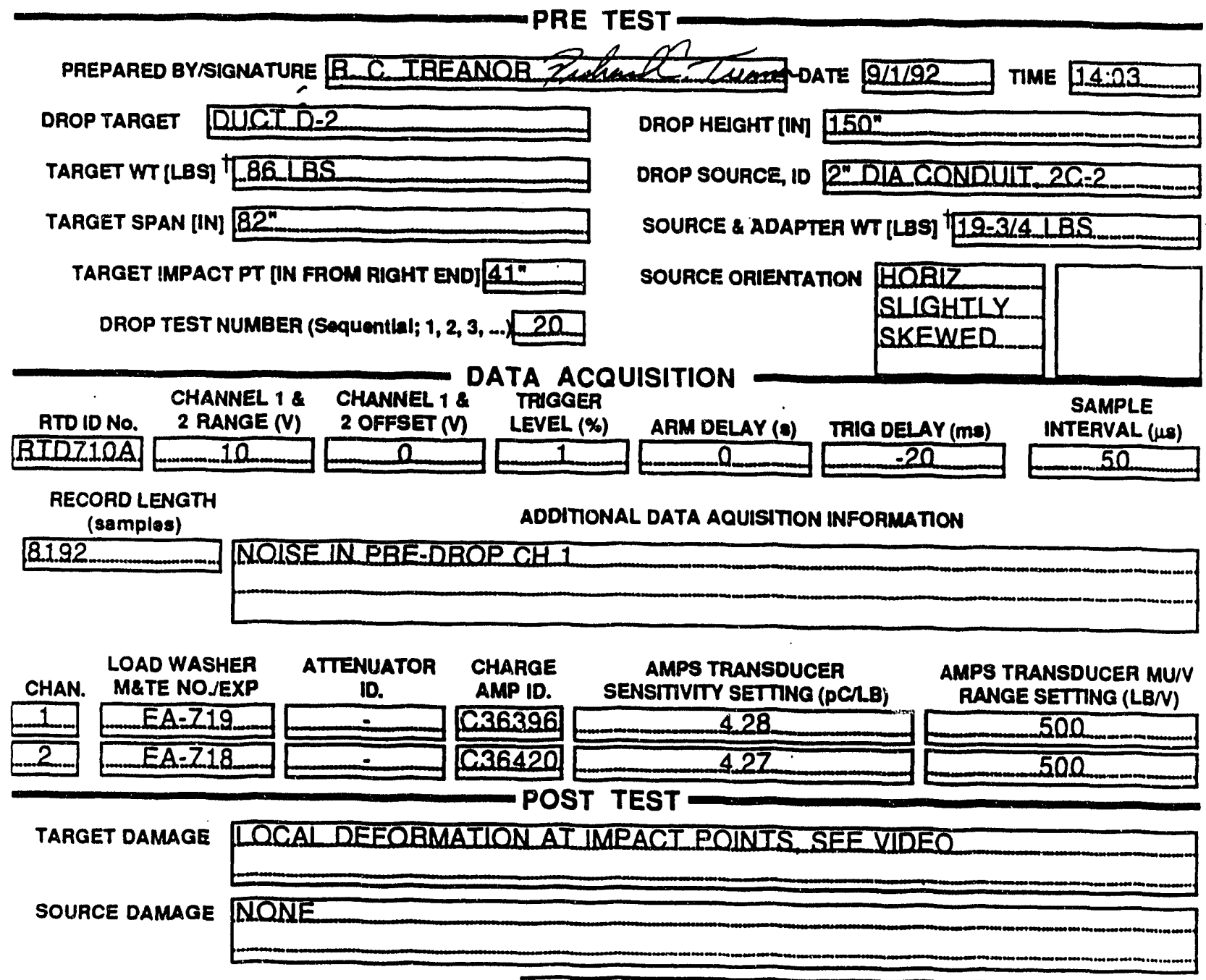

HAND HELD VIDEO START \& STOP POSITION NIA

HIGH SPEED VIDEO START \& STOP POSITION $27: 27=27: 35$

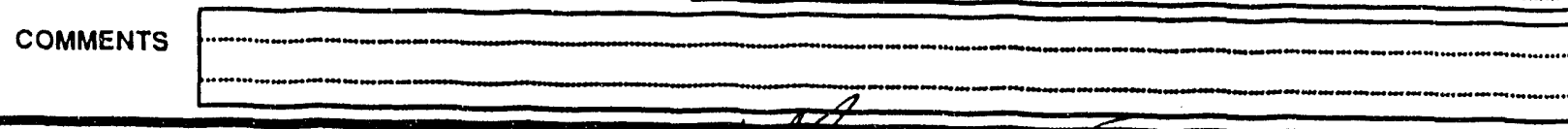

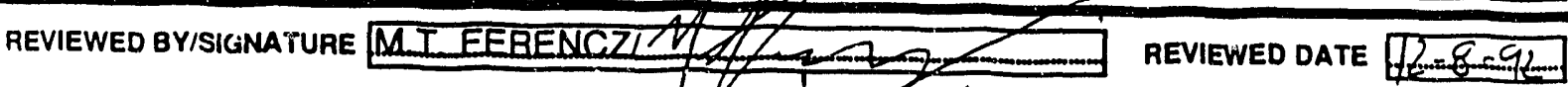
APPROVED BYISIGNATURE BRIAN IHOMASA APAOVED DATE 1279

${ }^{\dagger}$ Approximate weight using M\&TE category 3 equipment.
} 
IVSRC-TR-93-0094

Attuchment 10. Test Data Sheets ( 44 of 155)

Savannah River Technology Center

Equipment Engineering

Seismic II// Drop Test Program

EES-FP-370, Rev. 1

Supported Beam Drop Tests

Date Approved: 8/28/92, Category 2

Page 16 of 18

\footnotetext{
8.5 ATTACHMENT 5 IEVT DATA GIIFET

PRE TEST

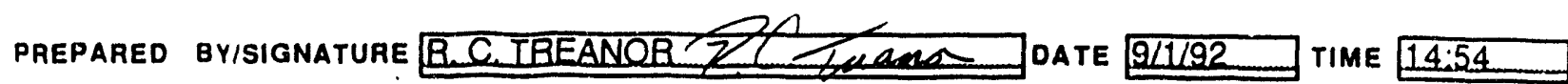
DROP TARGET DUCTD-2 DROP HEIGHT (IN] 150" TARGET WT ILBS] 86 LBS

TARGET SPAN [IN] $82^{n}$

TARGET IMPACT PT IIN FROM RIGHT ENO] $33^{\mathrm{m}}$ SOURCE ORIENTATION HQRIZONTAI DROP TEST NUMBER (Sequentlal; $1,2,3, \ldots 2$

DATA ACQUISITION SLIGHTLYY SKEWED CHANNEL 1 \& CHANNEL 1 \& TRIGGER BID710A 10 RECORD LENGTH (samples)

ADDITIONAL DATA AQUISITION INFORMATION 8192 CH. L OAD CE L WAS QVERL OADED IHUS AVEBAGE PLOT IS AVG OE QVERANGE LIMIT ANDCH.2IN THEELATABEAOE THE PLOT.

\begin{tabular}{|c|c|c|c|c|c|}
\hline CHAN. & $\begin{array}{l}\text { LOAD WASHER } \\
\text { M\&TE NO./EXP }\end{array}$ & $\begin{array}{l}\text { ATTENUATOR } \\
\text { ID. }\end{array}$ & $\begin{array}{l}\text { CHARGE } \\
\text { AMP ID. }\end{array}$ & $\begin{array}{l}\text { AMPS TRANSDUCER } \\
\text { SENSITIVITY SETTING (PC/LB) }\end{array}$ & $\begin{array}{l}\text { AMPS TRANSDUCER MU/V } \\
\text { RANGE SETTING (LB/V) }\end{array}$ \\
\hline 1 & EA-719 & - & C36396 & 4.28 & 500 \\
\hline 2 & $E A \cdot 718$ & - & C36420 & 4.27 & 500 \\
\hline
\end{tabular}

SOURCE DAMAGE NONE

HAND HELD VIDEO START \& STOP POSITION NLA

HIGH SPEED VIOEO START \& STOP POSITION $27: 3.5-27: 48$

COMMENTS

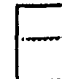

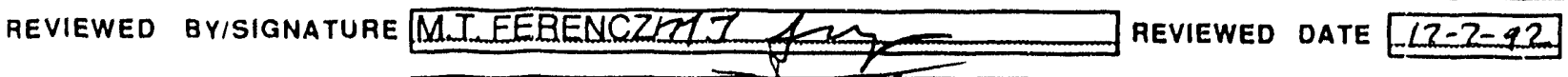
APPROVED BYISIGNATURE BBIANIHQMAS

${ }^{\dagger}$ Approximate weight using M\&TE category 3 equipment.
} 
IVSRC-TR-93-0094

Attachment 10. Test Data Sheets (45 of 155 )

Savannah River Technology Center Equipment Engineering

EES-FP-370, Rev. 1

Seismic II/I Drop Test Prograni

Supported Beam Drop Tests

\subsection{ATTACHMENT 5}

IEST DATA SHEET

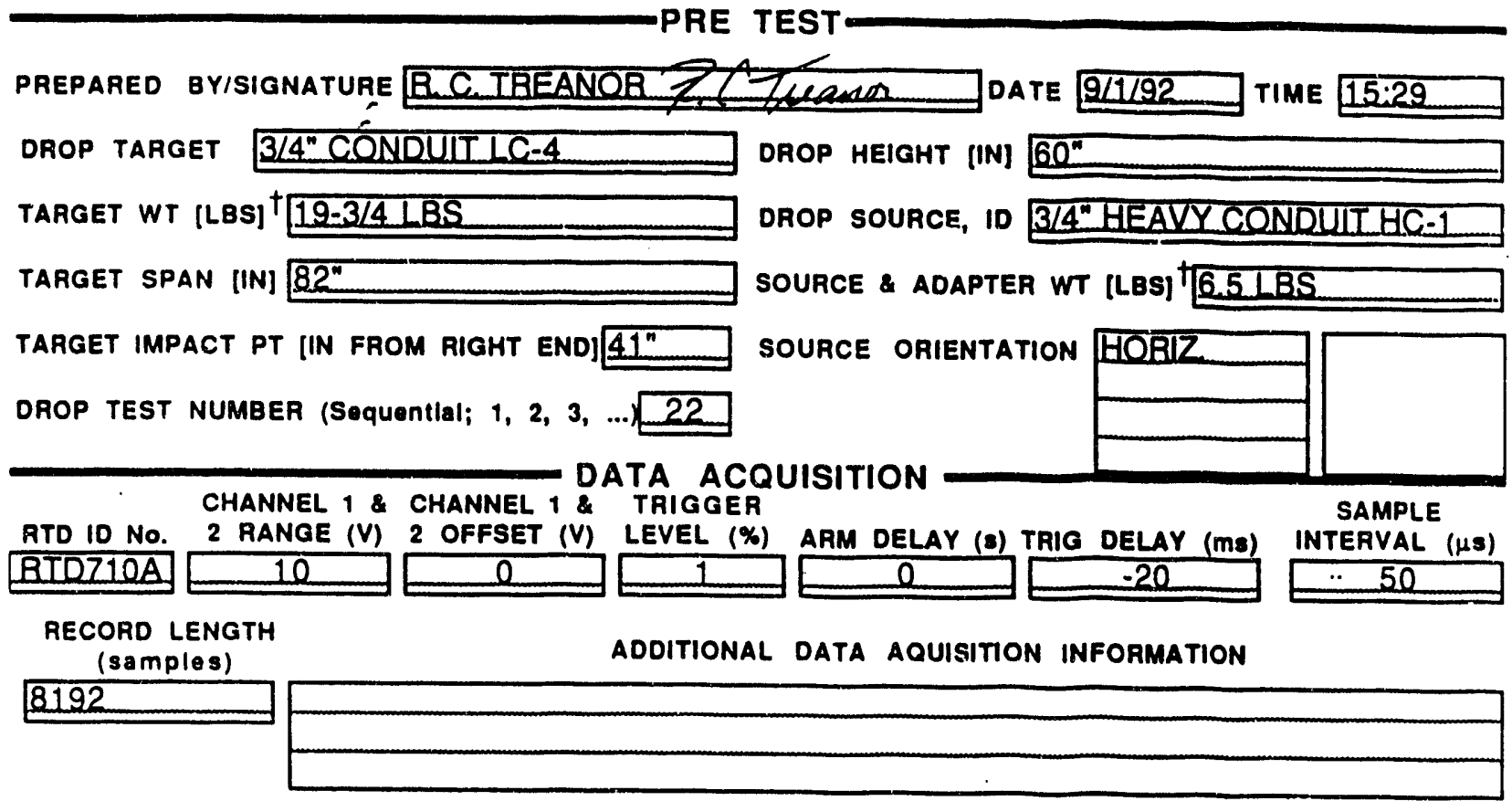

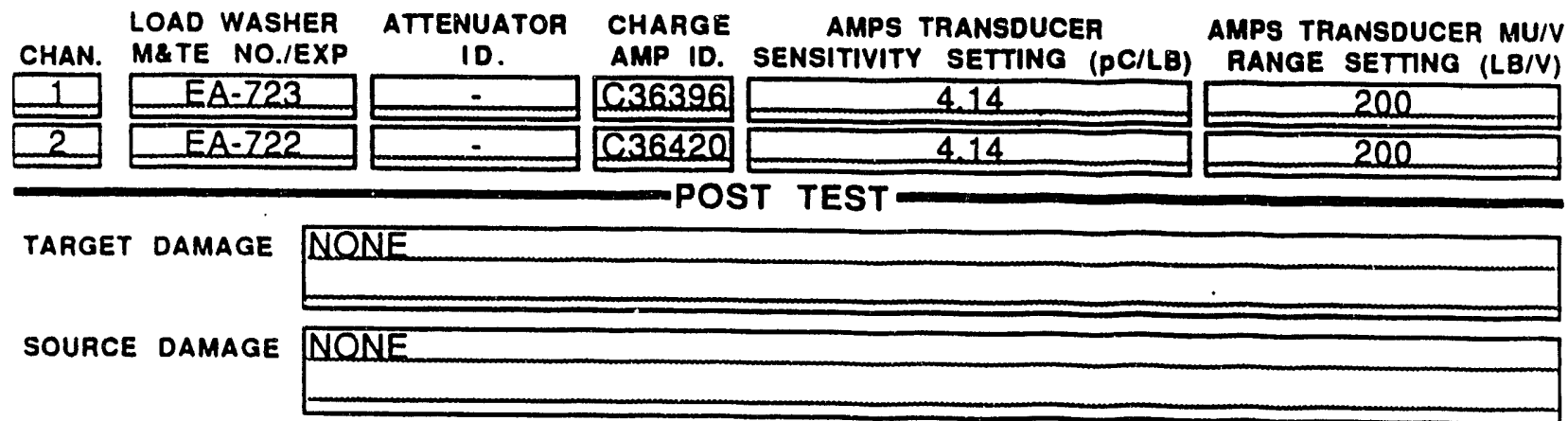

HAND HELD VIDEO START \& STOP POSITION NILA

HIGH SPEED VIDEO START \& STOP POSITION $27: 48-28: 11$

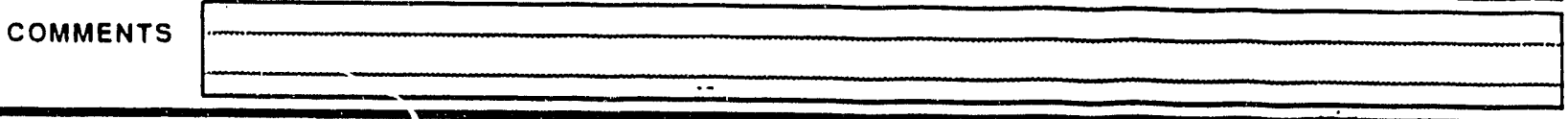

REVIEWED BYISIGNATURE M.T.FEBENCZIY Y I

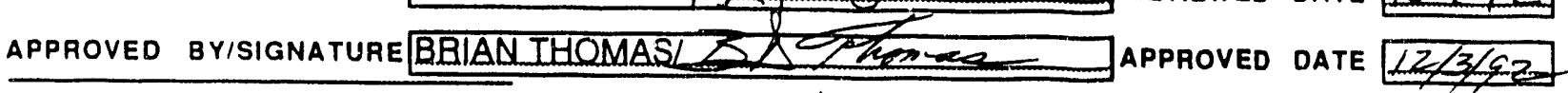

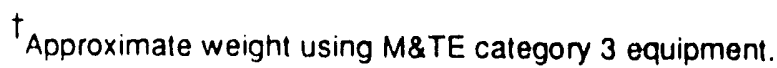


IVSRC-TR-93-0094

Attachment 10. Test Data Sheets ( 46 of 155)

Savannah River Technology Center Equipment Engineering

Seismic IVI Drop Test Program

Supported Beam Drop Tests

EES-FP-370, Rev. 1

Date Approved: 8/28/92, Category 2

Page 16 of 18

\subsection{ATTACHMENT 5 \\ IFST DATA STIEET}
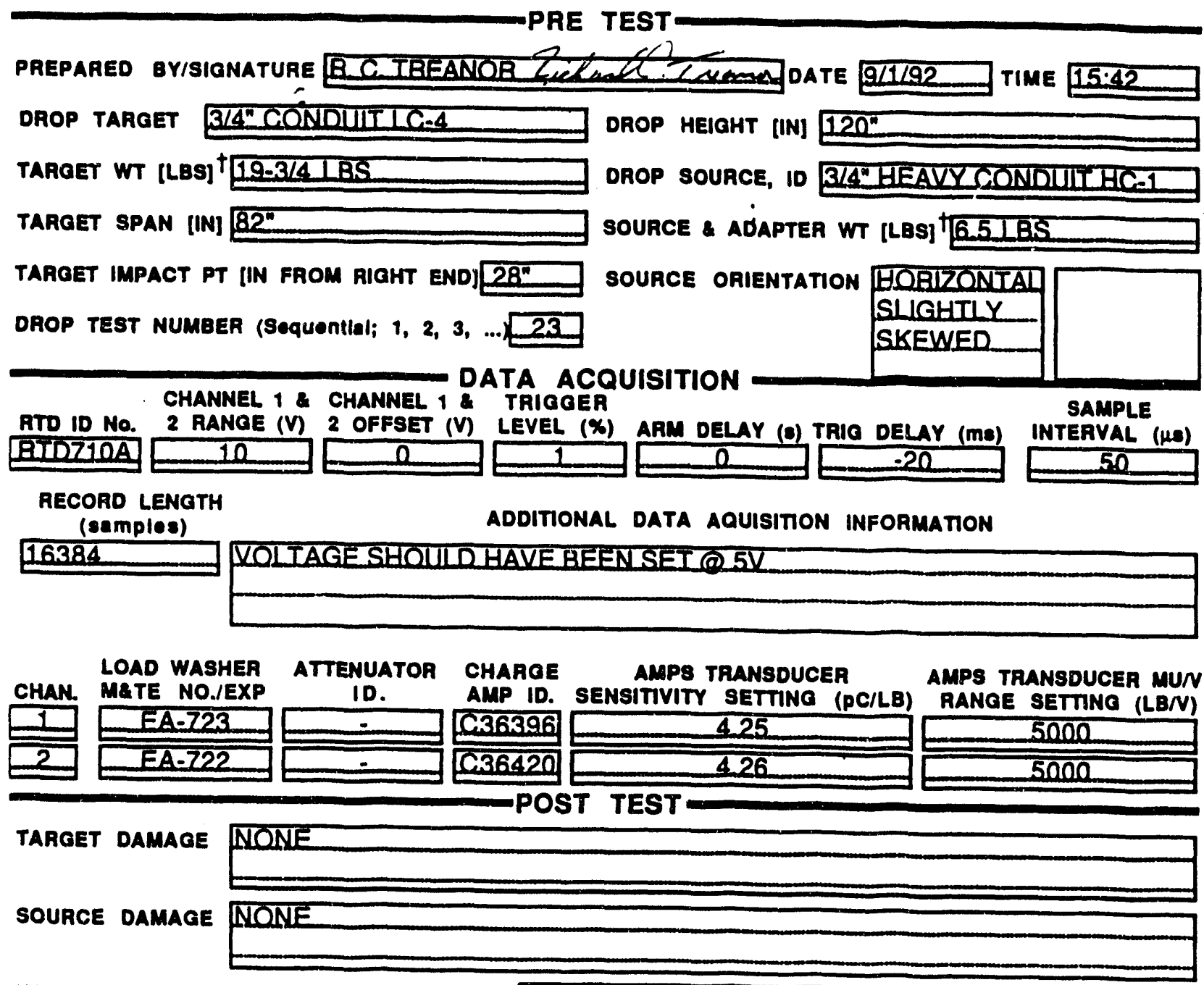

HAND HELD VIDEO START \& STOP POSITION NIA

HIGH SPEED VIDEO START \& STOP POSITION 28:11_ $28: 54$

COMMENTS

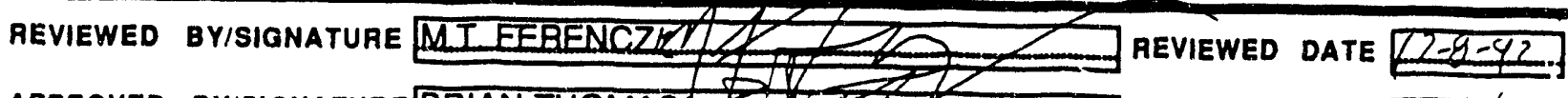
APPROVED BYISIGNATUAE BRIAN THOMAST

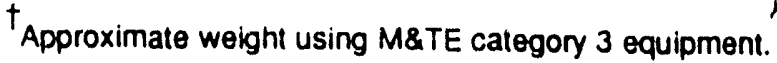


WSRC-TR-93-0094

Attachment 10. Test Data Sheets (47 of 155)

Savannah River Technology Center

EES-FP-370, Rev. 1

Equipment Engineering

Seismic IV/I Drop Test Program

Date Approved: $8 / 28 / 92$, Category 2

Supported Beam Drop Tests

\subsection{ATTACHMENT 5 IESI UAIA SHEEI}

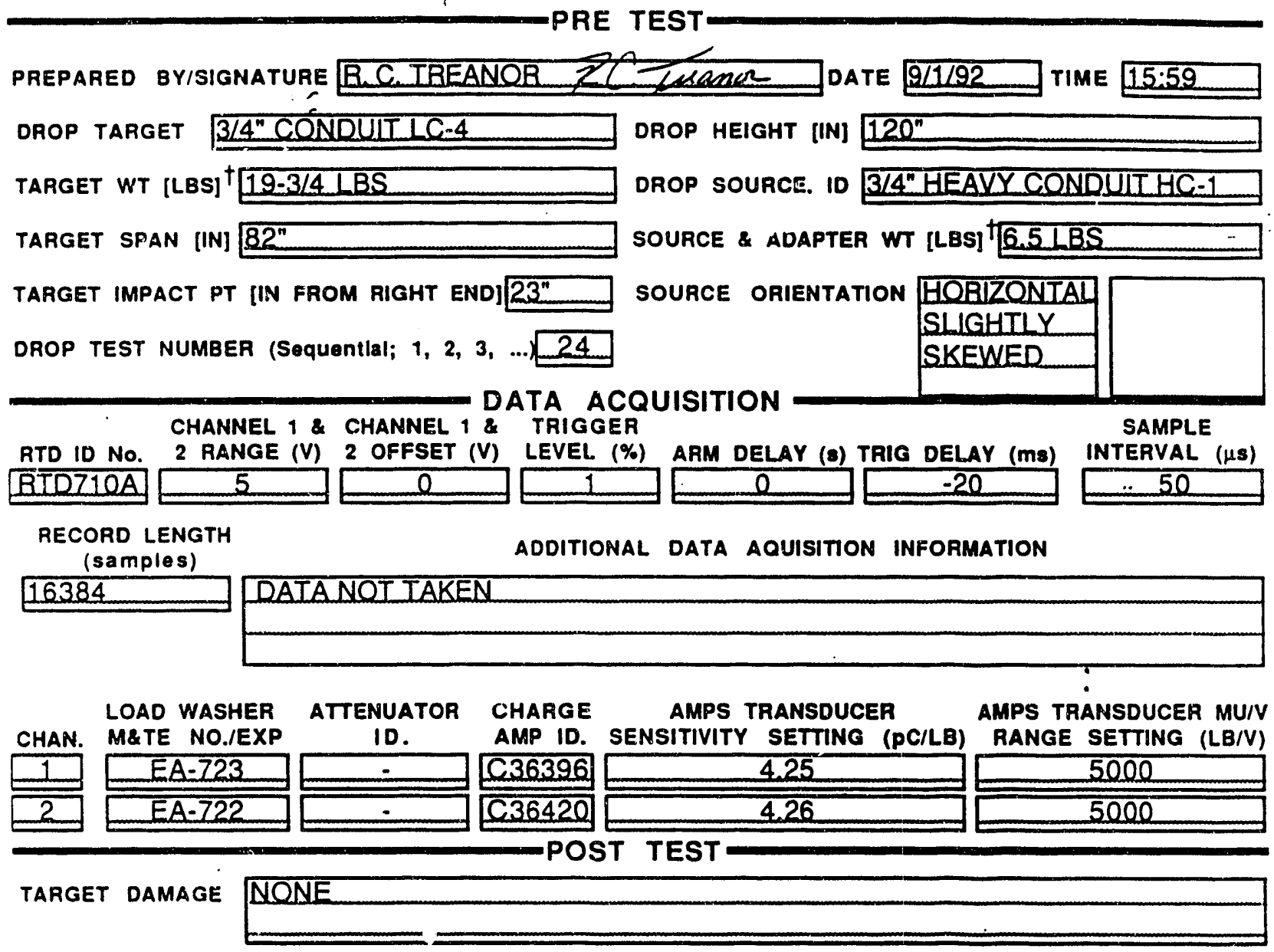

SOURCE DAMAGE NONE

HAND HELD VIDEO START \& STOP POSITION NIA

HIGH SPEED VIDEO START \& STOP POSITION 28:54-29:18

coMMENTS SOUBCE GRAZED THE TARGET NQTA SQLIDIMPACT

REVIEWED BYISIGNATURE MTEERENCZIM Y I L REVIEWED DATE $12-2-22$

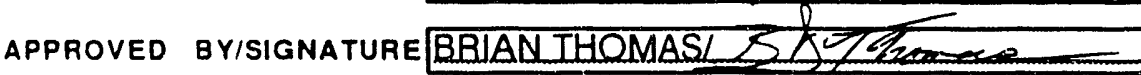
APPROVED DATE

${ }^{\dagger}$ Approximate weight using M\&TE category 3 equipment. 
WSRC-TR-93-0094

Attachment 10. Test Data Sheets (48 of 155)

Savannah River Technology Center

Equipment Engineering

Seismic II/I Drop Test Program

EES-FP-370, Rev. 1

Supported Beam Drop Tests

Date Approved: $8 / 28 / 92$, Category 2

Page 16 of 18

\subsection{ATTACHMENT 5 \\ TEST DATA SHEET}
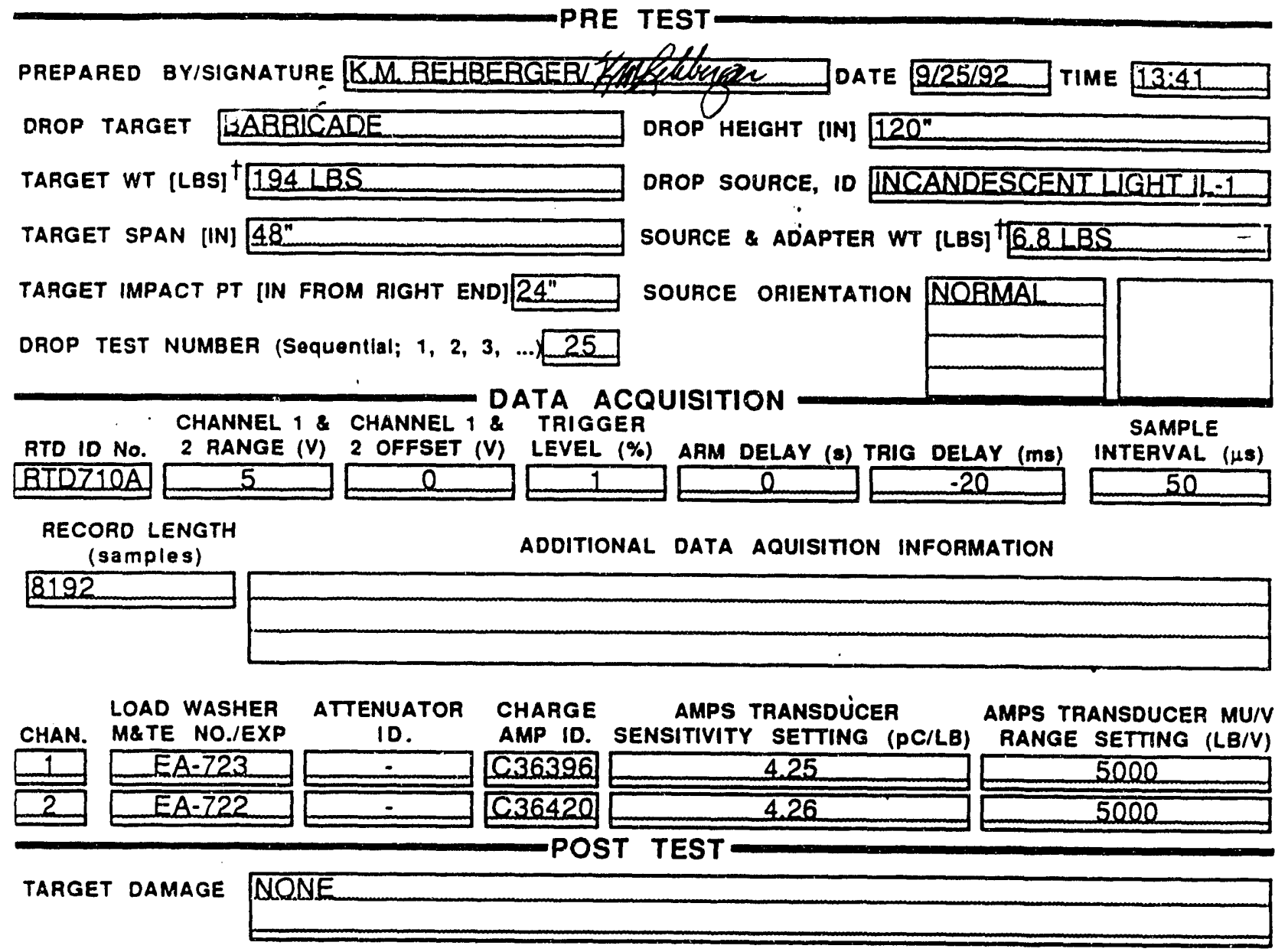

SOURCE DAMAGE SMALL SCRATCHES

HAND HELD VIDEO START \& STOP POSITION NLA

HIGH SPEED VIDEO START \& STOP POSITION $29: 18-29: 49$

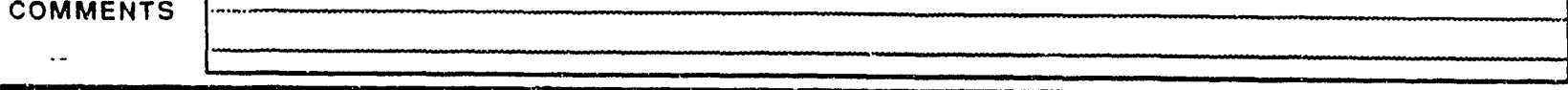

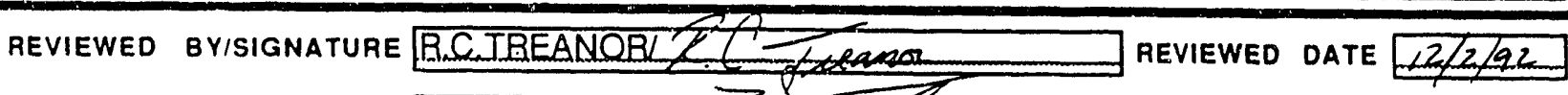
APPROVEO BYISIGNATURE BRIAN IHOMASI $\quad$ LAPROVED DATE $12 / 3 / 92$

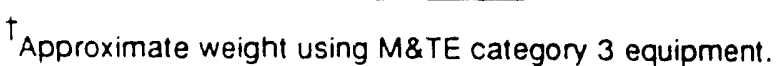


WSRC-TR-93-0094

Attachment 10. Test Data Sheets (49 of 155)

Savannah River Technology Center

Equipment Engineering

Seismic II/I Drop Test Program

EES-FP-370, Rev. 1

Supported Beam Drop Tests

\subsection{ATTACHMENT 5 IESI DATA SHEET}

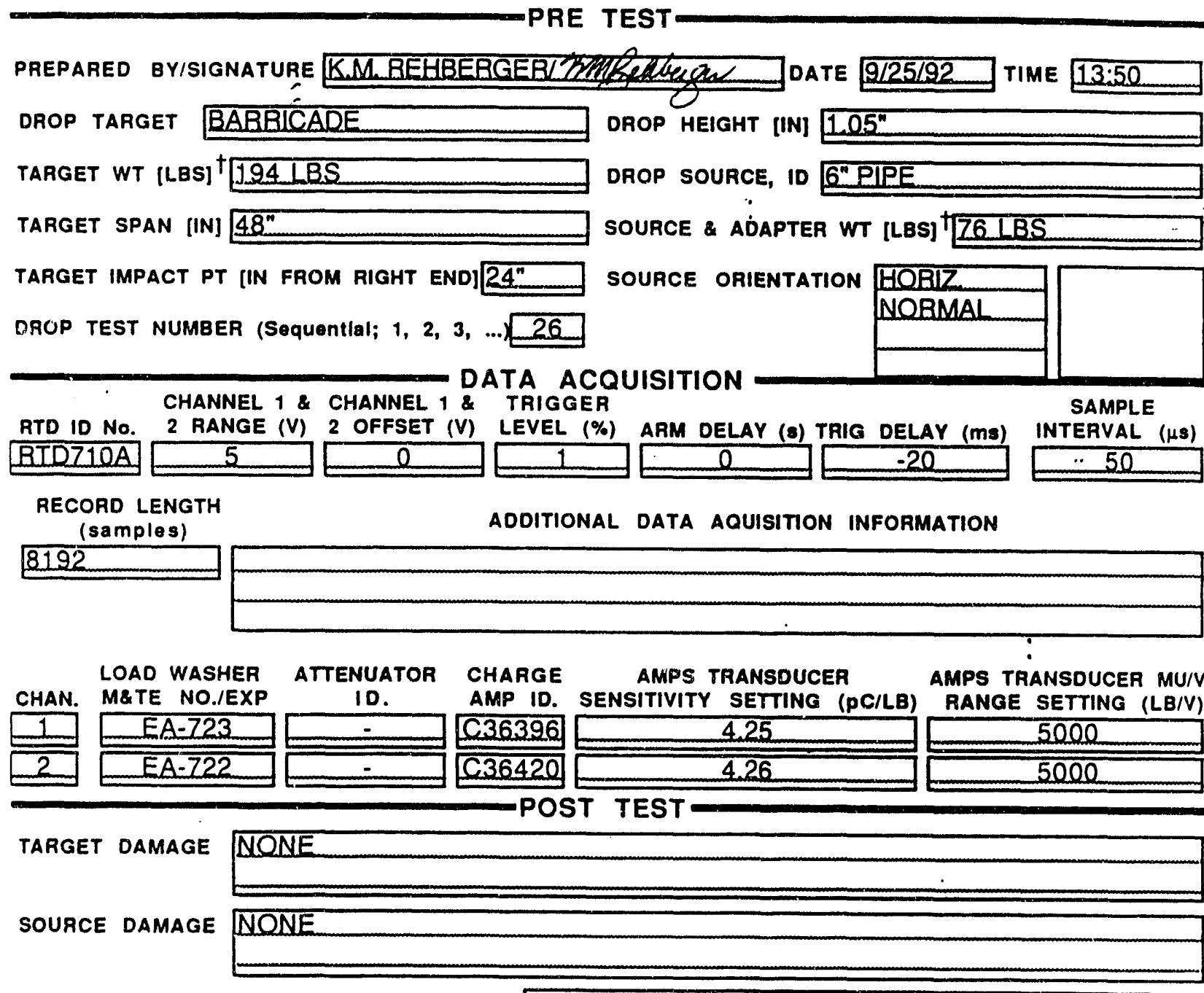

HAND HELD VIDEO START \& STOP POSITION NIA

HIGH SPEED VIDEO START \& STOP POSITION 29:49-29:59

COMMENTS

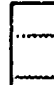

REVIEWED BYISIGNATURE B.C.TBEANQR/ REVIEWED DATE $/ 2 / 2 / 92$ APPROVED BYISIGNATURE BRIANIHOMASL AAPPROVED DATE $12 / 3 / 5$

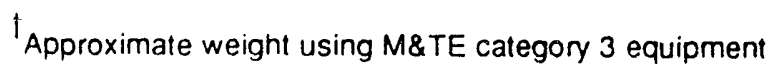


WSRC-TR-93-0094

Attachment 10. Test Data Sheets (50 of 155)

Savannah.River Technology Center

Equipment Engineering

EES-FP-370, Rev. 1

Seismic II/I Drop Test Program

Supported Beam Drop Tests

\subsection{ATTACHMENT 5 \\ TFST DATA SHEFT}

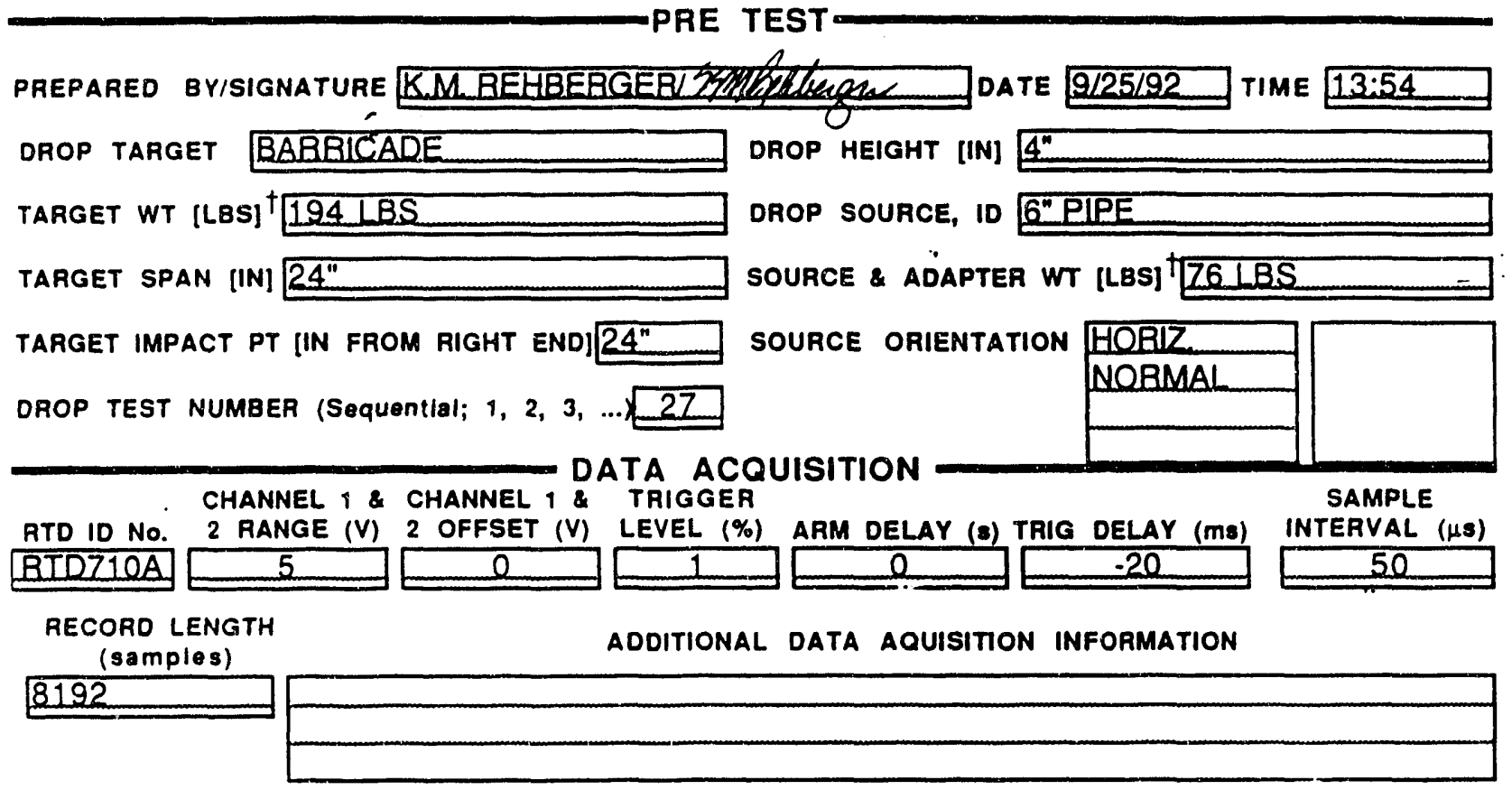

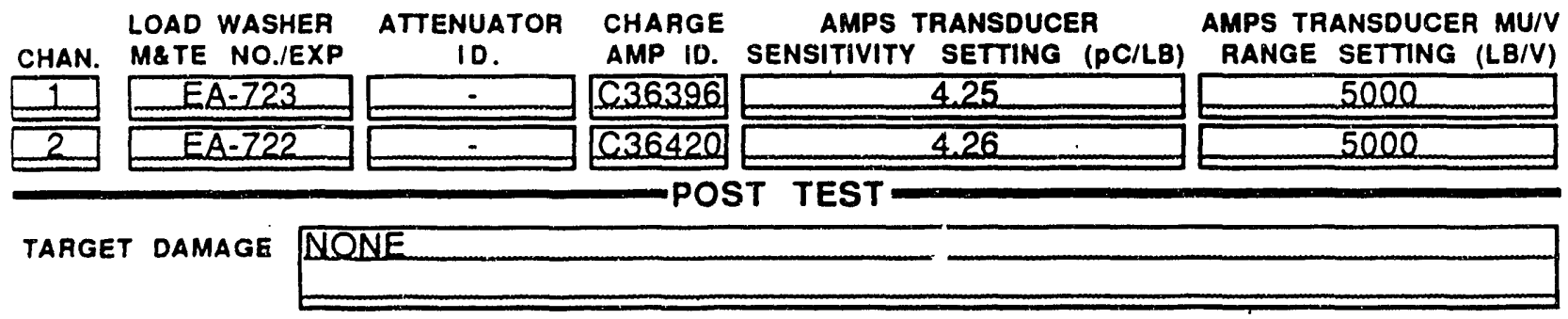

SOURCE DAMAGE NONE

HAND HELD VIDEO START \& STOP POSITION NILA

HIGH SPEED VIDEO START \& STOP POSITION $29: 5.9-30: 15$

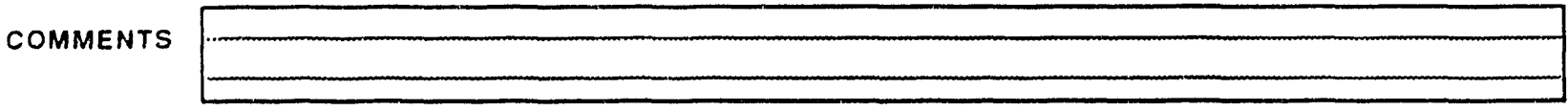

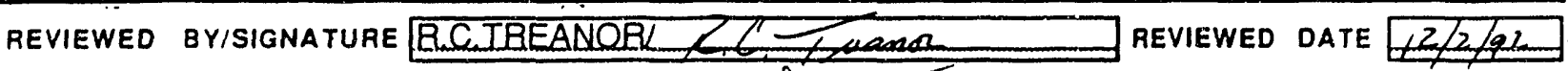

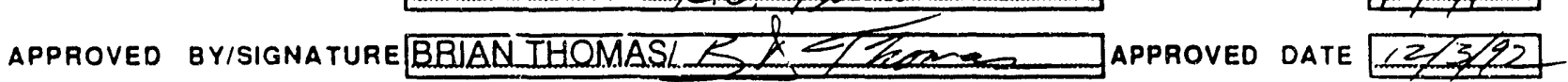

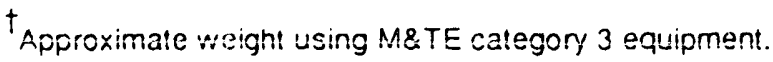


WSRC-TR-93-0094

Attachment 10. Test Data Sheets (5i of 155)

Savannah River Technology Center Equipment Engineering Seismic II/I Drop Test Program Supported Beam Drop Tests

EES-FP-370, Rev. 1 Date Approved: 8/28/92, Category 2

Page 16 of 18

\subsection{ATTACHMENT 5}

TEST UATA SHEET
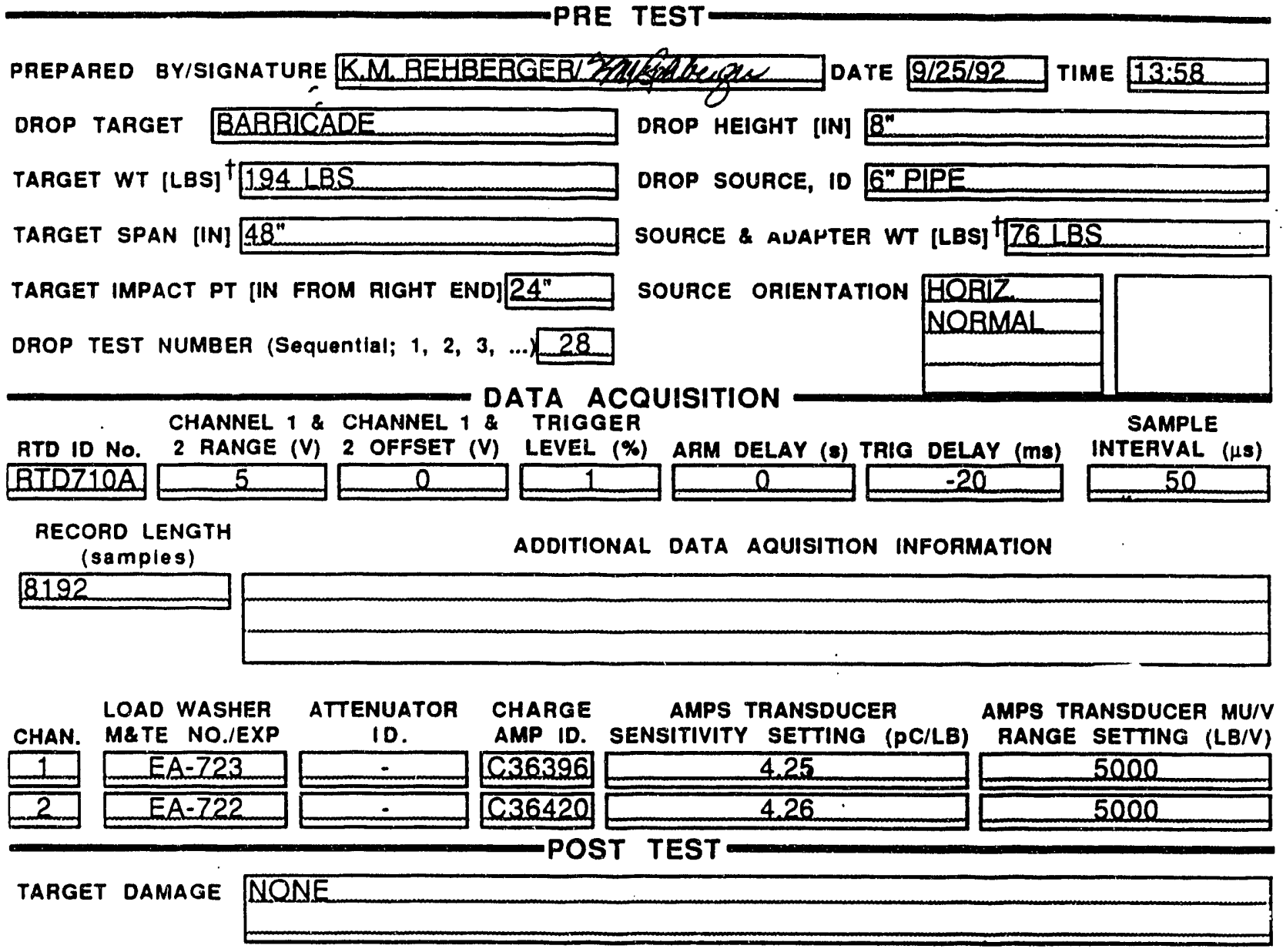

SOURCE DAMAGE NQNE

HAND HELD VIDEO START \& STOP POSITION NLA

HIGH SPEED VIDEO START \& STOP POSITION $30: 15=30: 54$

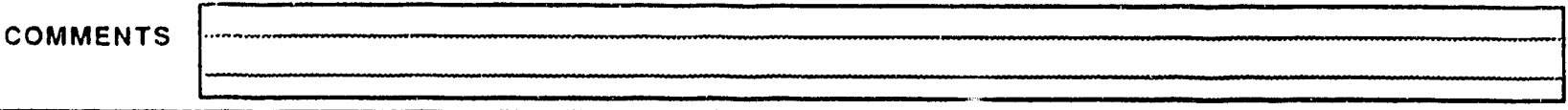

REVIEWED BYISIGNATURE B,C.TBEANOR/ 27 REVIEWED DATE $12 / 2 / 92$ APPROVED BYISIGNATURE BRIANTHQMASI S T TAPPROVED DATE

${ }^{\dagger}$ Approximate weight using M\&TE category 3 equipment. 
WSRC-TR-93-0094

Attuchment 10. Test Data Sheets (52 of 155)

Savannah River Technology Center

EES-FP-370, Rev. 1

Equipment Engineering

Seismic 11/I Drop Test Program

Date Approved: 8/28/92, Category 2

Supported Beam Drop Tests

\subsection{ATTACHMENT 5 TEET EATA EHEET \\ PRE TEST}

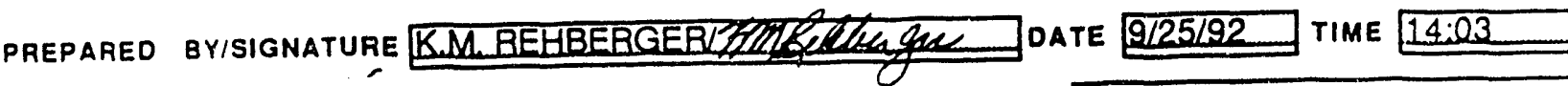
DROP TARGET BABRICADE DROP HEIGHT [IN] $12^{N}$ TARGET WT [LBS] 194 LBS DROP SOURCE, 10 6" $6^{\prime \prime}$ IPE

TARGET SPAN [IN] $48^{n}$

TARGET IMPACT PT IIN FROM RIGHT END) $24^{\prime \prime}$

DROP TEST NUMBER (Sequential; 1, 2, 3,...29

DATA ACQUISITION

SAMPLE

CHANNEL 1 \& CHANNEL 1 \& TRIGGER

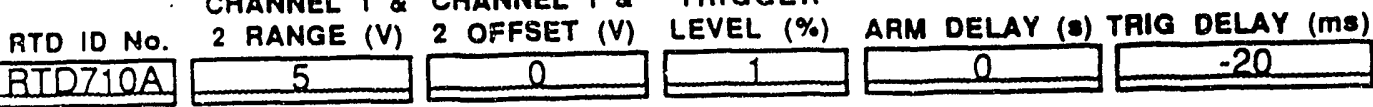

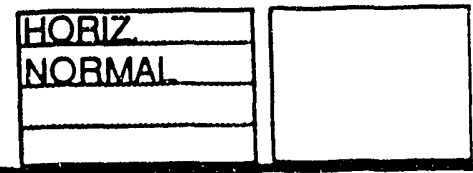

INTERVAL ( $\mu s)$

\footnotetext{
RECORD LENGTH

ADDITIONAL DATA AQUISITION INFORMATION
}

(samples)

OVEBLOAD CH 1: CBACKED HOLDDOWN WELD: SINCE LOAD CELLS OVERLOADED DID NOT IAKE DATA DID SEVERAL DROPS AT $10^{\circ}$

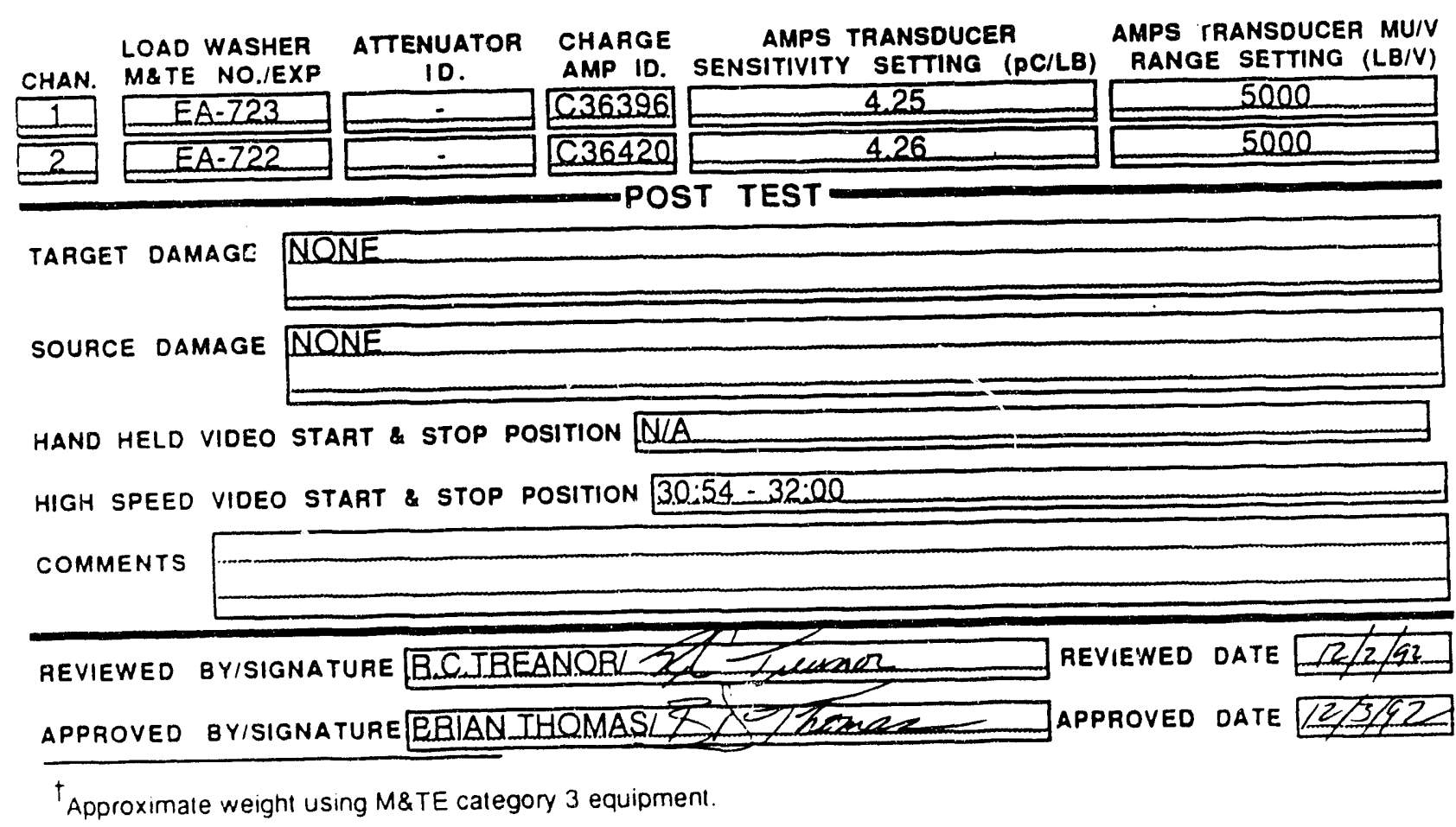


WSRC-TR-93-0094

Attachment 10. Test Data Sheets (53 of 155)

Savannah River Technology Center

Equipment Engineering

EES-FP-370, Rev. 1

Seismic II// Drop Test Program

Date Approved: $8 / 28 / 92$, Category 2

Supported Beam Drop Tests

Page 16 of 18

\subsection{ATTACHMENT 5}

TEST DATA SHEET

-PRE TEST
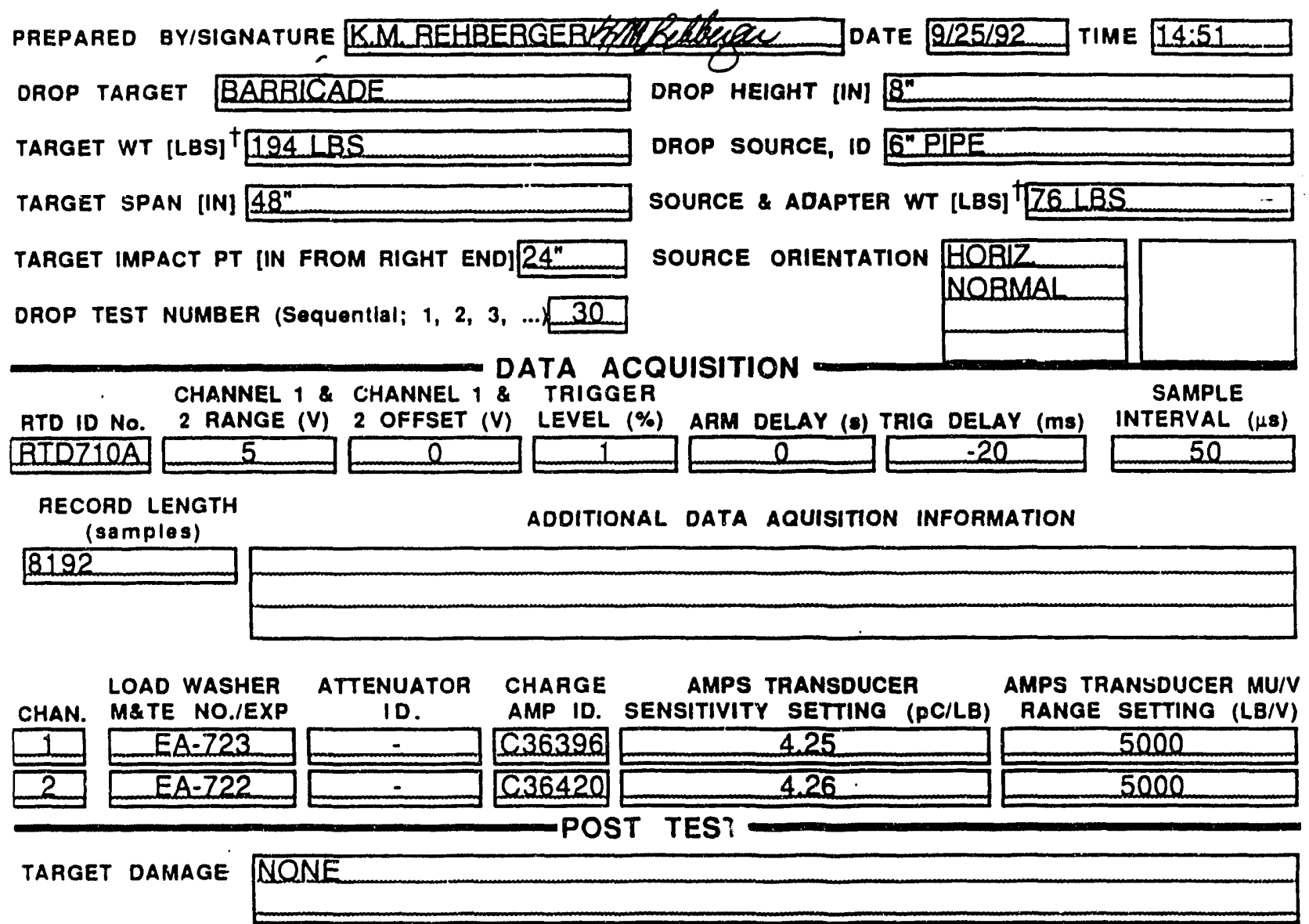

SOURCE DAMAGE NONE

HANO HELD VIDEO START \& STOP POSITION NLA

HIGH SPEED VIDEO START \& STOP POSITION $32: 20-33: 26$

COMMENTS

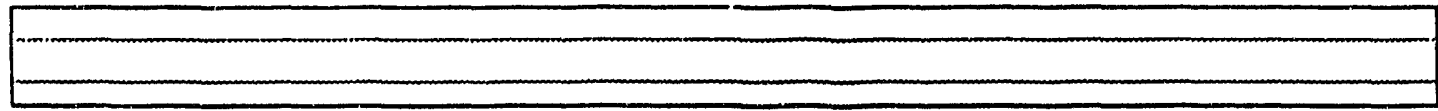

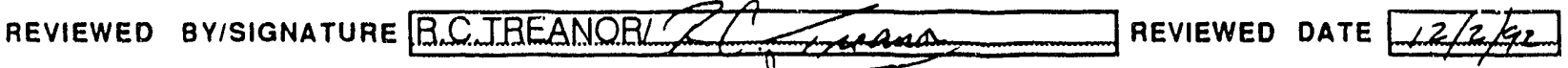

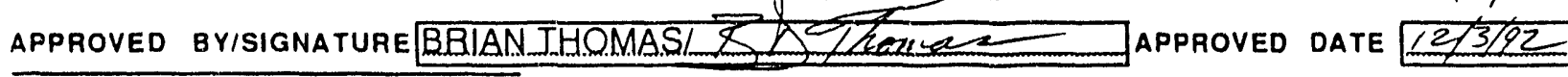

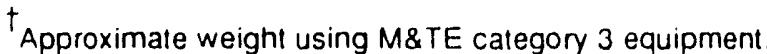


WSRC-TR-93-0094

Attachment 10. Test Data Sheets (54 of 155)

Savannah River Technology Center

EES-FP-370, Rev. 1

Equipment Engineering

Seismic II/I Drop Test Program

Date Approved: $8 / 28 / 92$, Category 2

Supported Beam Drop Tests

Page 16 of 18

\subsection{ATTACHMENT 5 \\ IESI UALA SHEEI}

PRE TEST

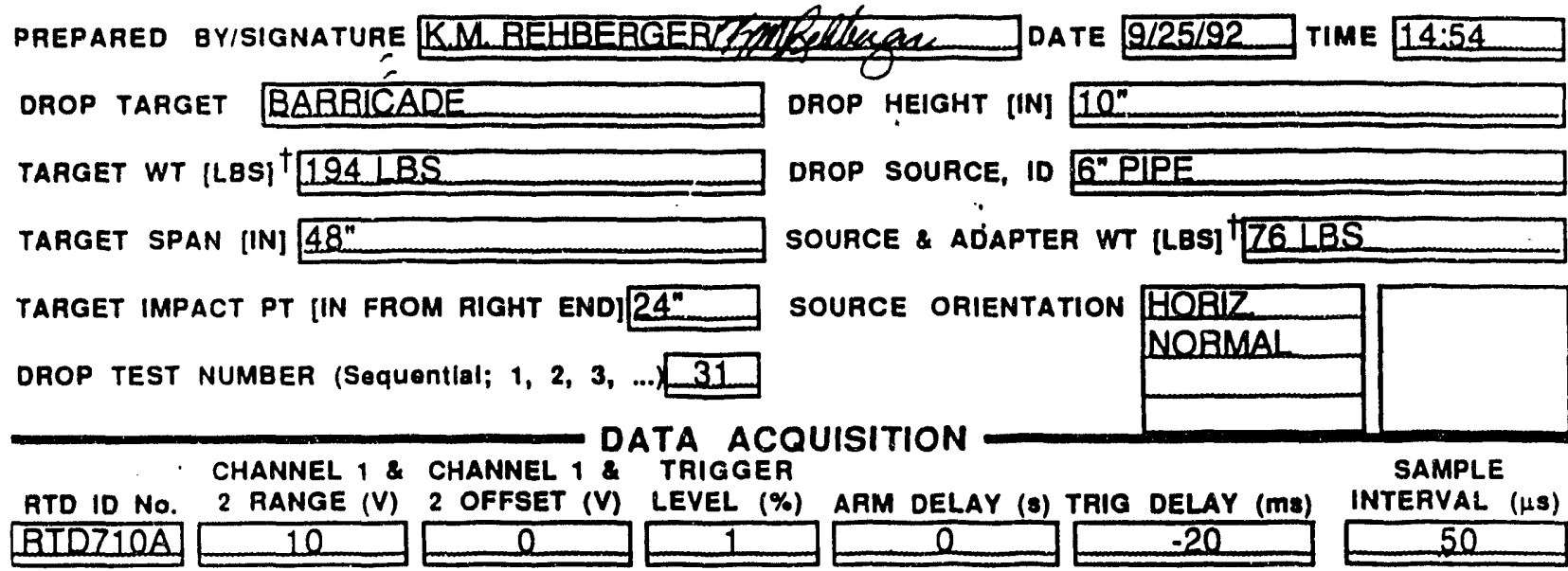

RECORD LENGTH

(samples)

8192
ADOITIONAL DATA AQUISITION INFORMATION

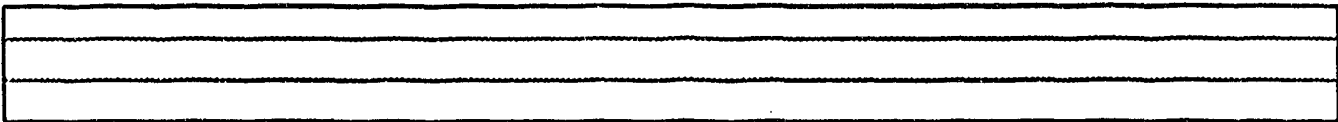

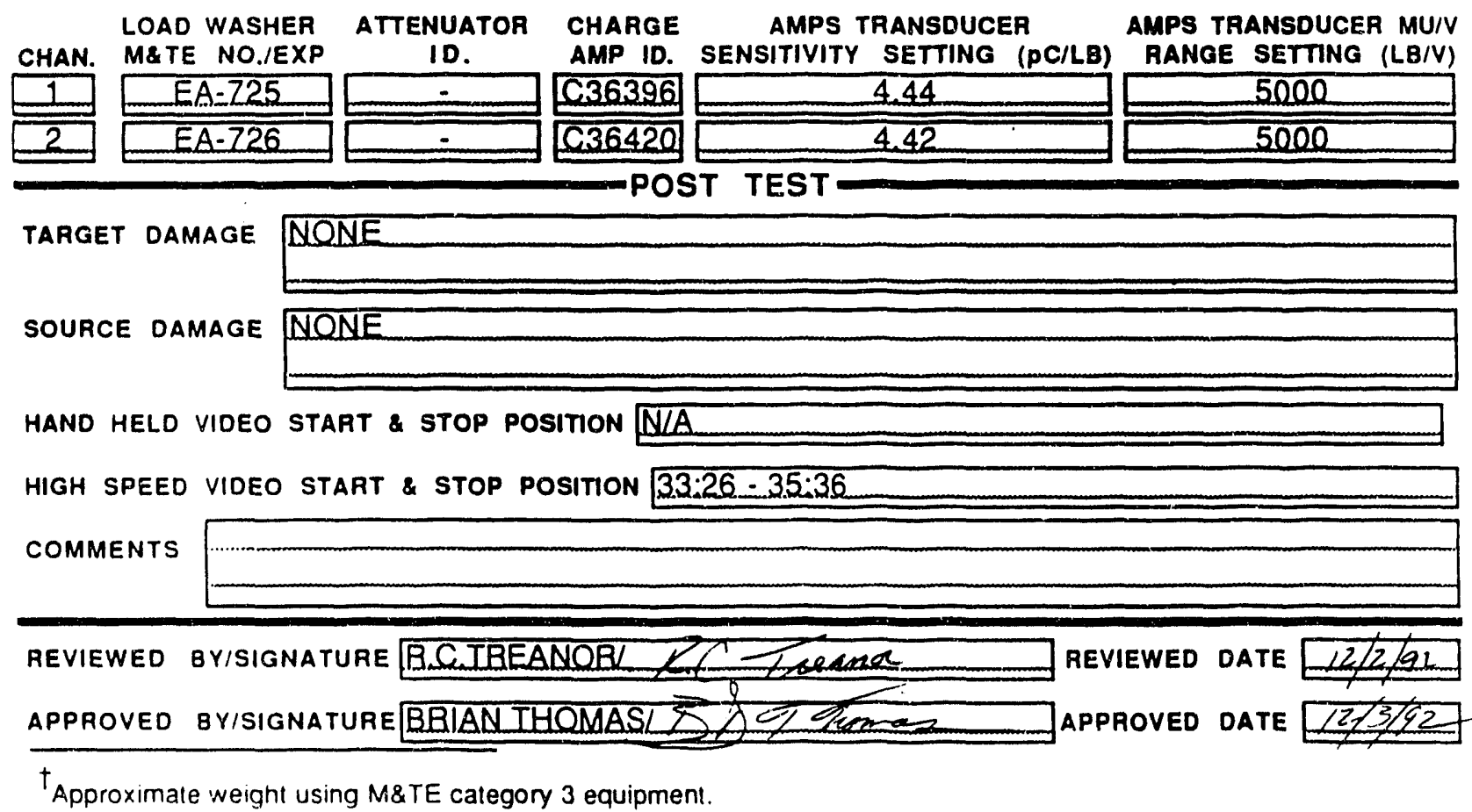


WSRC-TR-93-0094

Attachment 10. Test Data Sheets (55 of 155)

Savannah River Technology Center

Equipment Engineering

EES-FP-370, Rev. 1

Seismic II// Drop Test Program

Supported Beam Drop Tests

Date Approved: $8 / 28 / 92$, Category 2

Page 16 of 18

\subsection{ATTACHMENT 5}

IESI UATA STHEET

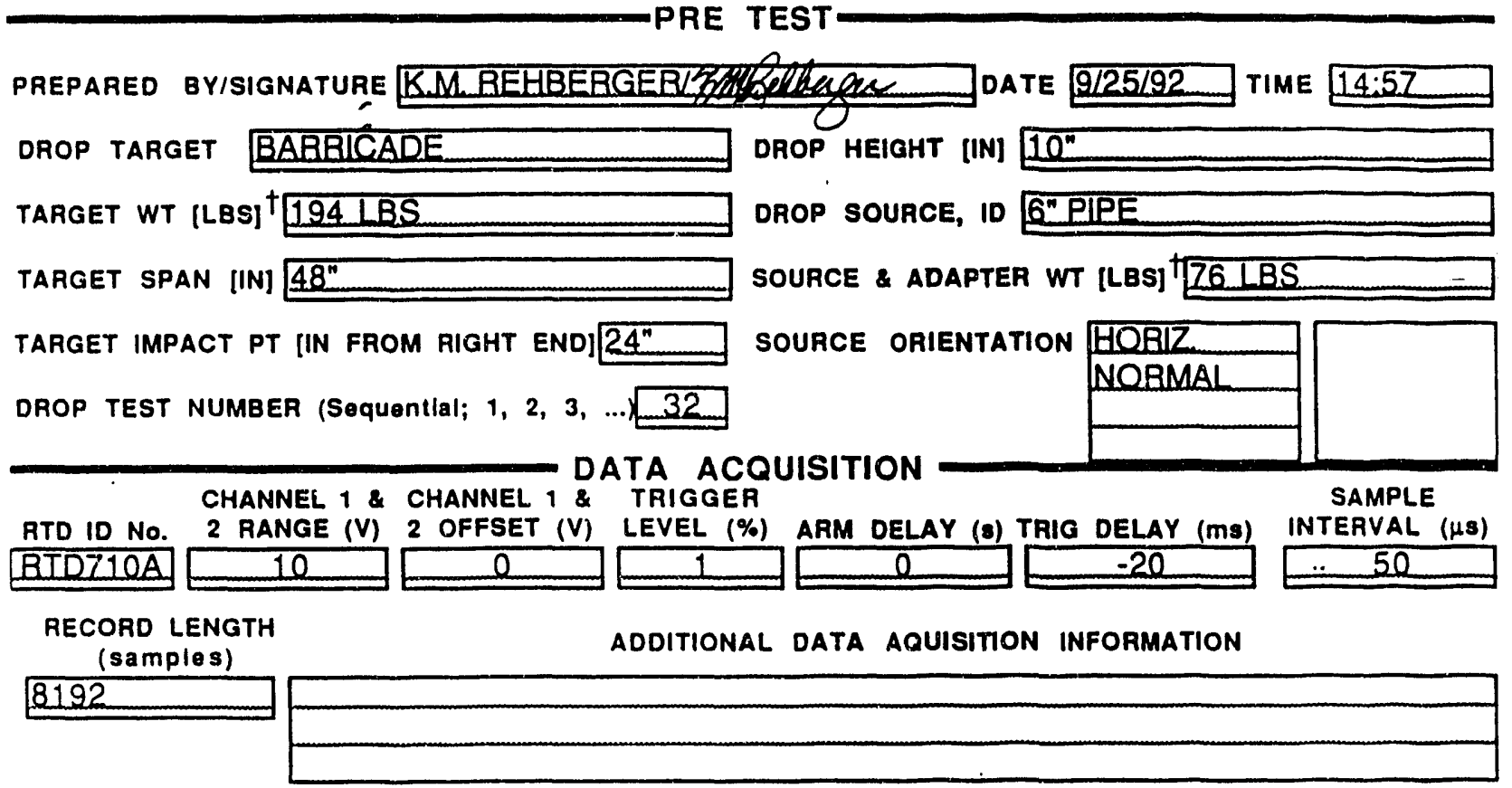

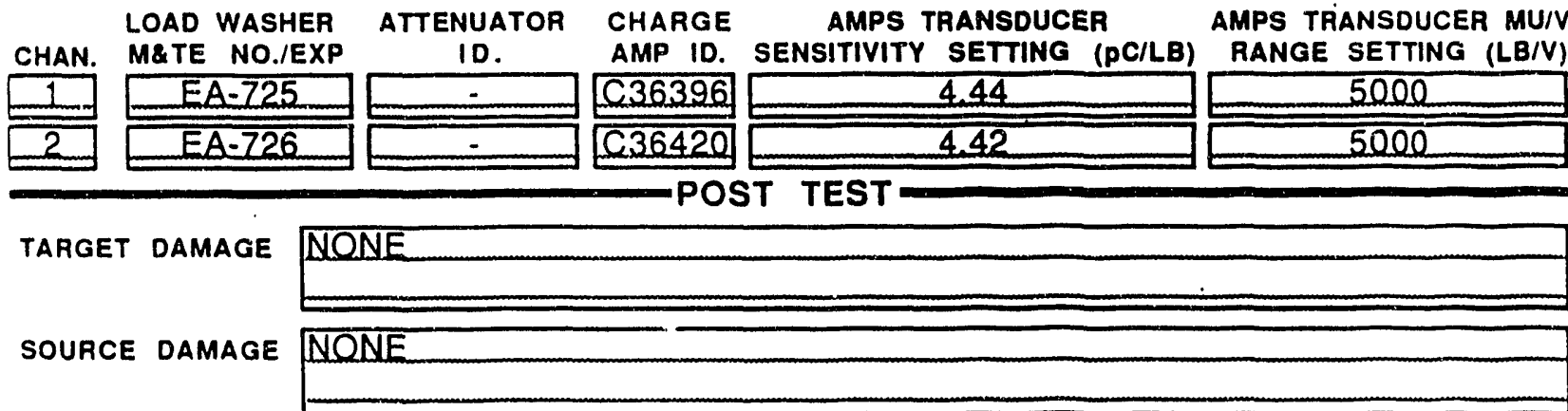

HAND HELD VIDEO START \& STOP POSITION DLA

HIGH SPEED VIDEO START \& STOP POSITION NQHIGHSPEEDVIDEQ TAKEN

COMMENTS

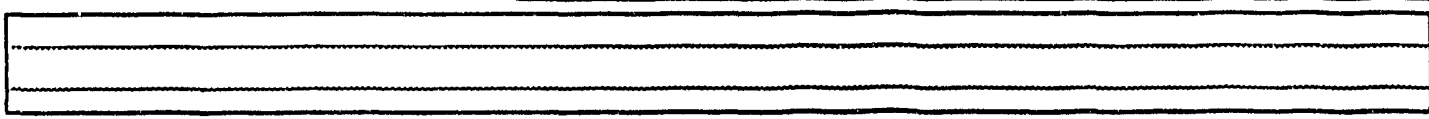

REVIEWEd By/SIGNature B.GTREANQR

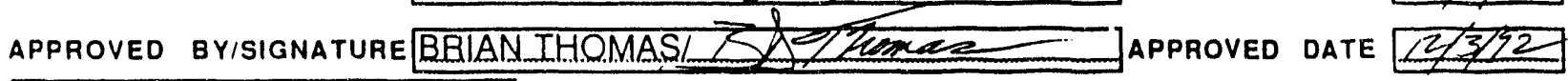

${ }^{\dagger}$ Approximale weight using M\&TE category 3 equipment. 
IVSRC.TR-93.0094

Attachment 10. Test Data Sheets (56 of 155)

Savannah River Technology Center Equipment Engineering Seismic IV/I Drop Test Program Supported Beam Drop Tests

EES-FP-370, Rev. 1
Date Approved: $8 / 28 / 92$, Category 2

Page 16 of 18

\subsection{ATTACHMENT 5 \\ TEST DATA SHEET}



HAND HELD VIDEO START \& STOP POSITION NLA

HIGH SPEED VIDEO START STOP POSITION $35: 36=36: 19$

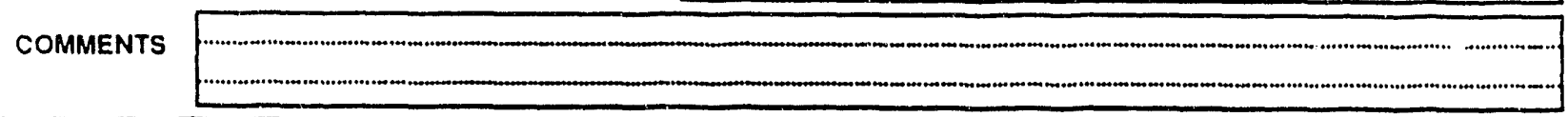

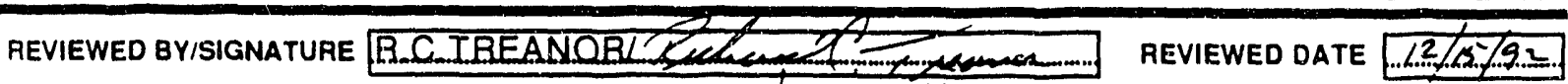

APPROVED BYISIGNATURE BRIAN THOMASI. B.

TApproximate weight using M\&TE category 3 equipment. 
WSRC-TR-93-0094

Attachment 10. Test Data Slueets (57 of' 155)

Savannah River Technology Center Equipment Engineering Seismic II/I Drop Test Program Supported Beam Drop Tests

EES-FP-370, Rev. 1 Date Approved: 8/28/92, Category 2 Page 16 of 18

\subsection{ATTACHMENT 5 IEST DATA BHIEET \\ PRE TEST}

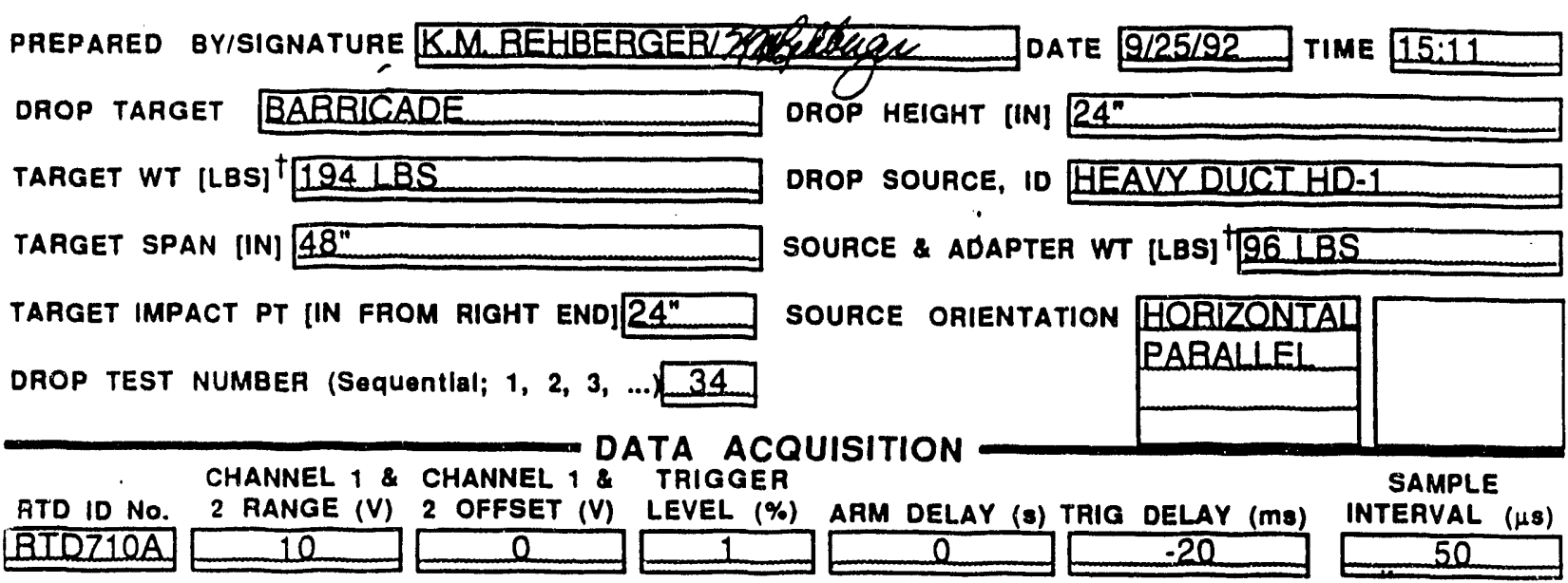

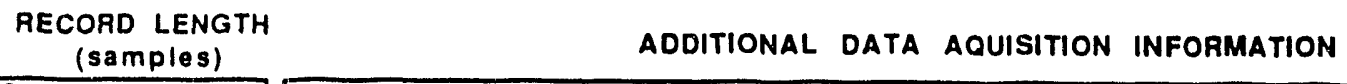


IVSRC-TR-93-0094

Attachment 10. Test Data Sheets (58 of 155)

Savannah River Technology Center Equipment Engineering Seismic II/I Drop Test Program Supported Beam Drop Tests

EES-FP-370, Rev. 1 Date Approved: $8 / 28 / 92$, Category 2 Page 16 of 18

\subsection{ATTACHMENT 5 \\ IEST DATA GHIEET}

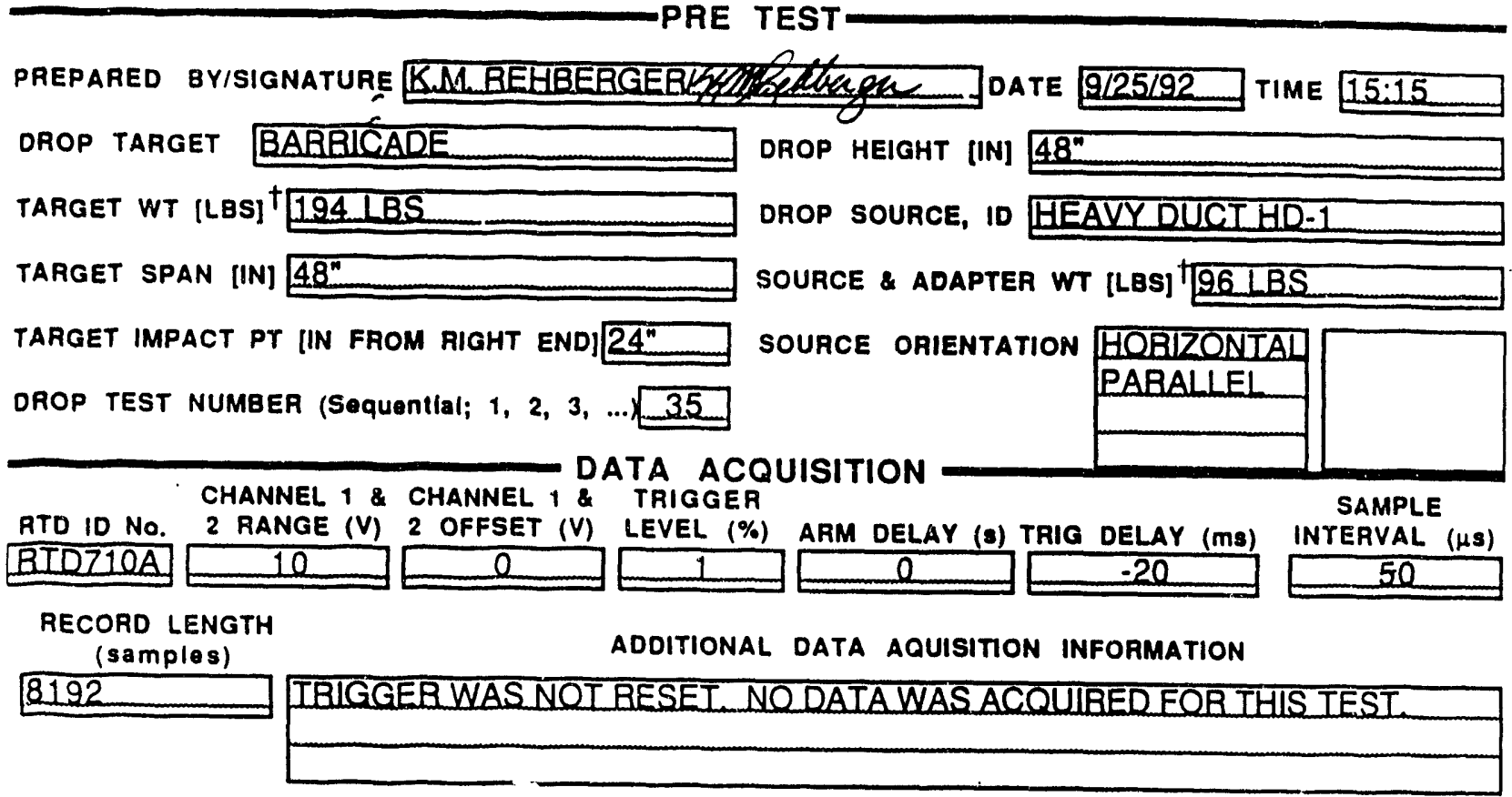

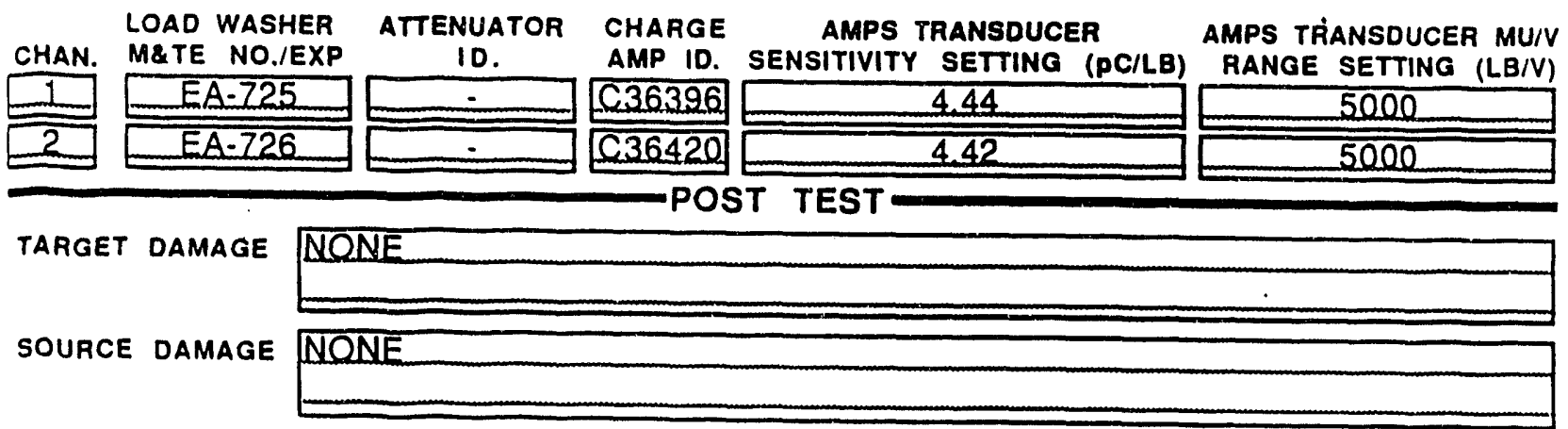

HAND HELD VIDEO START \& STOP POSITION N/A.

HIGH SPEED VIDEO START \& STOP POSITION $3: 2: 15-38: 00$

COMMENTS NQDATA FORTHISDRQP

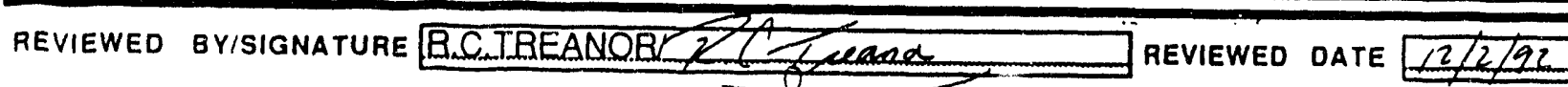
APPROVED BYISIGNATURE BBIANIHOMAS/

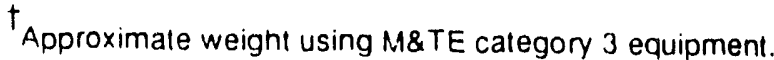


WSRC-TR-93-0094

Attachment 10. Test Data Sheets (59 of 155)

Savannah River Technology Center

Equipment Engineering

EES-FP-370, Rev. 1

Seismic II/I Drop Test Program

Supported Beam Drop Tests

\subsection{ATTACHMENT 5 \\ IEST UATA STIEET \\ PRE TEST}

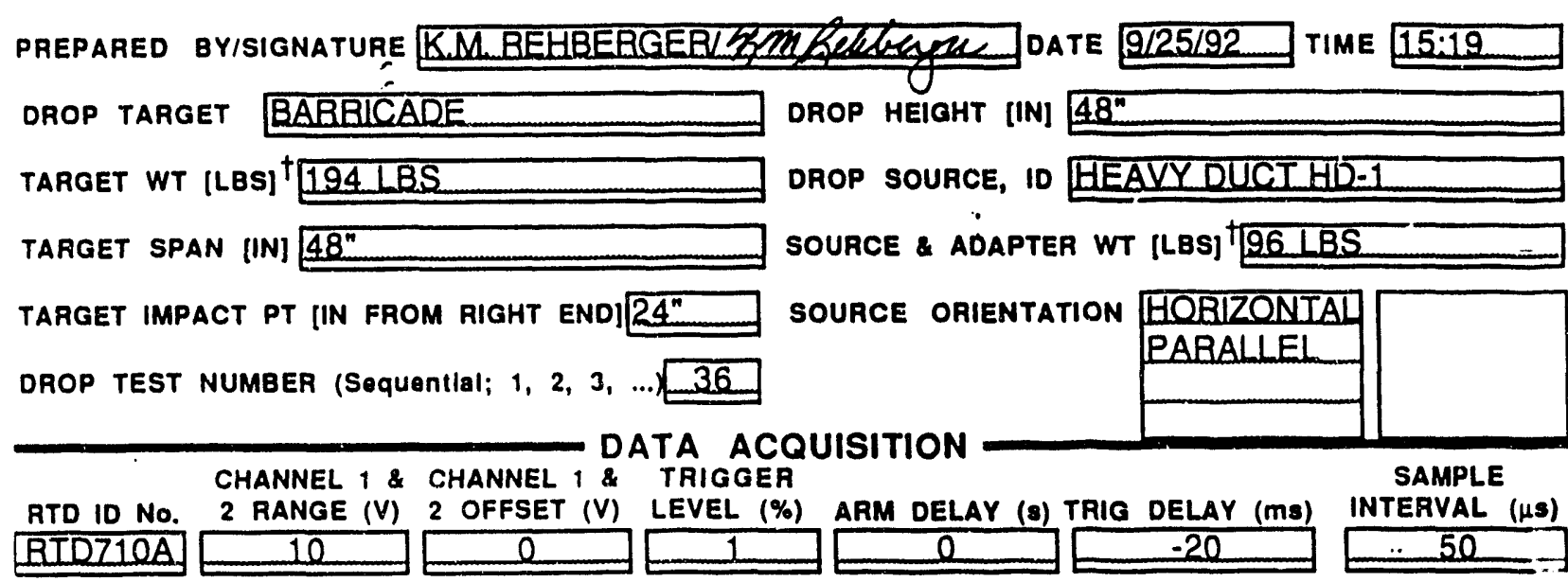

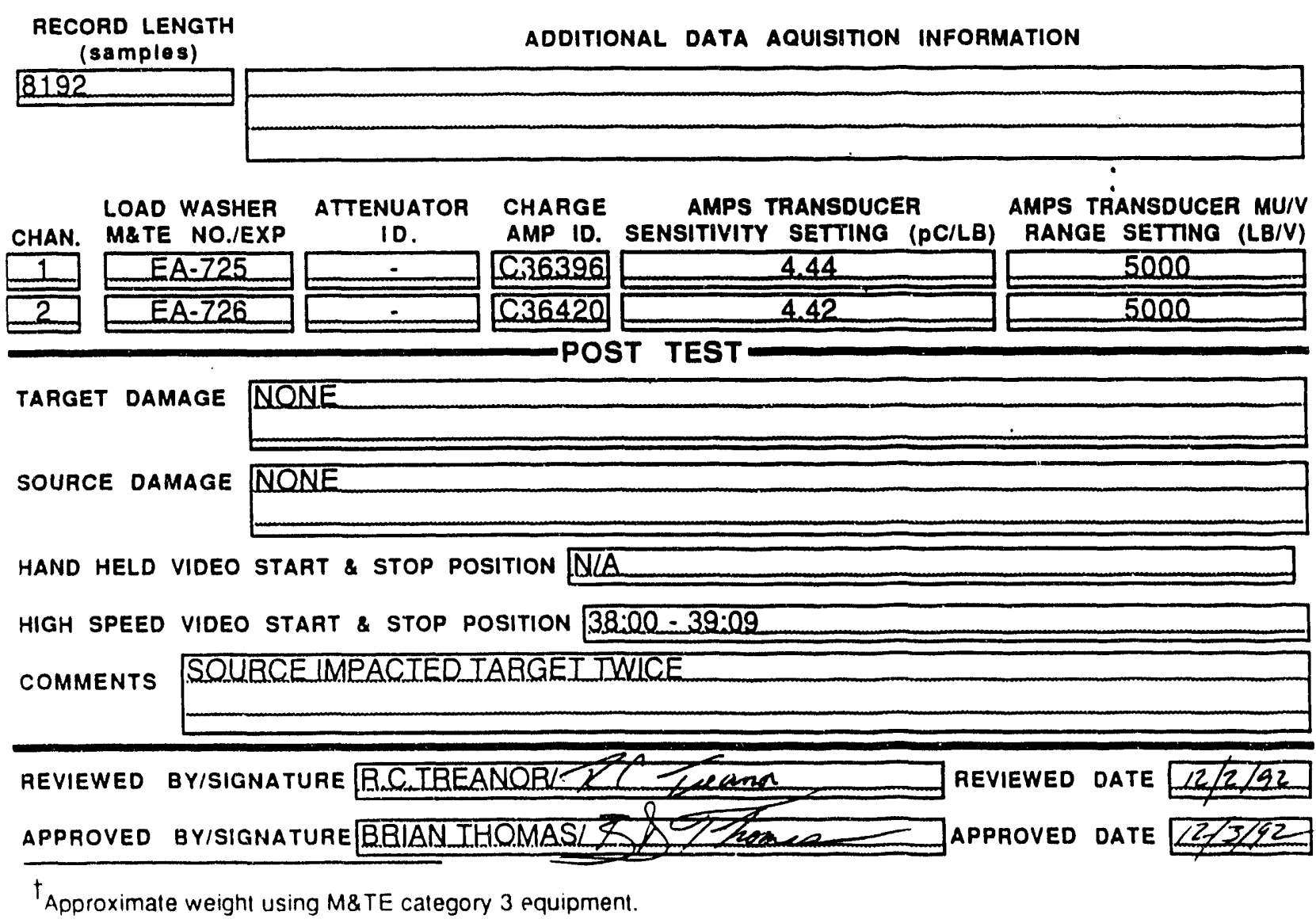


IVSRC-TR-93-0094

Attachment 10. Test Data Shects (60 of 155)

Savannah River Technology Center

EES-FP-370, Rev. 1

Equipment Engineering

Date Approved: $8 / 28 / 92$, Category 2

Seismic II/I Drop Test Program

Page 16 of 18

Supported Beam Drop Tests

\subsection{ATTACHMENT 5}

IEST DATA SHEET

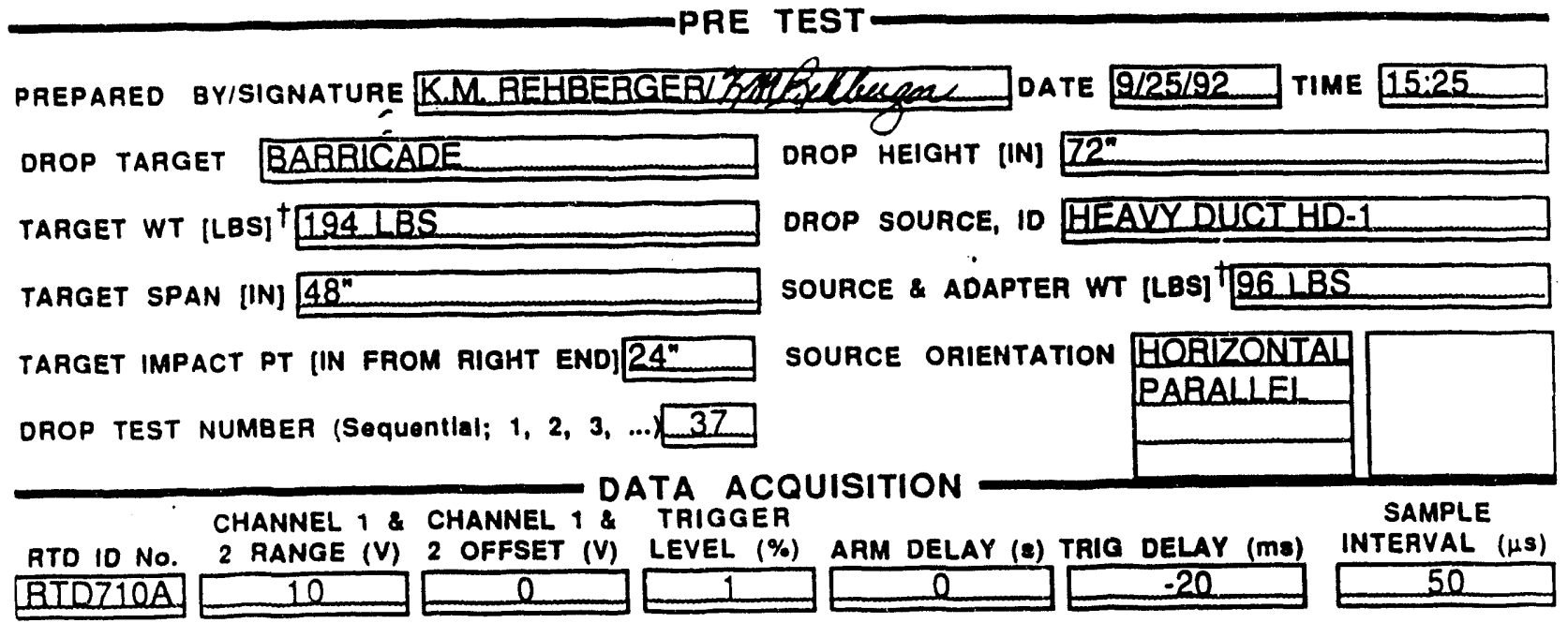

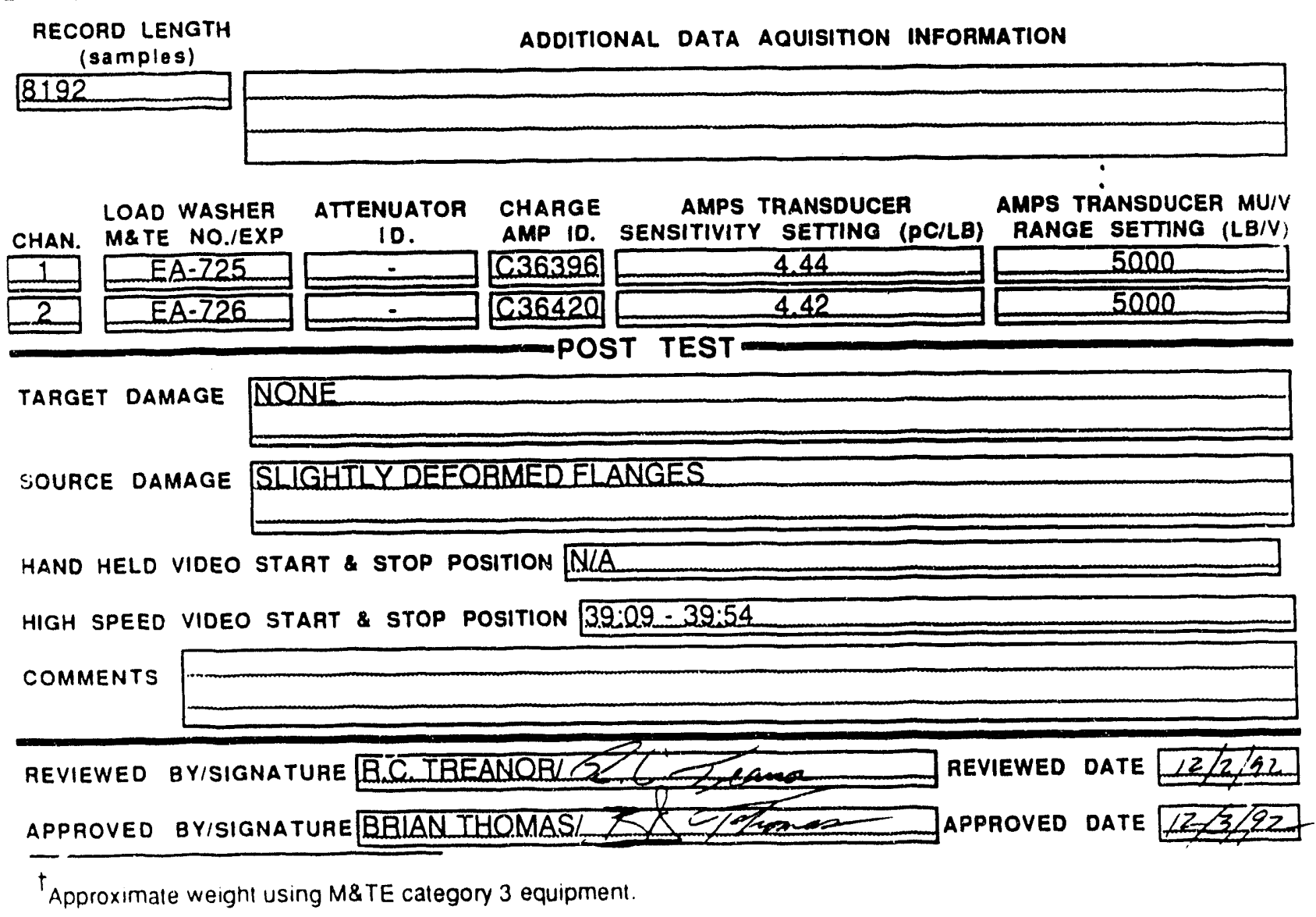


WSRC-TR-93-0094

Attachment 10. Test Data Sheets (61 of 155)

Savannah River Technology Center

Equipment Engineering

EES-FP-370, Rev. 1

Seismic II/I Drop Test Program

Supported Beam Drop Tests

Date Approved: $8 / 28 / 92$, Category 2

Page 16 of 18

\subsection{ATTACHMENT 5 \\ IEST EATA SHIEET}

PRE TEST

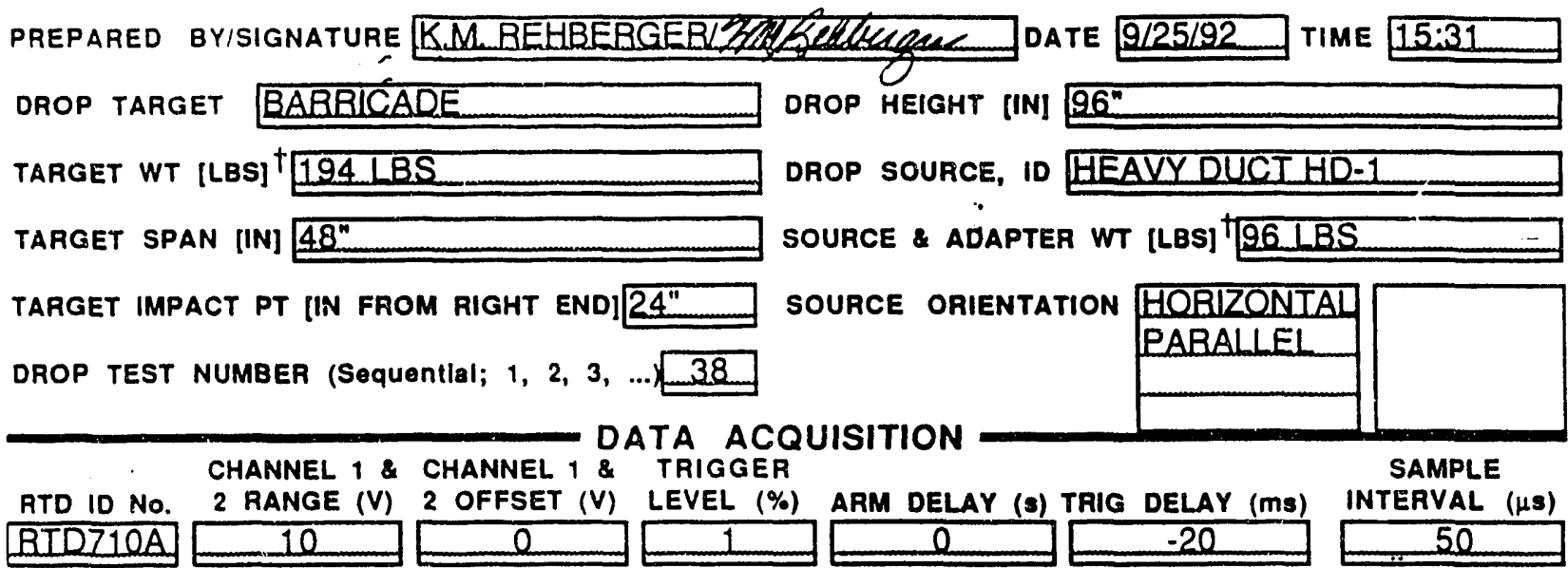

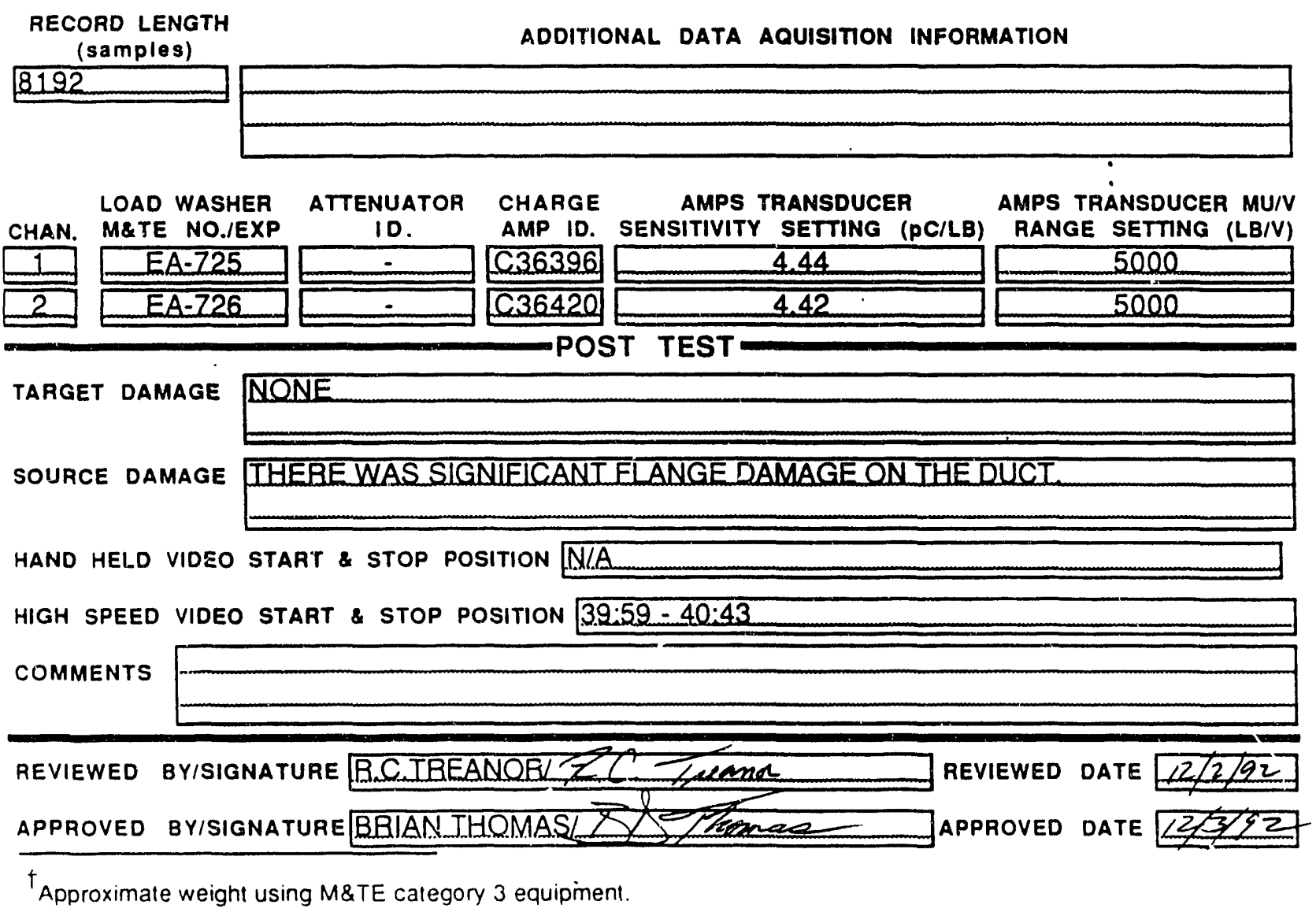


WSRC.TR-93-0094

Attachment 10. Test Data Sheets (62 of 155)

Savannah River Technology Center Equipment Engineering

Seismic II/I Drop Test Program Supported Beam Drop Tests
EES-FP-370, Rev. 1

Date Approved: 8/28/92, Category 2

Page 16 of 18

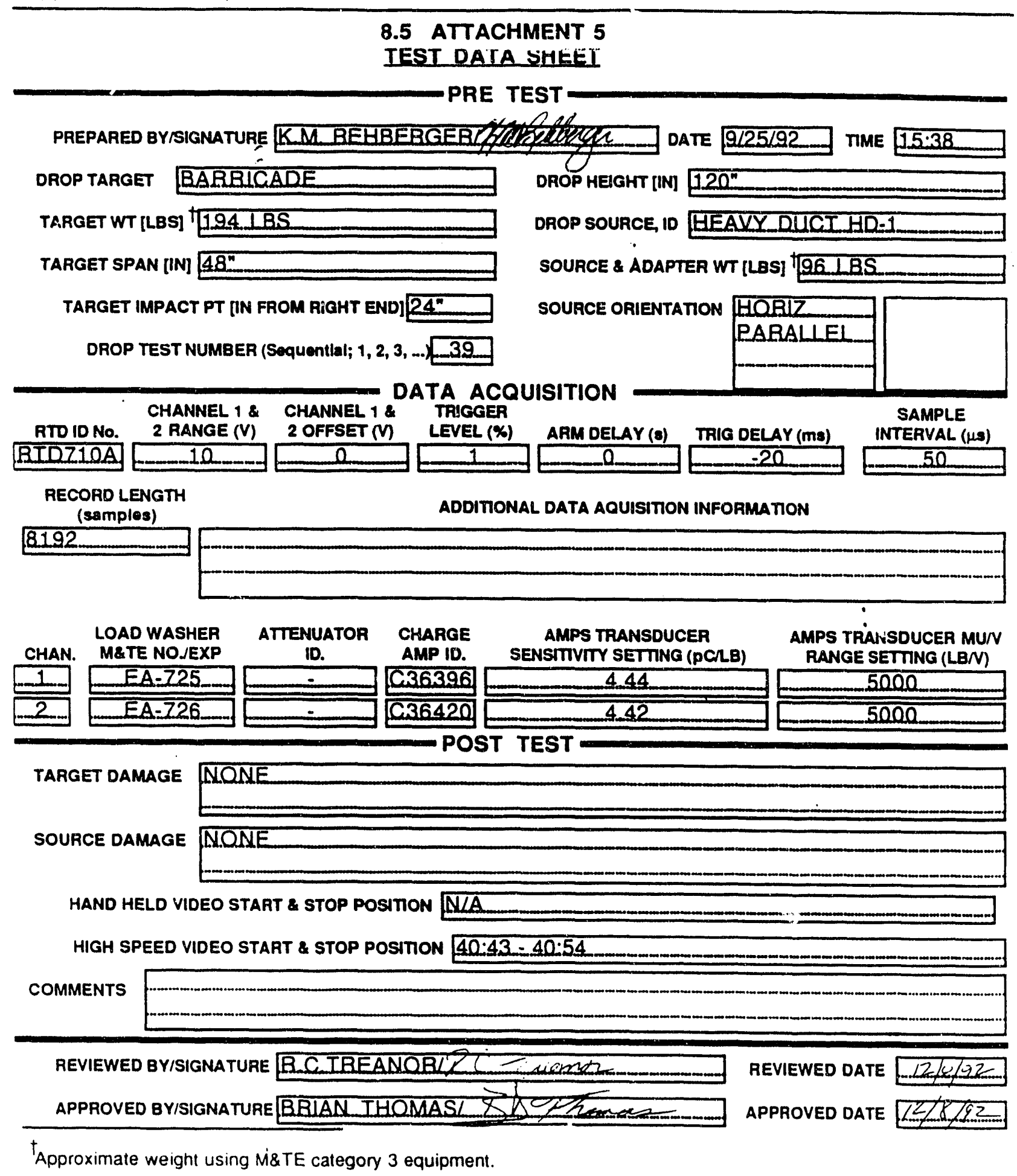

8.5 ATTACHMENT 5

PRE TEST

PREPARED BYISIGNATURE KM BEHBEBGEB DATE $9225 / 92$ TME $1.5: 38$

DROP TARGET BARBICAADE

TARGET WT [LBS] T.94 IBS

10 HEAVY_DUCIHD=1

TARGET SPAN [IN] 48

SOURCE \& ADAPTER WT [LBS] 96 LBS

TARGET IMPACT PT [IN FROM RIGHT END] 24"

DROP TEST NUMBER (Sequentlal; 1, 2, 3, ... 39

DATA ACQUISITION

SAMPLE

TARGET DAMAGE NQNE

NONE

HAND HELD VIDEO START \& STOP POSITION NIA 
WSRC-TR-93-0094

Attachment 10. Test Data Sheets (63 of 155)

Savannah River Technology Center

Equipment Engineering

Seismic II/I Drop Test Program

EES-FP-370, Rev. 1

Supported Beam Drop Tests

Date Approved: $8 / 28 / 92$, Category 2

Page 16 of 18

\subsection{ATTACHMENT 5}

IESI UAIA SHEET

PRE TEST
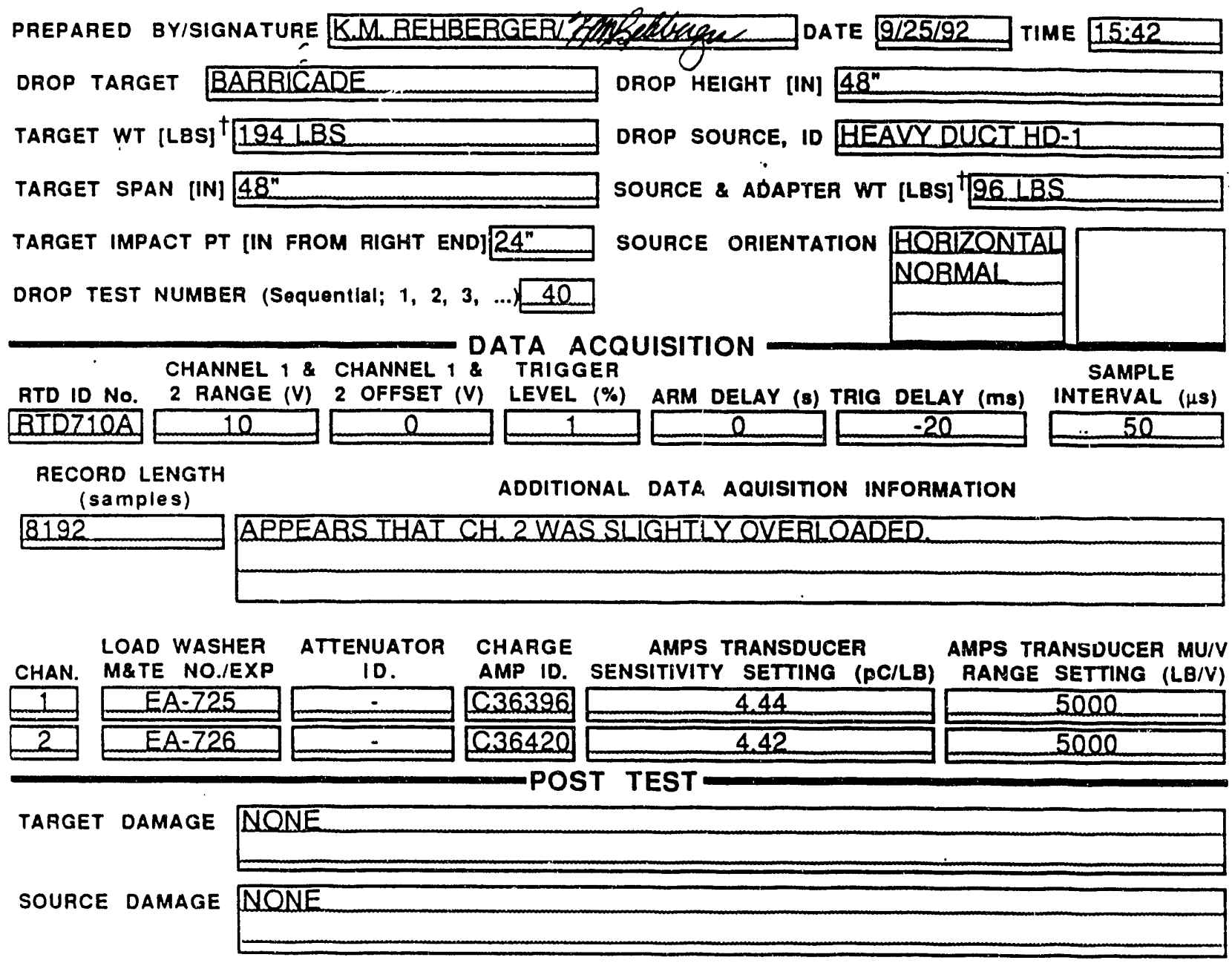

HAND HELD VIDEO START \& STOP POSITION N/A

HIGH SPEED VIDEO START \& STOP POSITION $40: 54-41: 50$

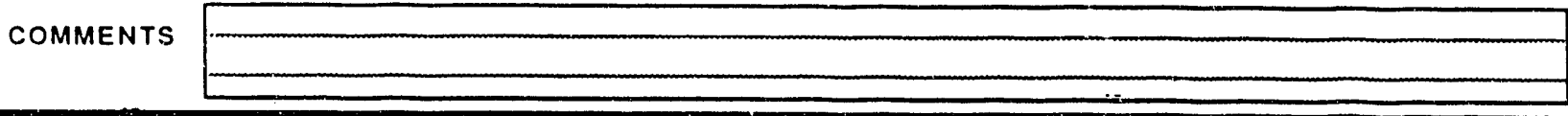

REVIEWED BY/SIGNATURE B.C.TREANORI

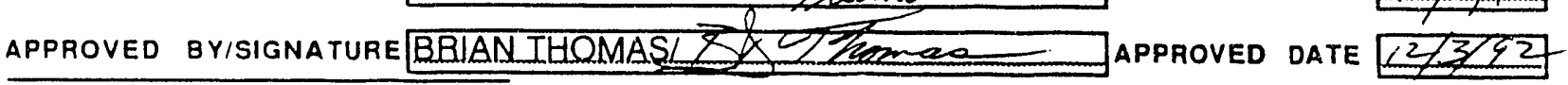

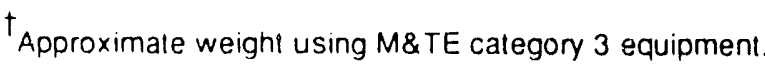


IVSRC-TR-93-0094

Attachment 10. Test Data Sheets (64 of 155)

Savannah River Technology Center

Equipment Engineering

Seismic II/I Drop Test Program

Supported Beam Drop Tests

EES-FP-370, Rev. 1

Date Approved: $8 / 28 / 92$, Category 2

Page 16 of 18

\subsection{ATTACHMENT 5}

IEST UATA STIEET

PRE TEST

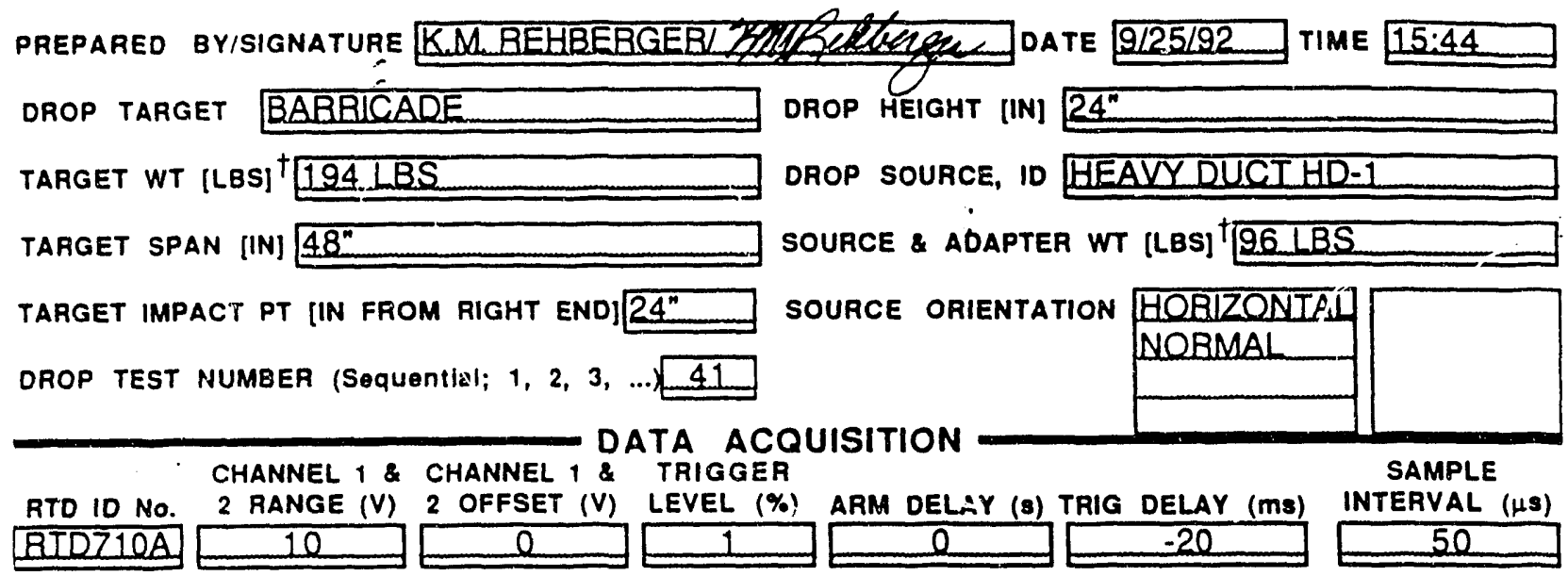

RECORD LENGTH

(samples)

8192
ADDITIONAL DATA AQUISITION INFORMATION

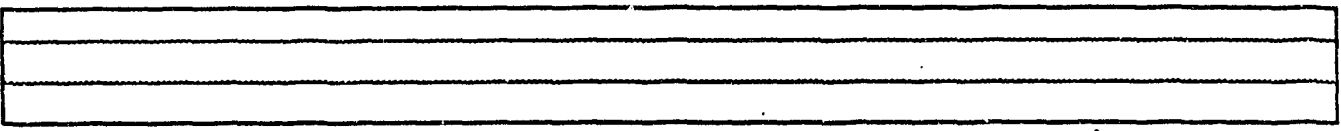

$\begin{array}{lcccc}\text { LOAD WASHER ATTENUATOR CHARGE } & \text { AMPS TRANSDUCER } & \text { AMPS TRANSDUCER MU/V } \\ \text { METE NO./EXP } & \text { ID. } & \text { AMP ID. SENSITIVITY SETTING (PC/LB) RANGE SETTING (LB/V) }\end{array}$

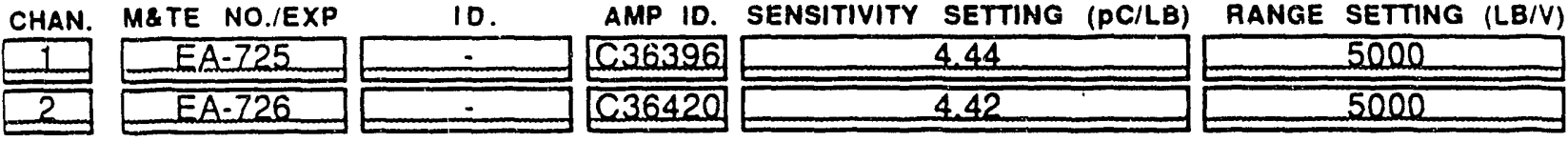

POST TEST

TARGET DAMAGE NQNE

SOURCE DAMAGE NONE

HAND HELD VIDEO START \& STOP POSITION NLA

HIGH SPEED VIOEO START \& STOP POSITION $41: 50-42: 15$

COMMENTS W

L

REVIEWED BYISIGNATURE B.JIBEANQR/ REVIEWED DATE $12 / 2 / 92$ APPROVED BYISIGNATURE BRIAN IHOMAS

${ }^{\dagger}$ Approximate weight using M\&TE category 3 equipment. 
WSRC-TR-93-0094

Attachment 10. Test Data Sheets (65 of 155)

Savannah River Technology Center

Equipment Engineering

EES-FP-370, Rev. 1

Seismic II/I Drop Test Program

Supported Beam Drop Tests

\section{Date Approved: 8/28/92, Category 2}

Page 16 of 18

\subsection{ATTACHMENT 5 \\ TEST DATÁ STHEET}

PRE TEST

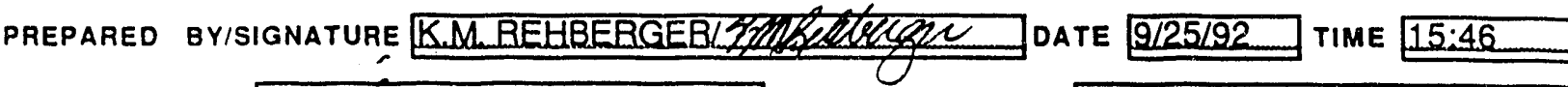

DROP TARGET BARBICADE DROP HEIGHT [IN] 24"

TARGET WT [LBS] ${ }^{\dagger} 194$ LBS

TARGET SPAN IIN] 48" SOURCE \& ADAPTER WT [LBS]

TARGET IMPACT PT (IN FROM RIGHT END) $24^{n}$ SOURCE ORIENTATION HEBIZONTA

DROP TEST NUMBER (Sequentlal; $1,2,3, \ldots 42$

DATA ACQUISITION

NORMAL

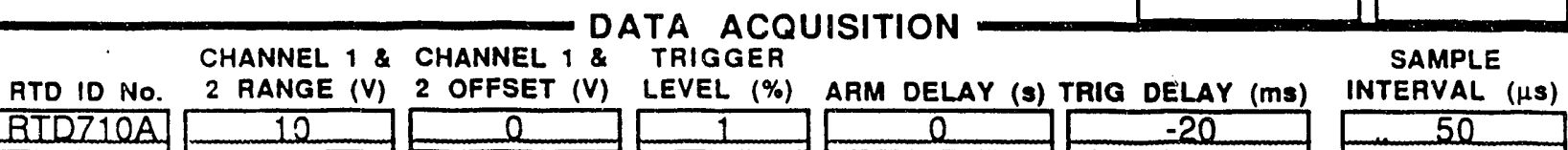

BTD710A 10 - 12

RECORD LENGTH

(samples)

ADDITIONAL DATA AQUISITION INFORMATION

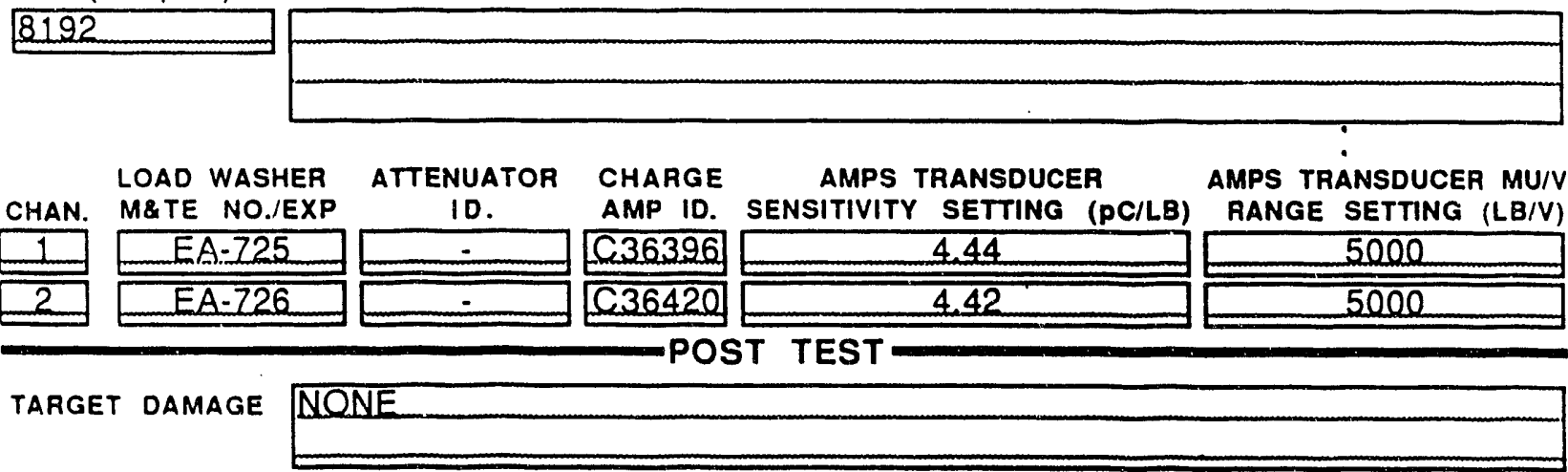

SOURCE DAMAGE NONE

HAND HELD VIDEO START \& STOP POSITION NLA

HIGH SPEED VIDEO START \& STOP POSITION $42: 15-42: 51$

COMMENTS

REVIEWED BYISIGNATURE BC.TBEANORL $/ 27^{\prime}$ REVIEWED DATE $12 / 2 / 92$

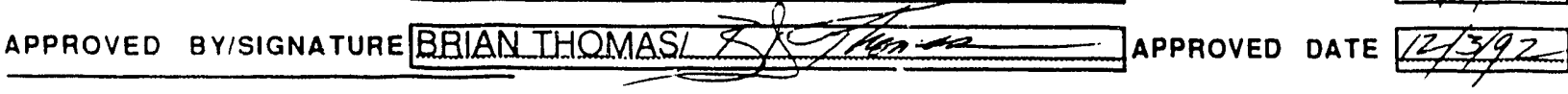

${ }^{\dagger}$ Approximale weight using M\&TE category 3 equipment. 
WSRC-TR-93-0094

Attachment 10. Test Data Sheets (66 of 155 )

Savännah River Technology Center Equipment Engineering Seismic II/I Drop Test Program Supported Beam Drop Tests
EES-FP-370, Rev. 1 Date Approved: $8 / 28 / 92$, Category 2

Page 16 of 18

\subsection{ATTACHMENT 5 \\ IEST DATA SHEET}

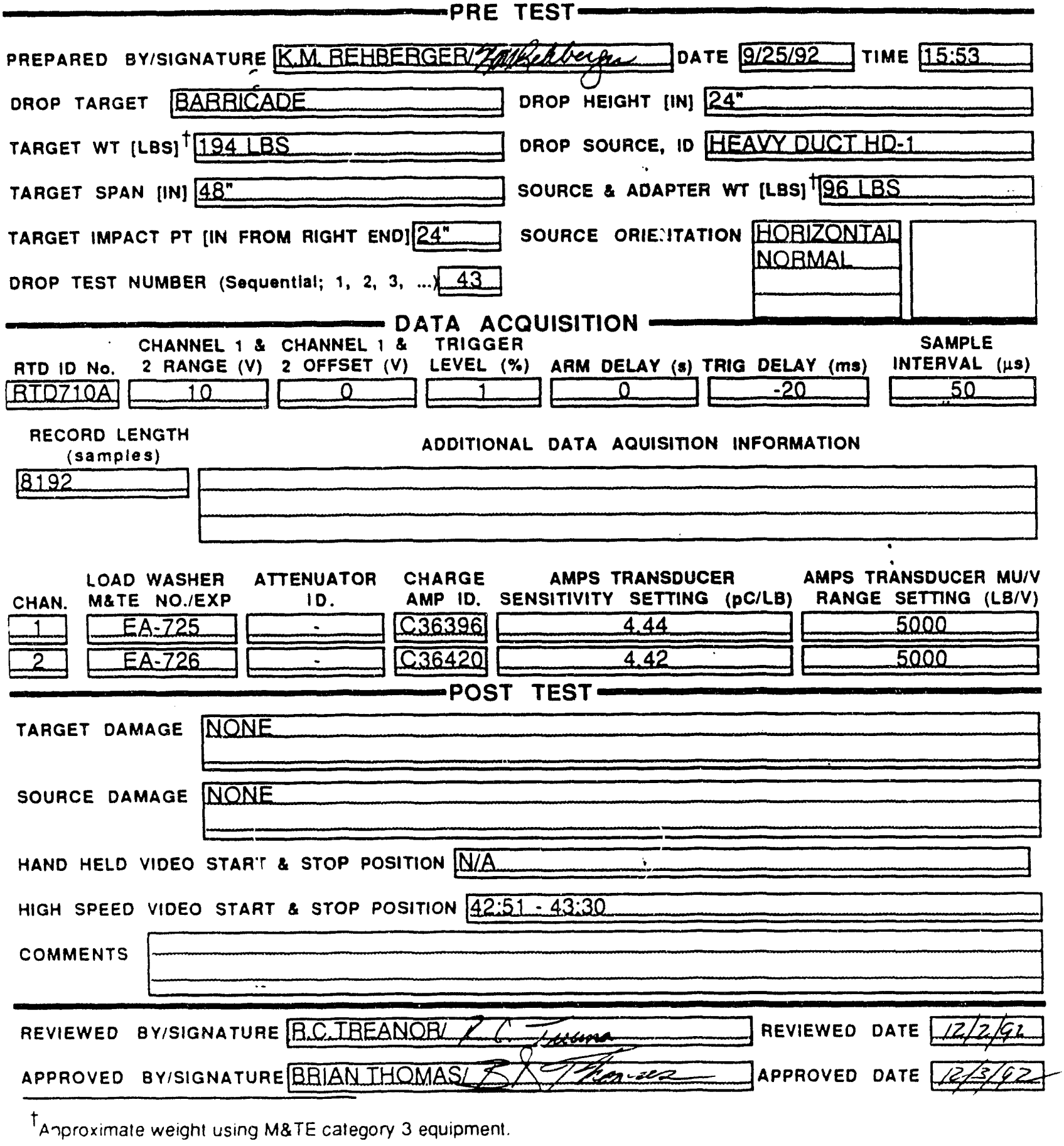


WSRC-TR-93-0094

Attachment 10. Test Data Sheets (67 of 155)

Savannah River Technology Center

Equipment Engineering

Seismic II/I Drop Test Program

EES-FP-370, Rev. 1

Supported Beam Drop Tests

\subsection{ATTACHMENT 5 \\ IEST DATA SHEET}

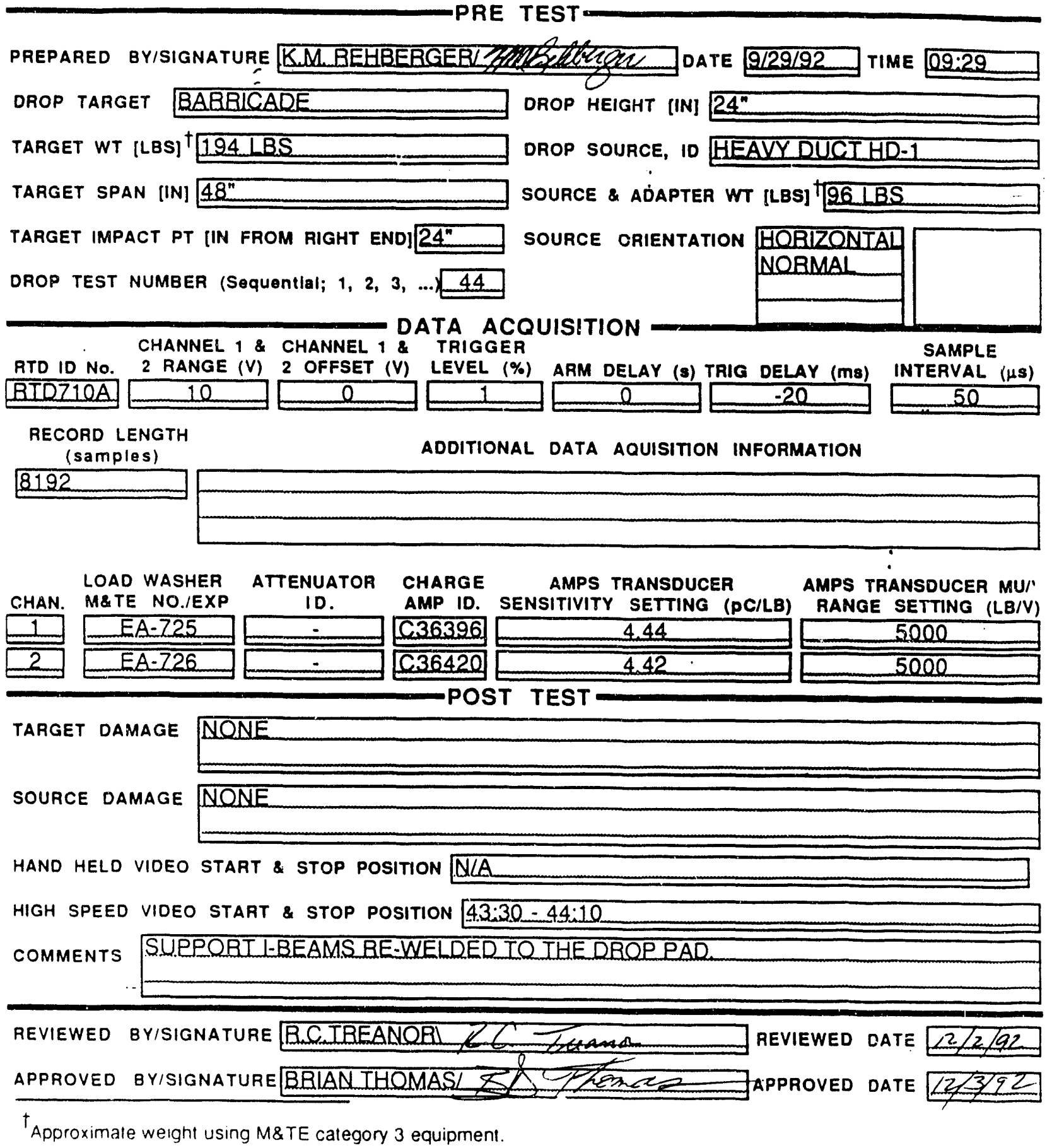


IVSRC-TR-93-0094

Attachment 10. Test Data Shects (68 of 155)

Savannah River Technology Center

Equipment Engineering

Seismic II/I Drop Test Program

EES-FP-370, Rev. 1

Supported Beam Drop Tests

\subsection{ATTACHMENT 5}

TEST DATA SHEET

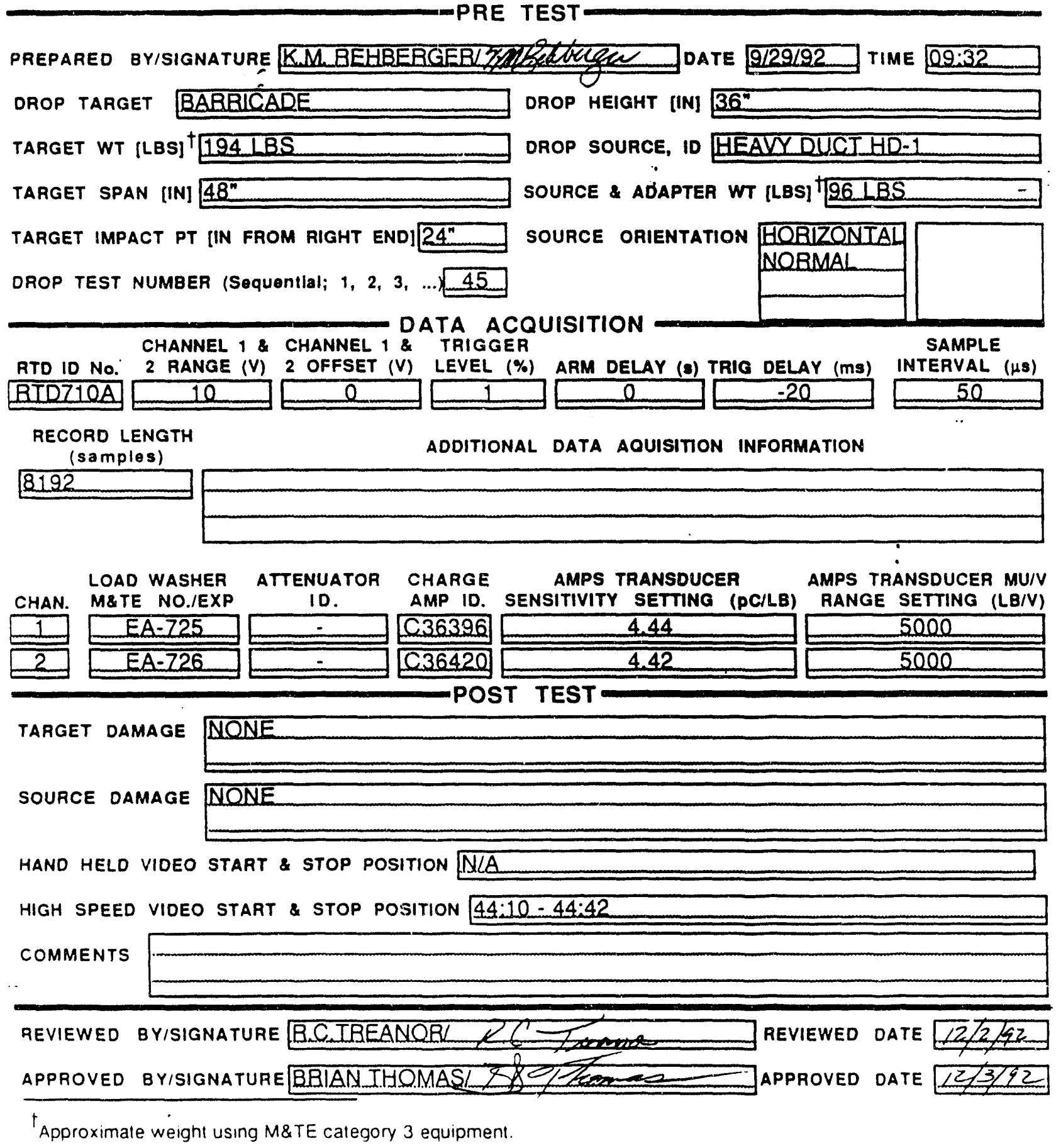


WSRC-TR-93-0094

Attachment 10. Test Data Sheets (69 of 155)

Savannah River Technology Center

Equipment Engineering

EES-FP-370, Rev. 1

Seismic II/I Drop Test Program

Supported Beam Drop Tests

Date Approved: $8 / 28 / 92$, Category 2

Page 16 of 18

\subsection{ATTACHMENT 5 \\ TEST DATA SHEET}

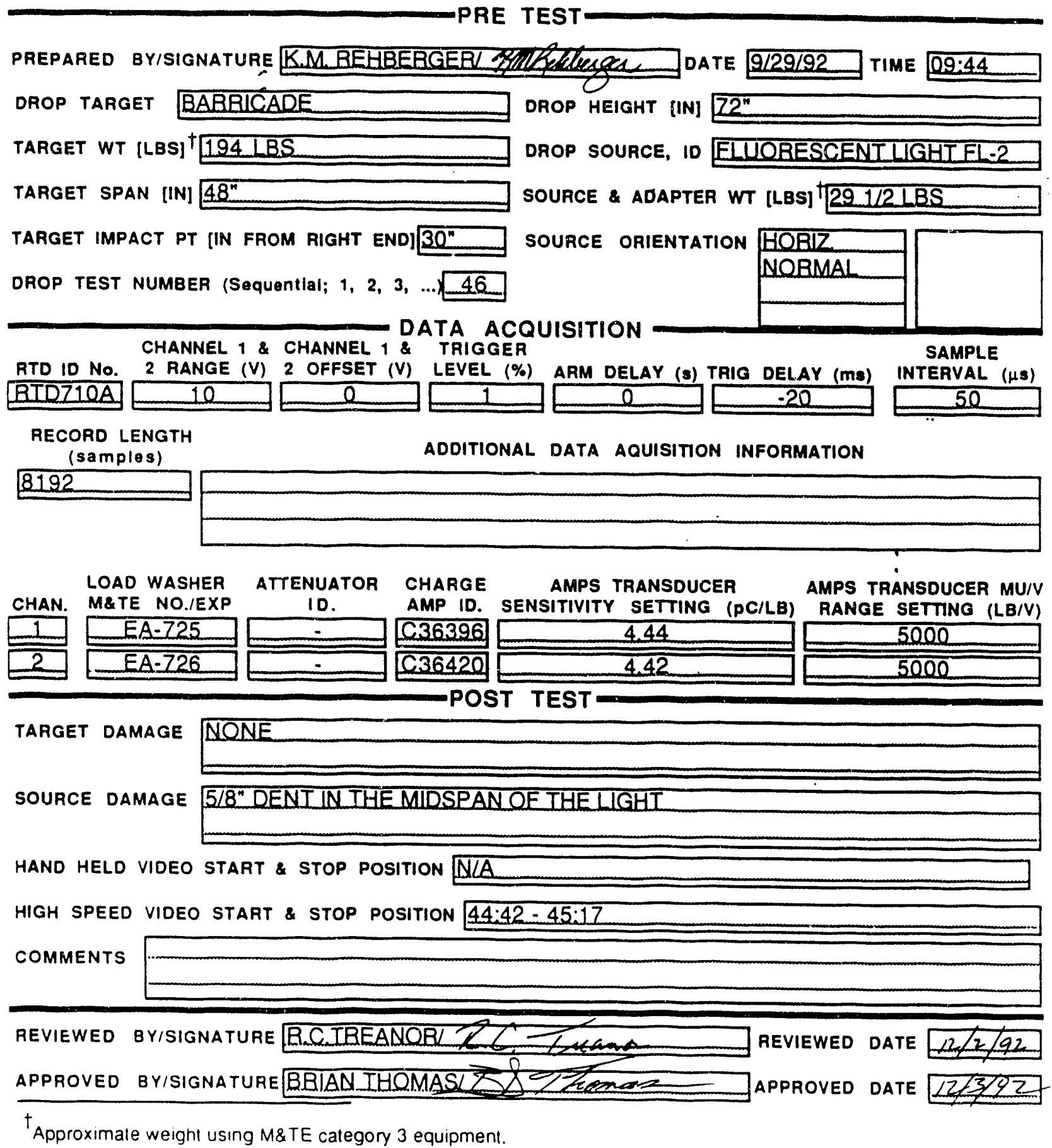


WSRC-TR-93-0094

Attachment 10. Test Data Sheets (70 of 155)

Savannah River Technology Center

EES-FP-370, Rev. 1

Equipment Engineering

Seismic II/I Drop Test Program

Supported Beam Drop Tests

Page 16 of 18

\subsection{ATTACHMENT 5 \\ TEST DATA SHEET}
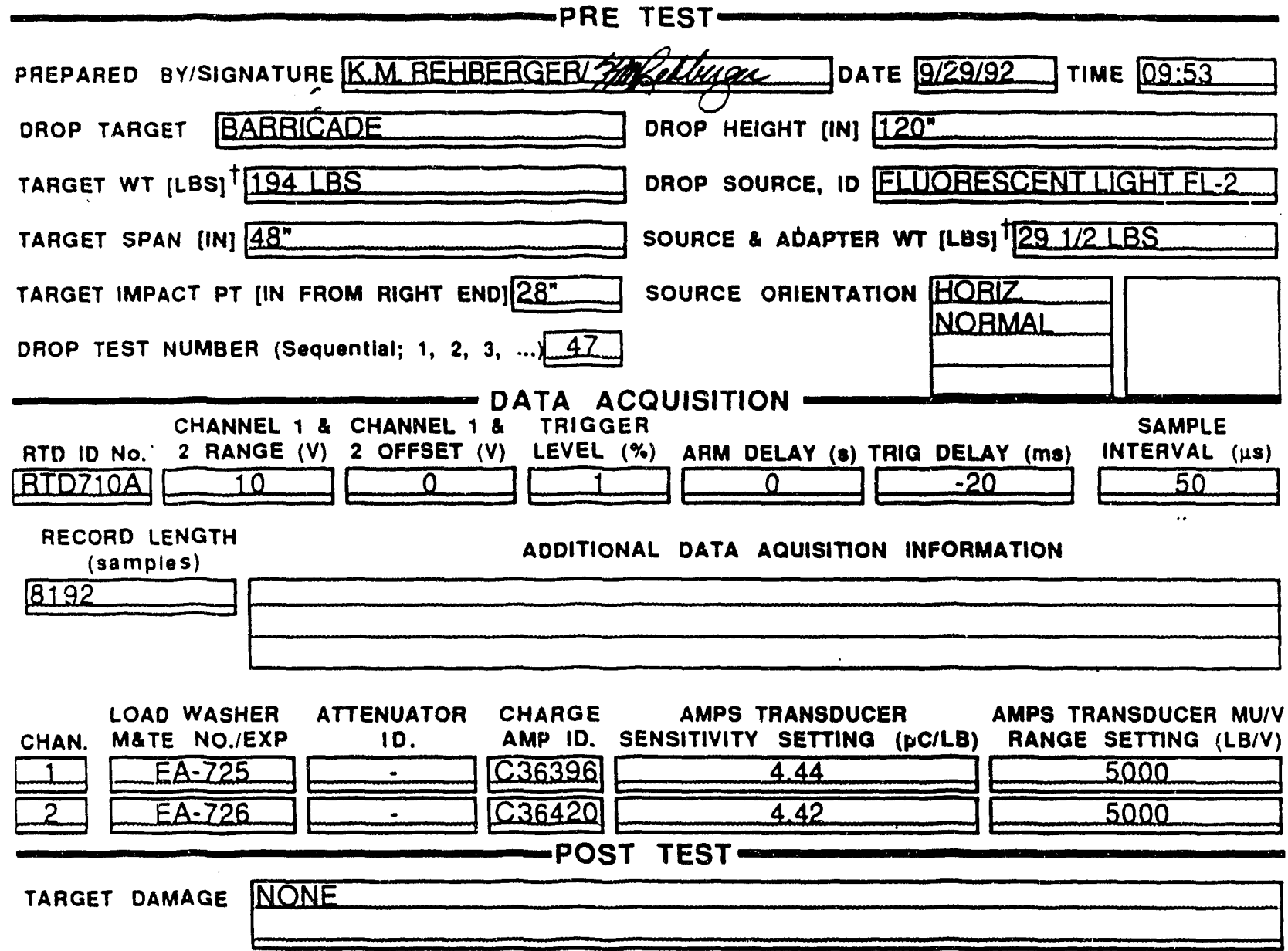

SOURCE DAMAGE OUTEREBAMEBBQKEN

HAND HELO VIDEO START \& STOP POSITION NLA

HIGH SPEED VIDEO START \& STOP POSITION $45: 17-45: 44$

COMMENTS

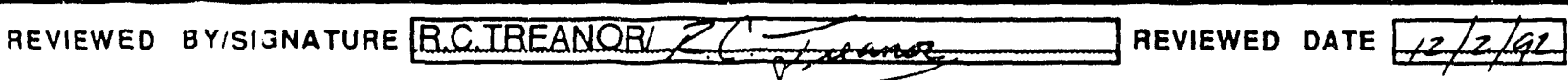

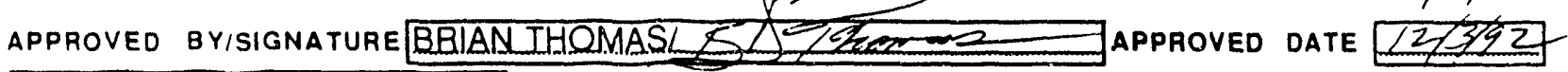

${ }^{\dagger}$ Approximate weight using M\&TE category 3 equipment. 
WSRC-TR-93-0094

Attachment 10. Test Data Sheets (71 of 155)

Savannah River Technology Center

Equipment Engineering

Seismic II/I Drop Test Program

EES-FP-370, Rev. 1

Supported Beam Drop Tests

Date Approved: 8/28/92, Category 2

Page 16 of 18

\subsection{ATTACHMENT 5}

IEST DATA STHEET

PRE TEST

PREPARED BYISIGNATURE K.M.REHBERGER/

DROP TARGET BARBICADE

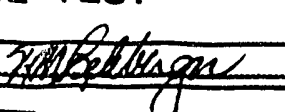

TARGET WT [LBS] ${ }^{\dagger} 194$ LBSS

DROP HEIGHT [IN] 180

DATE 9/29/92

TIME 10:00

TARGET SPAN [IN] $48^{\prime \prime}$

DROP SOURCE, I0 ELUQRESCENT LIGHTFL-2

TARGET IMPACT PT [IN FROM RIGHT END] 30"

SOURCE \& ADAPTER WT [LBS] 22 112LBS

DROP TEST NUMBER (Sequentlal; $1,2,3, \ldots 48$

SOURCE ORIENTATION HORIZONIAL

NORMAL

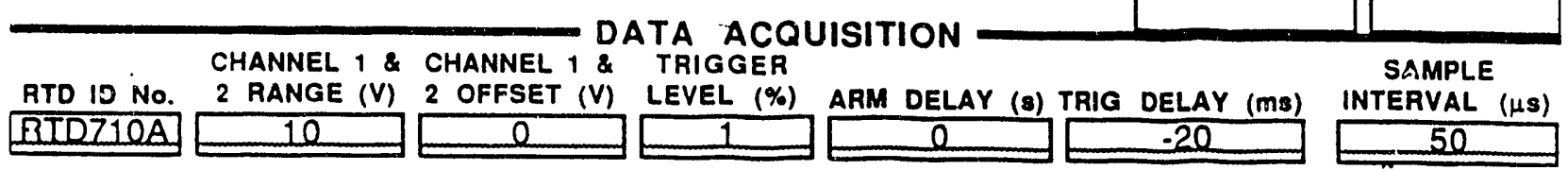

RECORD LENGTH

(samples)

ADDITIONAL DATA AQUISITION INFORMATION

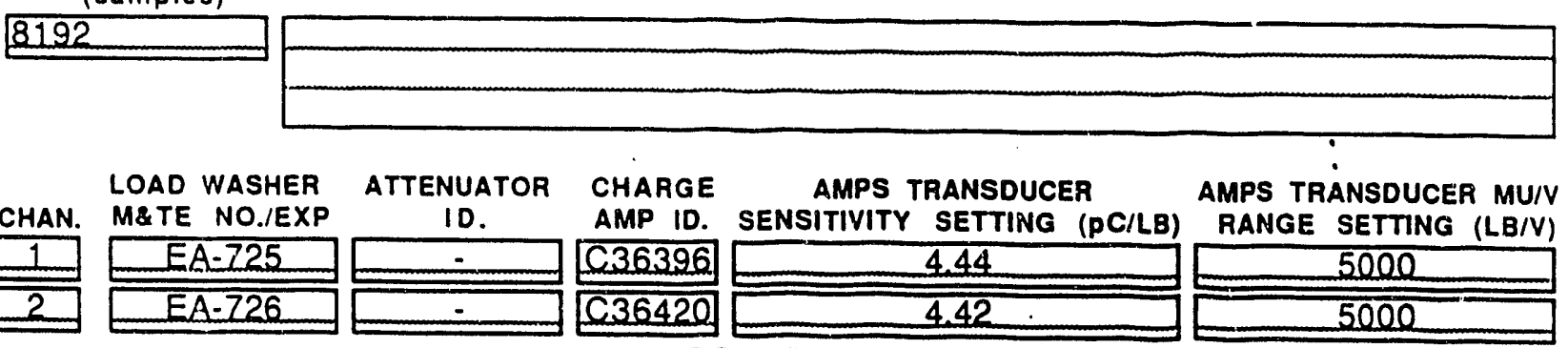

POST TEST

\begin{tabular}{ll} 
TARGET DAMAGE NONE \\
SOURCE DAMAGE \\
BROKOTAL DEFORMATION (SAME SOUBCE USED EROMDBORS 46 AND 47) \\
\hline
\end{tabular}

HAND HELD VIDEO START \& STOP POSITION N/A

HIGH SPEED VIDEO START \& STOP POSITION $45: 44-46: 28$

COMMENTS

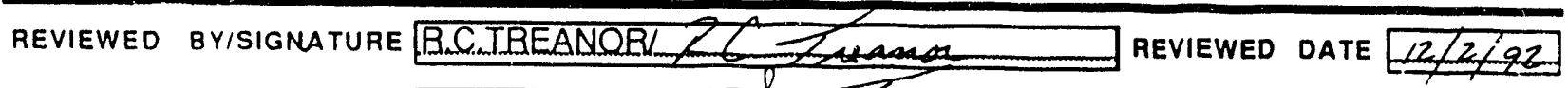

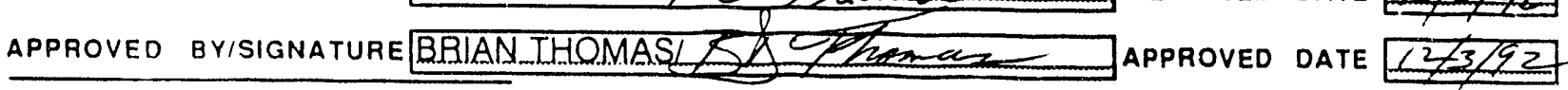

${ }^{\dagger}$ Approximate weight using M\&TE category 3 equipment. 
IVSRC-TR-93-0094

Attachment 10. Test Data Sheets (72 of 155 )

Savannah River Technology Center

Equipment Engineering

Seismic II/I Drop Test Program

Supported Beam Drop Tests

EES-FP-370, Rev. 1

Date Approved: 8/28/92, Category 2

Page 16 of 18

\subsection{ATTACHMENT 5 \\ IEST DATA SHEET}

PRE TEST

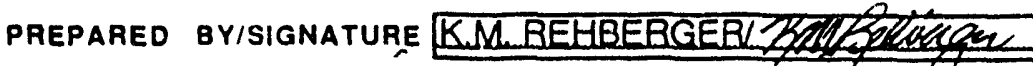

OROP TARGET BABBICADE.

DROP HEIGHT [IN] $60^{\circ}$

TARGET WT [LBS] 194 LBS

DROP SOURCE, ID WALLBOABDWB-2

TARGET SPAN (IN] 48"

SOURCE \& ADAPTER WT [LBS] 11 LBS

TARGET IMPACT PT [IN FROM RIGHT END] $24^{\prime \prime}$

SOURCE ORIENTATION HORIZ

DROP TEST NUMBER (Sequential; $1,2,3, \ldots 49$

DATA ACQUISITION

NOBMAL

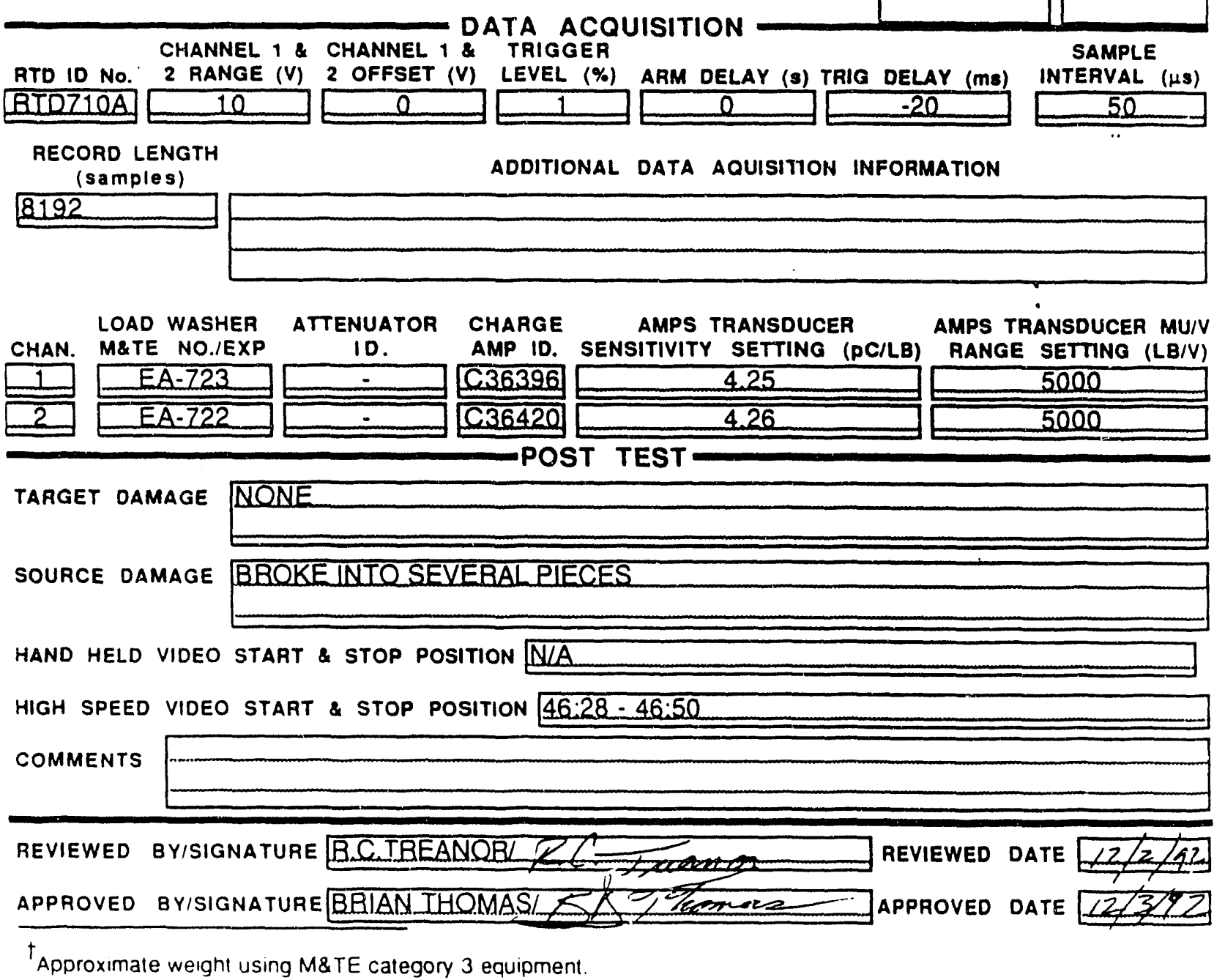


WSRC-TR-93-0094

ttachment 10 . Tesi dia Sheets (73 of 155)

Savannah River Technology Center

Equipment Engineering

Seismic II// Drop Test Program

EES-FP-370, Rev. 1

Supported Beam Drop Tests

Date Approved: $8 / 28 / 92$, Category 2

Page 16 of 18

\subsection{ATTACHMENT 5 \\ TEST DATA SHEET}

PRE TEST

PREPARED BYISIGNATURE K.M.REHBERGERI OROP TARGET BARBICACE DROP HEIGHT [IN] 60"

TARGET WT [LBS] ${ }^{\dagger} 194$ LES

TARGET SPAN [IN] $48^{\prime \prime}$

TARGET IMPACT PT [IN FROM RIGHT END] $24^{n}$

DROP TEST NUMBER (Sequential; $1,2,3, \ldots 50$
DROP SOURCE, ID MALLBOABDWB-3

SOURCE \& ADAPTER WT [LBS] 11LBS

SOURCE oRIENTATION VERTICAL

DATA ACQUISITION

CHANNEL 1 \& CHANNEL 1 \& TRIGGER
RTO ID No. 2 RANGE (V) 2 OFFSET (V) LEVEL (\%) ARM'DELAY (s) TRIG DELAY (ms) INTERVAL ( $\%$ S) BIDT10A 10

RECORD LENGTH

(samples)

ADDITIONAL DATA AQUISITION INFORMATION

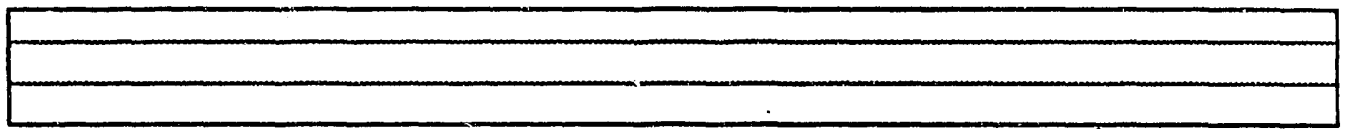

LOAD WASHER ATTENUATOR CHARGE AMPS TRANSDUCER AMPS TRANSDUCER MU/V

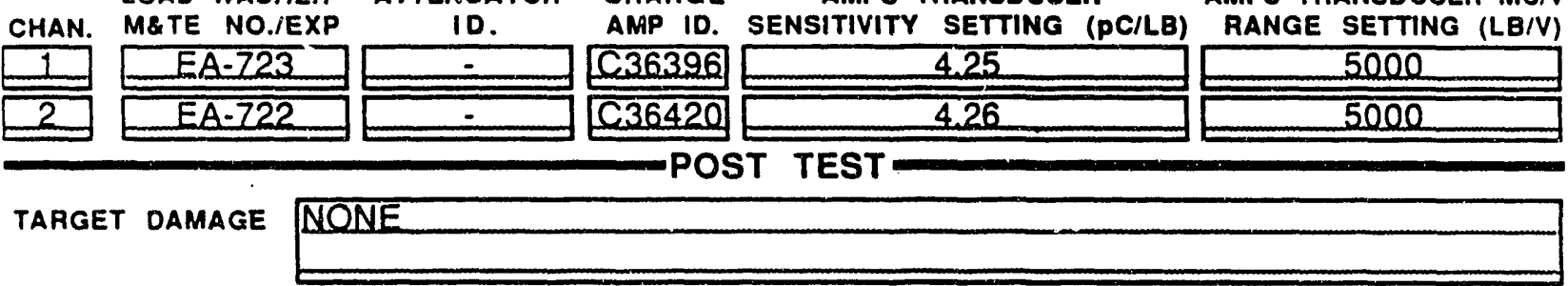

SOURCE DAMAGE LQCAL DAMAGEAT POINT OFIMPACT

HAND HELD VIDEO START \& STOP POSITION W/A

HIGH SPEED VIDEO START \& STOP POSITION $46: 50-47: 21$

COMMENTS

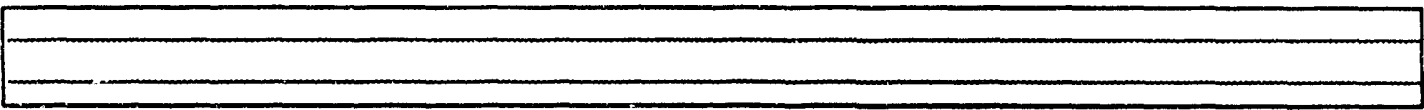

Reviewed byisignature BucIBEANOB APPROVED BYISIGNATURE BRIANIHQMAS/

$\dagger_{\text {Approximate weight using M\&TE category } 3 \text { equipment }}$ 
WSRC-TR-93-0094

Attachment 10. Test Data Sheets (74 of 155)

Savannah River Technology Center

EES-FP-370, Rev. 1

Equipment Engineering

Seismic IVI Drop Test Program

Supported Beam Drop Tests

\subsection{ATTACHMENT 5 \\ IEST DATA SHEET}

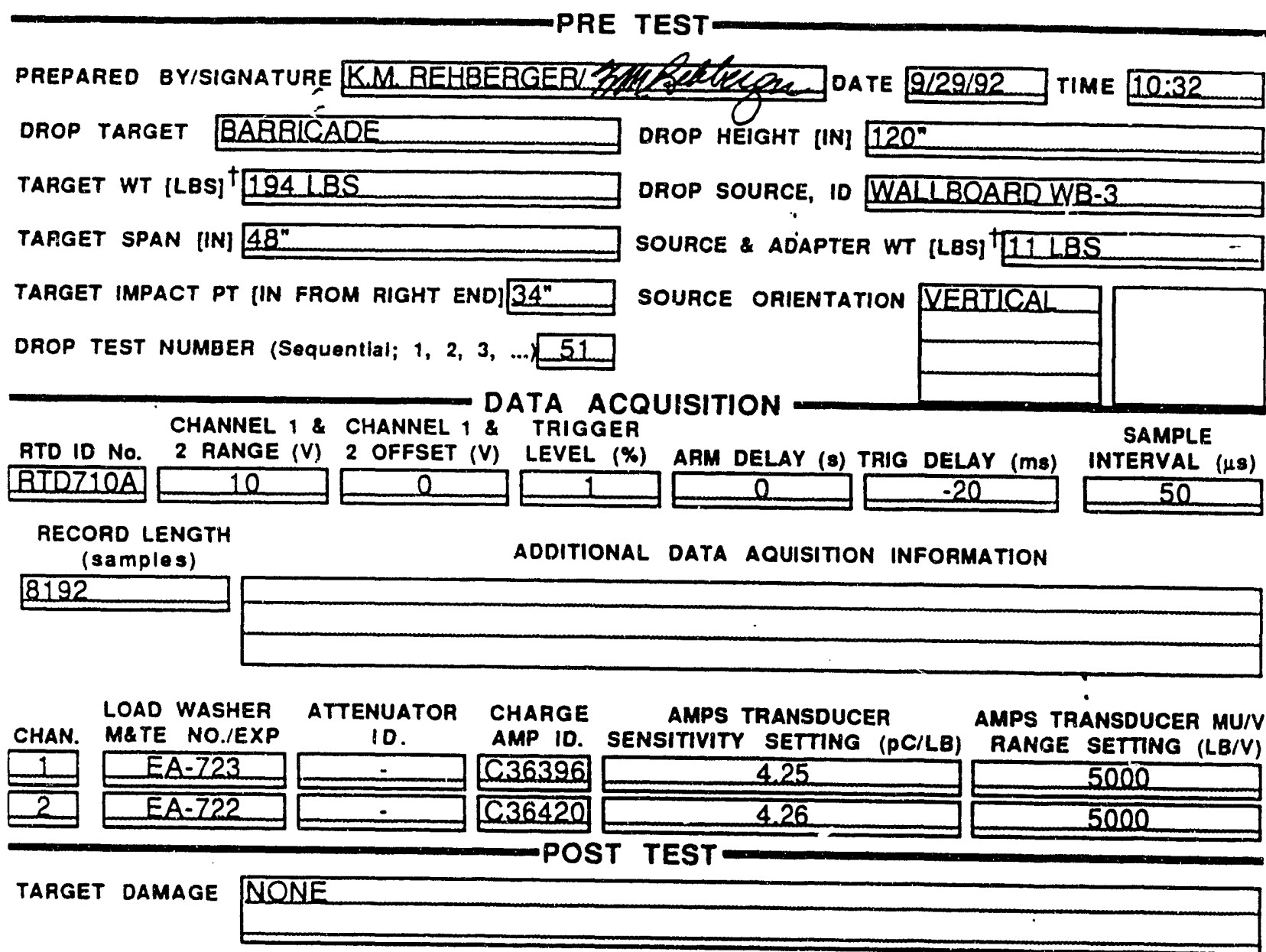

SOUACE DAMAGE LOCAL DAMAGEAI POINI OE IMPACT

HANO HELD VIDEO START STOP POSITION NIA

HIGH SPEED VIDEO START \& STOP POSITION $4 Z: 21-47: 39$

COMMENTS

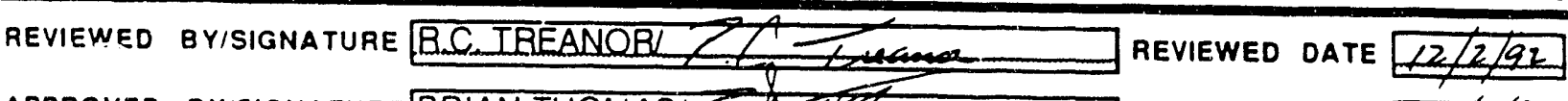

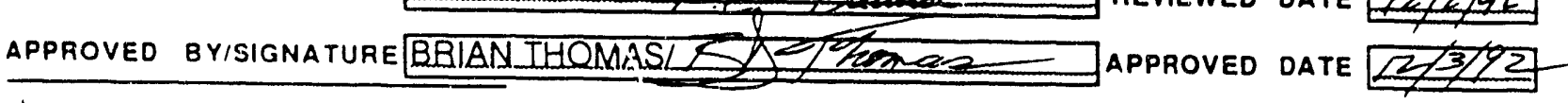

$\dagger^{\dagger}$ Approximate weight using M\&TE category 3 equipment 
WSRC-TR-93-0094

Attachment 10. Test Data Sheets (75 of 155)

Savannah River Technology Center

Equipment Engineering

Seismic II/I Drop Test Program

EES-FP-370, Rev. 1

Supported Beam Drop Tests

\section{Date Approved: $8 / 28 / 92$, Category 2}

Page 16 of 18

\subsection{ATTACHMENT 5 \\ TEST DATA SHEET}

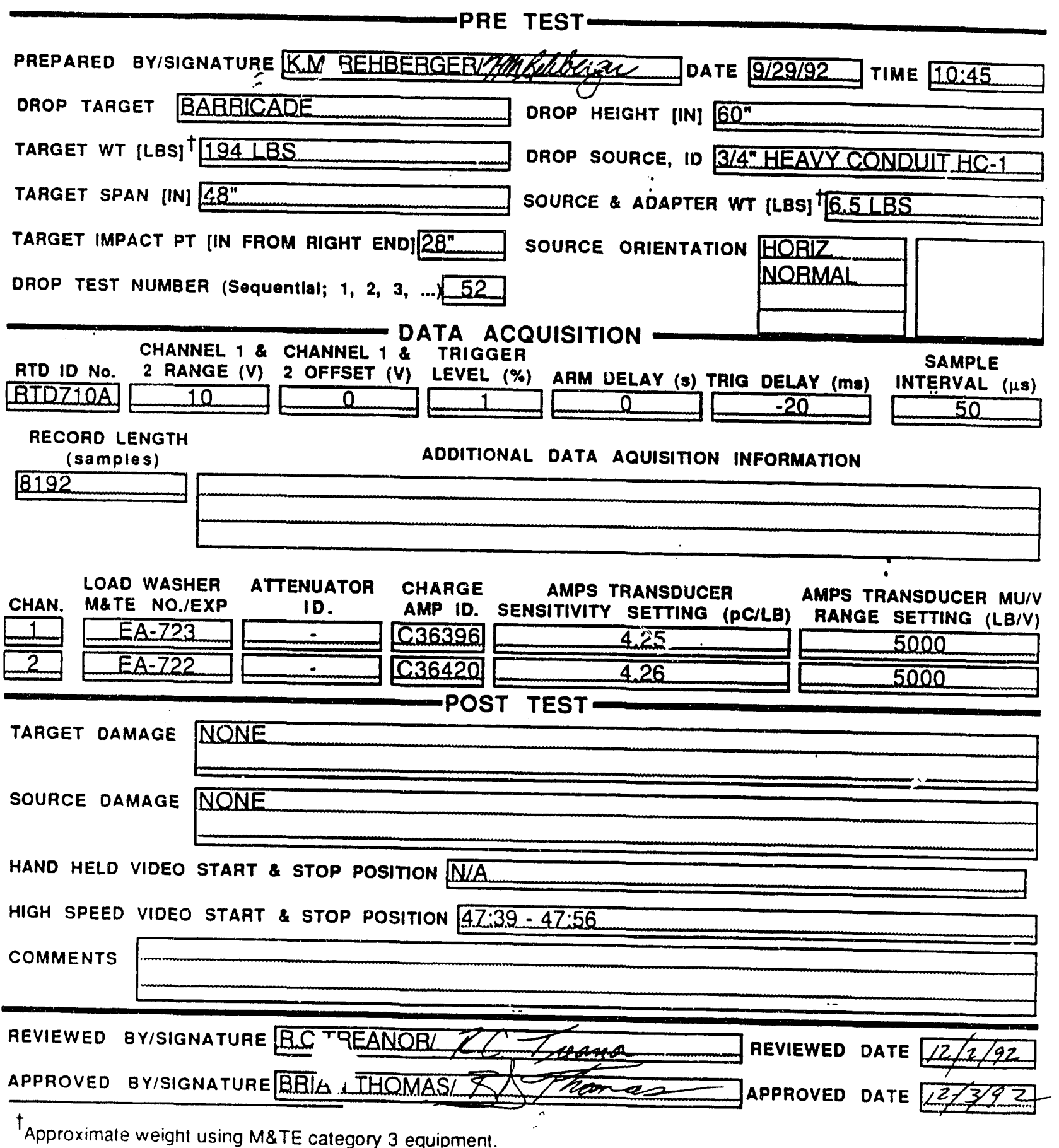


IVSRC-TR-93-0(194

Attachment 10. Test Data Sheets (76 of 155)

Savannah Fiver Technology Center

Equipment Engineering

EES-FP-370, Rev. 1

Seismic 11/1 Drop Test Program

Supported Beam Drop Tests

Date Approved: 8/28/92, Category 2

Page 16 of 18

\subsection{ATTACHMENT 5 \\ IESI UATA SHEEI}
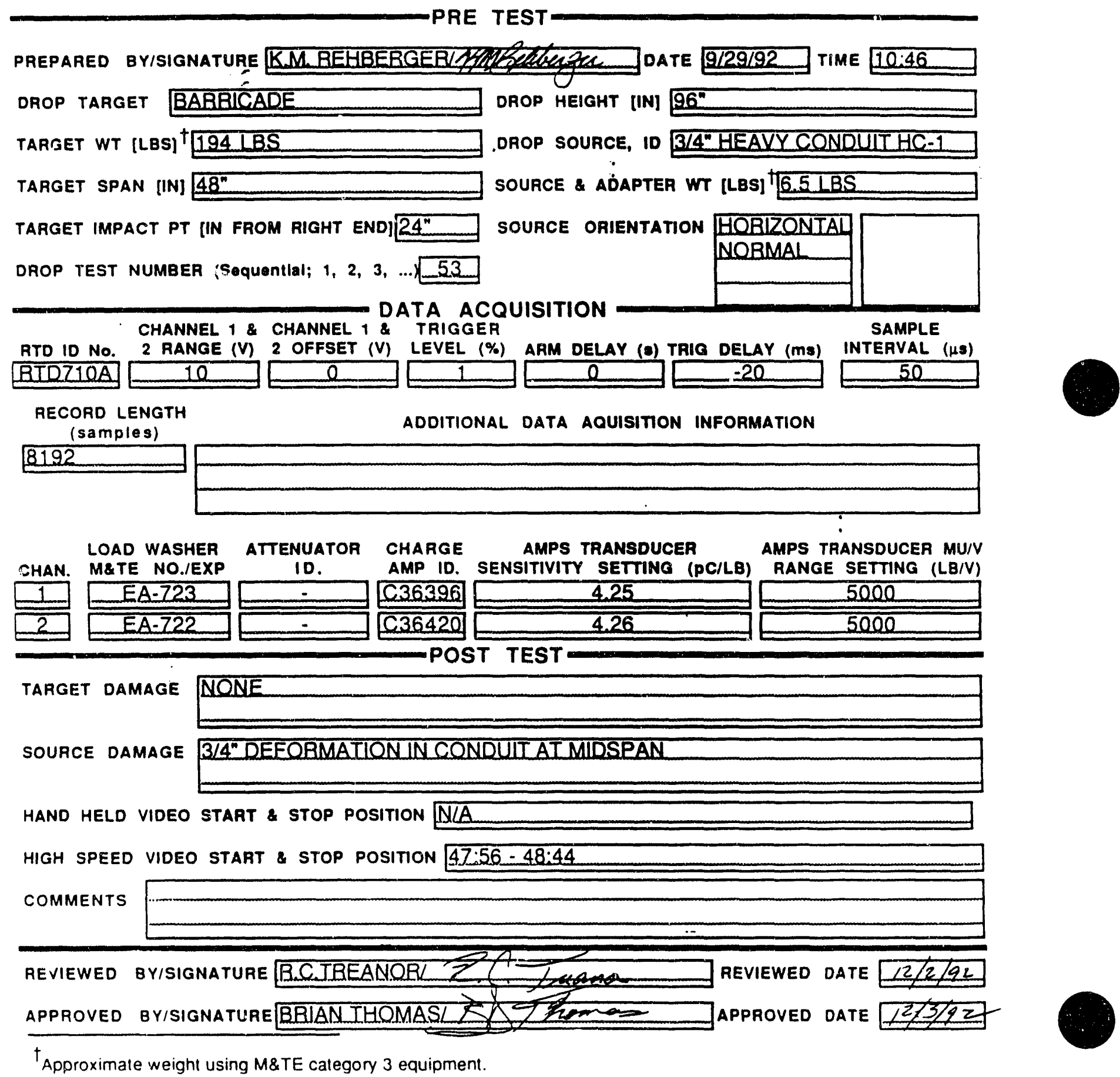
WSRC-TR-93.0094

Attachment 10 . Test Data Sheets (77 of 155)

Savannah River Technology Center

Equipment Engineering

Seismic II/I Drop Test Program

Supported Beam Drop Tests

EES-FP.370, Rev. 1

Date Approved: 8/28/92, Category 2

Page 16 of 18

\subsection{ATTACHMENT 5}

IEST UATA STIEET

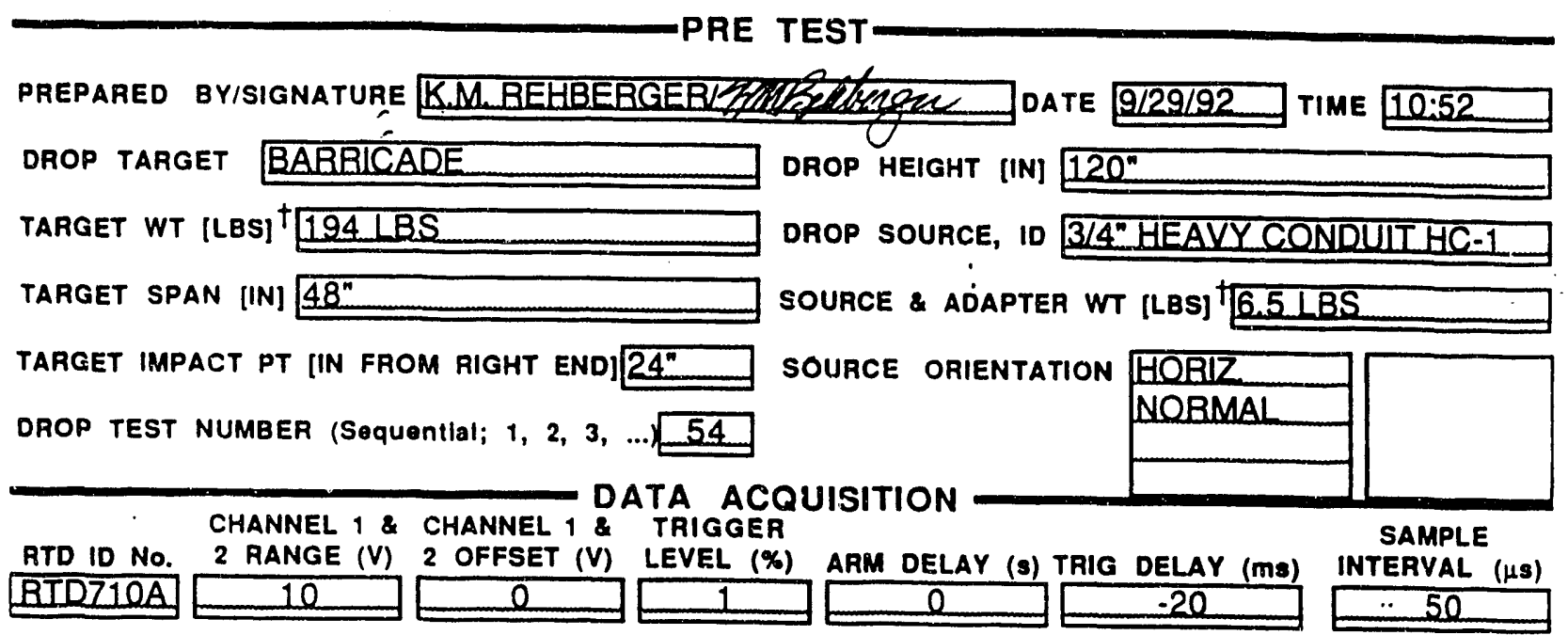

ADDITIONAL DATA AQUISITION INFORMATION

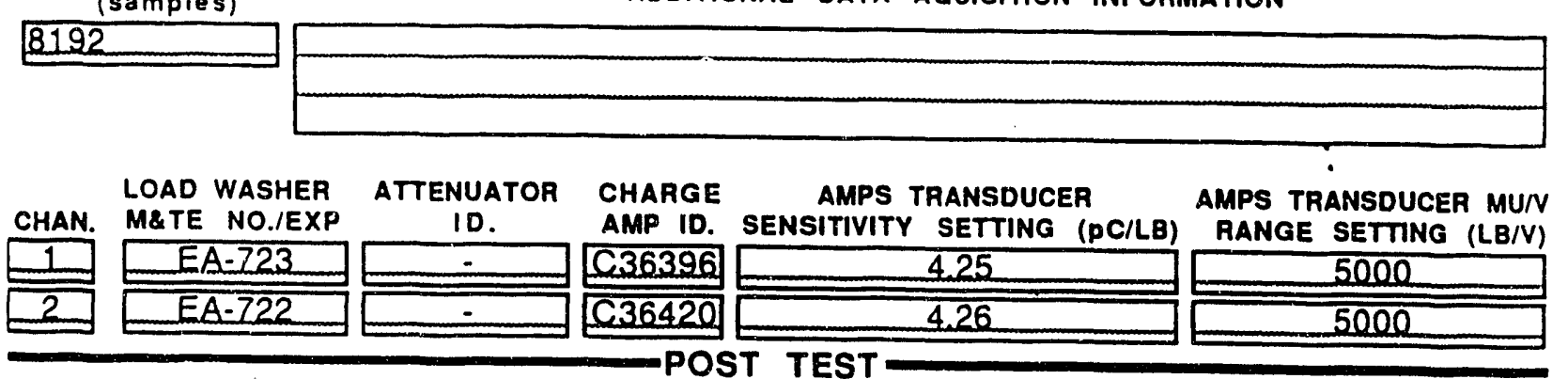

POST TEST

TARGET DAMAGE NQNE

SOURCE DAMAGE APPROX,3/4" DEFORMATION OCCURED ON TOP OF 3/4" DEEOBMATION EROMRREVIOUS DROR.

HAND HELD VIDEO START \& STOP POSITION N/A

HIGH SPEED VIDEO START \& STOP POSITION $48: 44-49: 22$

COMMENTS

REVIEWED BYISIGNATURE B.CIREANOBL APPROVED BYISIGNATURE BRIANTHOMAS/

${ }^{\dagger}$ Approximate weight using M\&TE category 3 equipment. 
IVSRC-TR-93-0094

Attachment 10. Test Data Sheets (78 of 155)

Savannah River Technology Center Equipment Engineering

Seismic II/I Drop Test Program

Aircraft Cable Drop Tests

EES-FP-380, Rev. 0

Date Approved: 9/16/92, Category 2

Page 12 of 14

\subsection{ATTACHMENT 2 \\ IEST DATA STIEET}

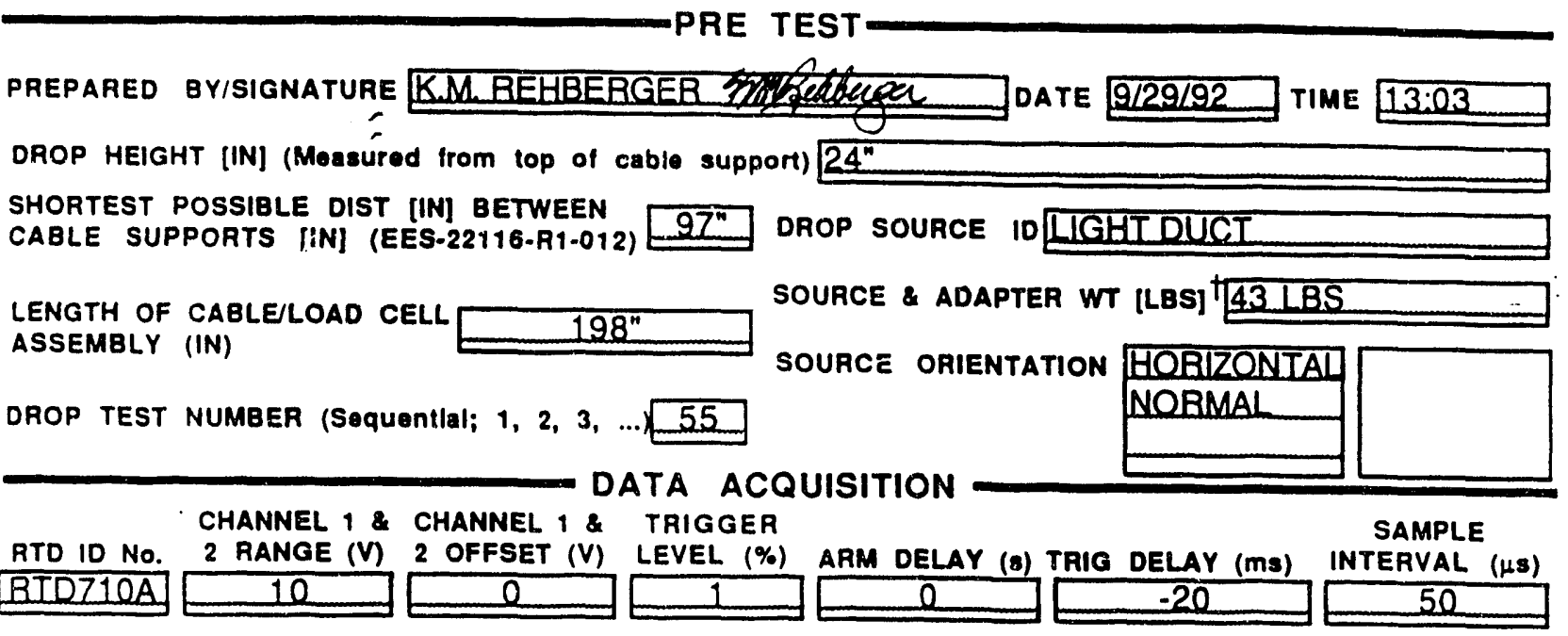

RECORD LENGTH

(samples)

ADDITIONAL DATA AQUISITION INFORMATION

E192 ONIY CAUGHT IBAIL EDGE OF LOAR SPIKE

NOISE HIGHLIGHTED BY THE SCALE ON THE GRAPH

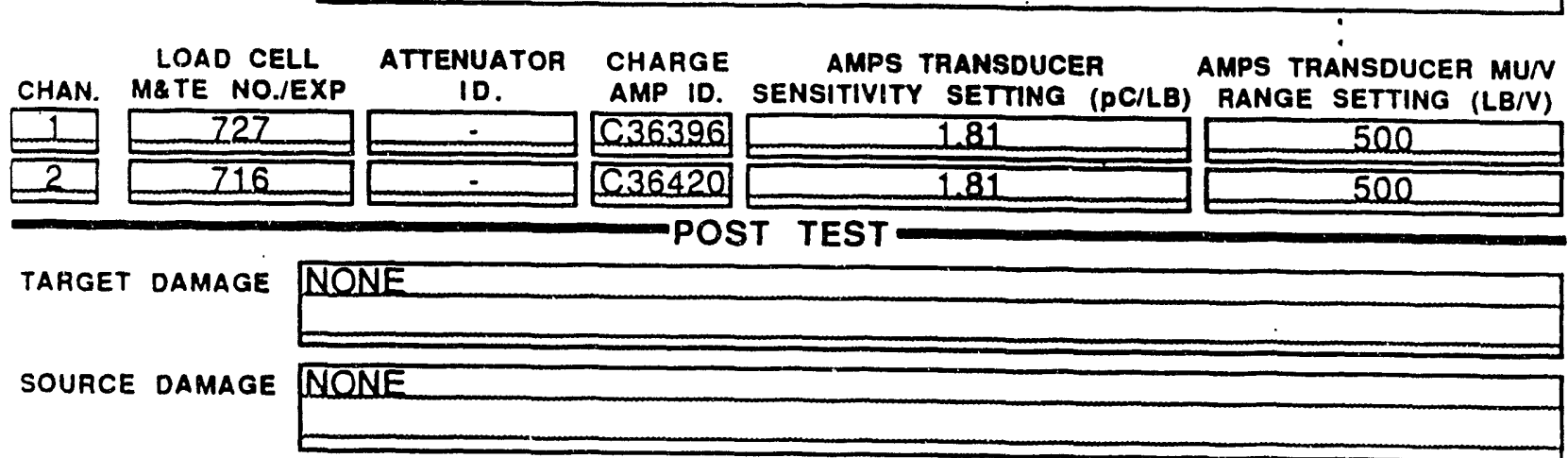

HAND HELD VIDEO START \& STOP POSITION NIA

HIGH SPEED VIDEO START \& STOP POSITION $00: 02-0,0: 45$

COMMENTS 30"PIPE ONCABLE

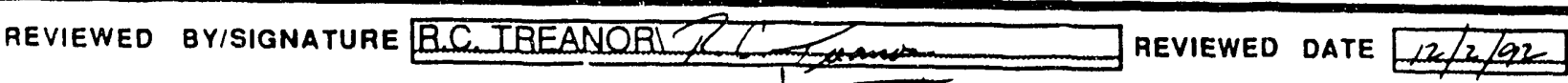
APPROVED BYISIGNATURE BRIANTHQMASI \&

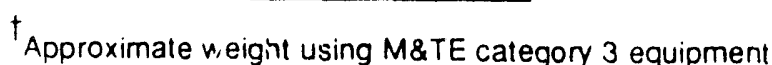


WSRC-TR-93-0094

Attachment 10. Test Data Sheets (79 of 155)

Savannah River Technology Center

Equipment Engineering

Seismic II/I Drop Test Program

Aircraft Cable Drop Tests

EES-FP-380, Rev. 0

Date Approved: 9/16/92, Category 2

Page 12 of 14

\subsection{ATTACHMENT 2}

IEST ŨATA SHEET

PRE TEST

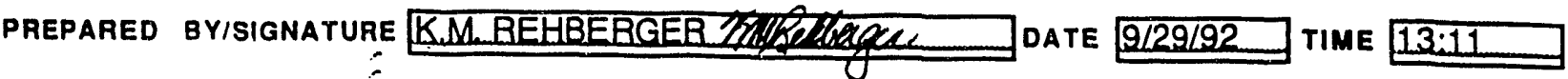
DROP HEIGHT [IN] (Measured from top of cable support) $48^{n}$

SHORTEST POSSIBLE DIST [IN] BETWEEN

CABLE SUPPORTS [IN] (EE.S-22116-R1-012)

LENGTH OF CABLELLAD CELL

ASSEMBLY (IN)

$198^{*}$

$97^{\prime \prime}$

DROP SOURCE, ID LIGHTDUCI

DROP TEST NUMBER (Sequentlal; 1, 2, 3, ...56

DATA ACQUISITION

CHANNEL 1 \& CHANNEL $1 \&$ TRIGGER

RTD ID No 2 RANGE (V) 2 OFFSET (V) LEVEL (\%) ARM DELAY (s) TARG DELAY (MS) INTERLE

BID710A E 10

RECORIO LENGTH

(samples)

ADDITIONAL DATA AQUISITION INFORMATION

8192

ONLY CAUGHT TRAILEDGE OE LOAD SPIKE

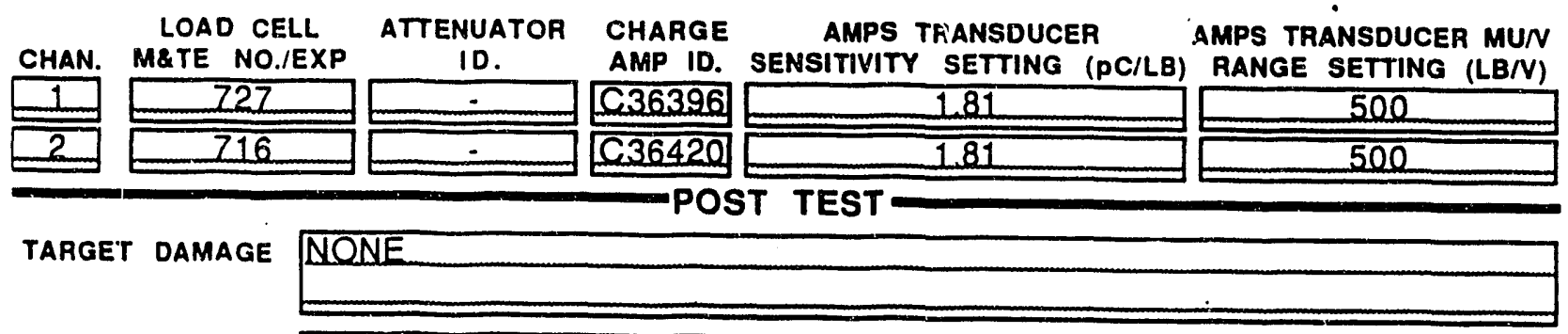

SOURCE DAMAGE SMALLDENT (APRBOX 1/4") ONONE CORNER

HAND HELD VIDEO START \& STOP POSITION N/A

HIGH SPEED VIDEO START \& STOP POSITION $00.45-01: 21$

COMMENTS 3." PIPE ONCABLE

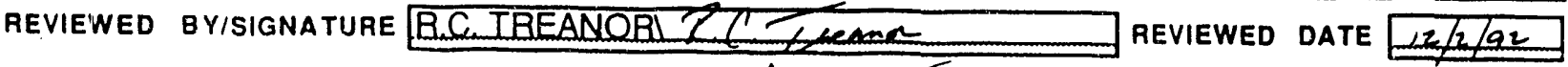

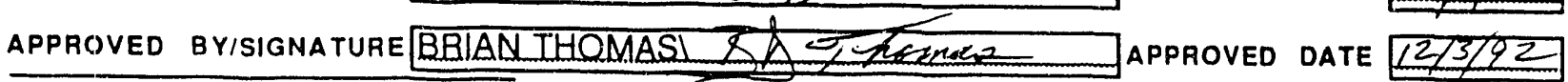

${ }^{\dagger}$ Approximate weight using M\&TE category 3 equipment. 
WSRC-TR-93-0094

Attachment 10. Test Data Sheets (80 of 155)

Savannah River Technology Center

Equipment Engineering

Seismic II/I Drop Test Program

Aircraft Cable Drop Tests

EES-FP-380, Rev. 0

Date Approved: 9/16/92, Category 2

Page 12 of 14

\subsection{ATTACHMENT 2 \\ IESI VAIA STIEET \\ PRE TEST}

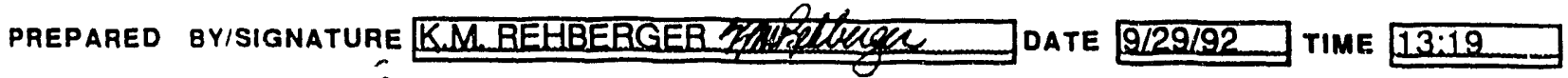
DROP HEIGHT [IN] (Measured from top of cable support) $48^{n}$

SHORTEST POSSIBLE DIST [IN] BETWEEN

CABLE SUPPORTS IIN] (EES-22116-R1.012) $97^{\prime \prime}$

LENGTH OF CABLE/LOAD CELL

ASSEMBLY (IN)

$198^{n}$

DROP TEST NUMBER (Sequentlal; $1,2,3, \ldots 57$

DATA ACQUISITION

CHANNEL 1 \& CHAN: EL 1 \& TAIGGER

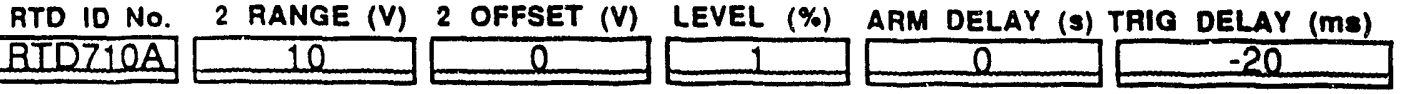

SAMPLE SOURCE \& ADAPTER WT [LBS] 43 LBS SOURCE ORIENTATION HOBIZONTAL NOBMAL.

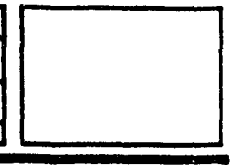

RECORD LENGTH

(samples)

8192

ADDITIONAL DATA AQUISITION INFORMATION QNIIY CAUGHT TBAILEDGE OE LOAD SPIKE

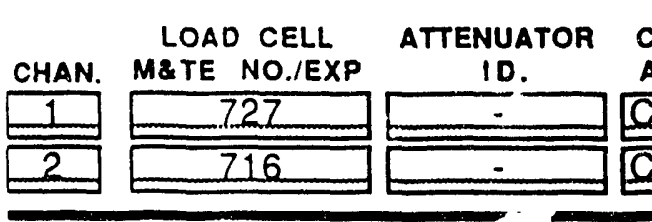

AMPS TRANSDUCER

AMPS TRANSDUCER MU/V AMP ID. SENSITIVITY SETTING (PC/LB) RANGE SETTING (LB/V) A36396 C36420

$\frac{1.81}{181}$

$\begin{array}{r}500 \\ \hline 500 \\ \hline\end{array}$

TEST

TARGET DAMAGE NQNE

SOURCE DAMAGE ARPROX 1/4" DEEORMATIONEROMEREVIOUS DROE NOADDITIONAL DEEORMATION.

HAND HELD VIDEO START \& STOP POSITION N/A

HIGH SPEED VIOEO START \& STOP POSITION $01.21-0.1 .59$

COMMENTS 30"PIPE ONCABLE

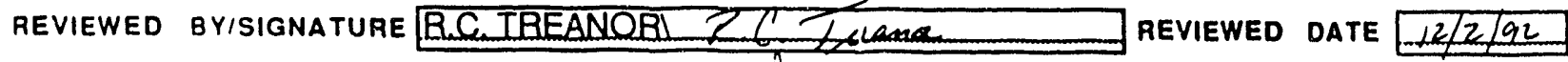
APPROVED BYISIGNATURE BRIANIHOMASI \& 12 DAPPROVED DATE 12.32

'Approximate weight using M\&TE category 3 equipment. 
WSRC-TR-93-0094

Attachment 10. Test Data Sheets (81 of 155)

Savannah River Technology Center

EES-FP-380, Rev. 0

Equipment Engineering

Seismic II/I Drop Test Program

Date Approved: $9 / 16 / 92$, Category 2

Aircraft Cable Drop Tests

Page 12 of 14

\subsection{ATTACHMENT 2}

IEST UATA STHEET

-PRE TEST

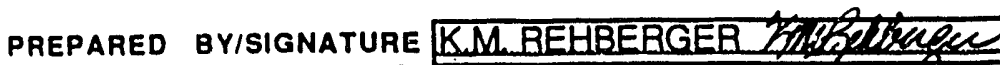
$=$ sured from top of cable support) $60^{n}$

DROP HEIGHT [IN] (Measured from top of cable support) 60

SHORTEST POSSIBLE DIST [IN] BETWEEN CABLE SUPPORTS [IN] (EES-22116-R1-012) $27^{n}$

LENGTH OF CABLE/LOAD CELL ASSEMBLY (IN) $198^{\prime \prime}$

DROP TEST NUMBER (Sequential; $1,2,3, \ldots 5 \overline{5}$

DATA ACQUISITION

CHANNEL 1 \& CHANNEL 1 \& TRIGGER

\begin{tabular}{l} 
RTD ID No. 2 RANGE (V) 2 OFFSET (V) LEVEL (\%) ARM DELAY (8) TRIG DELAY (ms) INTERVAL ( $\mu$ S) \\
\hline BTD710A \\
\hline 10
\end{tabular}

RECORD LENGTH

(samples)

8192 ONIY CAUGHT TBAIL EDGE QF LOAD SPIKE

\section{ADDITIONAL DATA AQUISITION INFORMATION} SOURCE \& AD́APTER WT [LBS] 43 LBS SOURCE ORIENTATION HOBIZONTAQ NORMAL
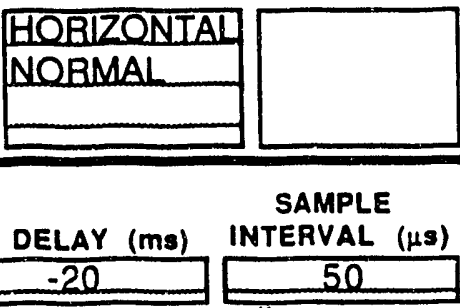

SAMPLE

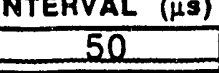

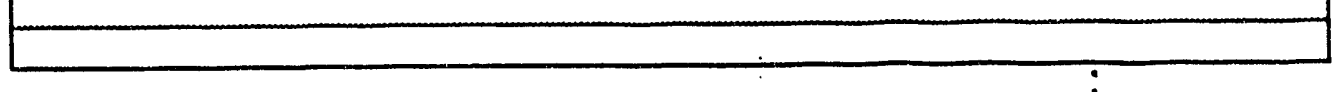

LOAD CELL

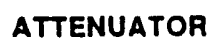

CHARGE

AMPS TRANSDUCER AMPS TRANSDUCER MUN

\begin{tabular}{c} 
CHANA. METE NO./EXP \\
\hline 1 \\
\hline 2 \\
\hline 127 \\
\hline
\end{tabular}

C363296 SENSITIVITY SETTING (PC/LB)

RANGE SETTING (LB/V)

\section{$=$}

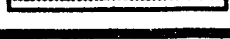

$\frac{1.81}{1.81}$

500

TARGET DAMAGE NONE

SOURCE DAMAGE APPROX.1"DENTAT IHE CORNERS.

HAND HELD VIDEO START \& STOP POSITION NIA

HIGH SPEED VIDEO START \& STOP POSITION $01: 59-02: 48$

COMMENTS 3."PIPE ONCABLLE.

REVIEWED BYISIGNATURe B.C.IBEANORI $R$ T ThaA REVIEWED DATE $12 / 2 / 52$

' Approximate weight using M\&TE category 3 equipment. 
WSRC-TR-93-0094

Attuchment 10. Test Data Sheets (82 of 155)

Savannah River Technology Center

Equipment Engineering

Seismic IVI Drop Test Program

EES-FP-380, Rev. 0

Aircraft Cable Drop Tests

Date Approved: 9/16/92, Category 2

Page 12 of 14

\subsection{ATTACHMENT 2 \\ IEST DATA GHEET \\ PRE TEST}

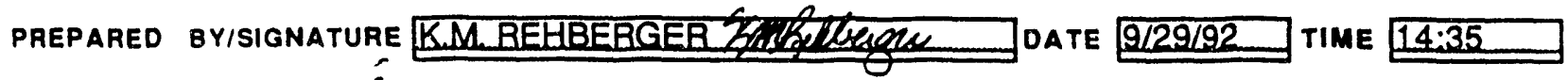
DROP HEIGHT [IN] (Measured from top of cable support) $6 \mathrm{O}^{n}$

SHORTEST POSSIBLE DIST [IN] BETWEEN

CABLE SUPPORTS (IN] (EES-22116-R1-012) $97^{\prime \prime}$

LENGTH OF CABLEJLOAD CELL ASSEMBLY (IN) $198^{\prime \prime}$

DROP TEST NUMBER (Sequential; 1, 2, 3, ... 59

\section{DATA ACQUISITION}

CHANNEL 1 \& CHANNEL 1 \& TAIGgER

RTD ID No. 2 RANGE (V) 2 OFFSET (V) LEVEL (\%)

BTD710A

10
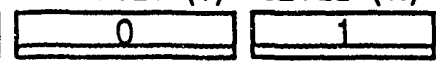

ARM DELAY (s)

ADDITIONAL DATA AQUISITION INFORMATION

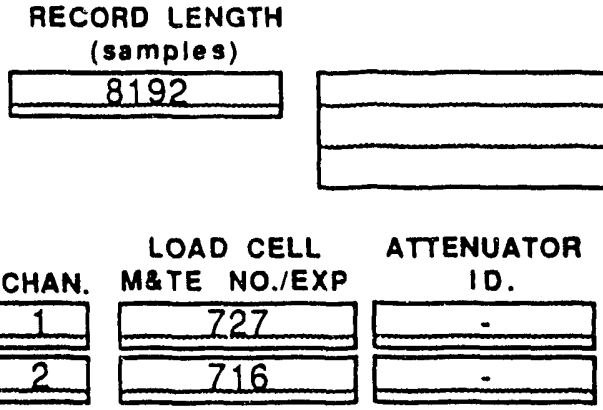

CHARGE

AMPS TRANSDUCER

AMPS TRANSDUCER MUN

C36396.

136420

SENSITIVITY SETTING (PC/LB)

\begin{tabular}{|c|}
\hline 500 \\
\hline 500 \\
\hline
\end{tabular}

SAMPLE INTERVAL ( $\mu s)$ 200

POST TEST

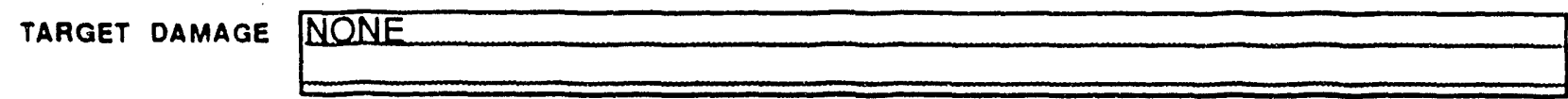

SOURCE DAMAGE LARGE DEFORMATLNATMIDSPANOE DUCT

HANO HELD VIDEO START \& STOP POSITION NLA

HIGH SPEED VIDEO START \& STOP POSITION 03:32-04:04

COMMENTS

3." PIPE ON CABLE: NO DATA SHEET WAITIENUP EOR DROP PRICR TO THIS DRQP@13:50 NQPIPE WAS ON CABLE:NODATA

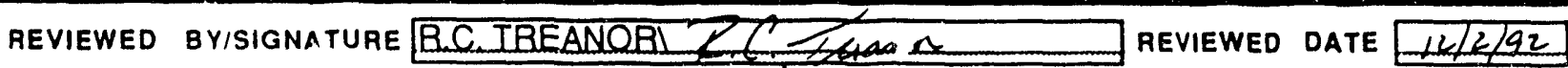

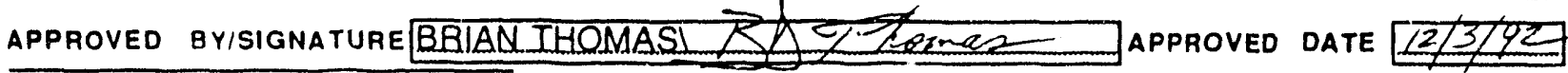

${ }^{\dagger}$ Approximate weight using M\&TE category 3 equipment 
WSRC.TR-93-0094

Attachment 10. Test Data Sheets (83 of 155)

Savannah River Technology Center Equipment Engineering Seismic II// Drop Test Program Aircraft Cable Drop Tests

EES-FP-380, Rev. 0 Date Approved: 9/16/92, Category 2

Page 12 of 14

\subsection{ATTACHMENT 2 \\ IEST DATA SIIEET \\ PRE TEST}

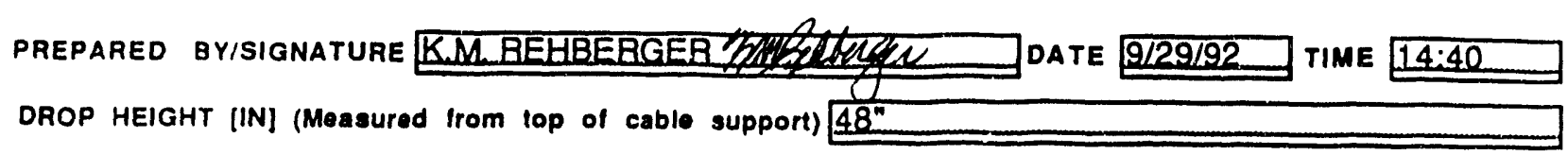
SHORTEST POSSIBLE DIST [IN] BETWEEN CABLE SUPPORTS [IN] (EES-22116-R1-012) $97^{*}$

LENGTH OF CABLE/LOAD CELL ASSEMBLY (IN)

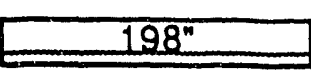

DROP TEST NUMBER (Sequential; 1, 2, 3, ... 60

\section{DATA ACQUISITION}

CHANNEL 1 \& CHANNEL 1 \& TRIGGER

RTD ID No. 2 RANGE (V) 2 OFFSET (V) LEVEL (\%)

BID710A 10 RECORD LENGTH (samples)

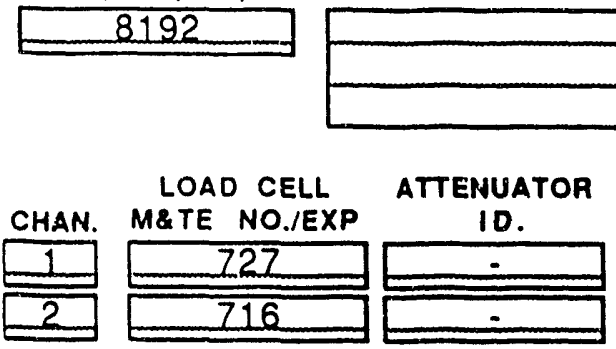

ADDITIONAL DATA AQUISITION INFORMATION SOURCE \& ADAPTER WT [LBS] 43 LBS SOURCE ORIENTATION HOBIZONTAL NOBMAL

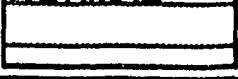

SAMPLE LEVEL (\%) ARM DELAY (s) TAIG DELAY (ms) INTERVAL (Hs)

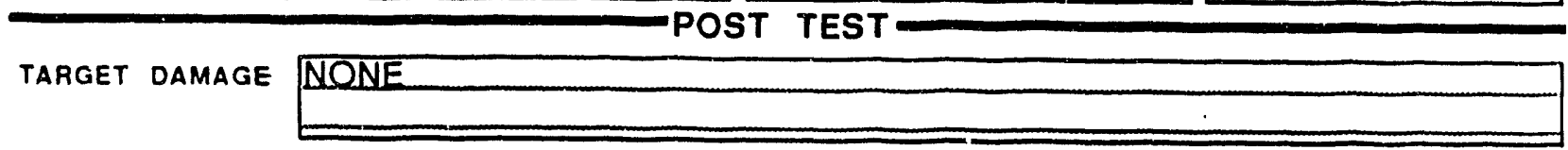

SOURCE DAMAGE NONE

HAND HELD VIDEO START \& STOP POSITION N/A

HIGH SPEED VIDEO START \& STOP POSITION $04: 04-04: 23$

COMMENTS $30^{\prime \prime}$ PIPEONCABLE

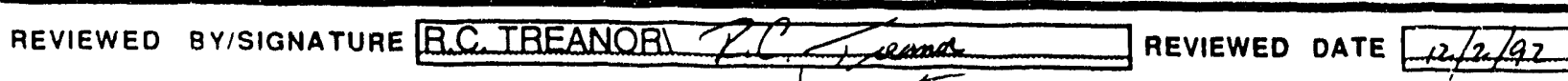
APPROVED BYISIGNATURE BRIAN THQMASI APPOVED DATE $12 / 3 / 92$

\footnotetext{
†Approximate weight using M\&TE category 3 equipment
} 
IVSRC.TR-93-0094

Attachment 10. Test Data Sheets $(8+$ of 155$)$

Savannah River Technology Center Equipment Engineering Seismic IVII Drop Test Program Aircraft Cable Drop Tests

EES-FP-380, Rev. 0 Date Approved: 9/16/92, Category 2

Page 12 of 14

\subsection{ATTACHMENT 2 \\ IEST UATA STIEEI \\ PRE TEST}

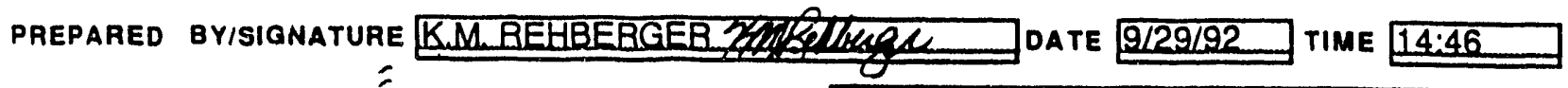
DROP HEIGHT [IN] (Measured from lop of cable support) 60" SHORTEST POSSIBLE DIST [IN] BETWEEN $97^{\circ}$ DROP SOURCE, IO LIGHIDUCT
CABLE SUPPORTS [IN] (EES-22116-RT-012) LENGTH OF CABLELOAO CELL
ASSEMBLY (IN) SOURCE \& AD́dAPTER WT [LBS] 43 LBSS SOURCE ORIENTATION HORIZONTAL

OROP TEST NUMBER (Sequential; 1, 2, 3,... 61

DATA ACQUISITION NOBMAL

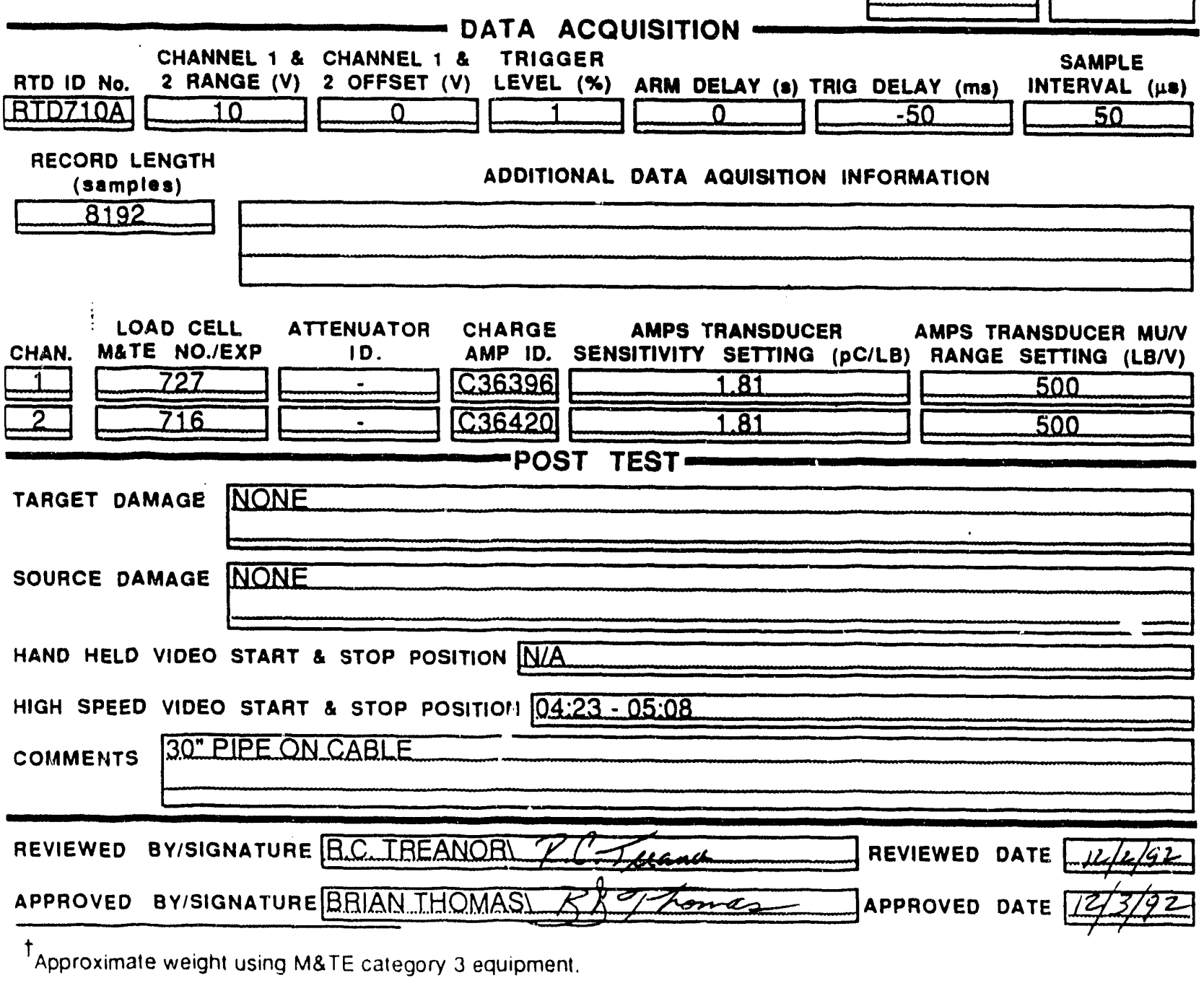


IVSRC-TR-93-0094

Attachment 10. Test Data Sheets (85 of 155)

Savannah River Technology Center

Equipment Engineering

EES-FP-380, Rev, 0

Seismic II/I Drop Test Program

Aircraft Cable Drop Tests

\subsection{ATTACHMENT 2 \\ TEST DATA SHEEI}

PRE TEST

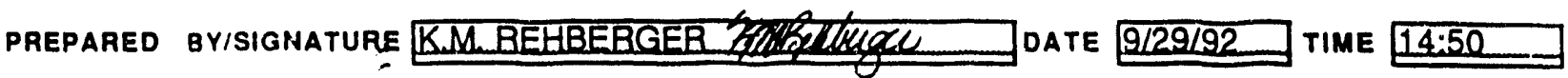
DROP HEIGHT [IN] (Measured from top of cable support) $48^{n}$

SHORTEST POSSIBLE DIST [IN] BETWEEN

CABLE SUPPORTS [IN] (EES-22116-R1-012)

LENGTH OF CABLELOAD CELL

ASSEMBLY (IN)

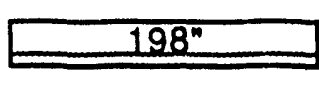

97

DROP SOUACE, 10 LIGHTDUSI

SOURCE \& ADAPTER WT [LBS] 43 LBS

DROP TEST NUMBER (Sequential; 1, 2, 3,... 62

\section{DATA ACQUISITION}

CHANNEL 1 \& CHANNEL 1 \& TAIGGER

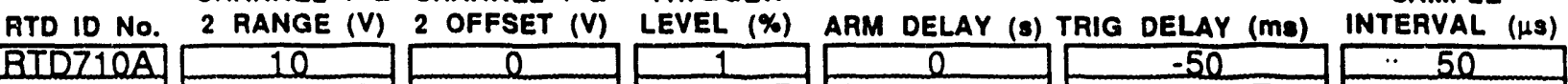

RECORD LENGTH

(samples)

ADOITIONAL DATA AQUISITION INFORMATION
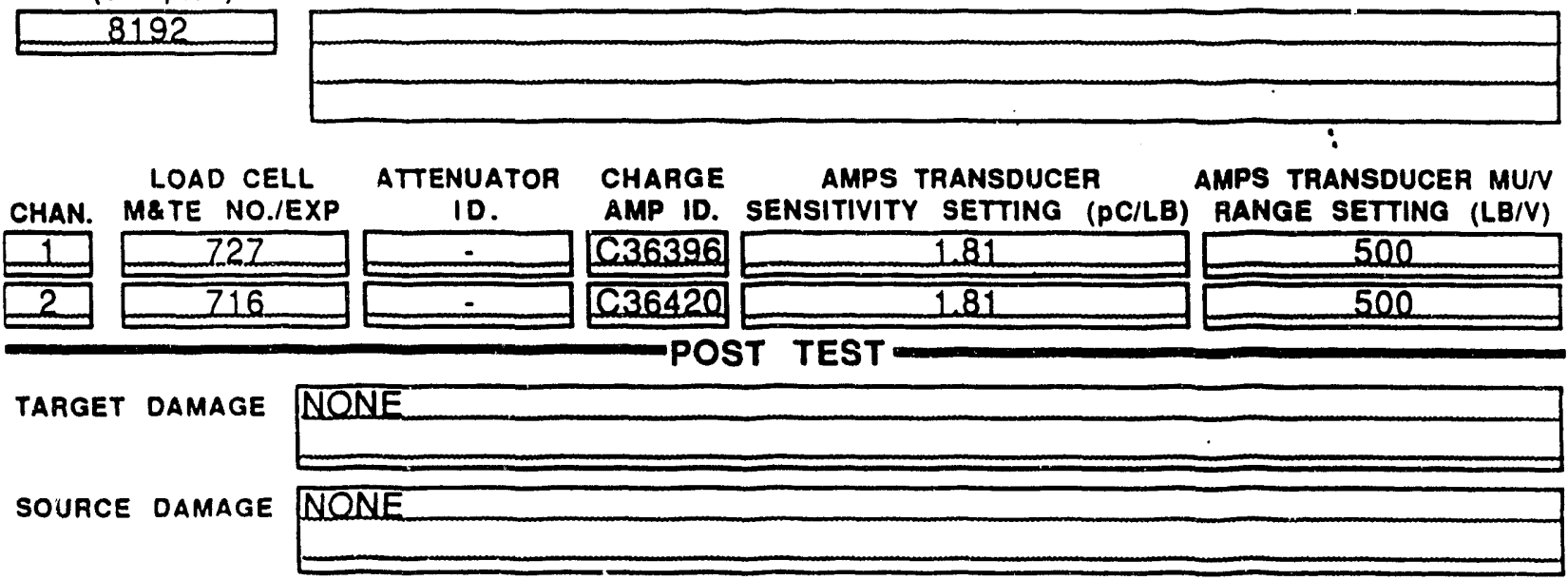

HAND HELD VIDEO START \& STOP POSITION NIA

HIGH SPEED VIDEO START \& STOP POSITION $05: 08-05: 43$

COMMENTS 30 "PIPE ONCABLE

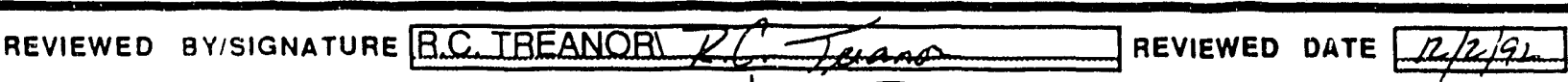

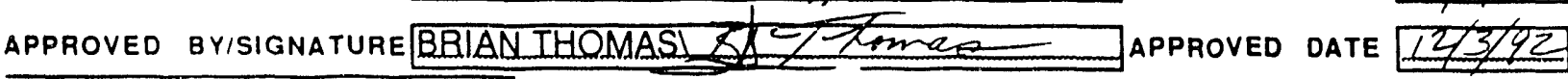

${ }^{\dagger}$ Approximate weight using M\&TE category 3 equipment. 
IVSRC-TR-93-0094

Attachment 10. Test Data Sheets (86 of 155)

Savannah River Technology Center

Equipment Engineering

EES-FP-380, Rev. 0

Seismic II// Drop Test Program

Aircraft Cable Drop Tests

\subsection{ATTACHMENT 2 \\ TEST UAIA SHEEI}

PRE TEST

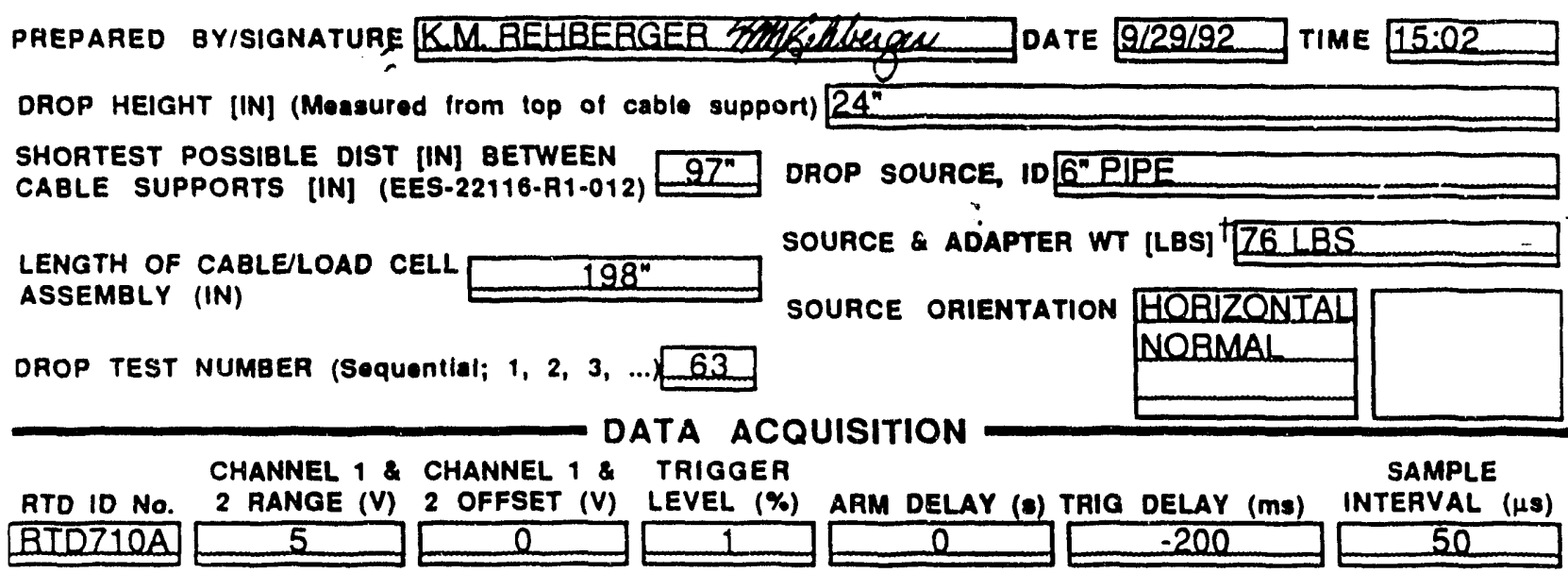

RECORD LENGTH

(samples)

8192
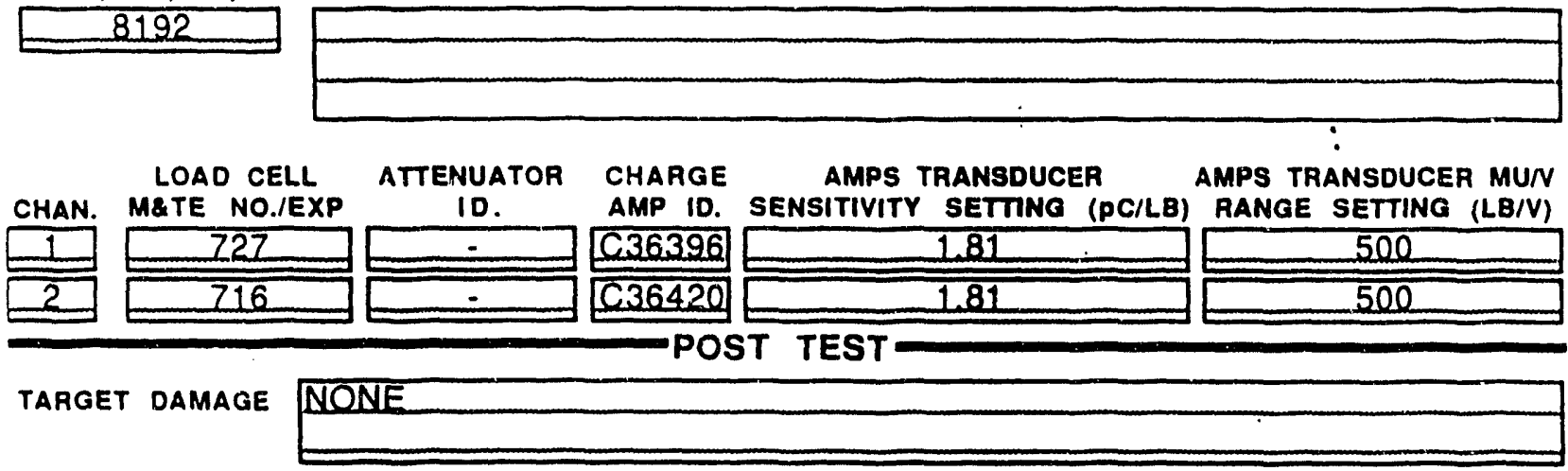

SOURCE DAMAGE NONE

HAND HELD VIDEO START \& STOP POSITION NIA

HIGH SPEED VIDEO START \& STOP POSITION $05: 43-06: 22$

COMMENTS 3." RIPEONCABLE

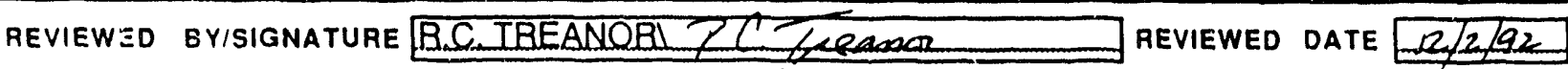
APPROVED BYISIGNATURE BRIAN IHOMASI KAY

†Approximate weight using M\&TE category 3 equipment. 
WSRC-TR-93-0094

Attachment 10. Test Data Sheets (87 of 155)

Savannah Hiver Technology Center

EES-FP-380, Rev. 0

Equipment Engineering

Seismic II/I Drop Test Program

Date Approved: 9/46/92, Category 2

Aircraft Cable Drop Tests

Page 12 of 14

\subsection{ATTACHMENT 2 \\ TEST DATA SHEET}

PRE TEST

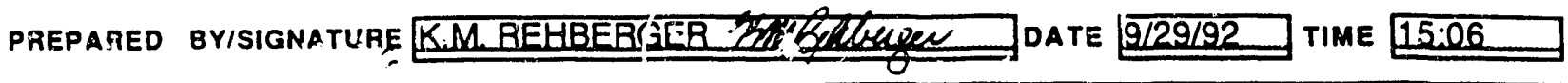
DROP HEIGHT [IN] (Measured from top of cable support) $36^{\text {" }}$

SHOATEST POSSIBLE DIST [IN] BETWEEN $97^{*}$ OROP SOURCE, ID $6^{*}$ EIPE
CABLE SUPPORTS [IN] (EES-22116-R1-U12)
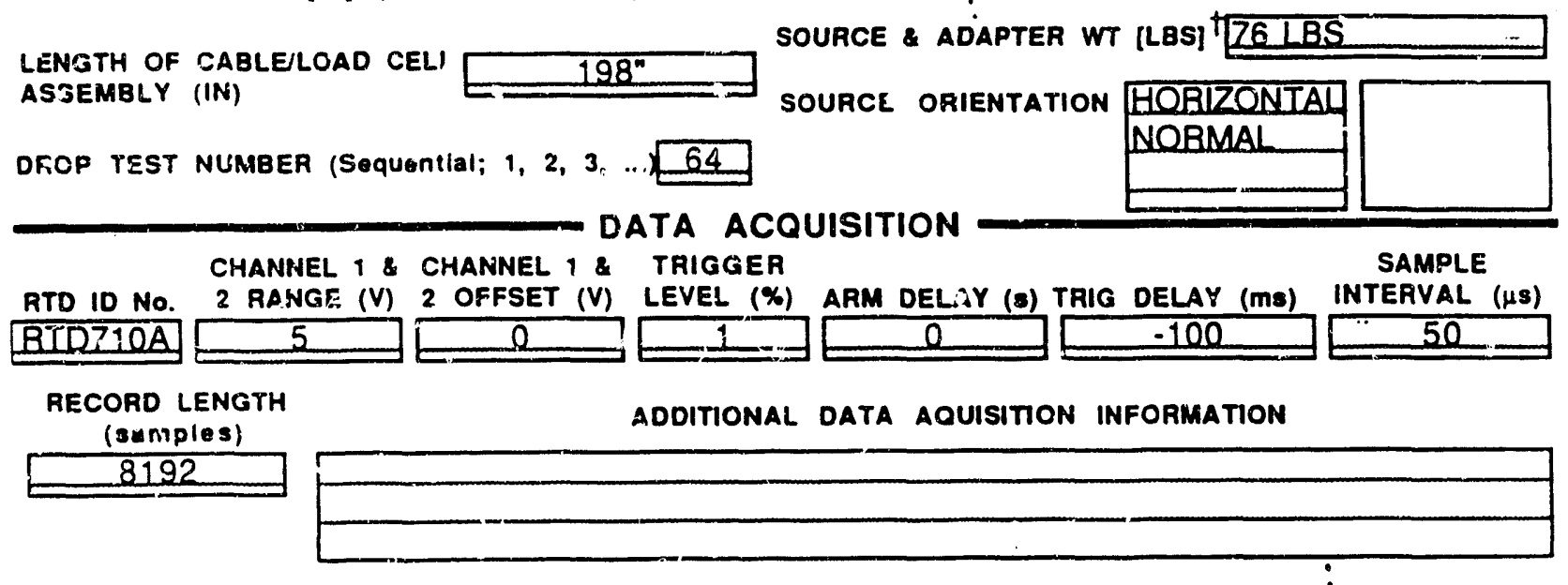

LOAD CELL ATTENUATOR CHARGE
CHAN. M\&TE NO./EXP AMPS TRANSDUCER
ID.

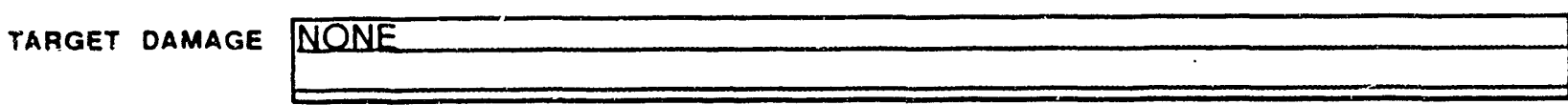

SOUPCE DAMAGE NONE

HAND HELD VIDEO START \& STOP POSITION NLA

HIGH SPEED VIDEO START \& STOP POSITION $06: 22-07: 12$

COMMENTS 3."PIPE ONCABLE

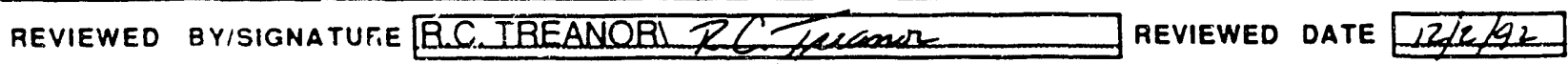

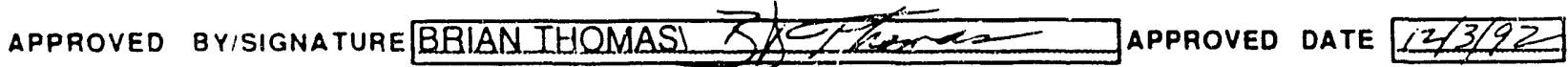

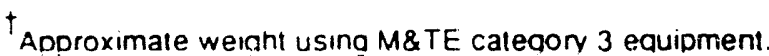


IVSRC-TR-93-0094

Attachment 10. Test Data Sheets (88 of 155)

Savannah River Technology Center

Equipment Engineering

Seismic II/I Drop Test Program

Aircraft Cable Drop Tests
EES-FP-380, REV. 0

Date Approved: 9/16/92, Category 2

Page 12 of 14

\subsection{ATTACHMENT 2}

TEST DATA SHEET

PRE TEST

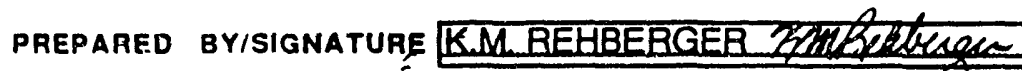

OROP HEIGHT [IN] (Measured from top of cable support) $36^{n}$

SHORTEST POSSIBLE DIST [IN] BETWEEN

CABLE SUPPORTS [IN] (EES-22116.A1-012)

LENGTH OF CABLEJLOAD CELL

ASSEMBLY (IN)

$198^{n}$

$97^{\prime \prime}$

DROP TEST NUMBER (Sequent al; 1, 2, 3, ... 65

DATA ACQUISITION

CHANNEL 1 \& CHA NNEL 1 \& TRIGGER

RTD ID No. 2 RANGE (V) 2 OF, SSET (V) LEVEL (\%)

BIDZ10A
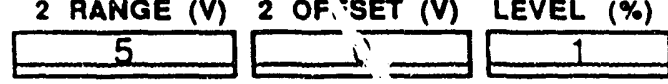

ARM DELAY (s) TRIO DELAY (ms) DATE $9 / 29 / 92$ TIME $15: 11$
SAMPLE INTERVAL ( $\mu \mathrm{s})$

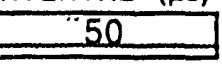

RECORD LENGTH

(samples)

8192
AODITIONAL DATA AQUISITION INFORMATION

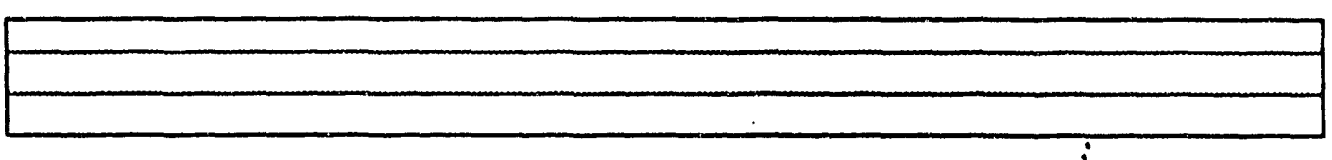
AMP ID. SENSITIVITY SETTING (PC/LB) RANGE SETTING (LBN)

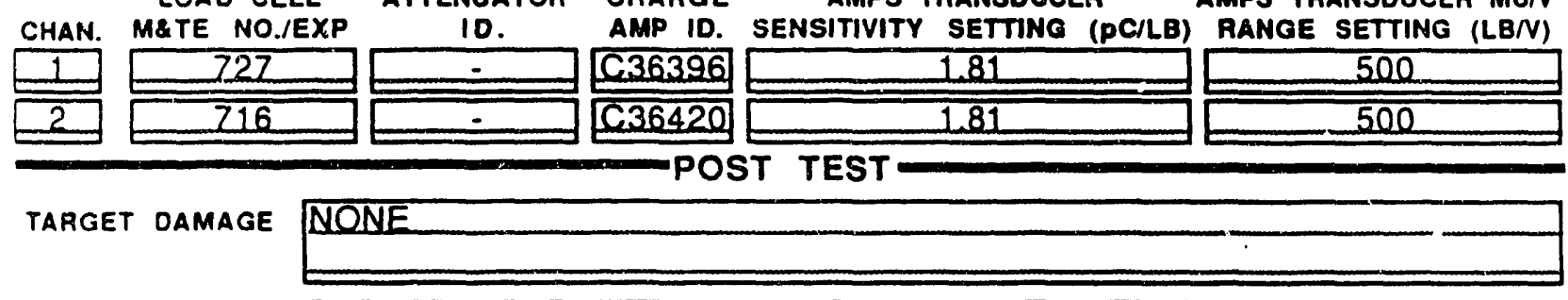

SOURCE DAMAGE NONE

HAND HELD VIDEO START \& STOP POSITION ULA

HIGH SPEED VIDEO START \& STOP POSITION $07: 12-07: 47$

COMMENTS 3." PIPE ONCABLE ANLINDIBECT HIT BY THE SQUBCE

CH2 AMP INDICATED AN OVERLOAD.HOWEVER PLOT ARPEARS TO BE GOOD

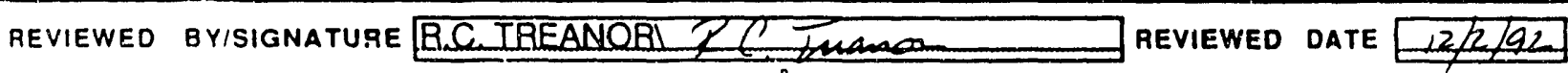
APPROVED BYISIGNATURE BBIAN THQMASL

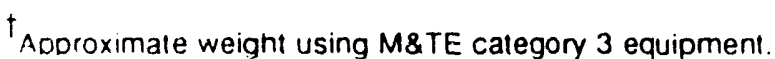


WSRC-TR-93-0094

Attachment 10. Test Data Sheets (89 of 155)

Savannah River Technology Center Equipment Engineering

EES-FP-380, Rev. 0

Seismic II/I Drop Test Program

Aircraft Cable Drop Tests

Date Approved: 9/16/92, Category 2

Page 12 of 14

\subsection{ATTACHMENT 2 \\ TEST DATA SHEET \\ PRE TEST}

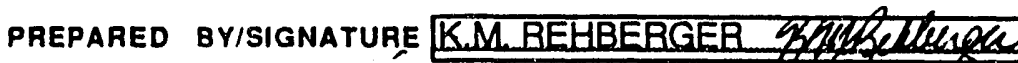

DROP HEIGHT [IN] (Moasured from top of cable support) $48^{\mathrm{n}}$

SHORTEST POSSIBLE DIST [IN] BETWEEN

CABLE SUPPORTS [IN] (EES-22116-R1-012) $97^{\prime \prime}$

DROP SOURCE, I0 $6^{\prime \prime}$ IIPE

LENGTH OF CABLE/LOAD CELL

ASSEMBLY (IN)

$198^{\prime \prime}$

SOURCE \& ADAPTER WT [LBS] 76 LBS

JROP TEST NUMBER (Sequentlal; $1,2,3, \ldots 6$

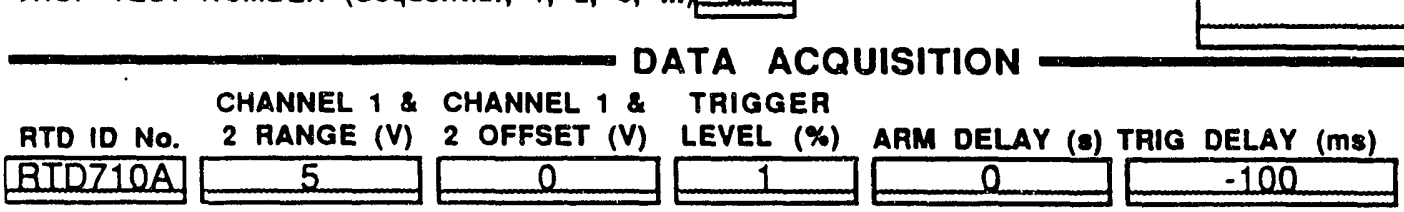

\begin{tabular}{l} 
CHANNEL 1 \& CHANNEL 1 \& TRIGGER \\
RTD ID No. 2 RANGE (V) 2 OFFSET (V) LEVEL (\%) ARM DELAY (8) TRIG DELAY (ms) \\
\hline BID710A \\
\hline 5
\end{tabular} SOURCE ORIENTATION HORIZONTAL

SAMPLE BID710A RECORD LENGTH (samples)

ADDITIONAL DATA AQUISITION INFORMATION 8192 PLOT INDICATES THAT WE MISSED THE IMPACT PEAK. NQISEIS AMPLIFIED BY THE SCALE

\begin{tabular}{|c|c|c|c|c|c|}
\hline HAN. & $\begin{array}{l}\text { LOAD CELL } \\
\text { METE NO./EXP }\end{array}$ & $\begin{array}{l}\text { ATTENUATOR } \\
\text { ID. }\end{array}$ & $\begin{array}{l}\text { CHARGE } \\
\text { AMP ID. }\end{array}$ & $\begin{array}{l}\text { AMPS TRANSDUCER } \\
\text { SENSITIVITY SETTING (pC/LB) }\end{array}$ & $\begin{array}{l}: \\
\text { AMPS TRANSDUCER MUN } \\
\text { RANGE SETTING (LB/V) }\end{array}$ \\
\hline 1 & 727 & - & C36396 & 1.81 & 500 \\
\hline$\overline{2}$ & $\overline{716}$ & - & C36420 & 181 & 500 \\
\hline
\end{tabular}

POST TEST

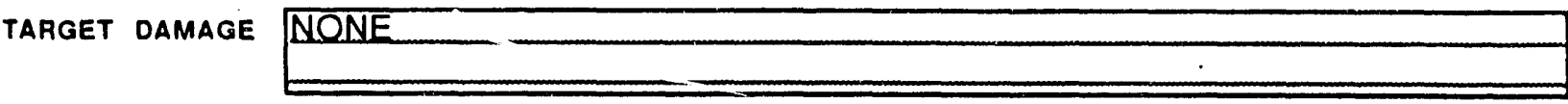

SOURCE DAMAGE NQNE

HAND HELO VIDEO START \& STOP POSITION NIA

HIGH SPEED VIDEO START \& STOP POSITION NQHIGH SPEED VIDEO TAKEN

COMMENTS $3.0^{n}$ PIPE ONCABLE

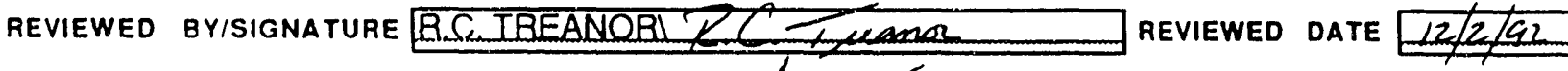

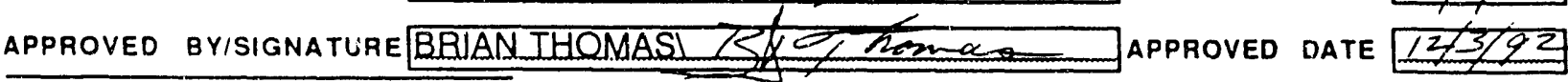

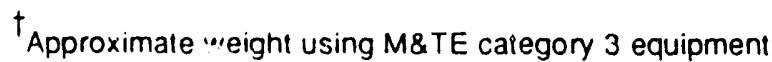


IVSRC-TR-93-0094

Attachment 10. Test Data Shects (90 of 155 )

Savannah River Technology Center

Equipment Engineering

EES-FP-380, Rev. 0

Seismic II/I Drop Test Program

Aircraft Cable Drop Tests

\section{Date Approved: 9/16/92, Category 2}

Page 12 of 14

\subsection{ATTACHMENT 2 \\ IESI UATA SHEET}

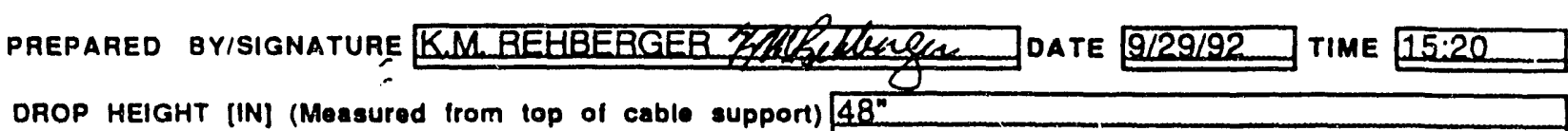

SHORTEST POSSIBLE DIST [IN] BETWEEN CABLE SUPPORTS [IN] (EES-22116-R1-012)

LENGTH OF CABLE/LOAD CELL ASSEMBLY (IN) $198^{m}$ $97^{n}$ DROP SOURCE, ID $6^{n}$ PIPE SOURCE \& ADAPTER WT [LBS] ZG LBS

DROP TEST NUMBER (Sequential; $1,2,3, \ldots 67$

DATA ACQUISITION

CHANNEL 1 \& CHANNEL 1 \& TRIGgeR SOURCE ORIENTATION HOBIZONTAL NOBMAL

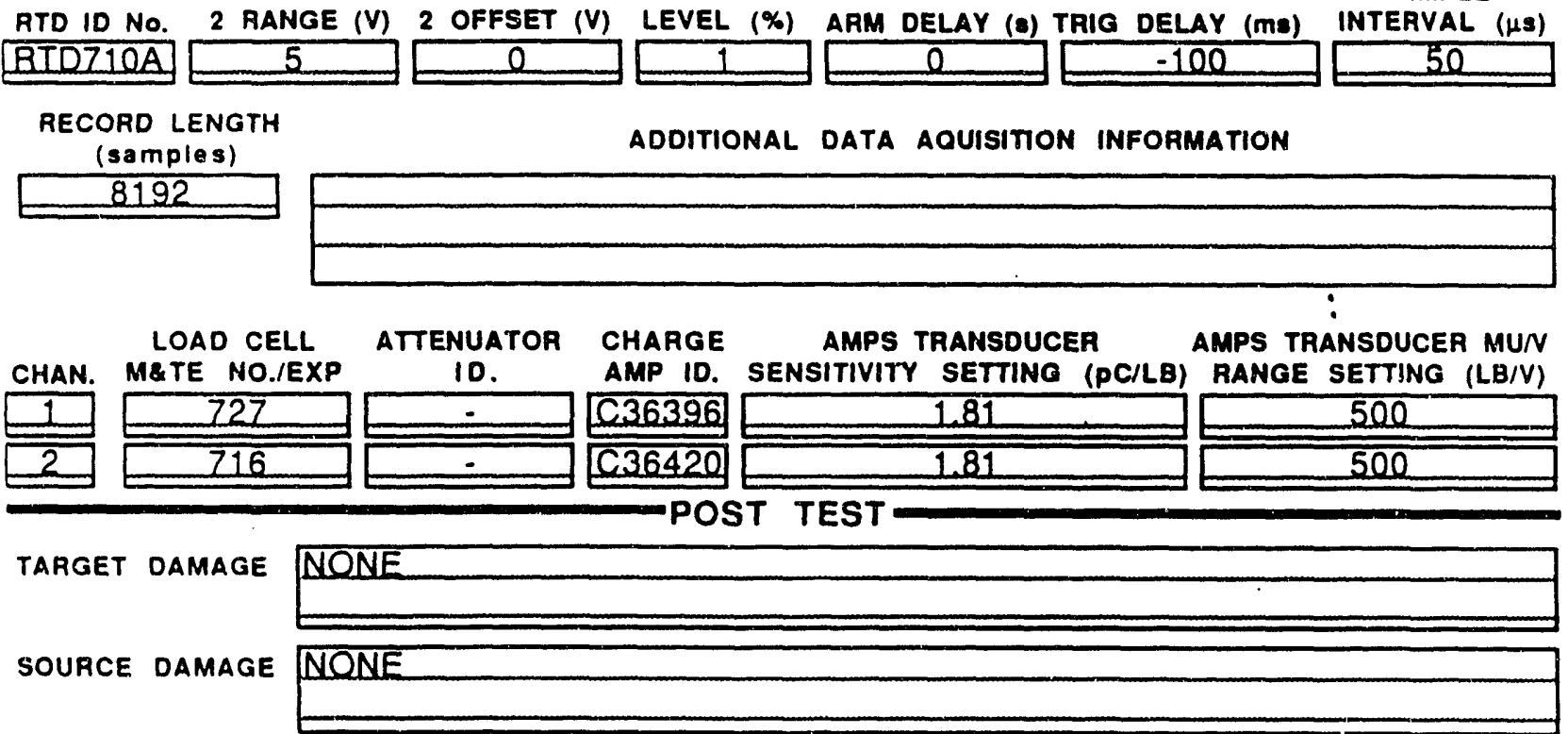

HAND HELD VIDEO START I STOP POSITION IILA

HIGH SPEED VIDEO START \& STOP POSITION $07: 47-08: 33$

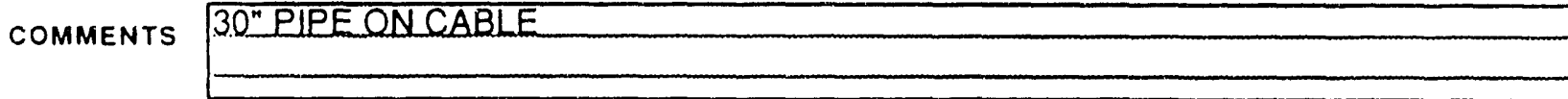

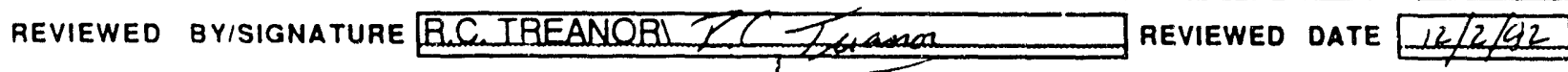

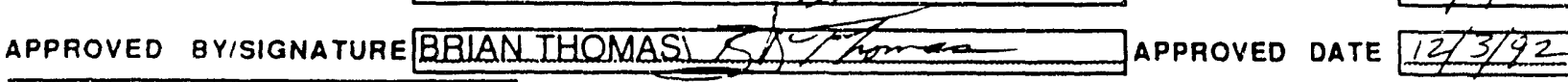

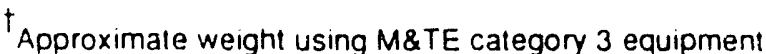


WSRC-TR-93-0094

Attachment 10. Test Data Sheets (91 of 155 )

Savannah River Technology Center

Equipment Engineering

EES-FP-380, Rev. 0

Seismic II// Drop Test Program

Date Approved: 9/16/92, Category 2

Aircraft Cable Drop Tests

\subsection{ATTACHMENT 2}

IEST DATA SHEEI

PRE TEST

PREPARED BYISIGNATURE KM. BEHBERGER Gelteales

DROP HEIGHT [IN] (Measured from top of cable support) $48^{n}$

SHORTEST POSSIBLE DIST [IN] BETWEEN CABLE SUPPORTS [IN] (EES-22116-R1.012)

LENGTH OF CABLELLOAD CELL ASSEMBLY (IN)

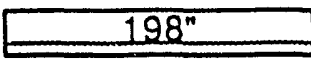
$97^{\prime \prime}$ DROP SOURCE, $106^{n}$ PIPE SOURCE \& ADAPTER WT [LBS] Z6 LBS

DROP TEST NUMBER (Sequentlal; $1,2,3, \ldots 68$

DATA ACQUISITION

CHANNEL 1 \& CHANNEL 1 \& TRIGGER SOURCE ORIENTATION HOBIZONTAL

NOBMAL

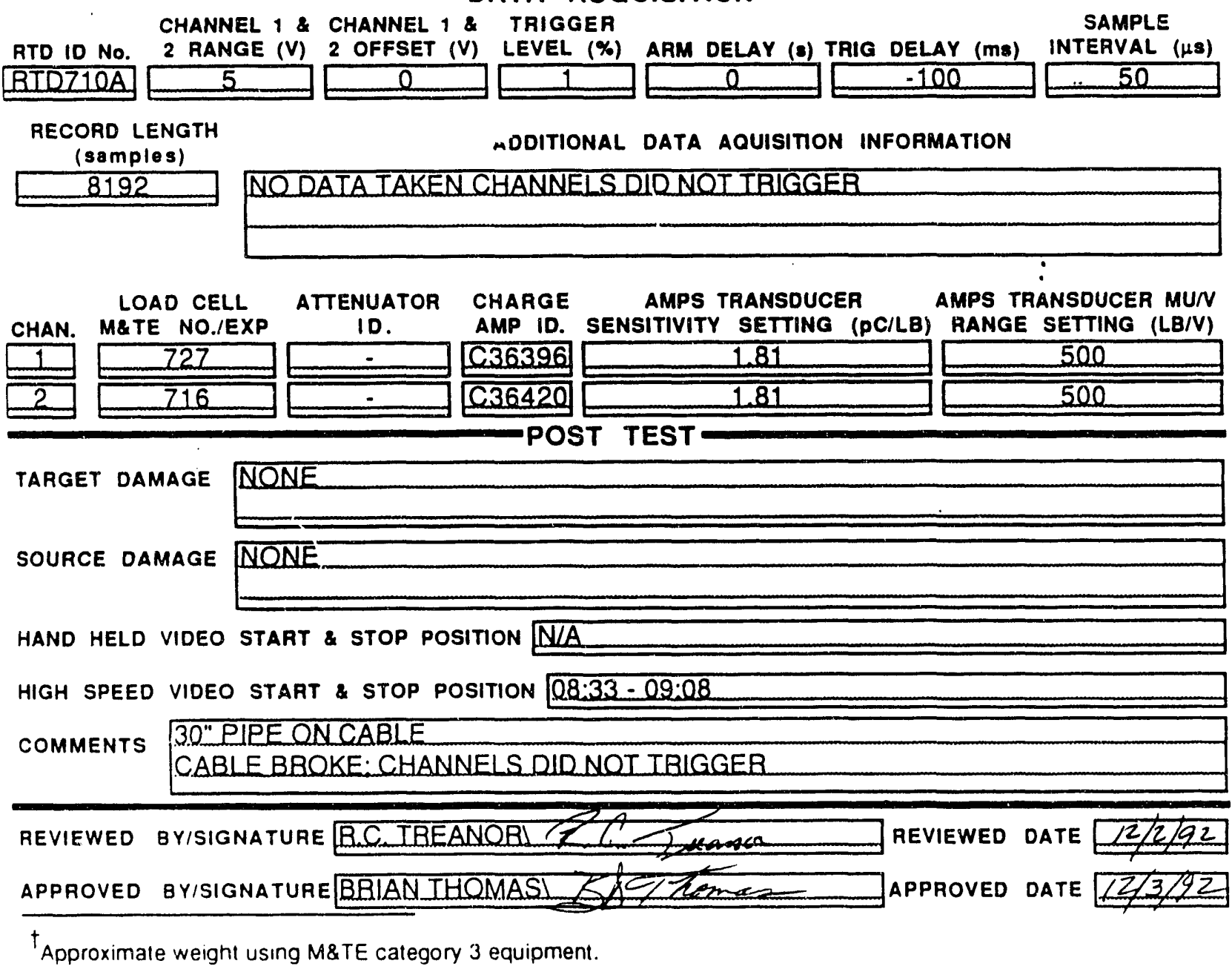


IVSRC-TR-93-0094

Attachment 10. Test Data Sheets (92 of 155 )

Savannah River Technology Center

Equipment Engineering

Seismic II// Drop Test Program

Aircraft Cable Drop Tests
EES-FP-380, Rev, 0

Date Approved: 9/16/92, Category 2

Page 12 of 14

\subsection{ATTACHMENT 2 \\ TEST DATA SHEET}

PRE TEST

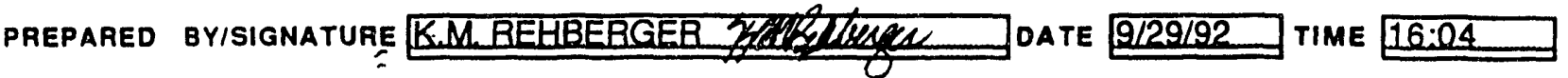
DROP HEIGHT [IN] (Messured from top of cable support) 24"

SHORTEST POSSIBLE DIST [IN] BETWEEN

CABLE SUPPORTS [IN] (EES-22116.R1-012)

LENGTH OF CABLELOAD CELL

ASSEMBLY (IN)

DROP TEST NUMBER (Sequentlal; $1,2,3, \ldots 69$
DROP SOURCE, IO CABLE IBAY

SOURCE \& ADAPTER WT [LBS] 101 LBS

SOURCE ORIENTATION HOBIZONTAI

DATA ACQUISITION NOBMAL

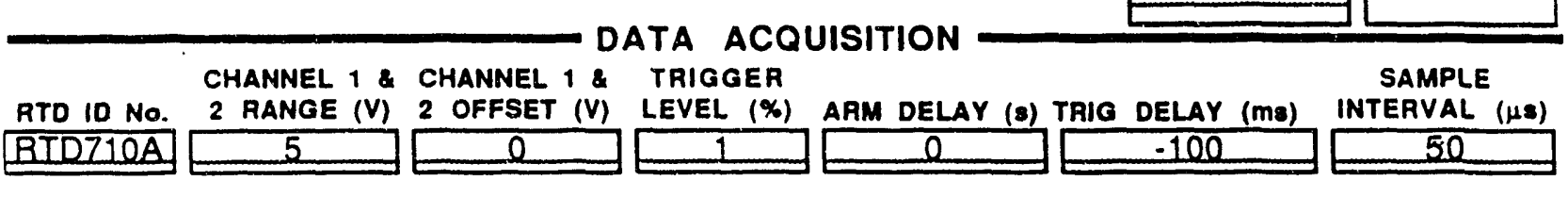

RECORD LENGTH

(samples)

8192

ADDITIONAL DATA AQUISITION INFORMATION
CHARGE AMPS TRANSDUCER AMPS TRANSDUCER MUN AMP ID. SENSITIVITY SETTING (PC/LB) RANGE SETTING (LB/V) C36396 836420 $\begin{array}{r}500 \\ \hline 500\end{array}$

\begin{tabular}{l} 
CHAN. M\&TE NO.IEXP \\
\hline 1 \\
\hline 2 \\
\hline 716 \\
\hline
\end{tabular}

POST TEST

TARGET DAMAGE NONE

SOURCE DAMAGE NONE

HAND HELD VIDEO START \& STOP POSITION NIA

HIGH SPEED VIOEO START \& STOP POSITION $0.9: 08-02: 46$

COMMENTS 30"PIPE ONCABLE

NEW CABLE WAS SET UP

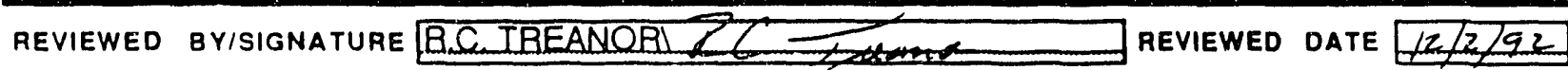

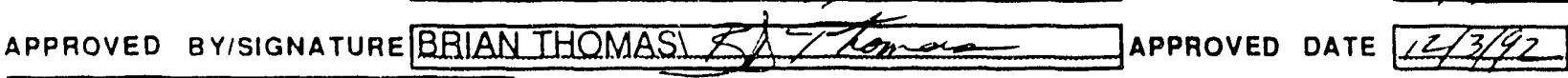

$\dagger^{\dagger}$ Approximale weight using M\&TE category 3 equipment. 
WSRC-TR-93-0094

Attachment 10. Test Data Sheets (93 of 155)

Savannah River Technology Center

Equipment Engineering

EES-FP-380, , Zev. 0

Seismic II/I Drop Test Program

Aircraft Cable Drop Tests

Date Approved: 9/16/92, Category 2

Page 12 of 14

\subsection{ATTACHMENT 2 \\ TEST DATA SHEET \\ PRE TEST}

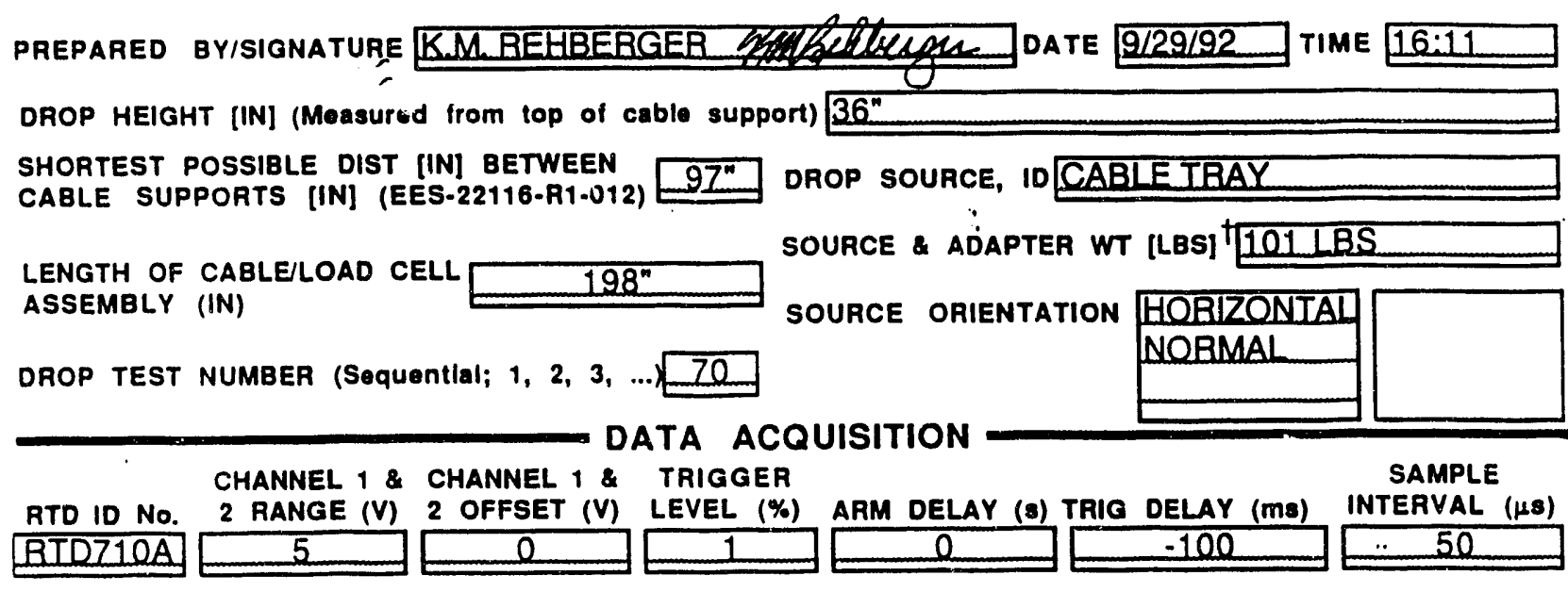

RECORD LENGTH

(samples)

AODITIONAL DATA AQUISITION INFORMATION

8122 ONLY CAUGHT TRAILEDGE OE LOAD SPIKE

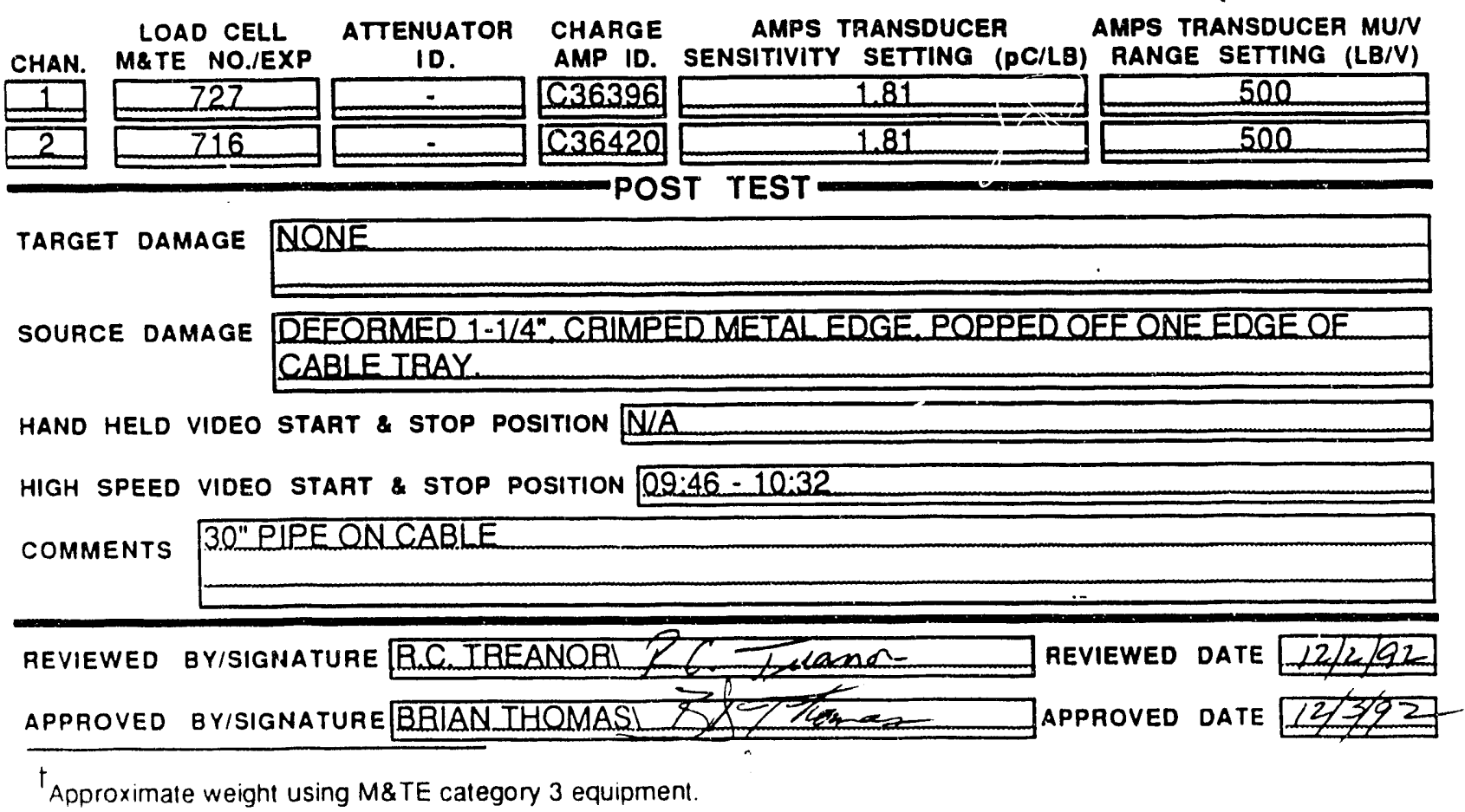


IVSRC.TR-93-0094

Attachment 10. Test Data Sheets (93a of 155)

Savannah River Technology Center

Equipment Engineering

Seismic II/I Drop Test Program

Aircraft Cable Drop Tests

EES-FP-380, Rev. 0

Date Approved: 9/16/92, Category 2

Page 12 of 14

\subsection{ATTACHMENT 2 \\ TEST DATA SHEET}

PRE TEST

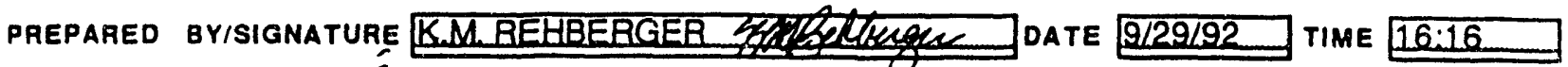
DROP HEIGHT [IN] (Measured from top of cable support) 24"

SHORTEST POSSIBLE DIST [IN] BETWEEN

CABLE SUPPORTS [IN] (EES-22116-R1.012) $97^{\circ}$

LENGTH OF CABLELOAD CELL

ASSEMBLY (IN)

$198^{\prime \prime}$

\section{ㄴ.}

DROP SOURCE, ID CABLETBAY

SOURCE \& AÖAPTER WT [LBS] T101LBS

SOURCE ORIENTATION HOBIZONTAL

DROP TEST NUMBER (Sequentlal; 1, 2, 3,... 71

NOBMAL

DATA ACQUISITION

CHANNEL 1 \& CHANNEL 1 \& TRIGGER

\begin{tabular}{l} 
RTO 10 No. 2 RANGE (V) 2 OFFSET (V) LEVEL (\%) ARM DELAY (s) TRIQ DELAY (ms) INTERVAL ( $\mu$ s) \\
BID710A \\
\hline 5
\end{tabular}

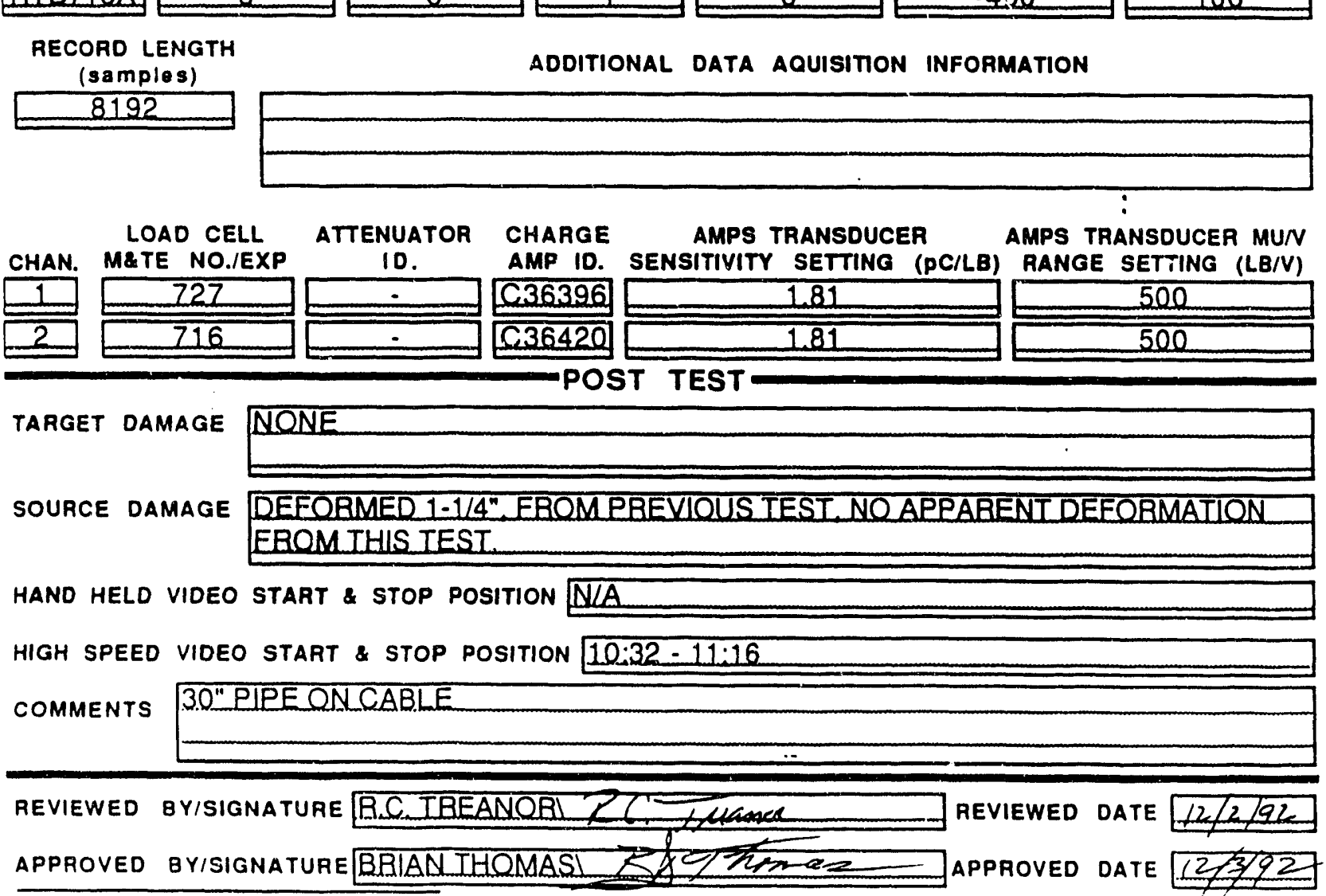

$\dagger^{\dagger}$ Approximale weight using M\&TE category 3 equiprnent. 
WSRC.TR-93-0094

Attachment 10. Test Data Sheets (94 of 155)

Savannah River Technology Center

EES-FP.380, Rev. 0

Equipment Engineering

Date Approved: 9/16/92, Category 2

Seismic II// Drop Test Program

Page 12 of 14

Aircraft Cable Drop Tests

\subsection{ATTACHMENT 2 \\ TEST DATA SHEEI}

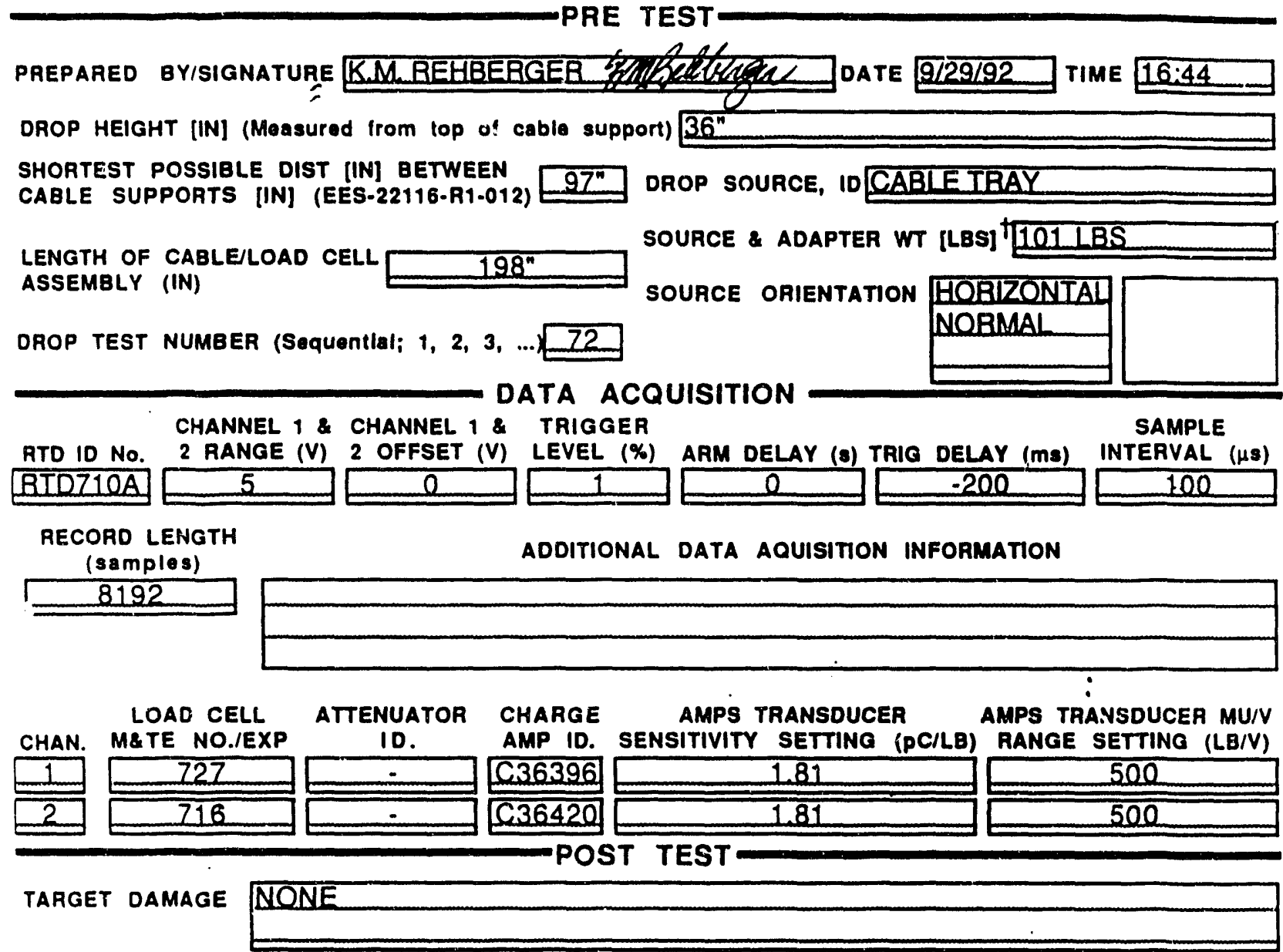

SOURCE DAMAGE NONE

HAND HELD VIDEO START \& STOP POSITION NIA

HIGH SPEED VIDEO START \& STOP POSITION $11: 16-11: 47$

COMMENTS 30 "PIPE ONCABLE

CH 2 SHOWED SIGNS OE NOT TBIGGEAING

REVIeWed byisignature B.C.TBEANOBI R Reviewed date $12 / 2 / 92$

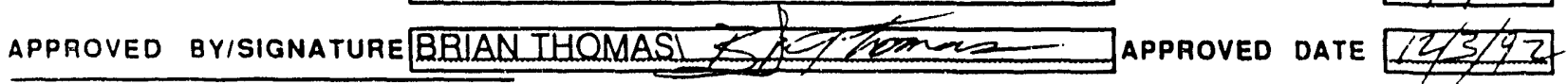

${ }^{\dagger}$ Approximate weight using M\&TE category 3 equipment. 
WSRC-TR-93-0094

Attachment 10. Test Data Sheets (95 of 155)

Savannah River Technology Center Equipment Engineering Seismic II/I Drop Test Program Aircraft Cable Drop Tests
EES-FP-380, Rev. 0 Date Approved: 9/16/92, Category 2

Page 12 of 14

\subsection{ATTACHMENT 2 \\ TEST DATA SHEEI \\ PRE TEST}

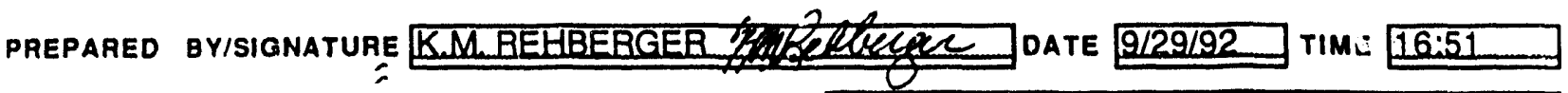
DROP HEIGHT [IN] (Measured from top of cable support) $36^{\text {" }}$

SHORTEST POSSIBLE DIST [IN] BETWEEN $97^{n}$ DROP SOURCE, ID 2nCONDUIT 2C-2
CABLE SUPPORTS [IN] (EES-22116-R1-012)

LENGTH OF CABLEILOAD CELL

ASSEMBLY (IN)

SOURCE \& AD́APTER WT [LBS] $193 / 4$ LBS

DROP TEST NUMBER (Sequentlal; 1, 2, 3, ... 73 SOURCE ORIENTATION HORIZONTAL

DATA ACQUISITION

CHANNEL 1 \&HANNEL 1 TRIGGER
RTD ID No. 2 RANGE (V) 2 OFFSET (V) LEVEL (\%) ARM DELAY (s) TAIO DELAY (ms) INTEAVAL (Hs)
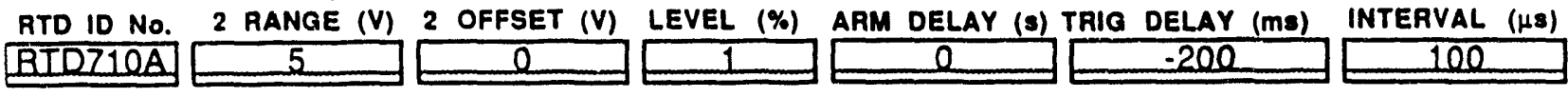

RECORD LENGTH

(samples)

8192
ADDITIONAL DATA AQUISITION INFORMATION
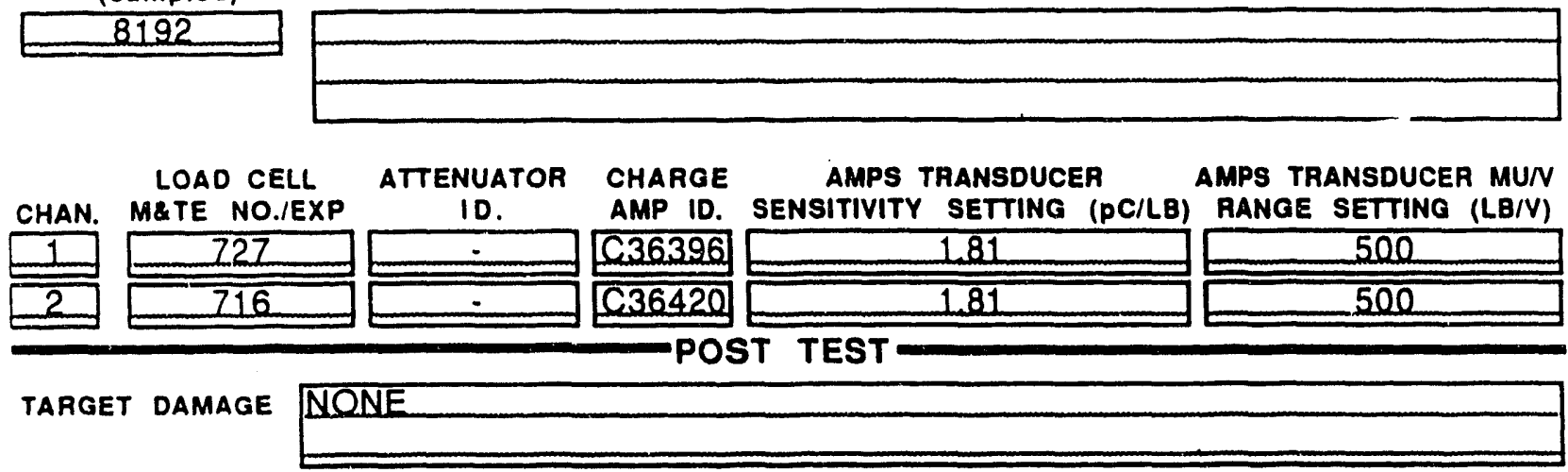

SOURCE DAMAGE NONE

HAND HELD VIDEO START \& STOP POSITION NLA

HIGH SPEED VIOEO START \& STOP POSITION NOHIGH SPEEDVIIDEO TAKEN

COMMENTS 30"PIEE ONCABLE

REVIEWED BYISIGNATURE B.C.TBEANOAI RY ReVIEWED DATE APPROVED BYISIGNATURE BRIAN THOMAS S Y Y Y

${ }^{\dagger}$ Approximate weight using M\&TE category 3 equipment. 
WSRC-TR-93-0094

Altachment 10. Test Data Sheets (96 of 155)

Savannah River Technology Center

EES-FP-380, Rev. 0

Equipment Engineering

Seismic II/I Drop Test Progre in

Aircraft Cable Drop Tests

Date Approved: 9/16/92, Category 2

Page 12 of 14

\subsection{ATTACHMENT 2 \\ IEST DATA SHEEI}

PRE TEST

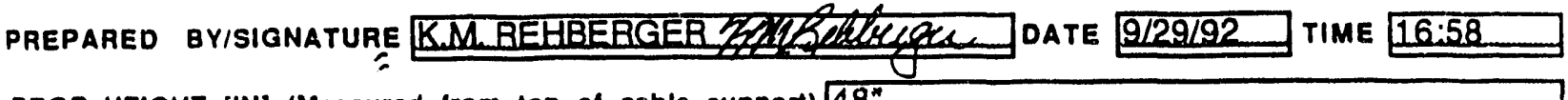
DROP HEIGHT [IN] (Moasured from top of cable support) $48^{*}$

SHORTEST POSSIBLE DIST [IN] BETWEEN

CABLE SUPPORTS [IN] (EES-22116-R1.012) $97^{n}$

LENGTH OF CABLE/LOAD CELL

ASSEMBLY (IN)

$198^{*}$

DROP SOURCE, ID $2^{n}$ CONDUII $2 \mathrm{C}-2$

SOURCE \& AÓAPTER WT [LBS] 19 3/4 LBS

DROP TEST NUMBER (Sequential; $1,2,3, \ldots 74$

SOURCE ORIENTATION HOBIZONTAL

DATA ACQUISITION

NOBMAL

CHANNEL 1 \& CHANNEL 1 \& TAIGGER

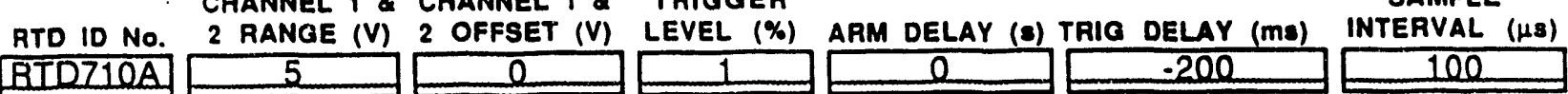

RECORD LENGTH

(samples)

ADOITIONAL DATA AQUISITION INFORMATION

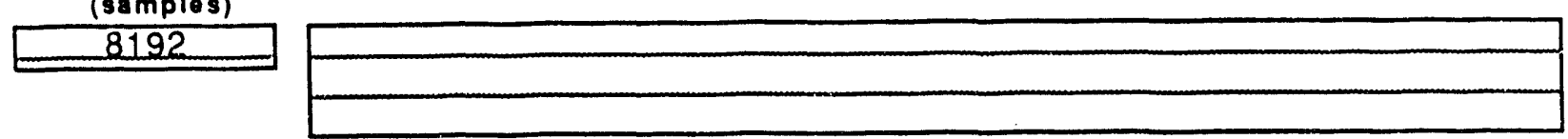

\begin{tabular}{|c|c|c|c|c|c|}
\hline CHAN. & $\begin{array}{l}\text { LOAD CELL } \\
\text { M\&TE NO./EXP }\end{array}$ & $\begin{array}{l}\text { ATTENUATOR } \\
\text { ID. }\end{array}$ & $\begin{array}{l}\text { CHARGE } \\
\text { AMP ID. }\end{array}$ & $\begin{array}{l}\text { AMPS TRANSDUCER } \\
\text { SENSITIVITY SETTING (PC/LB) }\end{array}$ & $\begin{array}{l}\text { AMPS TRANSDUCER MU/V } \\
\text { RANGE SETTING (LB/V) }\end{array}$ \\
\hline 1 & 727 & - & C36396 & 1.81 & 500 \\
\hline$\overline{2}$ & 716 & - & C.36420 & 181 & 500 \\
\hline
\end{tabular}

TARGET DAMAGE NONE POST TEST

SOURCE DAMAGE NONE

HAND HELD VIDEO START \& STOP POSITION NLA

HIGH SPEED VIDEO START \& STOP POSITION $12: 01-12: 32$

COMMENTS $30 "$ PIPEQNCABLE

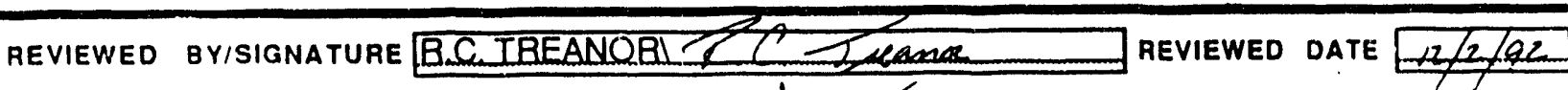

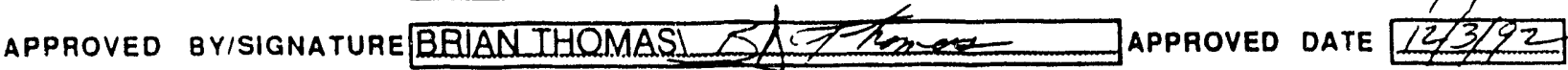

${ }^{\dagger}$ Approximale weight using M\&TE category 3 equipment. 
IVSRC-TR-93-0094

Attuchment 10. Test Duta Sheets (97 of 155)

Savannah River Technology Center

EES-FP.380, Rev. 0
Date Approved: $9 / 16 / 92$, Category 2

Equipment Engineering

Seismic II/I Drop Test Program

Aircraft Cable Drop Tests

Page 12 of 14

\subsection{ATTACHMENT 2 \\ TEST DATA SHEET}

PRE TEST


HAND HELD VIDEO START \& STOP POSITION NIA

HIGH SPEED VIOEO START \& STOP POSITION $12: 32-12: 54$

COMMENTS $30^{\prime \prime}$ DIEE ONCABLE

2" CONDUIIIMPACTED TARGET OEF CENTER

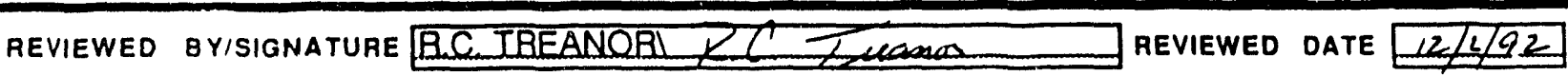

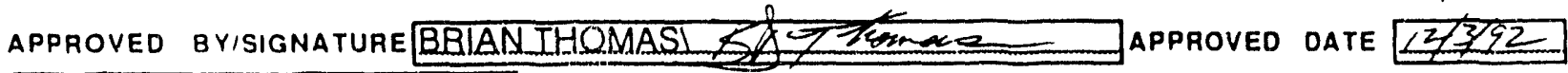

${ }^{\dagger}$ Approximate weight using M\&TE category 3 equipment. 
WSRC-TR-93-0094

Attuchment 10. Test Duta Sheets (98 of 155)

Savannah River Technology Center

EES-FP-380, Rev. 0

Equipment Engineering

Seismic II/I Drop Test Program

Date Approved: 9/16/92, Category 2

Aircraft Cable Drop Tests

Page 12 of 14

\subsection{ATTACHMENT 2 \\ TEST DATA SHEEI}

PRE TEST

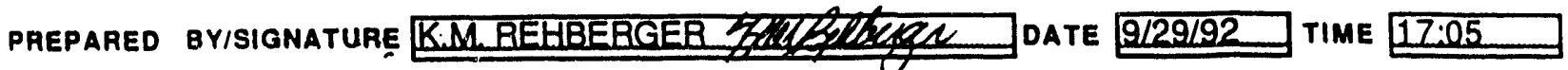

DROP HEIGHT [IN] (Measured from top of cable support) $72^{n}$

SHORTEST POSSIBLE DIST [IN] BETWEEN $97^{*}$ DROP SOURCE, I0 2n CONDUIT 2C-2
CABLE SUPPORTS [IN] (EES-22116-R1-012)

LENGTH OF CABLELLAD CELL SOURCE \& ADAPTER WT [LBS] 19 3/4 LBS

ASSEMBLY (IN) SOURCE ORIENTATION HOBIZONTAL

DROP TEST NUMBER (Sequential; $1,2,3, \ldots 76$

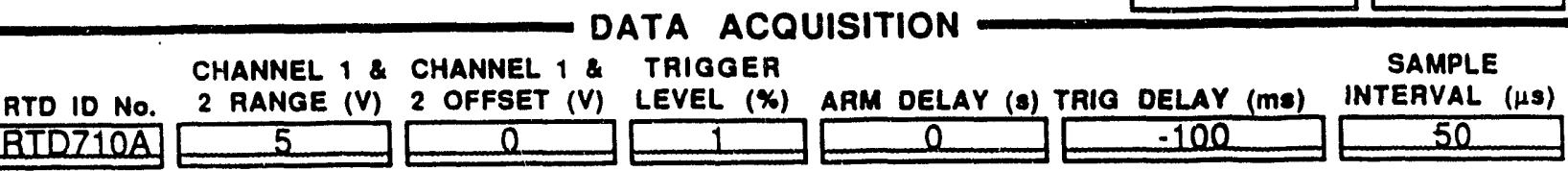

RECORD LENGTH

(samples)

ADDITIONAL DATA AQUISITION INFORMATION

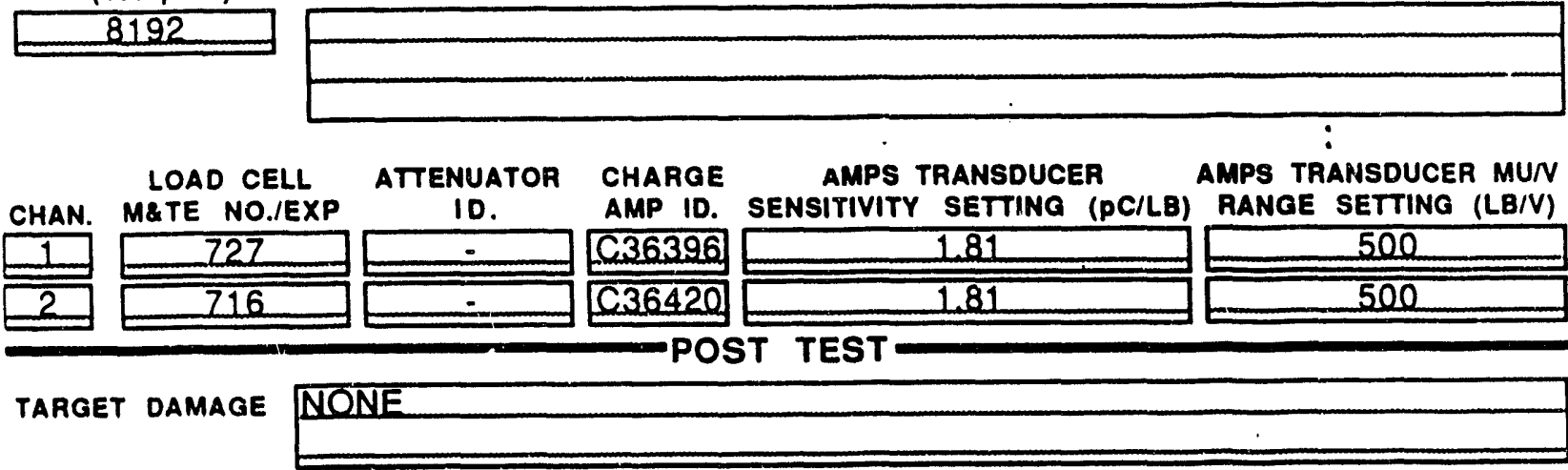

SOURCE DAMAGE NONE

HAND HELD VIDEO START \& STOP POSITION N/L

HIGH SPEED VIDEO START \& STOP POSITION $12: 54-13: 41$

COMMENTS 3.0"RIPE ONCABLE

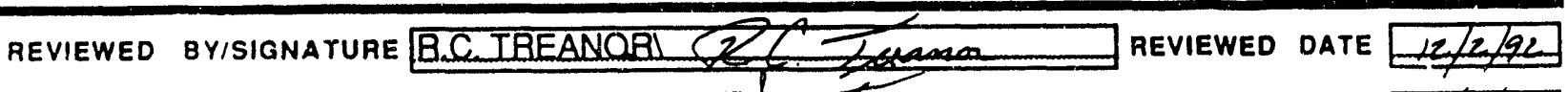

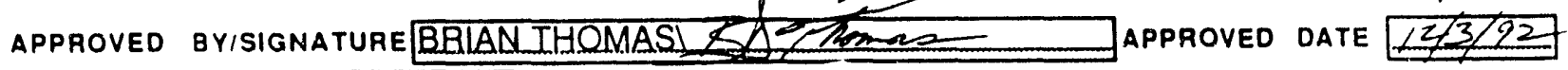

${ }^{\dagger}$ Approximale weight using M\&TE category 3 equipment. 
WSRC-TR-93-0094

Attuchment 10. Test Dutu Sheets (99 of 155$)$

Savannah River Technology Center Equipment Engineering Seismic II/I Drop Test Program Aircraft Cable Drop Tests
EES-FP-380, Rev. 0

Date Approved: 9/16/92, Category 2 Page 12 of 14

\section{Q.2 ATTACHMENT 2}

IEST DATA SHEET

PRE TEST

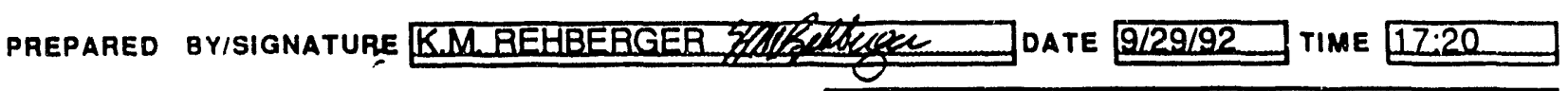

DROP HEIGHT [IN] (Measured from top of cable support) $26^{\prime \prime}$

SHORTEST DOSSIBLE DIST [IN] BETWEEN $97^{m}$ DROP SOURCE, $102^{n \text { CONDUIIT 2C-2 }}$
CABLE SUPPORTS (IN) (EES-22116-R1-012)

LENGTH OF CABLELOAD CELL

ASSEMBLY (IN)

SOURCE \& ADAPTER WT [LBS] $193 / 4$ LBS

DROP TEST NUMBER (Sequentlal; $1,2,3, \ldots 7$

SOURCE ORIENTATION HOAIZONTAL

DATA ACQUISITION

NORMAL

CHANNEL 1 \& CHANNEL 1 \& TRIGGER
2 RANGE (V) 2 OFFSET (V) LEVEL (\%)

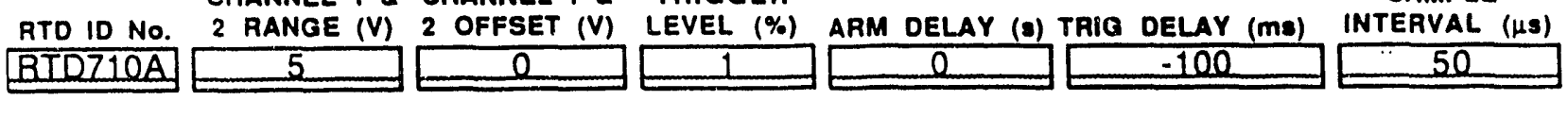

RECORD LENGTH
(samples)

ADDITIONAL DATA AQUISITION INFORMATION

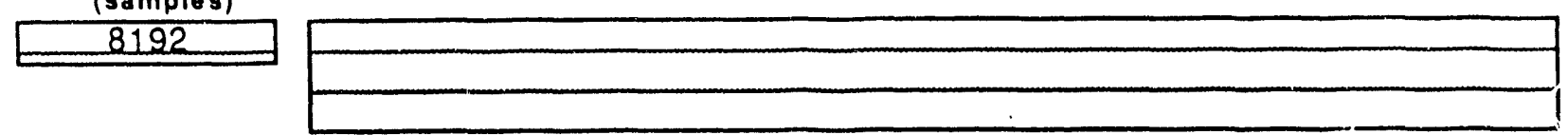

\begin{tabular}{l} 
LOAD CELL ATTENUATOR CHARGE \\
ID. \\
CHAN. M\&TE NO.IEXP AMPS TRANSDUCER \\
AMP ID. SENSITIVITY SETTING (PCILB) RANGE SETTING (LBIV) \\
\hline 127
\end{tabular}

TARGET DAMAGE NONE

SOURCE DAMAGE NQNE

HAND HELD VIDEO START \& STOP POSITION NLA

HIGH SPEED VIDEO START \& STOP POSITION 14:25-14:34.VIDEQCUTOEF

COMMENTS 30" PIPEQNCABLE VIDEQ CUT QEF

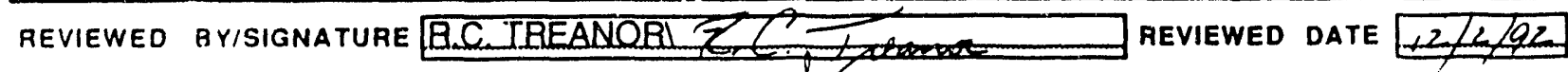

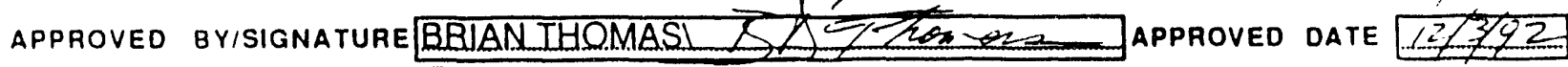

${ }^{\dagger}$ Approximate weight using M\&TE category 3 equipment. 
IWSRC-TR-93-0094

Attachment 10. Test Data Sheets (100 of 155)

Savannah River Technology Center

EES:FP-379, Rev. 0

Equipment Engineering

Seismic II/I Drop Test Program

Instrumented Cabinet Drop Tests

\subsection{ATTACHMENT 4 \\ TFST DATA SHEET \\ (PAGE I OF 2)}

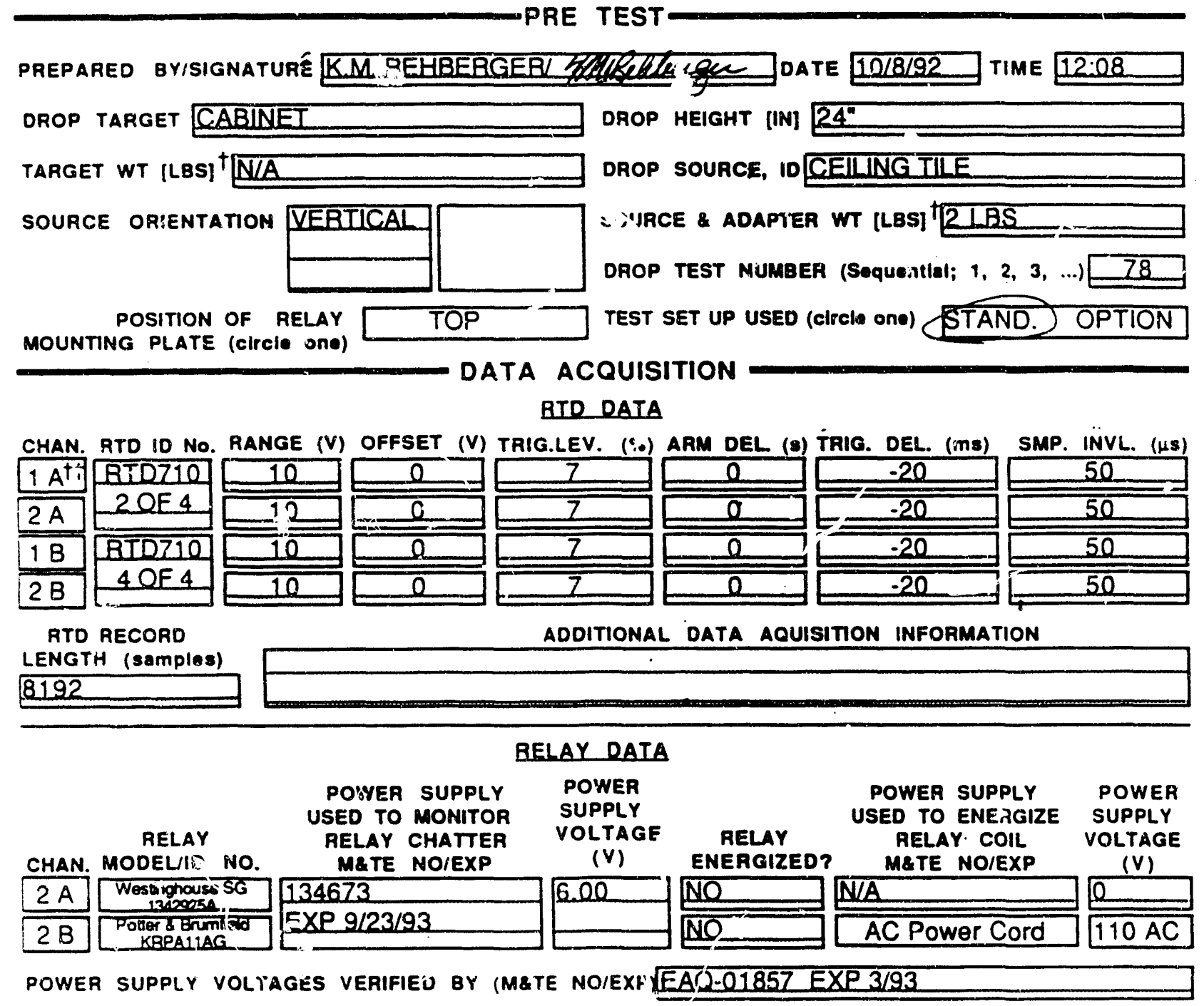

\section{ACCELER'DMEIER DATA}

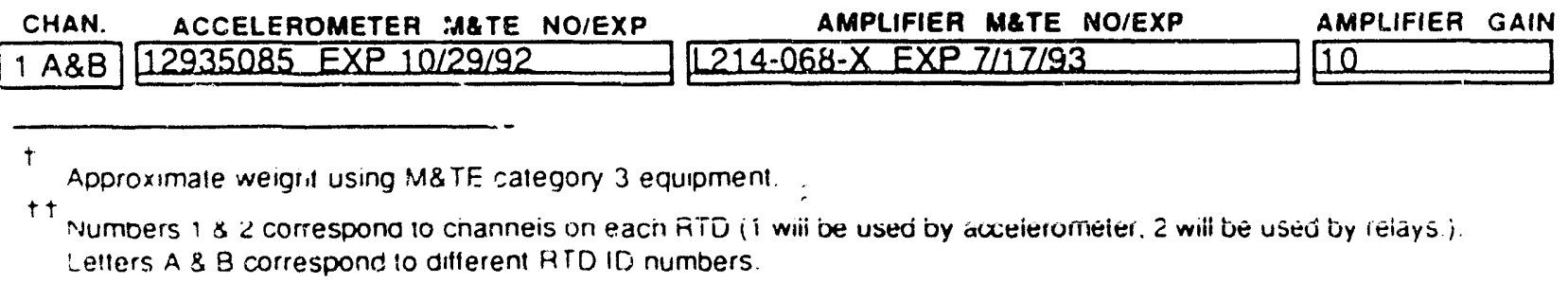


WSRC-TR-93-0094

Attachment 10. Test Data Sheets (101 of 155 )

Savannah River Technology Center

Equipment Engineering

EES-FP-379, Rev. 0

Seismic IVI Drop Test Program Instrumented Cabinet Drop Tests

Date Approved: 9/24/92, Category 2

Page 16 of 18

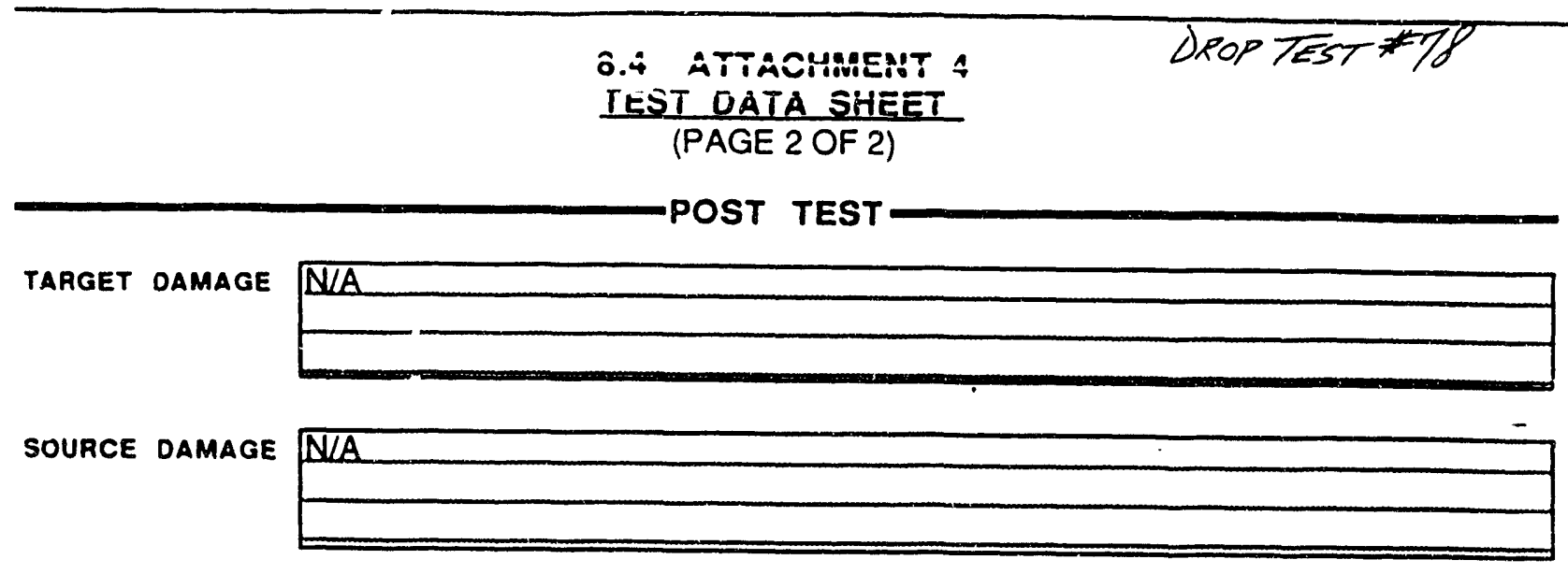

RelaY CHATtER IOENTIFIEd ON POTTER \& BRUMFIELD RELAY (Y/N) NONE

IF YES, DURATION OF CHATTER (ms] SEEPLOT

RELAY CHATTER IDENTIFIED ON WESTINGHOUSE RELAY (YIN) YES

IF YES, DURATION OF CHATTER [ms] SEEPLOT

HAND HELD VIDEO START \& STOP POSITION NLA

HIGH SPEED VIDEO START \& STOP POSITION $14: 34 \cdot 15: 50$

COMMENTS

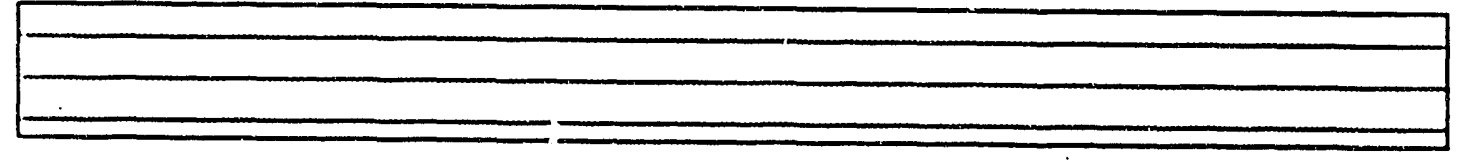

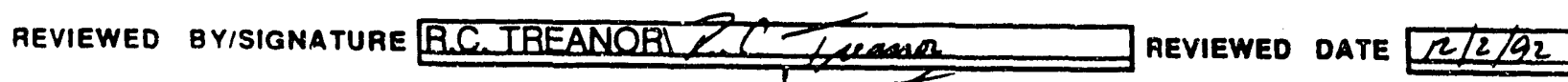
APPROVEO BYISIGNATURE BRIAN THOMAS $>$ Tomes 
WSRC-TR-93-0094

Attachment 10. Test Data Sheets (102 of 155)

Savannah River Technology Center

Equipment Engineering

Seismic II/I Drop Test Program

Instrumented Cabinet Drop Tests

EES-FP-379, Rev. 0

Date Approved: 9/24/92, Category 2

Page 15 of 18

\subsection{ATTACHMENT 4 \\ TEST DATA SHEET \\ (PAGE 1 OF 2)}

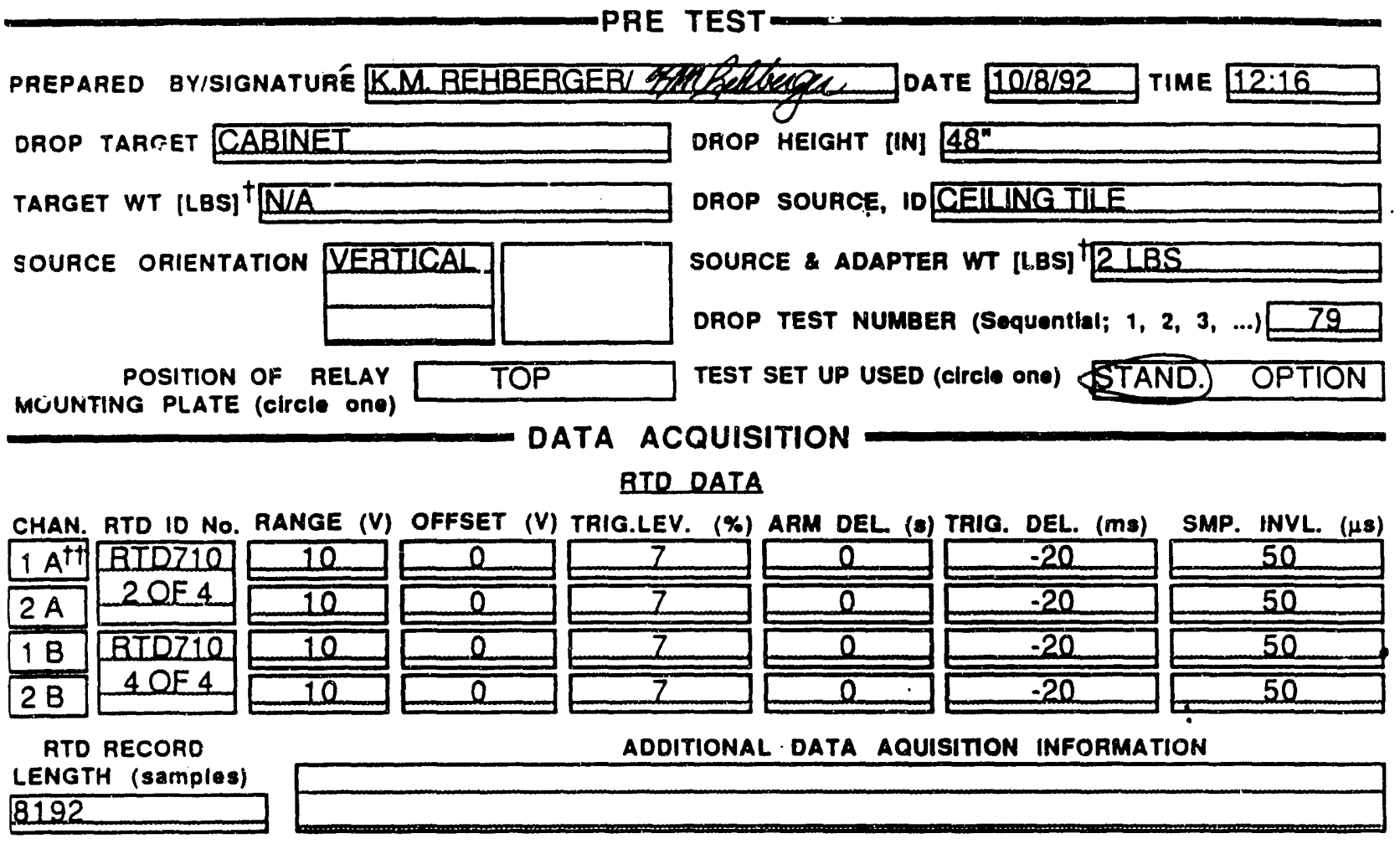

\begin{tabular}{|c|c|c|c|c|c|c|}
\hline \multicolumn{7}{|c|}{ BELAY DATA } \\
\hline CHAN. & $\begin{array}{c}\text { RELAY } \\
\text { MODELIID NO. }\end{array}$ & $\begin{array}{l}\text { POWER SUPPLY } \\
\text { USED TO MONITOR } \\
\text { RELAY CHATTER } \\
\text { METE NOIEXP }\end{array}$ & $\begin{array}{l}\text { POWER } \\
\text { SUPPLY } \\
\text { VOLTAGE } \\
\text { (V) }\end{array}$ & $\begin{array}{l}\text { RELAY } \\
\text { ENERGIZED? }\end{array}$ & $\begin{array}{l}\text { POWER SUPPLY } \\
\text { USED TO ENERGIZE } \\
\text { RELAY COIL } \\
\text { METE NO/EXP }\end{array}$ & $\begin{array}{l}\text { POWER } \\
\text { SUPPLY } \\
\text { VOLTAGE } \\
\text { (V) }\end{array}$ \\
\hline $2 A$ & \begin{tabular}{|c|} 
Westinghouse SG \\
12 i2005A
\end{tabular} & 134673 & 6, & $\mathrm{NQ}$ & N/A & $Q$ \\
\hline $2 B$ & 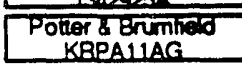 & EXP 9/23/93 & & $\mathrm{NQ}$ & AC Power Cord & $110 \mathrm{AC}$ \\
\hline
\end{tabular}

POWER SUPPLY VOLTAGES VERIFIED BY (M\&TE NOIEXP) EAQ-01857 EXP 3/93

\section{ACCELEROMETER DATA}

\begin{tabular}{l} 
CHAN. ACCELEROMETER M\&TE NO/EXP AMPLIFIER M\&TE NOIEXP \\
1 A\&B 12235085 EXP $10 / 29 / 92$ \\
\hline
\end{tabular}

\footnotetext{
Approximate weight using M\&TE category 3 equipment.

${ }^{\dagger \dagger}$ Numbers 1 \& 2 correspond to channels on each RTD ( 1 will be used by accelerometer, 2 will be used by relays.). Letters $\wedge$ \& $Q$ correspond to ditterent RTD ID numbers.
} 
WSRC-TR-93-0094

Attachment 10. Test Data Sheets (103 of 155)

Savannah River Technology Center Equipment Engineering Seismic II/I Drop Test Program Instrumented Cabinet Drop Tests

EES-FP-379, Rev. 0 Date Approved: 9/24/92, Category 2 Page 16 of 18

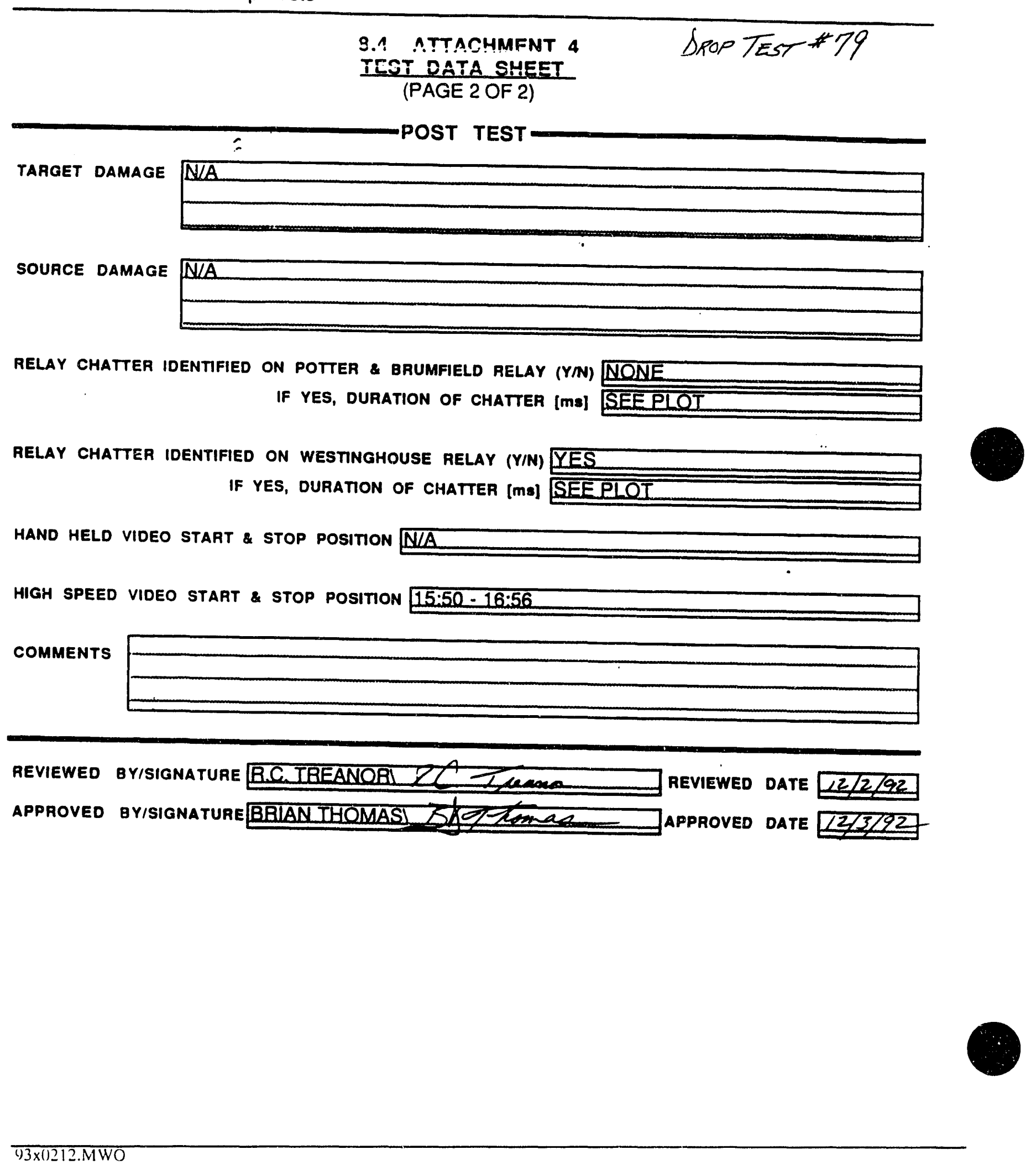


IVSRC-TR-93-0094

Attachment 10. Test Data Sheets (104 of 155)

Savannah River Technology Center

Equipment Engineering

Seismic II/I Drop Test Program

EES-FP-379, Rev. 0

Instrumented Cabinet Drop Tests

Date Approved: 9/24/92, Category 2

Page 15 of 18

\subsection{ATTACHMENT 4 \\ TEST DATA SHEET \\ (PAGE 1 OF 2)}

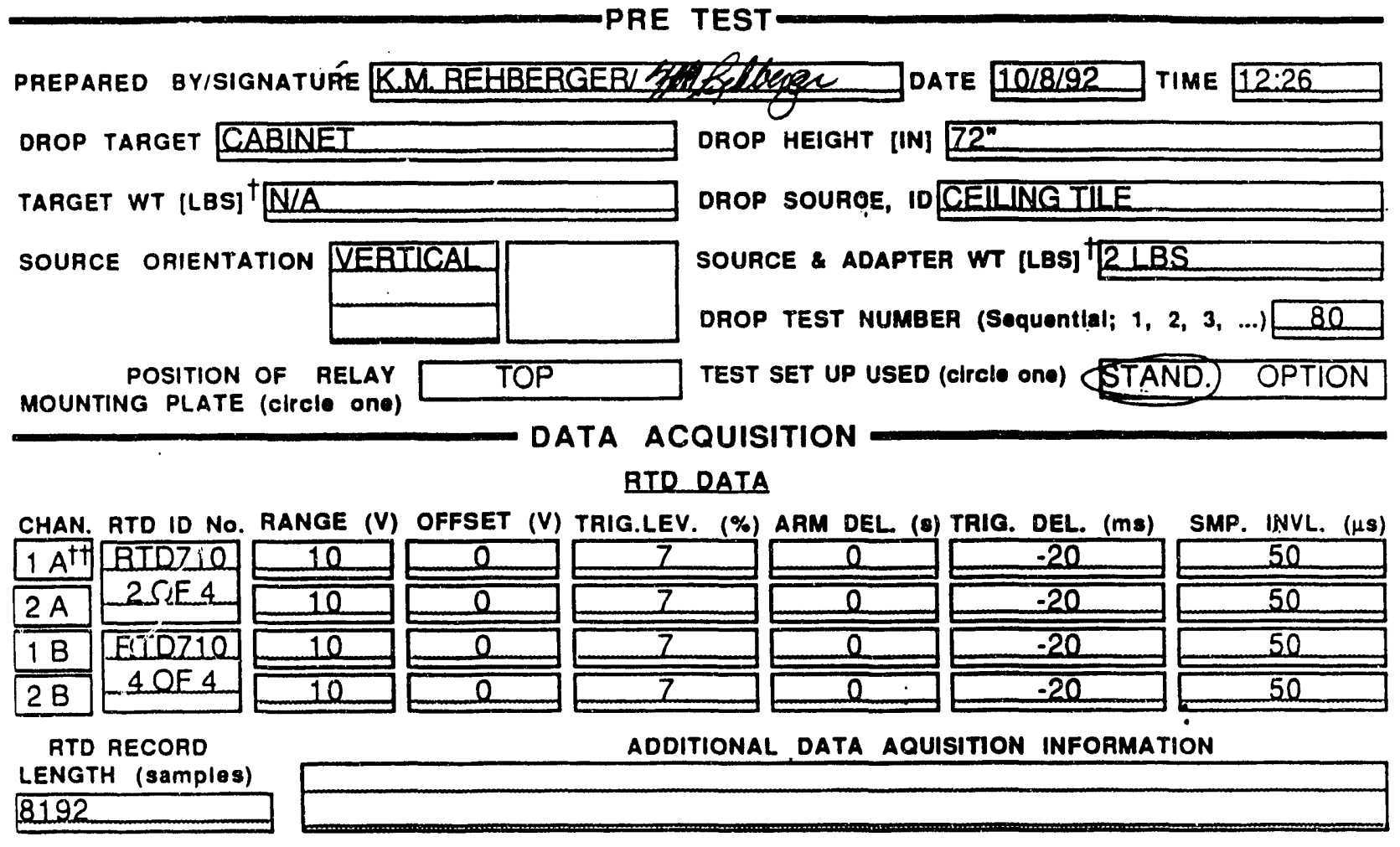

\begin{tabular}{|c|c|c|c|c|c|c|}
\hline \multirow[b]{2}{*}{ CHAN. } & \multicolumn{6}{|c|}{ BELAY DATA } \\
\hline & $\begin{array}{c}\text { RELAY } \\
\text { MODEL/ID NO. }\end{array}$ & $\begin{array}{l}\text { POWER SUPPLY } \\
\text { USED TO MONITOR } \\
\text { RELAY CHATTER } \\
\text { METE NO/EXP }\end{array}$ & $\begin{array}{l}\text { POWER } \\
\text { SUPPLY } \\
\text { VOLTAGE } \\
\text { (V) }\end{array}$ & $\begin{array}{l}\text { RELAY } \\
\text { ENERGIZED? }\end{array}$ & $\begin{array}{c}\text { POWER SUPPLY } \\
\text { USED TO ENERGIZE } \\
\text { RELAY COIL } \\
\text { M\&TE NO/EXP }\end{array}$ & $\begin{array}{l}\text { POWER } \\
\text { SUPPLY } \\
\text { VOLTAGE } \\
\text { (V) }\end{array}$ \\
\hline $2 A$ & Wesinghouse SG & 134673 & 6.00 & $\mathrm{NQ}$ & $\mathrm{N} / \mathrm{A}$ & 0 \\
\hline $2 B$ & 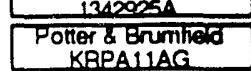 & EXP 9/23/93 & & $\mathrm{NQ}$ & AC Power Cord & $110 \mathrm{AC}$ \\
\hline
\end{tabular}

\section{ACCELERQMETER DATA}

CHAN. ACCELEROMETER M\&TE NO/EXP

$1 \mathrm{~A} \& B \quad 12935085 \mathrm{EXP} 10 / 29 / 92$

\begin{tabular}{l} 
AMPLIFIER M\&TE NOIEXP \\
\hline $214-068-X$ EXP $/ 117193$ \\
\hline
\end{tabular}

AMPLIFIER GAIN

10

† Approximate weight using M\&TE category 3 equipment.

t† Numbers 1 \& 2 correspond to channels on each RTD ( 1 will be used by accelerometer, 2 will be used by relays.)

Lelters A \& B correspond to different RTD ID numbers. 
WSRC-TR-93-0094

Attachment 10. Test Data Sheets (105 of 155 )

Savannah River Technology Center

EES-FP-379, Rev. 0

Equipment Engineering

Seismic II/I Drop Test Program

Instrumented Cabinet Drop Tests

$\therefore$

TARGET DAMAGE N/A

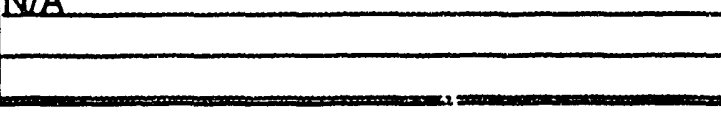

SOURCE DAMAGE N/A

RELAY CHATTER IDENTIFIED ON POTTER \& BRUMFIELD RELAY (YIN) NONE

IF YES, DURATION OF CHATTER [ms] SEEPLOT

RELAY CHATTER IDENTIFIED ON WESTINGHOUSE RELAY (Y/N) YES

IF YES, DURATION OF CHATTER Ims] SEEPLQT

HAND HELD VIDEO START \& STOP POSITION N/A

HIGH SPEED VIDEO START \& STOP POSITION $16: 56 \cdot 18: 43$

COMMENTS

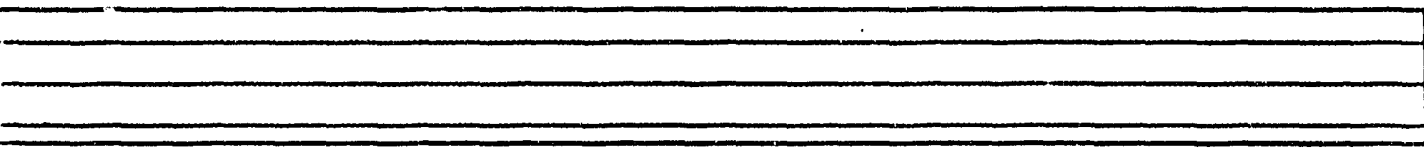

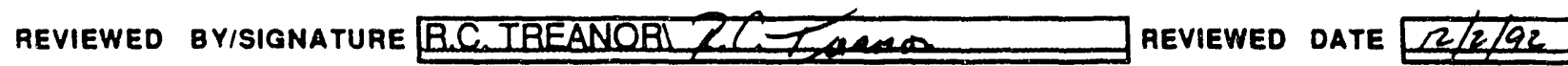

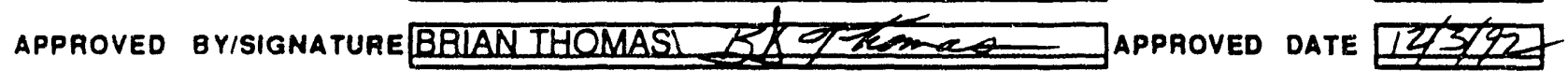


IVSRC-TR-93-0094

Attachment 10. Test Data Sheets (106 of 155)

Savannah River Technology Center

EES-FP-379, Rev. 0

Equipment Engineering

Seismic It/I Drop Test Program

Instrumented Cabinet Drop Tests

Date Approved: 9/24/92, Category 2

Page 15 of 18

\subsection{ATTACHMENT 4 \\ IEST DATA SHEET \\ (PAGE 1 OF 2)}

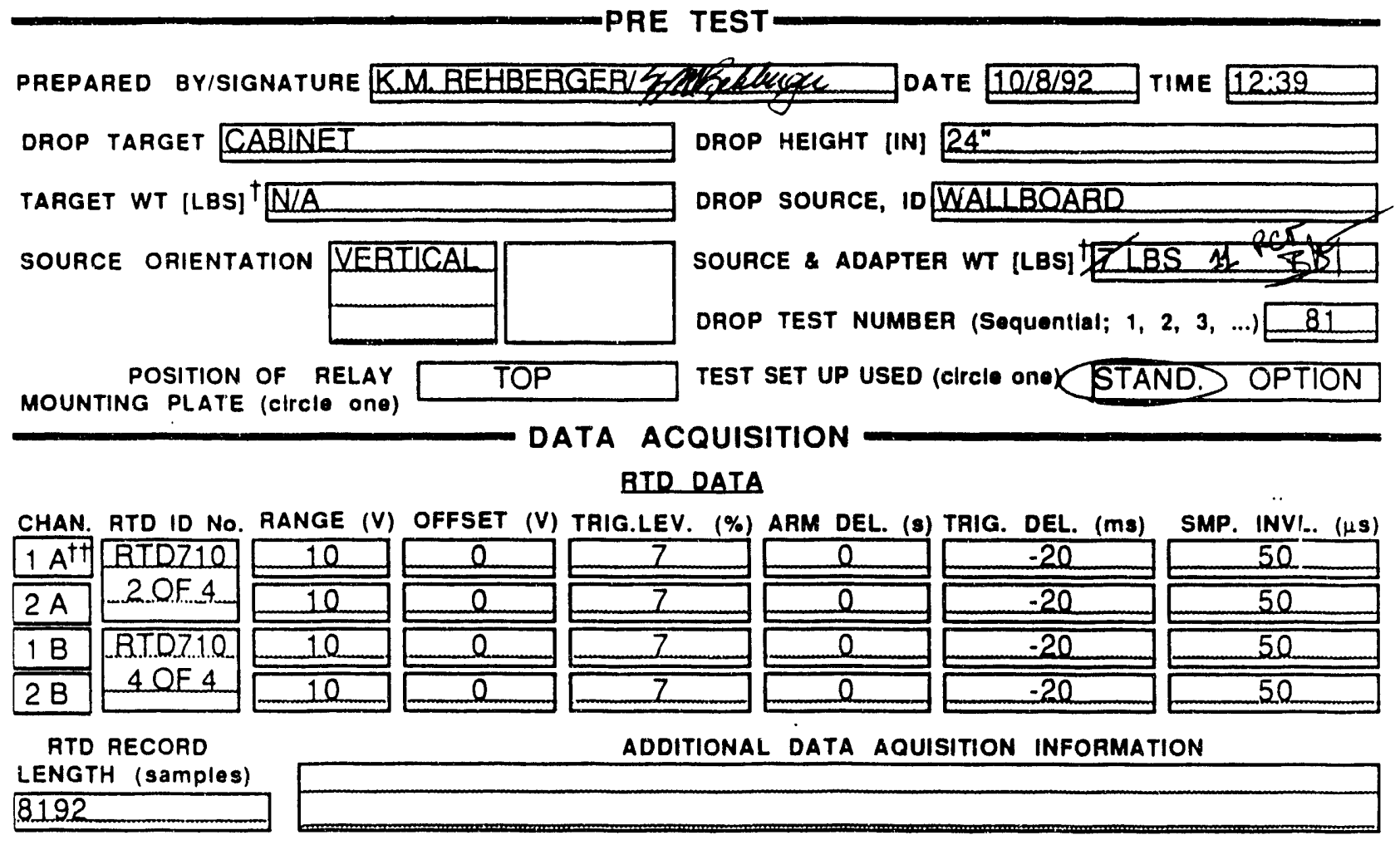

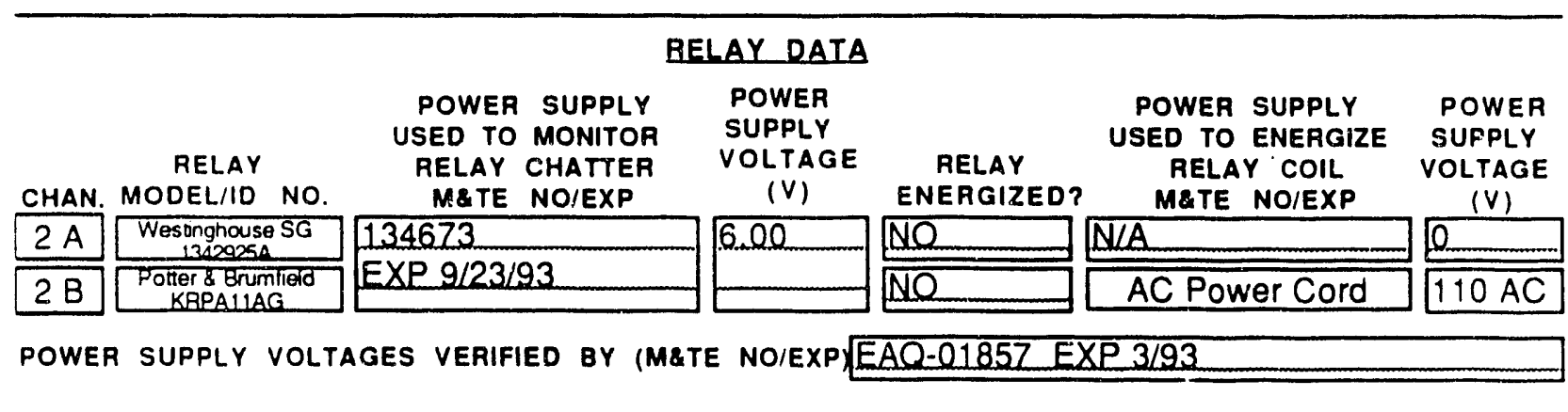

\section{ACCELEROMETER DATA}

CHAN. ACCELEROMETER M\&TE NO/EXP

1 A\&B 12935085 EXP 10/29/92

\begin{tabular}{c} 
AMPLIFIER M\&TE NO/EXP \\
\hline $214-068-X$ EXP $/ 17 / 93$ \\
\hline
\end{tabular}

AMPLIFIER GAIN

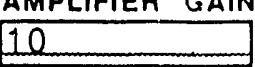

† Approximate weight using M\&TE category 3 equipment.

${ }^{\dagger}{ }^{\dagger}$ Numbers $1 \& 2$ correspond 10 channels on each RTD ( 1 will be used by accelerometer, 2 will be used by relays.)

Letters A \& B correspond to different RTD ID numbers. 
WSRC-TR-93-0094

Attachment 10. Test Data Sheets (107 of 155)

Savannah River Technology Center

Equipment Engineering

Seismic II/I Drop Test Program

Instrumented Cabinet Drop Tests

EES-FP-379, Rev. 0

Date Approved: 9/24/92, Category 2

Page 16 of 18

Q.1 ATTACHAENT 1

DROP TEST \# 81

TEST DATA GHEET

(PAGE 2 OF 2)

POST TEST

TARGET DAMAGE N/A

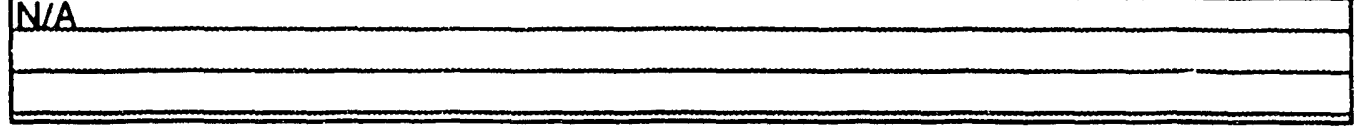

RELAY CHATTER IDENTIFIED ON POTTER \& BRUMFIELD RELAY (YNN) NONE IF YES, DURATION OF CHATTER [ms] SEEPLOT

RELAY CHATTER IOENTIFIED ON WESTINGHOUSE RELAY (YIN) YES

IF YES, DURATION OF CHATTER [ms] SEEPLOT

HAND HELD VIDEO START \& STOP POSITION N/A

HIGH SPEED VIDEO START \& STOP POSITION $18: 43-19: 32$

COMMENTS

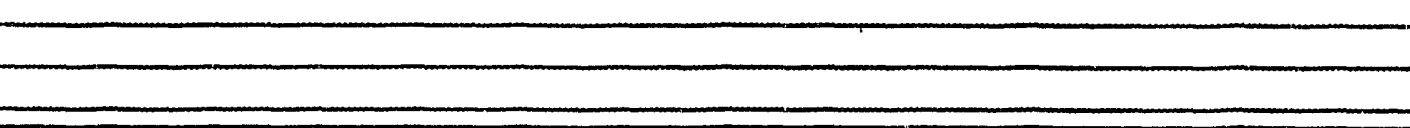

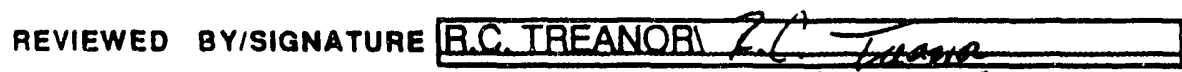

APPROVED BYISIGNATUAE BRIANTHOMASI BL Thomea

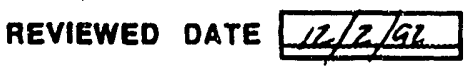


WSRC-TR-93-0094

Attachment 10. Test Data Sheets (108 of 155)

Savannah River Technology Center

Equipment Engineering

Seismic li/l Drop Test Program

Instrumented Cabinet Drop Tests

EES-FP.379, Rev. 0

Date Approved: 9/24/92, Category 2

Page 15 of 18

\section{S.1 ATTACHARENT A \\ TEST DATA SHEET}

(PAGE 1 OF 2)

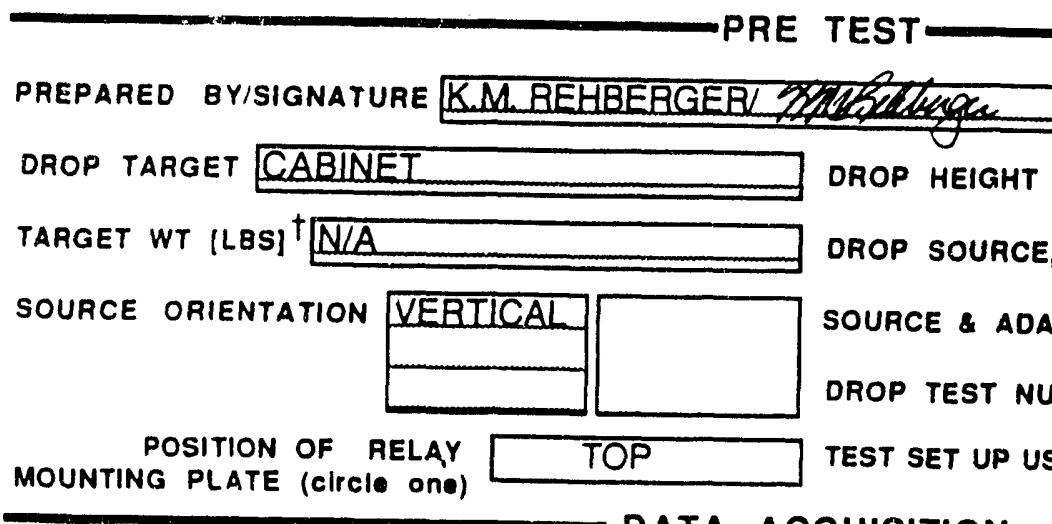

RE TEST

DROP HEIGHT [IN] $48^{n}$

TARGET WT [LBS] N/A

DROP SOURCE, 10 WALLBOARD

SOURCE ORIENTATION VERTICAL

SOURCE \& ADAPTER WT [LBS]

DROP TEST NUMBER (Sequentiai; $1,2,3, \ldots) 82$

MOUNTING PLATE (circlo one)

TEST SET UP USED (clrcle ono) STAND.) OPTION

\section{DATA ACQUISITION}

RTD DATA

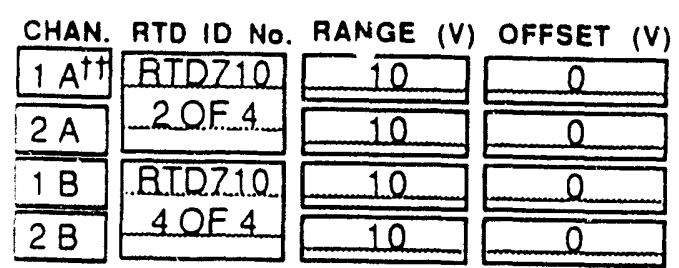

RTD RECORD

LENGTH (samples) 8192

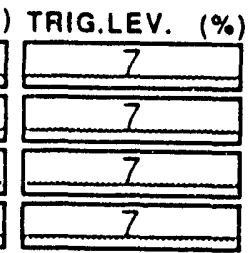

ADDITIONAL DATA AQUISITION INFORMATION

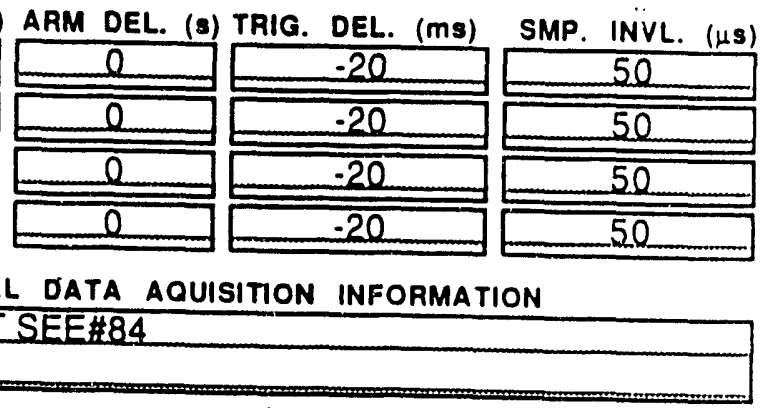

NQ DATA TAKEN:BE-DIR TEST SEE\#84

RELAY DATA
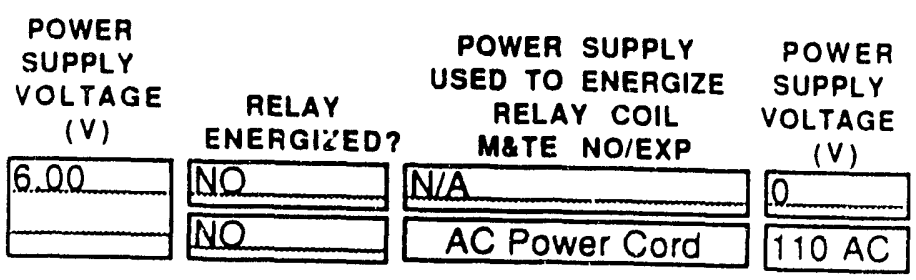

POWER SUPPLY POWER

POWER SUPPLY USED TO MONITOR

RELAY

RELAY CHATTER

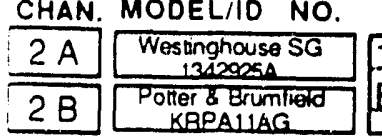

134673

EXP $9 / 23 / 93$

VOLTAGE

2 B KRPAllaG

NO AC Power Cord

$110 \mathrm{AC}$

POWER SUPPLY VOLTAGES VERIFIED OY (M\&TE NO/EXP EAQ-01857 EXP 3/93

\section{ACCELEROMETER DATA}

CHAN. ACCELEROMETER M\&TE NO/EXP $1 \mathrm{A \& B} 12935085$ EXP $10 / 29 / 92$

AMPLIFIER METE NO/EXP
L214-068-X EXP Z/17/93

AMPLIFIER GAIN

10

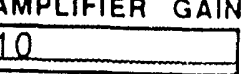

$\uparrow$ Approximate weight using M\&TE calegory 3 equipment

${ }^{\dagger}$ Numbers 1 \& 2 correspond to channels on each RTD (1

Letters A \& B correspond to different RTD ID numbers. 
IVSRC-TR-93-0094

Attuchment 10. Test Data Shects (109 of 155 )

Savannah River Technology Center

Equipment Engineering

Seismic IVI Drop Test Program

EES-FP-379, Rev. 0 Instrumented Cabinet Drop Tests

\subsection{ATTACHMENT 4 DROP TEST \#82 IEST DATA SHEET (PAGE 2OF 2)}

\section{POST TEST}

TARGET DAMAGE NIA

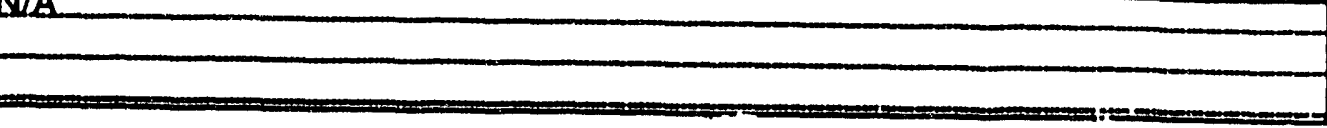

SOUACE DAMAGE N/A

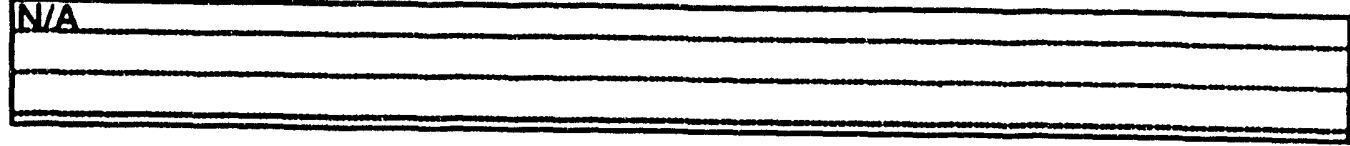

RELAY CHATTER IDENTIFIED ON POTTER \& BRUMfield RELAY (Y/N) N/A IF YES, DURATION OF CHATTER [ma] WIIA

RELAY CHATTER IDENTIFIEd ON WESTINOHOUSE RELAY (YN) NIA

IF YES, DURATION OF CHATTER (ma] NUA

HAND HELD VIDEO START \& STOP POSITION NIA

HIOH SPEED VIDEO START \& STOP POSITION 19:32-20:18

COMMENTS

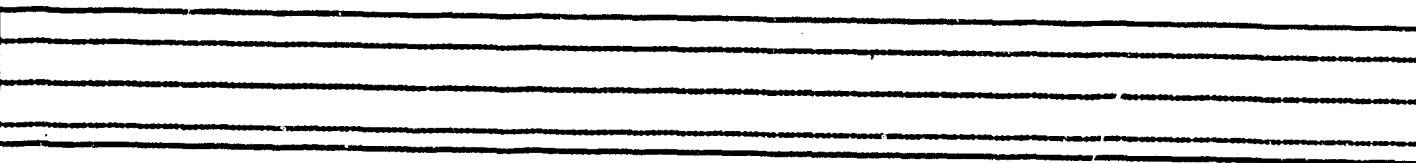

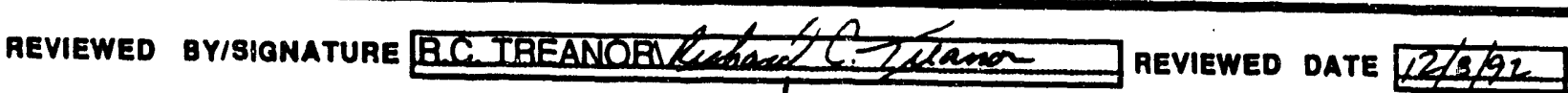

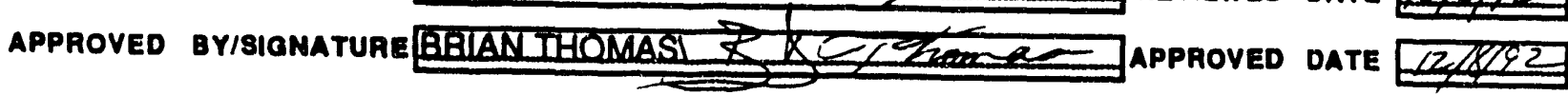


IVSRC-TR-93-0094

Attachment 10. Test Data Sheets (110 of 155)

Savannah River Technology Center

Equipment Engineering

EES.FP.379, Rev. 0

Seismic II/I Drop Test Program

Instrumented Cabinet Drop Tests

\subsection{ATTACHMENT 4 \\ TEST DATA SHEET \\ (PAGE 1 OF 2)}

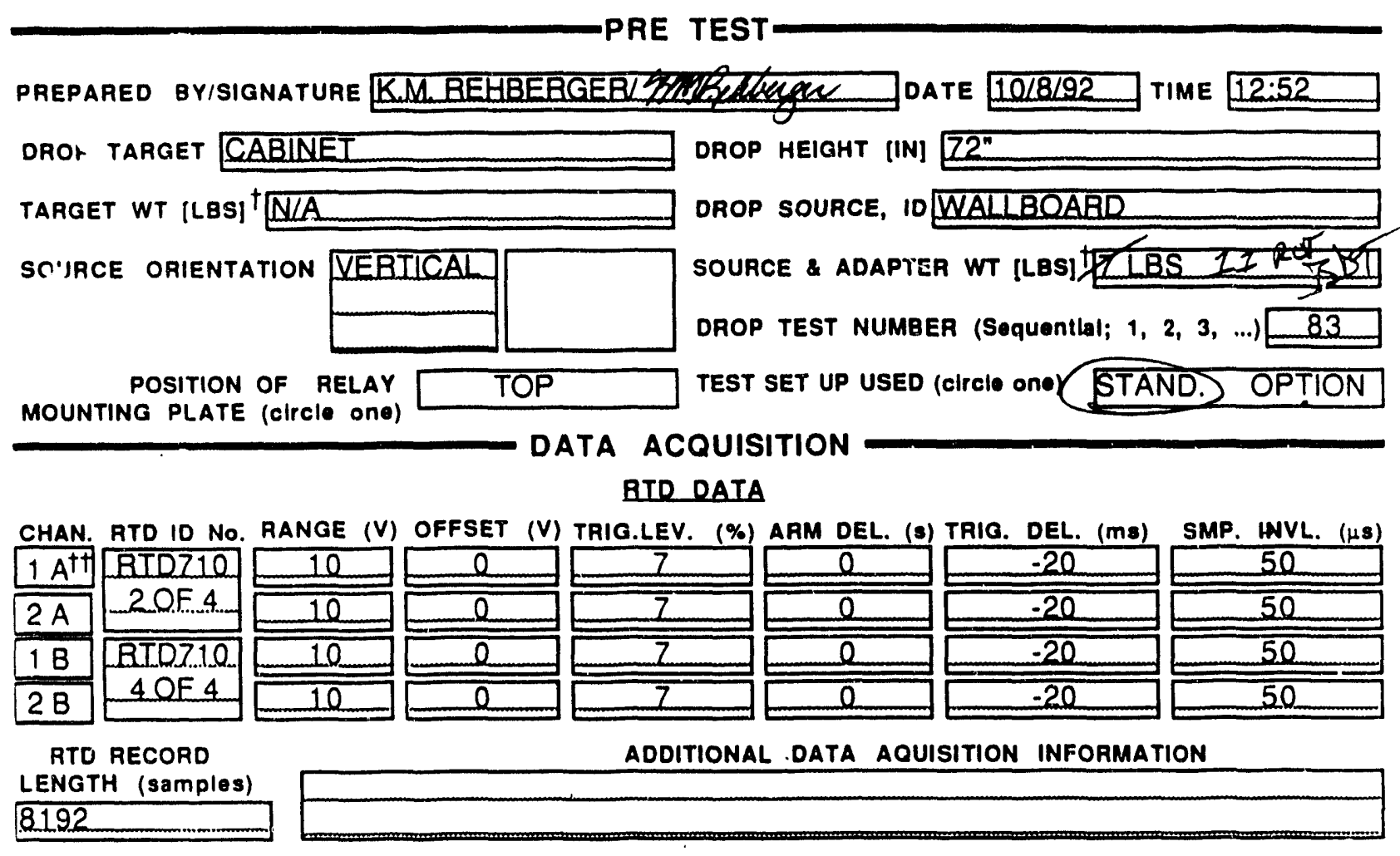

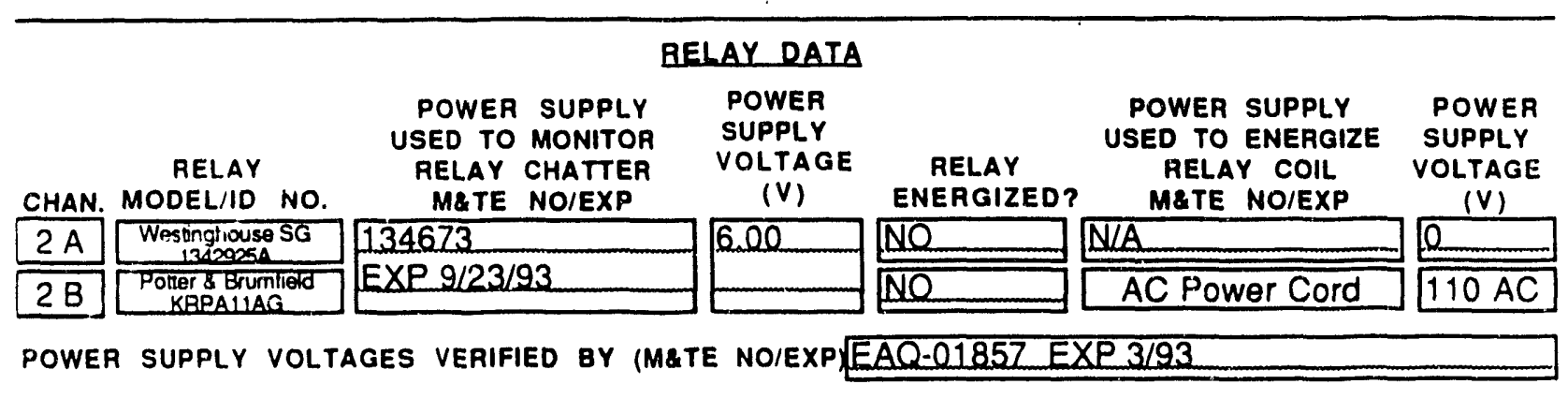

\section{ACCELEROMETER DATA}

CHAN. ACCELEROMETER METE NO/EXP

1 A\&B 12235085 EXP $10 / 29 / 22$

AMPLIFIER M\&TE NO/EXP
L214-068-X EXP ZL17/93

AMPLIFIER GAIN 10

$\dagger$ Approximate weight using M\&TE category 3 equipment.

${ }^{t \dagger}$ Numbers 1 \& 2 correspond to channels on each ATD ( 1 will be used by accelerometer, 2 will be used by relays.) Lelters A \& B correspond to different RTD ID numbers. 
WSRC-TR-93-0094

Attachment 10. Test Data Sheets (111 of 155)

Savannah River Technology Center

Equipment Engineering

Seismic II/I Drop Test Program

EES-FP-379, Rev. 0

Instrumented Cabinet Drop Tests

Date Approved: 9/24/92, Category 2

Page 16 of 18

\subsection{ATTACMMENT A XROP TEST \# IEST DATA SHEET \\ (PAGE 2 OF 2)}

POST TEST

TARGET DAMAGE N/A

SOURCE DAMAGE N/A

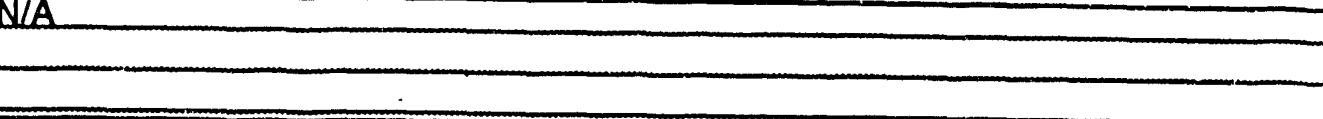

RELAY CHATtER IDENTIFIED ON POTTER \& BRUMFIELD RELAY (YNN) NONE

IF YES, DURATION OF CHATTER [ms] SEEPLOT

RELAY CHATTER IDENTIFIED ON WESTINGHOUSE RELAY (Y/N) YES

IF YES, DURATION OF CHATTER (ms) SEEPLOT

HAND HELD VIDEO START \& STOP POSITION NI/A

HIGH SPEED VIDEO START \& STOP POSITION 20:18-21:19

COMMENTS

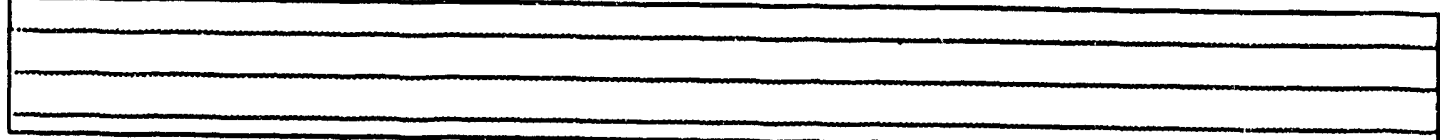

REVIEWED BYISIGNATURE BC.TBEANORI R.C T Tama

REVIEWED DATE L/E/GL

APPROVED BYISIGNATURE BRIAN IHOMAS LSA $/$ rena

APPROVED DATE 121302 
WSRC-TR-93-0094

Attachment 10. Test Data Sheets (112 of 155)

Savannah River Technology Center

Equipment Engineering

Seismic II// Drop Test Program

Instrumented Cabinet Drop Tests

EES-FP-379, Rev. 0

Date Approved: 9/24/92, Category 2

\subsection{ATTACHMENT 4 \\ IEST DATA SHEET \\ (PAGE 1 OF 2)}

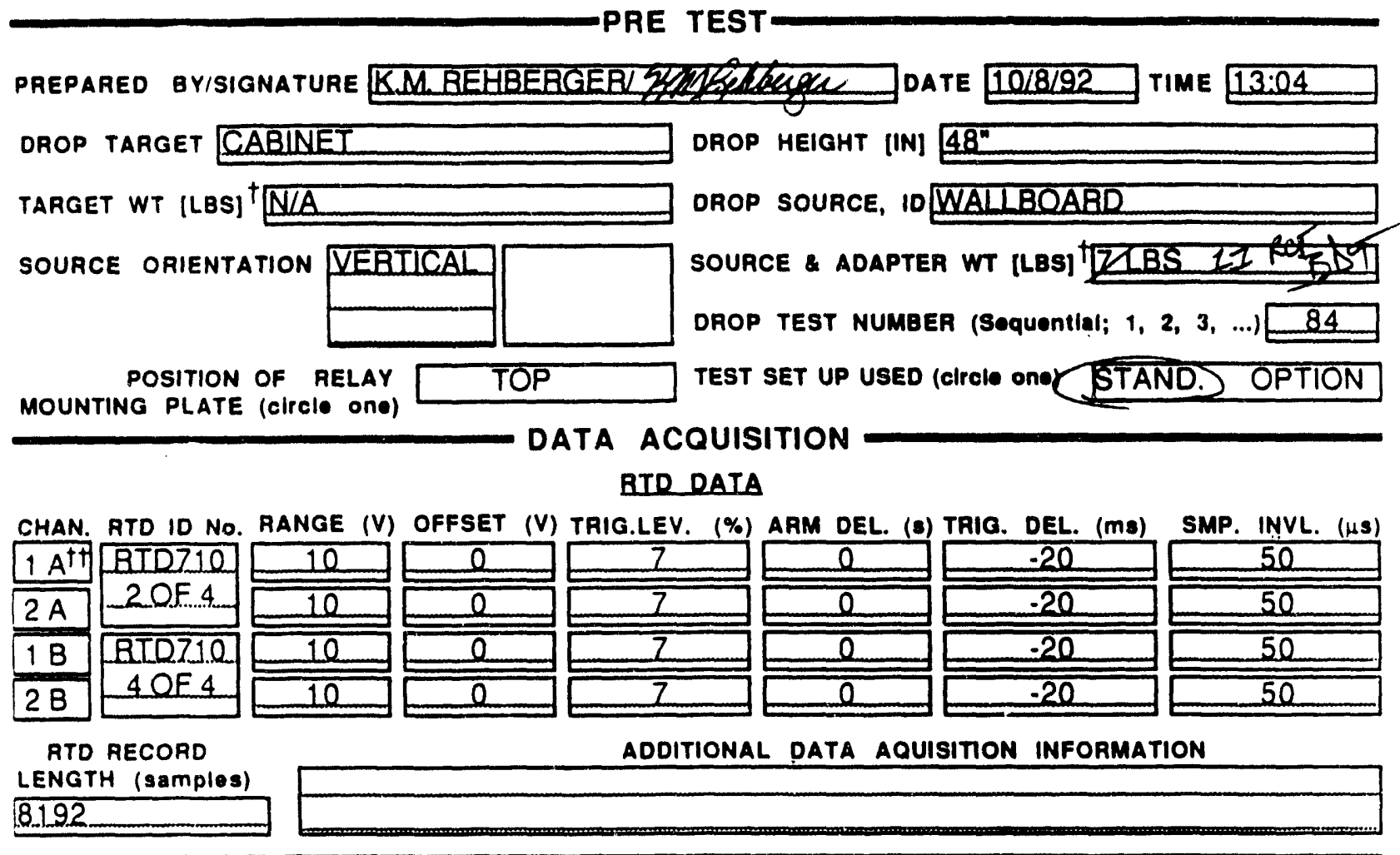

\begin{tabular}{|c|c|c|c|c|c|c|}
\hline \multicolumn{7}{|c|}{ BELAY DATA } \\
\hline CHAN. & $\begin{array}{c}\text { RELAY } \\
\text { MODEL/ID NO. }\end{array}$ & $\begin{array}{l}\text { POWER SUPPLY } \\
\text { USED TO MONITOR } \\
\text { RELAY CHATTER } \\
\text { M\&TE NOIEXP }\end{array}$ & $\begin{array}{l}\text { POWER } \\
\text { SUPPLY } \\
\text { VOLTAGE } \\
\text { (V) }\end{array}$ & $\begin{array}{c}\text { RELAY } \\
\text { ENERGIZED? }\end{array}$ & $\begin{array}{l}\text { POWER SUPPLY } \\
\text { USED TO ENERGIZE } \\
\text { RELAY COIL } \\
\text { MQTE NO/EXP }\end{array}$ & $\begin{array}{l}\text { POWER } \\
\text { SUPPLY } \\
\text { VOLTAGE } \\
\text { (V) }\end{array}$ \\
\hline $2 A$ & \begin{tabular}{|c|} 
Wesonghouse SG \\
$12120025 A$ \\
\end{tabular} & 134673 & 6.00 & $\mathrm{NQ}$ & $\mathrm{N} / \mathrm{A}$ & 0 \\
\hline 28 & 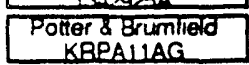 & EXP 9/23/93 & & $\mathrm{NO}$ & AC Power Cord & $110 \mathrm{AC}$ \\
\hline
\end{tabular}

\section{ACCELEROMETER DATA}

\begin{tabular}{l} 
CHAN. ACCELEROMETER M\&TE NO/EXP AMPLIFIER M\&TE NO/EXP \\
1 A\&B 12935085 EXP $10 / 29 / 92$ \\
\hline
\end{tabular}

$\dagger$ Approximale weight using M\&TE category 3 equipment.

${ }^{\dagger}$ Numbers 1 \& 2 correspond to channels on each RTD ( 1 will be used by accelerometer, 2 will be used by relays.) Lellers A \& $B$ correspond to different RTD ID numbers. 
WSRC.TR.93-0094

Attachment 10. Test Data Sheets (113 of 155)

Savannah River Technology Center

EES-FP-379, Rev. 0

Equipment Engineering

Seismic IV// Drop Test Program

Instrumented Cabinet Drop Tests

Date Approved: 9/24/92, Category 2

Page 16 of 18

\subsection{ATTMCHMENT 4 \\ DEOP TEST \#84 \\ IEST DATA SHEET \\ (PAGE 2 OF 2)}

POST TEST

TARGET DAMAGE NIA

SOURCE DAMAGE N/A

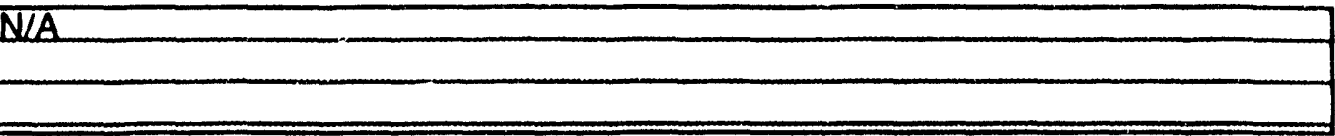

RELAY CHATISR IDENTIFIED ON POTTER BAUMFIELD RELAY (YNN) NONE

IF YES, DURATION OF CHATTER (ms) SEEPLOT

pelay Chatter IDENTIFIEd ON WESTINGHOUSE RELAY (YIN) YES

IF YES, DURATION OF CHATTER (ms) SEERLOT

HAND HELD VIOEO START \& STOP POSITION NIA

HIGH SPEED VIDEO START \& STOP POSITION $21: 19 \cdot 22: 05$

COMMENTS

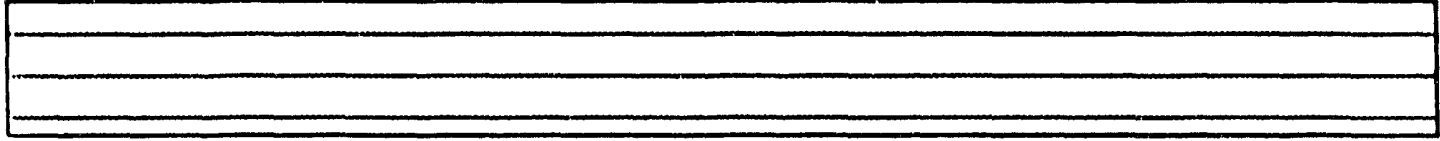

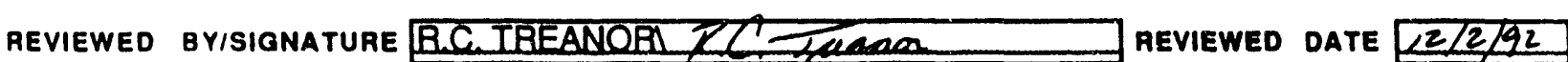

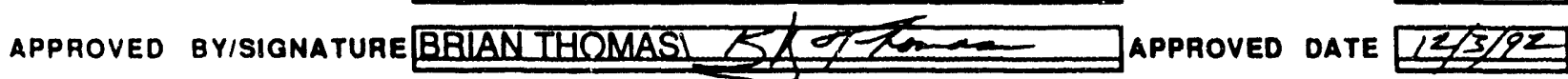


WSRC-TR-93-0094

Attachment 10. Test Data Sheets (114 of 155)

Savannah River Technology Center

EES-FP-379, Rev. 0

Equipment Engineering

Seismic II// Drop Test 'sogram

Instrumented Cabinet Drop Tests

\subsection{ATTACHMENT 4 \\ TEST DATA SHEET}

(PAGE 1 OF 2)

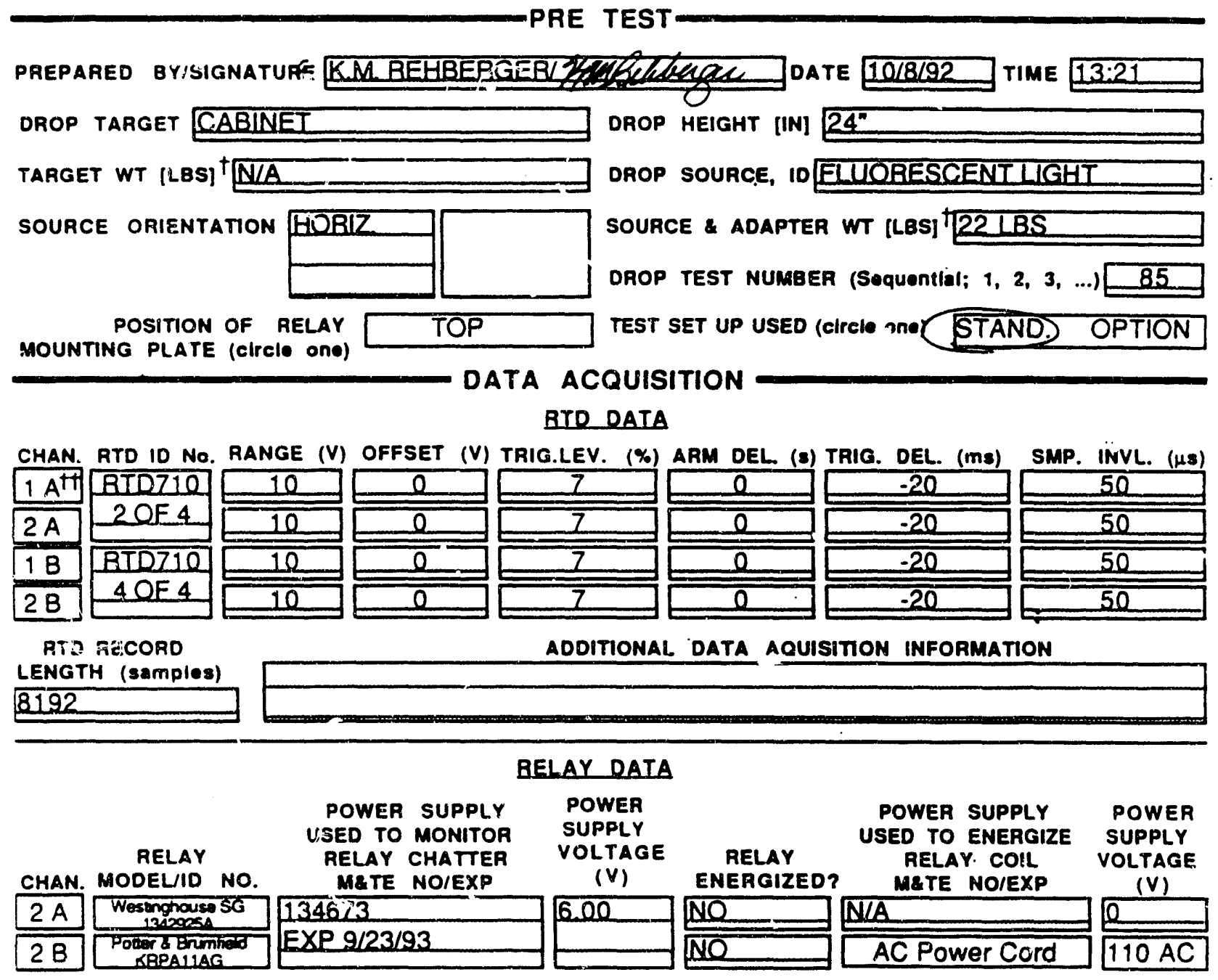

POWER SUPPLY VOLTAGES VERIFIED BY (METE NO/EXP EAQ-01857 EXP 3/93

ACCELEROMETER DATA

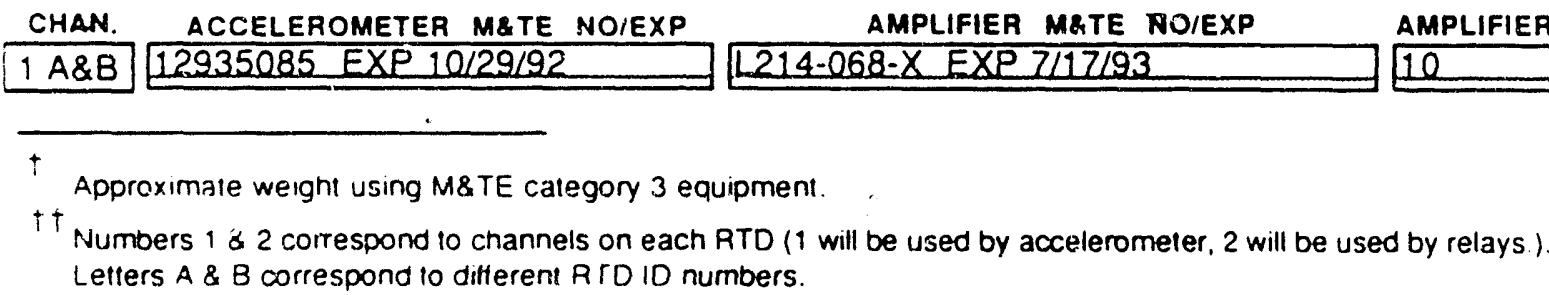

$\uparrow$ Approximate weight using M\&TE category 3 equipment

it Numbers 1 \& 2 correspond 10 channels on each RTD ( 1 will be used by accelerometer, 2 will be used by relays.) Lefters A \& B correspond 10 different RTD 10 numbers. 
WSRC-TR-93-0094

Attachment 10. Test Data Sheets (115 of 155)

Savarinah River Technology Center

EES-FP-379, Rev. 0
Date Approved: $9 / 24 / 92$, Category 2

Equipment Engineering

Seismic II/I Drop Test Program

Instrumented Cabinet Drop Tests

Page 16 of 18

Instrumented Cabinet Drop Tests

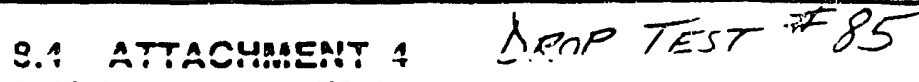

IEST DATA SHEET

(PAGE 2 OF 2)

POST TEST

TARGET DAMAGE NIA

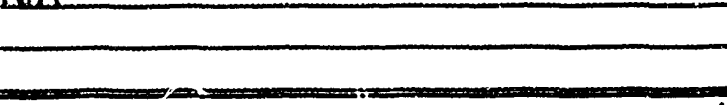

SOURCE DAMAGE N/A

RELAY CHATTER IDENTIFIEd ON POTTER \& BRUMFIELD RELAY (YNN) NONE

IF YES, DURATION OF CHATTER [ms] SEFPLOT

RELAY CHATTER IDENTIFIED ON WESTINGHOUSE RELAY (Y/N) YES

IF YES, DURATION OF CHATTER [ms] SEEPLOT

HANO HELO VIOEO START \& STOP POSITION NIA

HIGH SPEED VIDEO START \& STOP POSITION $22: 05-22: 25$

COMMENTS
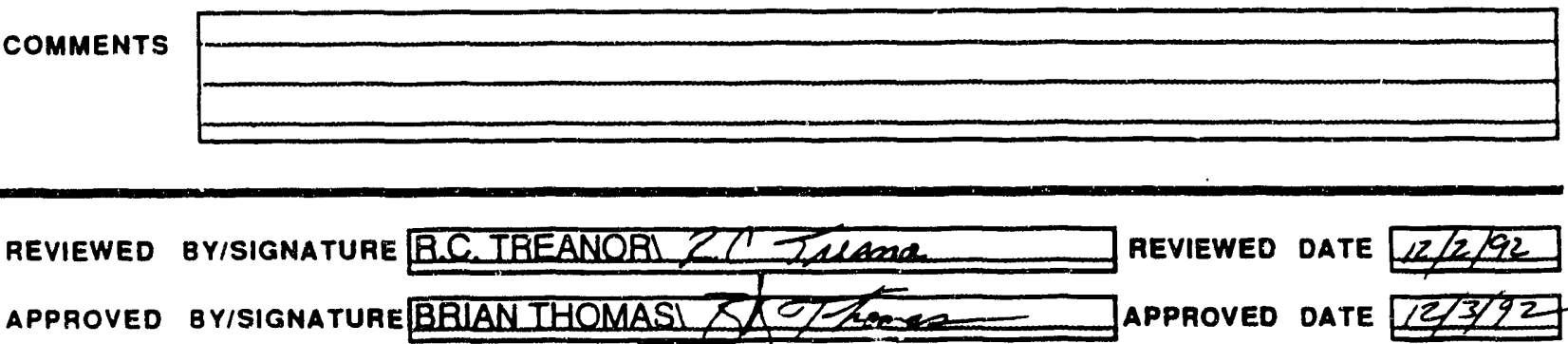
WSRC-TR-93-0094

Attachment 10. Test Data Sheets (116 of 155)

Savannah River Technology Center

EES-FP-379, Rev. 0

Equipment Engineering

Seismic II/I Drop Test Program

Instrumented Cabinet Drop Tests

\subsection{ATTACHMENT 4 \\ IEST DATA SHEEY \\ (PAGE 1 OF 2)}

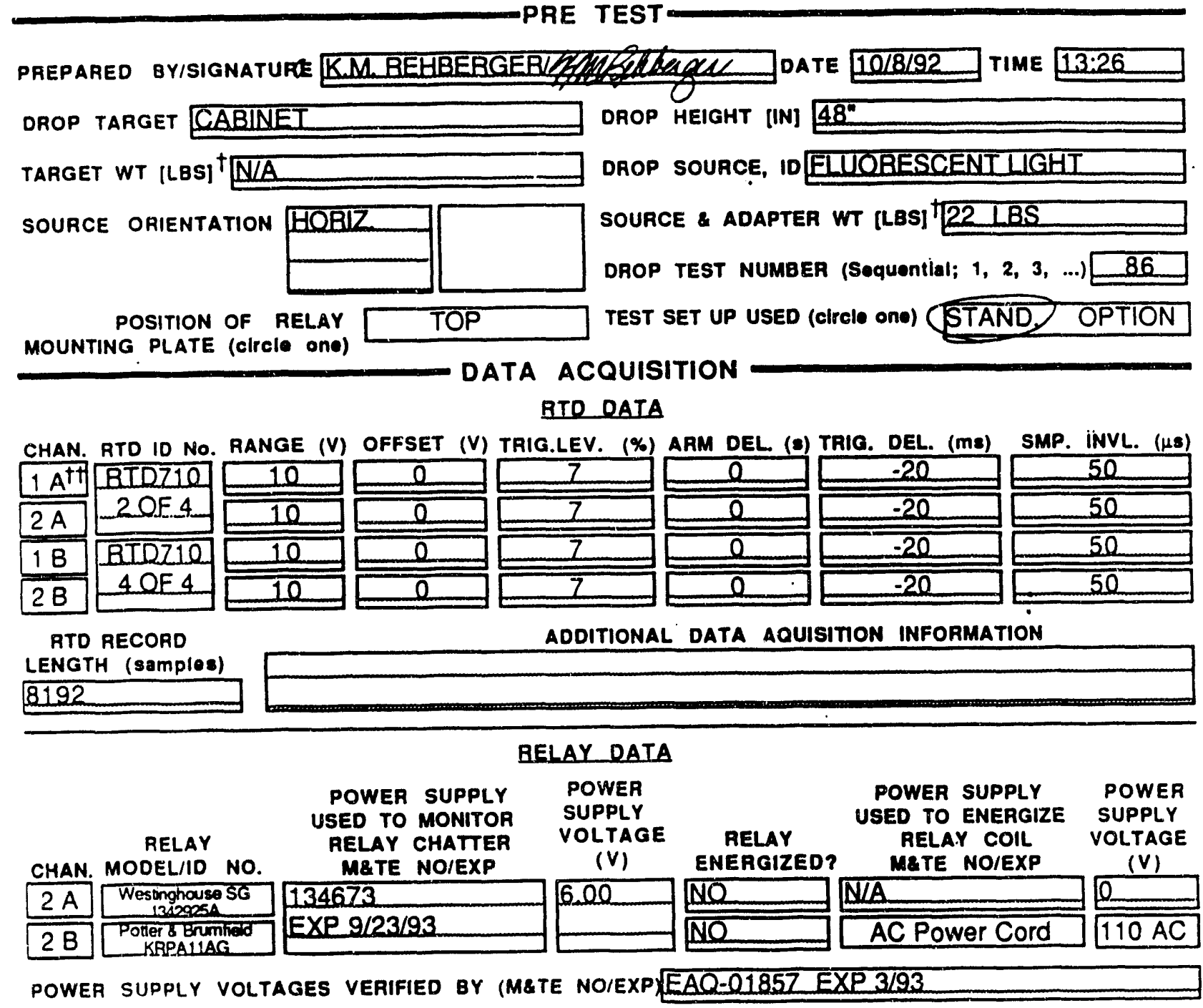

\section{ACCELEROMETER DATA}

CHAN. ACCELEROMETER METE NOIEXP

$1 \mathrm{~A} \& \mathrm{~B} 12235085$ EXP $10 / 29 / 92$

AMPLIFIER M\&TE NO/EXP

AMPLIFIER GAIN

$\dagger$ Approximate weight using M\&TE category 3 equipment.

t+ Numbers 1 \& 2 correspond to channeis on each RTO ( $i$ will be used by accelerometer, 2 will be used by relays.)

Letters A \& B correspond to diffe'ent RTD ID numbers. 
WSRC-TR-93-0094

Attachment 10. Test Duta Sheets (117 of 155$)$

Savannah River Technology Center Equipment Engineering

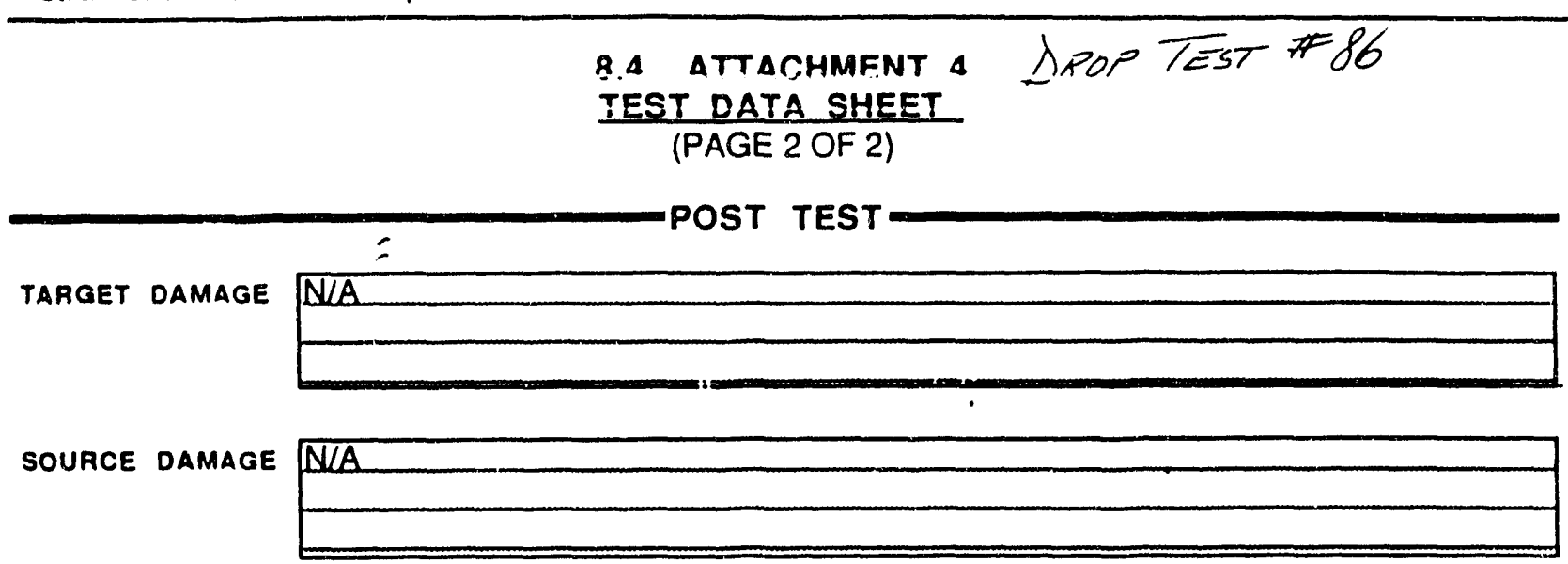

RELAY CHATtER IDENTIFIED ON POTTER BRUMFIELD RELAY (Y/N) NONE

IF YES, DURATION OF CHATTER [ms] SEEPLOT

RELAY ChATTER IDENTIFIEd ON WESTINGHOUSE RELAY (Y/N) YES

IF YES, DURATION OF CHATTER (ms] SEEPLOT

HANO HELO VIDEO START \&TOP POSITION N/A

HIGH SPEED VIDEO START \& STOP POSITION $22: 25-22: 45$

COMMENTS
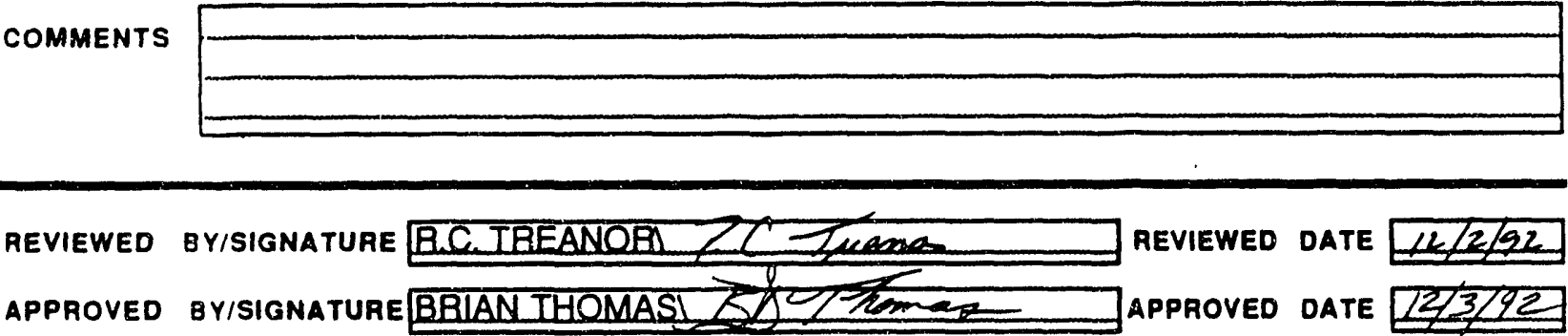
WSRC-TR-93-0094

Attachment 10. Test Data Sheets (118 of 155)

Savannah River Technology Center

Equipment Engineering

Seismic II/I Drop Test Program

Instrumented Cabinet Drop Tests

EES-FP-379, Rev. 0

Date Approved: 9/24/92, Category 2

Page 15 of 18

\subsection{ATTACHMENT 4 \\ IESI UAIA SHEEI \\ (PAGE 1 OF 2)}

PRE TEST

PREPARED BYISIGNATURE KMMBEHBERGEB/ TIME 13:28 DROP TARGET CABINET DROP HEIGHT [IN] 72

TARGET WT [LBS] N/Ä DROP SOURCE, 10 ELUORESCENT LIGHT

SOURCE ORIENTATION HQBIZ.

POSITION OF RELAY MOUNTING PLATE (circle ONe)
SOURCE \& ADAPTER WT [LBS] 22 LBS

DROP TEST NUMBER (Sequentlal; 1, 2, 3, ...) 87 TEST SET UP USED (circle one) STAND. OPTION

DATA ACQUISITION

BTD DATA

CHAN. RTD ID No. RANGE (V)

\begin{tabular}{|c|c|}
\hline $1 A^{+1}$ & BIDZ10 \\
\hline $2 \mathrm{~A}$ & $20 \mathrm{~F}_{4}$ \\
\hline $1 \mathrm{~B}$ & $\mathrm{BID710}$ \\
\hline $2 \mathrm{~B}$ & 4 OF 4 \\
\hline
\end{tabular}

RTD RECORD LENGTH (samples) 8192
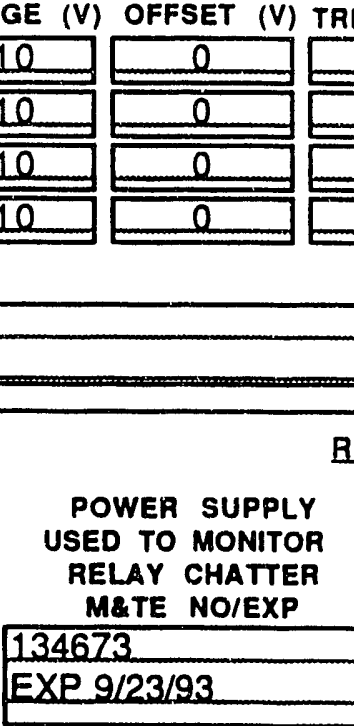

ADDITIONAL DATA AQUISITION INFORMATION
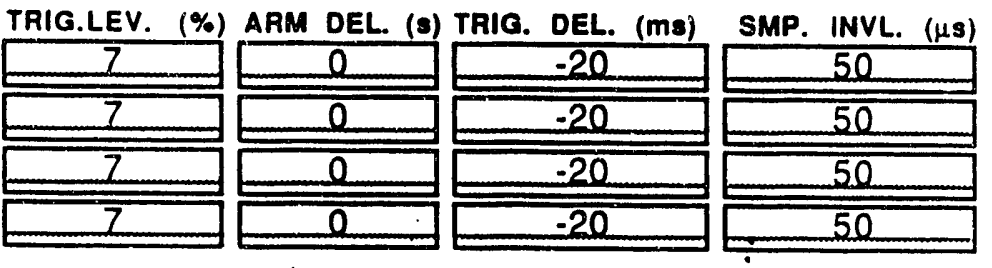

BELAY DATA
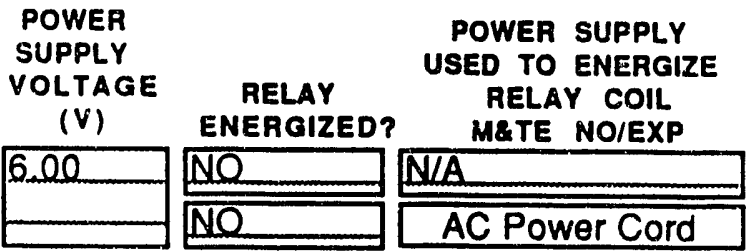

POWER

SUPPLY

VOLTAGE

CHAN. MODEL/ID NO.

\begin{tabular}{|c|c|}
\hline $2 \mathrm{~A}$ & Westinghouse SG \\
\hline $2 B$ & $\begin{array}{c}\text { Potier \& Brumined } \\
\text { KBPALAG }\end{array}$ \\
\hline
\end{tabular}

KRPALIAG

POWER SUPPLY VOLTAGES VERIFIED BY (M\&TE NO/EXP EAQ-01857 EXP 3/93

\section{ACCELEROMETER DATA}

CHAN. ACCELEROMETER MQTE NO/EXP $1 \mathrm{A \& B} 12935085$ EXP $10 / 29 / 92$

L214-068-X EXP 7/17/93

AMPLIFIER GAIN

(1)

† Approximate weight using M\&TE category 3 equipment.

t ${ }^{+}$Numbers $1 \& 2$ correspond to channels on each RTD ( 1 will be used by accelerometer, 2 will be used by relays.)

Leilers A \& B correspond io dirierent RTO IO numbers. 
WSRC-TR-93-0094

Attachment 10. Test Data Sheets (119 of 155)

Savannah River Technology Cènter

Equipment Engineering

Seismic II/I Drop Test Program

Instrumented Cabinet Drop Tests

EES-FP-379, Rev. 0

Date Approved: 9/24/92, Category 2

Page 16 of 18

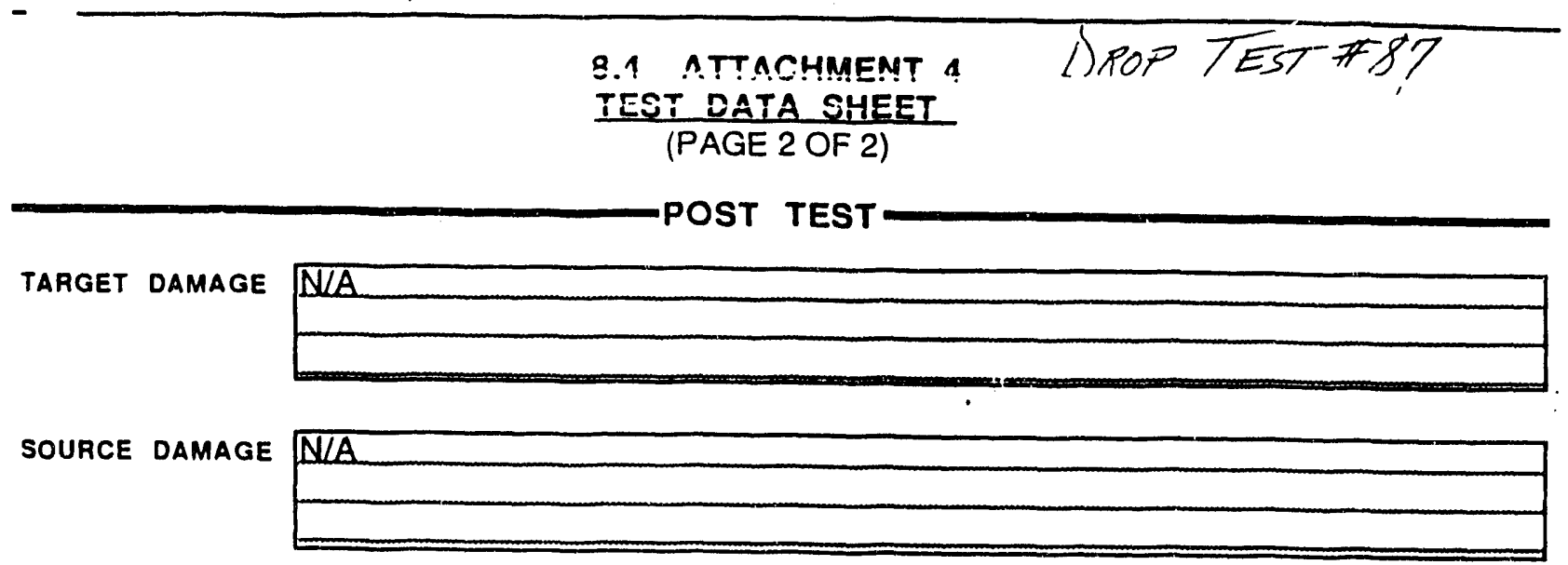

RELAY CHATTER IDENTIFIED ON POTTER \& BRUMFIELD RELAY (Y/N) NONE

IF YES, DURATION OF CHATTER ims] SEEPLOT

RELAY CHATTER IDENTIFIED ON WESTINGHOUSE RELAY (YIN) YES

IF YES, DURATION OF CHATTEA [ms] SEEPLOT

HAND HELD VIDEO START \& STOP POSITION NIA

HIGH SPEED VIDEO START \& STOP POSITION $22: 45-23: 22$

COMMENTS

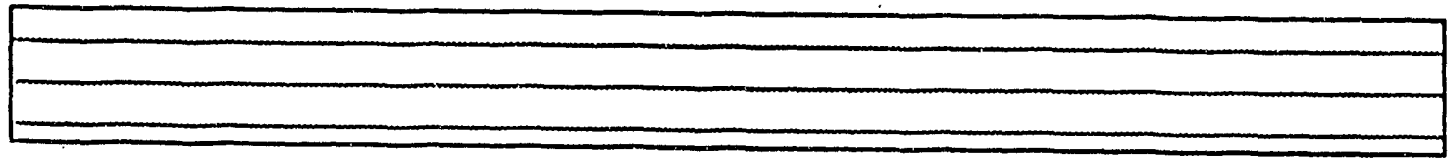

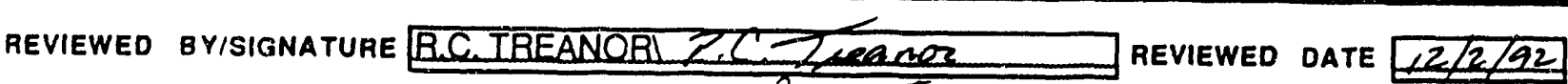

APPROVED BYISIGNATURE BRIAN IHQMAS 
IVSRC-TR-93-0094

Attachment 10. Test Data Sheets (120 of 155)

Savannah River Technology Center

EES-FP-379, Rev. 0

Equipment Engineering

Seismic II// Drop Test Program

Instrumented Cabinet Drop Tests

Date Approved: 9/24/92, Category 2

Page 15 of 18

\subsection{ATTACHMENT 4 \\ TEST DATA SHEET}

(PAGE 1 OF 2)

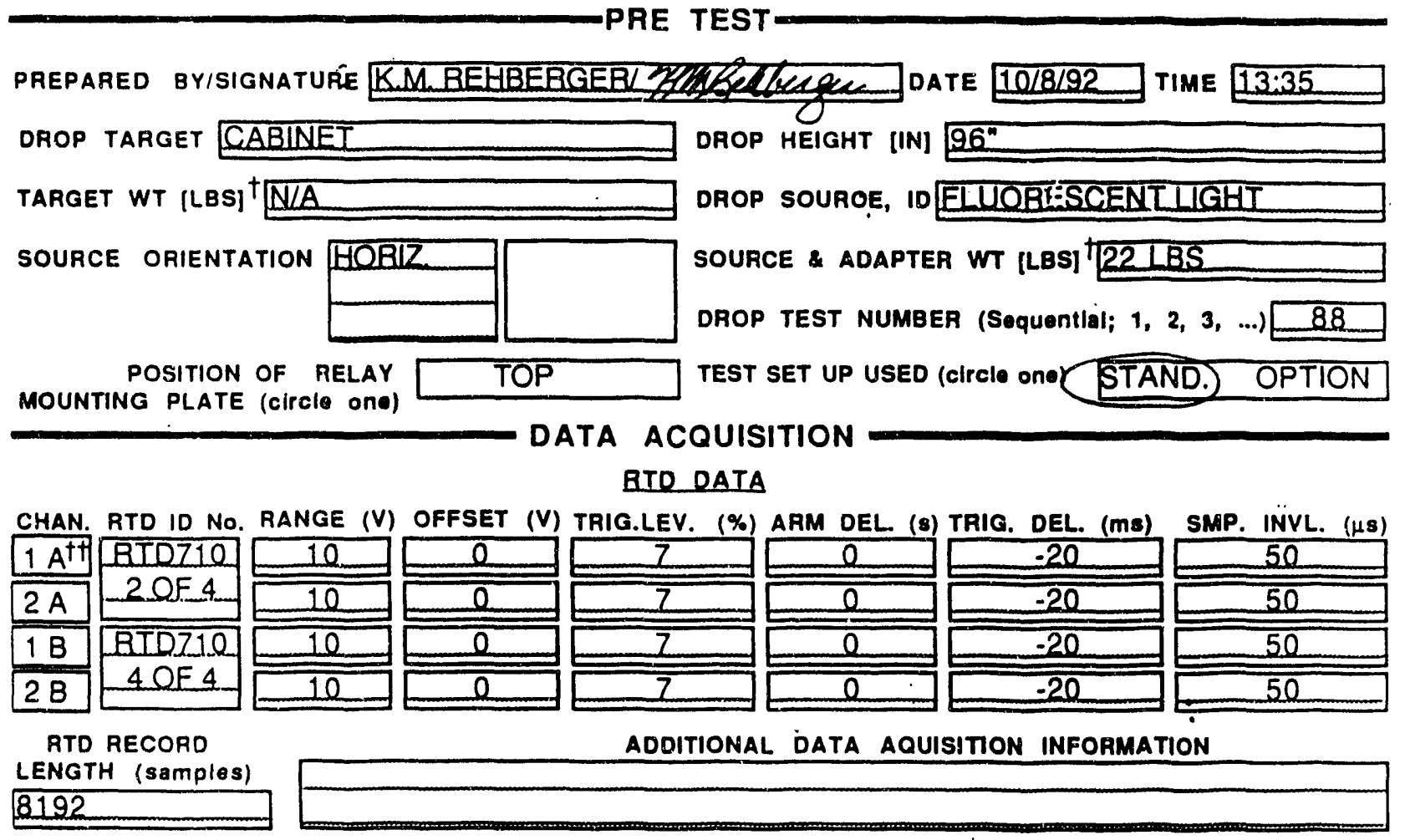

\begin{tabular}{|c|c|c|c|c|c|c|}
\hline \multicolumn{7}{|c|}{ BELAY DATA } \\
\hline CHAN. & $\begin{array}{c}\text { RELAY } \\
\text { MODEL/ID NO. }\end{array}$ & $\begin{array}{l}\text { POWER SUPPLY } \\
\text { USED TO MONITOR } \\
\text { RELAY CHATTER } \\
\text { M\&TE NOIEXP }\end{array}$ & $\begin{array}{l}\text { POWER } \\
\text { SUPPLY } \\
\text { VOLTAGE } \\
\text { (V) }\end{array}$ & $\begin{array}{c}\text { RELAY } \\
\text { ENERGIZED? }\end{array}$ & $\begin{array}{l}\text { POWER SUPPLY } \\
\text { USED TO ENERGIZE } \\
\text { AELAY COIL } \\
\text { M\&TE NO/EXP }\end{array}$ & $\begin{array}{l}\text { POWER } \\
\text { SUPPLY } \\
\text { VOLTAGE } \\
\text { (V) }\end{array}$ \\
\hline $2 A$ & \begin{tabular}{|c|} 
Westinghouse SG \\
$13{ }_{13} \times 251$
\end{tabular} & 134673 & 6.00 & $\mathrm{NQ}$ & $\mathrm{N} / \mathrm{A}$ & $Q$ \\
\hline $2 B$ & 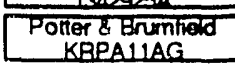 & EXP 9/23/93 & & $\mathrm{NO}$ & AC Power Cord & $110 \mathrm{AC}$ \\
\hline
\end{tabular}

\section{ACCELEROMETER DATA}

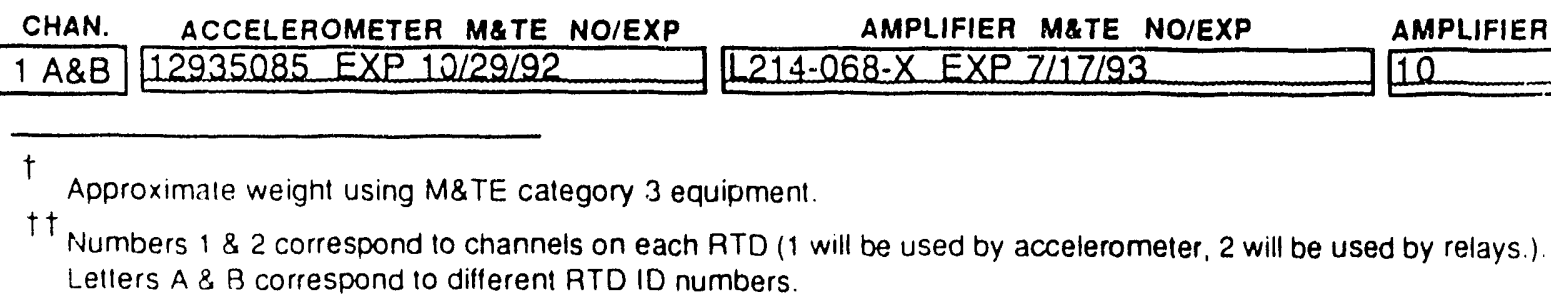


WSRC-TR-93-0094

Attachment 10. Test Data Sheets (121 of 155)

Savannah River Technology Center Equipment Engineering Seismic IVI Drop Test Program

EES-FP-379, Rev. 0 Date Approved: 9/24/92, Category 2

Page 16 of 18

Instrumented Cabinet Drop Tests

\subsection{ATTACHMENT 4 \\ $\Lambda P \cap D T E S T P \perp$ \\ IEST DATA SHEET \\ (PAGE 2 OF 2)}

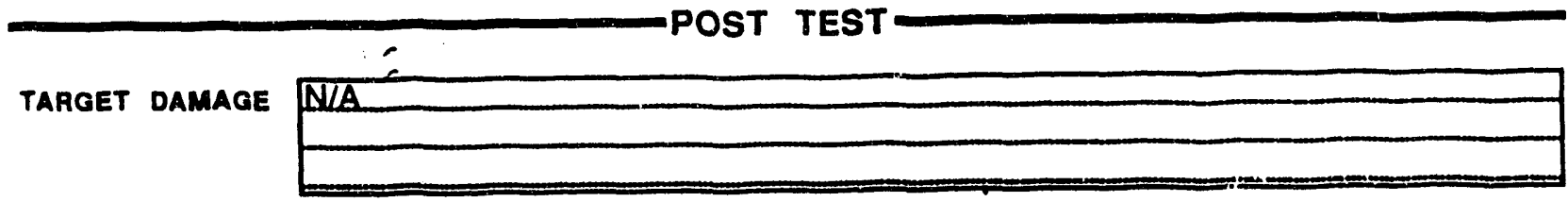

SOURCE DAMAGE NIA

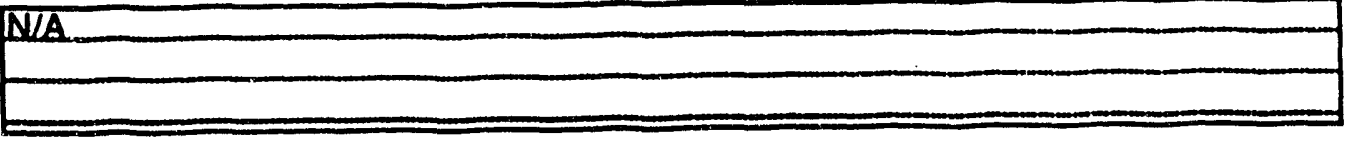

RELAY. CHATTER IDENTIFIED ON POTTER \& BRUMFIELd RELAY (Y/N) NONE

IF YES, DURATION OF CHATTER [ms] SEEPLOT

RELAY CHATTER IDENTIFIEd ON WESTINGHOUSE RELAY (YN) YES

IF YES, DURATION OF CHATTER [ms] SEEPIOT

HAND HELD VIDEO START STOP POSITION NIA

HIGH SPEED VIDEO START \& STOP POSITION 23:22-23:46

COMMENTS ROTIER\&BRUMEIEIDWAS CHECKED AND IT WASNOT RAOPEBL Y SEATED HOWEVER ELECTRICAL CONNECTIONWLASSTILLMADE

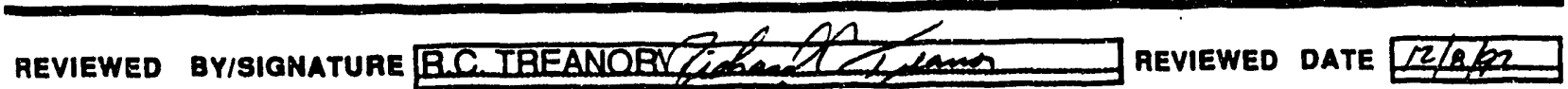

APPROVED BYISIONATURE BRIAN THOMASI F Then 
IVSRC-TR-93-0094

Attachment 10. Test Data Sheets (122 of 155)

Savannah River Technology Center Equipment Engineering Seismic IV/I Drop Test Program Instrumented Cabinet Drop Tests
EES-FP.379, Rev. 0 Date Approved: 9/24/92, Category 2

Page 15 of 18

\subsection{ATTACHMENT 4 \\ IESI DATA SHEET \\ (PAGE 1 OF 2) \\ PRE TEST}

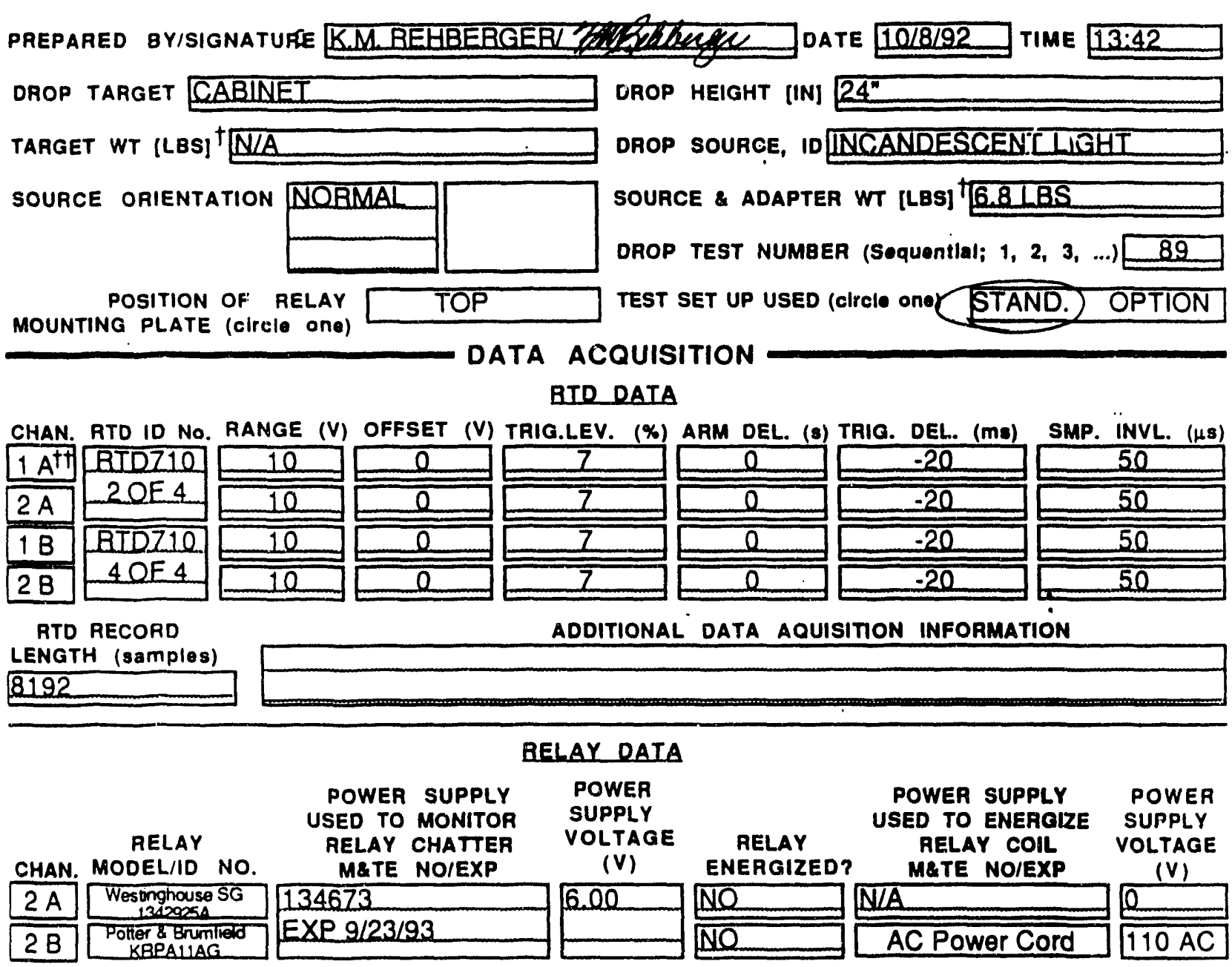

POWER SUPPLY VOLTAGES VERIFIED BY (M\&TE NO/EXP) EAQ-01857 EXP $3 / 93$

\section{ACCELEROMETER DATA}

CHAN. ACCELEROMETER M\&TE NOIEXP

$1 \mathrm{~A} \& B \quad 12935085 \mathrm{EXP} 10 / 29 / 92$

AMPLIFIER M\&TE NO/EXP
L214-068-X EXP Z/17/23

AMPLIFIER GAIN

10

$\dagger$ Approximate weight using M\&TE category 3 equipment.

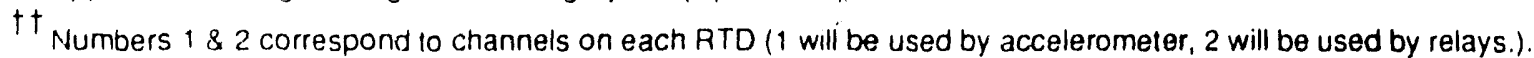
Lellers A \& B correspond to different RTD ID numbers. 
IVSRC-TR-93-0094

Attuchment 10. Test Data Sheets (123 of 155)

Savannah River Technology Center

Equipment Engineering

Seismic II// Drop Test Program Instrumented Cabinet Drop Tests

EES-FP-379, Rev. 0 Date Approved: 9/24/92, Category 2

Page 16 of 18

\section{Q.1 ATTA.CHA.ENT 4}

TEST DATA SHEET

(PAGE 2 OF 2)

\section{POST TEST}

TARGET DAMAGE N/A

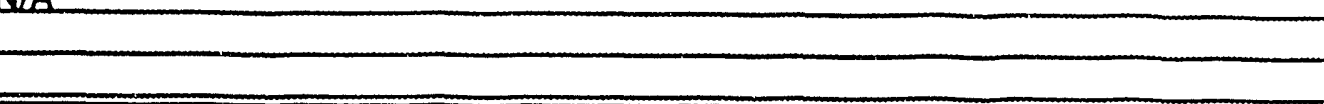

RELAY CHATTER IDENTIFIED ON POTTER \& BRUMFIELD RELAY (Y/N) NONE

IF YES, DURATION OF CHATTER (ms] SEEPLOI

RELAY CHATTER IDENTIFIED ON WESTINGHOUSE RELAY (YIN) YES

IF YES, DURATION OF CHATTER [ms] SEEPLQT

HANO HELD VIDEO START \& STOP POSITION NIA

HIGH SPEED VIDEO START \& STOP POSITION $23: 46-24: 05$

COMMENTS
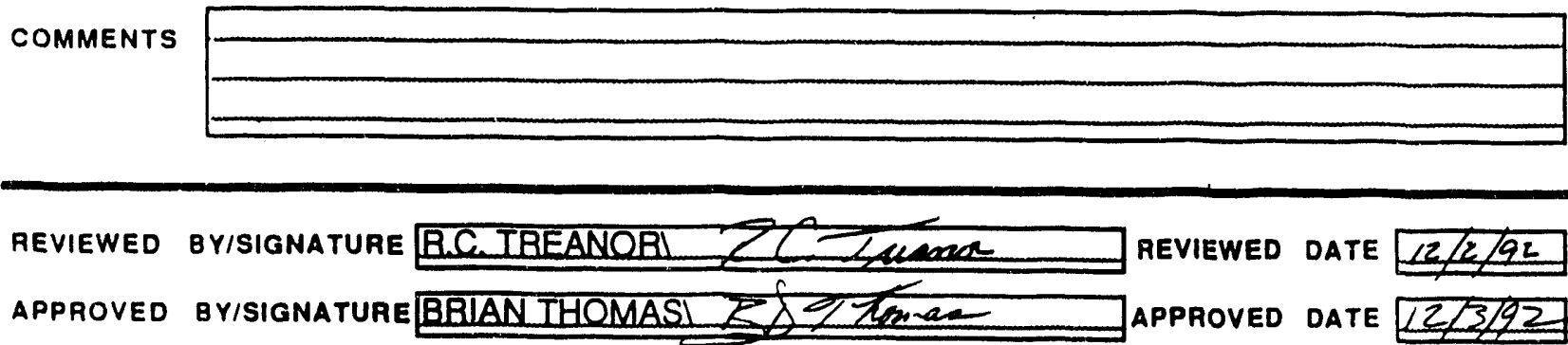
IVSRC-TR-93-0094

Attachment 10. Test Data Sheets (124 of 155)

Savannah River Technology Center

Equipment Engineering

EES-FP-379, Rev. 0

Seismic II/I Drop Test Program

Instrumented Cabinet Drop Tests

\subsection{ATTACHMENT 4}

TEST DATA SHEET

(PAGE I OF 2)

PRE TEST

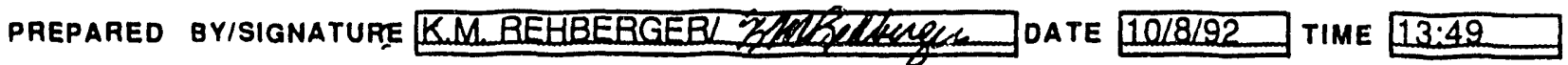

DROP TARGET CABINET

TARGET WT [LBS] N/A

SOURCE ORIENTATION NOBMAL

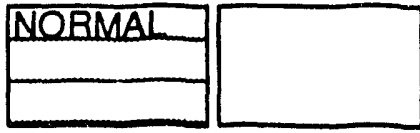

POSITION OF RELAY

MOUNTING PLATE (circle one)
DROP HEIGHT [IN] $48^{N}$

DROP SOURCE, IO INCANDESCENT LIGHT _

SOURCE \& ADAPTER WT [LBS] 6.8 LBS

DROP TEST NUMBER (Sequentlal; 1, 2, 3, ...) 90

TEST SET UP USED (clrclo one) STAND OPTION

\section{DATA ACQUISITION}

RTD DATA

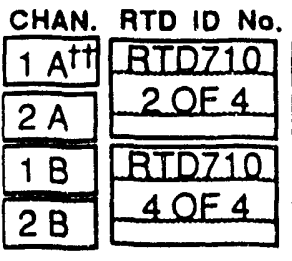

RTO RECORD LENGTH (samples) 8192
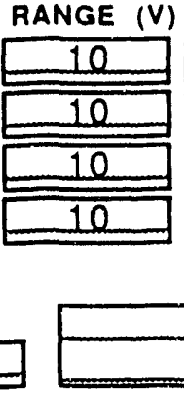
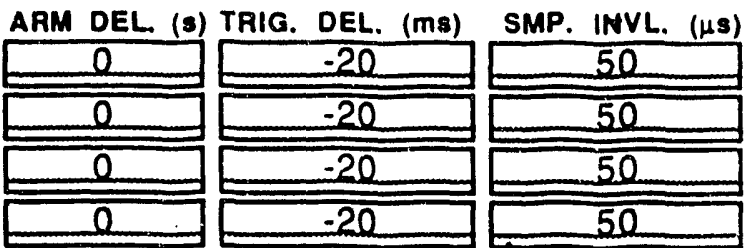

ADDITIONAL DATA AQUISITION INFORMATION
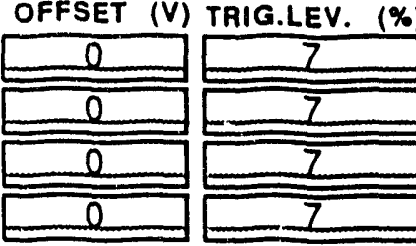
in

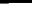

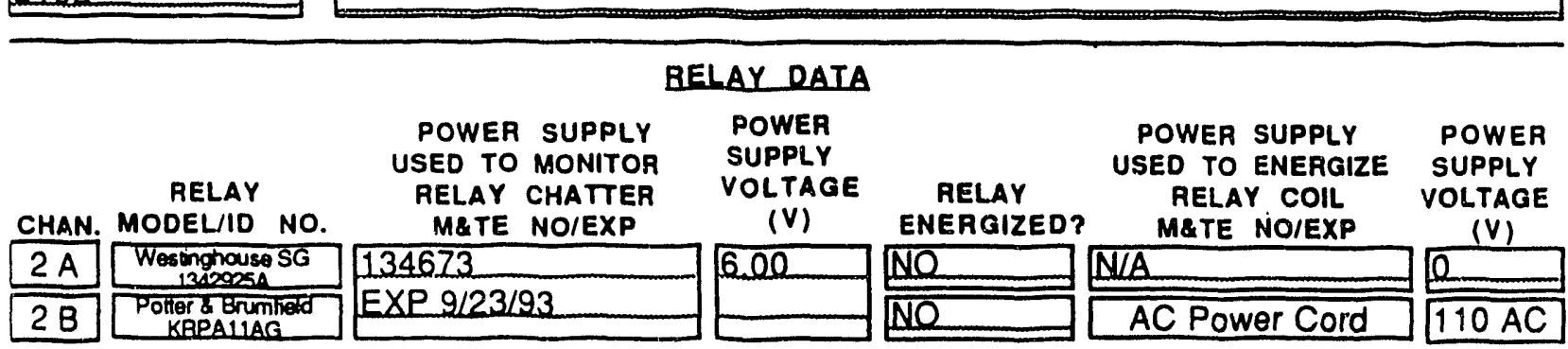

POWER SUPPLY VOLTAGES VERIFIED BY (M\&TE NOIEXP EAQ-01857 EXP $3 / 23$

\section{ACCELEROMETER DATA}

CHAN. ACCELEROMETER M\&TE NO/EXP
1 A\&B 12935085 EXP $10 / 29 / 92$
$1214-068-X$ EXP $7117 / 93$

$\dagger$ Approximate weight using M\&TE calegory 3 equipment.

t† Numbers 1 \& 2 correspond 10 channels on each RTD ( 1 will be used by accelerometer, 2 will be used by relays.). Lellers A \& B correspond to different RTD ID numbers. 
WSRC-TR-93-0094

Attuchment 10. Test Data Sheets (125 of 155)

Savannah River Technology Center

Equipment Engineering

EES-FP-379, Rev. 0

Seismic II/I Drop Test Program

Date Approved: 9/24/92, Category 2

Instrumented Cabinet Drop Tests

Page 16 of 18

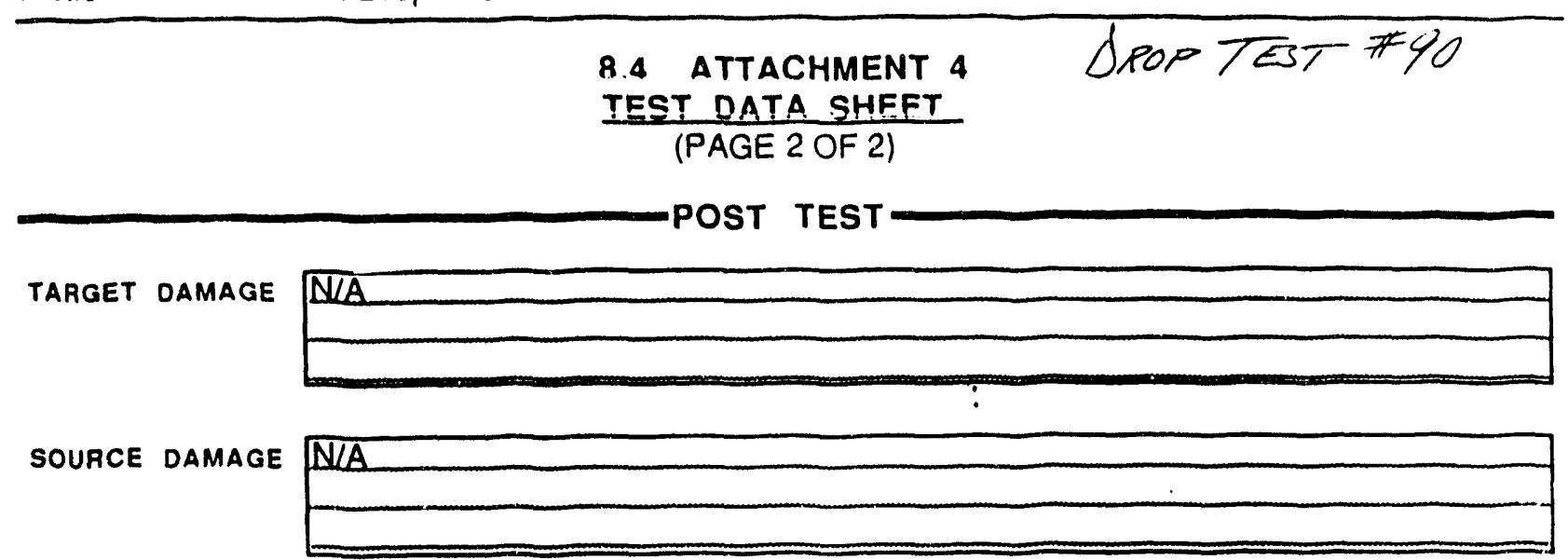

RELAY ChATter IDENTIFIEd ON POTTER \& BRUMFIELD RELAY (Y/N) NONE

IF YES, DURATION OF CHATTER (ms] SEEPLOI

RELAY CHATTER IDENTIFIED ON WESTINGHOUSE RELAY (YIN) YES

IF YES, DURATION OF CHATTER [ms] SEEPLOT

HANO HELD VIOEO START \& STOP POSITION NLLA

HIGH SPEED VIDEO START \& STOP POSITION 24:05-24:27

COMMENTS

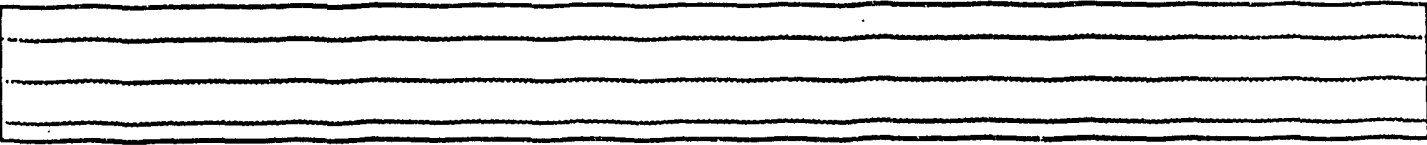

REVIEWED BYISIGNATURE BCGTBEANOAI L a

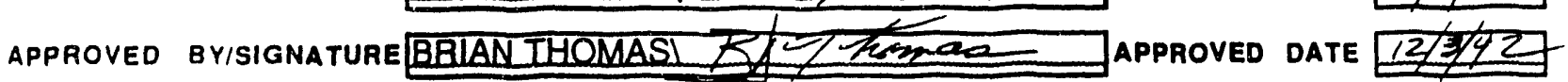


IVSRC-TR-93-0094

Attachment 10. Test Data Sheets (126 of 155)

Savannah River Technology Center

Equipment Engineering

EES-FP-379, Rev. 0

Seismic IV/I Drop Test Program

Date Approved: 9/24/92, Category 2

Instrumented Cabinet Drop Tests

Page 15 of 18

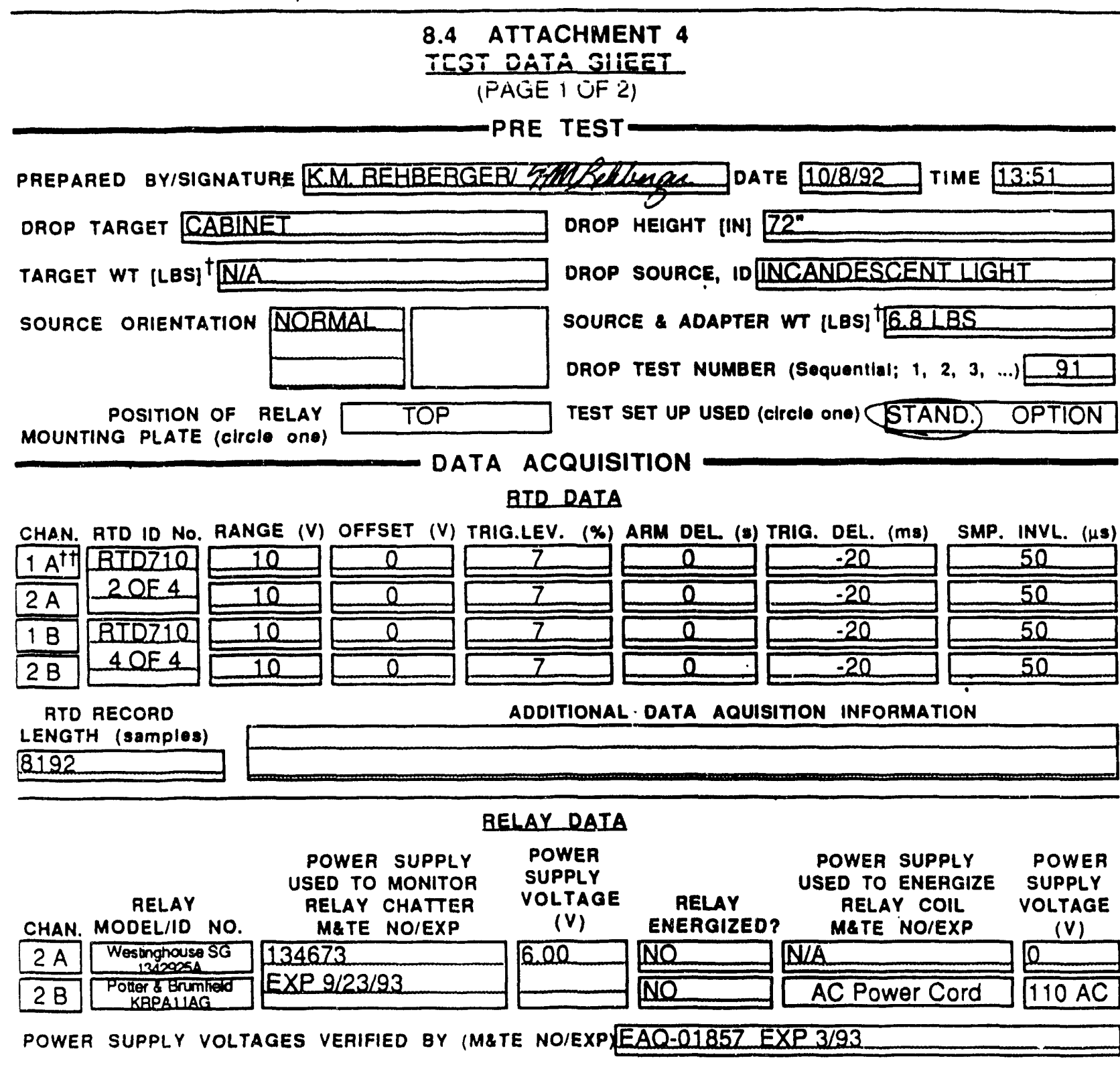

\section{ACCELEROMETER DATA}

CHAN. ACCELEROMETER M\&TE NO/EXP $1 \mathrm{~A} \& B \quad 12935085 \mathrm{EXP} 10 / 29 / 92$

AMPLIFIER M\&TE NO/EXP L214-068-X EXP Z117/93

AMPLIFIER GAIN

Approximate weight using M\&TE category 3 equipment.

${ }^{\dagger}$ Numbers 1 \& 2 correspond to channels on each RTD ( 1 will be used by accelerometer, 2 will be used by relays.) Letters A \& $B$ correspond 10 different RTD ID numbers. 
IVSRC.TR-93.0094

Attuchment 10. Test Data Sheets (127 of 155)

Savannah River Technology Center

EES-FP-379, Rev. 0

Equipment Engineering

Seismic II/I Drop Test Program

Instrumented Cabinet Drop Tests

Date Approved: 9/24/92. Category 2

Page 16 of 18

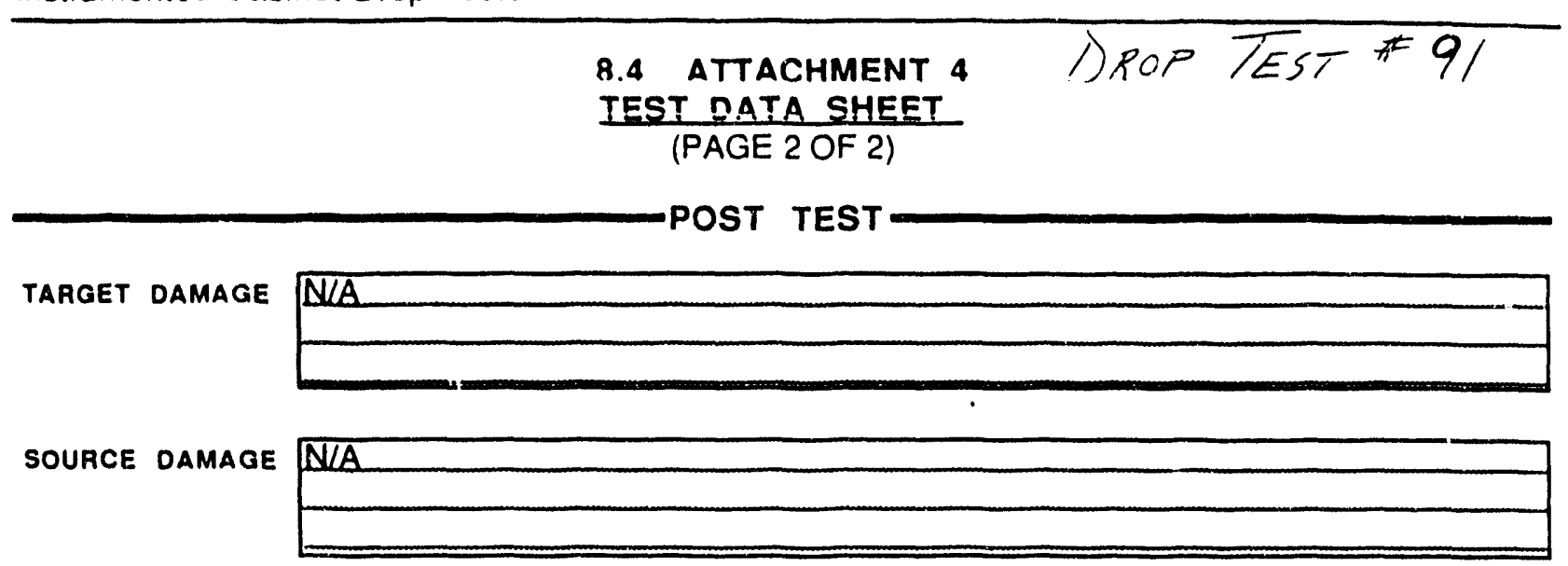

RELAY CHATTER IDENTIFIED ON POTTER \& BRUMFIELD RELAY (YIN) NONE

IF YES, DURATION OF CHATTER (ms) SEEPLOT

RELAY CHATTER IDENTIFIED ON WESTINGHOUSE RELAY (YIN) YES

IF YES, DURATION OF CHATTER (ms) SEEPLOT

HAND HELD VIOEO START \& STOP POSITION NIA

HIGH SPEED VIDEO START \& STOP POSITION $24: 27-25: 04$
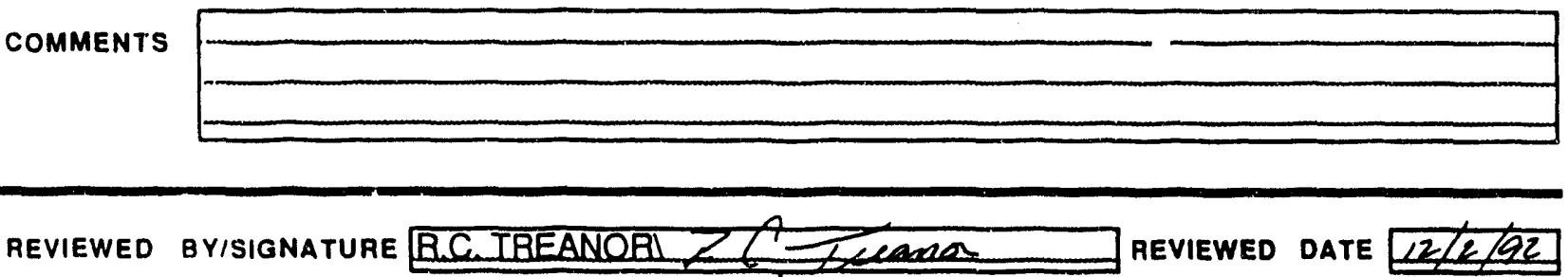

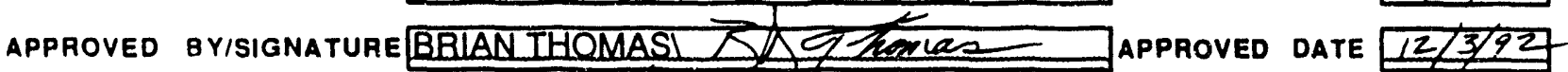


WSRC-TR-93-0094

Attachment 10. Test Data Sheets (128 of 155 )

Savannah River Technology Center

EES-FP-379, Rev. 0

Equipment Engineering

Date Approved: 9/24/92, Category 2

Seismic IV/I Drop Test Program

Page 15 of 18

Instrumented Cabinet Drop Tests

\subsection{ATTACHMENT 4 \\ IEST DATA SHEEI \\ (PAGE 1 OF 2) \\ PRE TEST}

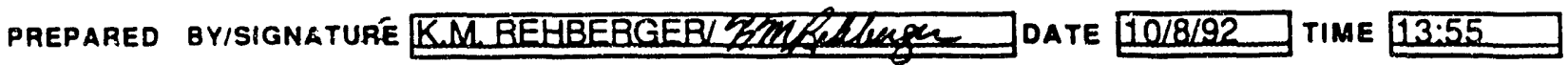

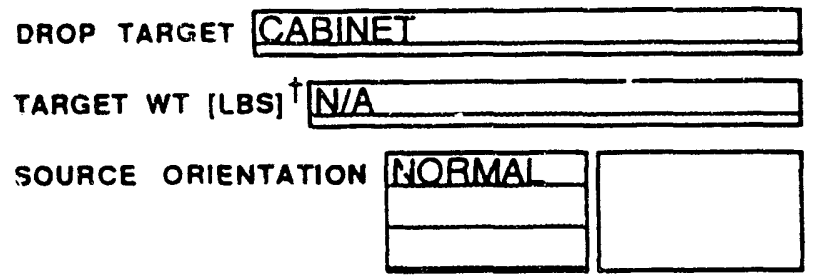

DROP HEIGHT [IN] $96^{\circ}$

POSITION OF RELAY

MOUNTING PLATE (circle One)

DROP SOURCE, ID INCANDESCENT LIGHT

SOURCE \& ADAPTER WT [LBS] 6.8 LBS

DROP TEST NUMBER (Sequontlal; $1,2,3, \ldots), 92$

TEST SET UP USED (eircle ine) STAND.) OPTION

\section{DATA ACQUISITION}

\section{BTO DATA}

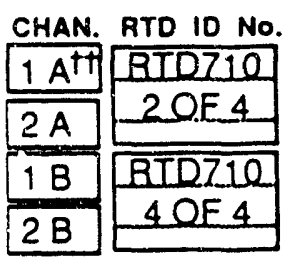

RTD RECORD LENGTH (samples) 8192
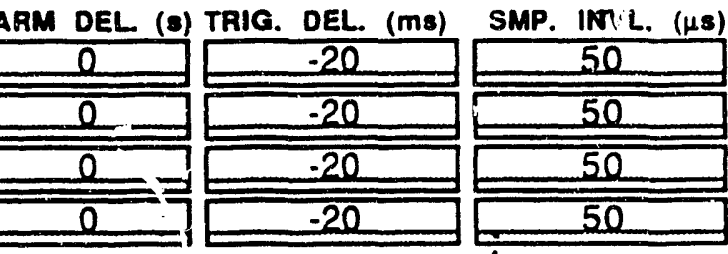

ADDITIONAL DATA AQUISITION INFORMATION

\begin{tabular}{|c|c|c|c|c|c|c|c|}
\hline \multicolumn{8}{|c|}{ RELAY DATA } \\
\hline CHAN. & $\begin{array}{c}\text { RELAY } \\
\text { MODEL/ID NO. }\end{array}$ & $\begin{array}{l}\text { POWER } \\
\text { USED TO } \\
\text { RELAY } \\
\text { M\&TE }\end{array}$ & $\begin{array}{l}\text { SUPPLY } \\
\text { MONITOR } \\
\text { CHATTER } \\
\text { NOIEXP }\end{array}$ & $\begin{array}{l}\text { POWER } \\
\text { SUPPLY } \\
\text { VOLTAGE } \\
\text { (V) }\end{array}$ & $\begin{array}{l}\text { RELAY } \\
\text { ENERGIZED? }\end{array}$ & $\begin{array}{c}\text { POWER SUPPLY } \\
\text { USED TO ENERGIZE } \\
\text { RELAY. COIL } \\
\text { METE NO/EXP }\end{array}$ & $\begin{array}{c}\text { POWER } \\
\text { SUPPLY } \\
\text { VOLTAGE } \\
\text { (V) }\end{array}$ \\
\hline $2 A$ & \begin{tabular}{|c|} 
Wesinghouse SG \\
1302025 A
\end{tabular} & 134673 & & (5) & $\mathrm{NQ}$ & N/A & 0 \\
\hline $2 B$ & 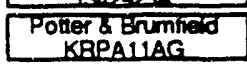 & EXP 9/23/ & & & $\mathrm{NO}$ & AC Power Cord & $110 \mathrm{AC}$ \\
\hline
\end{tabular}

POWER SUPPLY VOLTAGES VERIFIED BY (M\&TE NO/EXP EAQ-01857 EXP 3/93

\section{ACCELEROMETER DATA}

\begin{tabular}{|c|c|c|c|}
\hline CHAN. & ACCELEMOMETER M\&TE NO/EXP & AMPLIFIER M\&TE NO/EXP & AMPLIFIER GAIN \\
\hline$\overline{1 A \& B}$ & 12935685 EXP $10 / 29 / 92$ & L214-068-X EXP Z/17/93 & 10 \\
\hline
\end{tabular}

Approximate weight using M\&TE category 3 equipment.

${ }^{\dagger \dagger}$ Numbers 1 \& 2 correspond to channels on each RTD ( 1 will be used by accelerometer, 2 will be used by relays.). Letters A \& B correspond to different RTD ID numbers. 
WSRC-TR-93-0094

Attachment 10. Test Data Sheets (129 of 155)

Savannah River Technology Center

Equipment Engineering

EES-FP-379, Rev. 0

Seismic II/I Drop Test Program

Instrumented Cabinet Drop Tests

Date Approved: 9/24/92, Category 2

Page 16 of 18

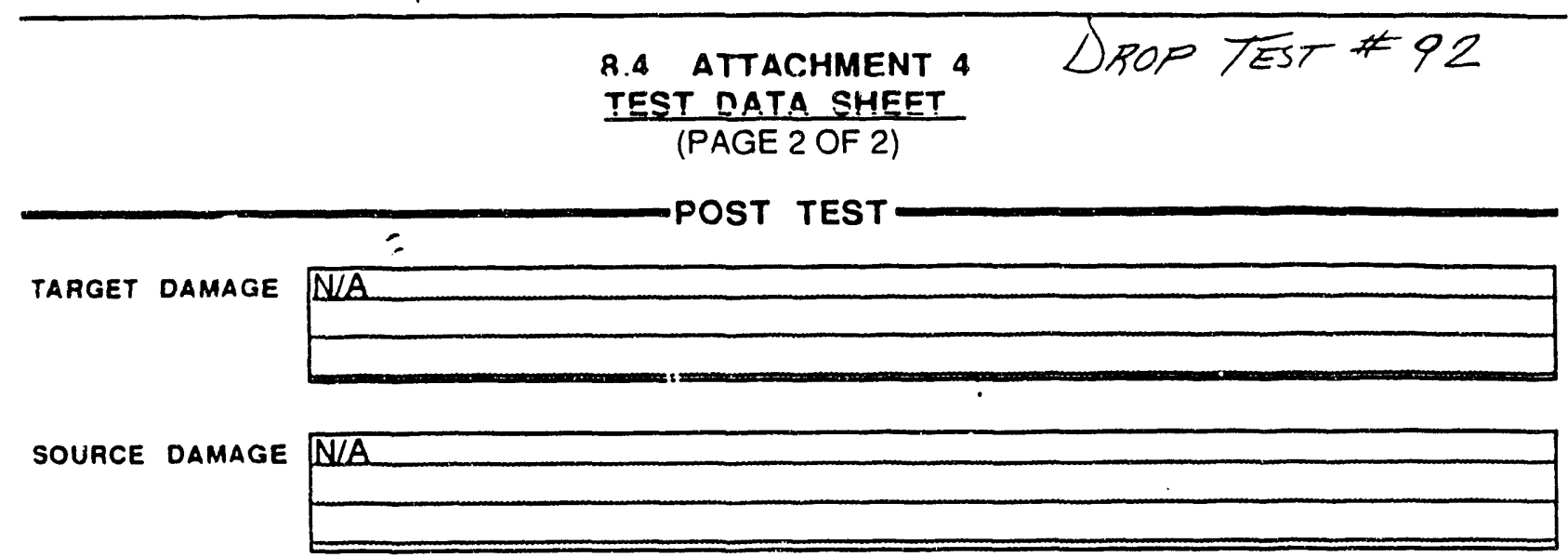

RELAY CHATTER IOENTIFIED ON POTTER \& BRUMFIELD RELAY (Y/N) NONE IF YES, DURATION OF CHATTER [ms] SEFPLOT

RELAY CHATTER IDENTIFIED ON WESTINGHOUSE RELAY (Y/N) YES

IF YES, DURATION OF CHATTER (ms] SEEPLOI

HAND HELD VIDEO START \& STOP POSITION NIA

HIGH SPEED VIDEO START \& STOP POSITION $25: 04-25: 34$

COMMENTS

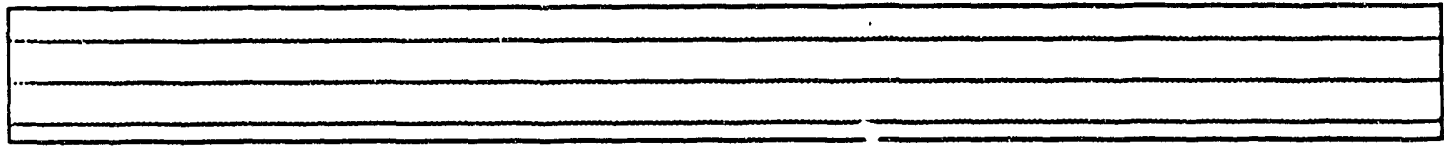

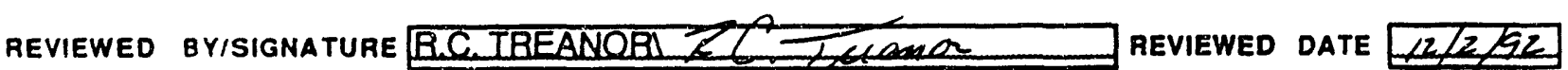

APPROVED BYISIGNATURE BRIANTHOMASI $<$ DAPPROVED DATE $12 / 3 / 22$ 
WSRC-TR-93-0094

Attachment 10. Test Data Sheets (130 of 155)

Savannah River Technology Center

EES-FP-379, Rev. 0

Equipment Engineering

Seismic II// Drop Test Program

Date Approved: $9 / 24 / 92$, Category 2

Instrumented Cabinet Drop Tests

Page 15 of 18

\subsection{ATTACHMENT 4}

TEST DATA SHEET

(PAGE 1 OF 2)

-PRE TEST

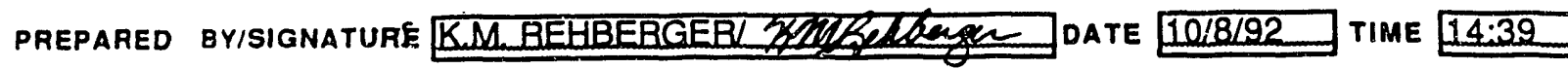

DROP TARGET CABINET DROP HEIGHT [IN] $170^{\text {" }}$

TARGET WT [LBS] ${ }^{\dagger}$ N/A UROP SOURCE, 10 SOLID OBJECT(sprinkler haad).

SOURCE OR!ENTATION NIA

SOURCE \& ADAPTER WT [LBS] 336 gMS

DROP TEST NUMBER (Sequential; $1,2,3, \ldots) 93$

POSITION OF RELAY

MOUNTING PLATE (circle one)

TEST SET UP USED (cirelo ono) STAND.) OPTION

DATA ACQUISITION

RTD DATA

CHAN. RTD ID No. RANGe (V) OFFSET (V) TRIG.LEV. (\%) ARM DEL. (8) TRIG. DEL. (ms) SMP. INVL. (HS)

\begin{tabular}{|c|c|}
\hline $1 A^{+f}$ & BTDI10 \\
\hline $2 A$ & 2 OF 4 \\
\hline $1 B$ & BTD210 \\
\hline $2 B$ & 4 OF 4 \\
\hline
\end{tabular}

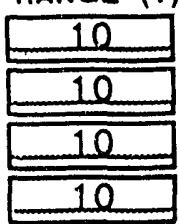

RTD RECORD LENGTH (samples) 8192
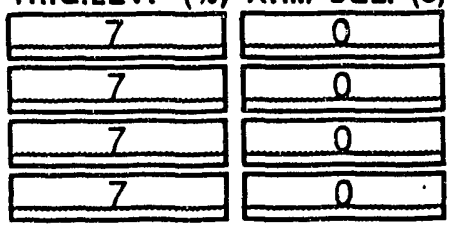
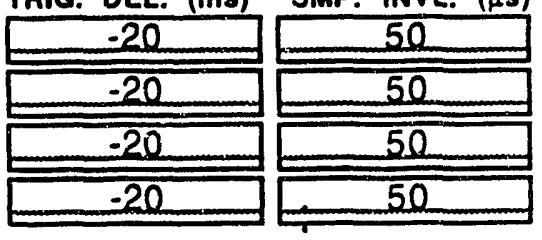

ADDITIONAL DATA AQUISITION INFORMATION

\begin{tabular}{|c|c|c|c|c|c|c|c|c|}
\hline \multirow[b]{2}{*}{ CHAN. } & \multicolumn{8}{|c|}{ BELAY DATA } \\
\hline & $\begin{array}{c}\text { RELAY } \\
\text { MODEL/ID }\end{array}$ & No. & $\begin{array}{l}\text { POWER } \\
\text { USED TO } \\
\text { RELAY } \\
\text { M\&TE }\end{array}$ & $\begin{array}{l}\text { SUPPLY } \\
\text { MONITOR } \\
\text { CHATTER } \\
\text { NO/EXP }\end{array}$ & $\begin{array}{l}\text { POWER } \\
\text { SUPPLY } \\
\text { VOLTAGE } \\
\text { (V) }\end{array}$ & $\begin{array}{c}\text { RELAY } \\
\text { ENERGIZED? }\end{array}$ & $\begin{array}{c}\text { POWER SUPPLY } \\
\text { USED TO ENERGIZE } \\
\text { RELAY COIL } \\
\text { METE NO/EXP } \\
\end{array}$ & $\begin{array}{c}\text { POWER } \\
\text { SUPPLY } \\
\text { VOLTAGE } \\
\text { (V) }\end{array}$ \\
\hline $2 A$ & Westinghouse & & 134673 & & 6.00 & $\mathrm{NO}$ & N/A & $Q$ \\
\hline $2 B$ & $\begin{array}{r}\text { Potter } 8 \text { Brum } \\
\text { KBPAIIAC }\end{array}$ & & FXP 9/23/S & 93 & & $\overline{\mathrm{NQ}}$ & AC Power Cord & $110 \mathrm{AC}$ \\
\hline
\end{tabular}

POWER SUPPLY VOLTAGES VERIFIED BY (M\&TE NO/EXP) EAQ-01857 EXP $3 / 93$

ACCELEROMETER DATA

\begin{tabular}{l} 
CHAN. ACCELEROMETER M\&TE NO/EXP 1 AMPLIFIER M\&TE NO/EXP \\
1 A\&B 12235085 EXP $10 / 29 / 92$ \\
\hline
\end{tabular}

t Approximate weight using M\&TE categony 3 equipment.

${ }^{\dagger \dagger}$ Numbers 1 \& 2 correspond to channels on each RTD ( 1 will be used by accelerometer, 2 will be used by relays.). Letters A \& B correspond to ditferent RTD ID numbers. 
WSRC-TR-93-0094

Attachment 10. Test Data Sheets (131 of 155)

Savannah River Technölogy Center Equipment Engineering Seismic IV/I Drop Test Program Instrumented Cabinet Drop Tests

EES-FP-379, Rev. 0 Date Approved: 9/24/92, Category 2 Page 16 of 18

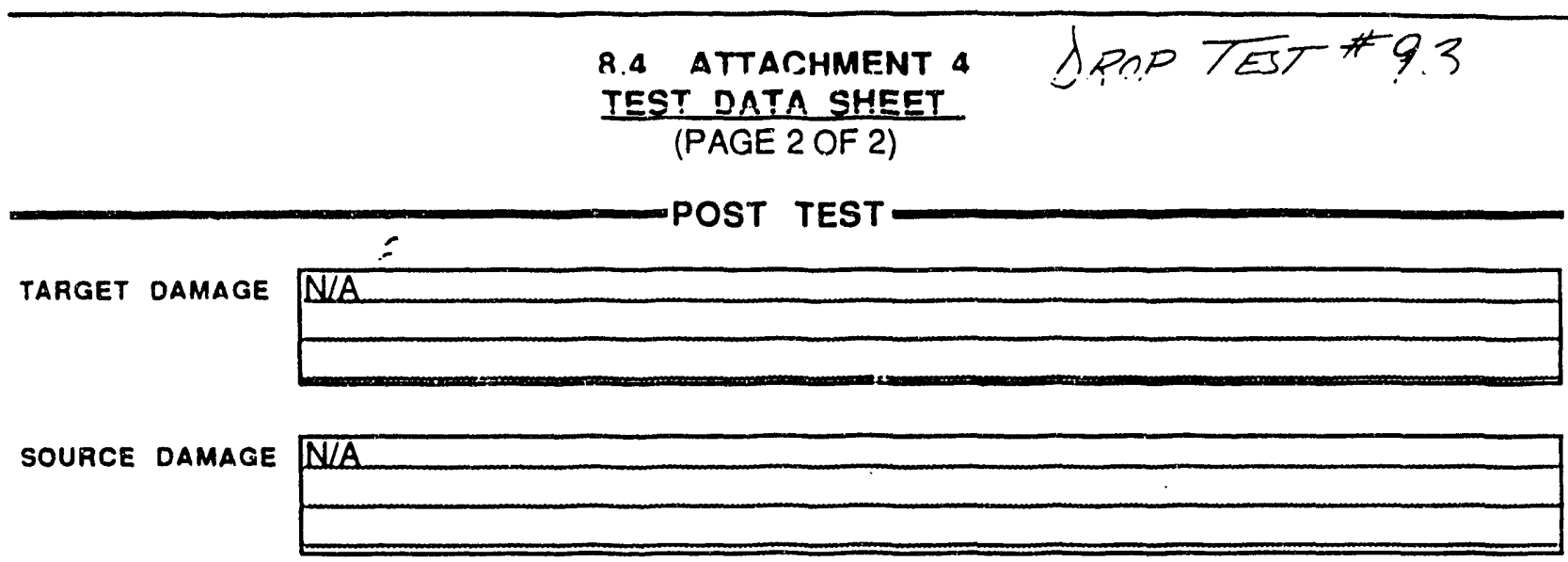

RELAY CHATtER IDENTIFIED ON POTTER BRUMfieLd RELAY (Y/N) NQME IF YES, DURATION OF CHATTER [ms] SEEPLOT

RELAY CHATTER IDENTIFIED ON WESTINGHOUSE RELAY (YIN) YES

IF YES, DURATION OF CHATTER [ms] SEEDLOI

HAND HELD VIDEO START \& STOP POSITION NLA

HIGH SPEED VIDEO START \& STOP POSITION $25: 34-25: 50$

COMMENTS SQURCEWASUSED IQ SIMULATE A TYRICAL SERINKLERHEAD

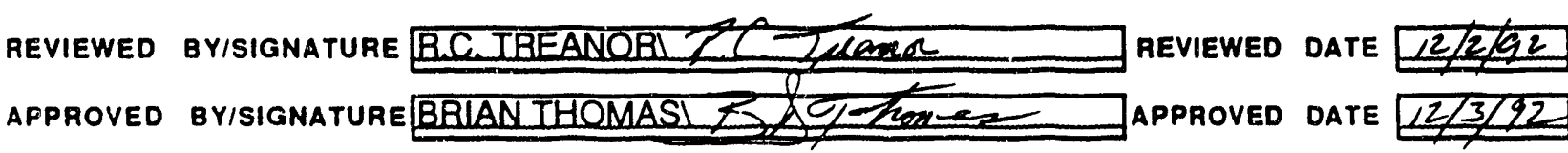


WSRC.TR-93.0094

Attachment 10. Test Data Sheets (132 of 155)

Savannah River Technology Center

Equipment Engineering

EES-FP-379, Rev. 0

Seismic II// Drop Test Program

Date Approved: 9/24/92, Category 2

Instrumented Cabinet Drop Tests

Page 15 of 18

\subsection{ATTACHMENT 4 \\ IEST DATA SHEET \\ (PAGE 1 OF 2)}

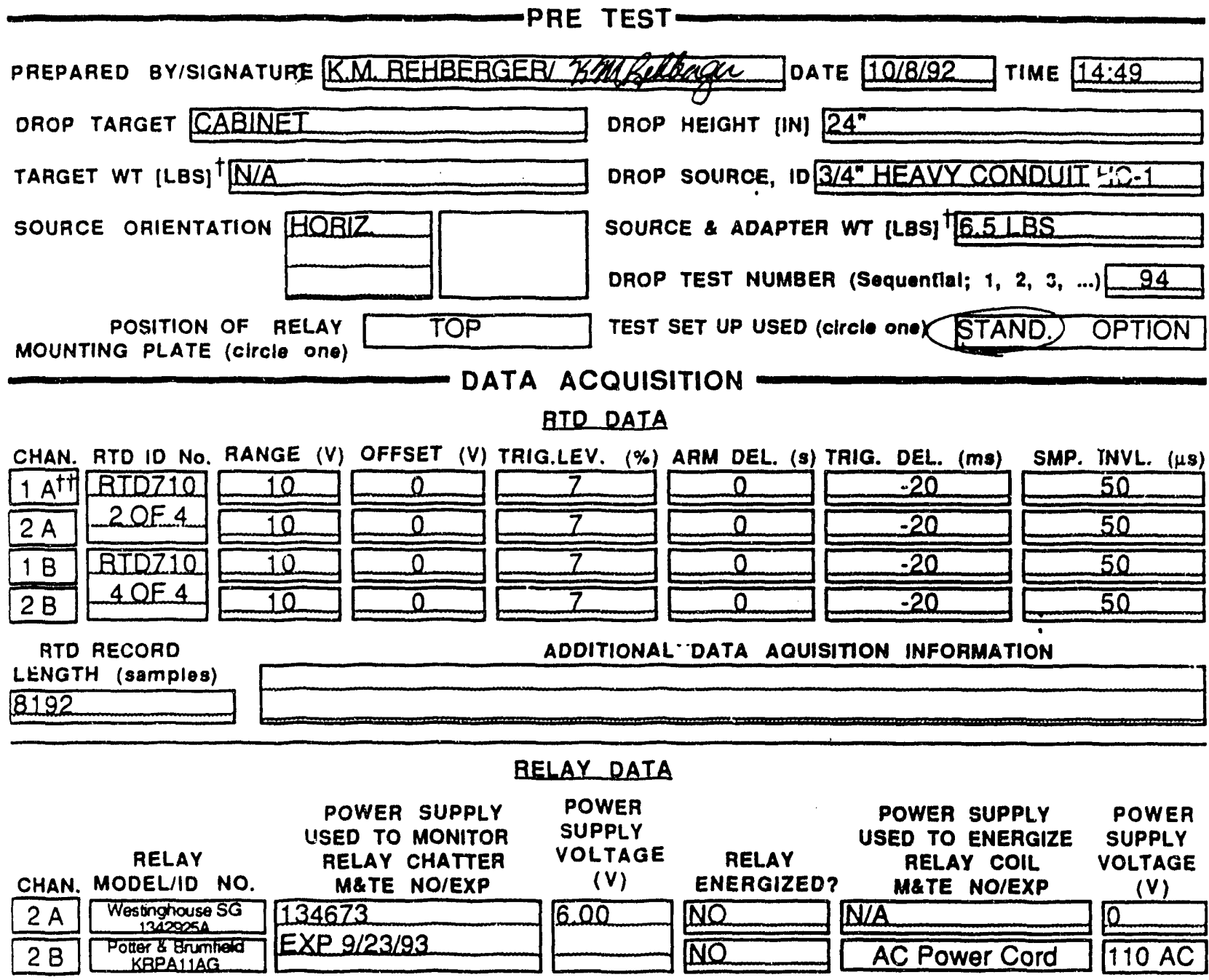

POWER SUPPLY VOLTAGES VERIFIED BY (M\&TE NO/EXP EAQ-01857 EXP 3/93

\section{ACCELEROMETER DATA}

CHAN. ACCELEROMETER M\&TE NO/EXP

$1 \mathrm{~A} \& B \mathrm{~B} 12935085 \mathrm{EXE} 10 / 29 / 92$

AMPLIFIER M\&TE NO/EXPL214-068-X EXP Z117/93

AMPLIFIER GAIN

$\dagger$

Approximate weight using $M \& T E$ category 3 equipment

${ }^{\dagger}$ ivumters $i$ a 2 correspond to channets on each RTD ( 1 will be usea by accelernmeter, 2 will be used by relays.). Lelters A \& B correspond to different RTD ID numbers. 
WSRC-TR-93-0094

Attachment 10. Test Data Sheets (133 of 155)

Savannah River Technology Center Equipment Engineering

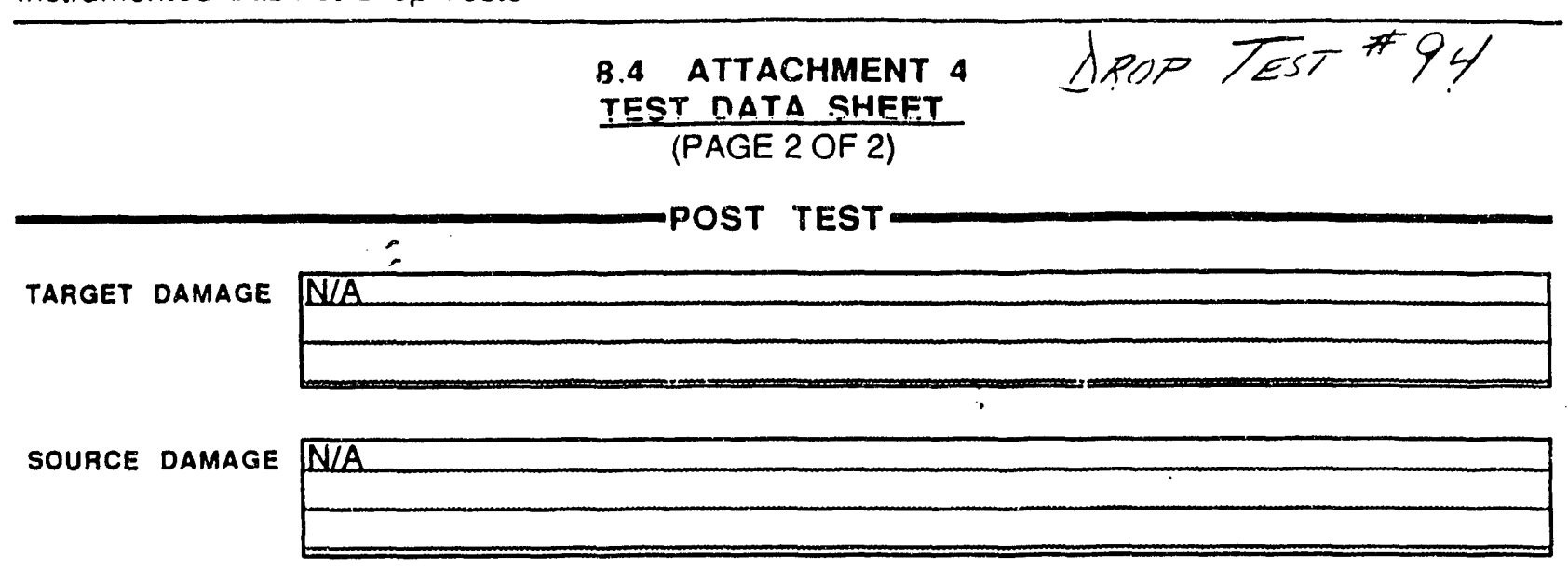

RELAY CHATTER IDENTIFIED ON POTTER \& BRUMFIELD RELAY (Y/N) NONE

IF YES, DUAATION OF CHATTER [ms] SEEPLOT

RELAY CHATTER IDENTIFIED ON WESTINGHOUSE RELAY (YIN) YES

IF YES, DURATION OF CHATTER [ms] SEEPLOI

HAND HELD VIDEO START \& STOP POSITION NIA

HIGH SPEEO VIDEO START \& STOP POSITION $25: 50-26: 23$

COMMENTS

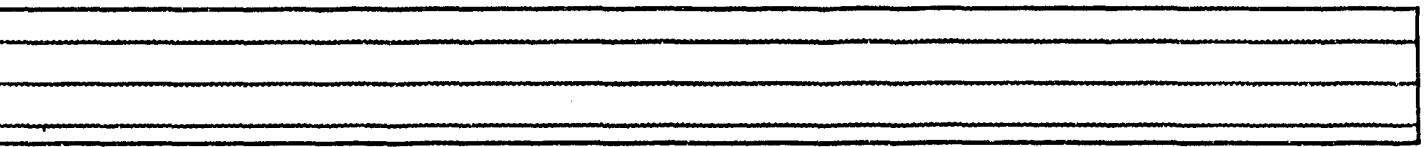

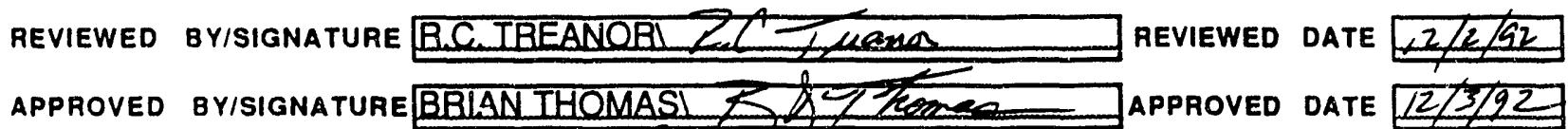


WSRC-TR-93-0094

Attachment 10. Test Data Sheets (134 of 155)

Savannah River Technology Center

EES-FP-379, Rev. 0

Equipment Engineering

Date Approved: 9/24/92, Category 2

Seismic 1!// Drop Test Program

Page 15 of 18

Instrumented Cabinet Drop Tests

\subsection{ATTACHMENT 4 \\ TEST D̈ATA SHEET \\ (PAGE 1 OF 2)}

PRE TEST

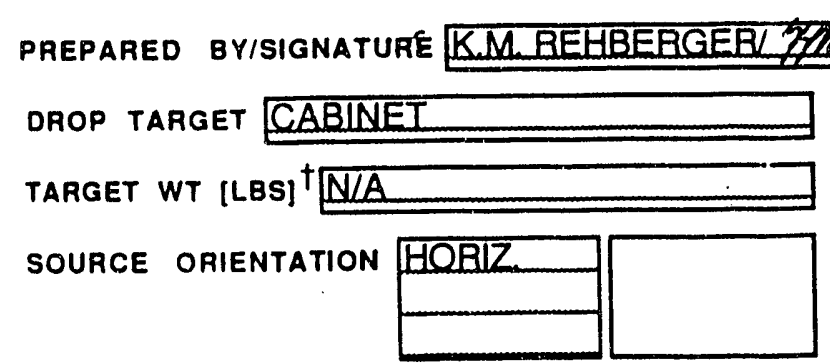

POSITION OF RELAY

MOUNTING PLATE (circle one)

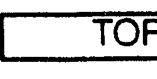

DATA ACQUISITION

\section{BTD DATA}

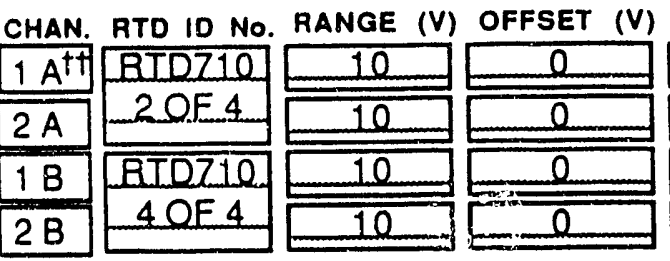

RTD RECORD

LENGTH (samples) 8192
DROP HEIGHT [IN] $48^{\circ}$

DROP SOURCE, ID $3 / 4^{\prime \prime} H E A V I^{\prime}$ CQNDUII HC-1.

SOURCE \& ADAPTER WT [LBS] 6.5 LBS

DROP TEST NUMBER (Sequential; 1, 2, 3, ...) 95

TEST SET UP USED (circle one) STAND. OPTION

TRIG.LEV. (\%)
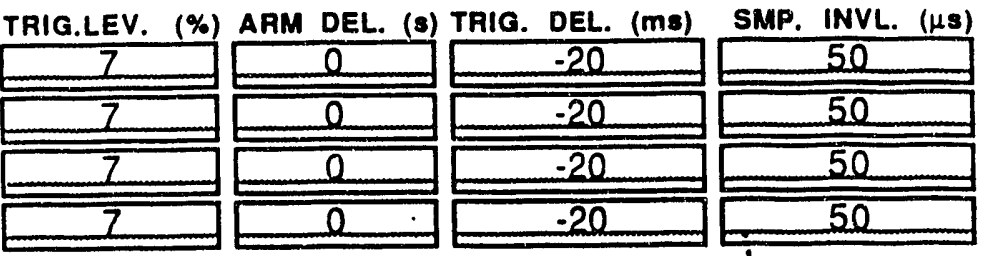

ADDITIONAL DATA AQUISITION INFORMATION

\begin{tabular}{|c|c|c|c|c|c|c|}
\hline \multirow[b]{2}{*}{ CHAN. } & \multicolumn{6}{|c|}{ BELAY DATA } \\
\hline & $\begin{array}{c}\text { RELAY } \\
\text { MODEL/ID NO. }\end{array}$ & $\begin{array}{l}\text { POWER SUPPLY } \\
\text { USED TO MONITOR } \\
\text { RELAY CHATTER } \\
\text { M\&TE NOIEXP }\end{array}$ & $\begin{array}{l}\text { POWER } \\
\text { SUPPLY } \\
\text { VOLTAGE } \\
\text { (V) }\end{array}$ & $\begin{array}{c}\text { RELAY } \\
\text { ENERGIZED? }\end{array}$ & $\begin{array}{c}\text { POWER SUPPLY } \\
\text { USED TO ENERGIZE } \\
\text { RELAY COIL } \\
\text { M\&TE NOIEXP }\end{array}$ & $\begin{array}{c}\text { POWER } \\
\text { SUPPLY } \\
\text { VOLTAGE } \\
\text { (V) }\end{array}$ \\
\hline $2 A$ & Westinghouse SG & 134673 & 6.00 & $\mathrm{NO}$ & $\mathrm{N} / \mathrm{A}$ & $Q$ \\
\hline $2 B$ & 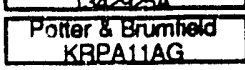 & EXP 9/23/93 & & $\mathrm{NQ}$ & AC Power Cord & $110 \mathrm{AC}$ \\
\hline
\end{tabular}

\section{ACCELEROMETER DATA}

CHAN. ACCELEROMETER M\&TE NO/EXP $1 \mathrm{~A} \& \mathrm{~B} 12935085 \mathrm{EXP} 10 / 29 / 92$

\section{L214-068-X EXP Z/17/93}

AMPLIFIER GAIN

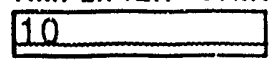

$\dagger$ Approximale weight using M\&TE category 3 equipment.

${ }^{\dagger}$ Numbers 1 \& 2 correspond to channels on each ATD ( 1 will be used by accelerometer, 2 will be used by relays.).

Letters A \& B correspond to different RTD ID numbers. 
WSRC-TR-93-0094

Attachment 10. Test Data Sheets (135 of 155)

Savannah River Technology Center Equipment Engineering

EES-FP.379, Rev. 0

Seismic 11/1 Drop Test Program Instrumented Cabinet Drop Tests
Date Approved: $9 / 24 / 92$, Category 2

Page 16 of 18

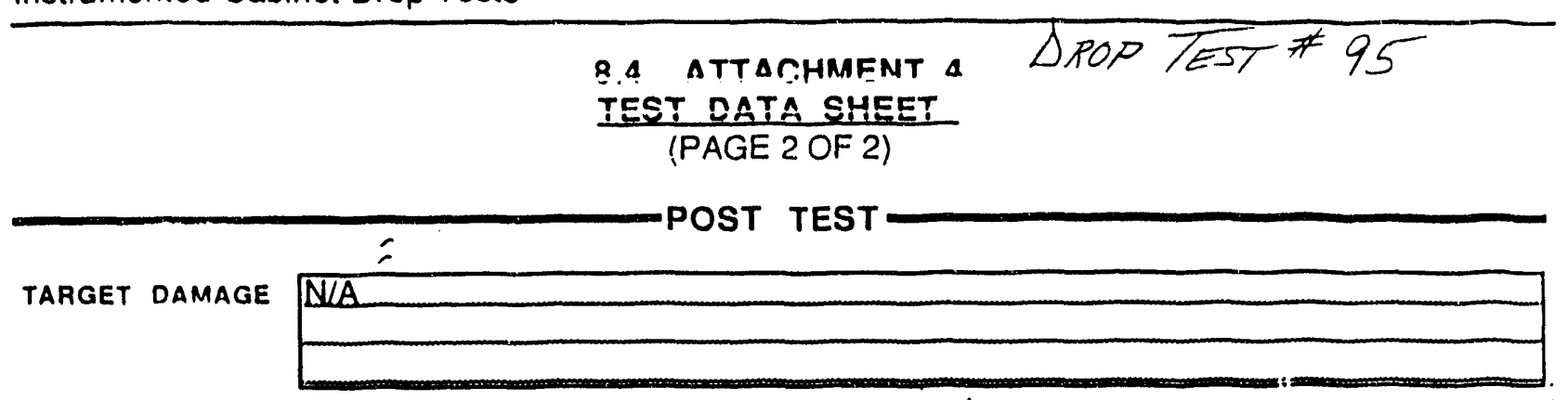

SOURCE DAMAGE N/A

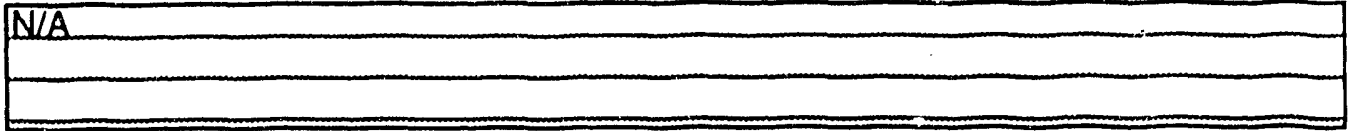

RELAY CHATTER IDENTIFIED ON POTTER \& BRUMFIELD RELAY (YIN) NQNE

IF YES, DURATION OF CHATTER [ms] SEEPLOT

RELAY CHATtER IDENTIFIED ON WESTINGHOUSE RELAY (YIN) YES

IF YES, DURATION OF CHATTER [ms] SEEPLOT

HAND HELD VIOEO START \& STOP POSITION NIA

HIGH SPEED VIDEO START \& STOP POSITION $26: 23-27: 29$

COMMENTS
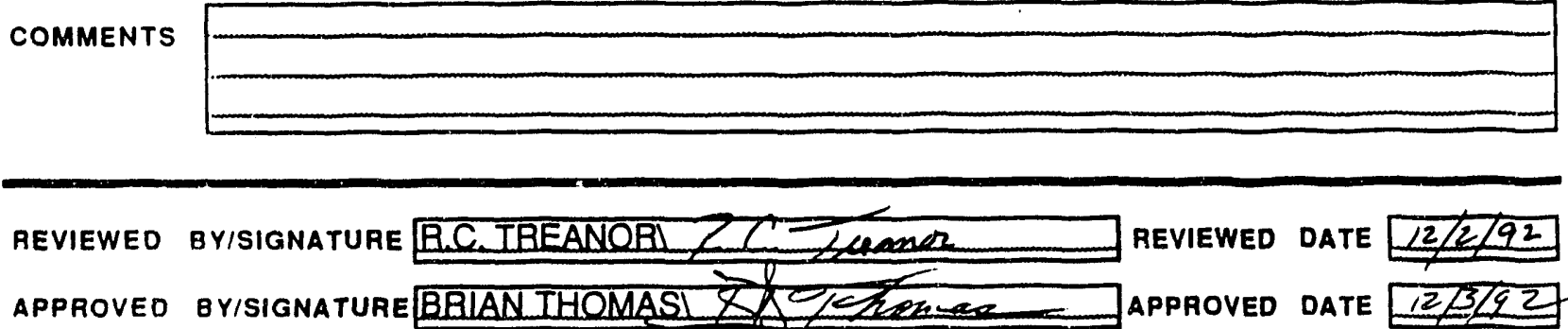
IVSRC-TR-93-0094

Altachment 10. Test Data Sheets (136 of 155)

Savannah River Technology Center

EES-FP-379, Rev. 0

Equipment Engineering

Seismic II// Drop Test Program

Date Approved: 9/24/92, Category 2

Instrumented Cabinet Drop Tests

Page 15 of 18

\subsection{ATTACHMENT 4 \\ TEST DATA SHEET \\ (PAGE 1 OF 2)}

PRE TEST

PREPARED BYISIGNATURE KM.BEHBEBGER/
DROP TARGET CABINET
TARGET WT ILBS] NIA
SOURCE ORIENTATION HQBIZ

POSITION OF RELAY TOP MOUNTING PLATE (circle one)

\section{DATA ACQUISITION}

BTD DATA

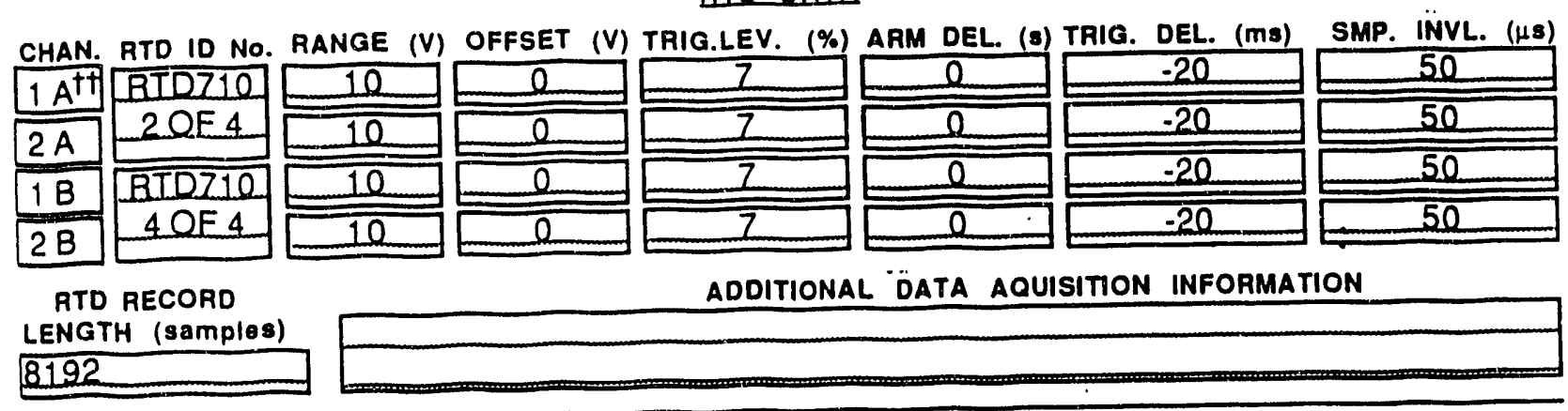

BELAY DATA

\begin{tabular}{|c|c|c|c|}
\hline $\begin{array}{l}\text { POWER } \\
\text { SUPPLY } \\
\text { VOLTAGE } \\
\text { (V) }\end{array}$ & $\begin{array}{c}\text { RELAY } \\
\text { ENERGIZED? }\end{array}$ & $\begin{array}{l}\text { POWER SUPPLY } \\
\text { USED TO ENERGIZE } \\
\text { RELAY COIL } \\
\text { METE NOIEXP }\end{array}$ & $\begin{array}{c}\text { POWER } \\
\text { SUPPLY } \\
\text { VOLTAGE } \\
\text { (V) }\end{array}$ \\
\hline 6.00 & $\mathrm{NO}$ & N/A & \\
\hline & $\sqrt{\mathrm{NO}}$ & AC Power Cord & $110 \mathrm{AC}$ \\
\hline
\end{tabular}
POWER SUPPLY USED TO MONITOR

RELAY RELAY CHATTER

CHAN. MODEL/ID NO. METE NO/EXP

\begin{tabular}{|c|c|c|}
\hline $2 A$ & Westinghouse SG & 134673 \\
\hline $2 B$ & $\begin{array}{c}13620000 \\
\text { Ponter \& Brumied } \\
\text { KRPA }\end{array}$ & EXP $9 / 23 / 93$ \\
\hline
\end{tabular}

DROP HEIGHT [IN] $48^{\text {" }}$

DROP SOUROCE, 10 3/4" HEAVYCONDUITHR.1

SOURCE \& ADAPTER WT [LBS] 6.5 LBS

DROP TEST NUMBER (Sequential; $1,2,3, \ldots) 96$

TEST SET UP USED (circle one) STAND. OPTION

POWER SUPPLY VOLTAGES VERIFIED BY (M\&TE NO/EXP) EAO-01857 EXP 3/93

\section{ACCELEROMETER DATA}

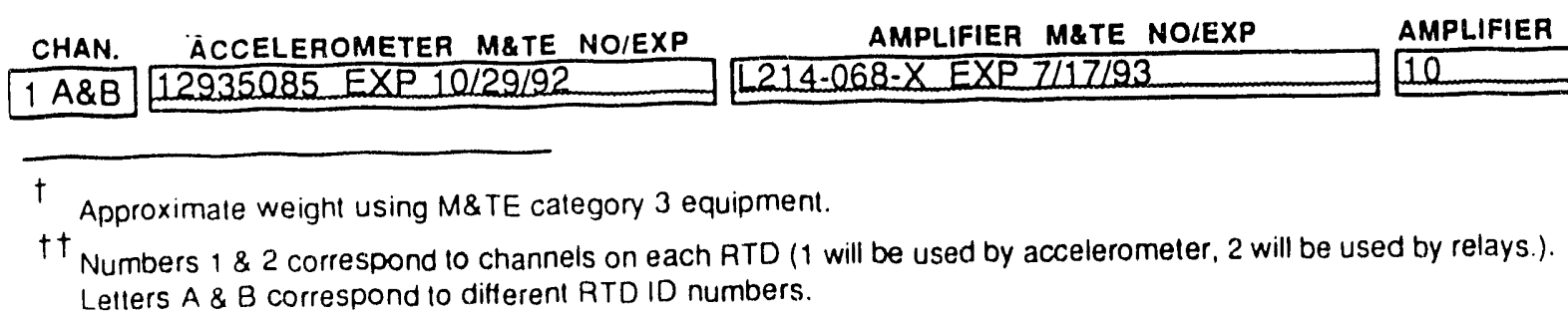


IVSRC-TR-93-0094

Attuchment 10. Test Data Sheets (137 of 155)

Savannah River Technology Center

Equipment Engineering

Seismic II// Drop Test Program

EES-FP-379, Rev. 0

Instrumented Cabinet Drop Tests

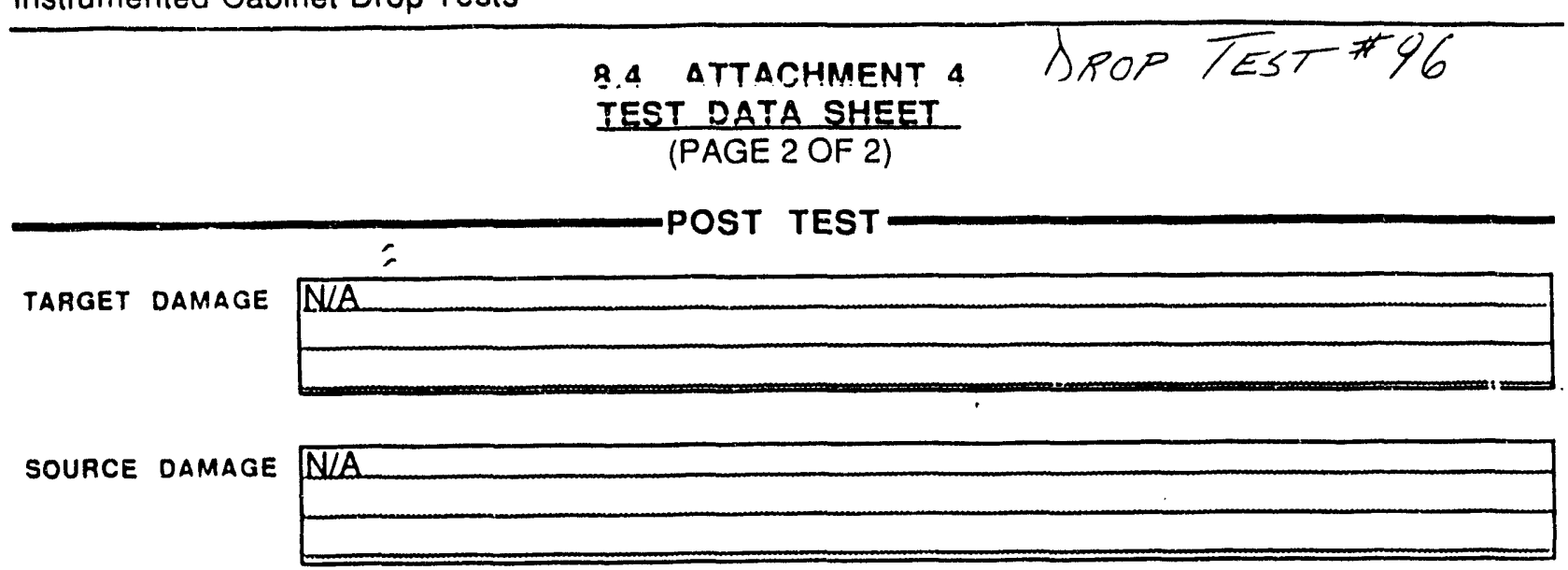

RELAY CHATTER IDENTIFIED ON POTTER \& BRUMFIELD RELAY (Y/N) NONE

IF YES, DURATION OF CHATTER [ms] SEEPLOT

RELAY CHATTER IDENTIFIED ON WESTINGHOUSE RELAY (YIN) YES

IF YES, DURATION OF CHATTER [ms] SEE PLOT

HAND HELO VIDEO START \& STOP POSITION NIA

HIGH SPEED VIDEO START \& STOP POSITION $27: 29-28: 17$

COMMENTS

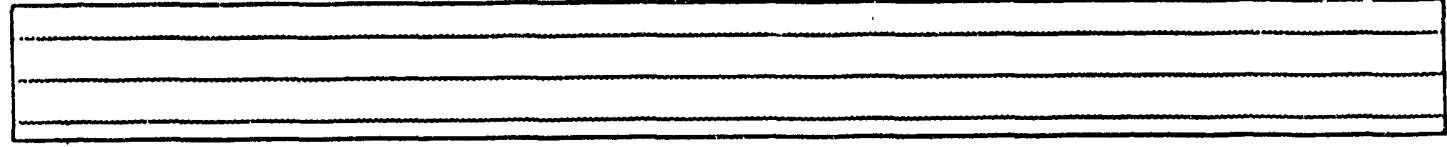

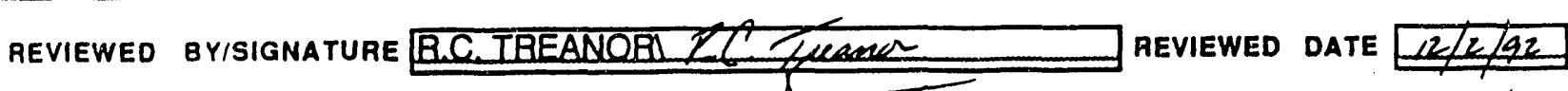
APPROVED BYISIGNATURE BRIANTHOMAS DAPPROVE DATE $12 / 3 / 22$ 
WSRC.TR-93-0094

Attachment 10. Test Duta Sheets (138 of 155)

Savannah River Technology Center

EES-FP-379, Rev. 0

Equipment Engineering

Seismic IV/I Drop Test Program

Instrumented Cabinet Drop Tests

Date Approved: 9/24/92, Category 2

Page 15 of 18

\subsection{ATTACHMENT 4 \\ TEST UATA STIEET}

(HAGE 1 UH 2)

PRE TEST

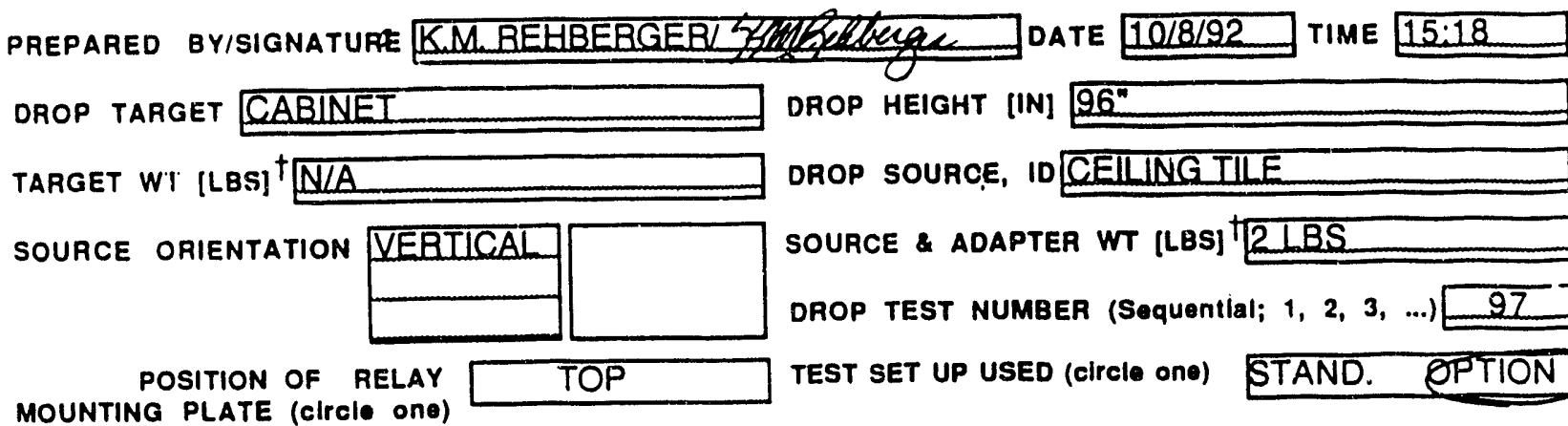

DATA ACQUISITION

BTD DATA

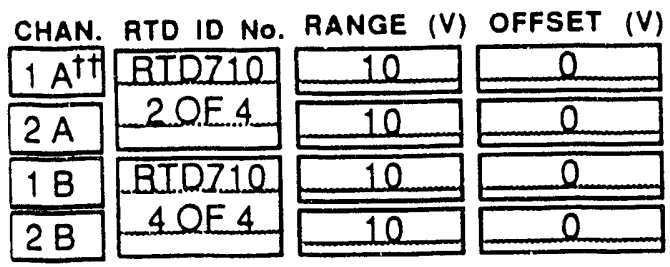

RTD RECORD LENGTH (samples) 8192

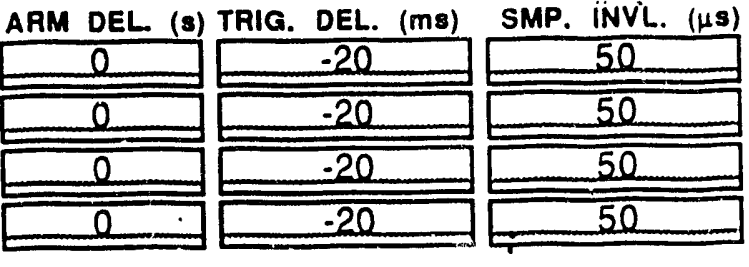

ADDITIONAL DATA AOUISITION INFORMATION

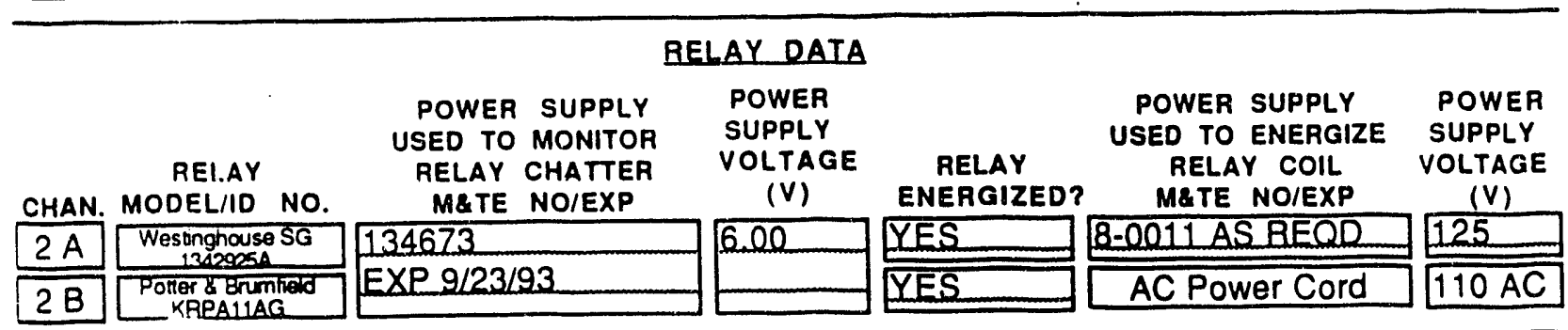

POWER SUPPLY VOLTAGES VERIFIED BY (M\&TE NOIEXP) EAO-01857 EXP 3/93

\section{ACCELEROMETER DATA}

CHAN. ACCELEROMETER M\&TE NO/EXP $1 \mathrm{~A} \& \mathrm{~B} 12235085 \mathrm{EXP} 10 / 29 / 92$

- AMPLIFIER METE NO/EXP $214-068-X$ EXP Z117193

$\dagger$ Approximate weight using M\&TE category 3 equipment.

${ }^{t}{ }_{\text {Numbers } 1}$ \& 2 correspond to channels on each RTD ( 1 will be used by accelerometer, 2 will be used by relays.).

Letlers A \& B correspond to different RTD ID numbers. 
WSRC-TR-93-0094

Attachment 10. Test Data Sheets (139 of 155)

Savannah River Technology Center Equipment Engineering Seismic II/I Drop Test Program Instrumented Cabinet Drop Tests

EES-FP.379, Rev. 0

Date Approved: $9 / 24 / 92$, Category 2

Page 16 of 18

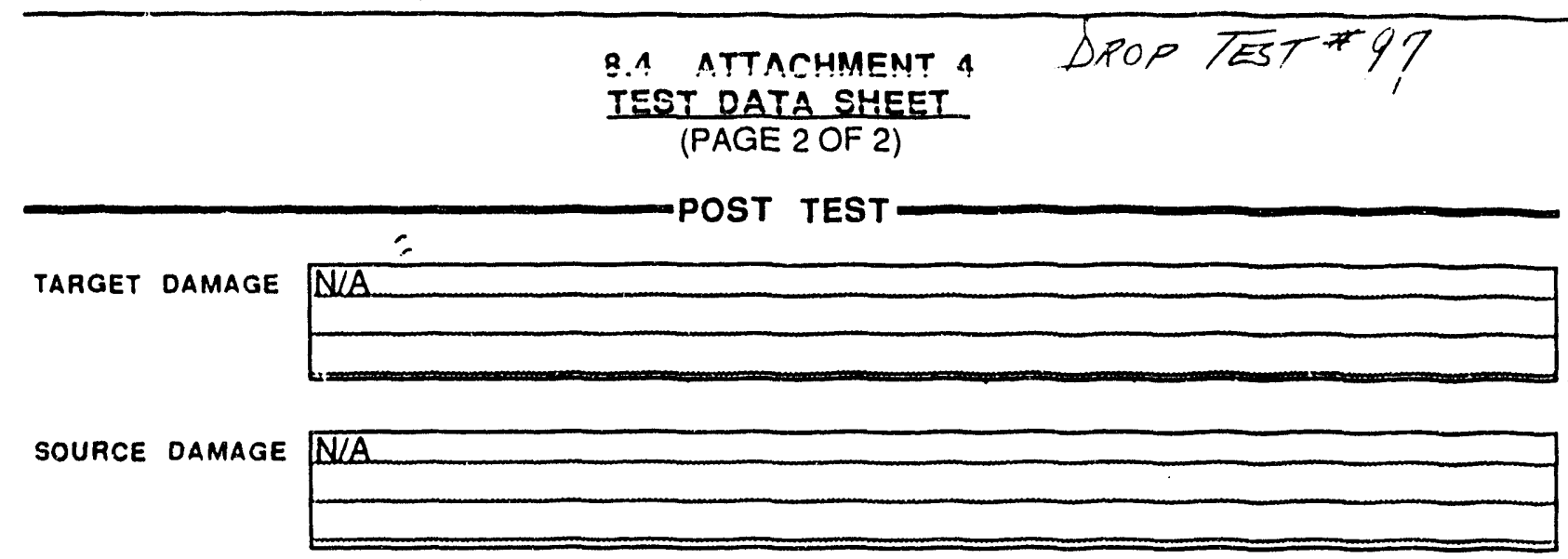

helay ChatTER IDENTIFIEd ON POTtea \& BaUMfield relay (Y/N) NONE IF YES, DURATION OF CHATTER [ms] SEEPLOT

RELAY CHATTER IDENTIFIED ON WESTINGHOUSE RELAY (YIN) YES

IF YES, DURATION OF CHATTER (ms] SEEPLOT

HAND HELD VIDEO START \& STOP POSITION NIA

HIGH SPEED VIDEO START \& STOP POSITION $28: 17-29: 45$

COMMENTS

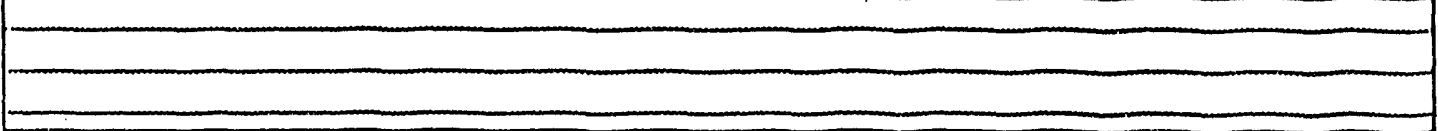

REVIEWED BYISIGNATURE B.C.TREANORI Z Trama REVIEWED DATE LE/2/92 APPROVED BYISIGNATURE BRIAN THOMAS $5 / 2 / 32$ 
IVSRC-TR-93-0094

Attachment 10. Test Data Sheets (140 of 155)

Savannah River Technology Center

EES-FP-379, Rev. 0

Equipment Engineering

Seismic II// Drop Test Program

Instrumented Cabinet Drop Tests

\subsection{ATTACHMENT 4 \\ IEST ÜATA SiTEET \\ (PAGE 1 OF 2)}

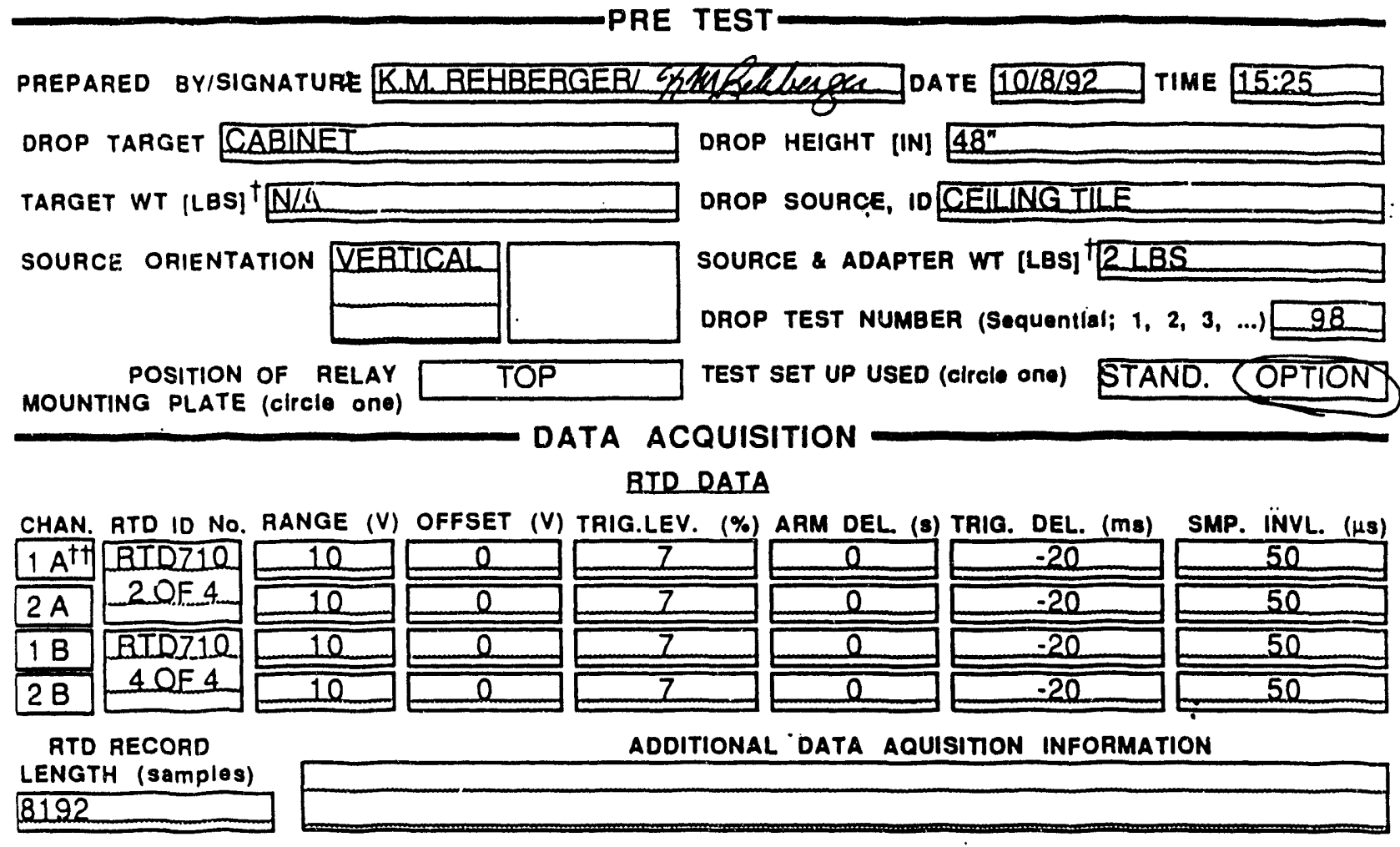

\begin{tabular}{|c|c|c|c|c|c|c|}
\hline \multicolumn{7}{|c|}{ BELAY DATA } \\
\hline CHAN & $\begin{array}{c}\text { RELAY } \\
\text { MODEL/ID NO. }\end{array}$ & $\begin{array}{l}\text { POWER SUPPLY } \\
\text { USED TO MONITOR } \\
\text { RELAY CHATTER } \\
\text { M\&TE NO/EXP }\end{array}$ & $\begin{array}{l}\text { POWER } \\
\text { SUPPLY } \\
\text { VOLTAGE } \\
\text { (V) }\end{array}$ & $\begin{array}{l}\text { RELAY } \\
\text { ENERGIZED? }\end{array}$ & $\begin{array}{l}\text { POWER SUPPLY } \\
\text { USED TO ENERGIZE } \\
\text { RELAY COIL } \\
\text { M\&TE NO/EXP }\end{array}$ & $\begin{array}{l}\text { POWER } \\
\text { SUPPLY } \\
\text { VOLTAGE } \\
\text { (V) }\end{array}$ \\
\hline $2 A$ & Westinghouse SG & 134673 & 6.02 & YES & 8.0011 AS BEOD & 125 \\
\hline $2 B$ & 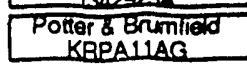 & EXP $9 / 23 / 93$ & & YES & AC Power Cord & $110 \mathrm{AC}$ \\
\hline
\end{tabular}

\section{ACCELEROMETER DATA}

CHAN. ACCELEROMETER M\&TE NO/EXP $1 \mathrm{~A} \& \mathrm{~B} 12935085 \mathrm{EXP} 10 / 29 / 92$

AMPLIFIER M\&TE NO/EXP $214-068-X$ EXP $7117 / 93$

AMPLIFIER GAIN

$\dagger$ Approximate weight using M\&TE category 3 equipment.

${ }^{\dagger \dagger}$ Numbers 1 \& 2 correspond to channels on each RTD ( 1 will be used by accelerometer, 2 will be used by relays.) Lelters A \& $B$ correspond 10 different RTD ID numbers. 
IVSRC-TR-93-0094

Attuchment 10. Test Data Sheets (141 of 155)

Savannah River Technology Center Equipment Engineering Seismic II// Drop Test Program Instrumented Cabinet Drop Tests

EES-FP-379, Rev. 0

Date Approved: 9/24/92, Category 2 Page 16 of 18

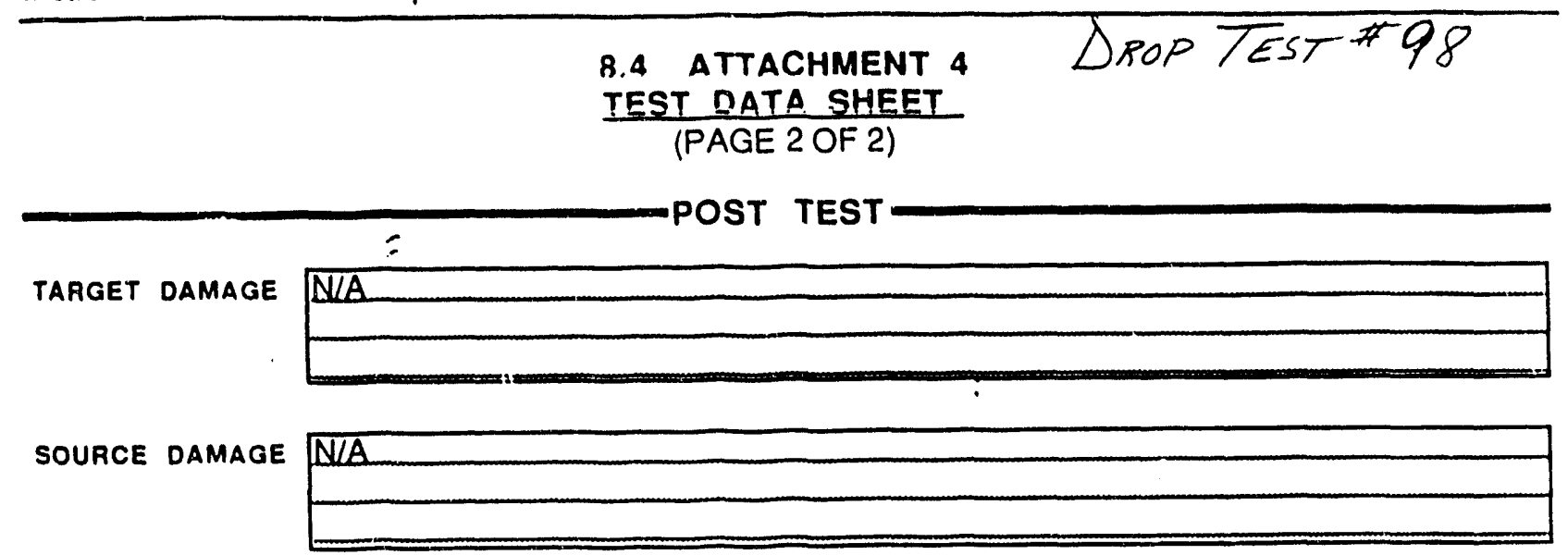

RELAY CHATTER IDENTIFIED ON POTTER \& BRUMFIELD RELAY (YIN) NONE IF YES, DURATION OF CHATTER [ms] SEERLOT

RELAY CHATTER IDENTIFIED ON WESTINGHOUSE RELAY (YIN) YES IF YES, DURATION OF CHATTER [ms] SEE PLOT

HAND HELD VIDEO START \& STOP POSITION NLA

HIGH SPEED VIDEO START \& STOP POSITION 29:45-31:01

COMMENTS

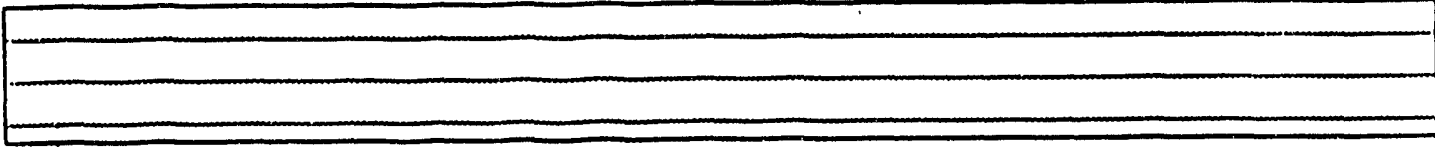

REVIEWED BYISIGNATURE B.C. TREANORI Rl Jimer

REVIEWED DATE $12 / 2 / 92$

APPROVED BYISIGNATURE BRIAN IHOMASI I C ThomaA APPROVED dATE $12 / 3 / 92$ 
IVSRC-TR-93-0094

Attachment 10. Test Data Sheets (142 of 155)

Savannah River Technology Center

Equipment Engineering

Se.smic IV/I Drop Test Program

EES-FP-379, Rev. 0

Instrumented Cabinet Drop Tests

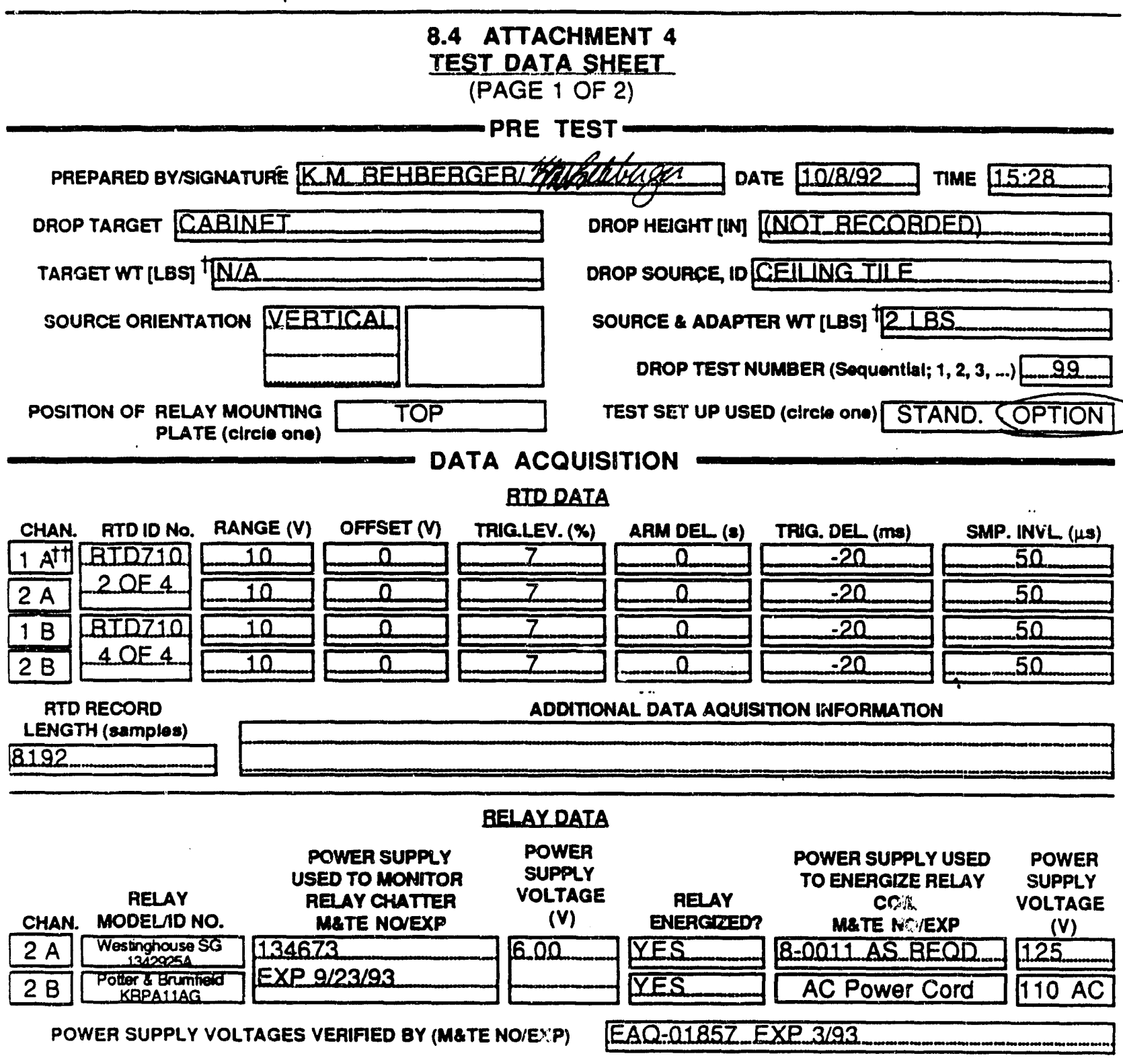

\section{ACCELEROMEIER DATA}

CHAN. ACCELEROMETER METE NO/EXP

$1 \mathrm{~A} \& \mathrm{~B} 12935.085$ EXP $1.0129 / 92$

AMPUFIER M\&TE NO/EXP 214-068-X..EXP 7/17/93.

\section{A A\&B 129350B5.}

$\dagger$ Approximate weight using M\&TE category 3 equipment.

\# Numbers $1 \& 2$ correspond to channels on each RTD ( 1 will be used by accelerometer, 2 will be used by relays.) 
WSRC-TR-93-0094

Attachment 10. Test Data Sheets (143 of 155)

Savannah River Technology Center Equipment Engineering EES-FP-379, Rev. 0 Seismic IVI Drop Test Program Date Approved: 9/24/92, Category 2 Instrumented Cabinet Drop Tests

\subsection{ATTACHMENT 4} DROP TEST \#99 TEST DATA SHEET (PAGE 2 OF 2)

TARGET DAMAGE N/A

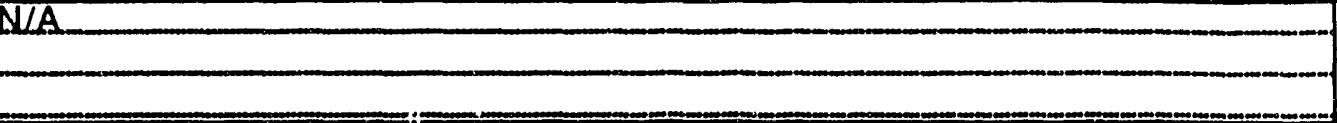

SOUACE DAMAGE NIA

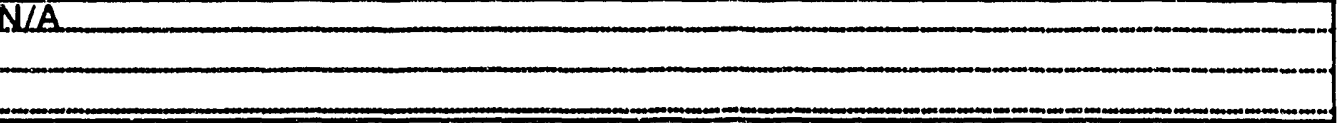

RELAY CHATTER IDENTIFED ON POTTER \& BRUMFELD RELAY (YN) NONE IF YES, DURATION OF CHATTER [ms] SEERLLII

RELAY CHATTER IDENTIFIED ON WESTINGHOUSE RELAY (YNM) YES IF YES, DURATION OF CHATTER [ms] SEEPIOI HAND HELD VIDEO START \& STOP POSITON NLA HIGH SPEED VIDEO START \& STOP POSMON 31:01-32:17 COMMENTS

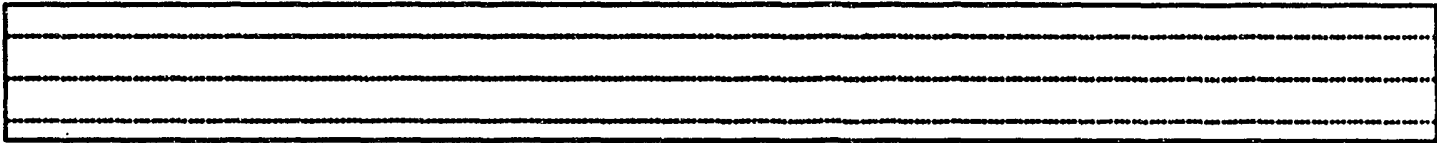


IWSRC-TR-93-0094

Attachment 10. Test Data Sheets (144 of 155)

Savannah River Technology Center

EES-FP-379, Rev. 0

Equipment Engineering

Seismic II/I Drop Test Program

Instrumented Cabinet Drop Tests

\subsection{ATTACHMENT 4 \\ TEST DATA SHEET \\ (PAGE 1 OF 2)}

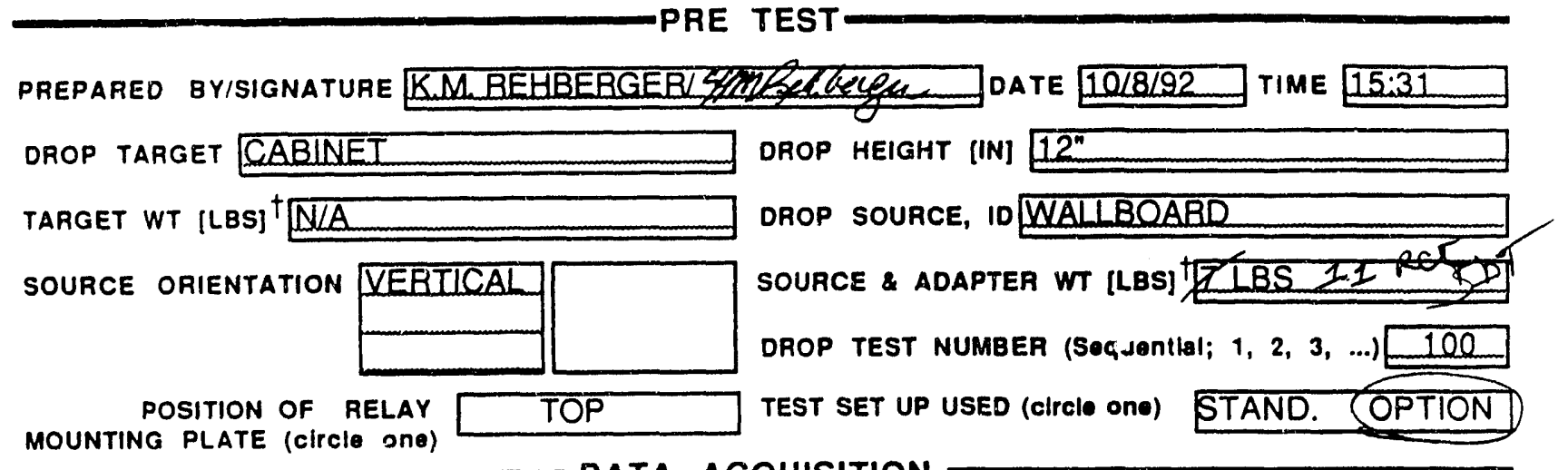

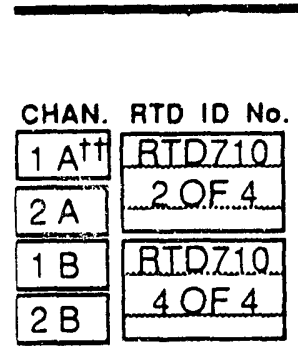

\section{DATA ACQUISITION \\ RTD DATA}

RTD RECORD LENGTH (samples) 8192
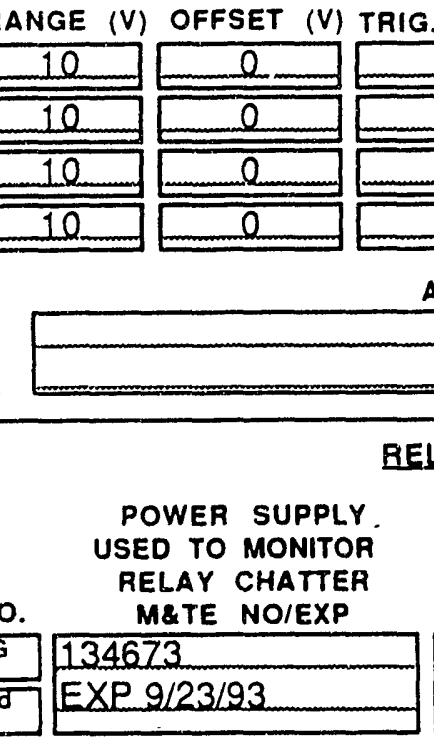
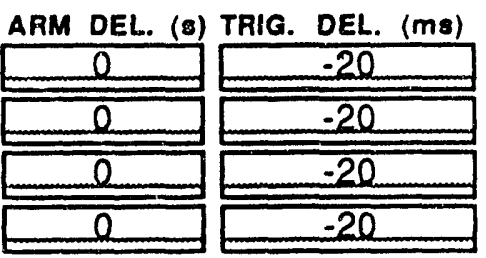

ADDITIONAL -DATA AQUISITION INFORMATION
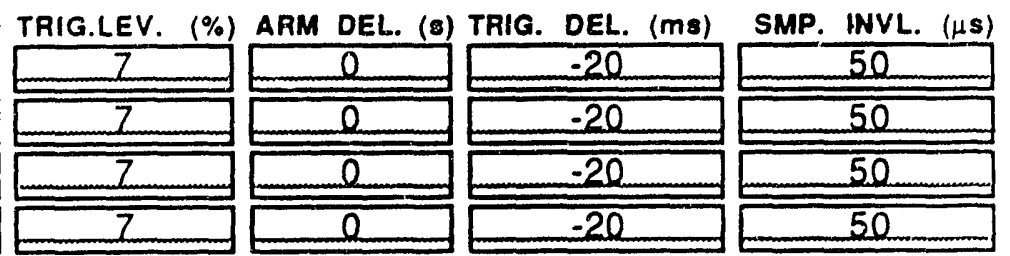

BELAY DATA

POWER

SUPPLY

VOLTAGE

(V)

\begin{tabular}{|c|c|c|c|c|c|c|}
\hline CHAN. & MODEL/ID NO. & M\&TE NO/EXP & (V) & ENERGIZED? & M\&TE NO/EXP & (V) \\
\hline $2 A$ & 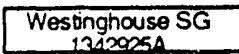 & 134673 & 6.00 & YES & $8-0011$ AS BEQD & 125 \\
\hline $2 B$ & $\begin{array}{c}\text { Potter \& Brumief } \\
\text { KRPALIAG }\end{array}$ & EXP $9 / 23 / 93$ & & YES & AC Power Cord & $110 \mathrm{AC}$ \\
\hline
\end{tabular}

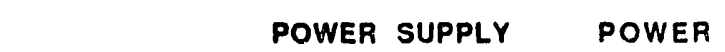

USED TO ENERGIZE SUPPLY RELAY COIL VOLTAGE ENERGIZED? METE NO/EXP (V) \begin{tabular}{|ll} 
YES \\
YES
\end{tabular}

POWER SUPPLY VOLTAGES VERIFIED BY (M\&TE NO/EXP) EAQ-01857 EXP 3/93

\section{ACCELEROMETER DATA}

CHAN. ACCELEROMETER M\&TE NO/EXP $1 \mathrm{~A} \& B \quad 12935085 \mathrm{EXP} 10 / 29 / 92$ L214-068-X EXP Z117/93

AMPLIFIER GAIN

10

\footnotetext{
† Approximate weight using Mi\&TE caiegory 3 equipmient.

${ }^{\dagger \dagger}$ Numbers 1 \& 2 correspond to channels on each RTD ( 1 will be used by accelerometer, 2 will be used by relays.) Letters A \& B correspond to different RTD ID numbers.
} 
WSRC-TR-93-0094

Attachment 10. Test Data Sheets (145 of 155)

Savannah River Technology Center

EES-FP-379, Rev. 0

Equipment Engineering

Date Approved: 9/24/92, Category 2

Seismic IVI Drop Test Program

Page 16 of 18

Instrumented Cabinet Drop Tests

\section{Q.A ATTACHAAENT ?}

DROP TEST 100

\section{TEGT DATA SHEET}

(PAGE 2 OF 2)

POST TEST

TARGET DAMAGE N/A

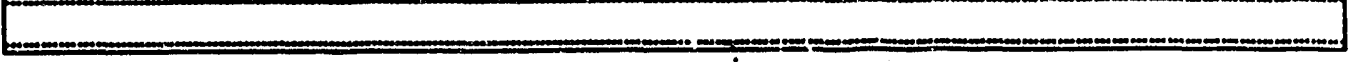

SOURCE DAMAGE NIA

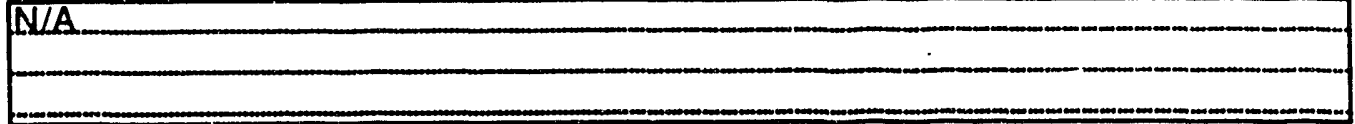

RELAY CHATTER IDENTIFED ON POTTER \& BRUMFELD RELAY (YNN) MONE

IF YES, DURATION OF CHATTER [ms] SSEE PIOI_

RELAY CHATTER IDENTIFIED ON WESTINGHOUSE RELAY (YN) YES IF YES, DURATION OF CHATTER [m\&] SEE RLOT

HAND HELD VIDEO START \& STOP POSITON NIA

HIGH SPEED VIDEO START \& STOP POSIION $32 \cdot 17-33: 12$

COMMENTS

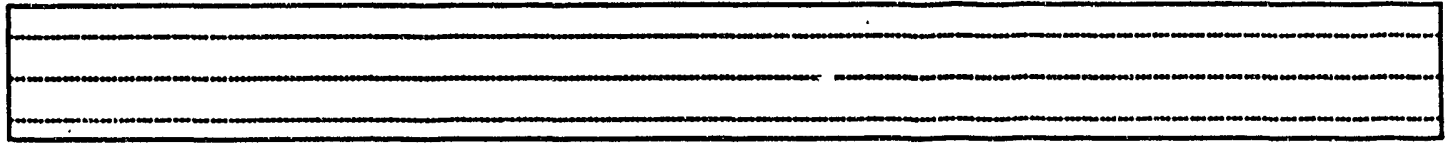

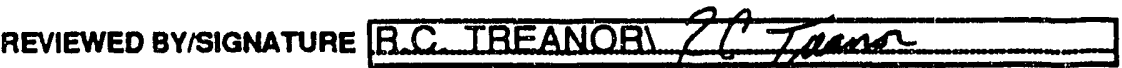

REVIEWED DATE Zis to

APPROVED BYISIGNATURE BEIAN IHOMASI $K$ I Y

APPROVED DATE $\angle Z Z Z Y Z$ 
WSRC-TR-93-0094

Attachment 10. Test Data Shects (146 of 155)

Savannah River Technology Center

Equipment Engineering

EES-FP-379, Rev. 0

Seismic IV/I Drop Test Program

Instrumented Cabinet Drop Tests

Date Approved: $9 / 24 / 92$, Category 2

Page 15 of 18

\subsection{ATTACHMENT 4 \\ TEST DATA SHEET \\ (PAGE 1 OF 2)}

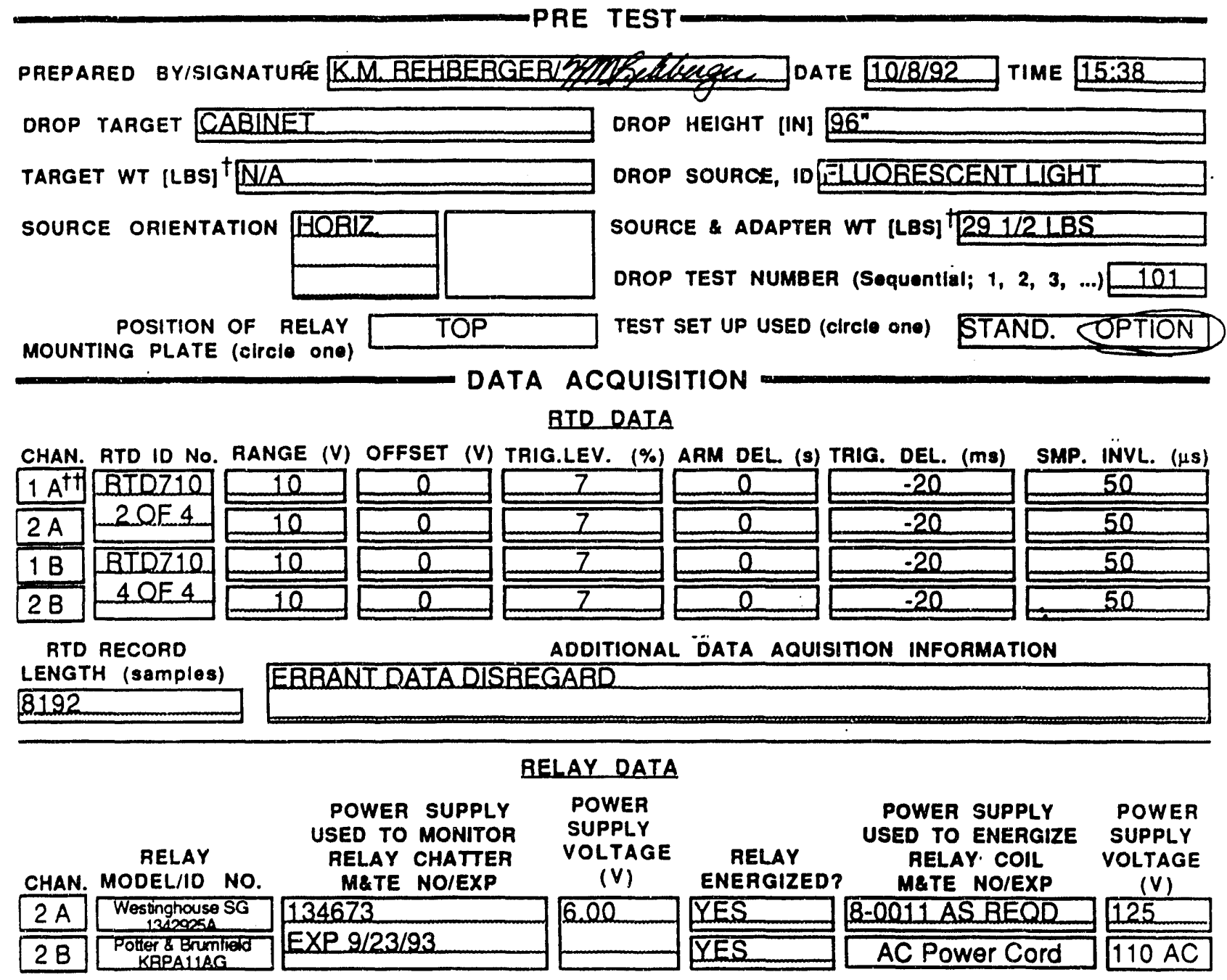

POWER SUPPLY VOLTAGES VERIFIED BY (M\&TE NO/EXP EAQ-01857 EXP 3/93

\section{ACCELEROMETER DATA}

CHAN. ACCELEROMETER M\&广TE NO/EXP $1 \mathrm{~A} \& \mathrm{~B} 12935085$ EXP $10 / 29 / 92$

AMPLIFIER M\&TE NO/EXP
L214-068-X EXP Z/17193

AMPLIFIER GAHN

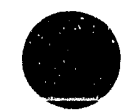

t Approximate weight using M\&TE category 3 equipment.

${ }^{\dagger}$ Numbers 1 \& 2 correspond to channels on each RTD ( 1 will be used by accelerometer, 2 will be used by relays.).

Leiters A \& B correspond to different RTD 10 numbers. 
WSRC-TR-93-0094

Attuchment 10. Test Data Sheets (147 of 155)

Savannah River Technology Center Equipment Engineering Seismic II// Drop Test Program EES-FP-379, Rev. 0 Instrumented Cabinet Drop Tests

8.4 ATTACHAENT 4

TARGET DAMAGE

\section{N/A}

-

SOURCE DAMAGE N/A

RELAY CHATTER IDENTIFIED ON POTTER \& BRUMFIELD RELAY (Y/N) NQNE

IF YES, DURATION OF CHATTER [ms] SEEPIOT

RELAY CHATTER IDENTIFIED ON WESTINGHOUSE RELAY (YIN) YES

IF YES, DURATION OF CHATTER [ms] SEEPLQT

HAND HELD VIDEO START \& STOP POSITION NLA

HIGH SPEED VIDEO START \& STOP POSITION $33: 12-33: 44$

COMMENTS

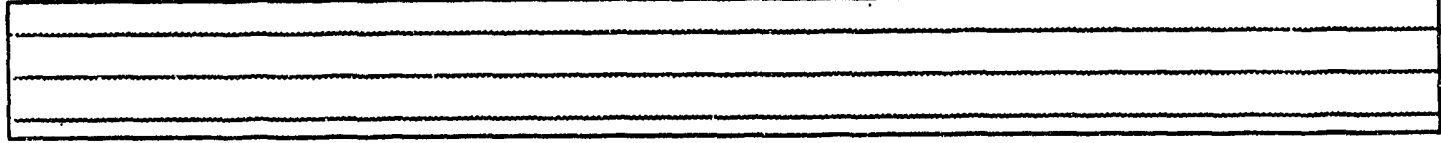

REVIEWED BY/SIGNATURE B.C.IBEANQBI,

REVIEWED DATE $12 / 2 / 92$

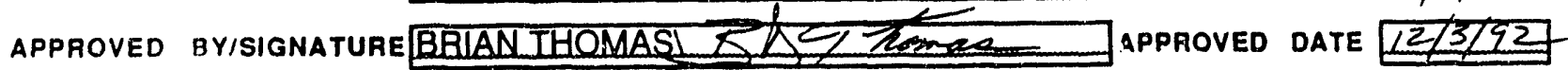


IVSRC-TR-93-0094

Attuchment 10. Test Duta Sheets (148 of 155)

Savannah River Technology Center

EES-FP-379, Rev. 0

Equipment Engineering

Seismic II/I Drop Test Program

Instrumented Cabinet Drop Tests

\subsection{ATTACHMENT 4 \\ IEST DAIA SHEET}

(PAGE 1 OF 2)

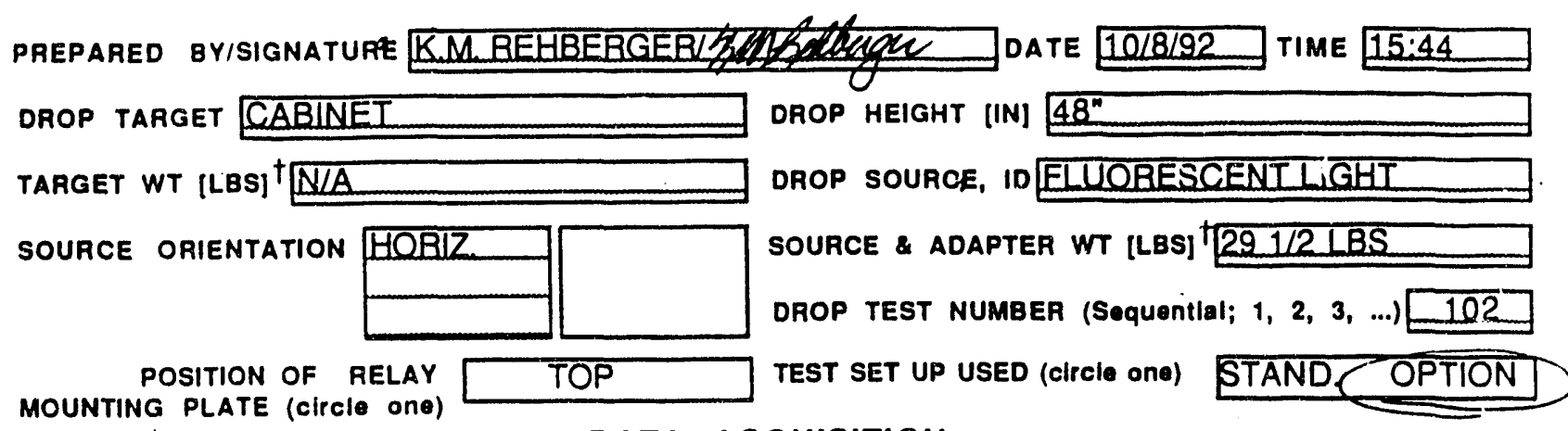

\section{DATA ACQUISITION}

\section{BTD DATA}

CHAN. RTD ID No. RANGE (V) OFFSET

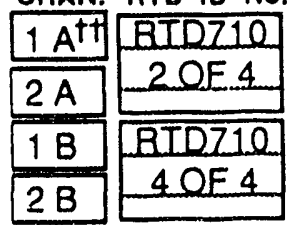

RTD RECORD LENGTH (samples) 8192

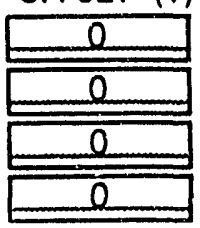

ta

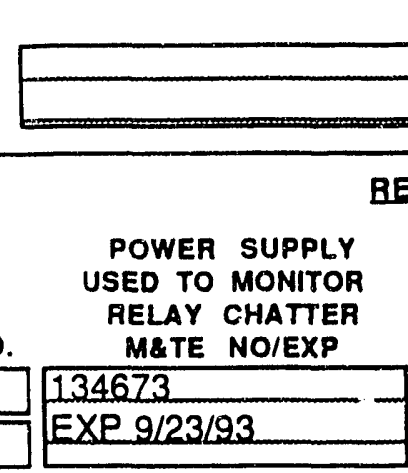

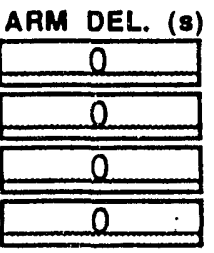
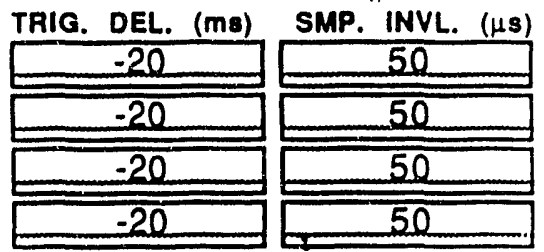

ADDITIONAL DATA AQUISITION INFORMATION

\begin{tabular}{|c|c|c|c|c|c|c|c|}
\hline \multicolumn{8}{|c|}{ BELAY DATA } \\
\hline CHAN. & $\begin{array}{c}\text { RELAY } \\
\text { MODEL/ID NO. }\end{array}$ & $\begin{array}{l}\text { POWER } \\
\text { USED TO } \\
\text { RELAY } \\
\text { M\&TE }\end{array}$ & $\begin{array}{l}\text { SUPPLY } \\
\text { MONITOR } \\
\text { CHATTER } \\
\text { NO/EXP }\end{array}$ & $\begin{array}{l}\text { POWER } \\
\text { SUPPLY } \\
\text { VOLTAGE } \\
\text { (V) }\end{array}$ & $\begin{array}{c}\text { RELAY } \\
\text { ENERGIZED? }\end{array}$ & $\begin{array}{l}\text { POWER SUPPLY } \\
\text { USED TO ENERGIZE } \\
\text { RELAY COIL } \\
\text { M\&TE NO/EXP }\end{array}$ & $\begin{array}{l}\text { POWER } \\
\text { SUPPLY } \\
\text { VOLTAGE } \\
\text { (V) }\end{array}$ \\
\hline $2 A$ & Wesinghouse SG & 134673 & & 6.00 & YES & $8=0011$ ASREQD & 125 \\
\hline $2 B$ & 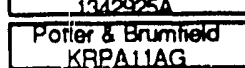 & EXP $9 / 23 /$ & $\angle 93$ & & YES & AC Power Cord & $110 \mathrm{AC}$ \\
\hline
\end{tabular}

POWER SIIPPLY VOLTAGES VERIFIED BY (M\&TE NO/EXP) EAQ-01857 EXP 3/93

\section{ACCELEROMETER DATA}

\footnotetext{
CHAN. ACCELEROMETER M\&TE NO/EXP $1 \mathrm{~A} \& \mathrm{~B} 12935285 \mathrm{EXP} 10 / 29 / 92$ $1214-068-X$ EXP $7117 / 93$

AMPLIFIER- METE NOIEXP

t

$\dagger$ Approximale weight using M\&TE category 3 equipment.

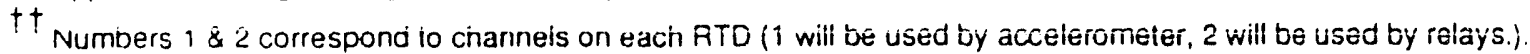
Letters $A \& B$ correspond to different RTD ID numbers.
} AMPLIFIER GAIN 
WSRC-TR-93-0094

Attachment 10. Test Data Sheets (149 of 155)

Savannah River Technology Center

Equipment Engineering

EES-FP-379, Rev. 0

Seismic II/I Drop Test Program Instrumented Cabinet Drop Tests

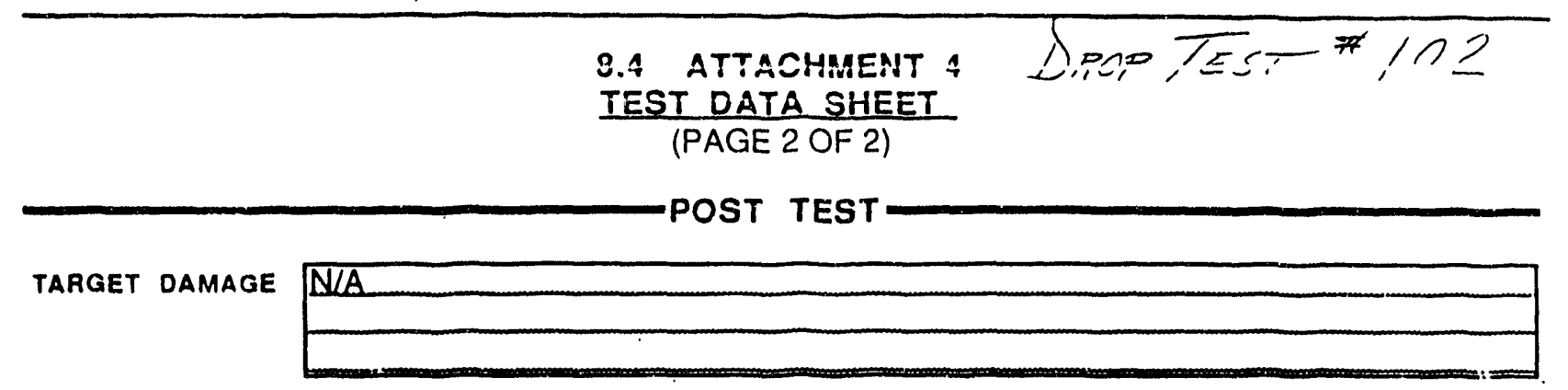

SOURCE DAMAGE NIA

RELAY CHATTER IDENTIFIED ON POTTER \& BRUMFIELD RELAY (YIN) NONE IF YES, DURATION OF CHATTER [ms] SEEPLOT

RELAY CHATTER IDENTIFIED ON WESTINGHOUSE RELAY (Y/N) NONE

IF YES, DURATION OF CHATTER [ms] SEEPLOT

HAND HELD VIDEO START \& STOP POSITION NIA

HIGH SPEED VIDEO START \& STOP POSITION $33: 44-34: 36$

COMMENTS

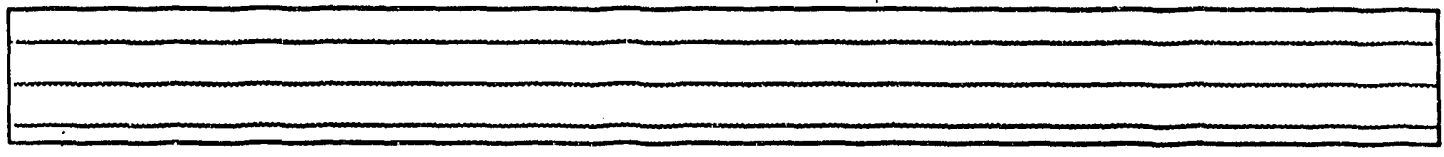

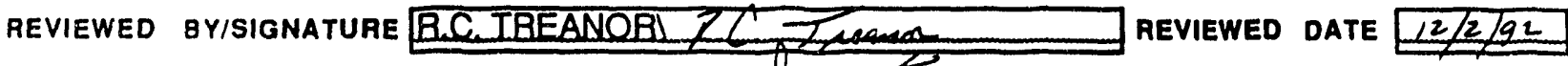
APPROVED BYISIGNATURE BBIANIHOMAS S DaTE $12 / 3 / 22$ 
IVSRC-TR-93-0094

Attachment 10. Test Data Sheets (150 of 155)

Savannah River Technology Center

Equipment Engineering

ĖES-FP-379, Rev. 0

Seismic II/I Drop Test Program Instrumented Cabinet Drop Tests

\subsection{ATTACHMENT 4 \\ TEST DATA SHEET \\ (PAGE 1 OF 2)}

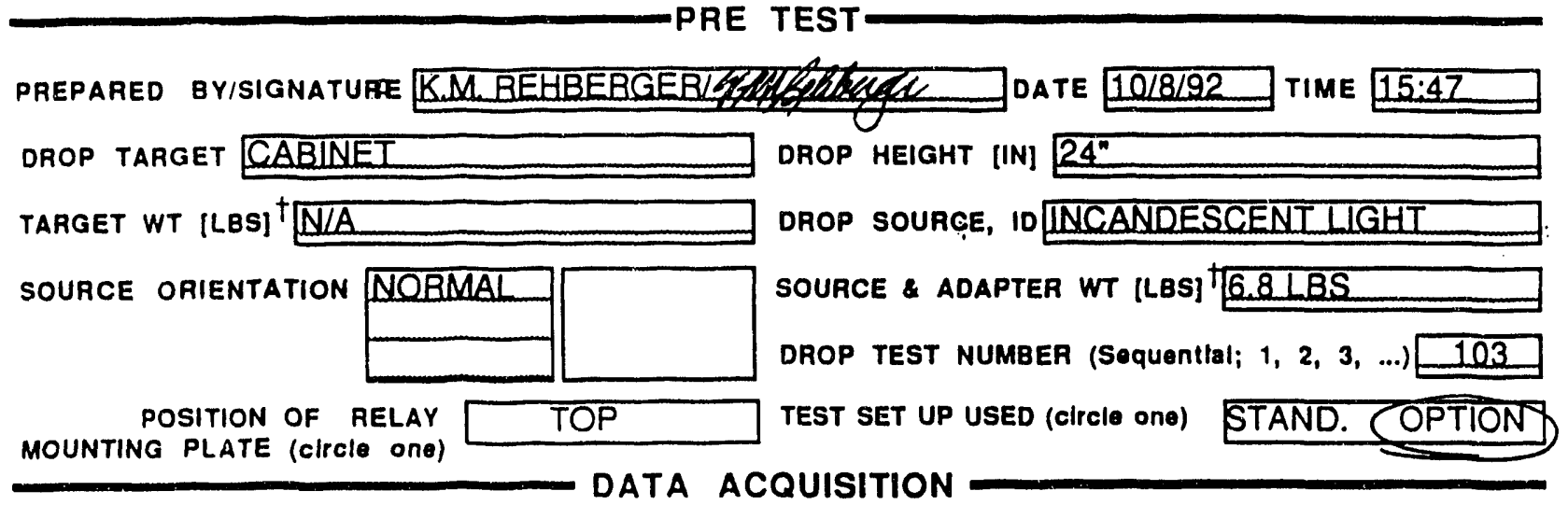

BTD DATA

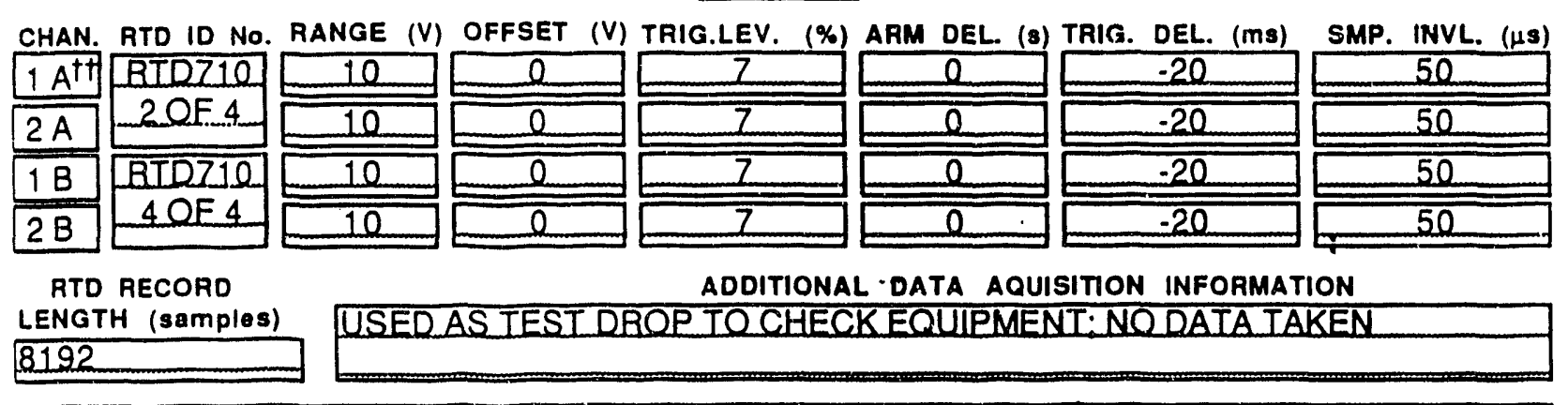

\begin{tabular}{|c|c|c|c|c|c|c|}
\hline \multicolumn{7}{|c|}{ RELAY DATA } \\
\hline CHAN & $\begin{array}{c}\text { RELAY } \\
\text { MODEL/10 NO. }\end{array}$ & $\begin{array}{l}\text { POWER SUPPLY } \\
\text { USED TO MONITOR } \\
\text { RELAY CHATTER } \\
\text { M\&TE NO/EXP }\end{array}$ & $\begin{array}{l}\text { POWER } \\
\text { SUPPLY } \\
\text { VOLTAGE } \\
\text { (V) }\end{array}$ & $\begin{array}{l}\text { RELAY } \\
\text { ENERGIZED? }\end{array}$ & $\begin{array}{l}\text { POWER SUPPLY } \\
\text { USED TO ENERGIZE } \\
\text { RELAY COIL } \\
\text { M\&TE NO/EXP }\end{array}$ & $\begin{array}{l}\text { POWER } \\
\text { SUPPLY } \\
\text { VOLTAGE } \\
\text { (V) }\end{array}$ \\
\hline $2 \mathrm{~A}$ & Westinghouse SG & 134673 & 6.00 & YES & 8-0011 AS BEQD & 125 \\
\hline 28 & Poter \& Bruming & EXP 9/23/93 & & YES & AC Power Cord & $110 \mathrm{AC}$ \\
\hline
\end{tabular}

\section{ACCELEROMETER DATA}

CHAN. ACCELEROMETER M\&TE NOTEXP

$1 \mathrm{A \& B} 12935085$ EXP $10 / 29 / 92$

\begin{tabular}{l} 
AMPLIFIER M\&TE NO/EXP \\
L214-068-X EXP Z117/93 \\
\hline
\end{tabular}

AMPLIFIER GAIN

10

$\dagger$ Approximate weight using M\&TE category 3 equipment.

†† Numbers 1 \& 2 correspond to channels on each RTD ( 1 will be used by accelerometer, 2 will be used by relays.).

Lelters $A \& B$ correspond in different RTD In numbers. 
WSRC-TR-93-0094

Attachment 10. Test Data Sheets (151 of 155)

Savannah River Technology Ceriter

Equipment Engineering

Seismic II/I Drop Test Program

Instrumented Cabinet Drop Tests

EES-FP-379, Rev, 0

Date Approved: 9/24/92, Category 2

Page 16 of 18

\subsection{ATTACHMENT 4 DROP TEST \#/03 TEST DATA SHEET (PAGE 2 OF 2)}

TARGET DAMAGE

\section{N/A}

SOURCE DAMAGE

\section{NLA}

RELAY CHATTER IDENTIFIED ON POTTER \& BRUMFIELD RELAY (Y/N) NONE

IF YES, DURATION OF CHATTER [ms] SEEPLOT

RELAY CHATTER IDENTIFIED ON WESTINGHOUSE RELAY (YIN) YES

IF YES, DURATION OF CHATTER (ms] SEEPLOT

HAND HELD VIOEO START \& STOP POSIMON N/A

$\cdots$

HIGH SPEED VIDEO START \& STOP POSITION $34: 36-34: 45$

COMMENTS
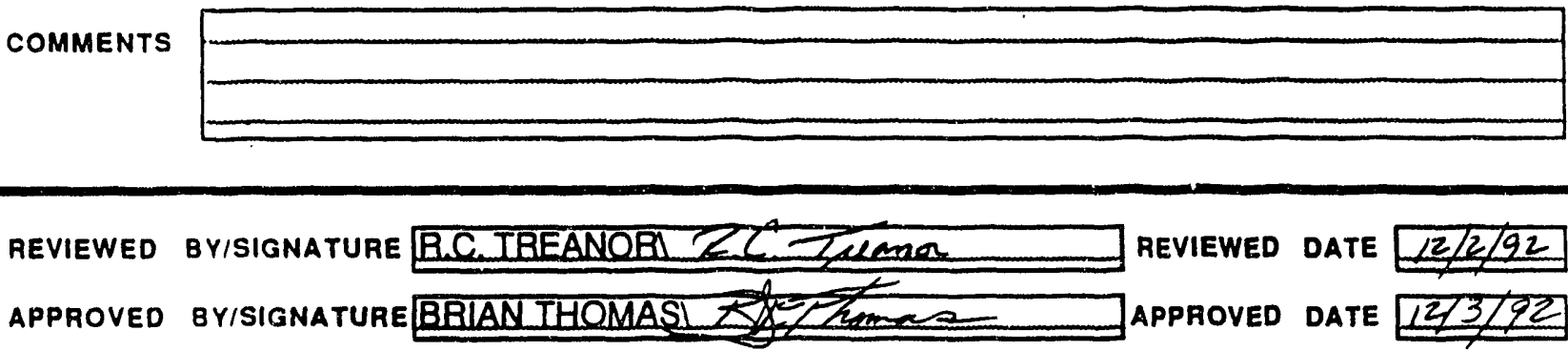
IVSRC-TR-93-0094

Attachment 10. Test Data Shcets (152 of 155)

Savannah River Technology Center

Equipment Engineering

Seismic IVI Drop Test Program

Instrumented Cabinet Drop Tests

EES-FP-379, Rev. 0

Date Approved: 9/24/92, Category 2

Page 15 of 18

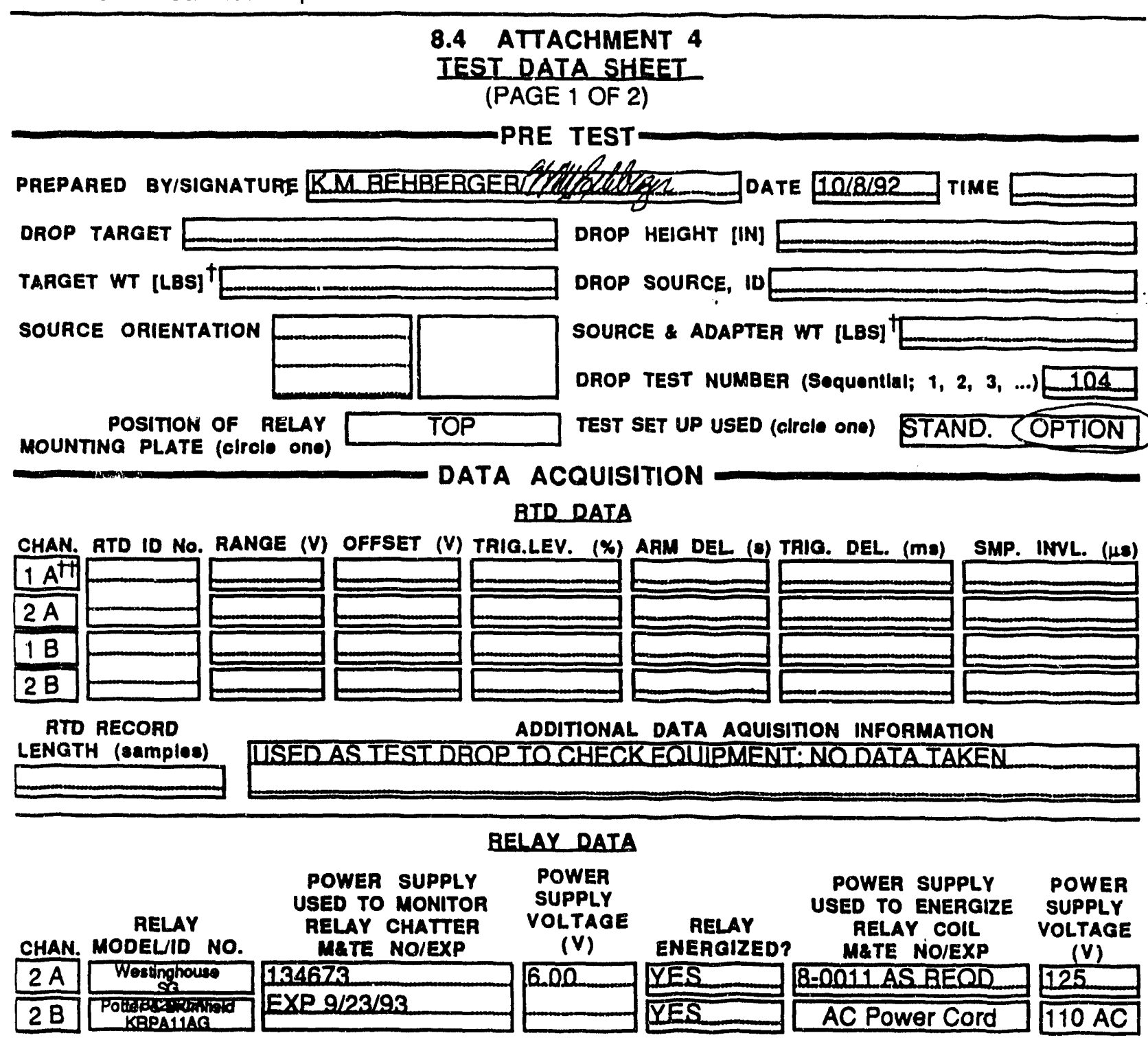

POWER SUPPLY VOLTAGES VERIFIED BY (M\&TE NO/EXP) EAQ

\section{ACCELEBOMETER DATA}

CHAN. ACCELEROMETER METE NO/EXP

AMPLIFIER MQTE NO/EXP

1 A\&B 12935085 EXP 10129192

$\dagger$ Approximate weight using M\&TE category 3 equipment.

tt Numbers 1 \& 2 correspond to channels on each RTD (1 will be used by accelerometer, 2 will be used by relays.). Letters A \& B correspond to different ATD ID numbers. 
WSRC-TR-93-0094

Attuchment 10. Test Data Shects (153 of 155 )

Savannah River Technology Center Equipment Engineering Seismic IVI Drop Test Program Instrumented Cabinet Drup Tests

EES-FP-379, Rev. 0 Date Approved: 9/24/92, Category 2

Page 16 of 18

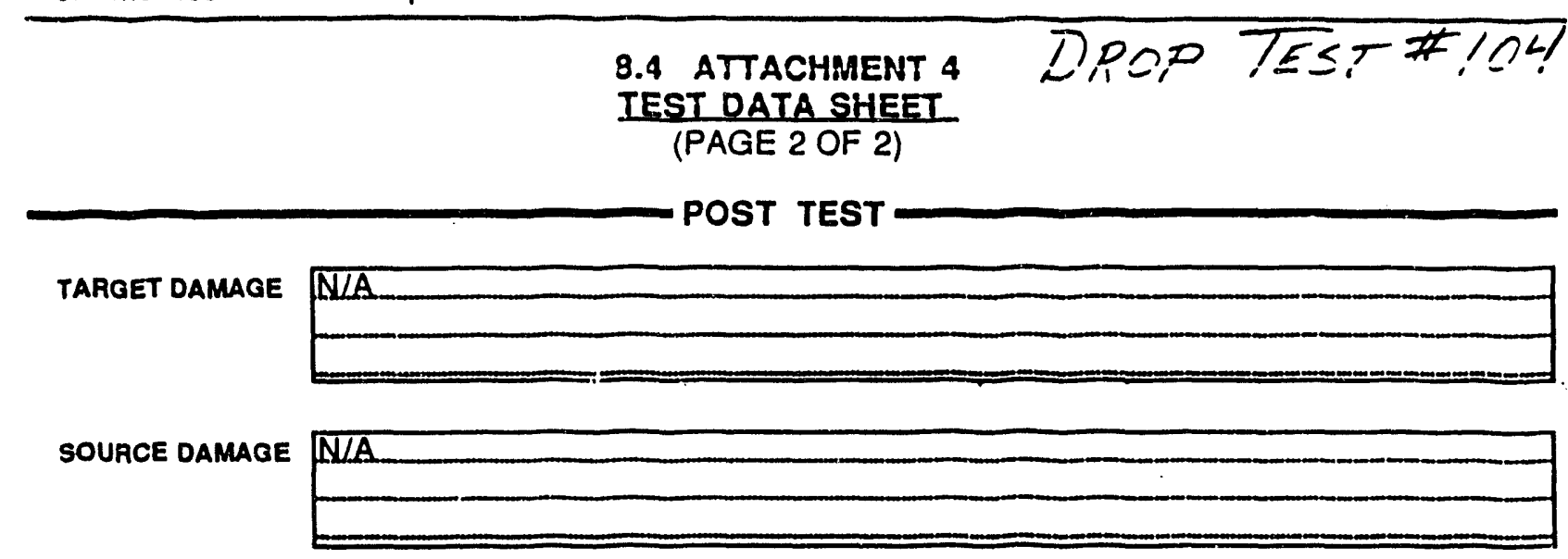

RELAY CHATTER IDENTIFED ON POTTER \& BRUMAELD RELAY (YN) NIA IF YES, DURATION OF CHATTER [Ms] NUA

RELAY CHATTER IDENTIFED ON WESTINGHOUSE REAY (YN) NIA IF YES, DURATION OF CHATTER [MU] NUA

HAND HELD VIDEO START \& STOP POSITION NIA

HIGH SPEED VIDEO START \& STOP POSMON NIA

COMMENTS NODATA IAKEN IEST USEDAS ANEOUIEMENICHECK IEST

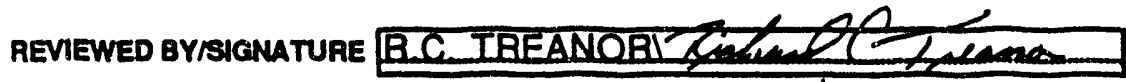

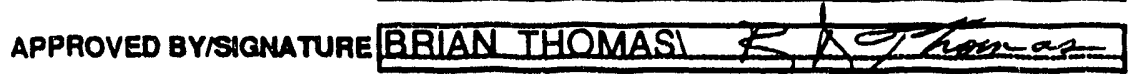
REVIEWED DATE 12 gaq APPROVED DATE $12 / 2792$ 
IVSRC-TR-93-0094

Attachment 10. Test Data Sheets (154 of 155)

Savannah River Technology Center

Equipment Engineering

EES-FP-379, Rev. 0

Seismic II// Drop Test Program

Instrumented Cabinet Drop Tests

Date Approved: 9/24/92, Category 2

Page 15 of 18

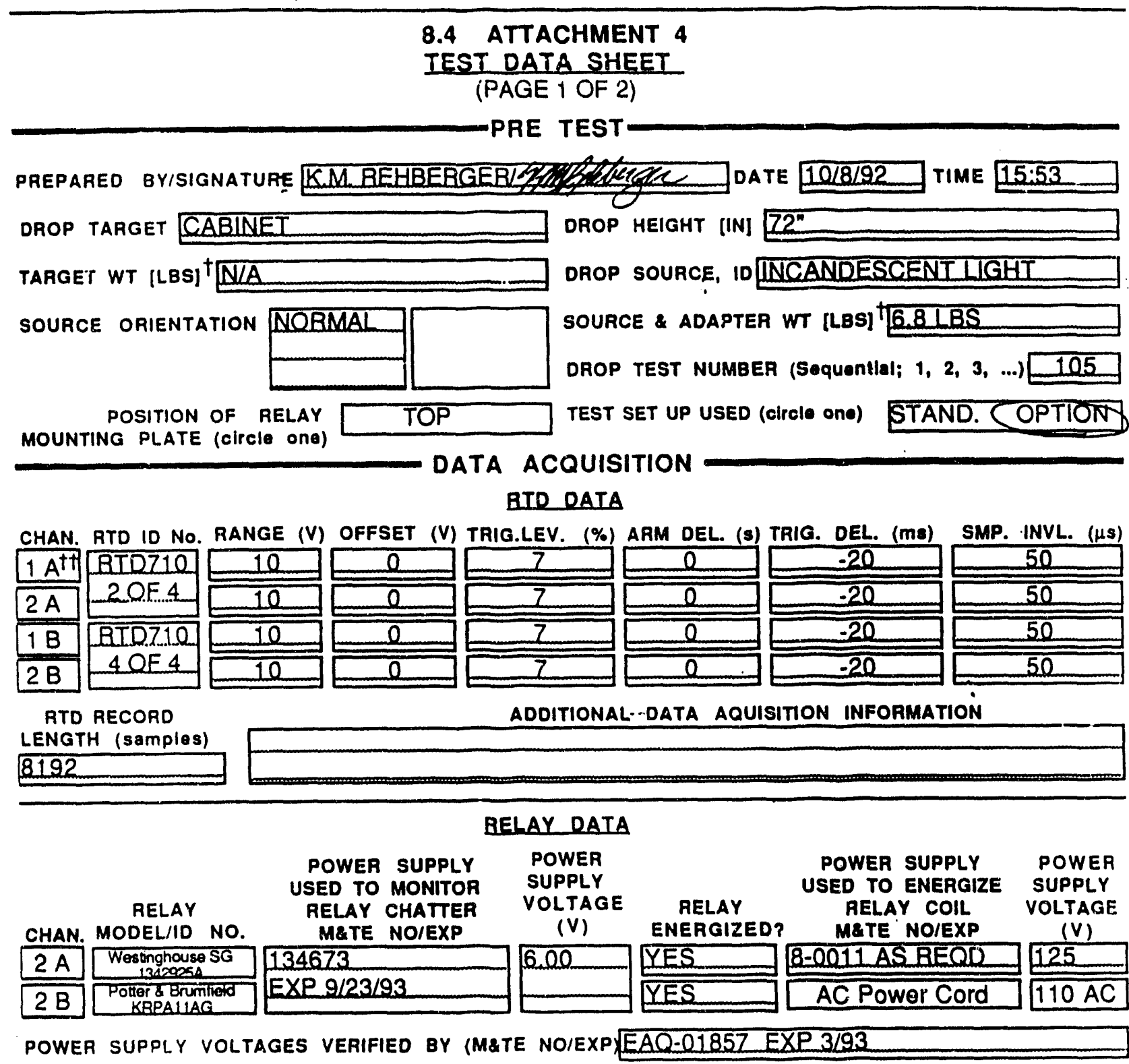

ACCELEROMETER DATA

CHAN. ACCELEROMETER M\&TE NO/EXP

1 A\&B 12935285 EXP $10 / 29 / 92$

AMPLIFIER M\&TE NO/EXP L214-068-X EXP Z117/93

AMPLIFIER GAIN

$\dagger$ Approximate weight using M\&TE category 3 equipment

${ }^{\dagger}$ Numbers 1 \& 2 correspond to channels on each RTD ( 1 will be usea oy accelerometer, 2 will be used by relays.)

Letters A \& B correspond to different RTD ID numbris. 
IVSRC-TR-93-0094

Attuchment 10. Test Duta Sheets (155 of 155)

Savannan Hiver Technology Center

Equipment Engineering

EES-FP.379, Rev. 0

Seismic 11/I Drop Test Program

Date Approved: 9/24/92, Category 2

Instrumented Cabinet Drop Tests

Page 16 of 18

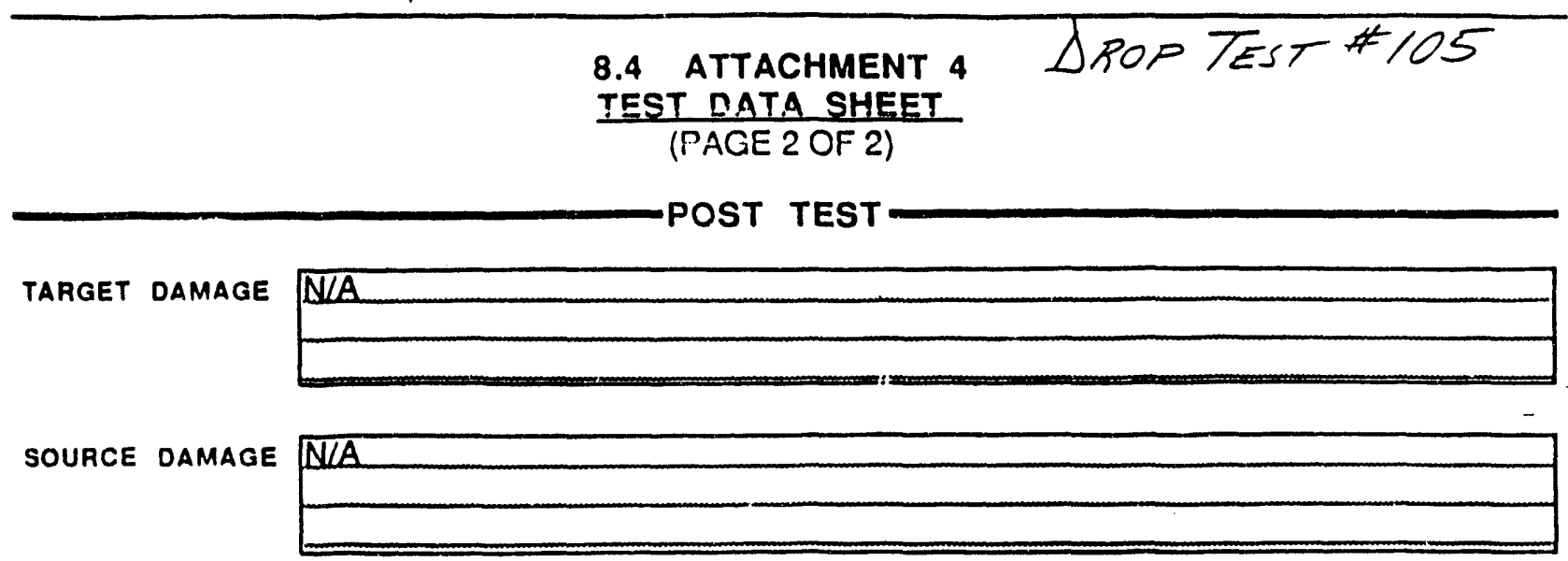

RELAY CHATTER IDENTIFIED ON POTTER \& BRUMFIELD RELAY (YIN) NONE

IF YES, DURATION OF CHATTER [ms] SEEPLOI

RELAY CHATTER IDENTIFIED ON WESTINGHOUSE RELAY (Y/N) YES

IF YES, DURATION OF CHATTER [ma] SEEPLOT

HAND HELD VIDEO START \& STOP POSITION NIA

HIGH SPEED VIDEO START \& STOP POSITION $34: 49-35: 31$

COMMENTS

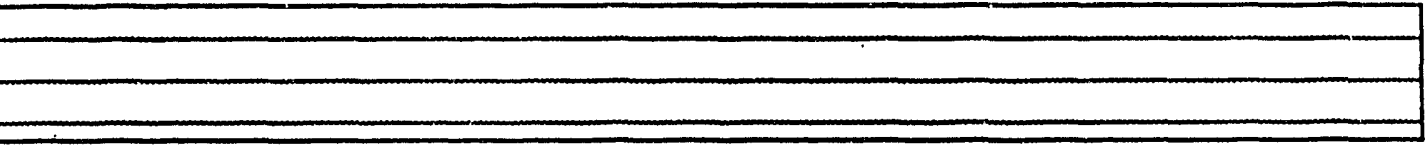

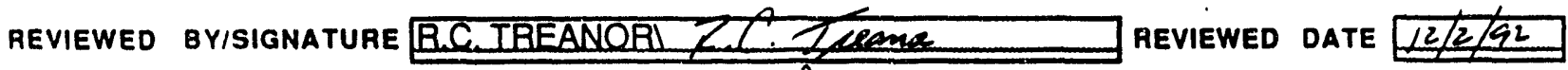
APPROVEO BYISIGNATURE BRIAN THOMAS $12 / 3 / 92$ 

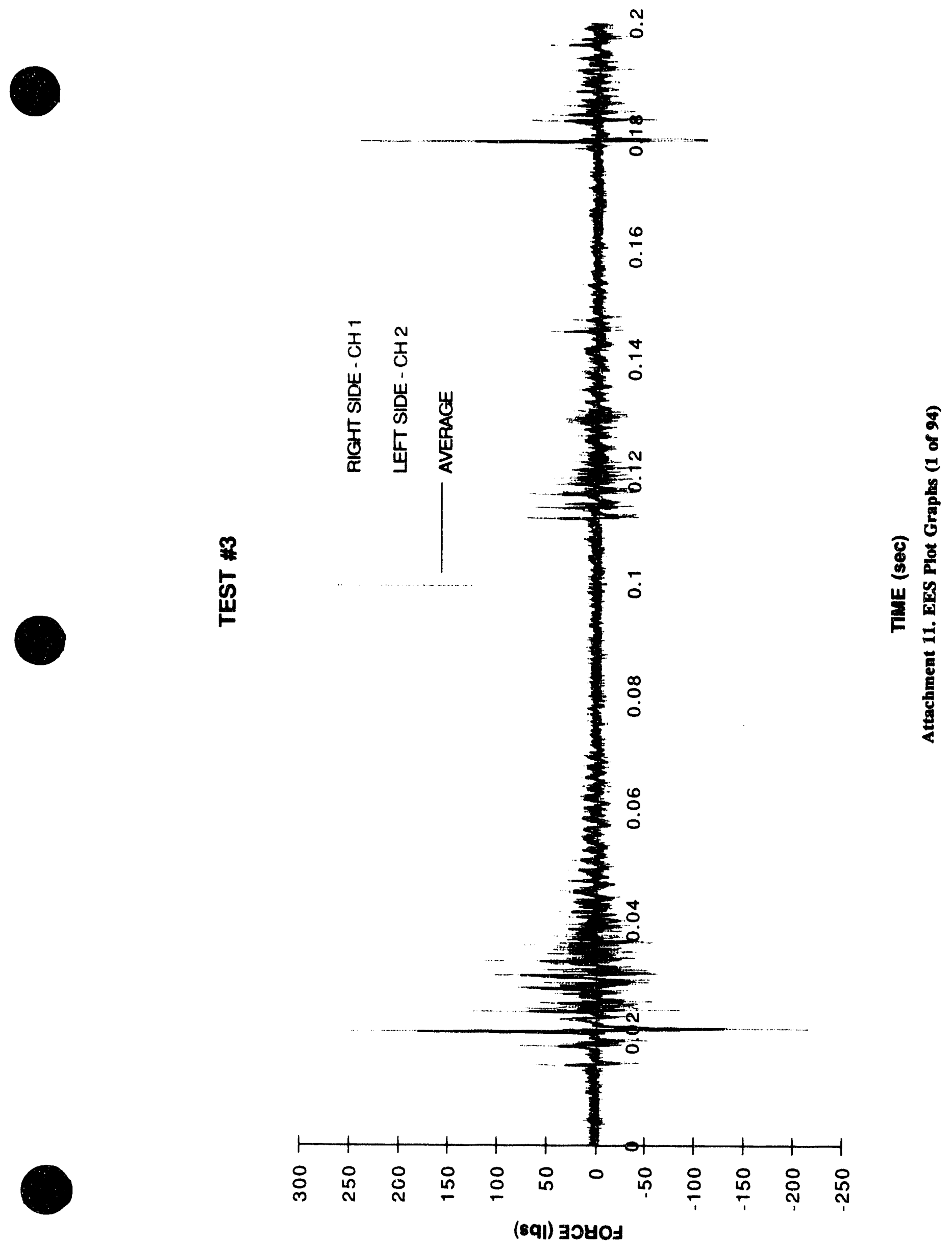


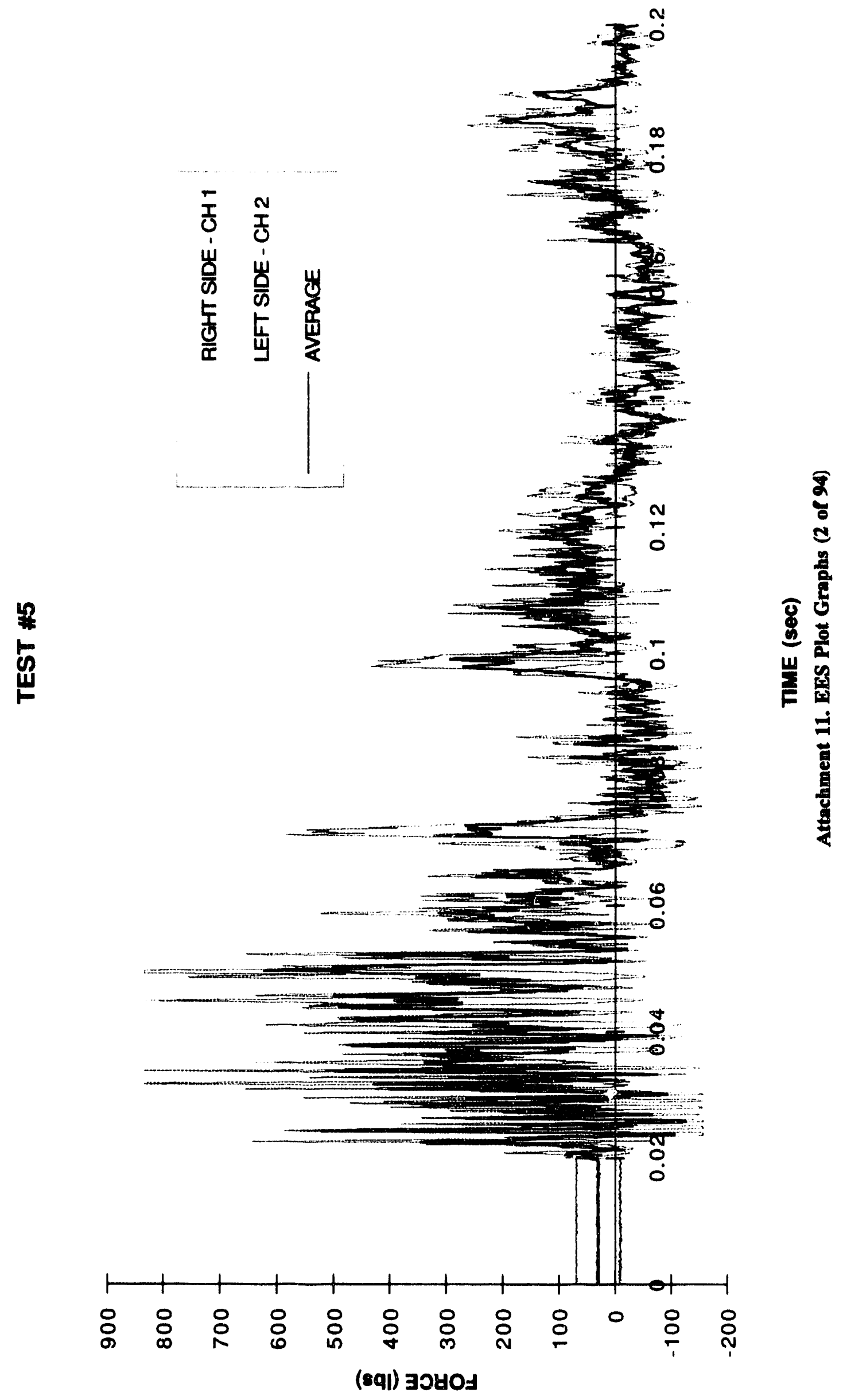




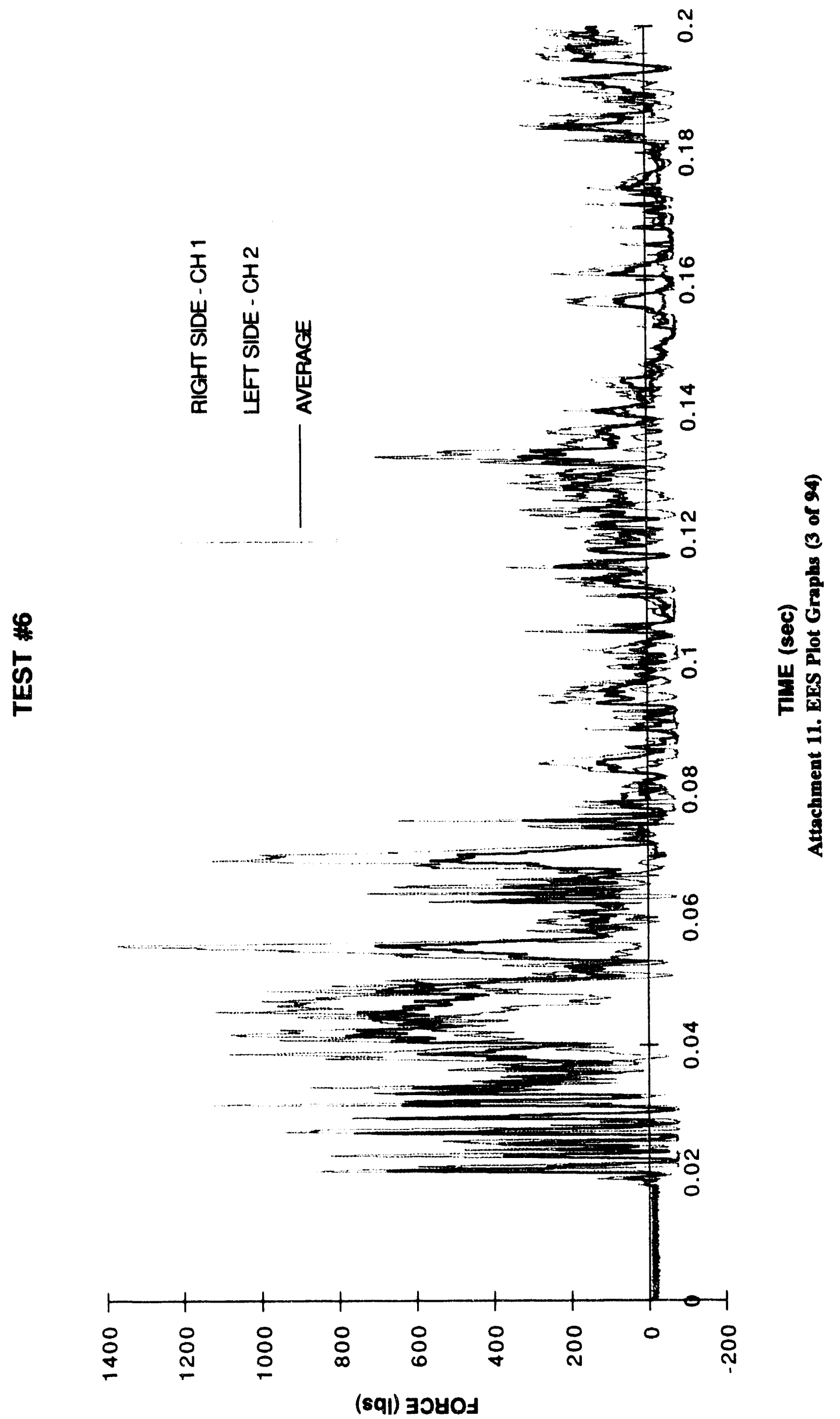




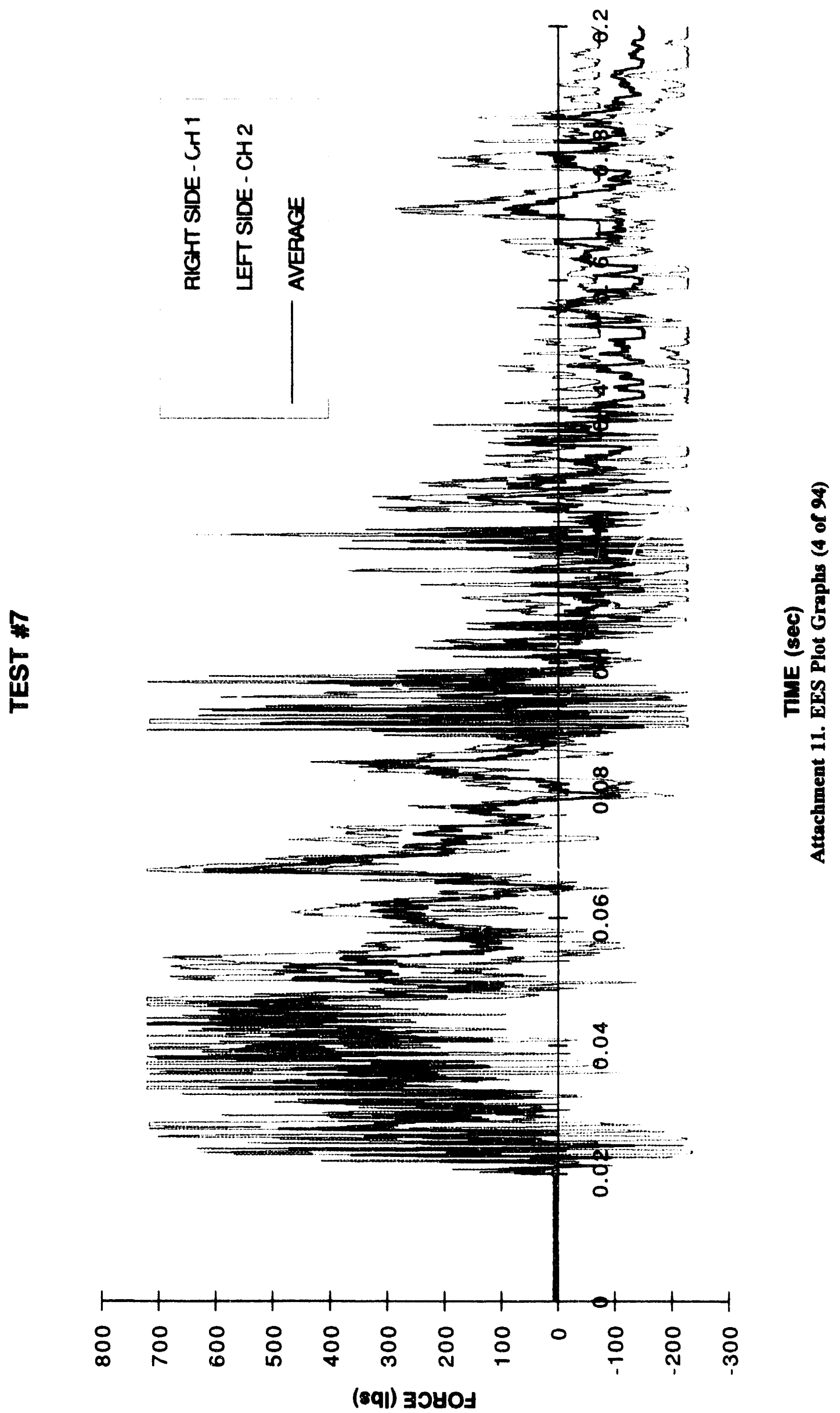




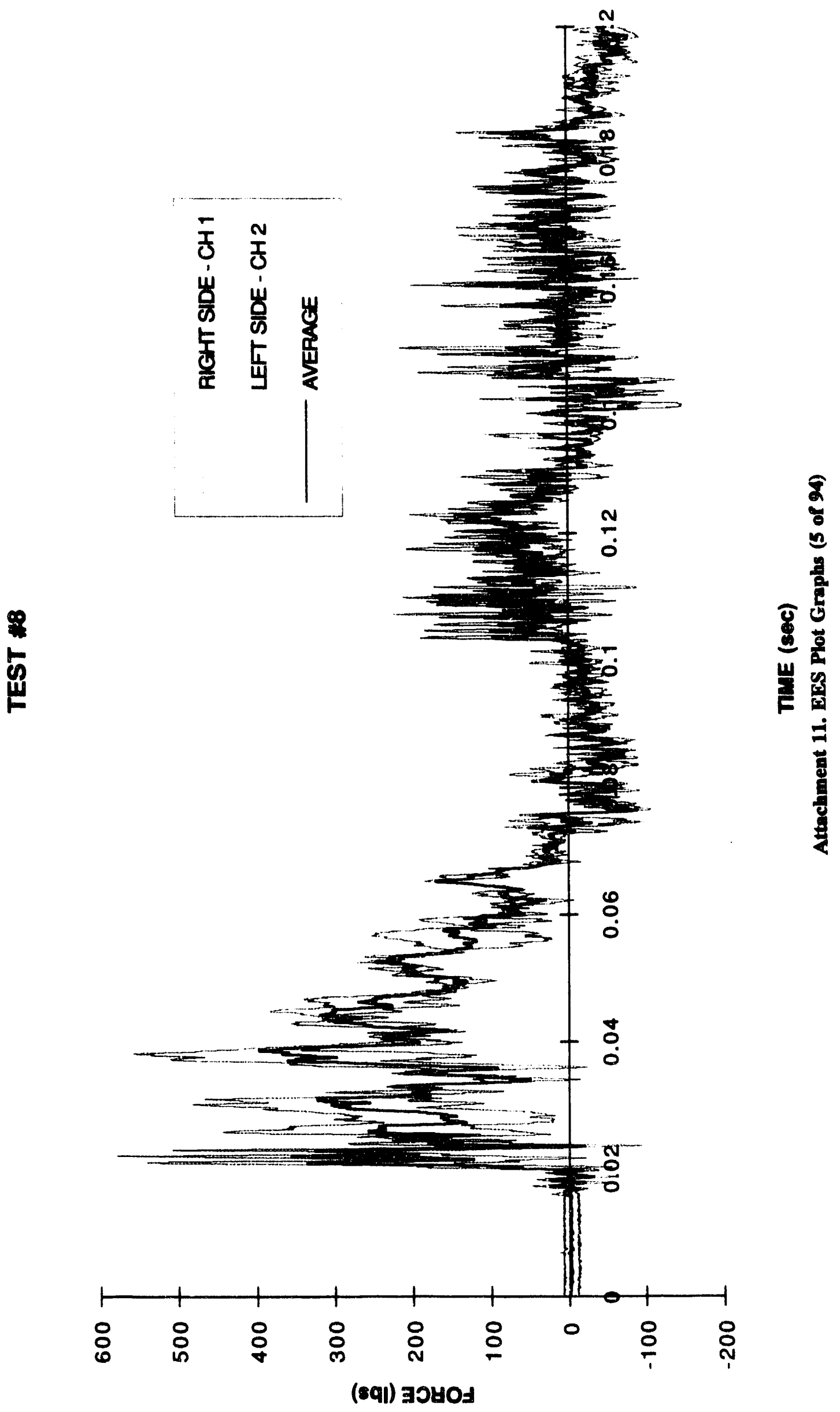




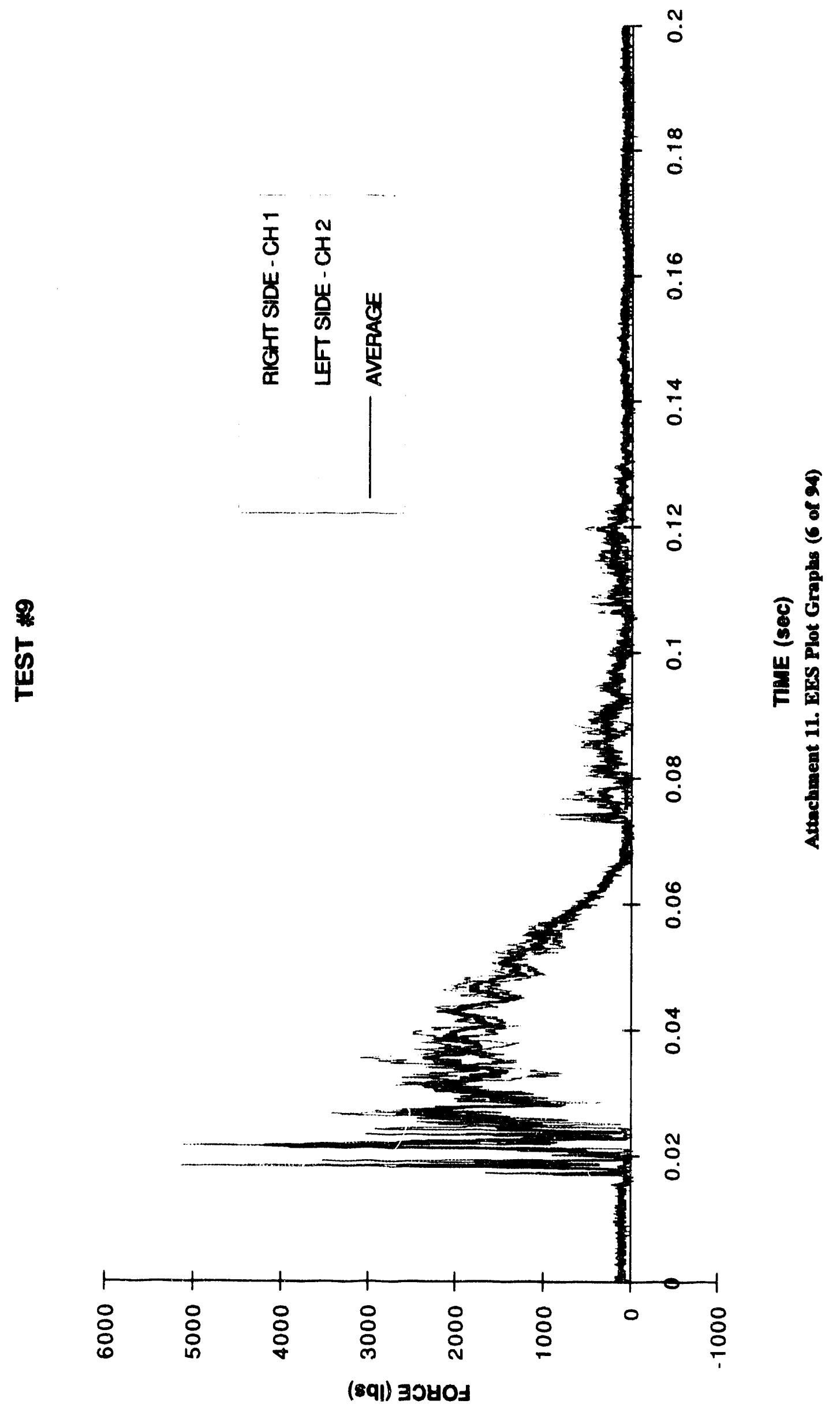


옴

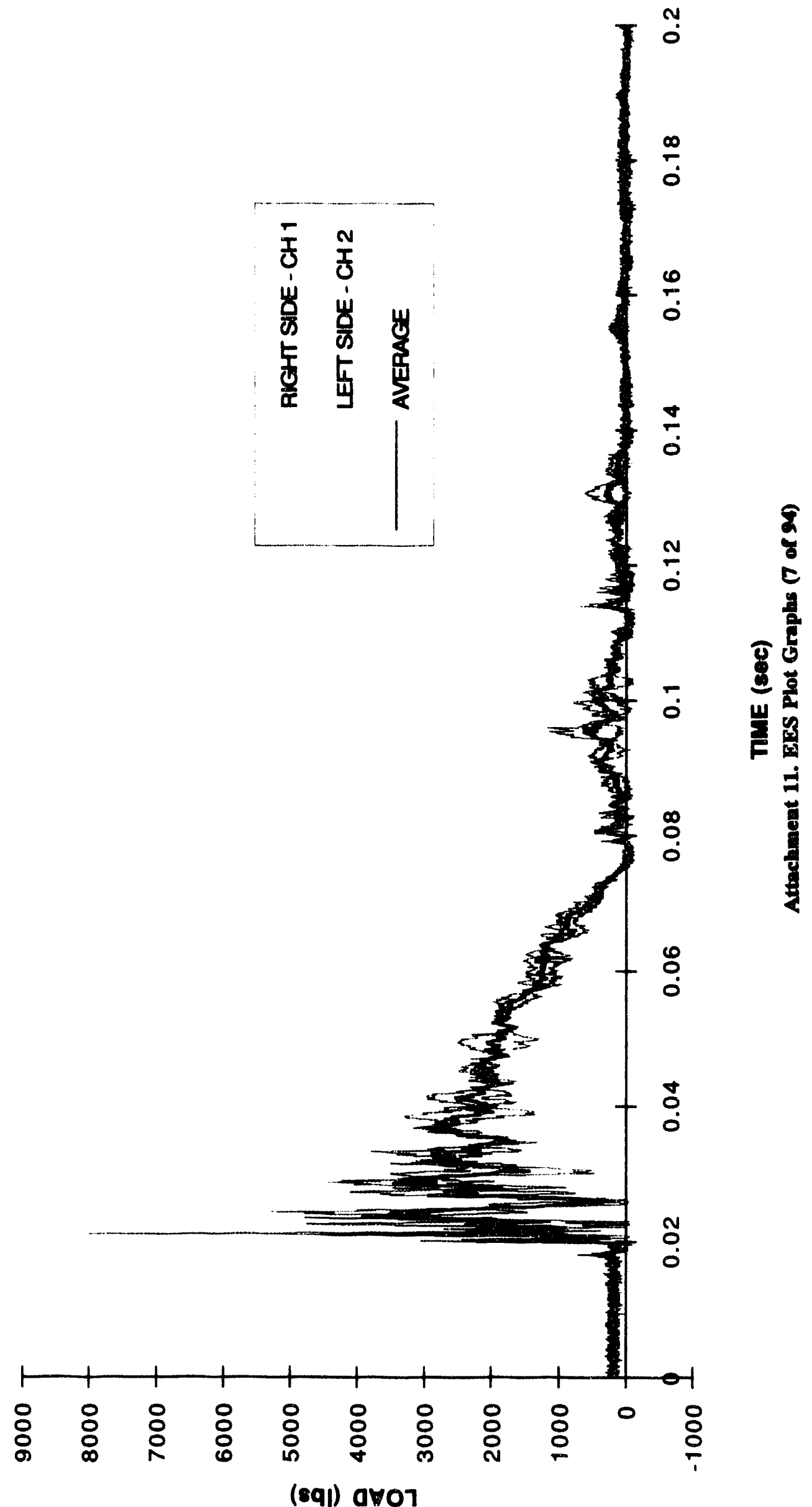




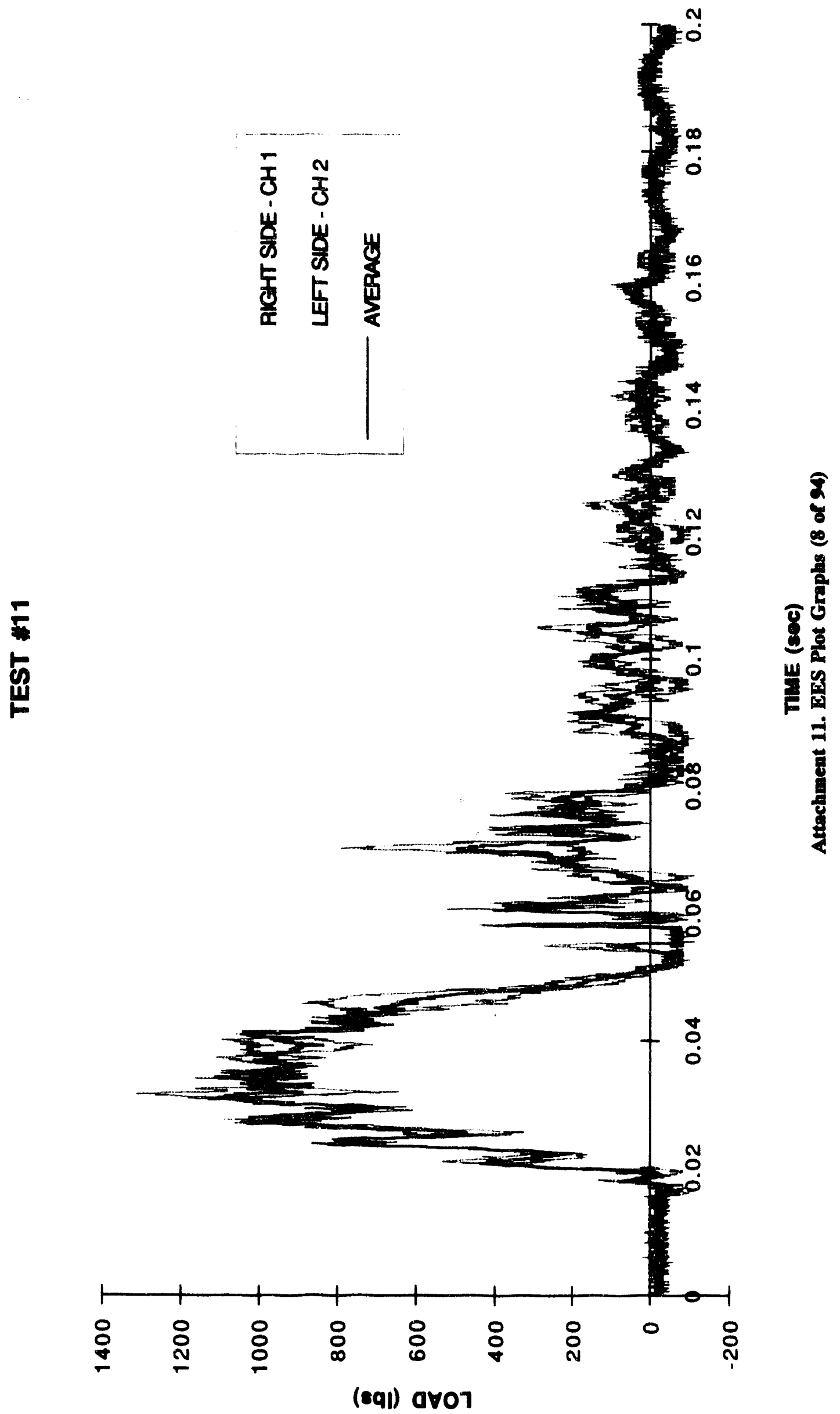




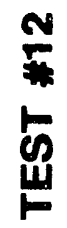

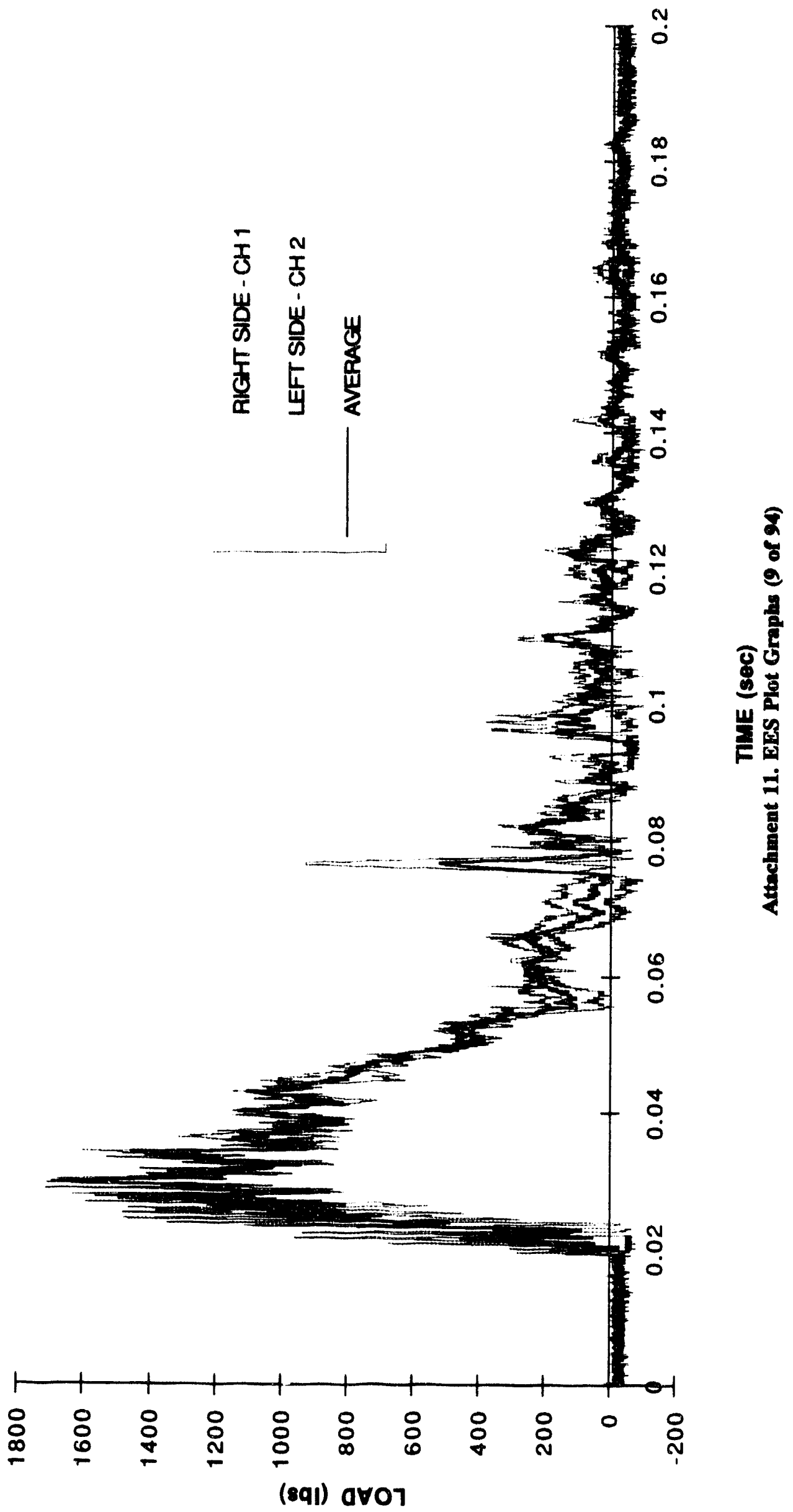




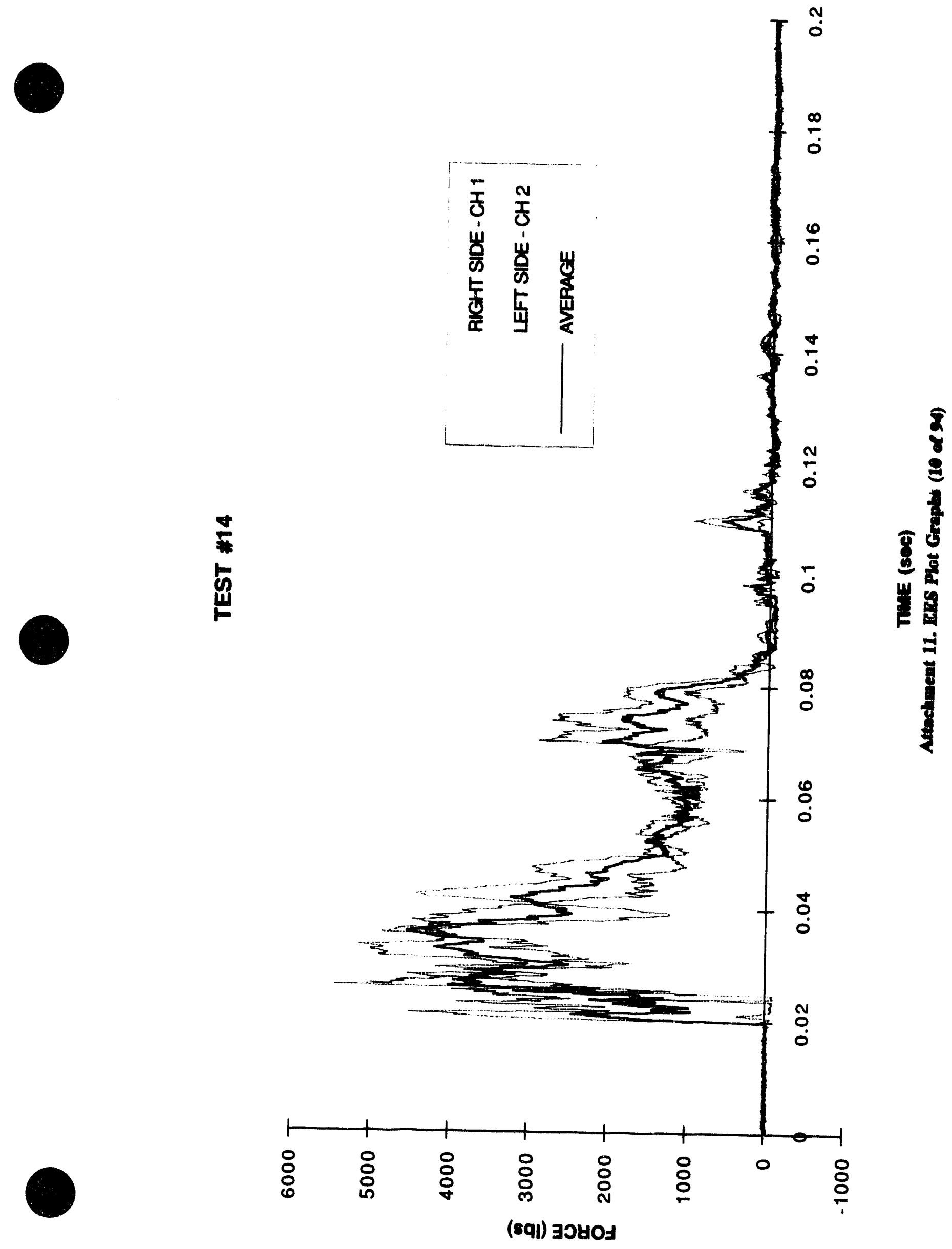



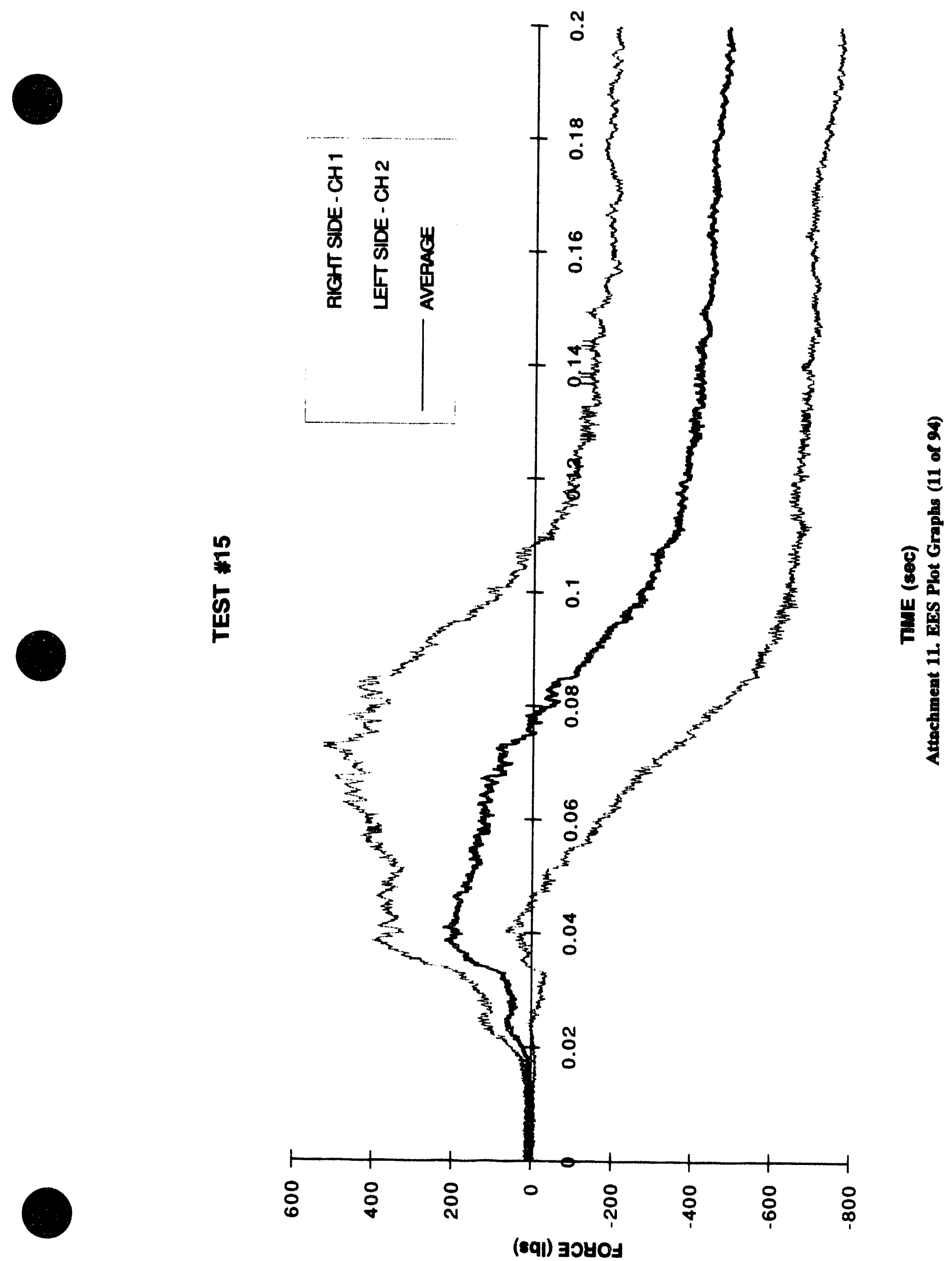

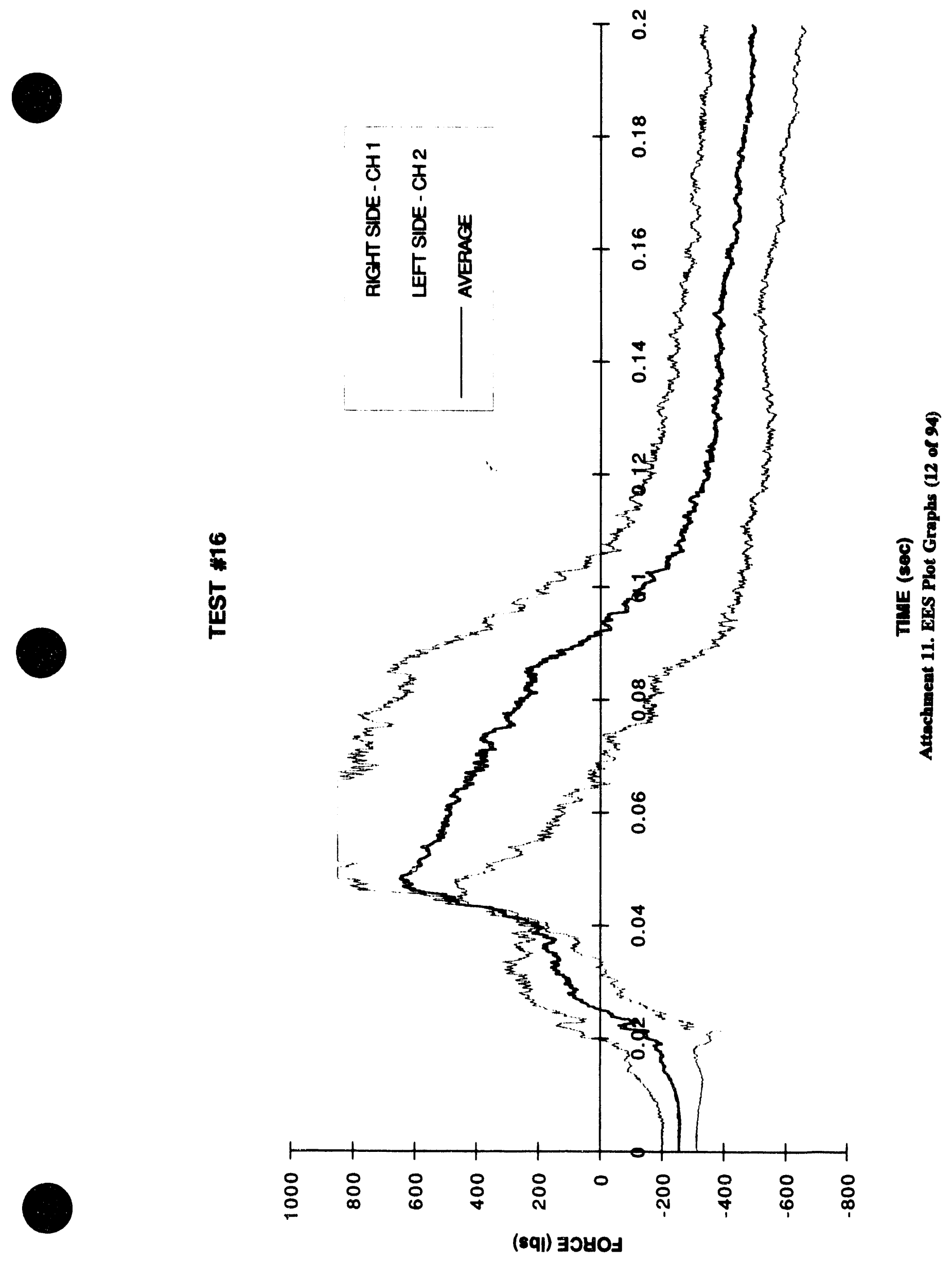


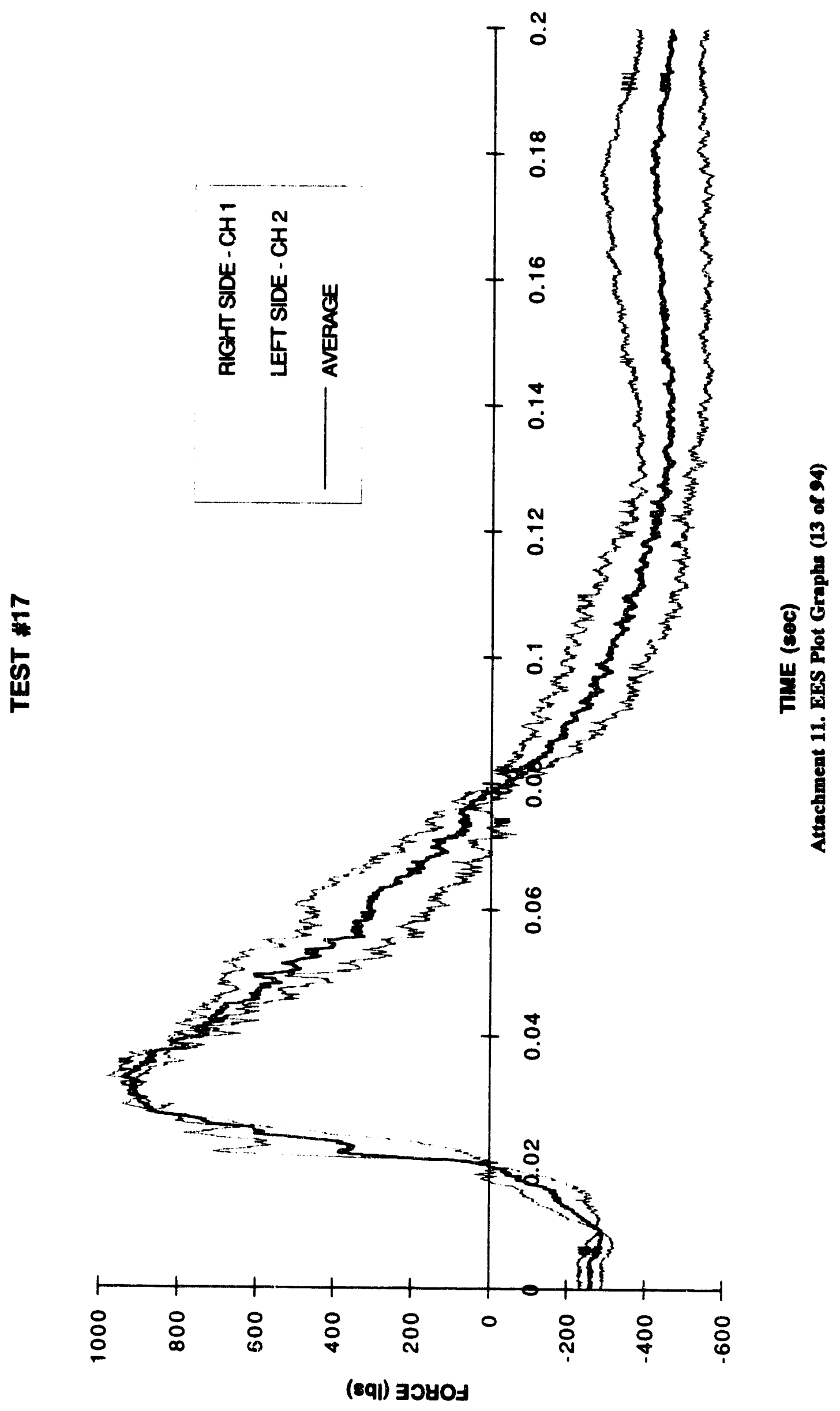



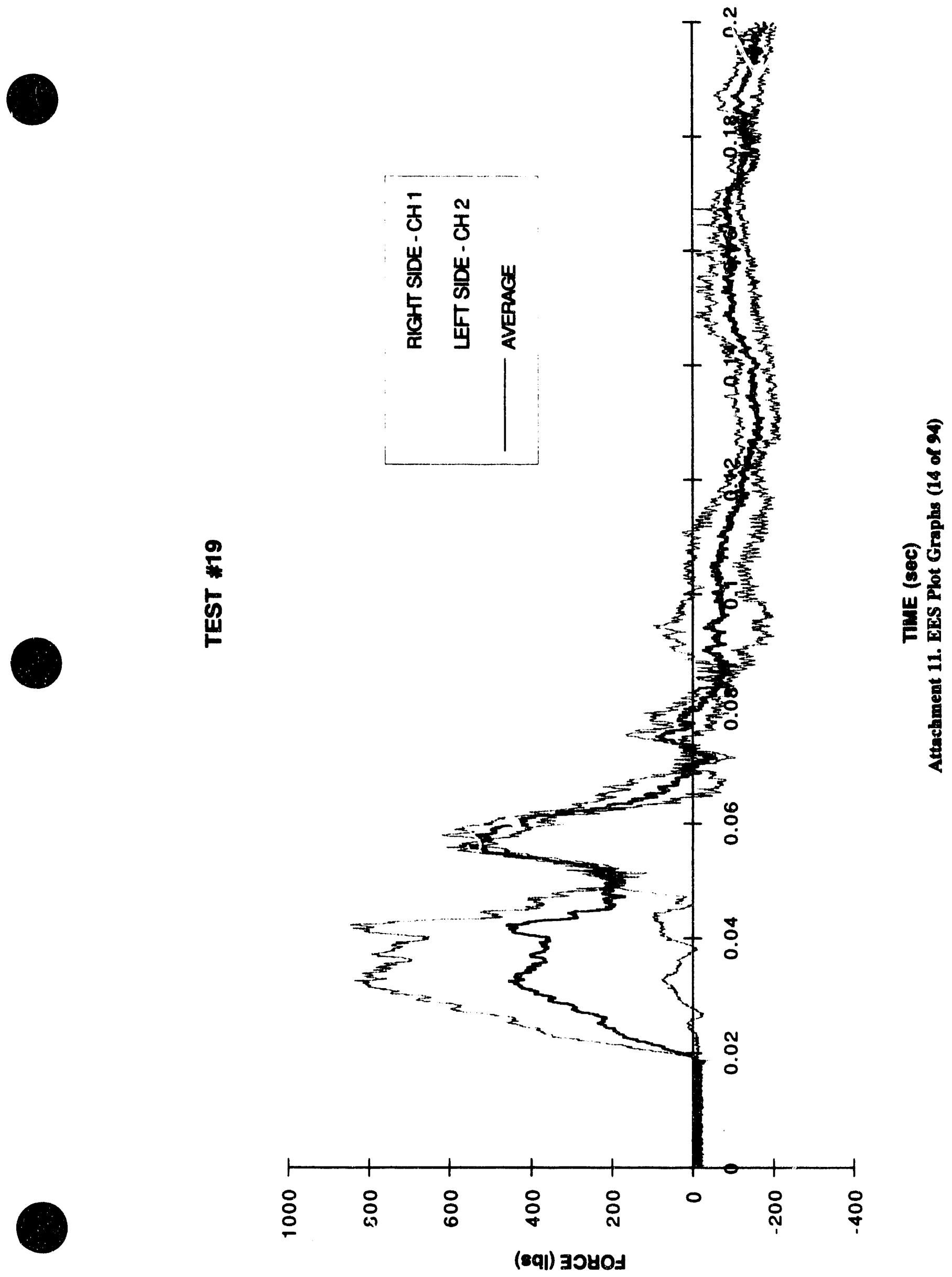


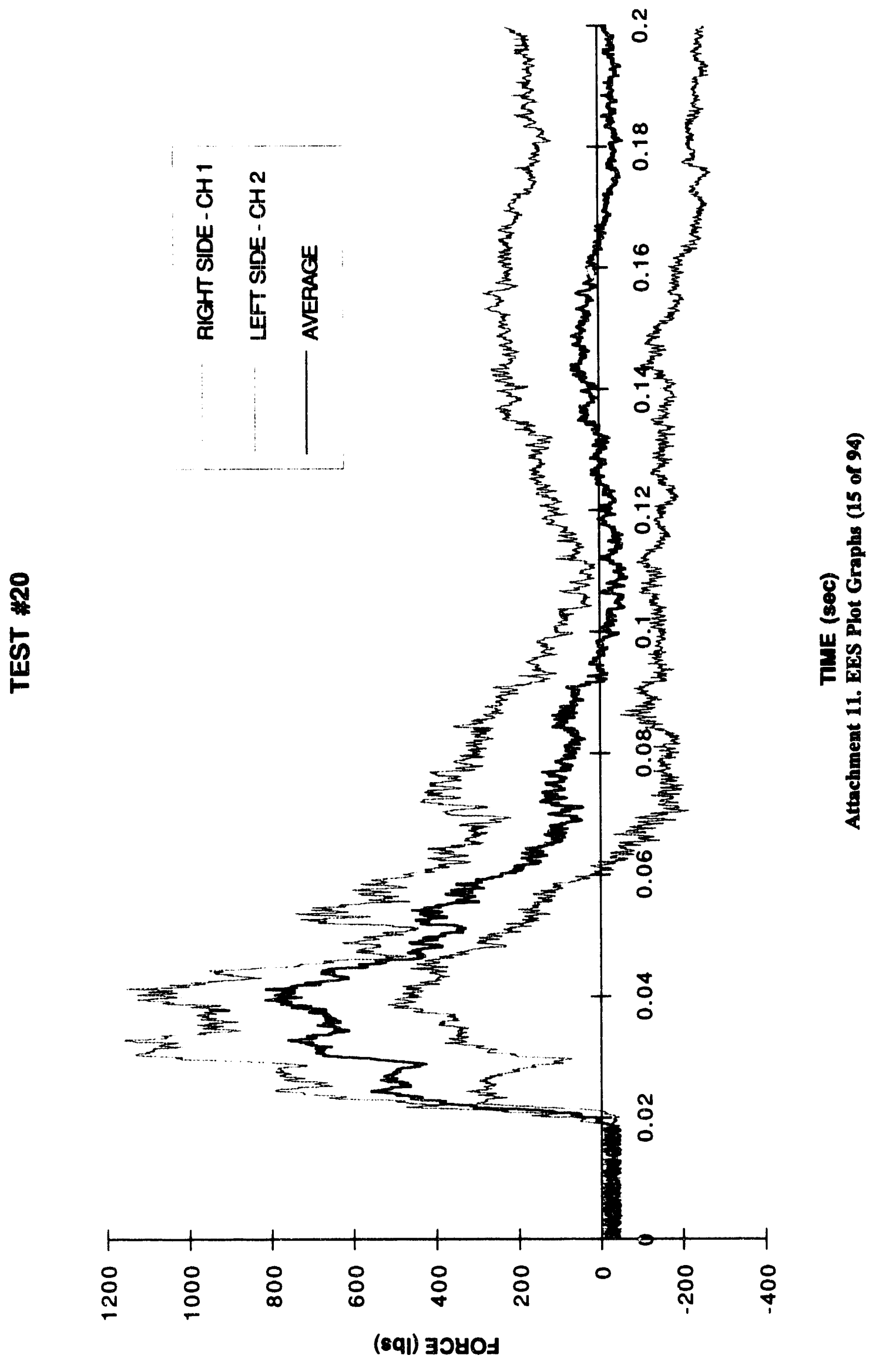




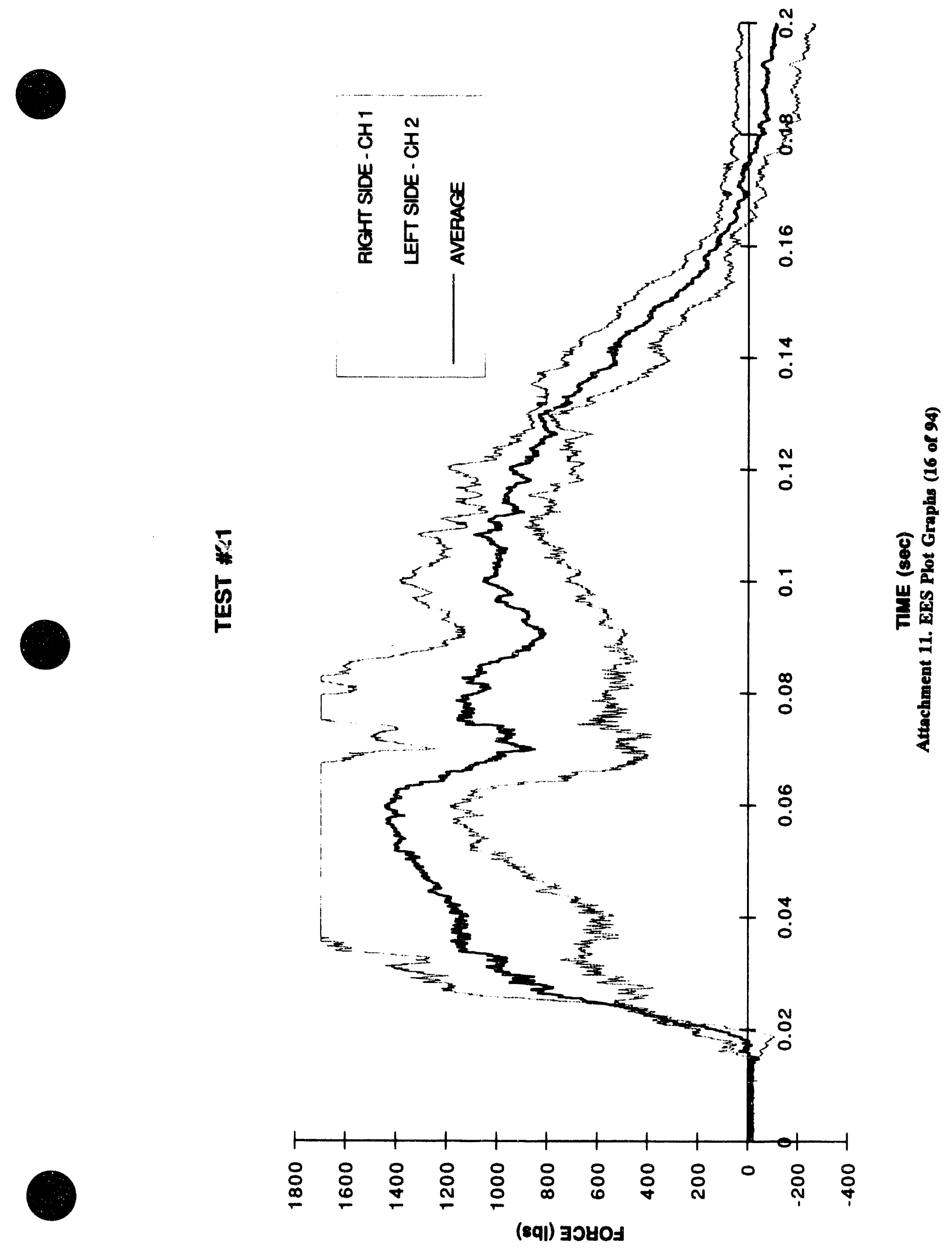




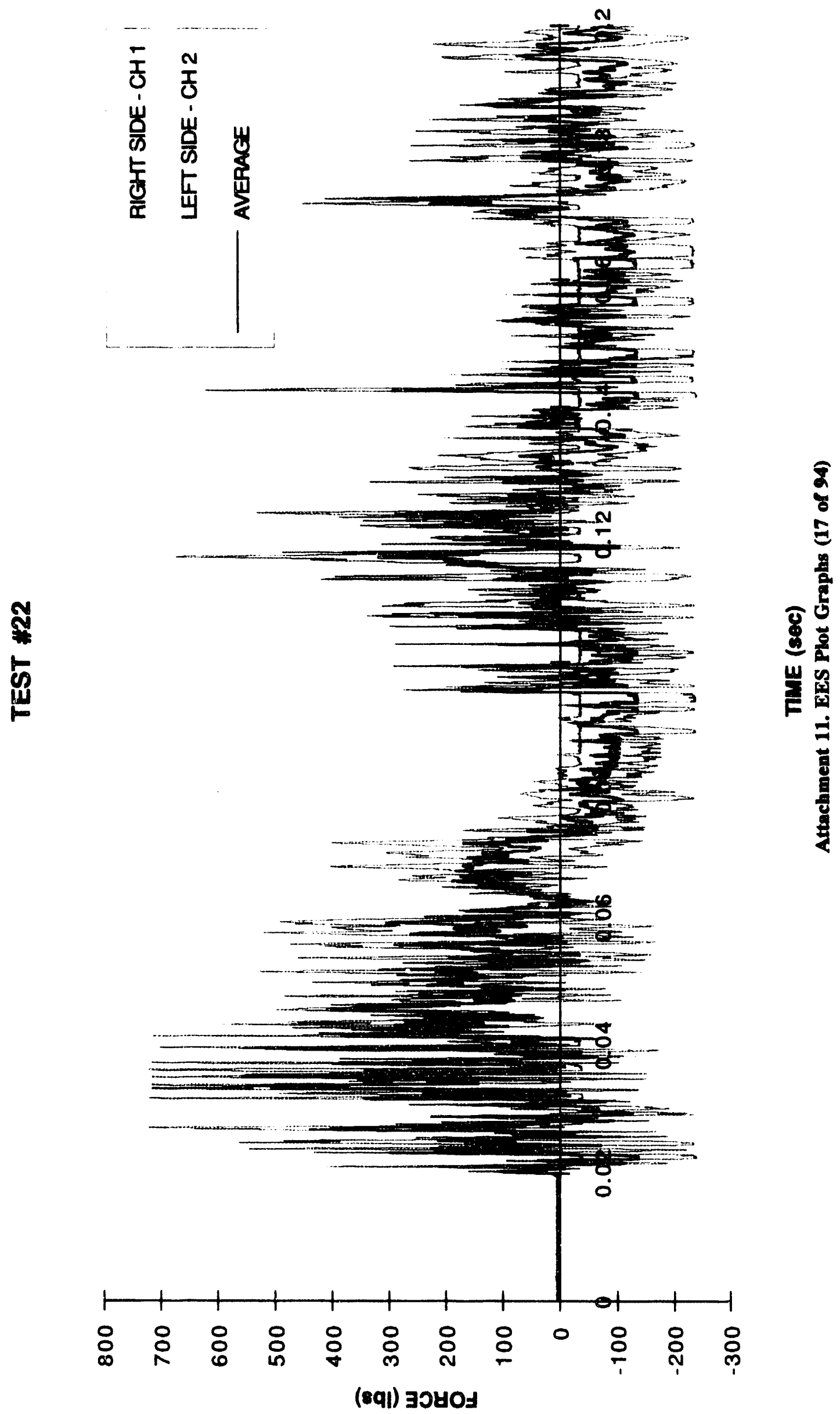




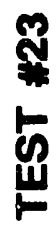

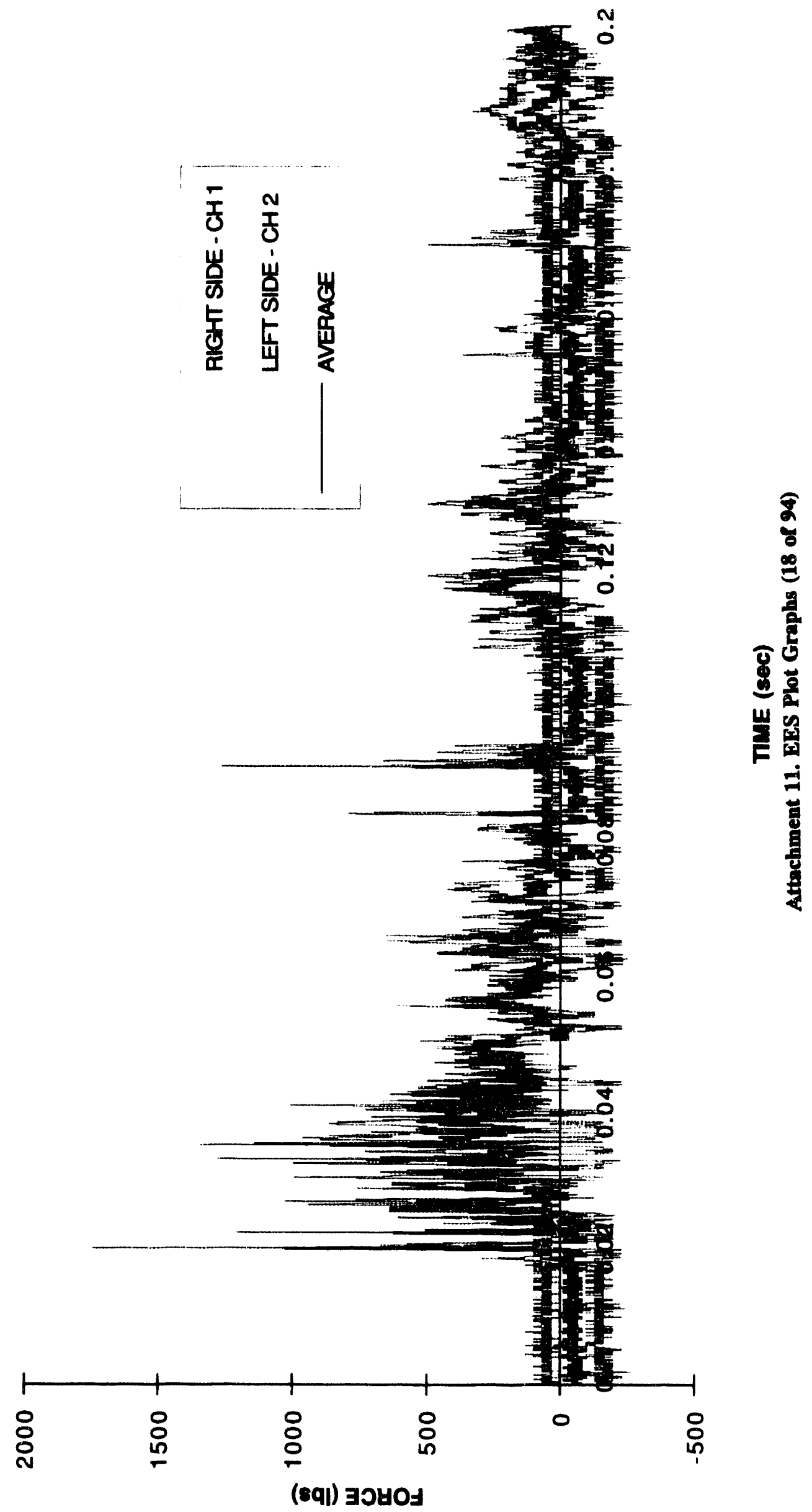




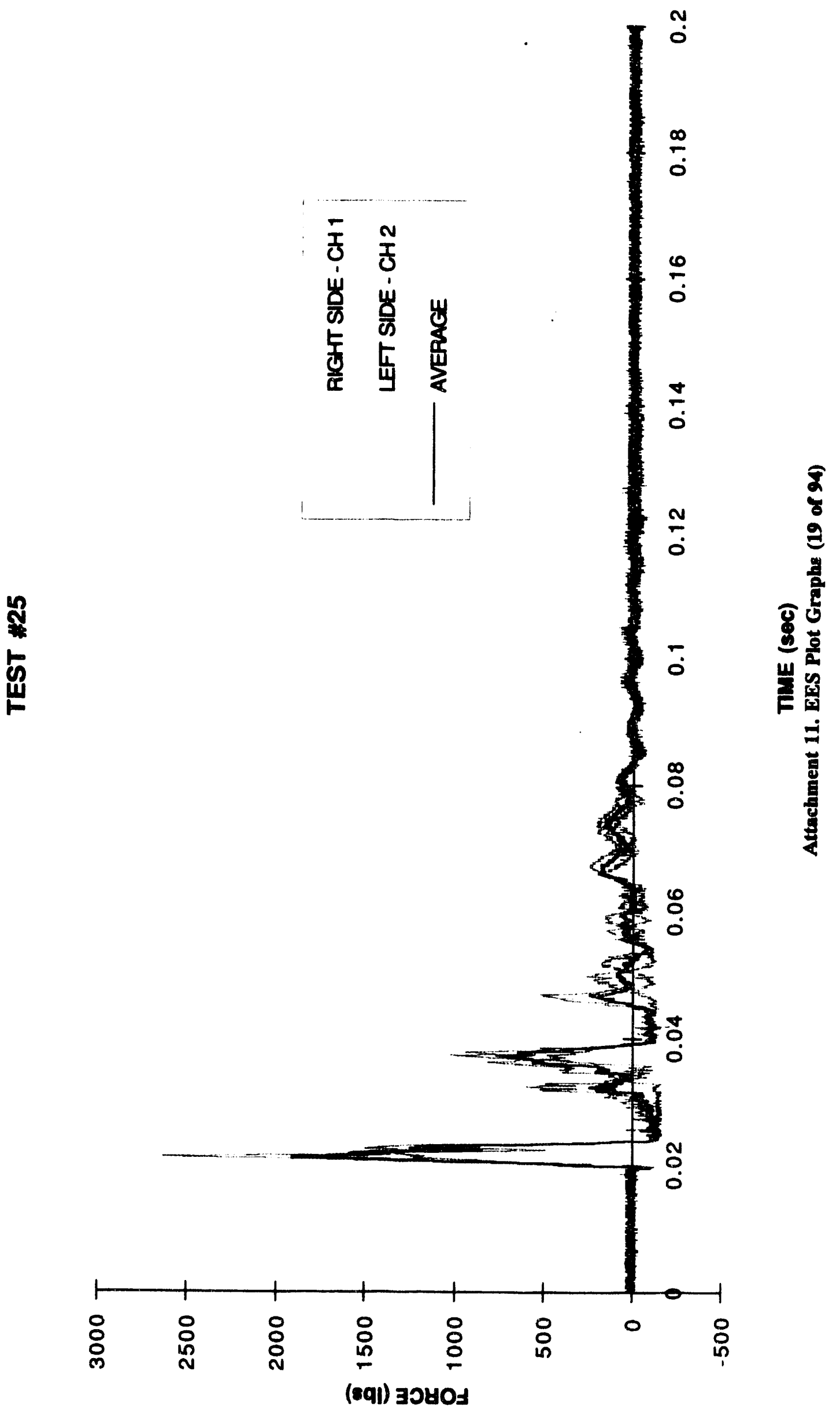




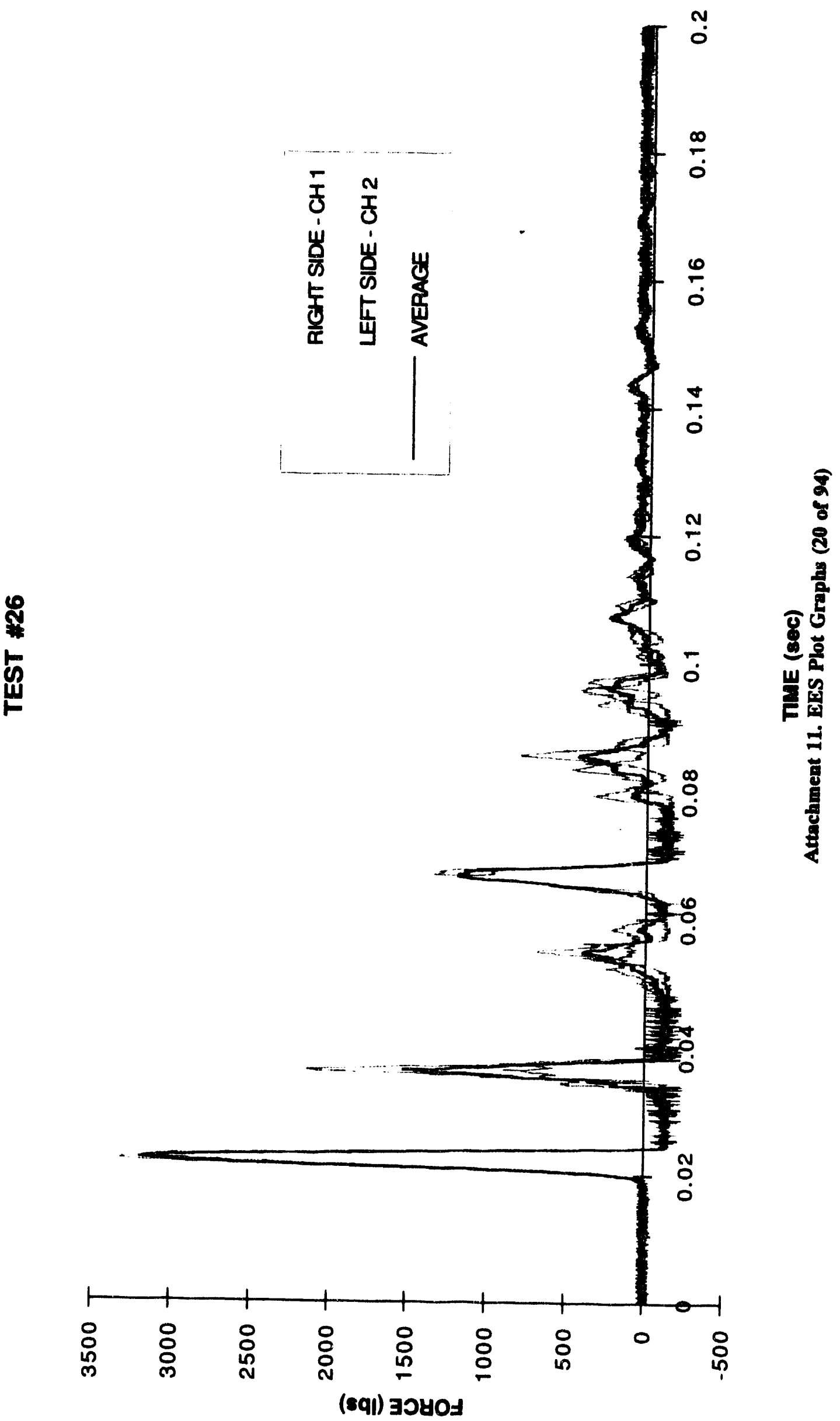




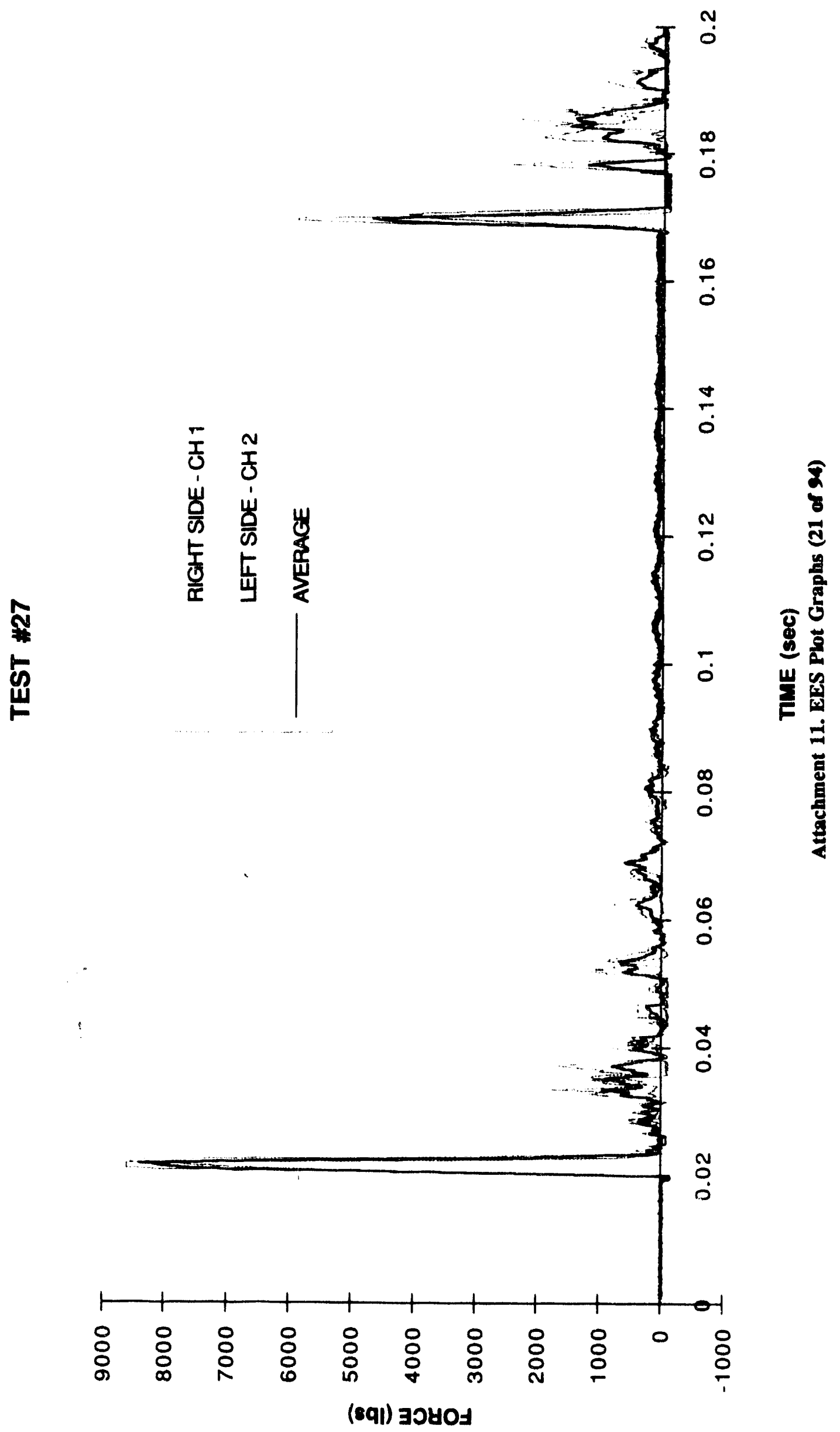




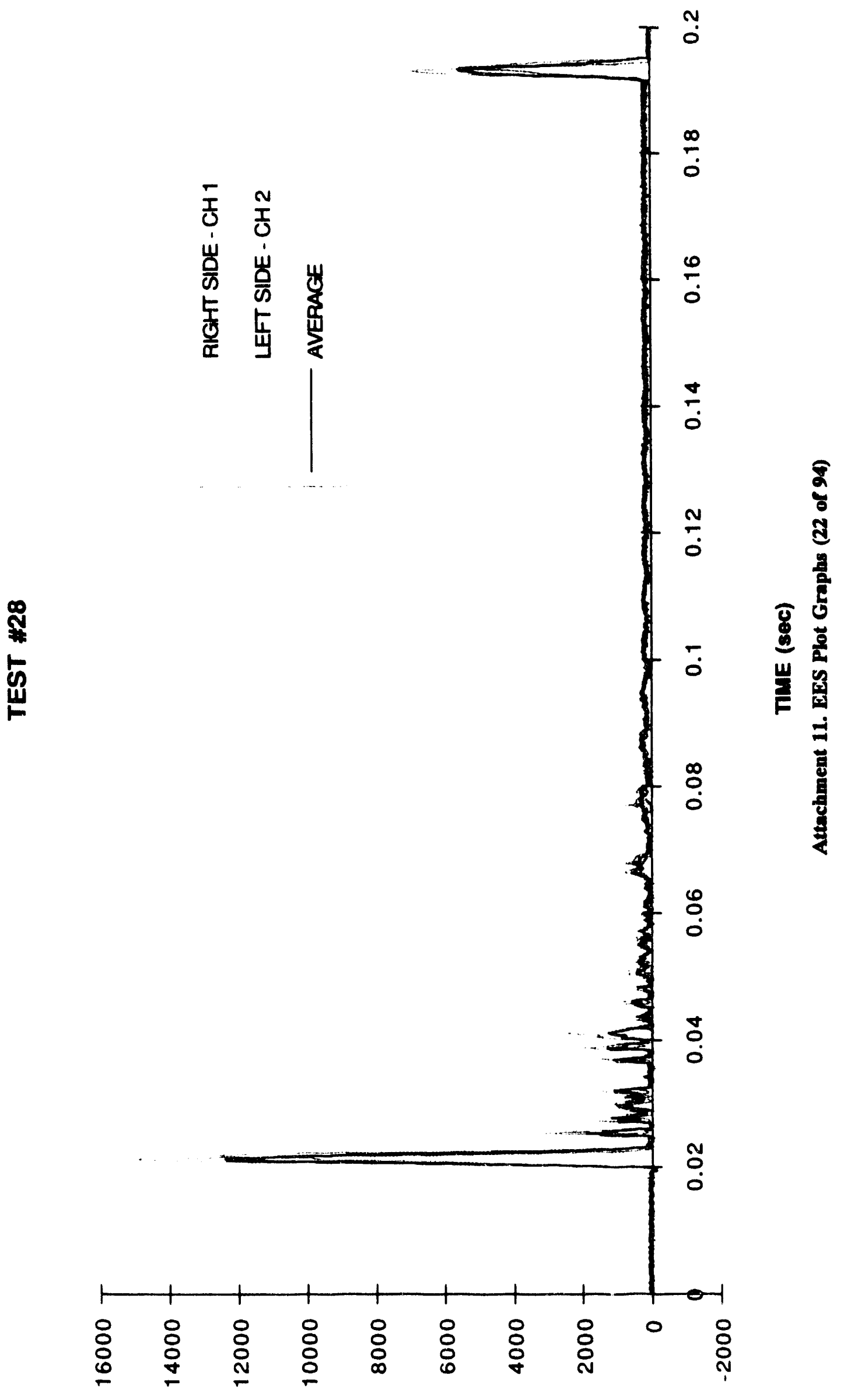

(8qा) 3อ40ड 


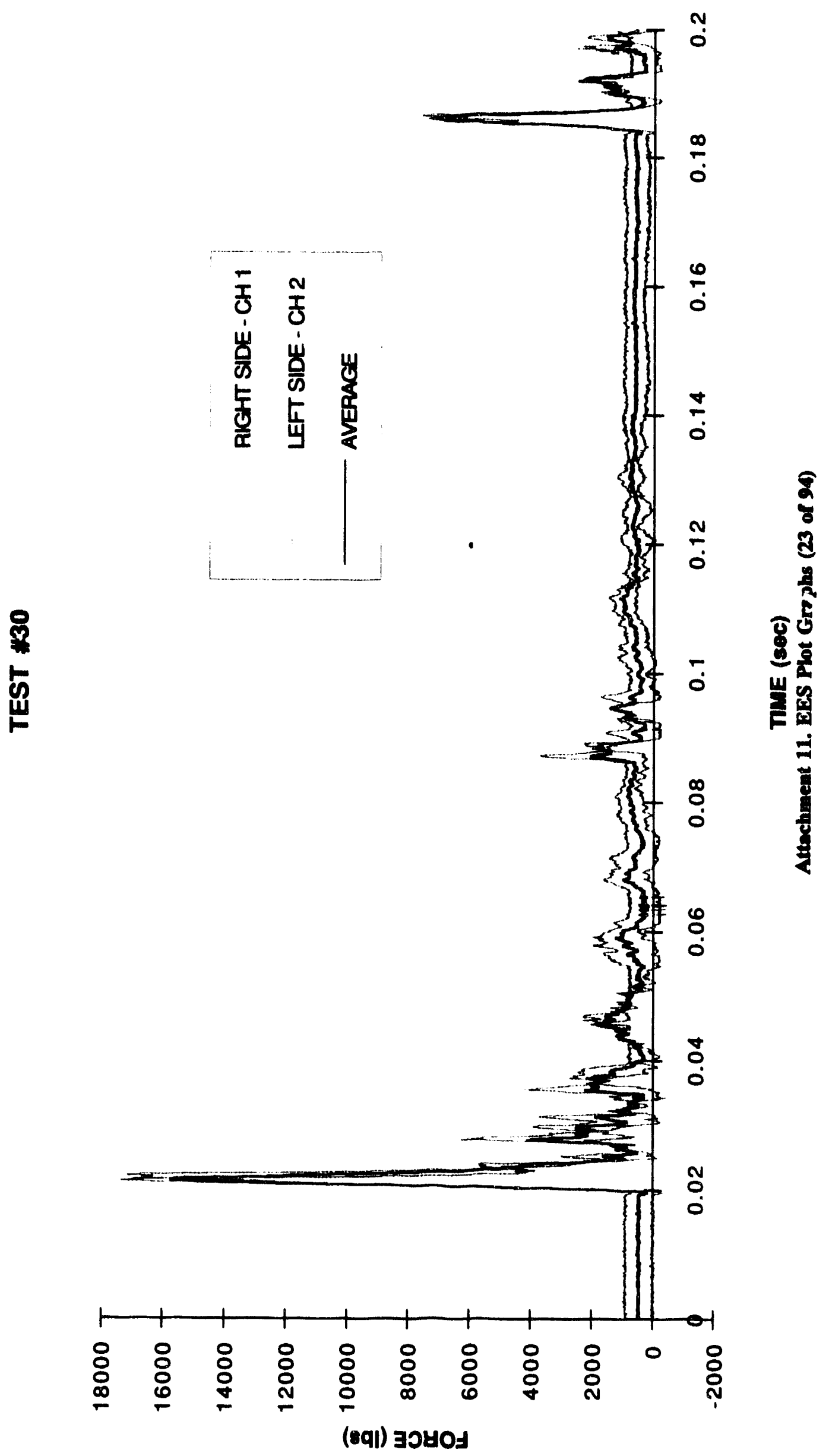




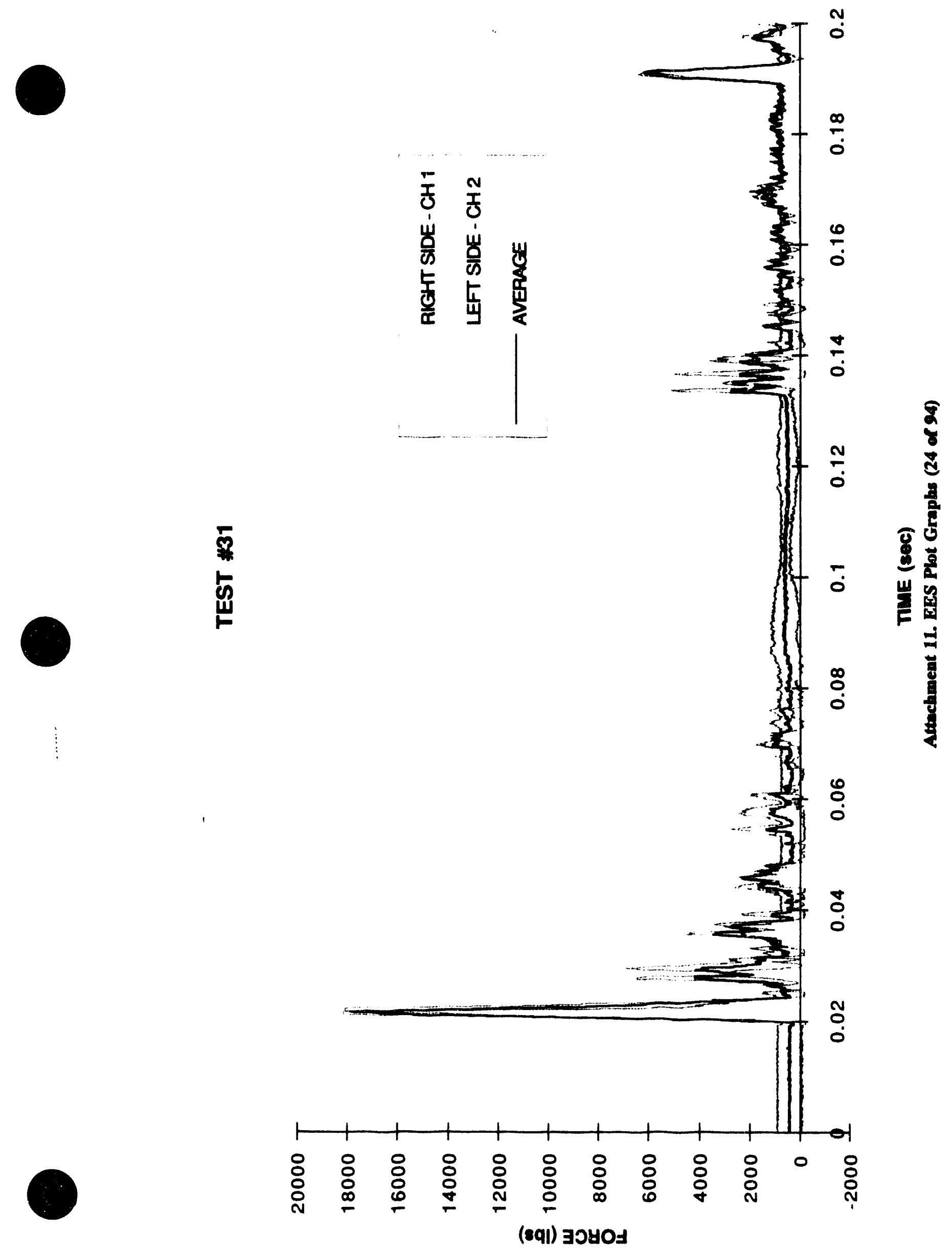




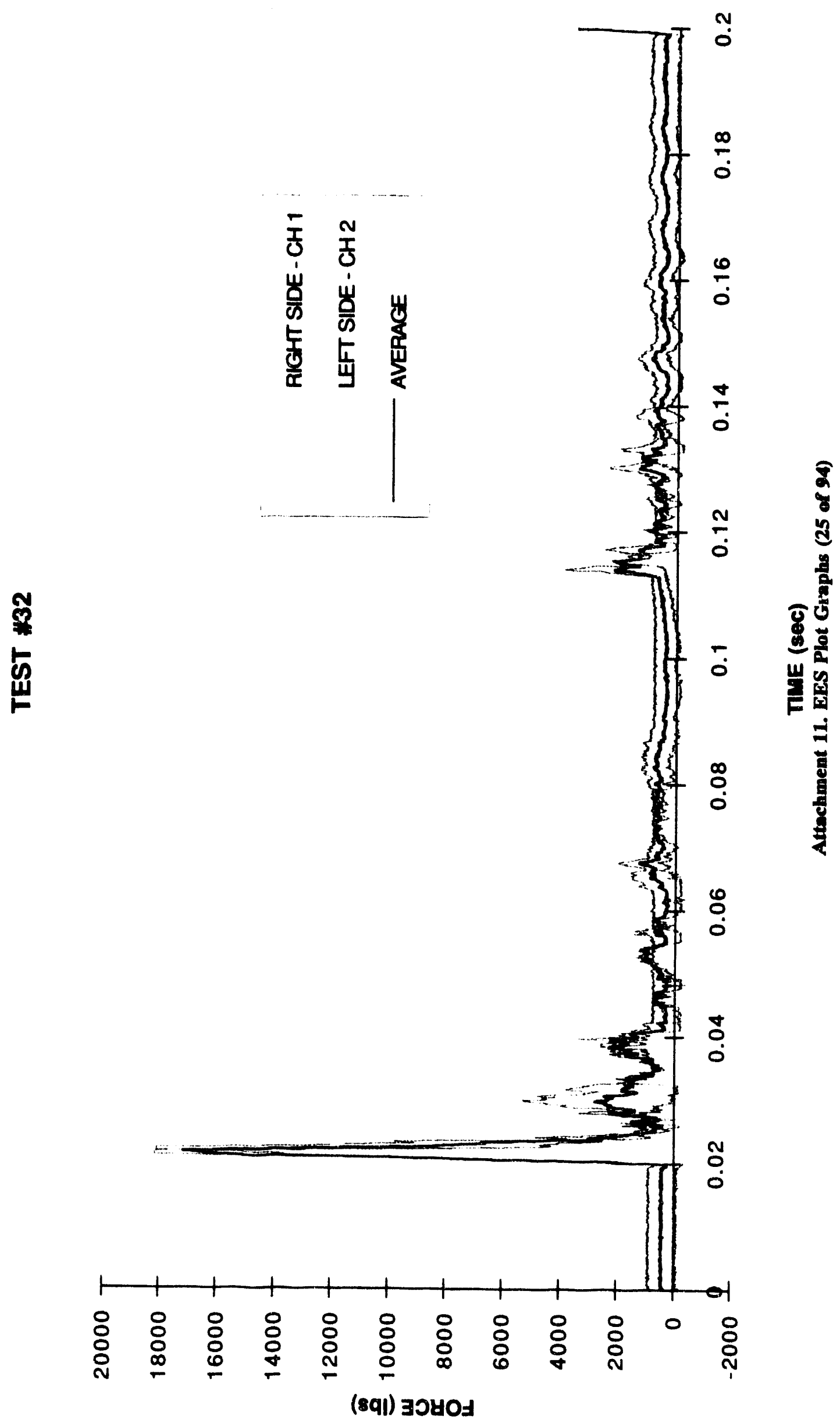




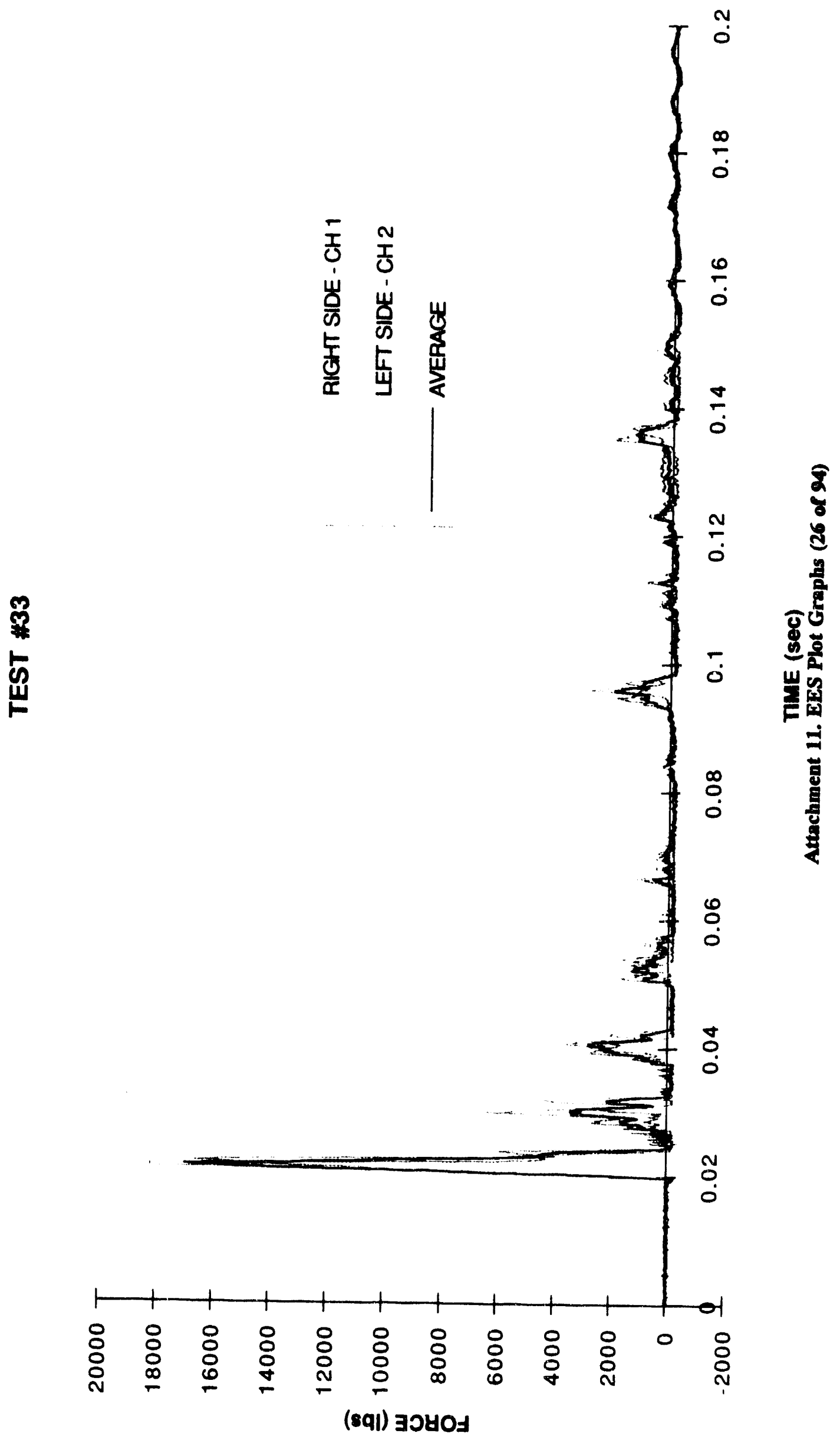




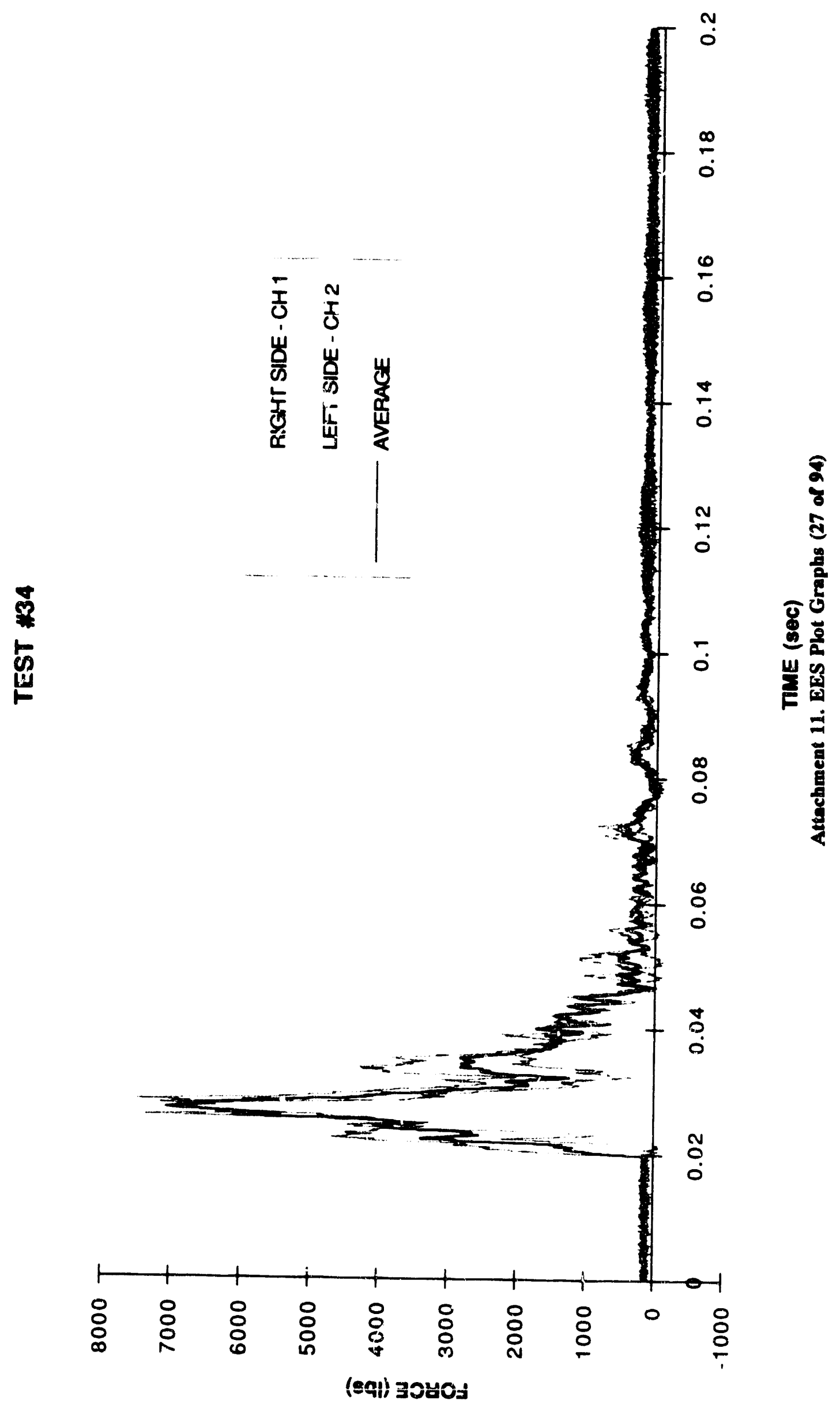




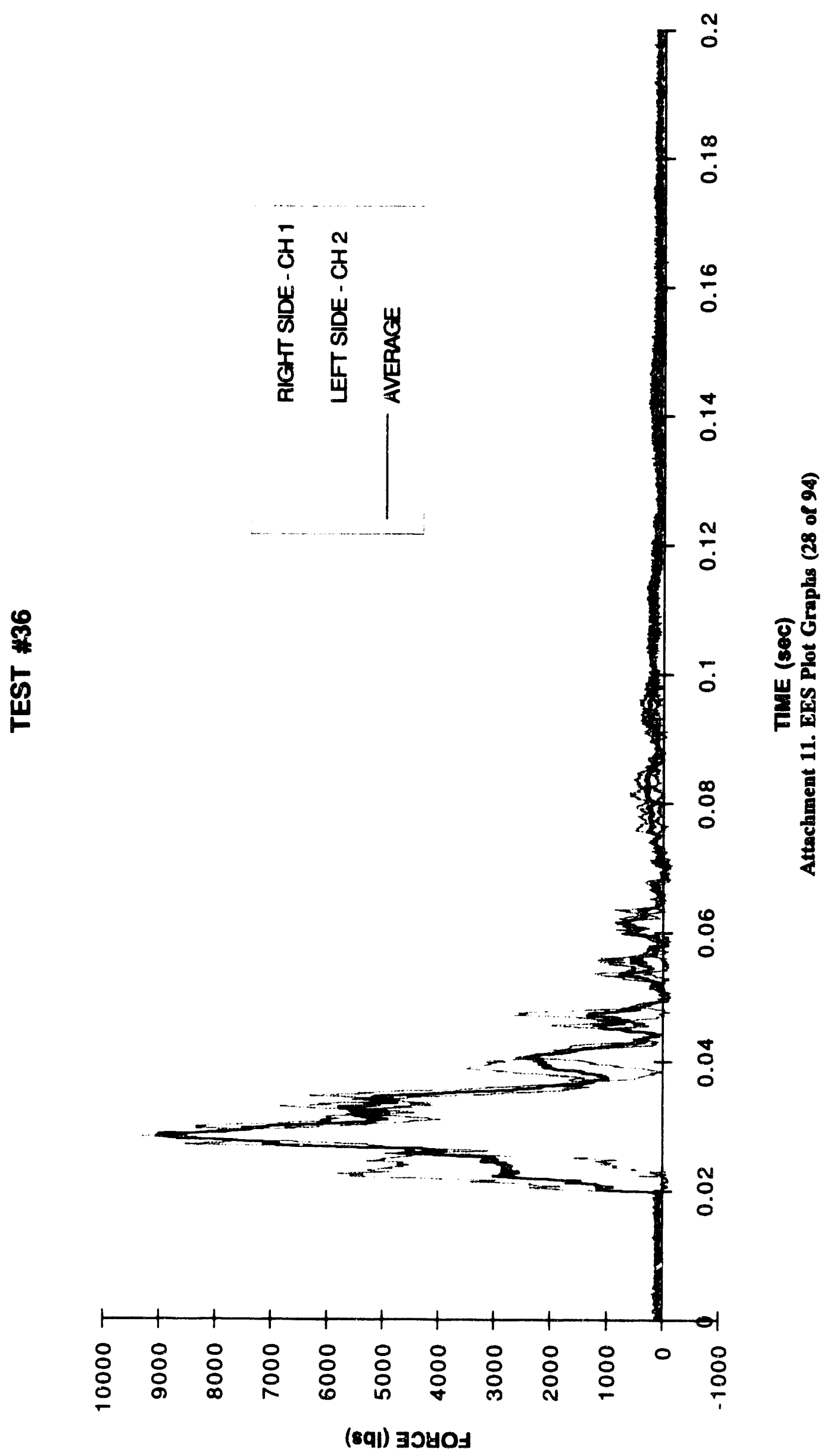




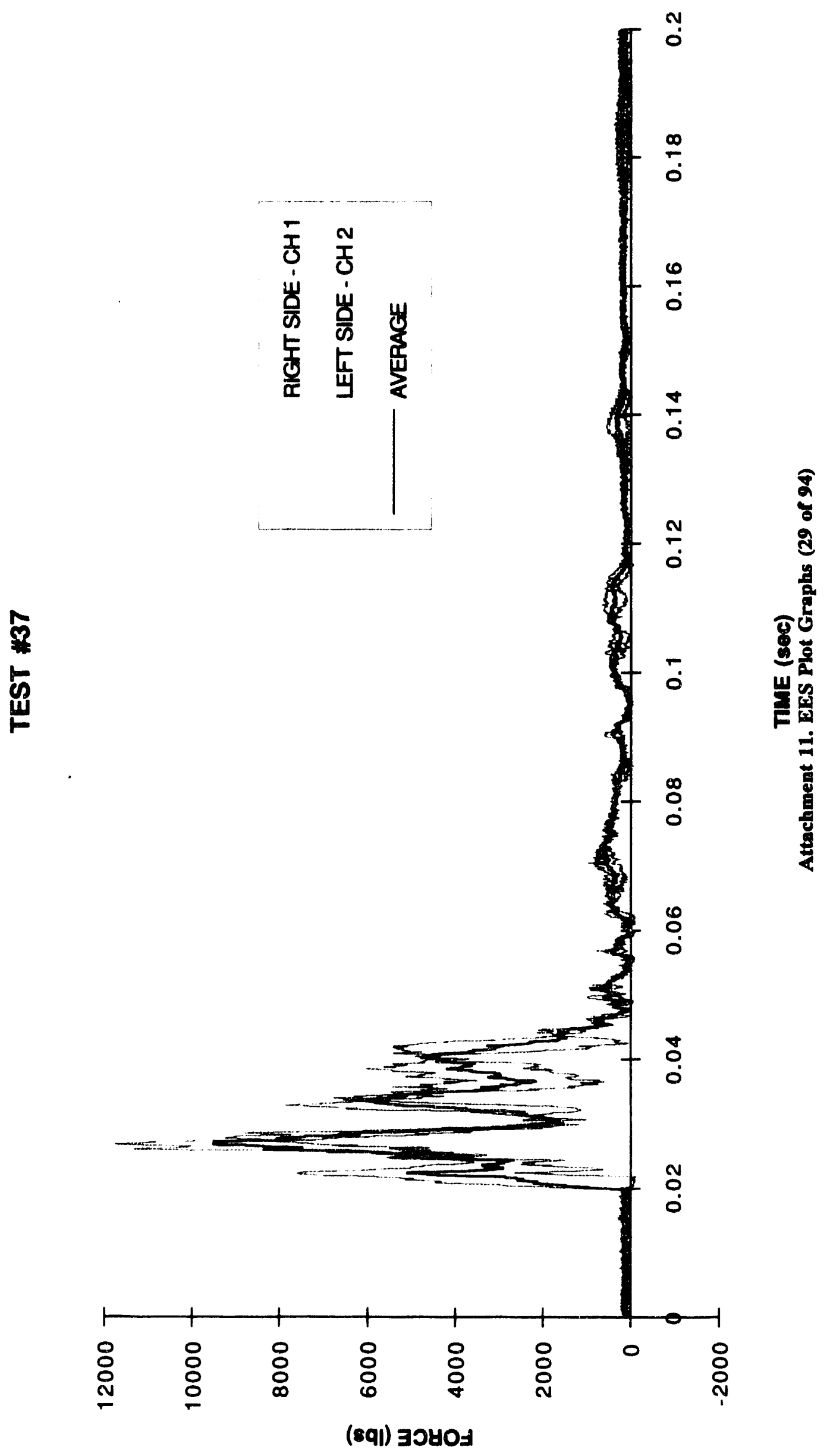




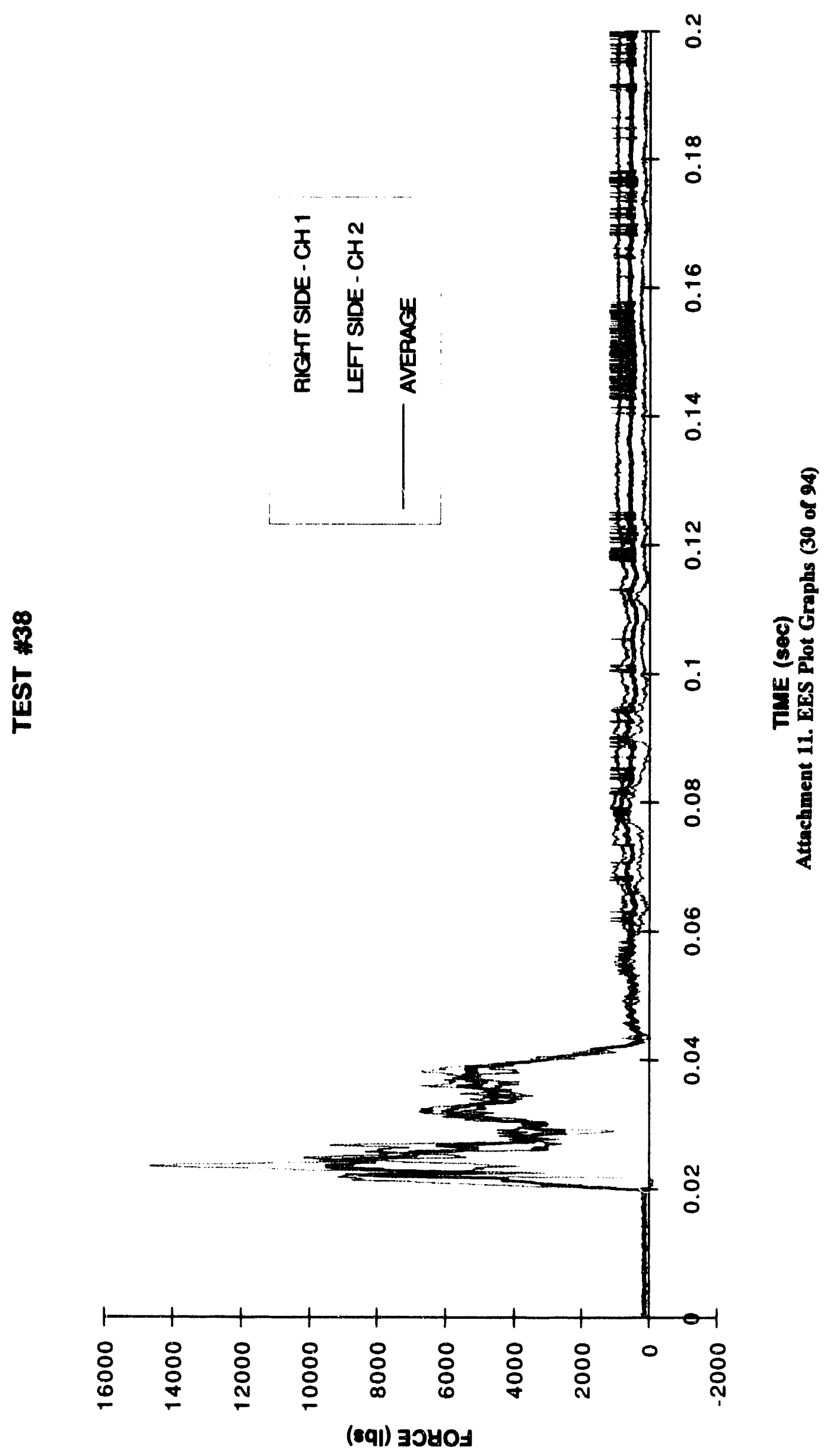




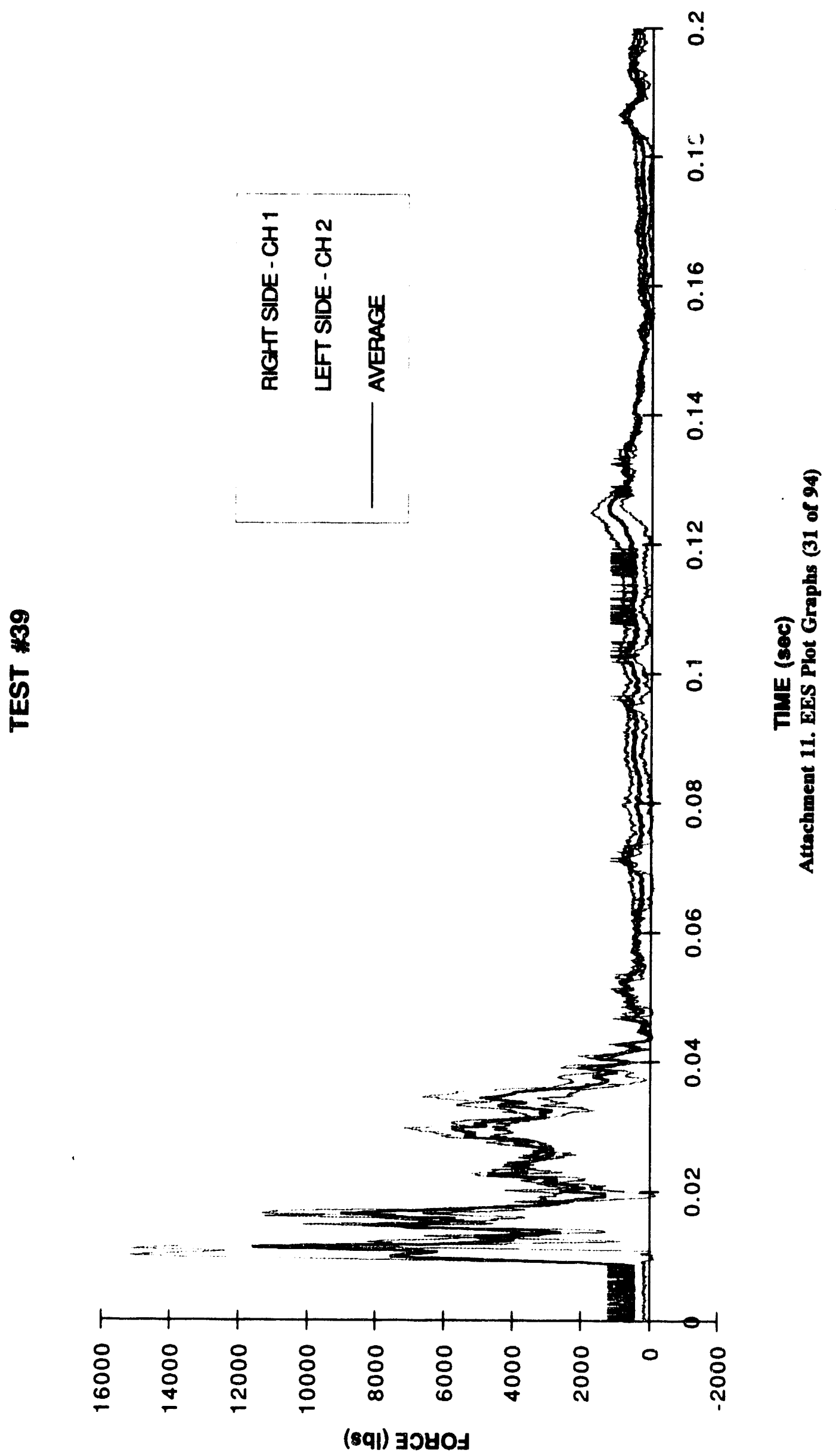




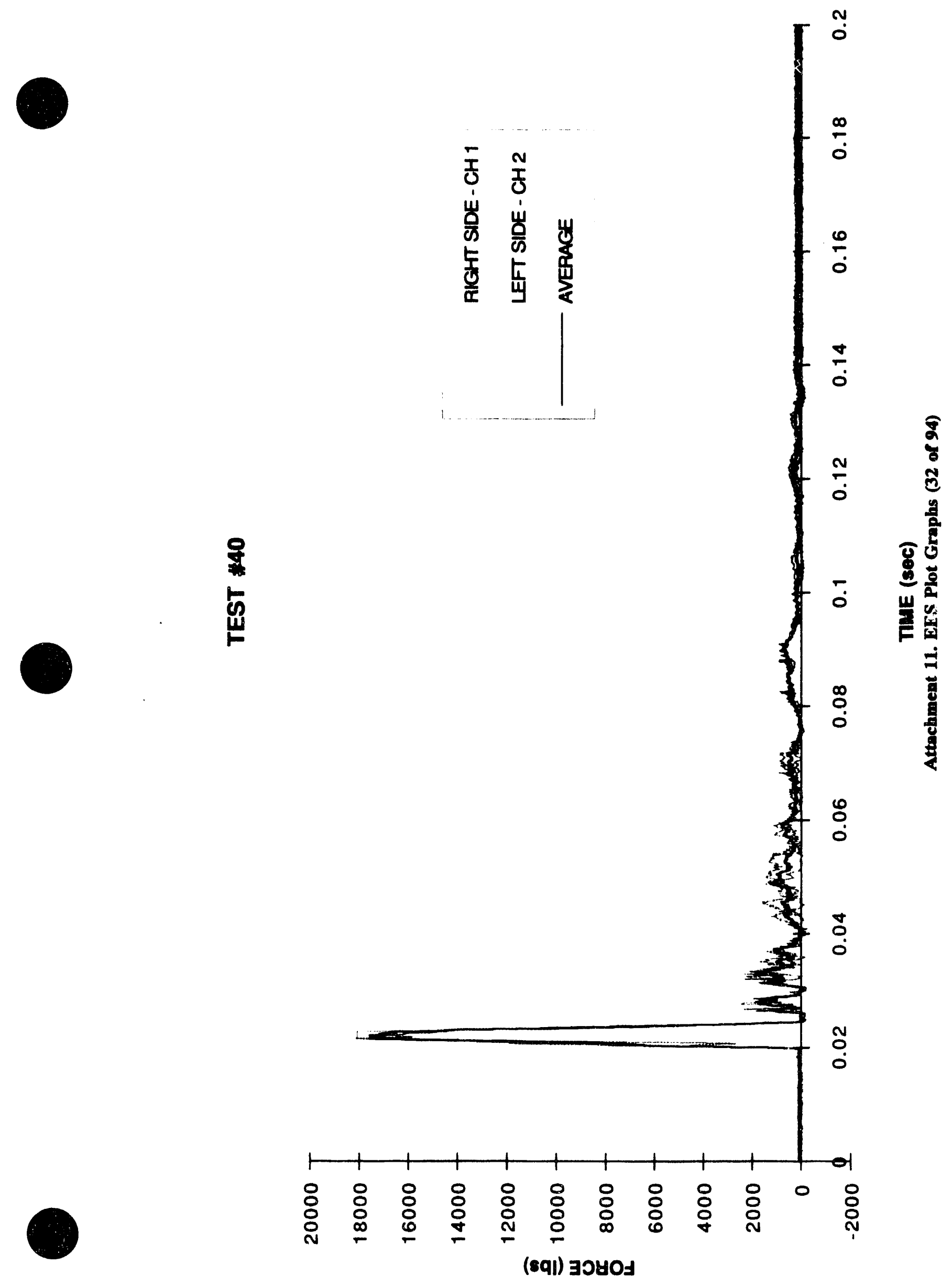




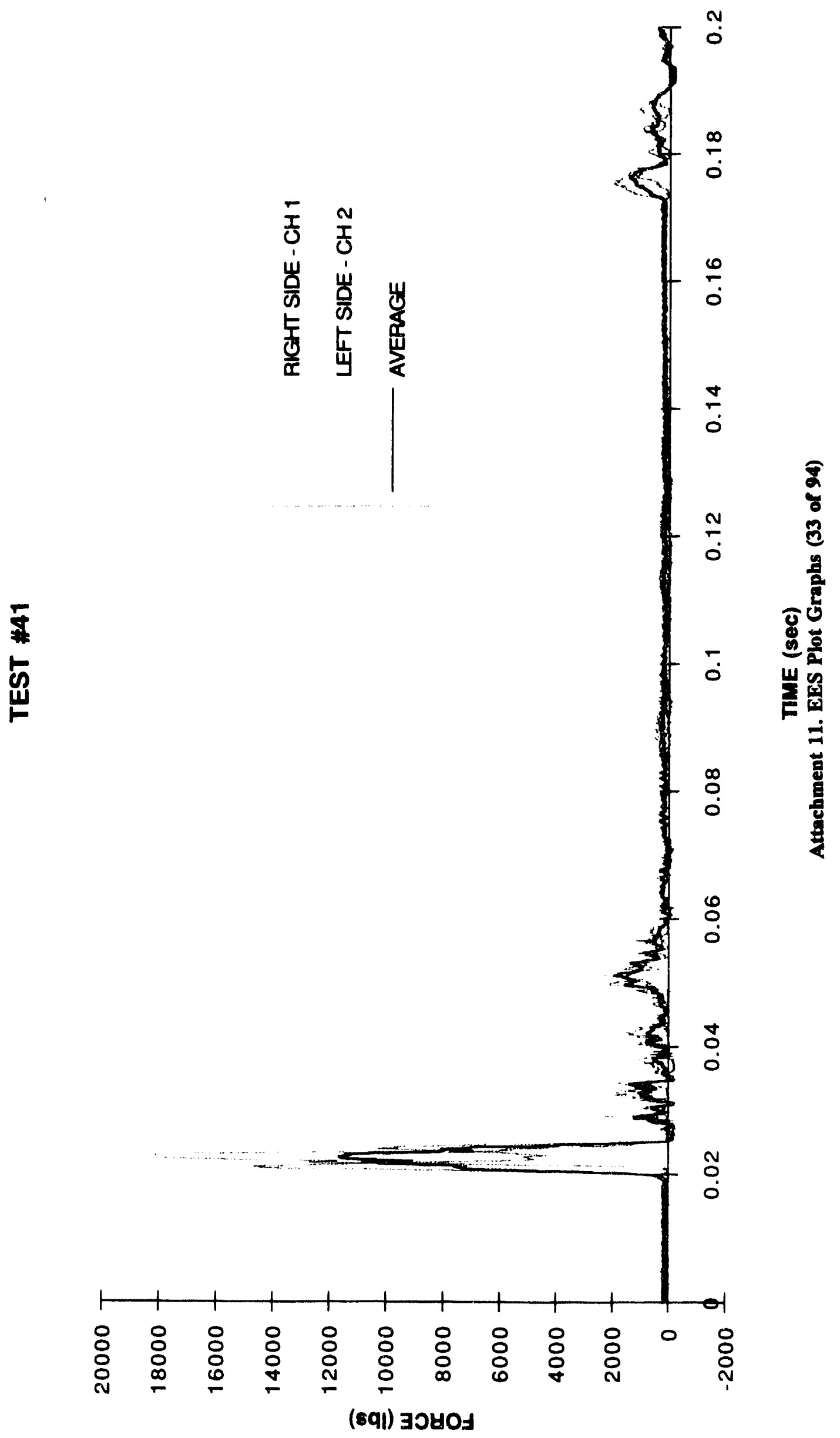




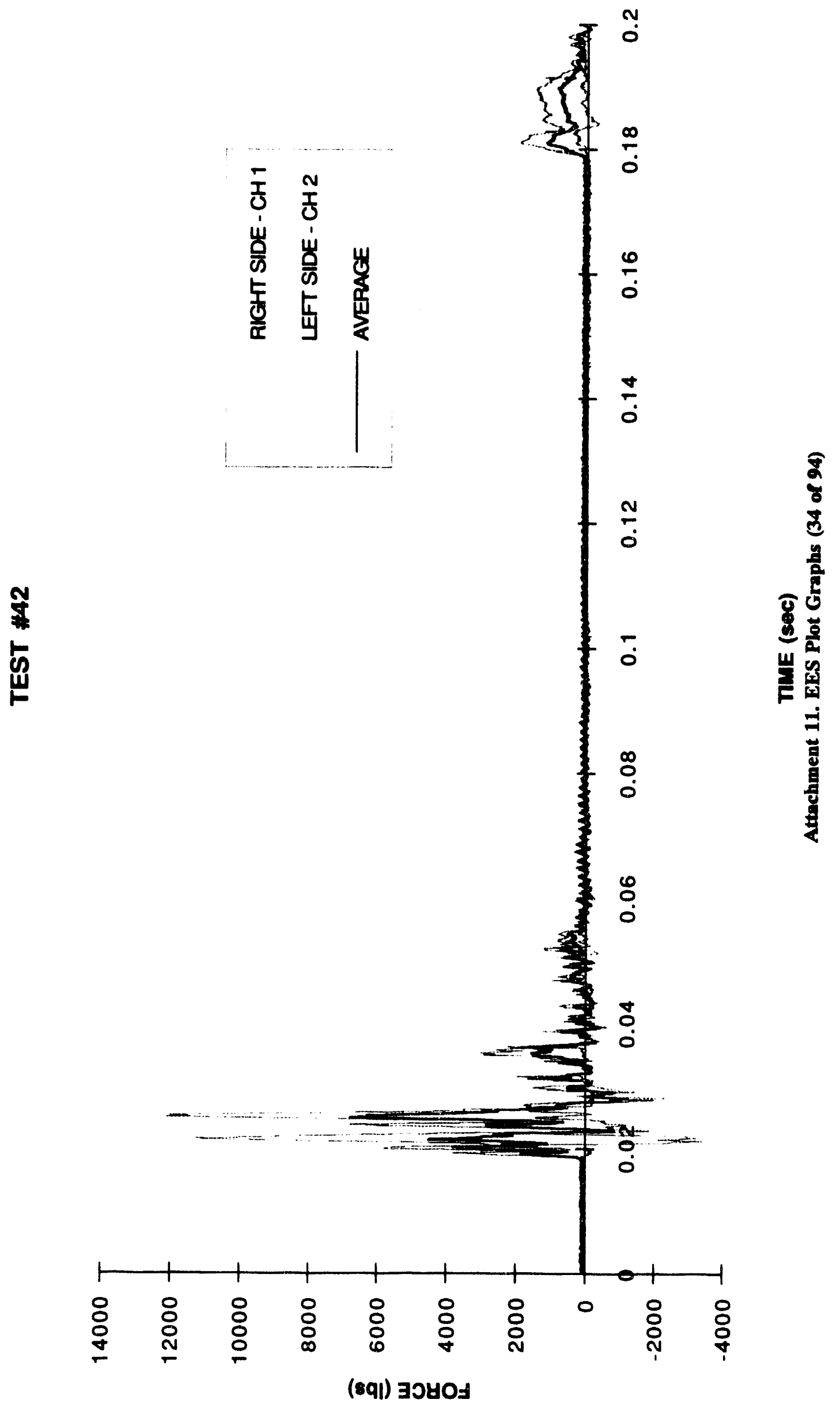




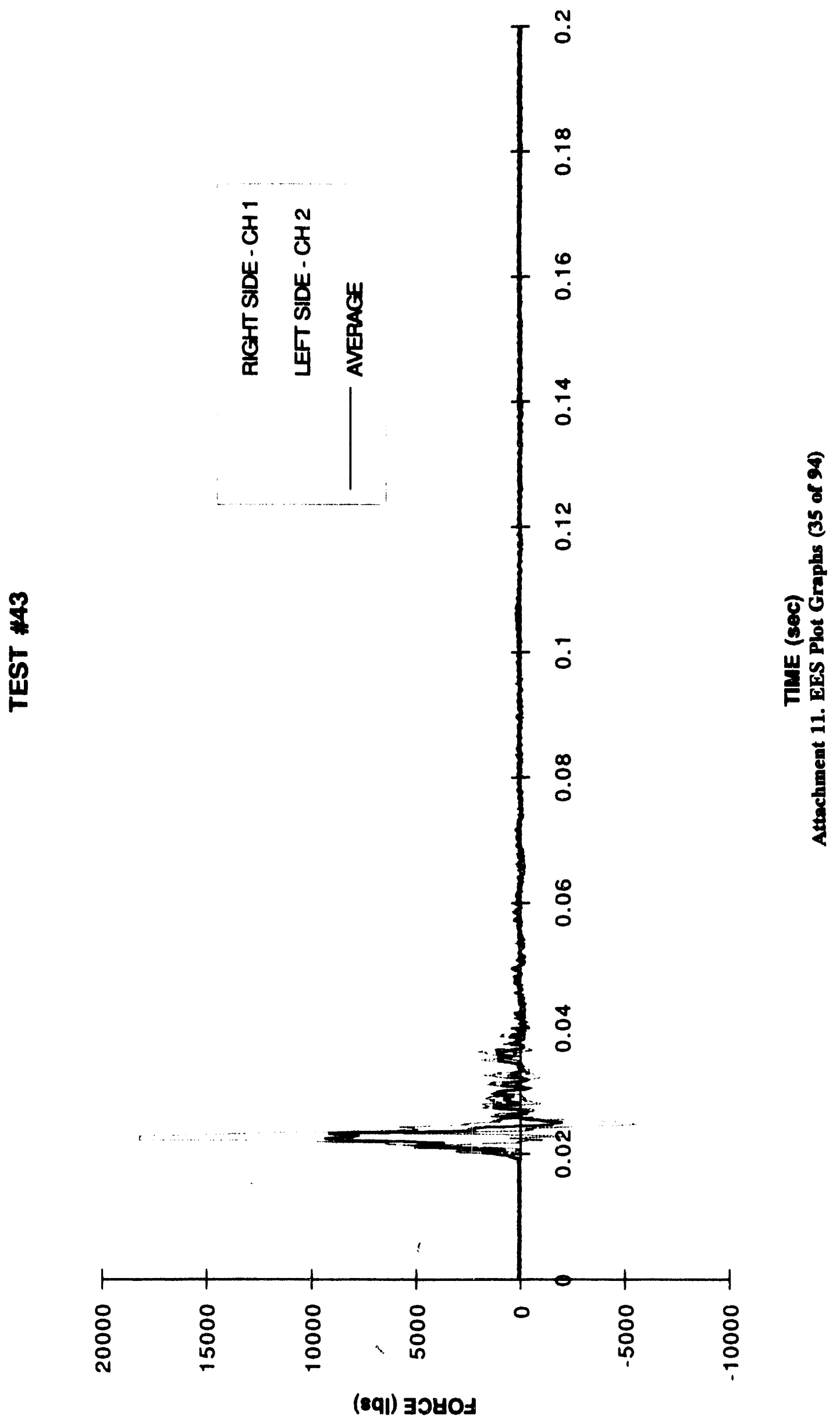




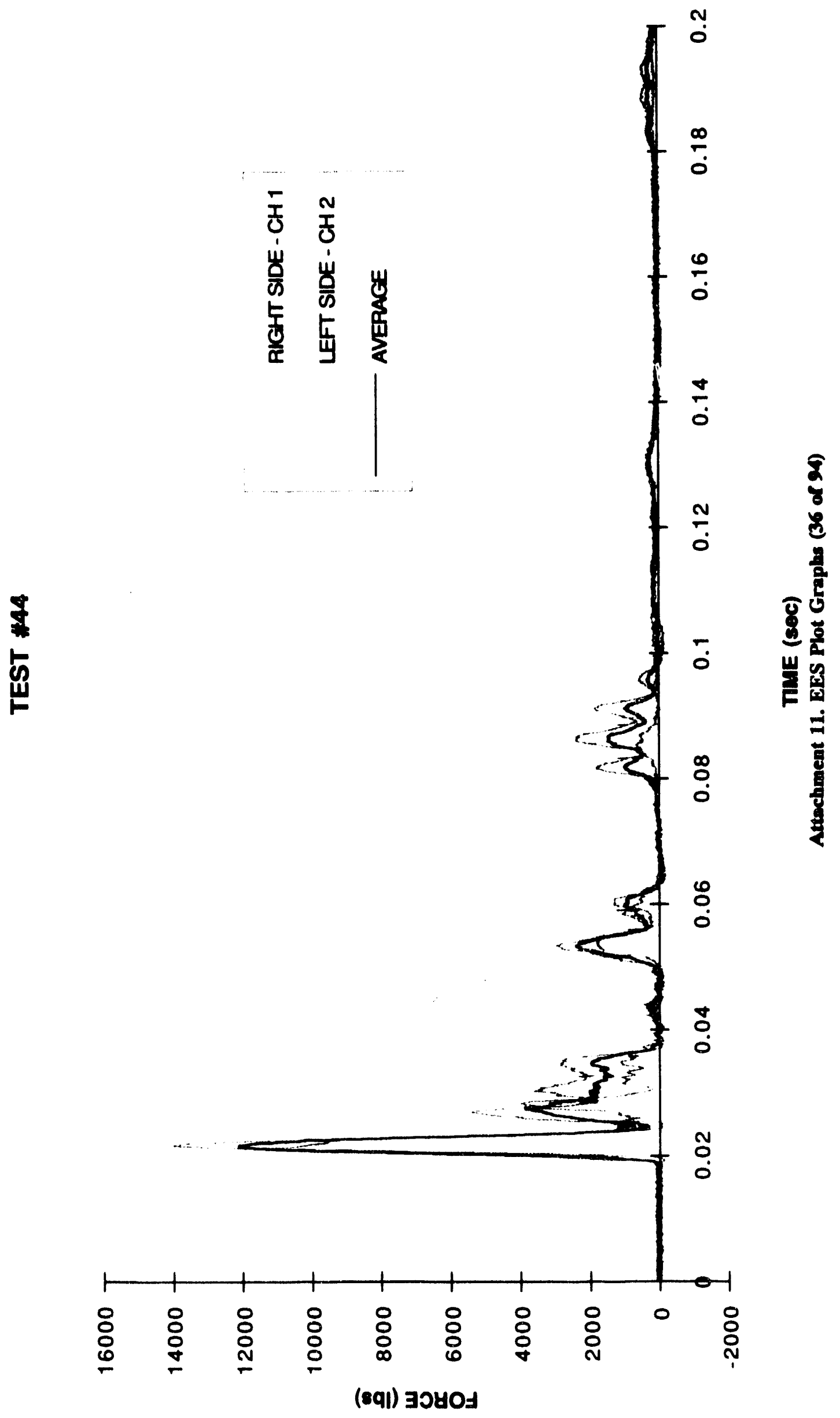




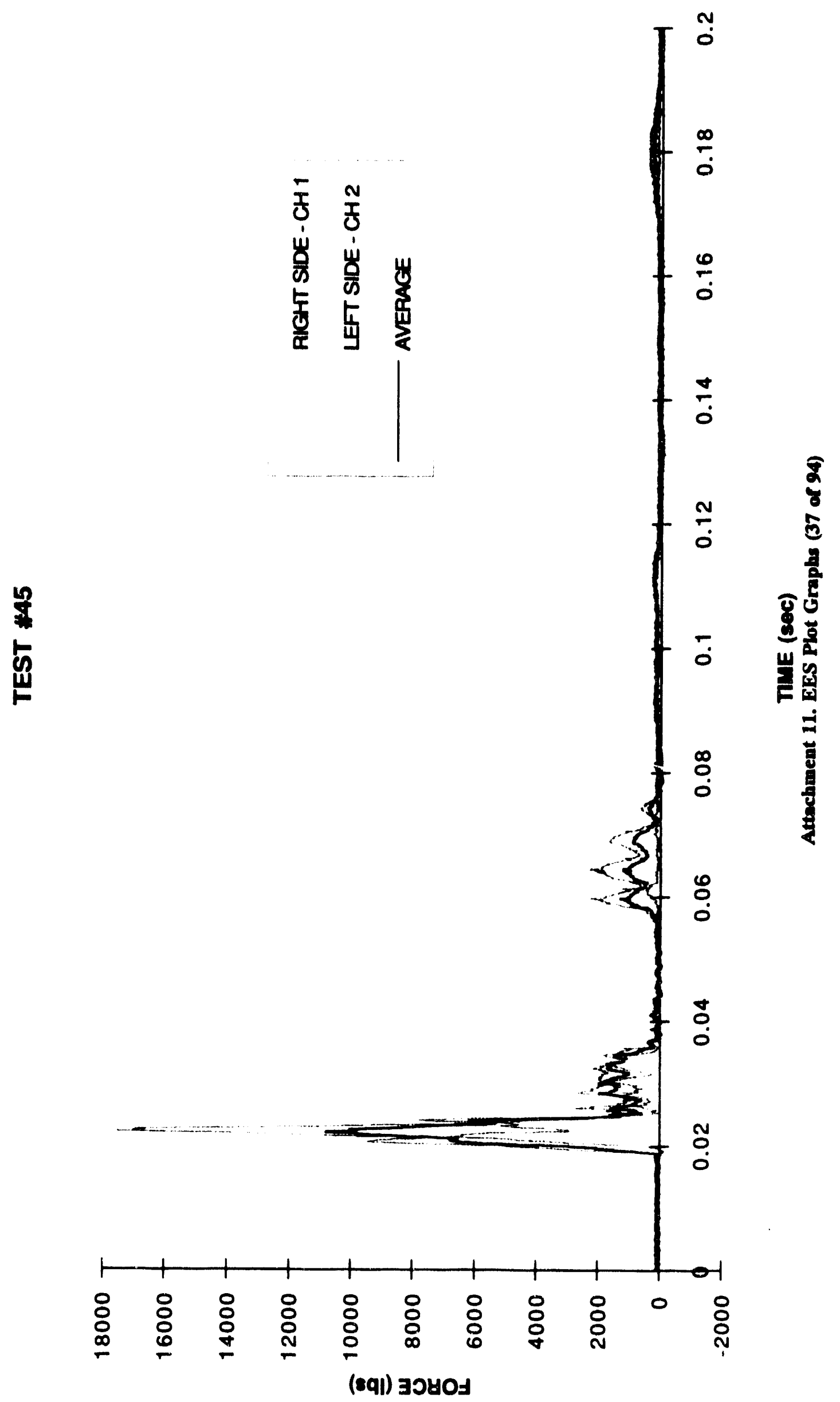




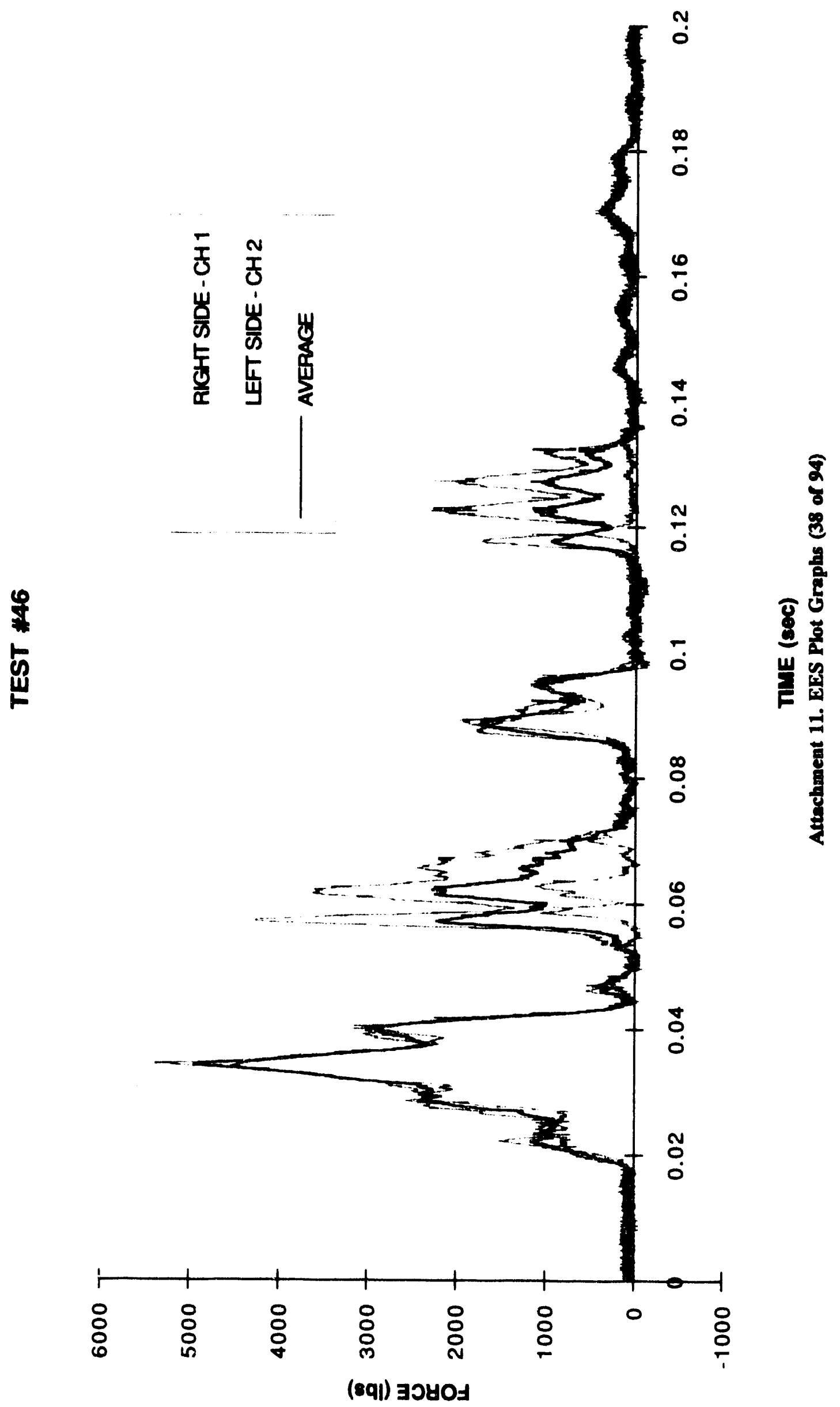




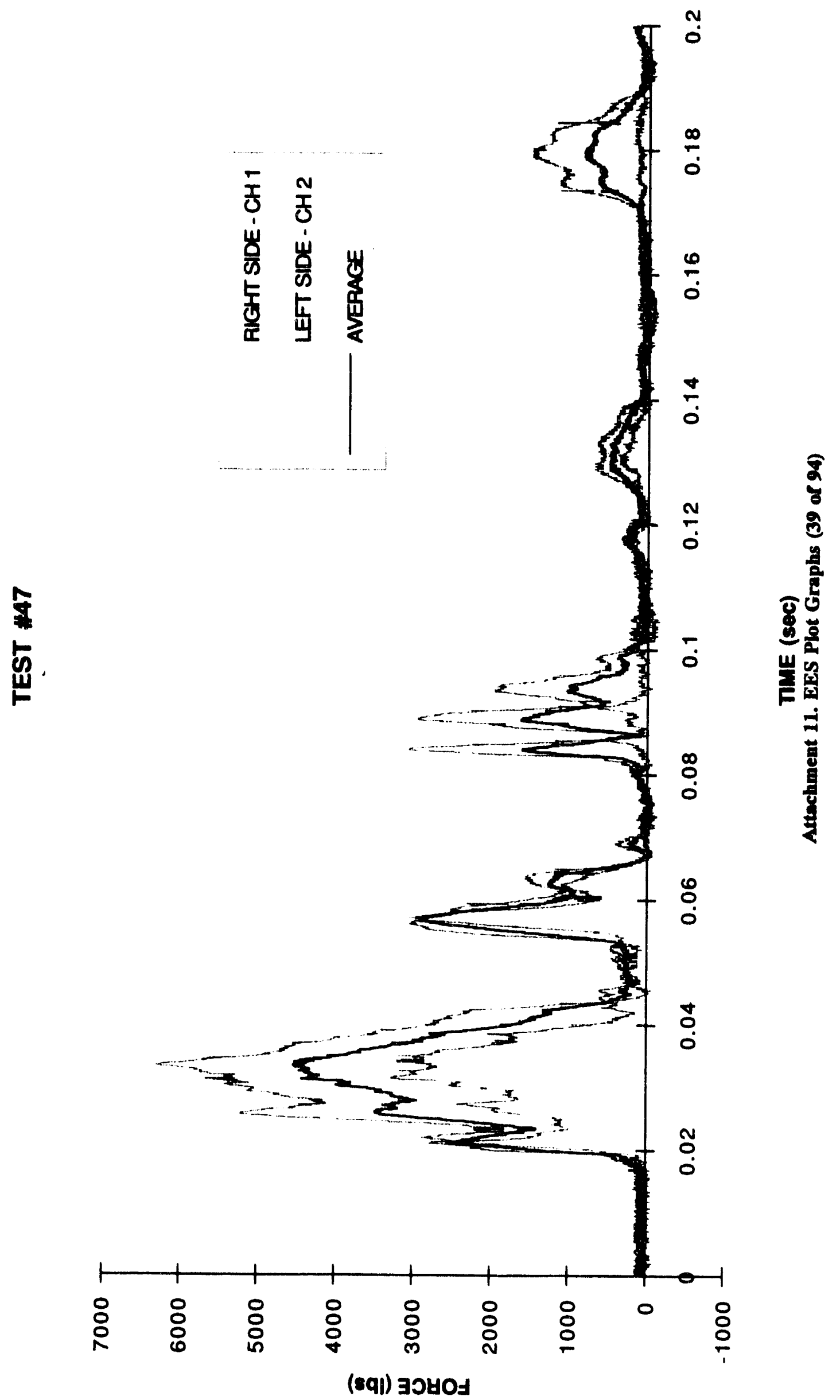




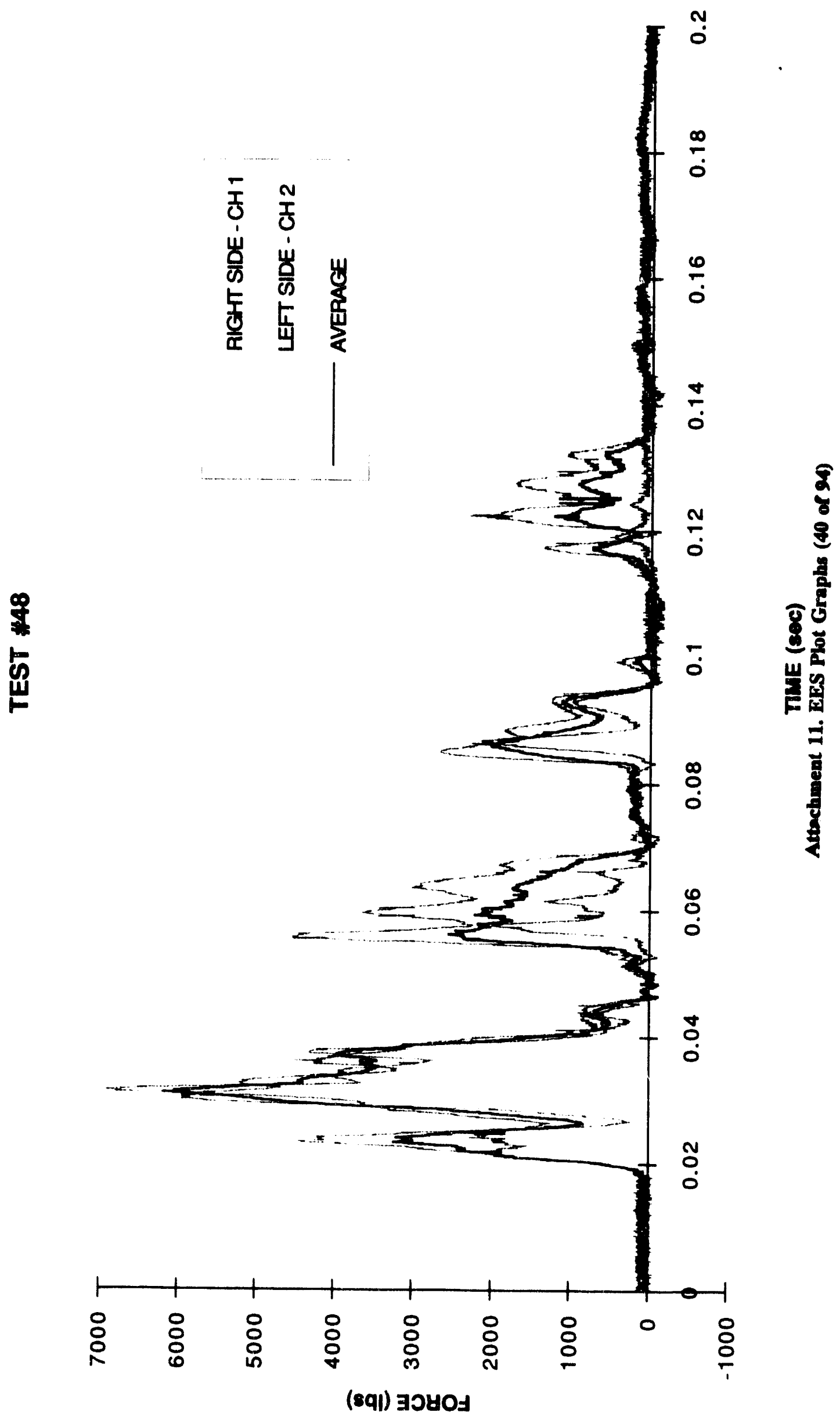




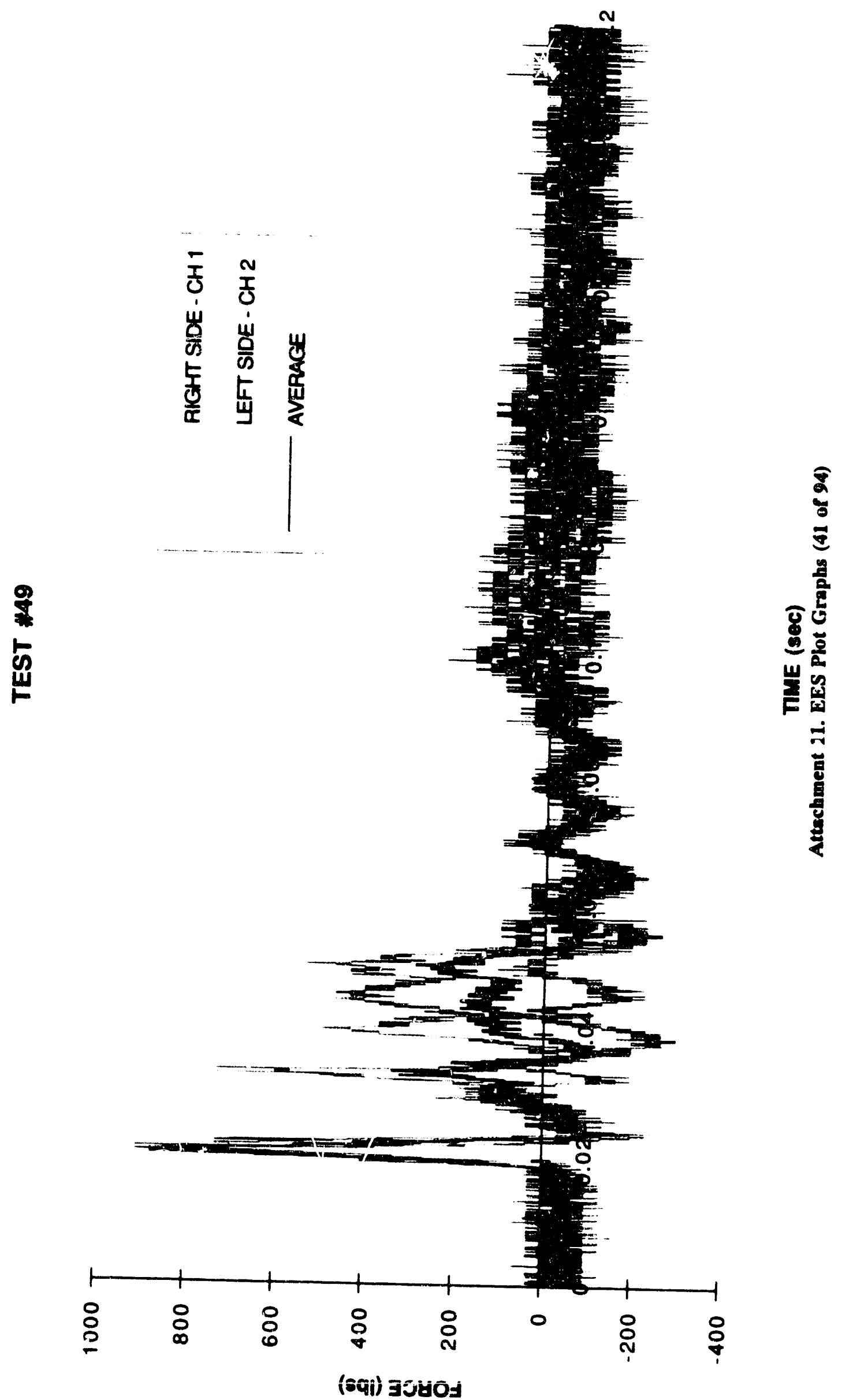




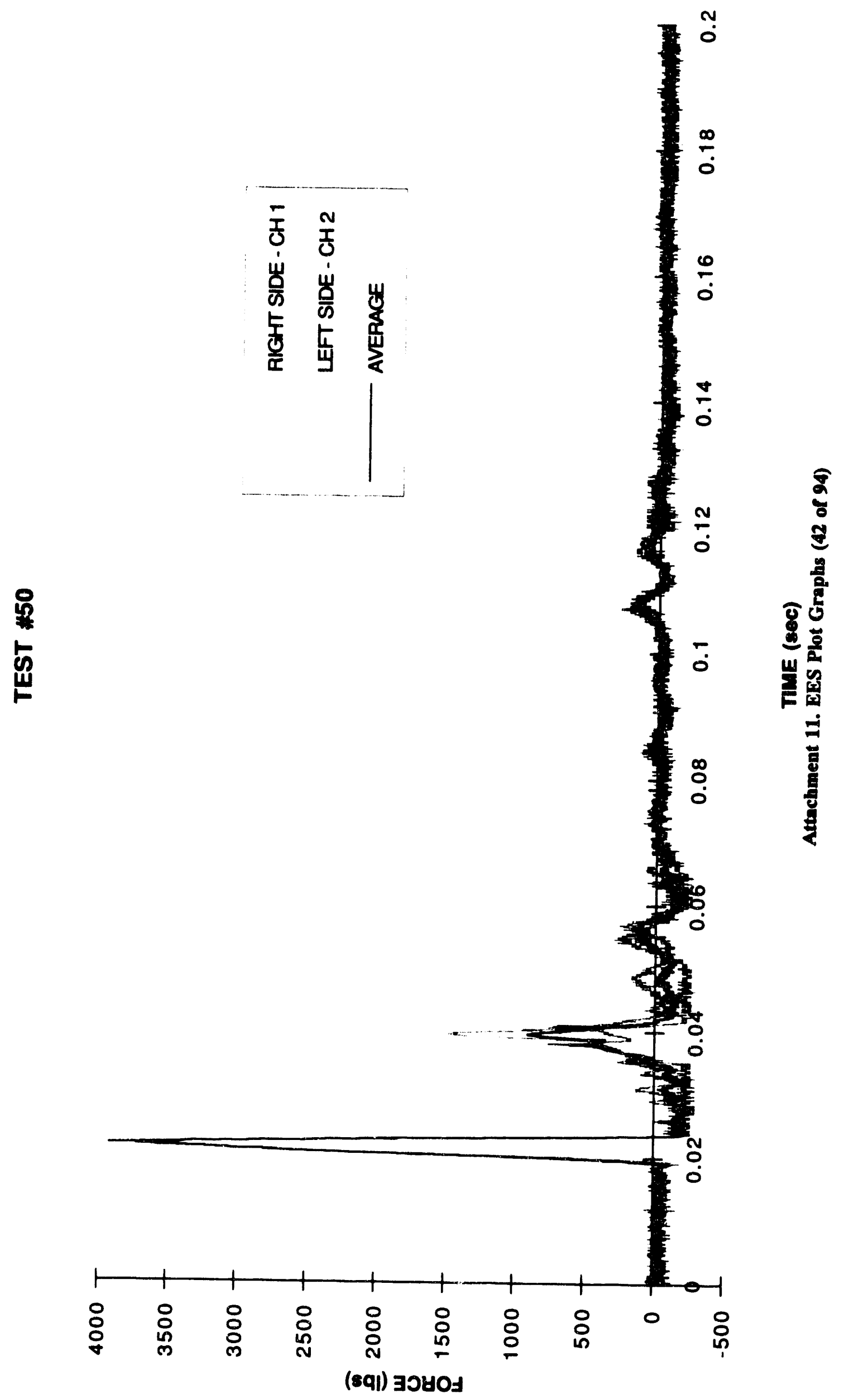




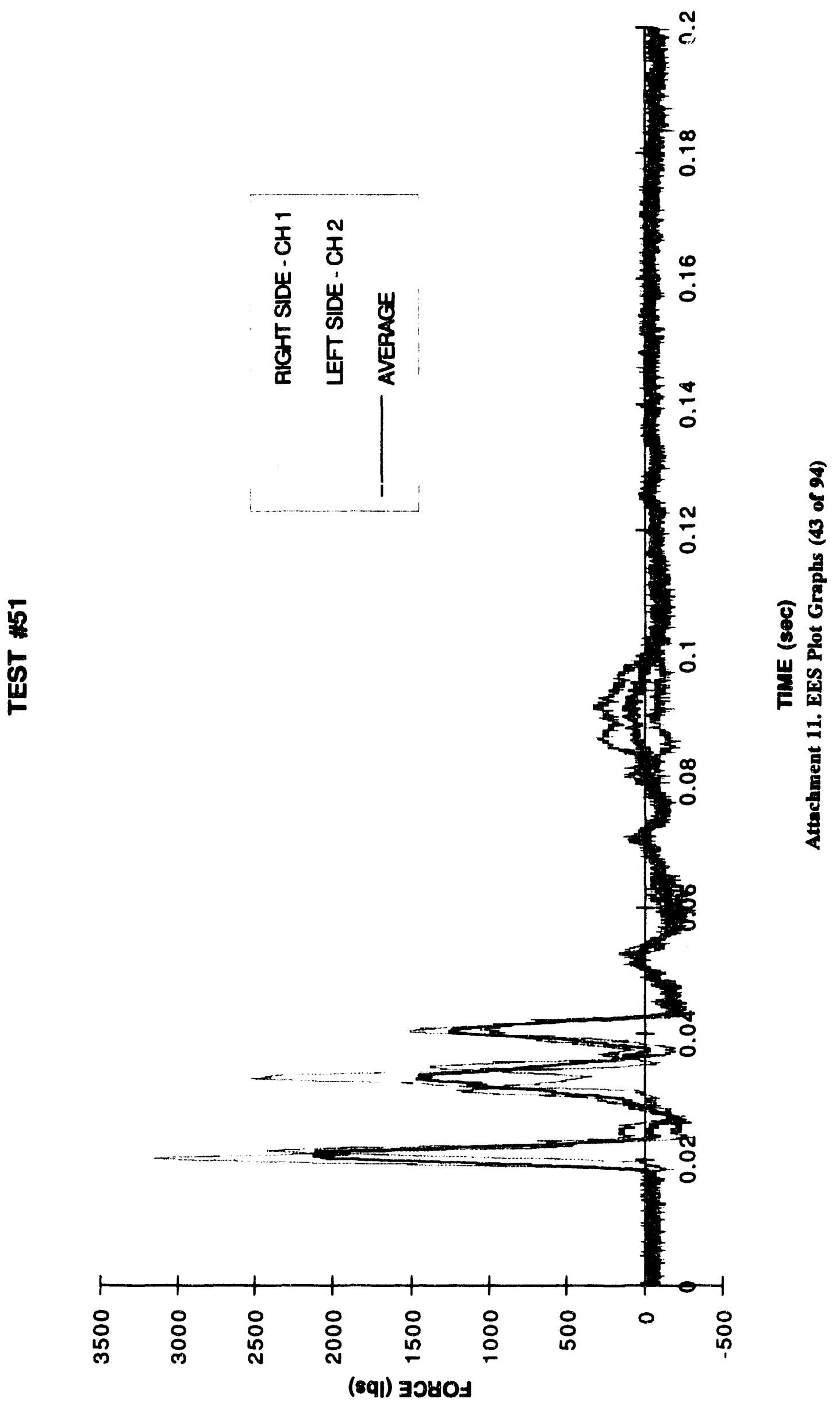




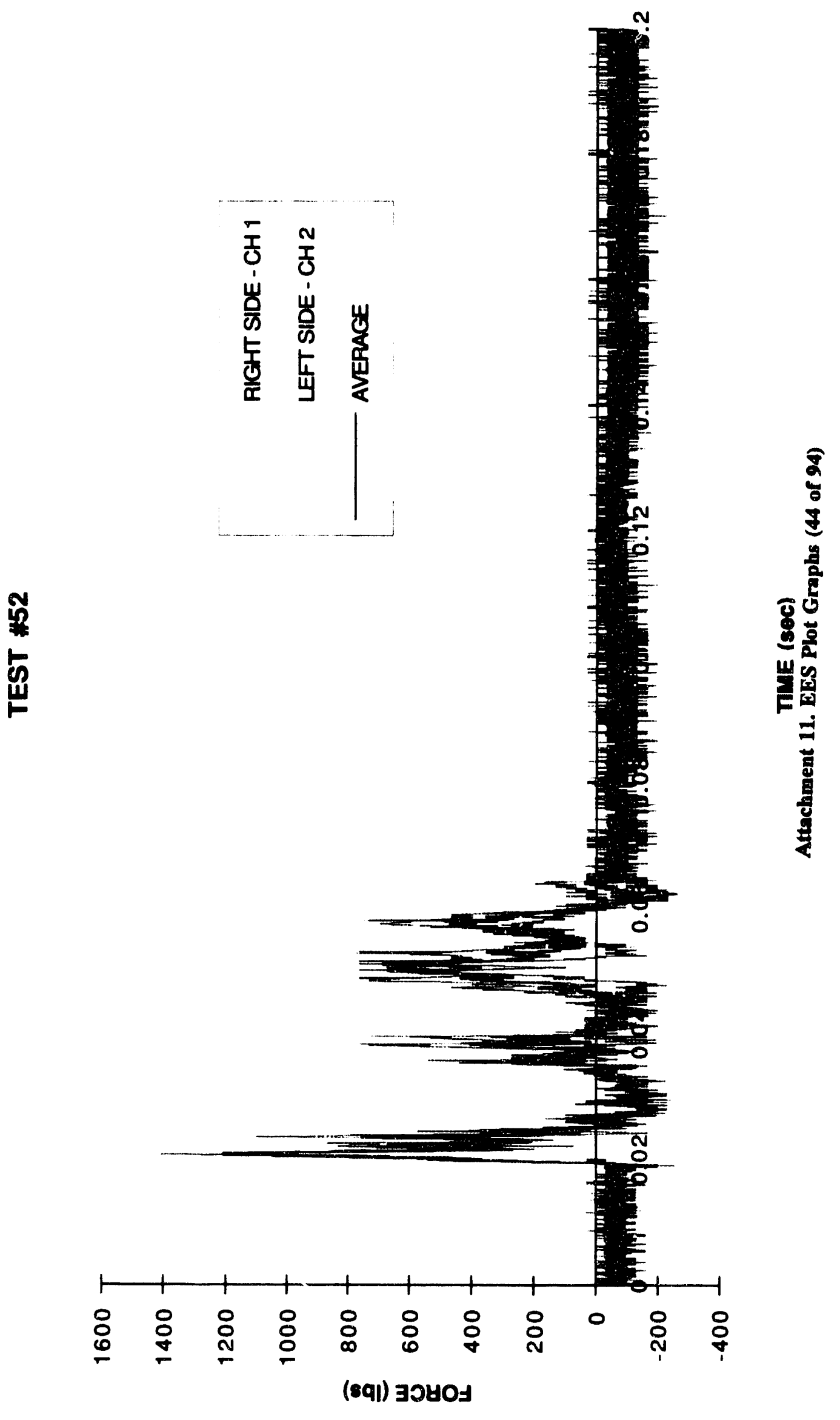




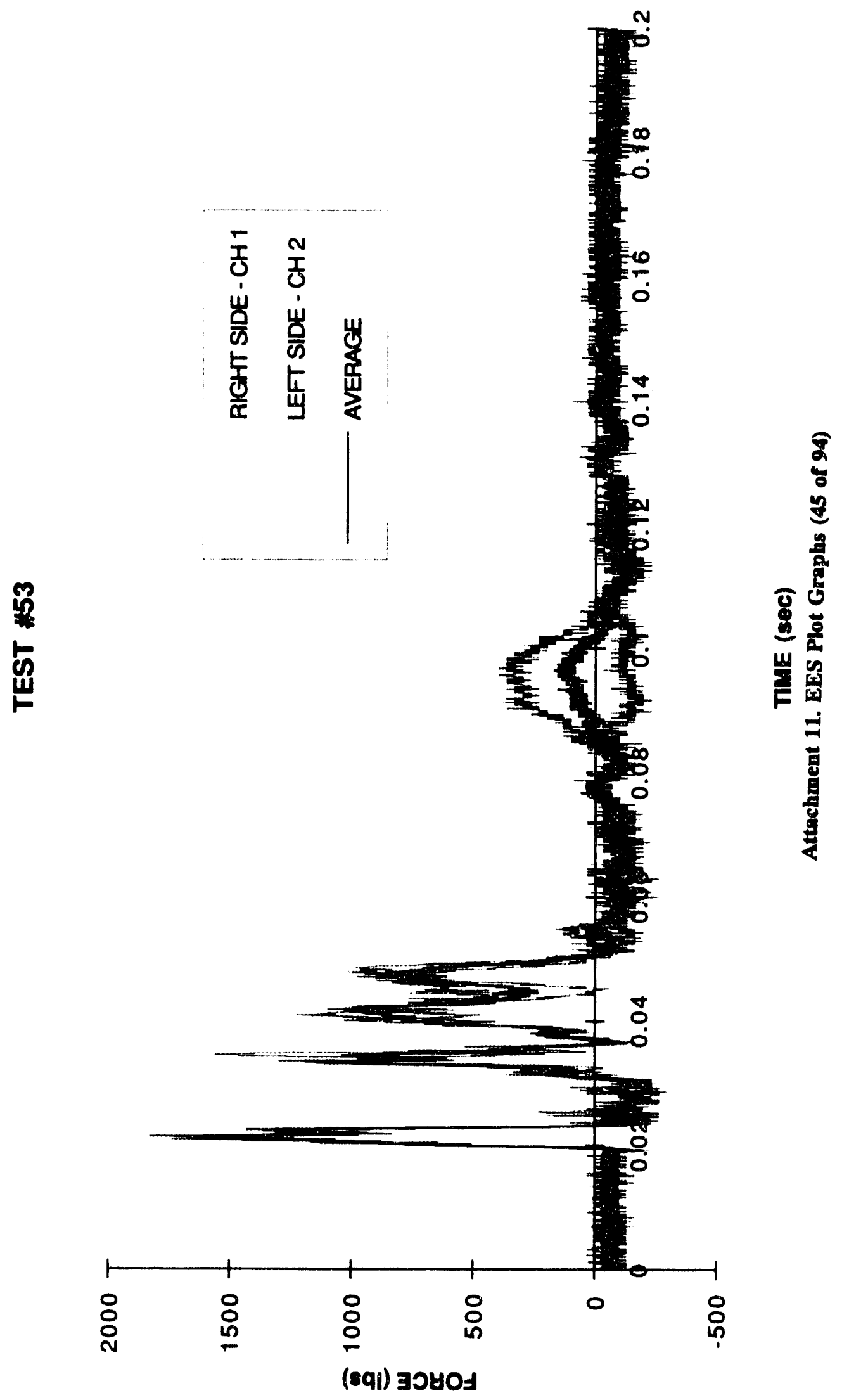




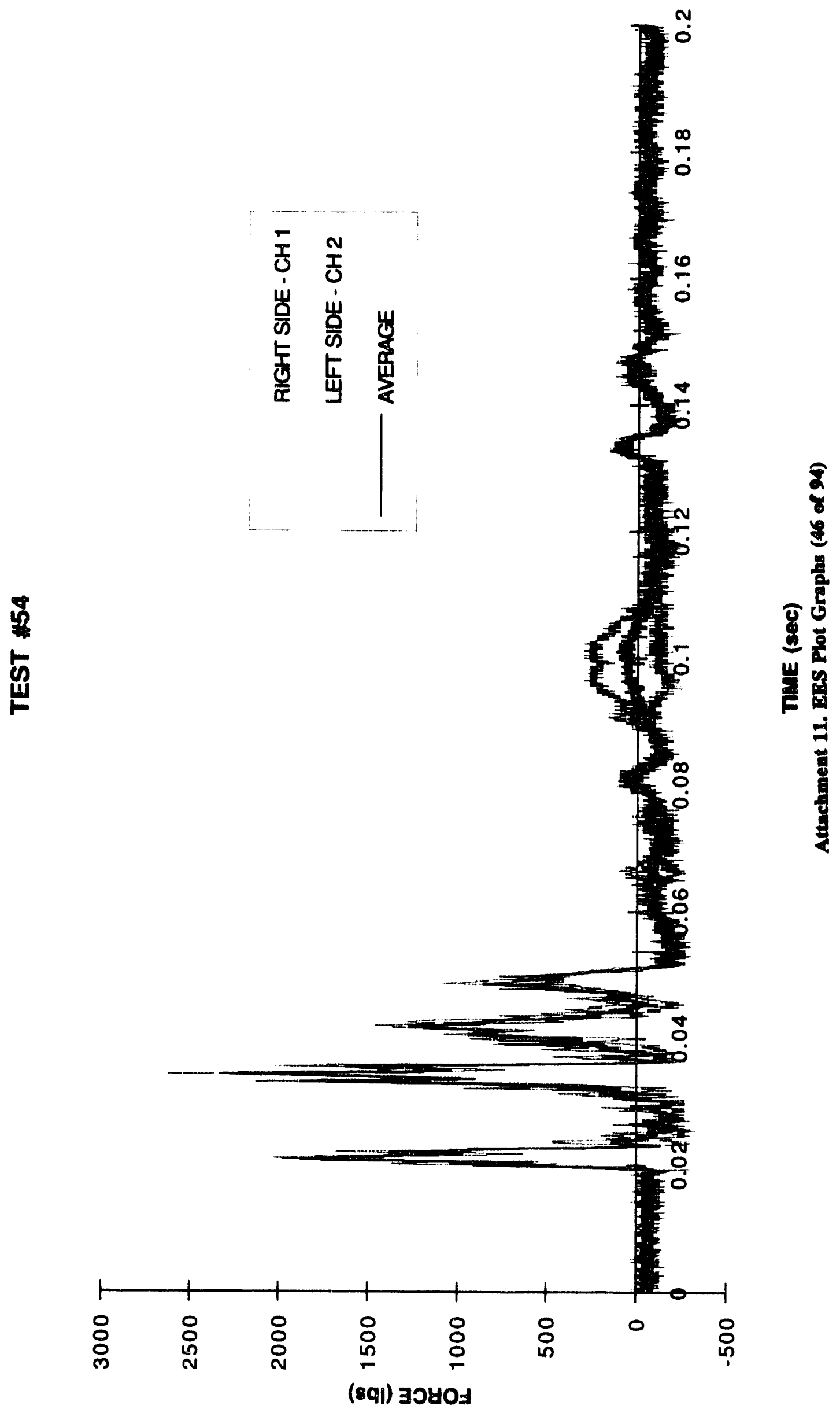



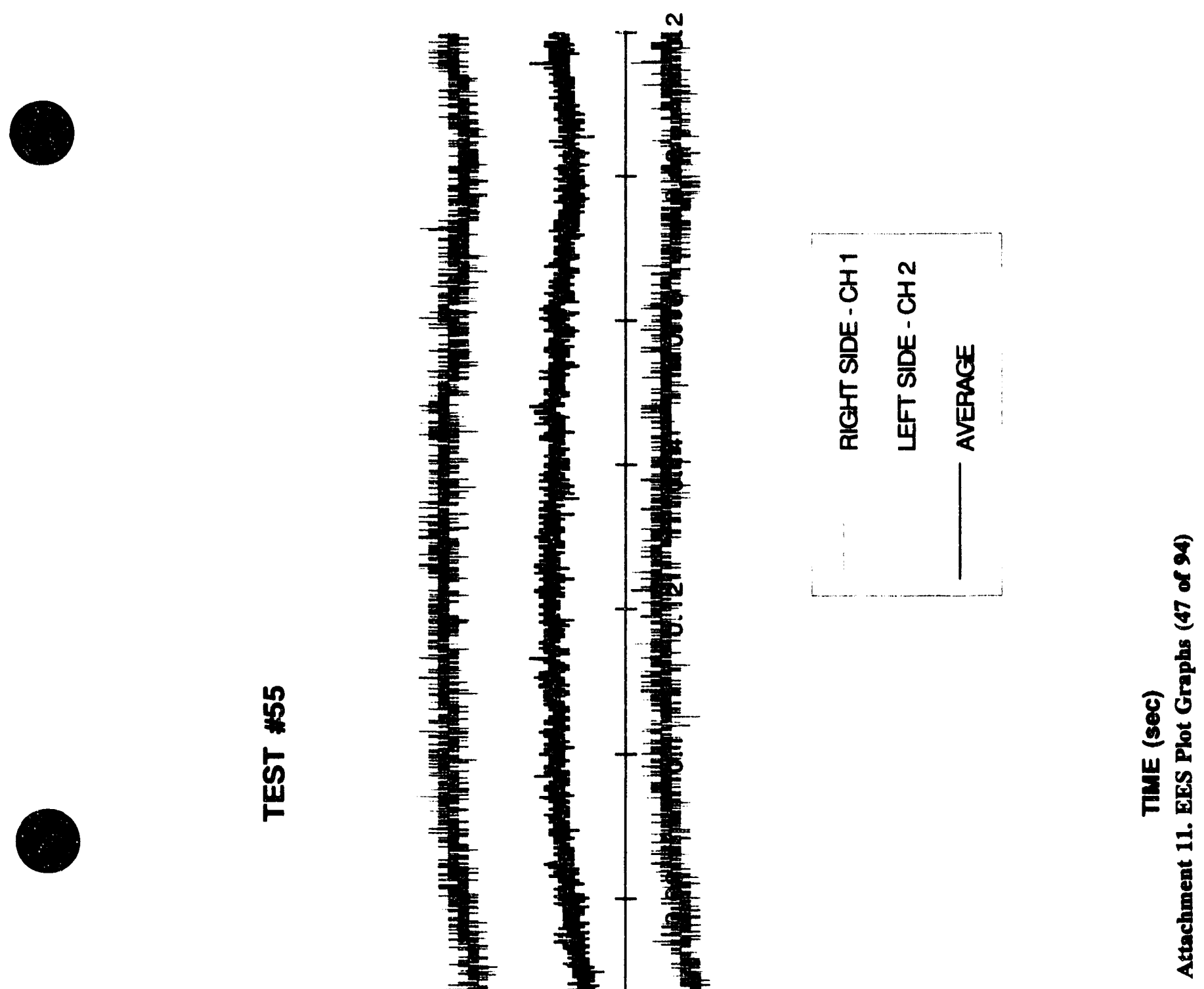


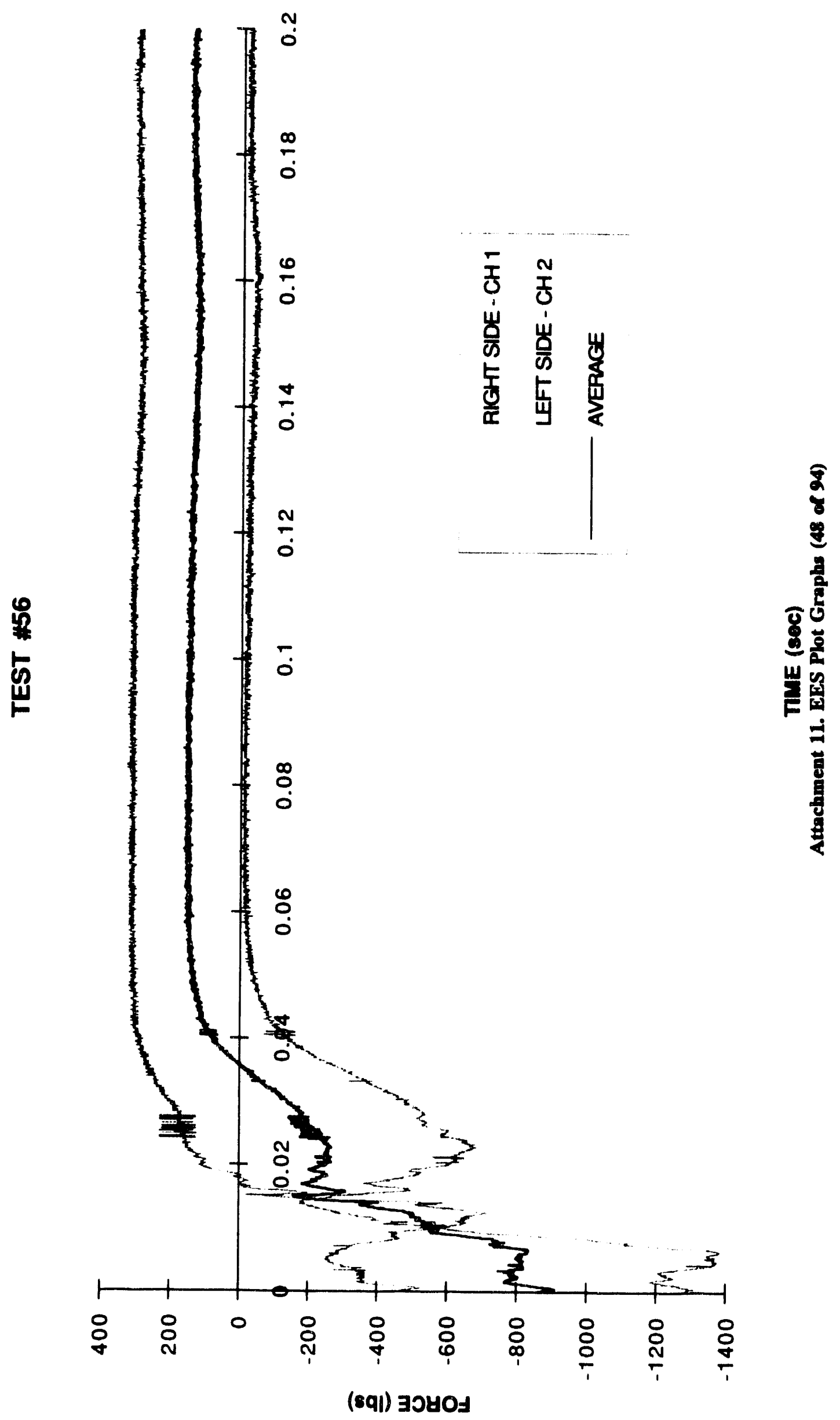




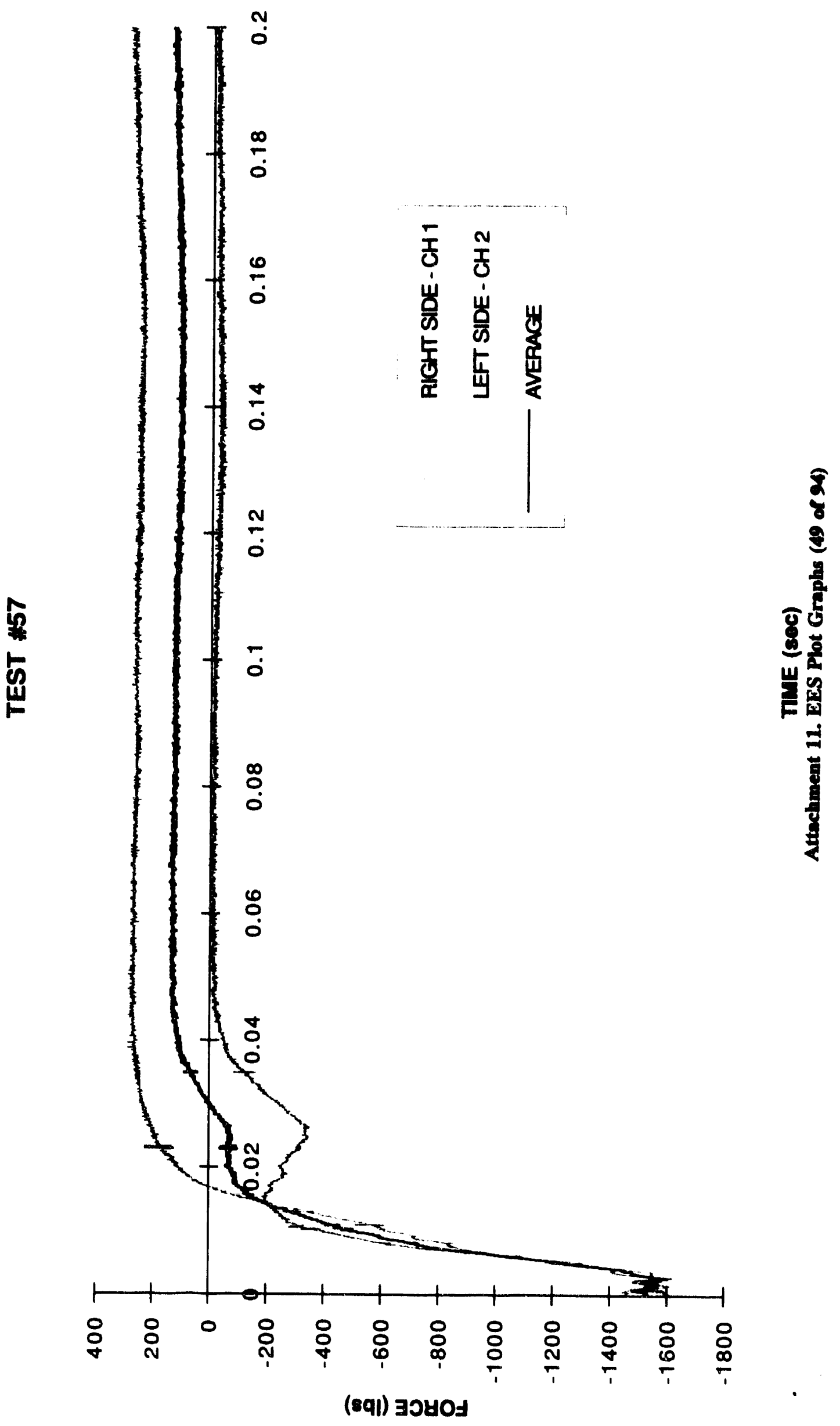




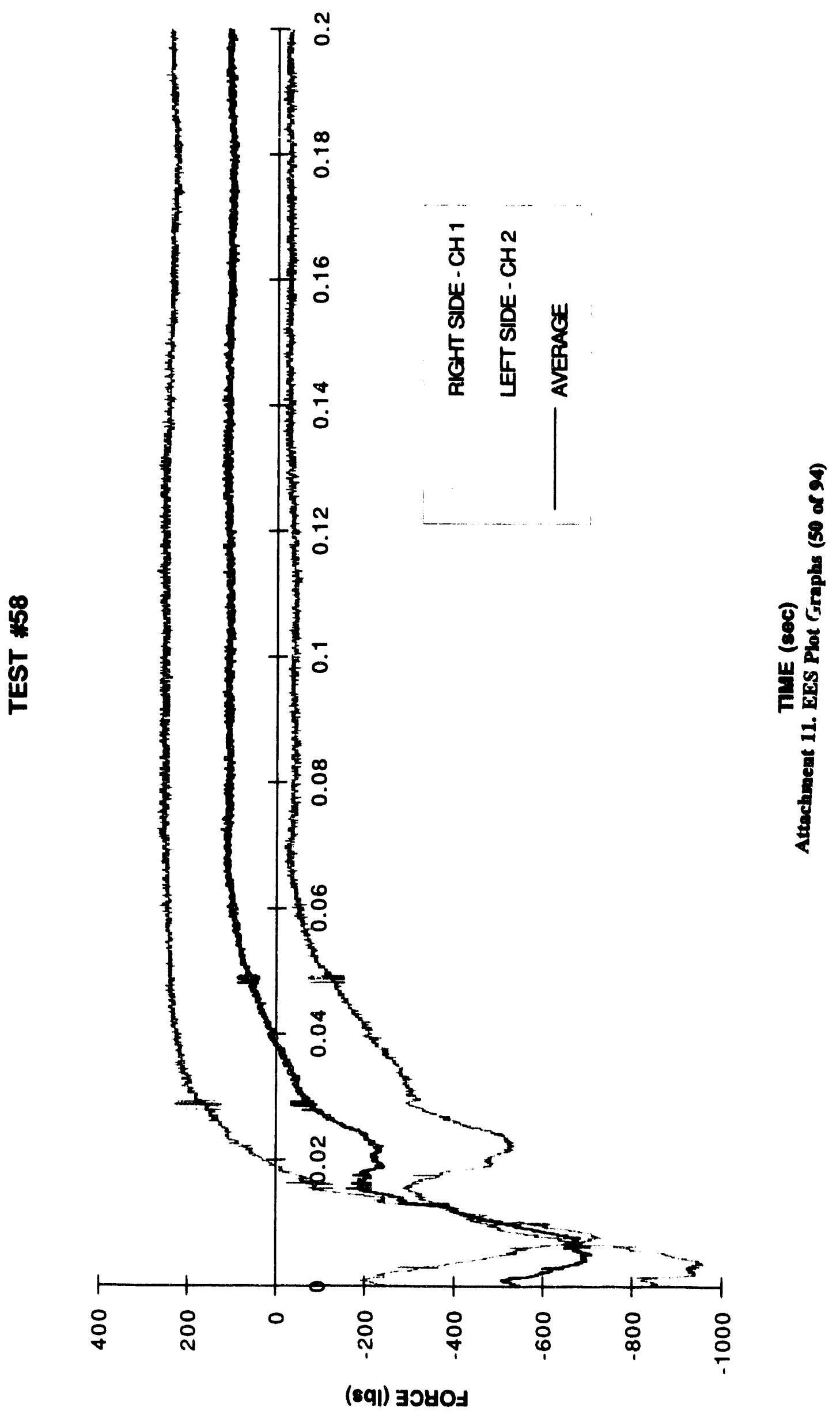




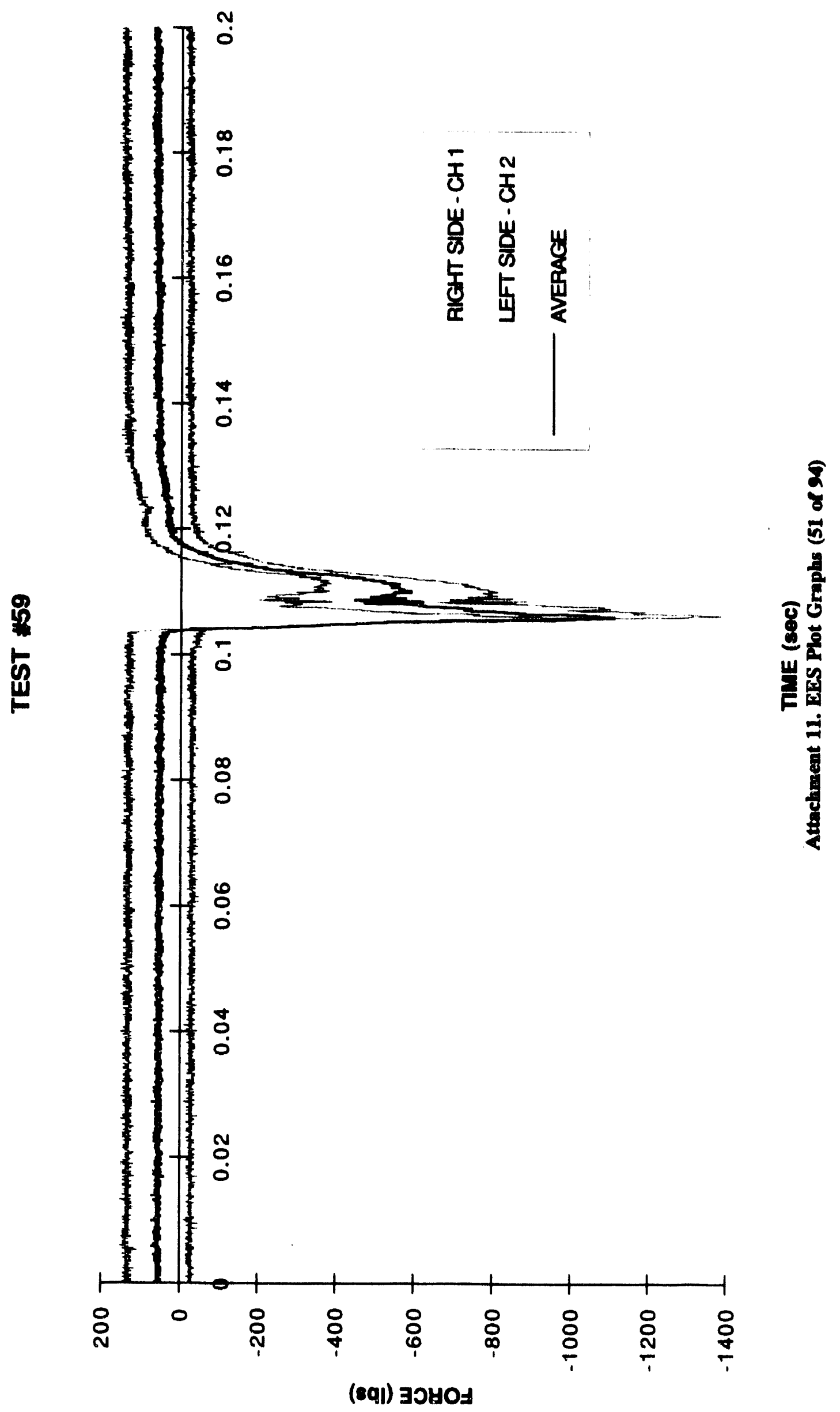




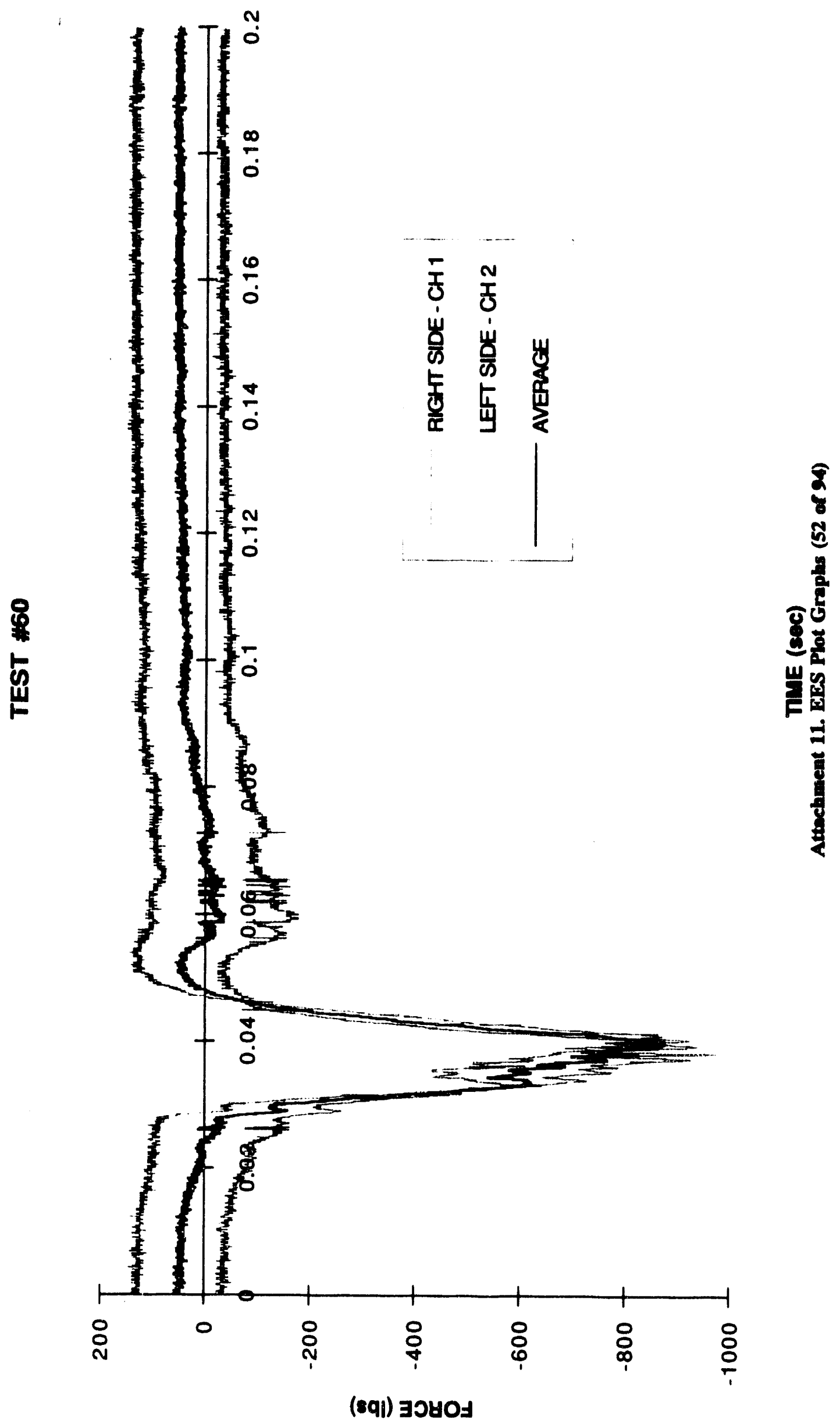




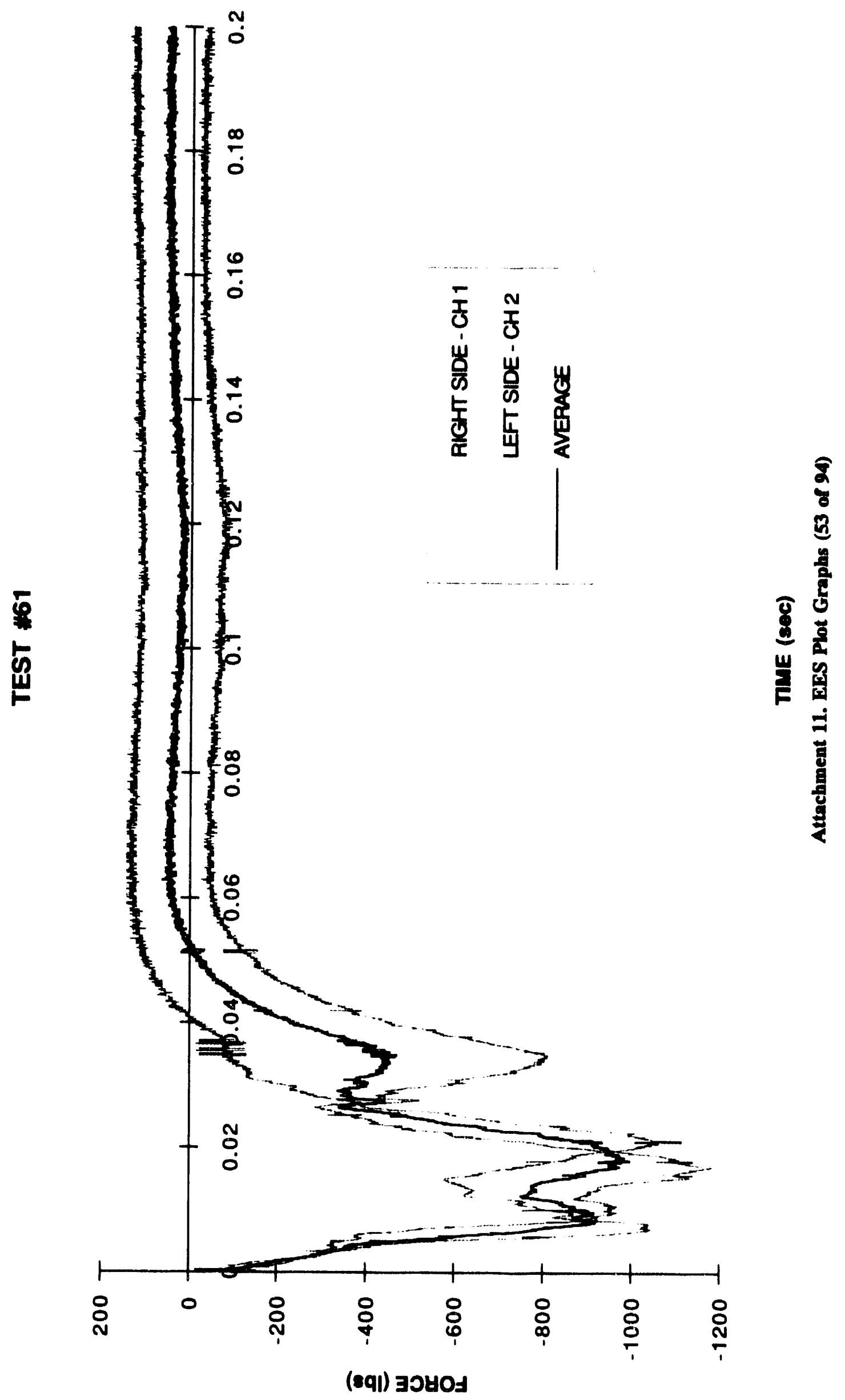




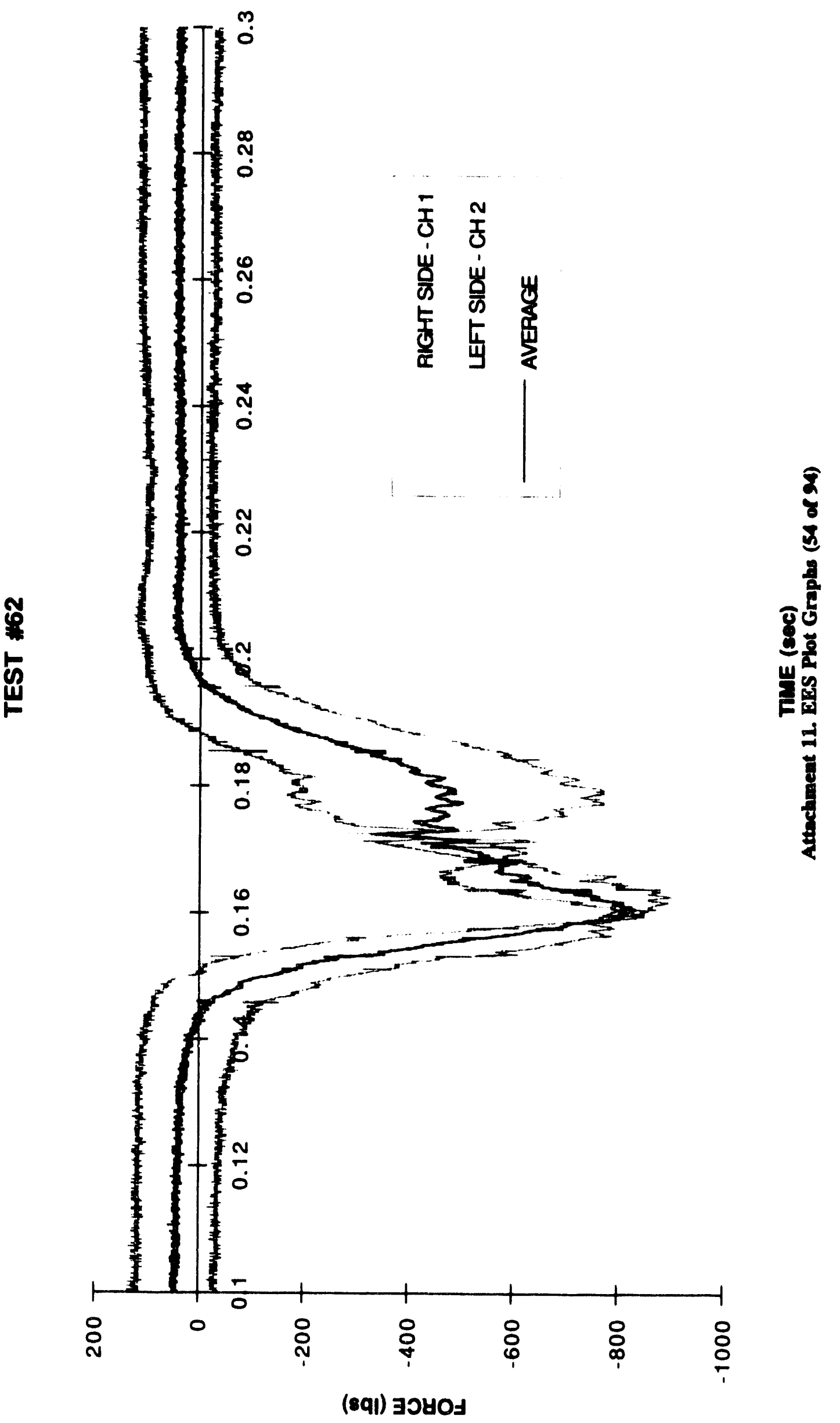




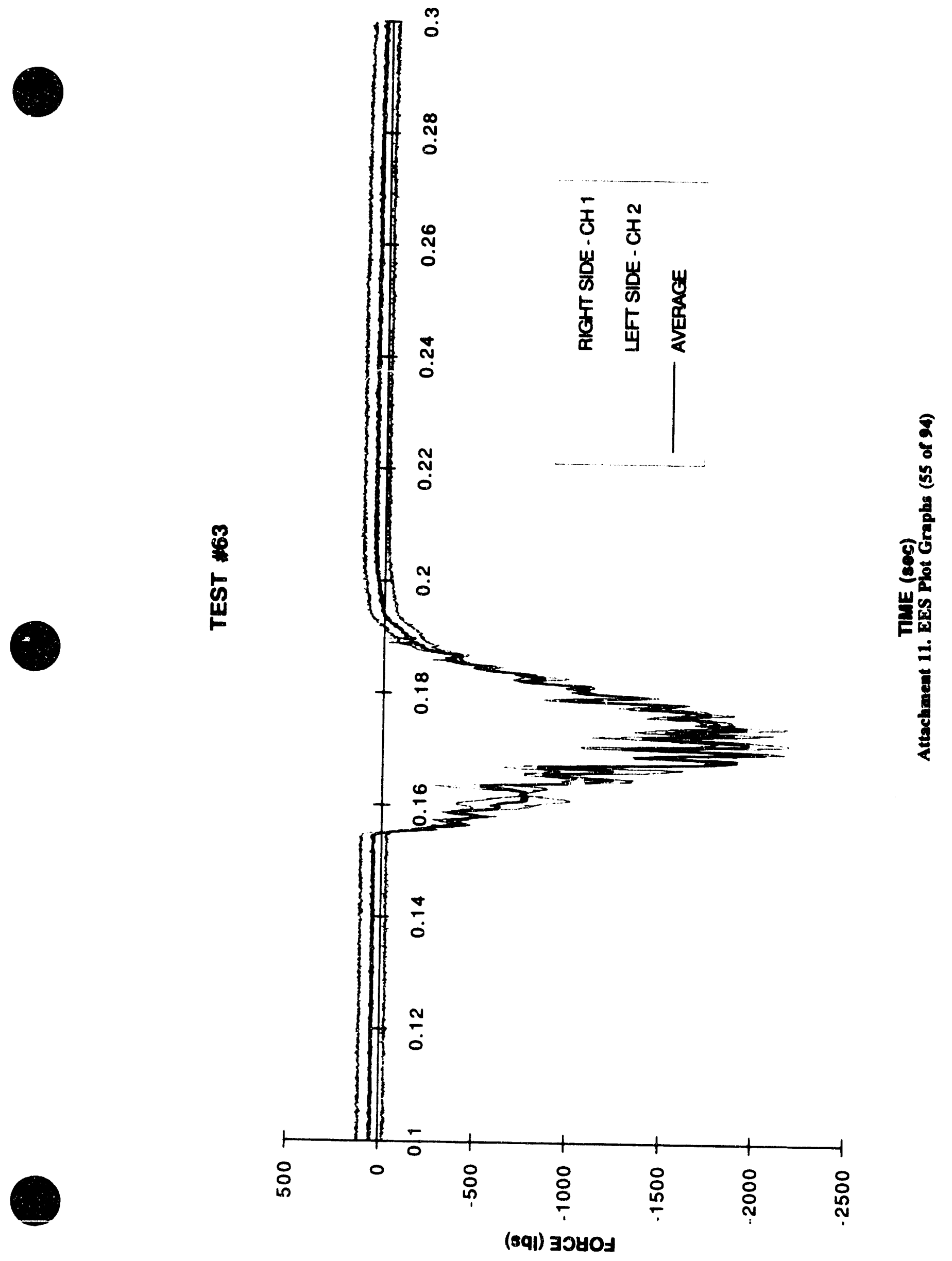




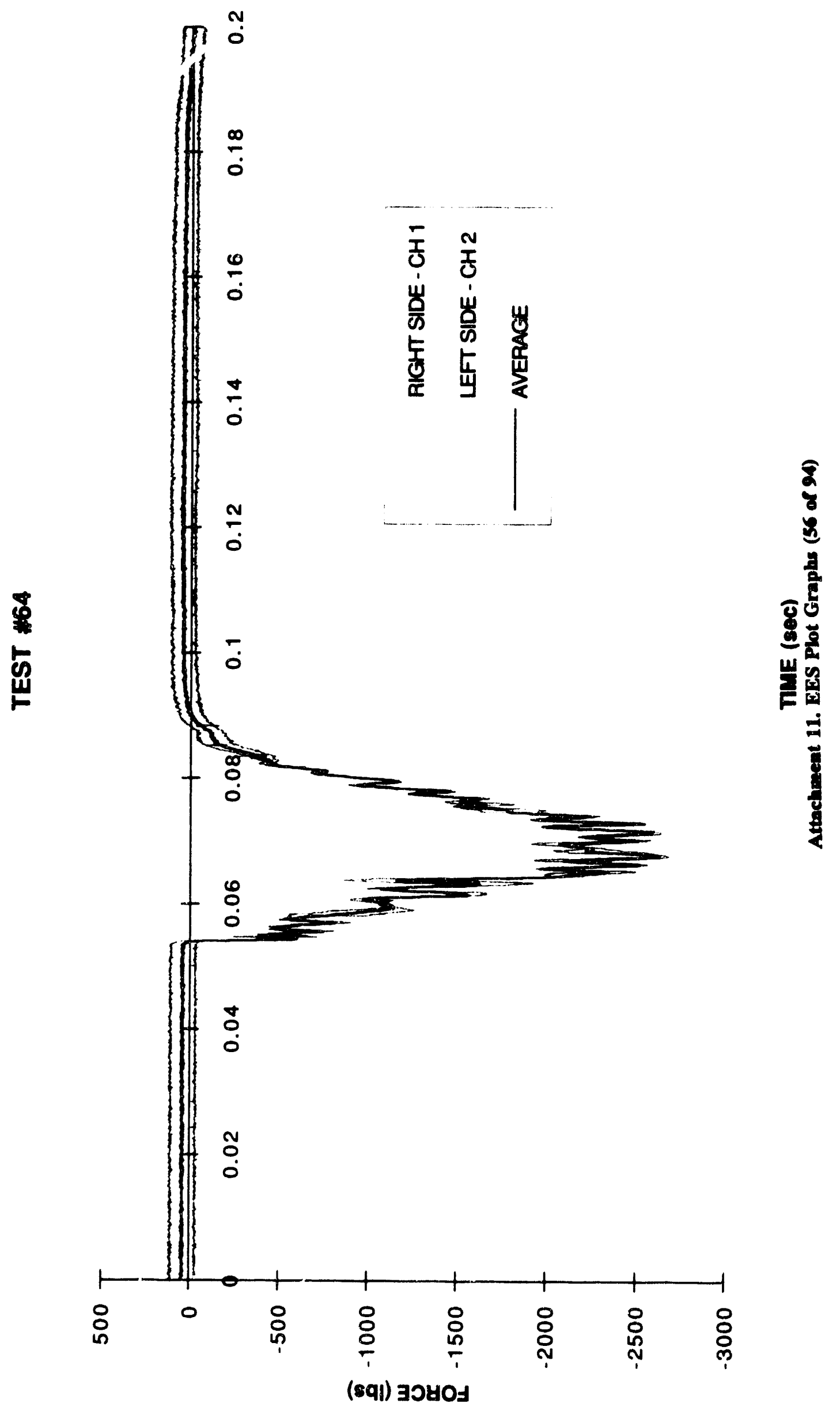




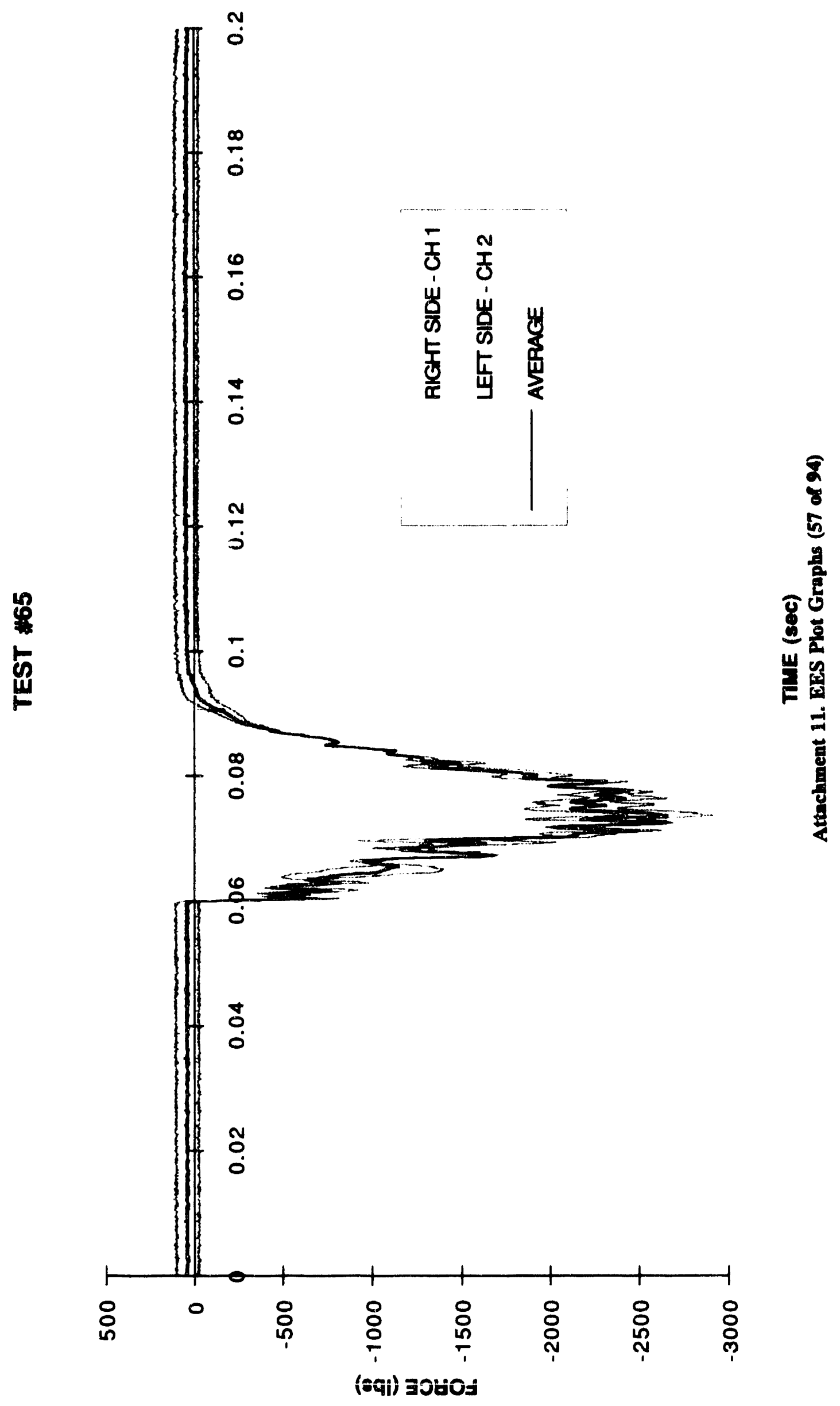




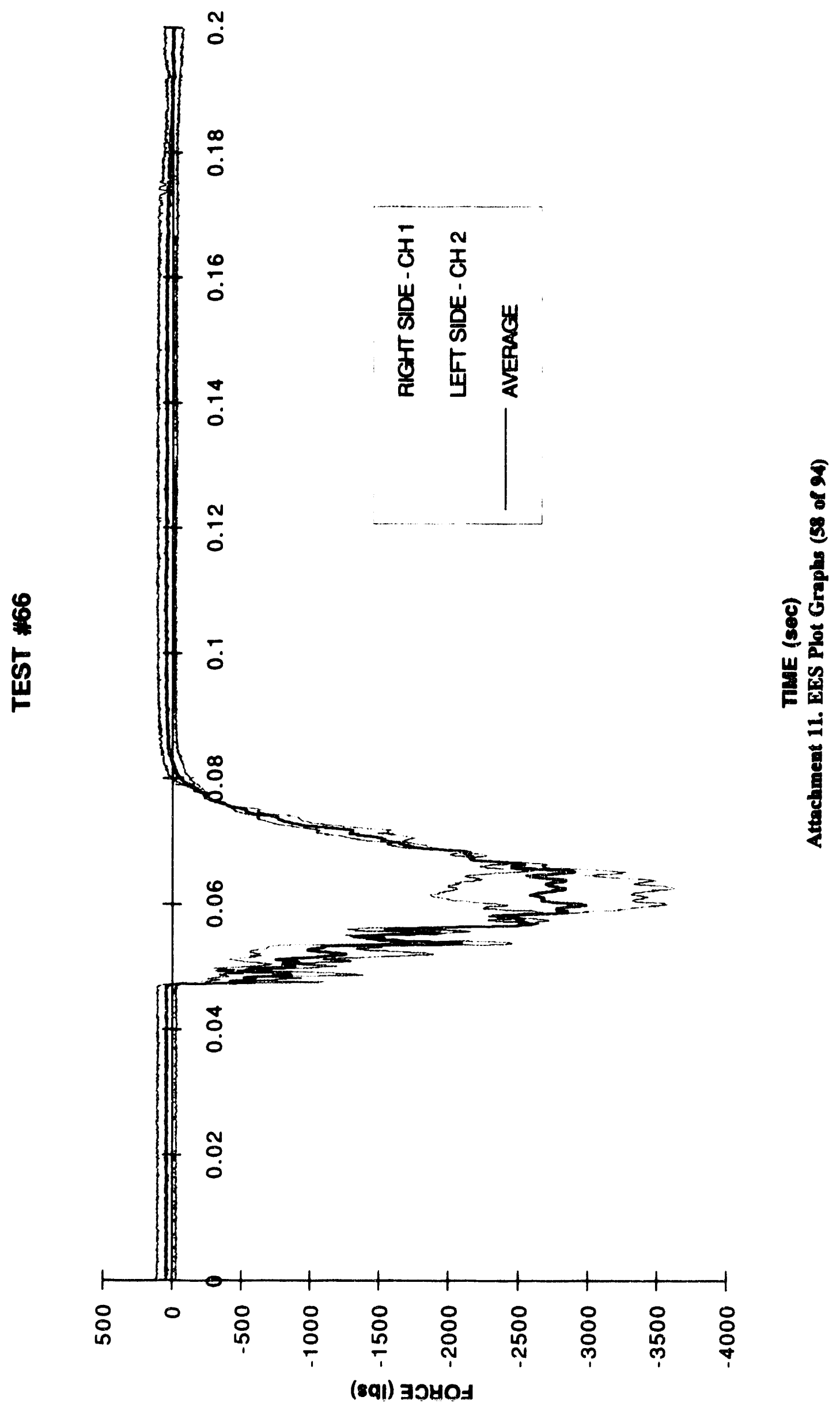




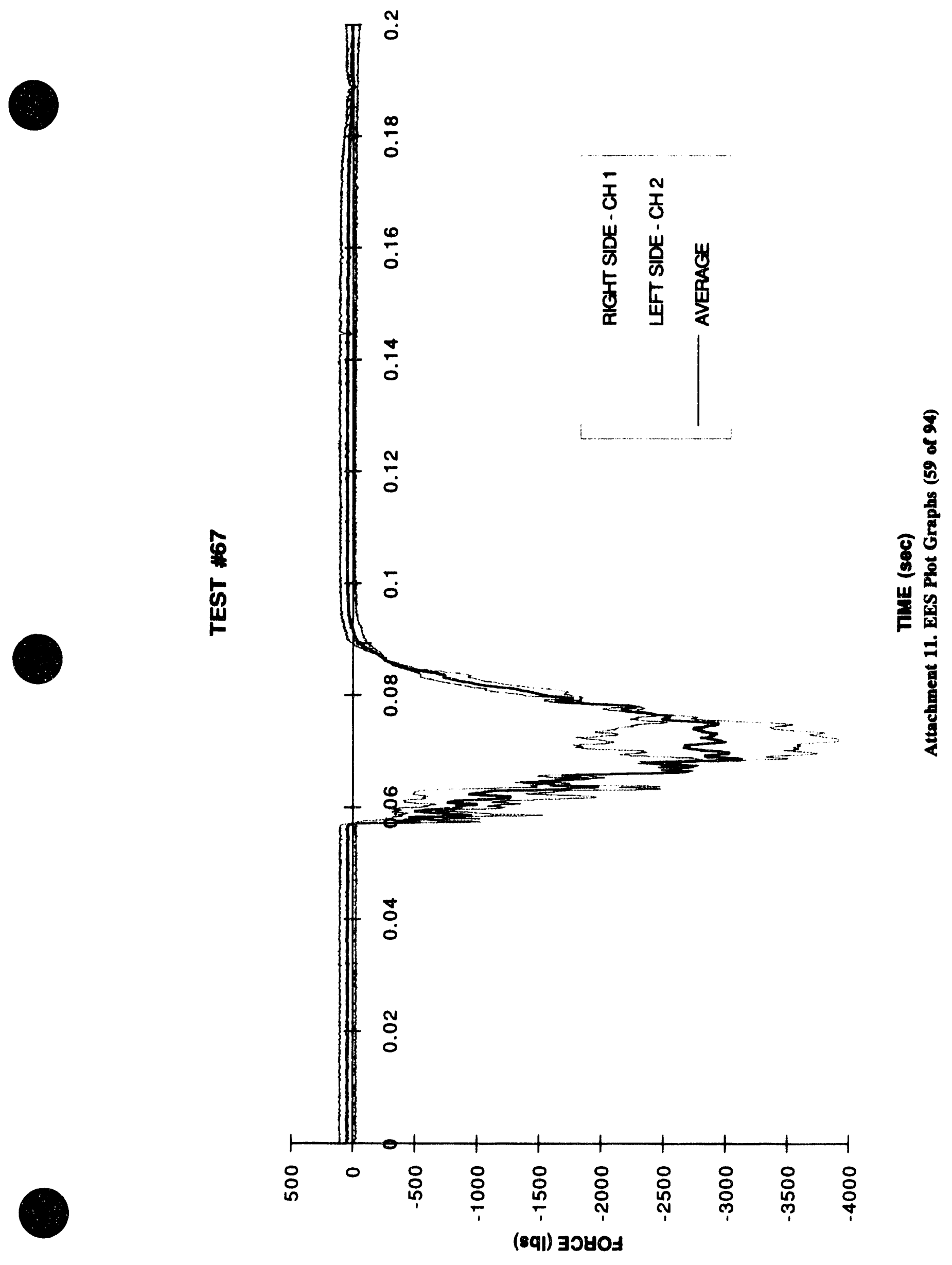




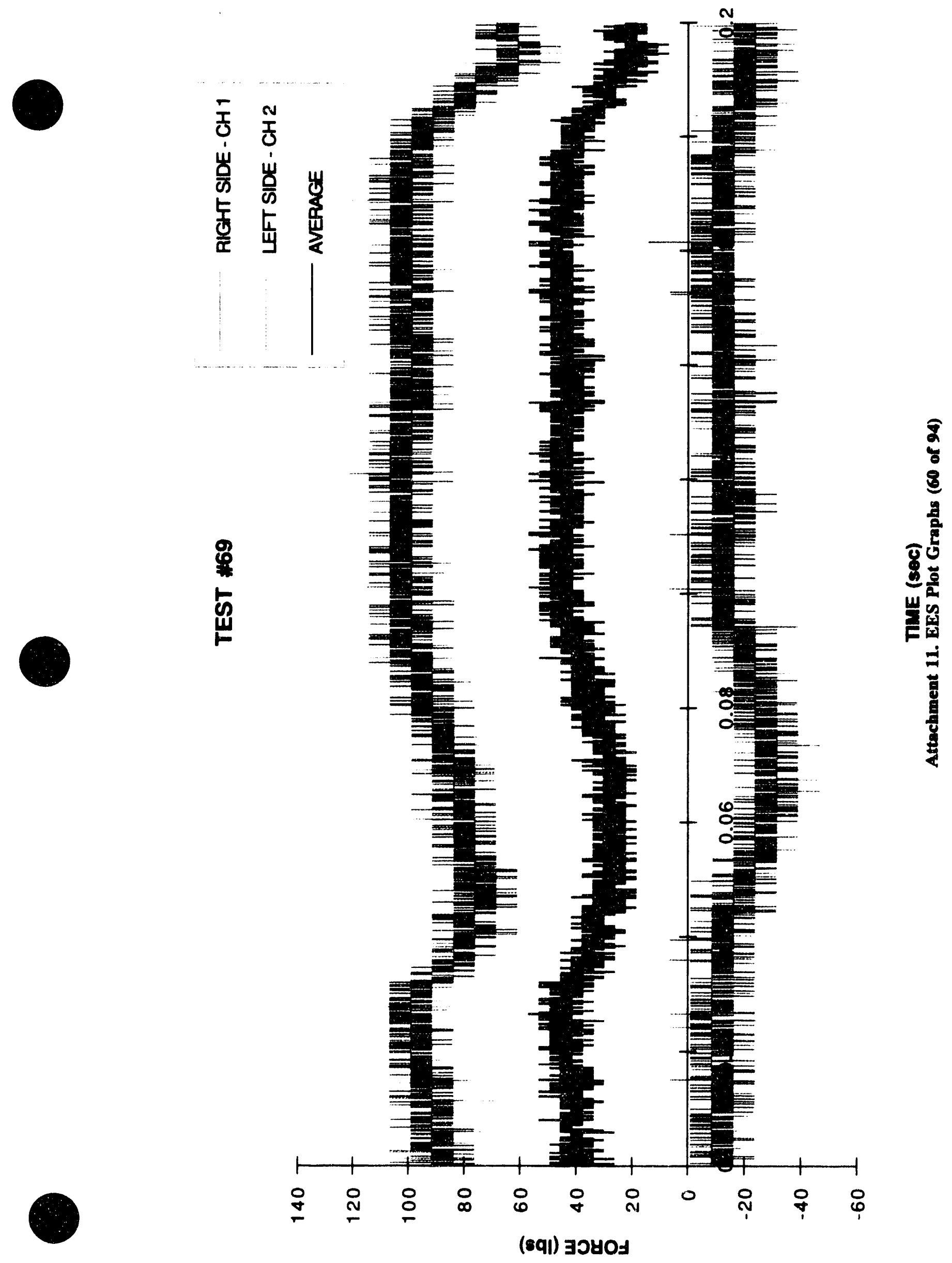




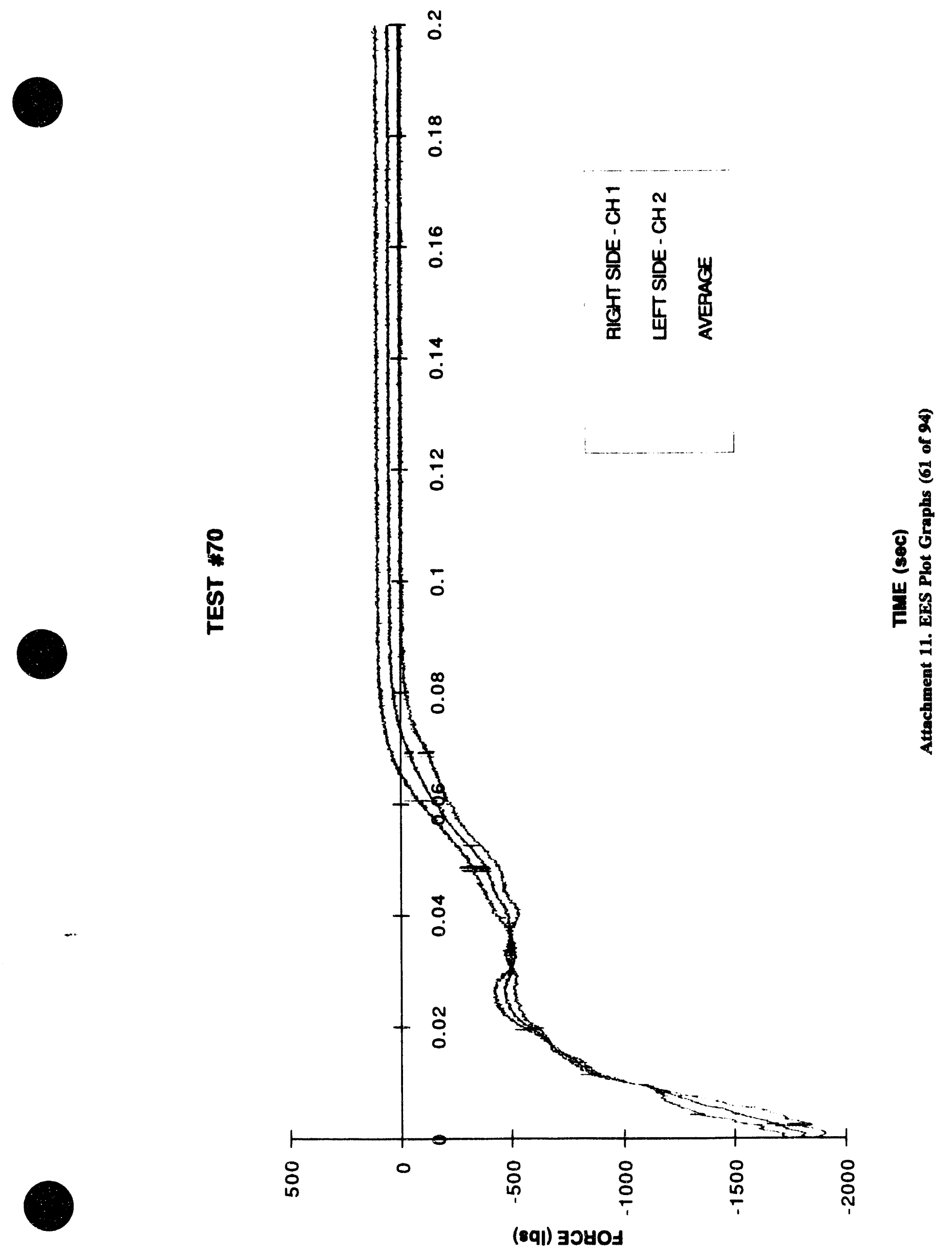




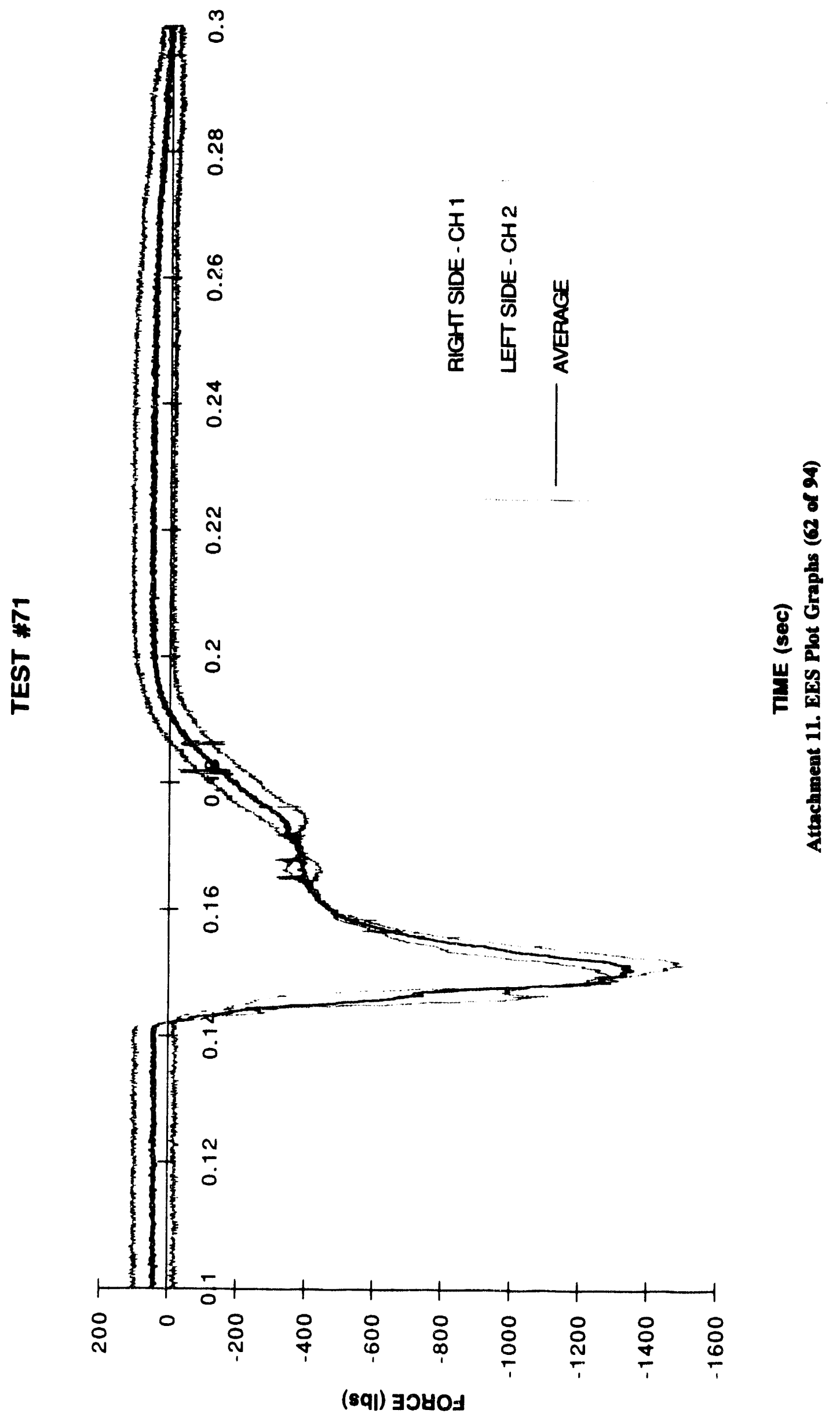




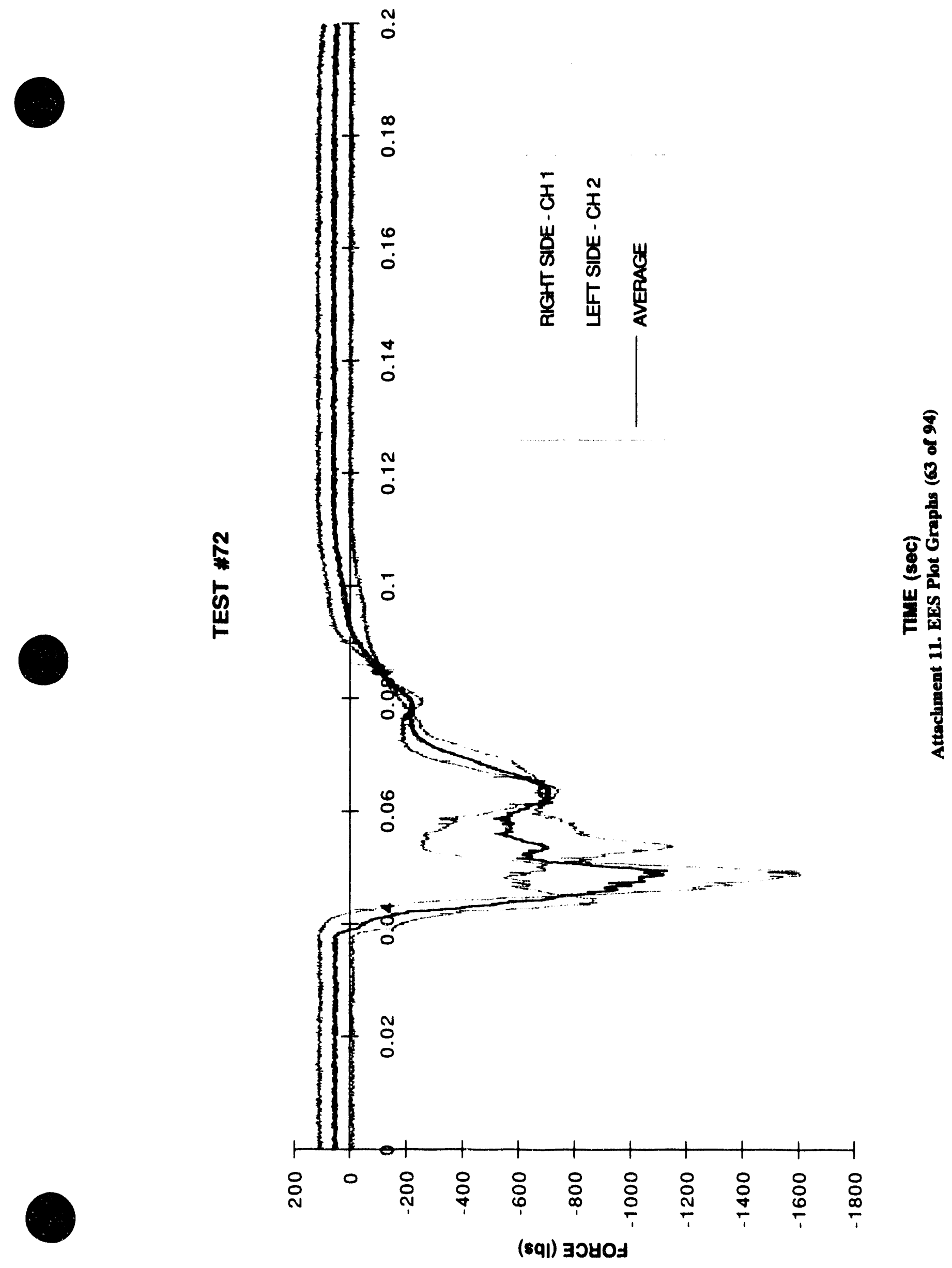




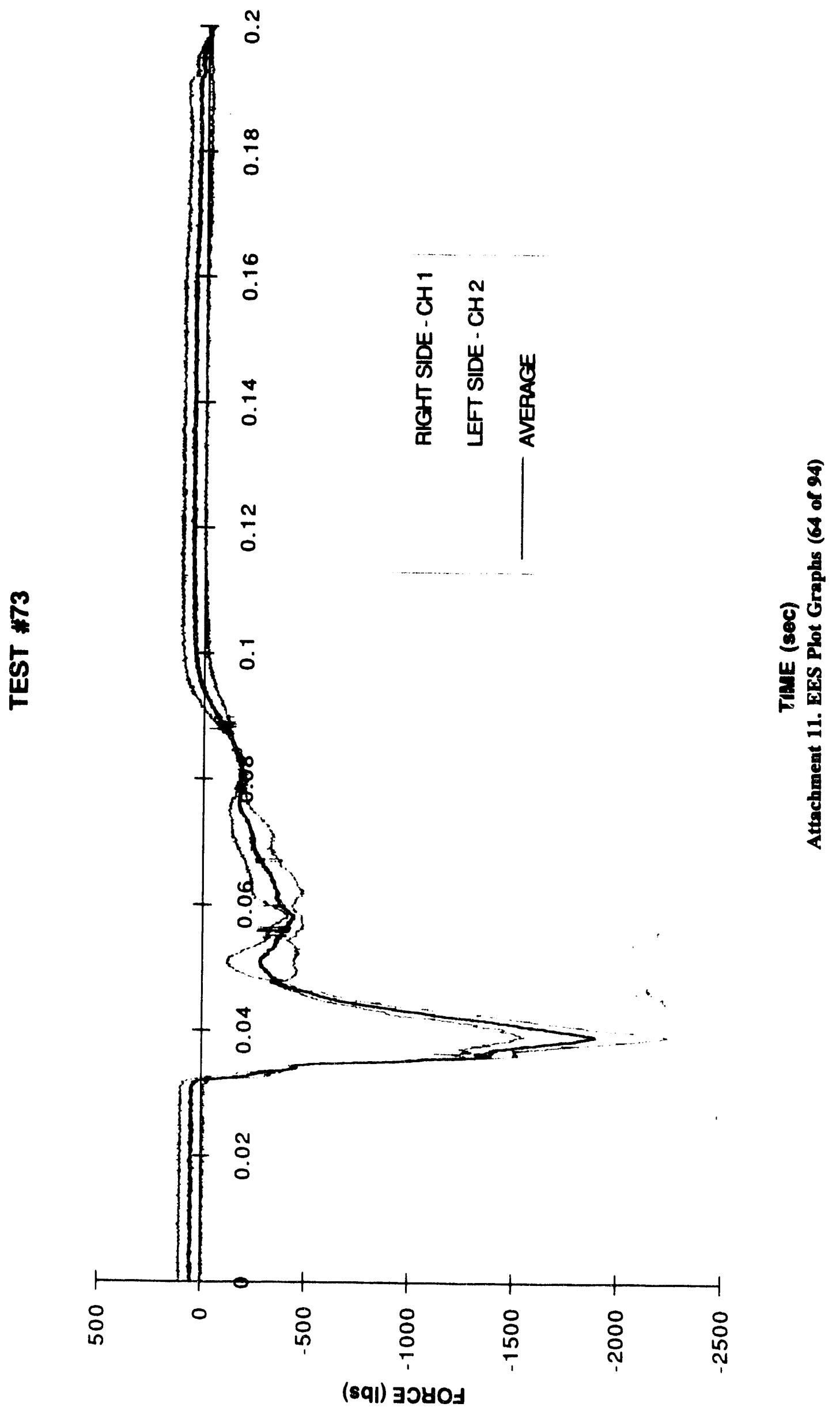




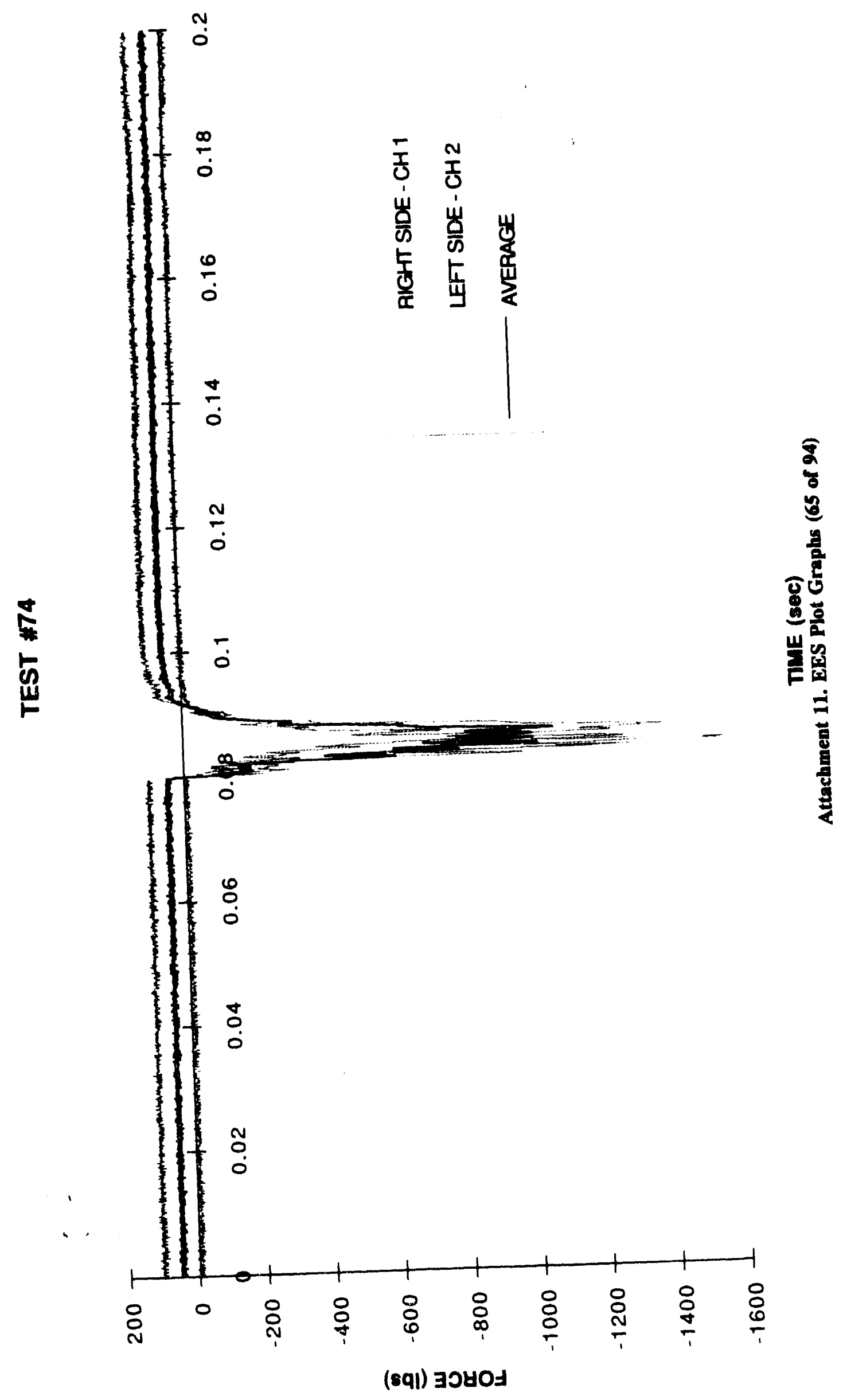




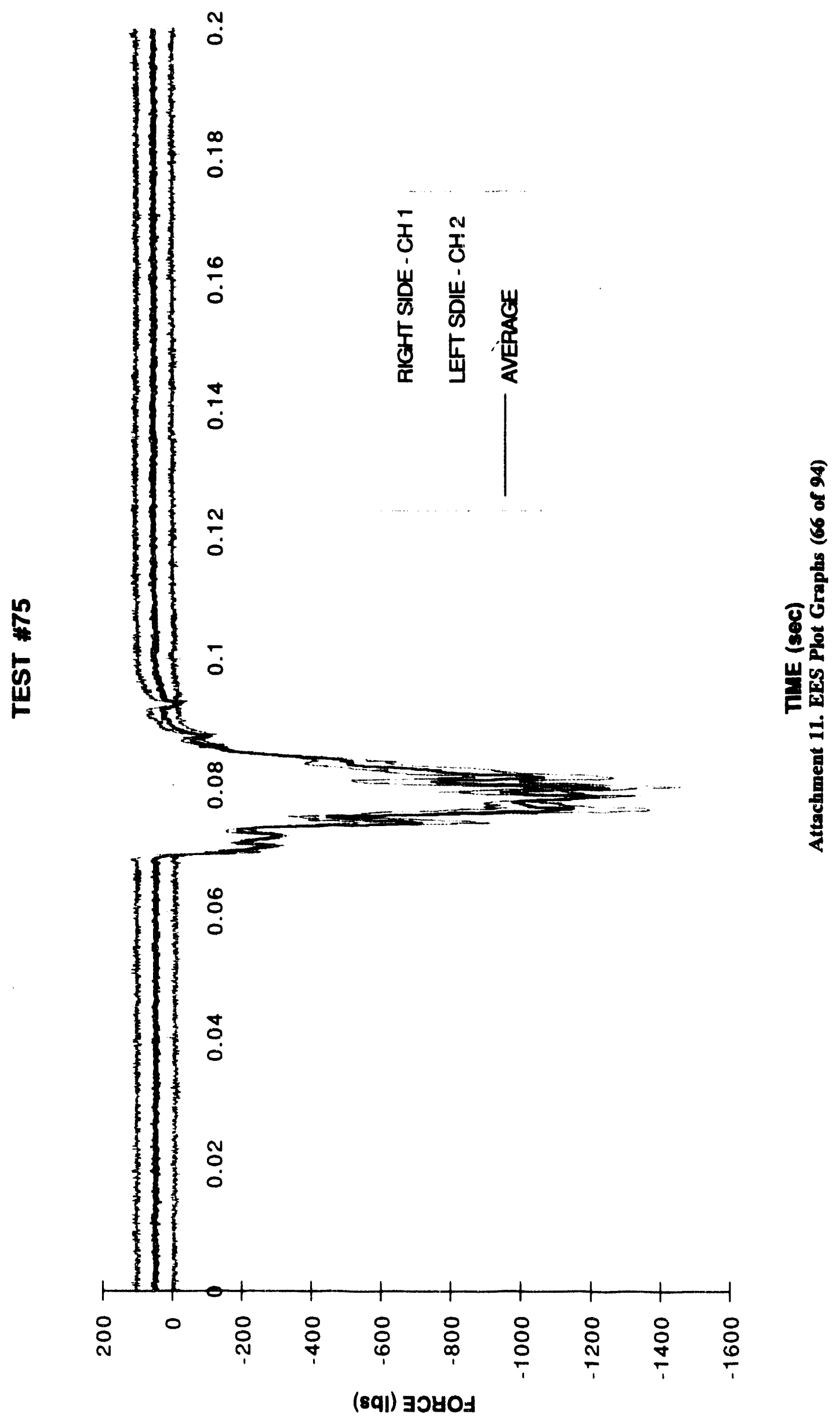




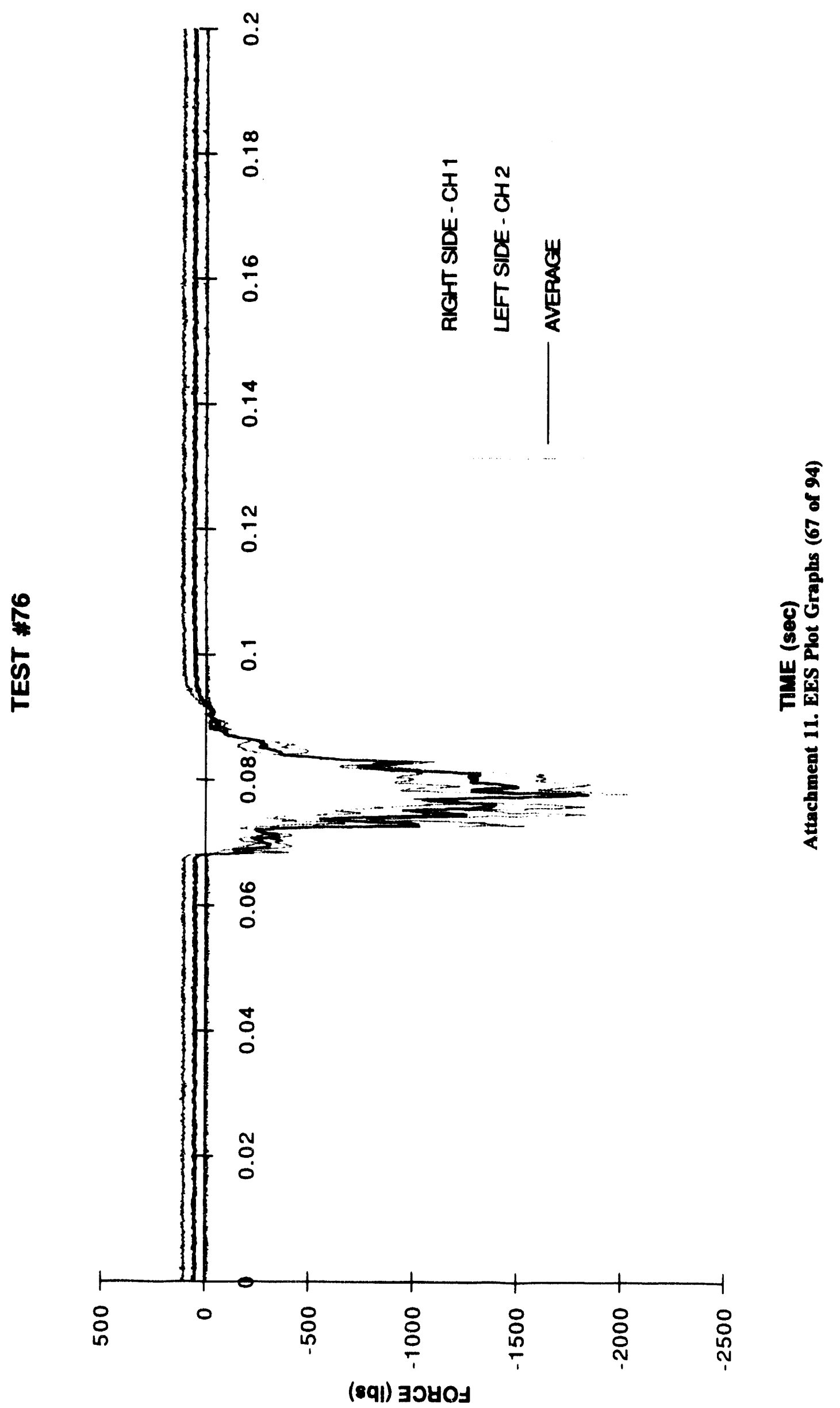




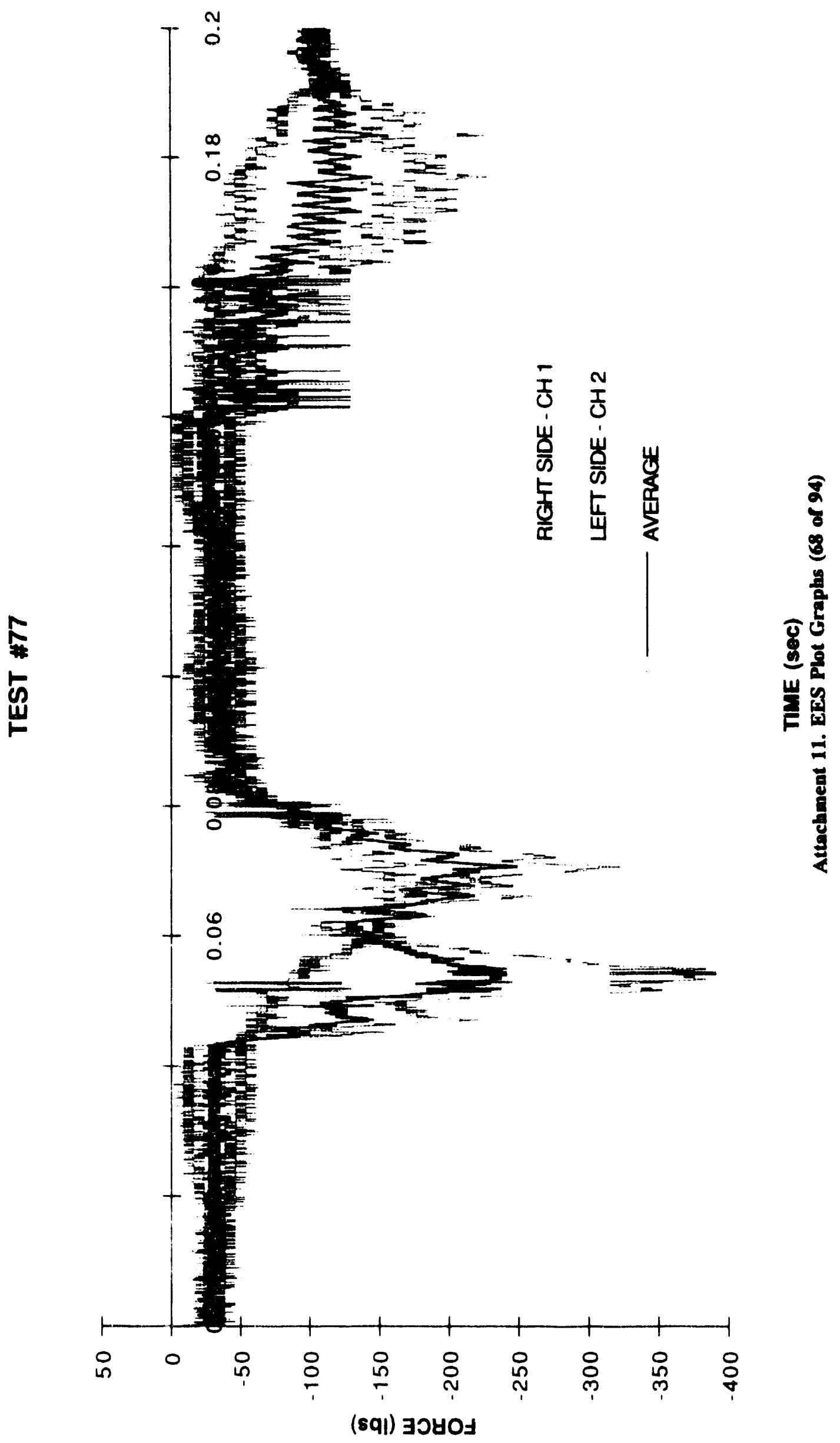




\section{(6) NOIL $8437300 \%$}

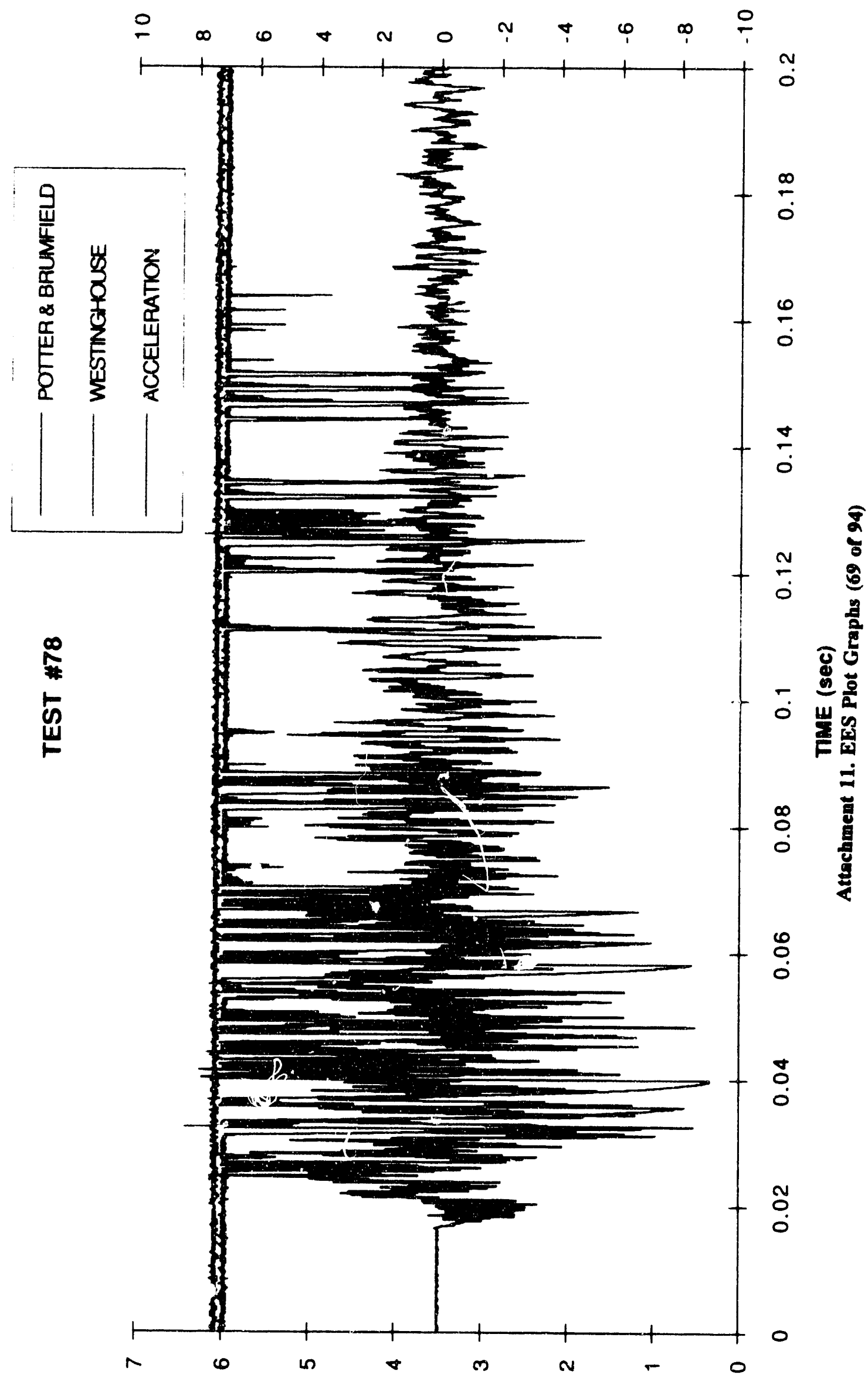

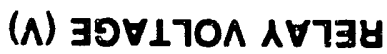


(6) Noแะชมาวอวท

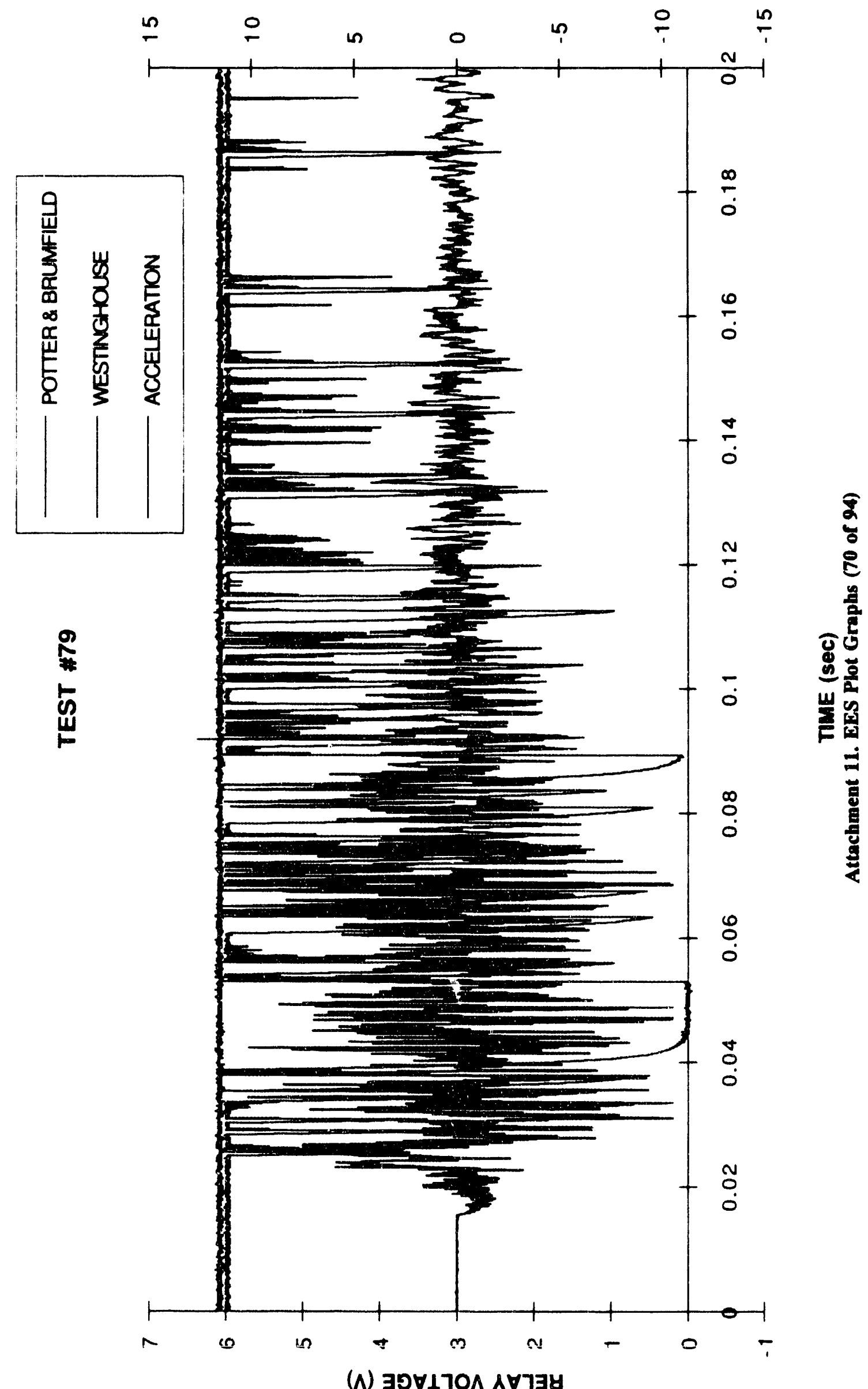


(6) NOIL ช49า3องท

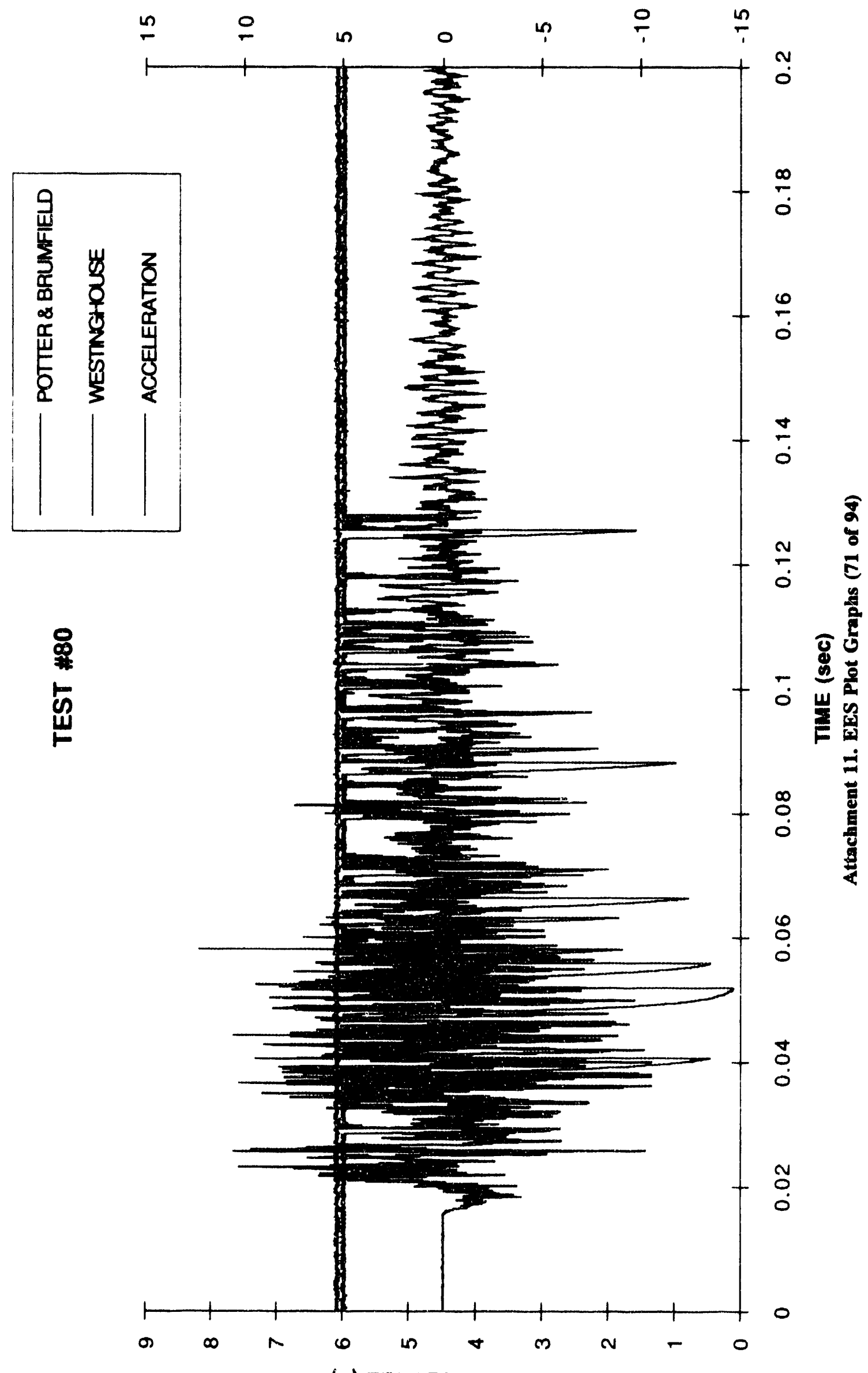

(^) $30 \forall 1 า 0 \wedge$ Аจา 
(6) NOI1 $\forall 437900 \forall$

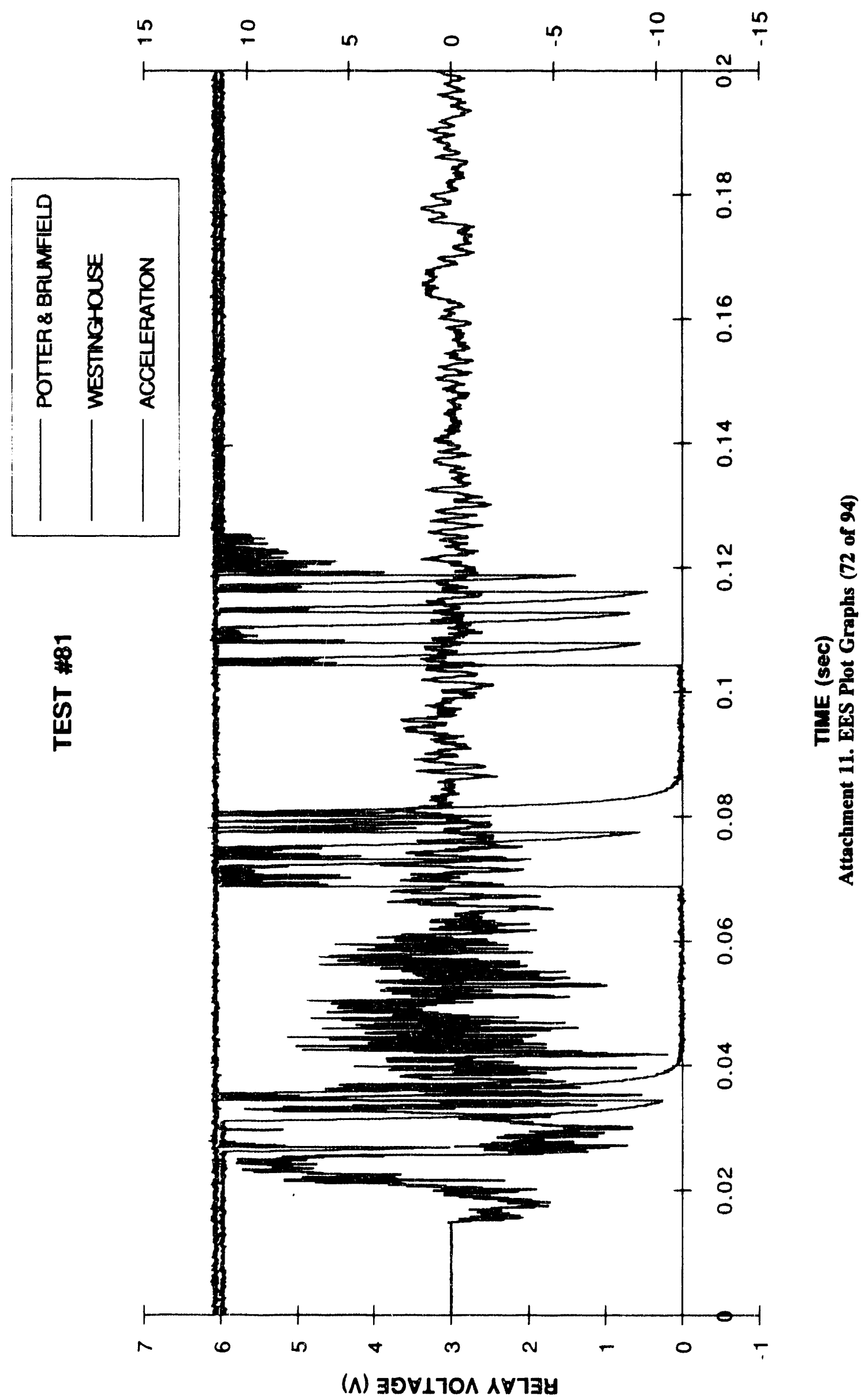


(B) NOIL $\forall 437 \exists ว O \forall$

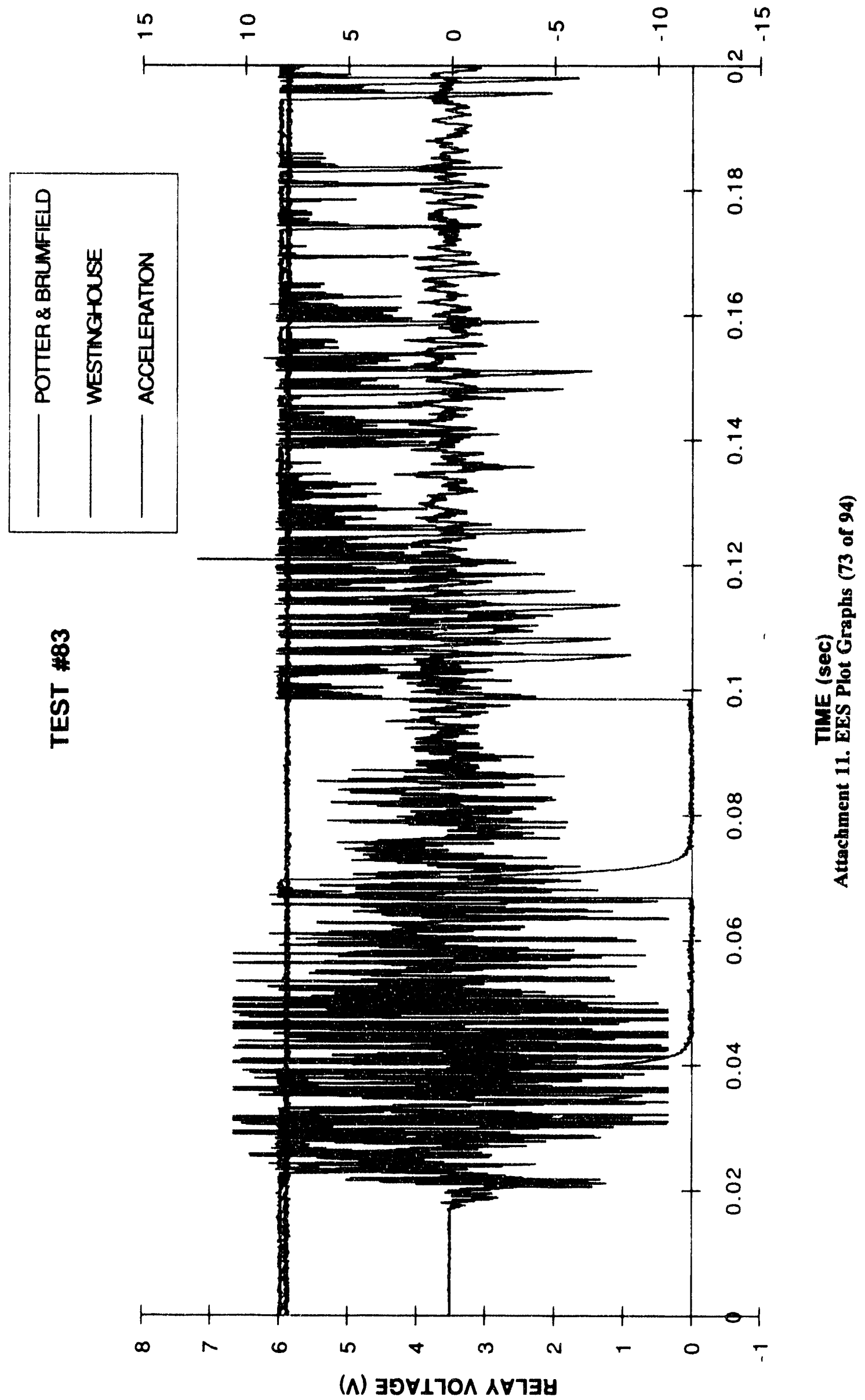


(6) NOI1 V8373วOV
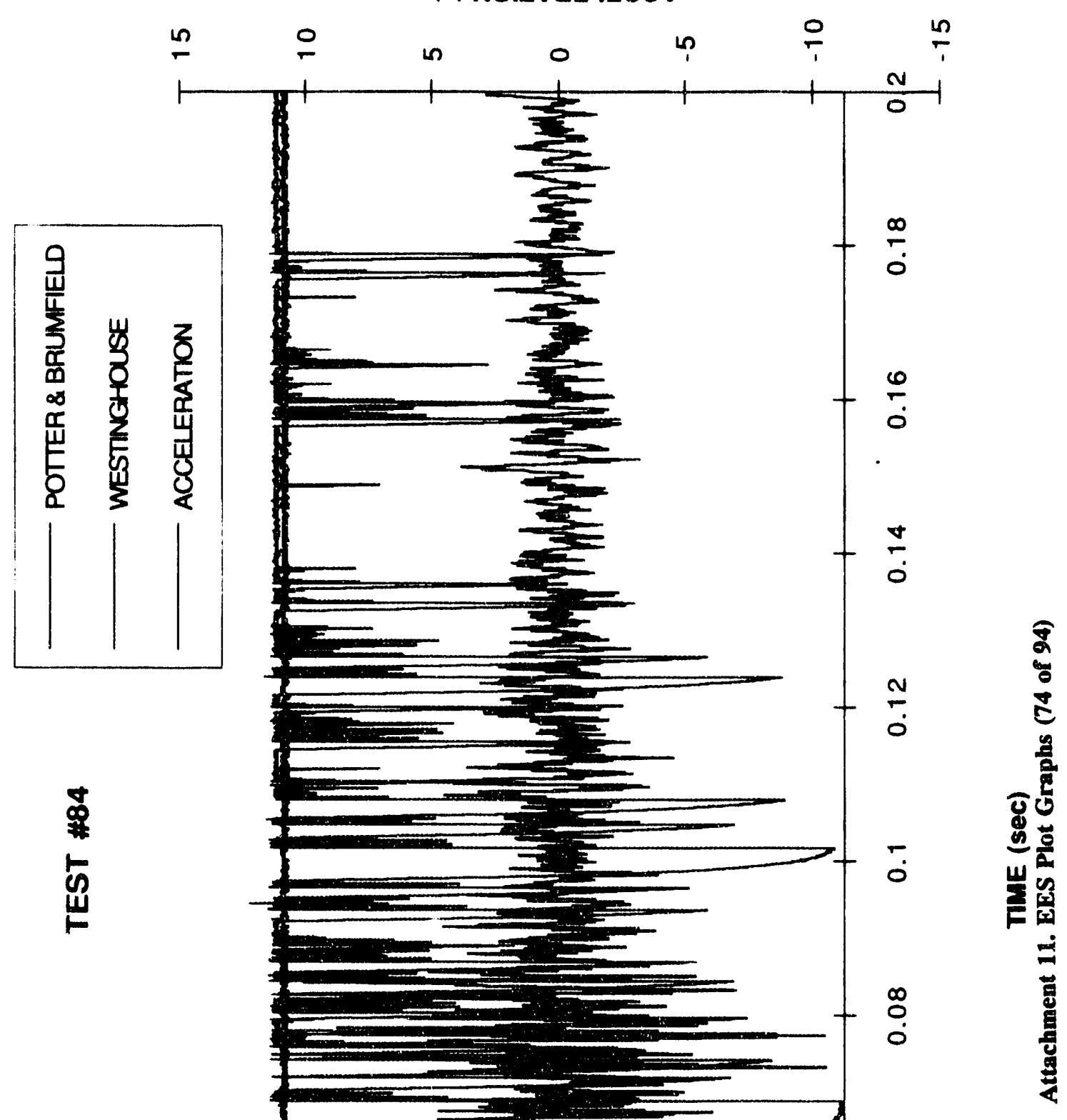

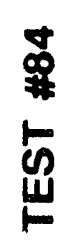

$\ddot{0}$

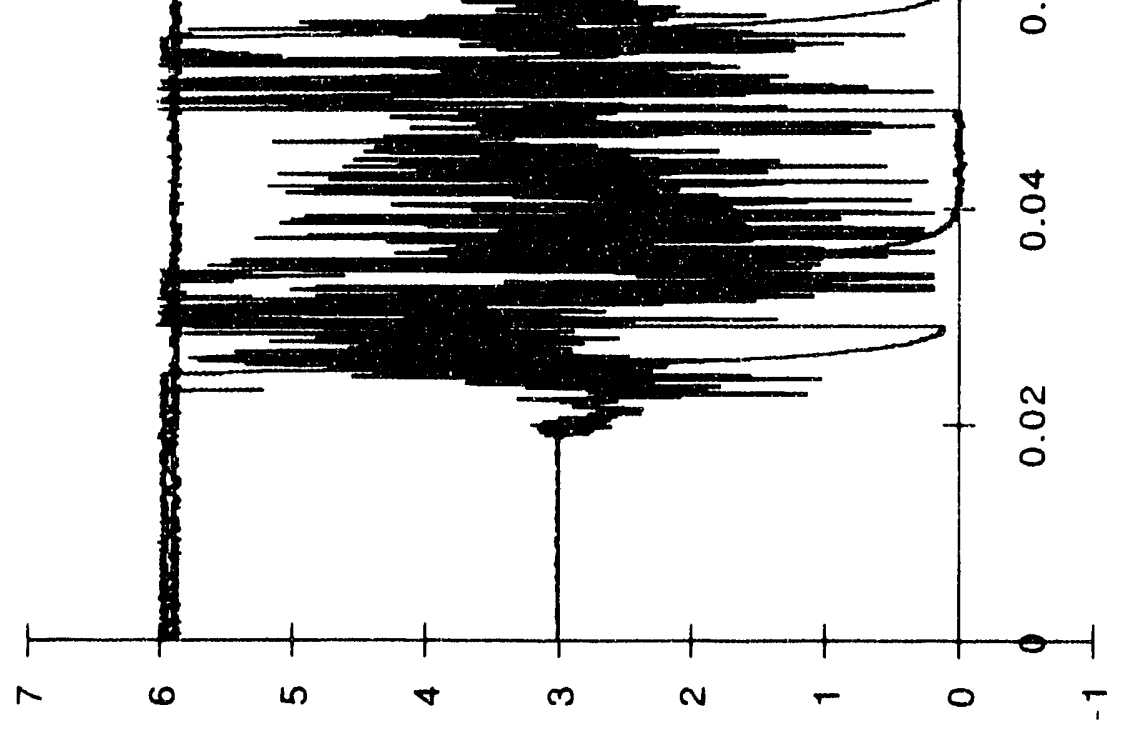

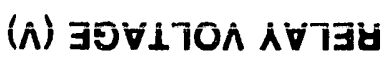




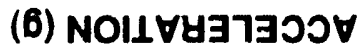

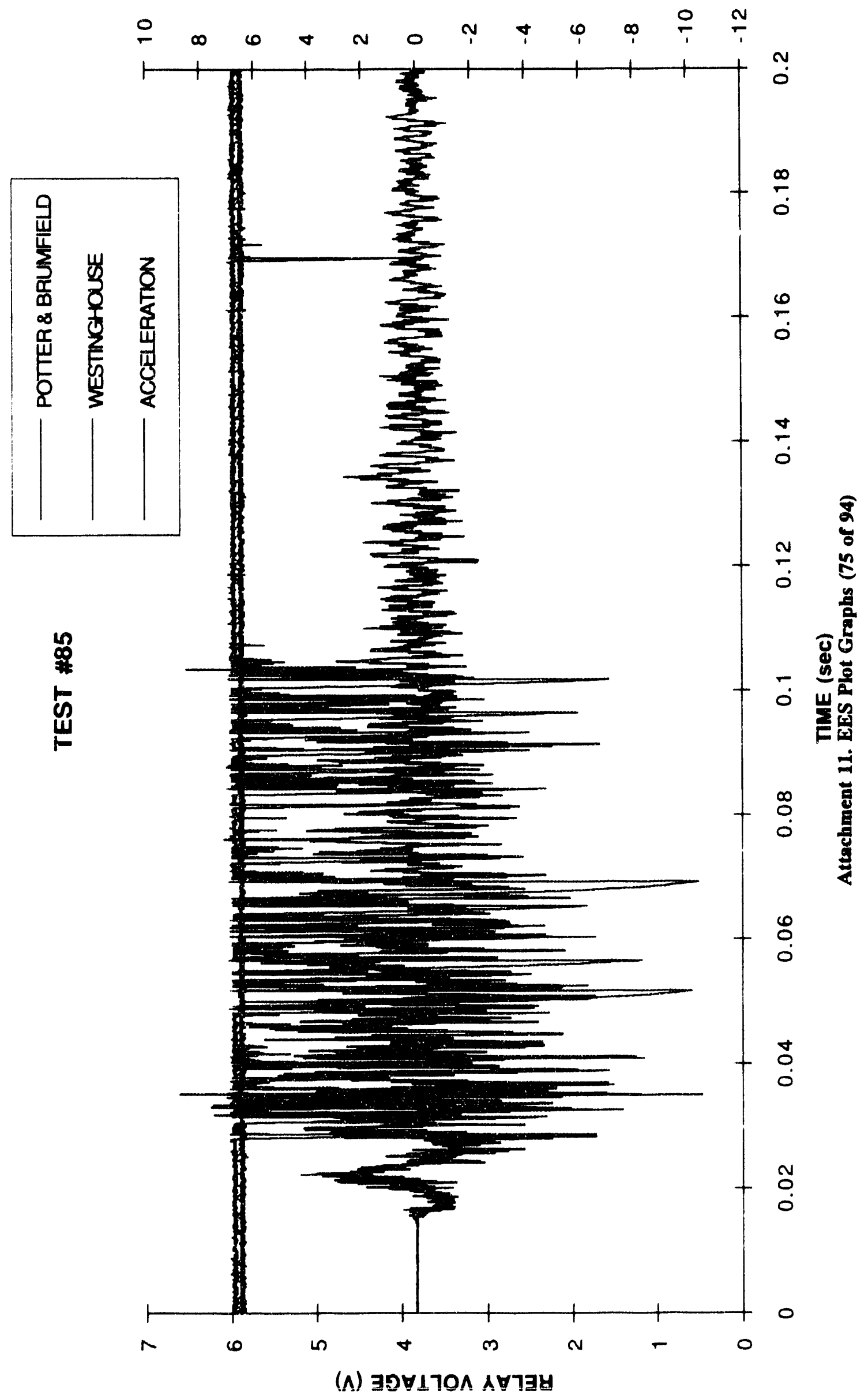


(6) NOIL $\forall 497300 \forall$

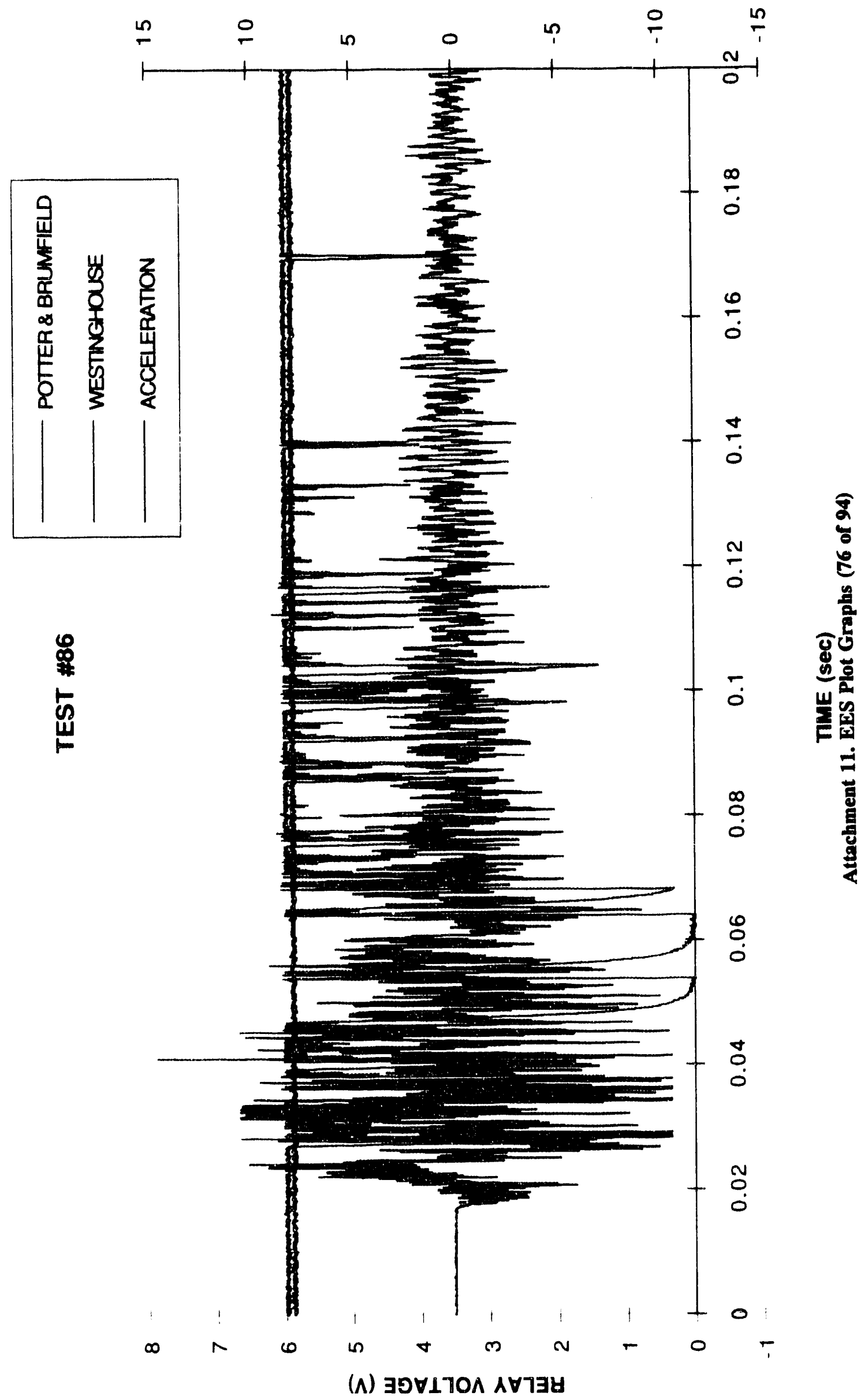




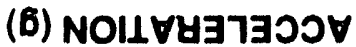

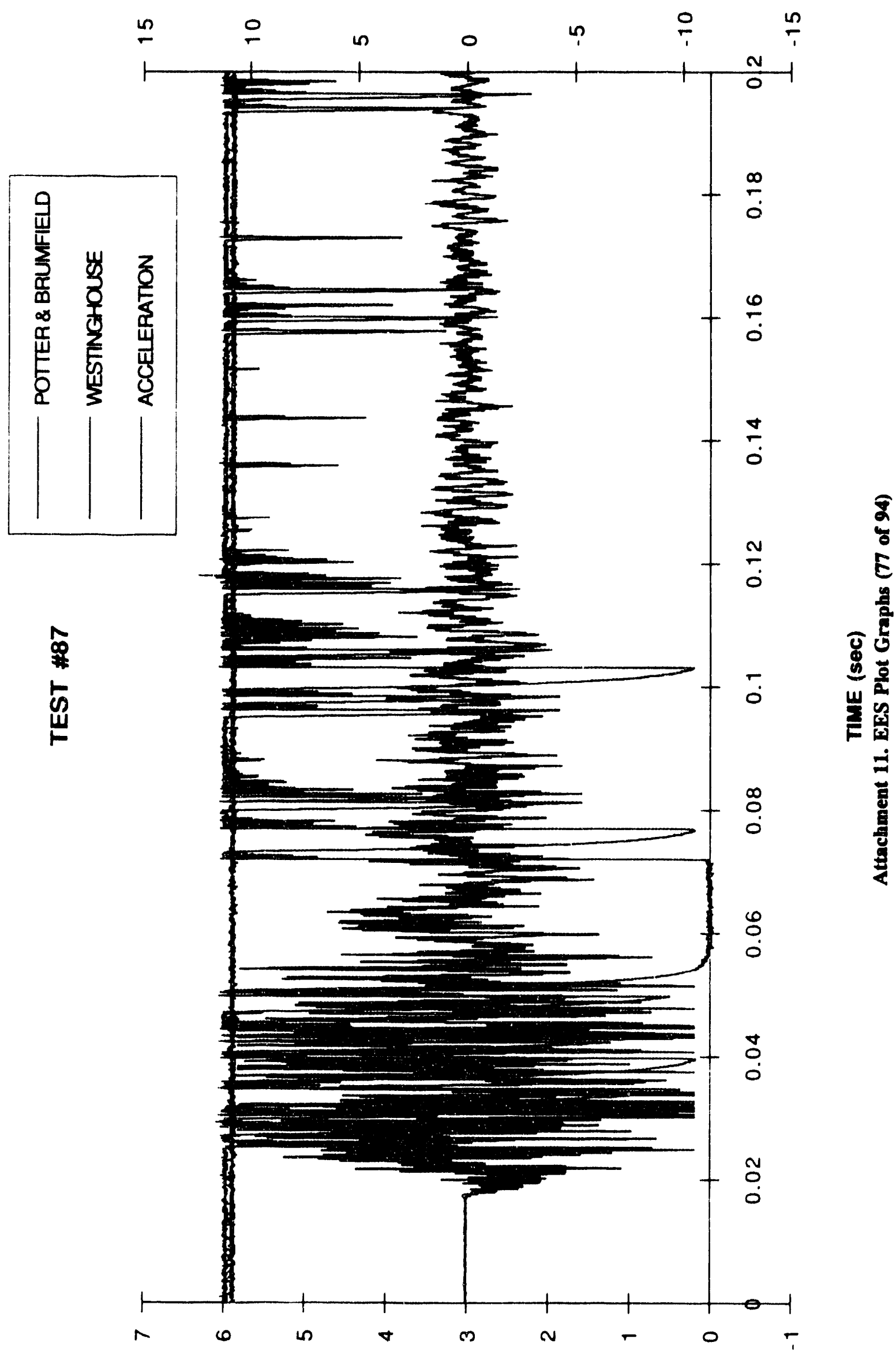

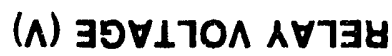


(B) NOIL $\forall y 97900 \forall$

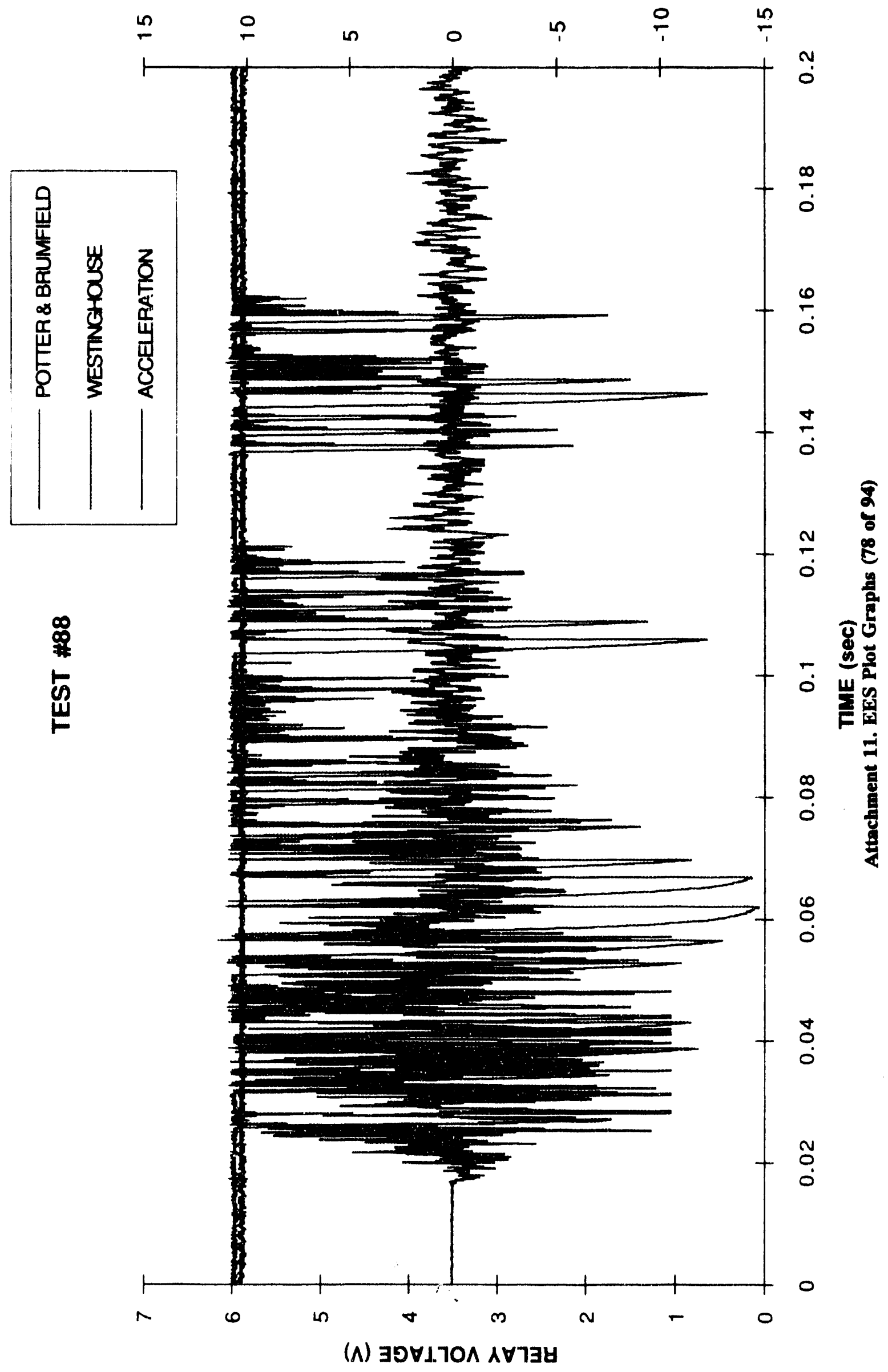


(6) NOI1

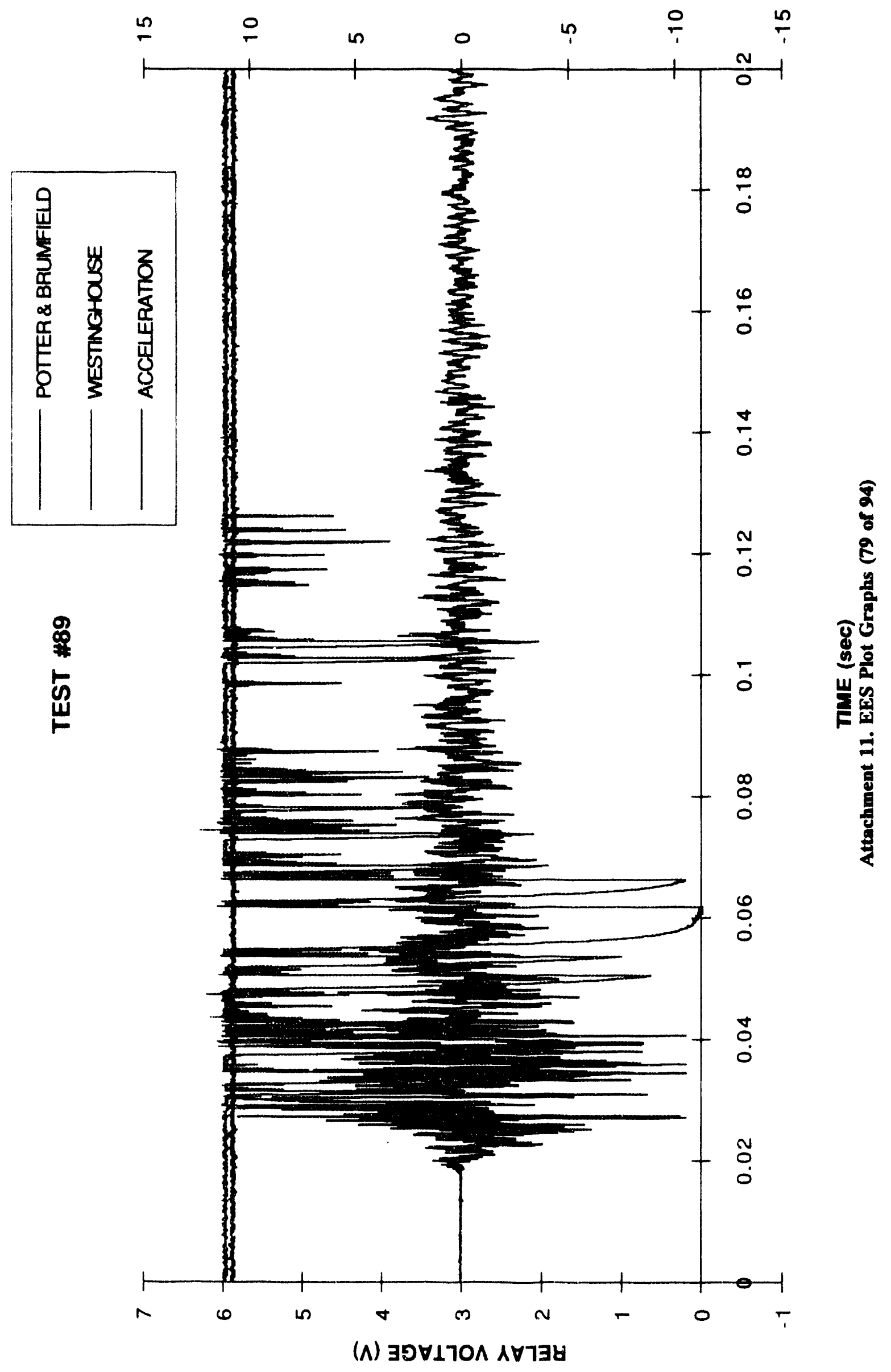




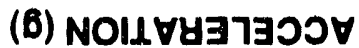

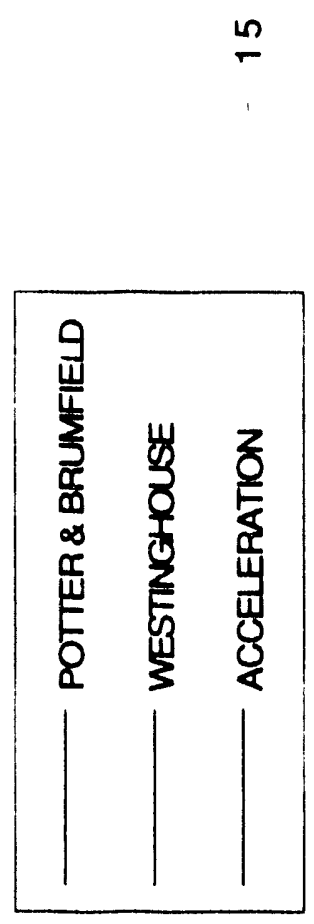

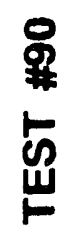

$\stackrel{n}{2}$ $\div$

in 0 in $\frac{0}{1}$ ?

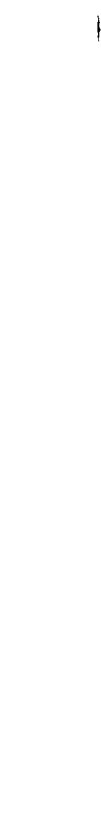

○
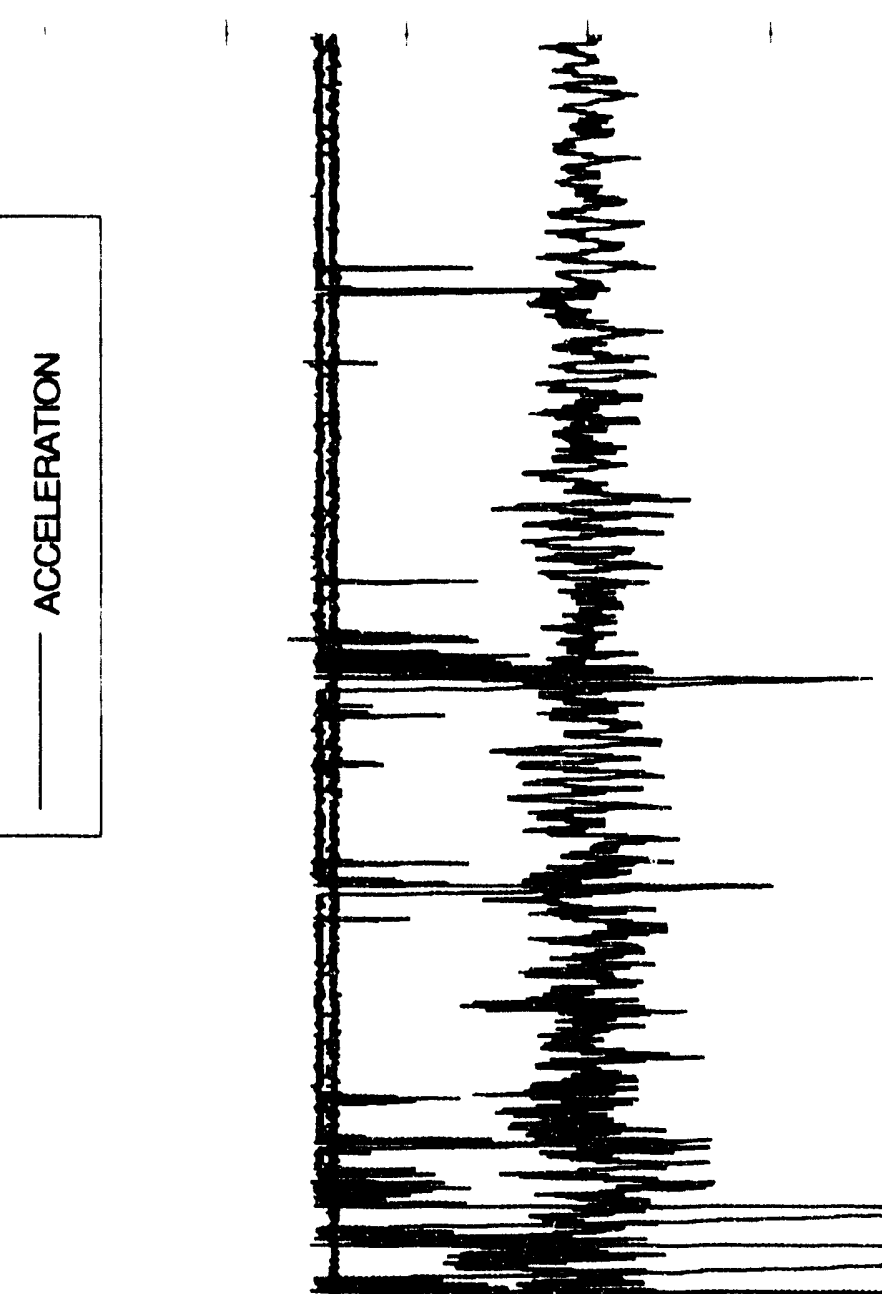

$\stackrel{0}{0}$

$\frac{\infty}{i}$

0

$\ddot{0}$

$\dot{0}$

$\stackrel{0}{0}$
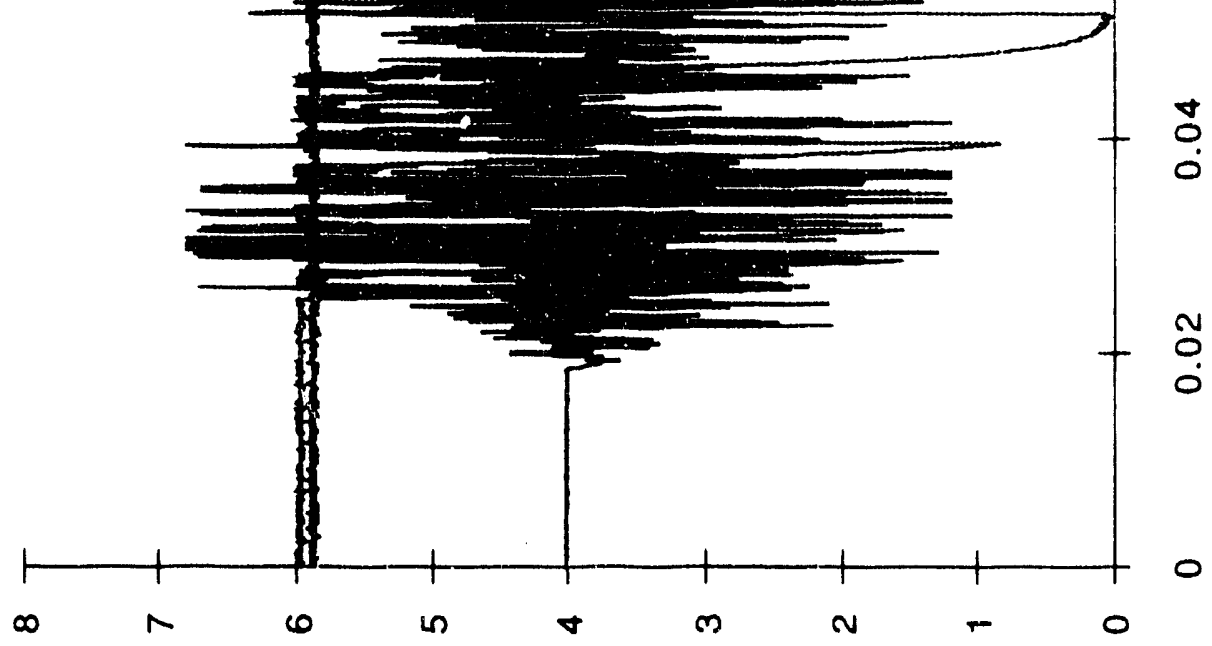

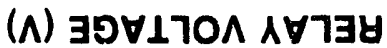




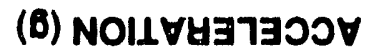

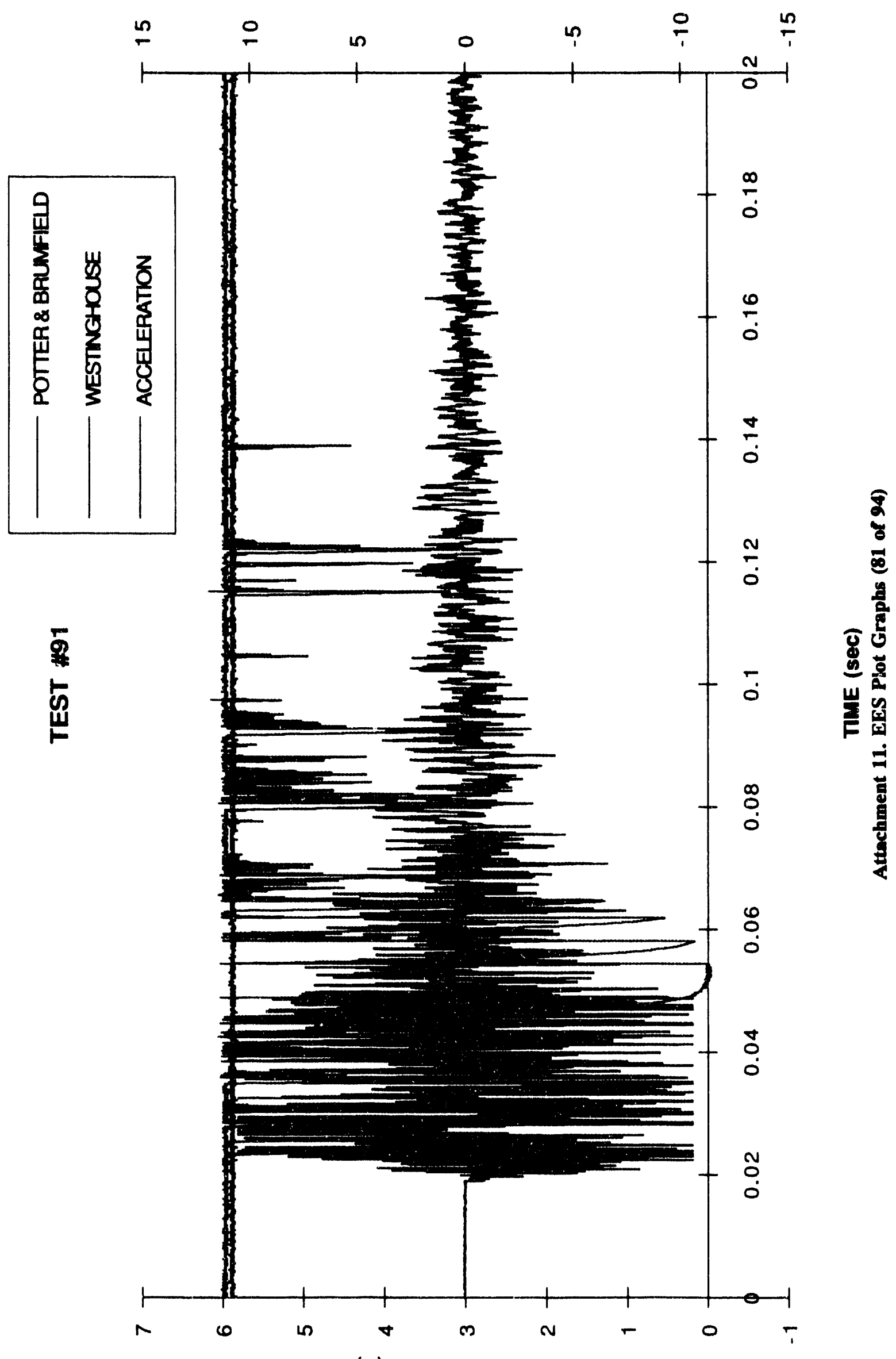

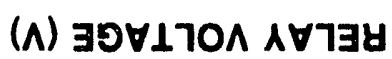


(6) NOIL $\forall y 37300 \vee$

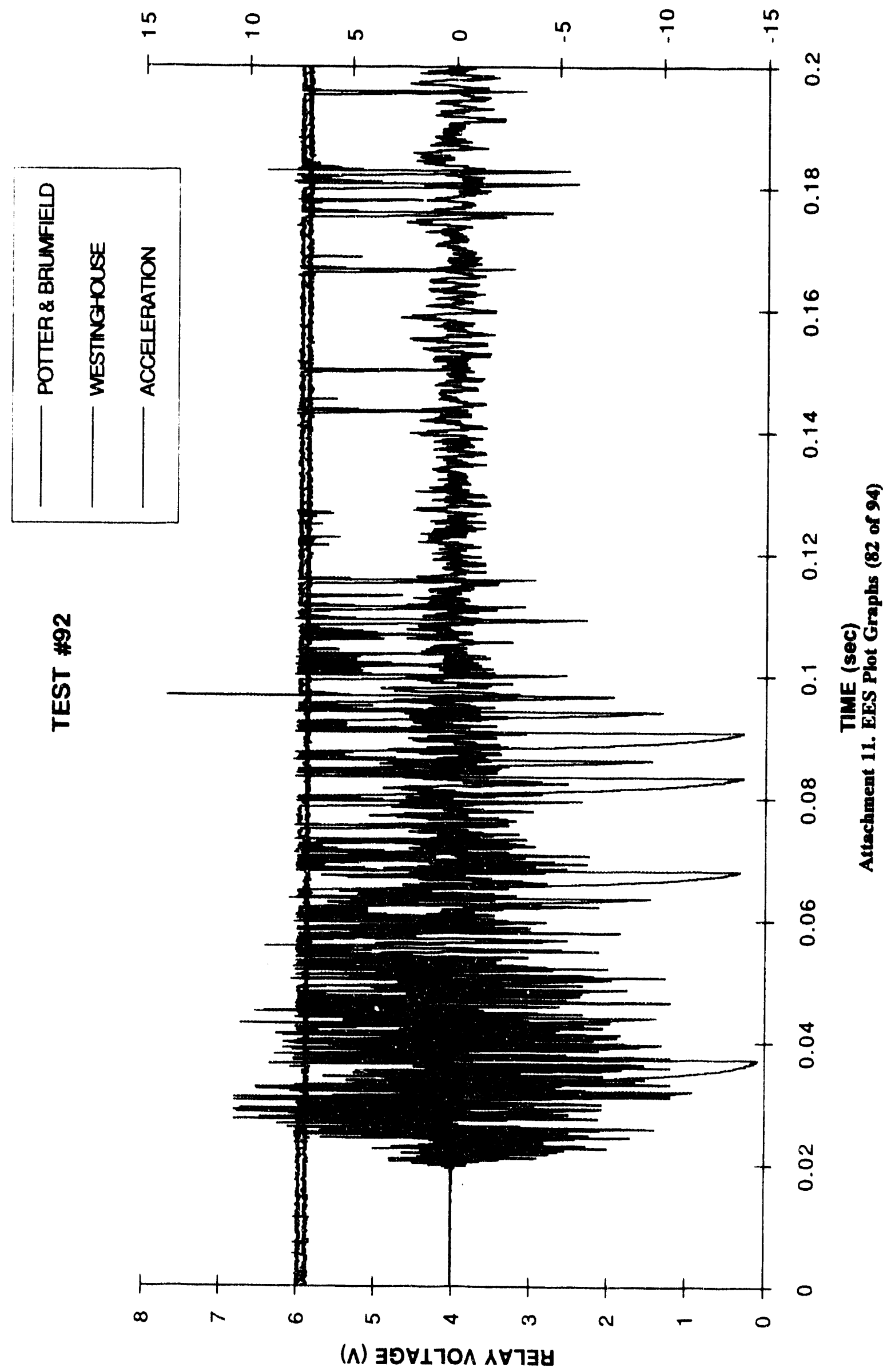


(6) NOII

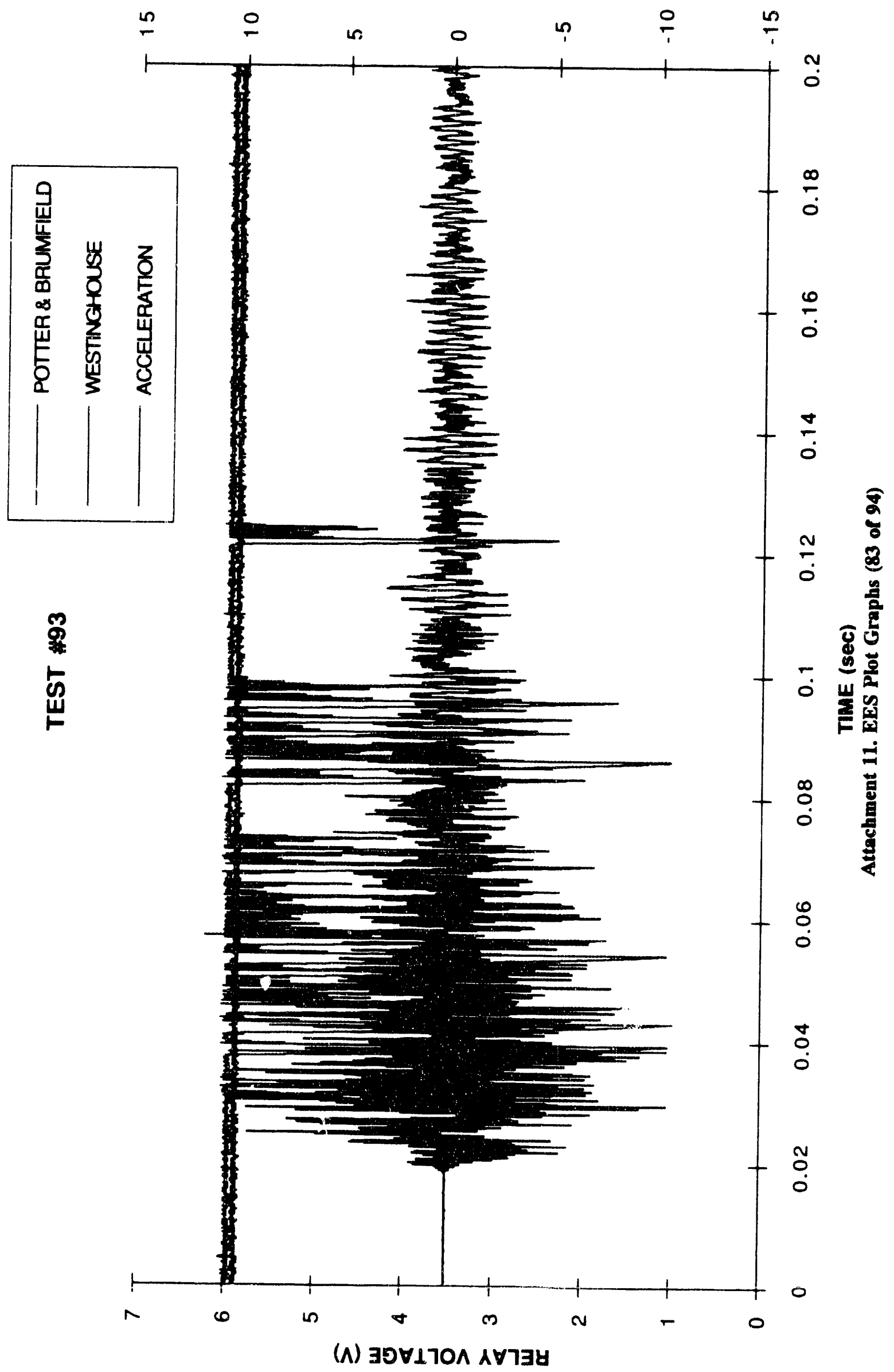




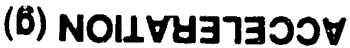

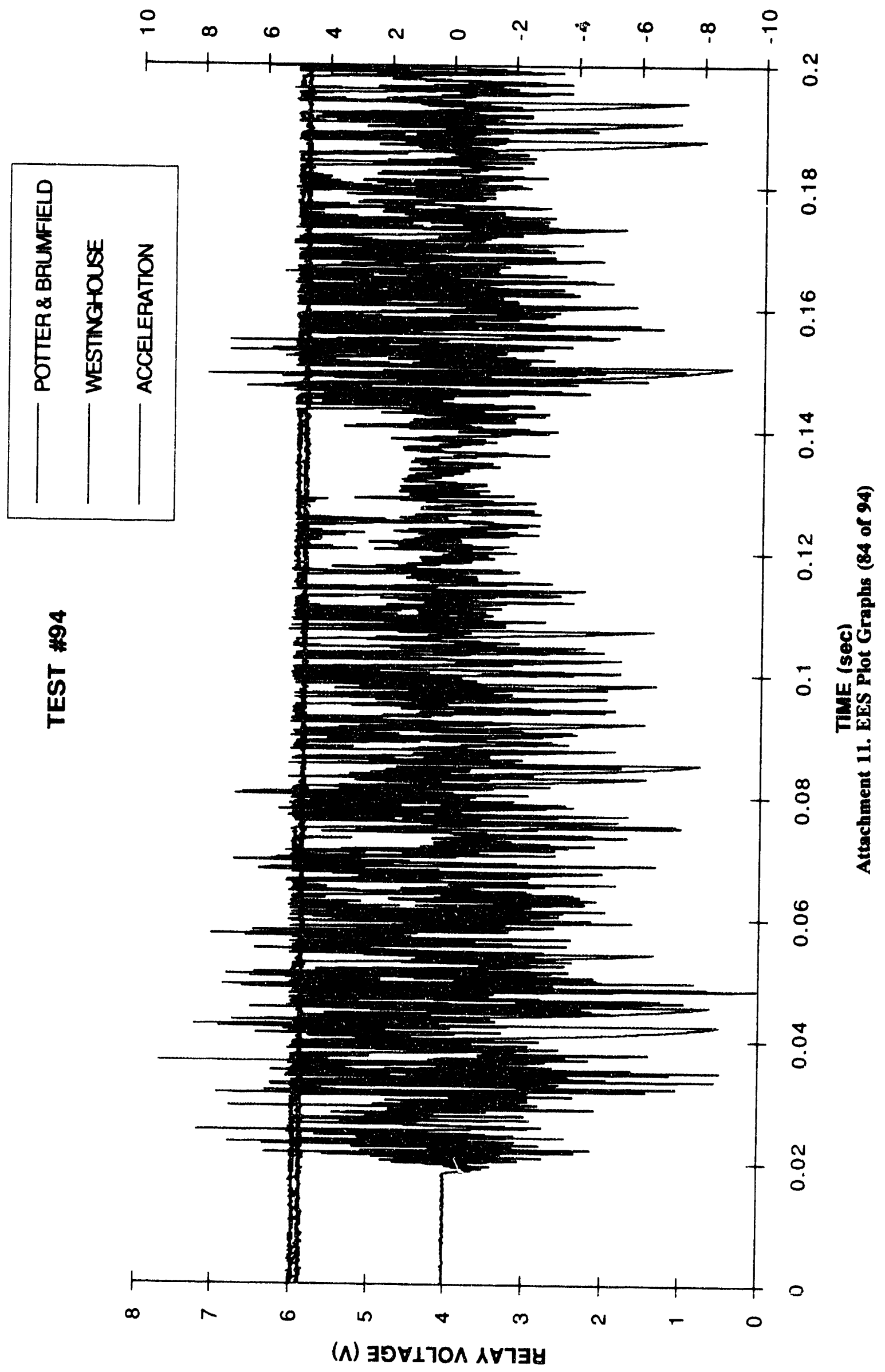




\section{(6) NOILซyตา $300 \forall$}

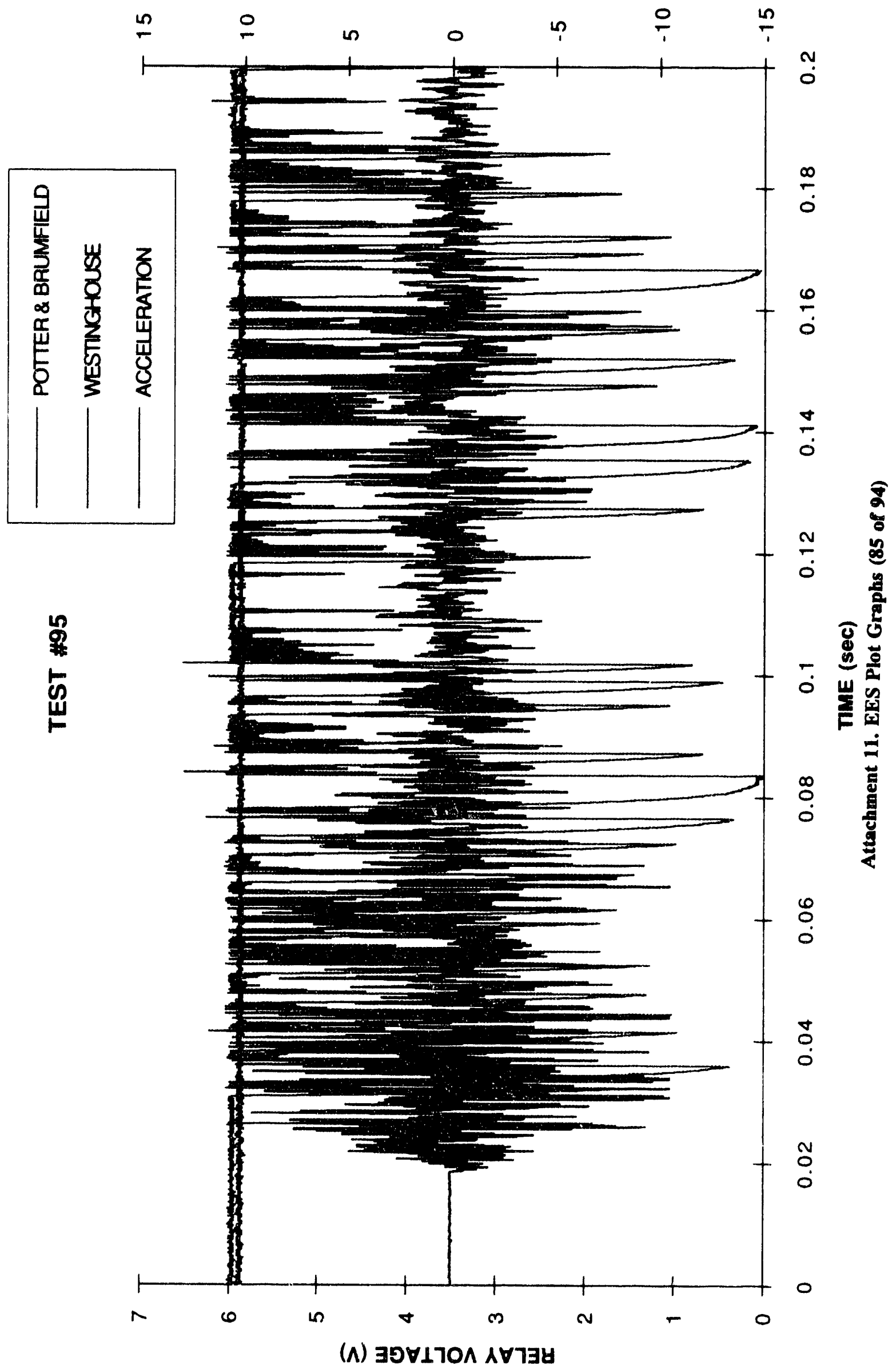




\section{(6) NOIL $\forall 4 \exists 7900 \forall$}

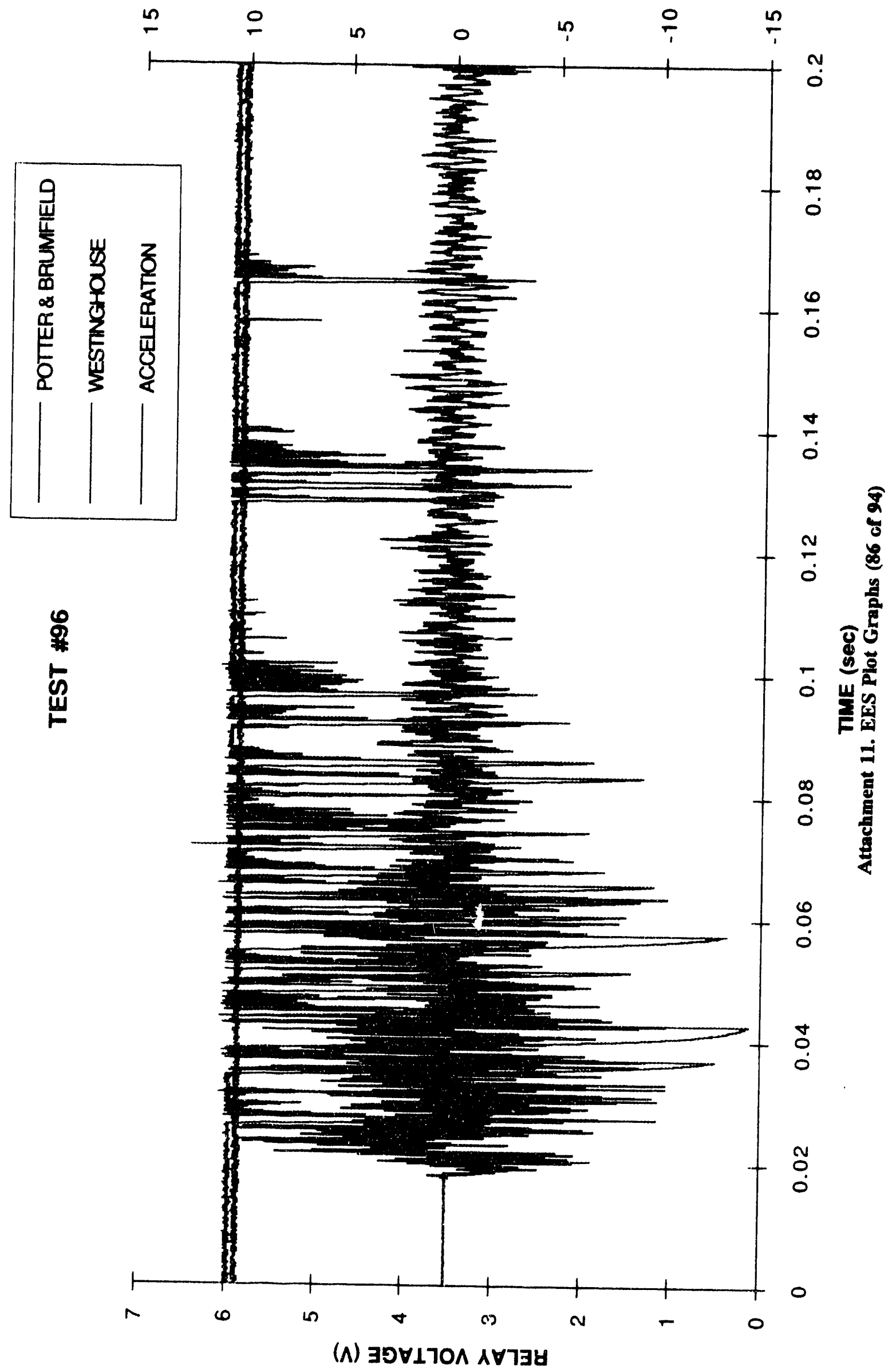


(6) NOIL $\forall 497300 \forall$
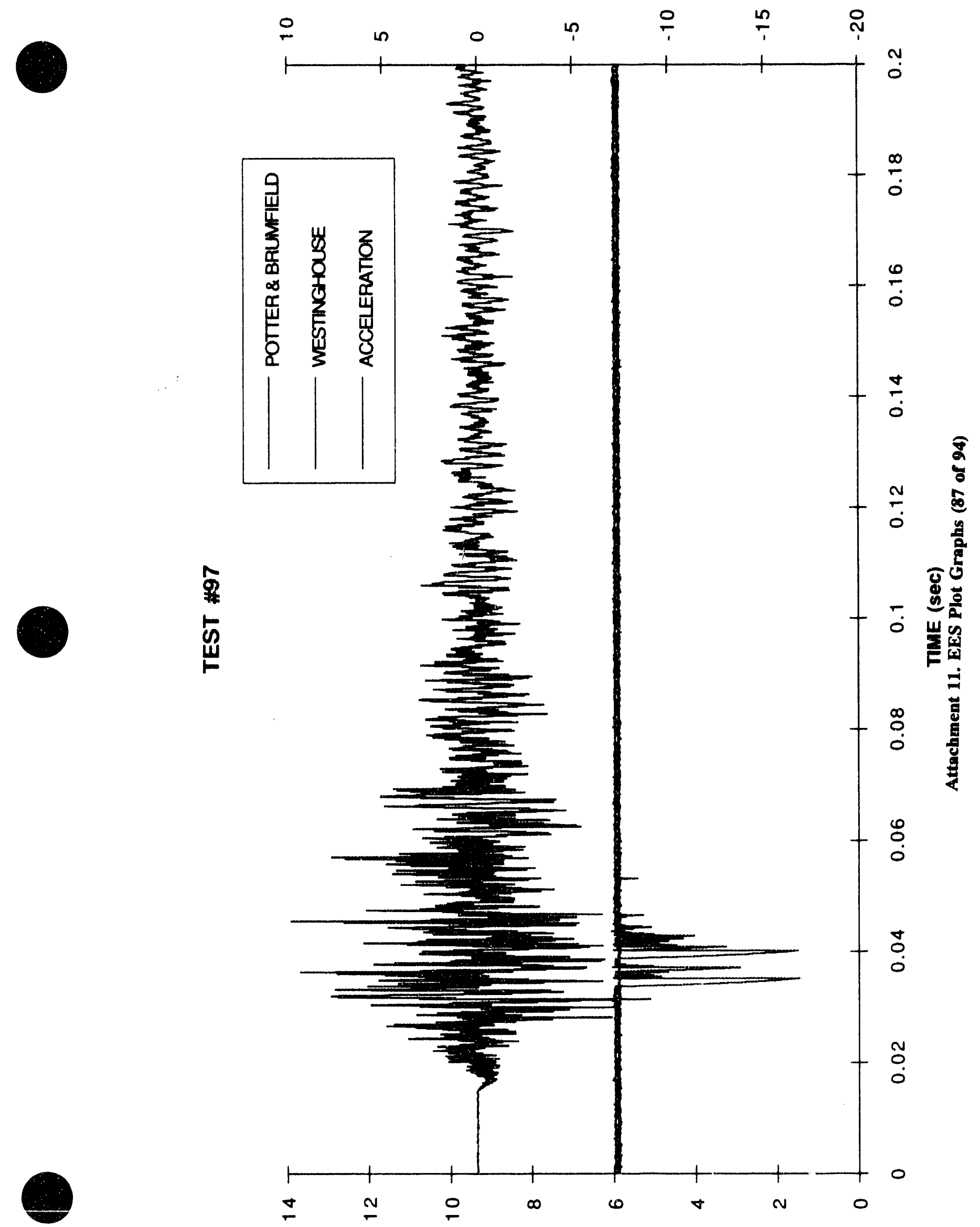

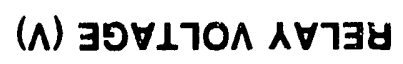




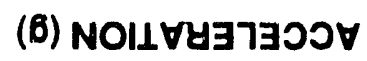

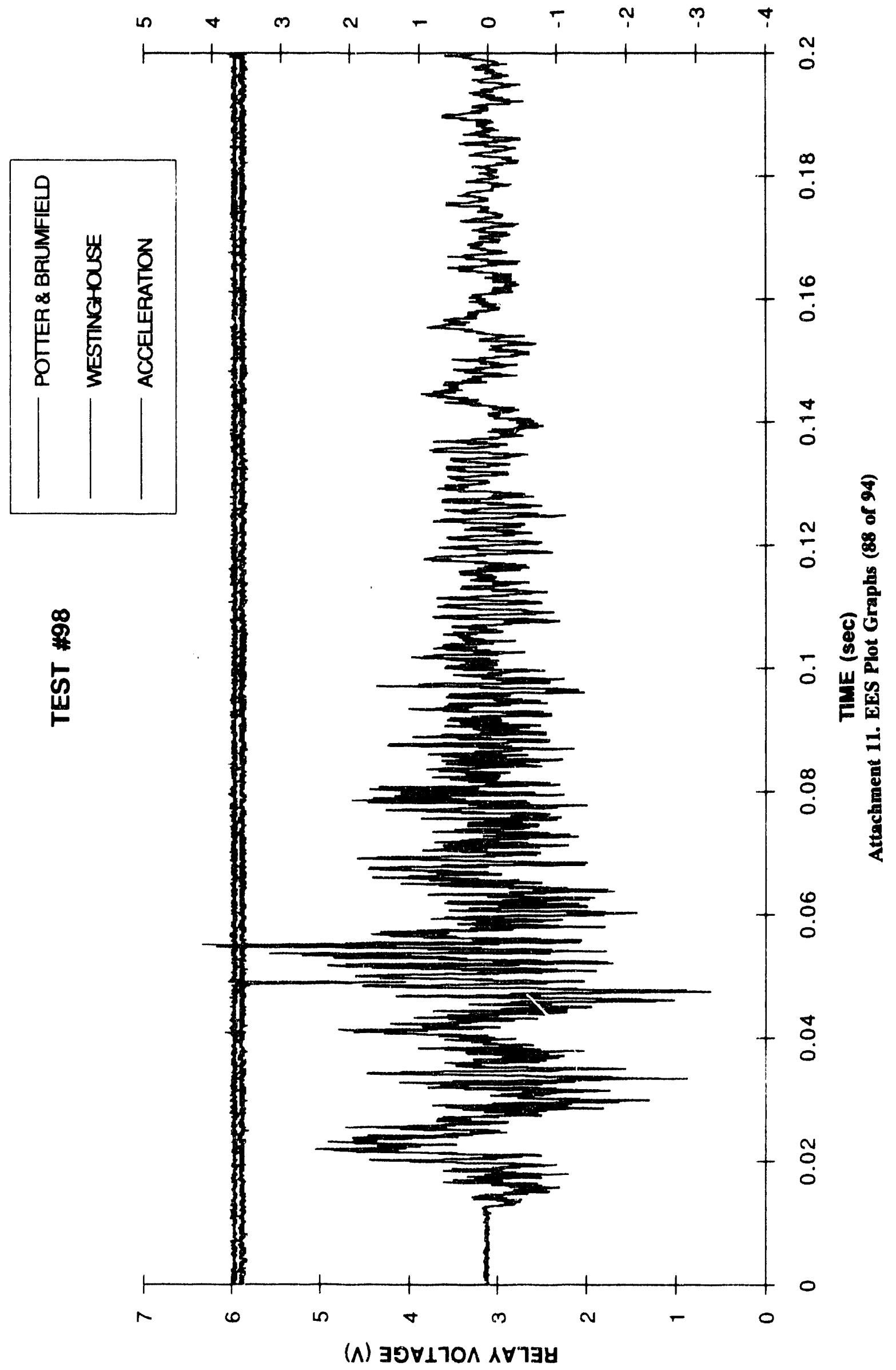




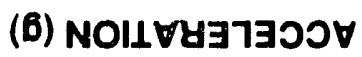

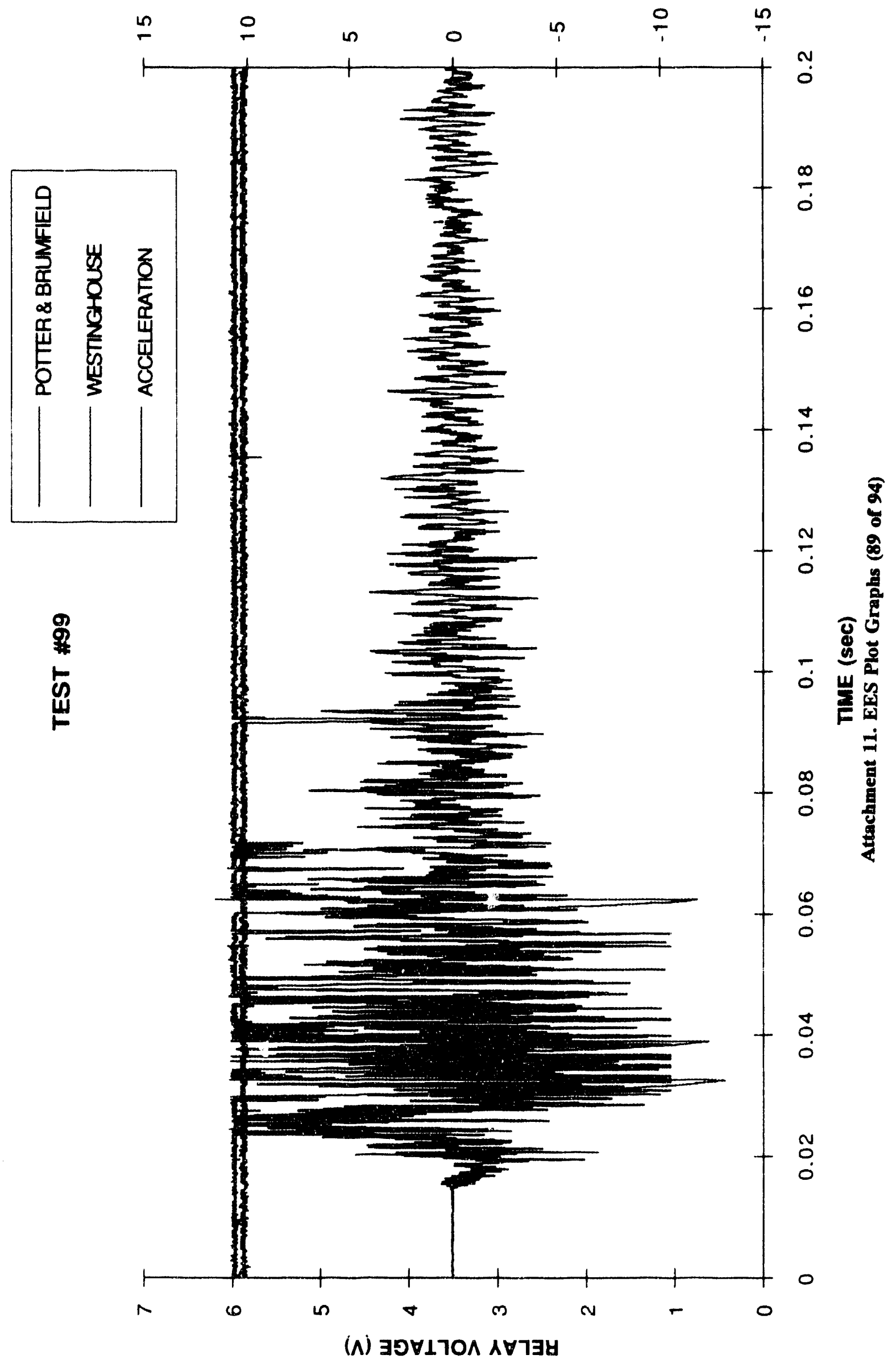




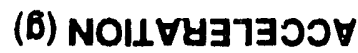

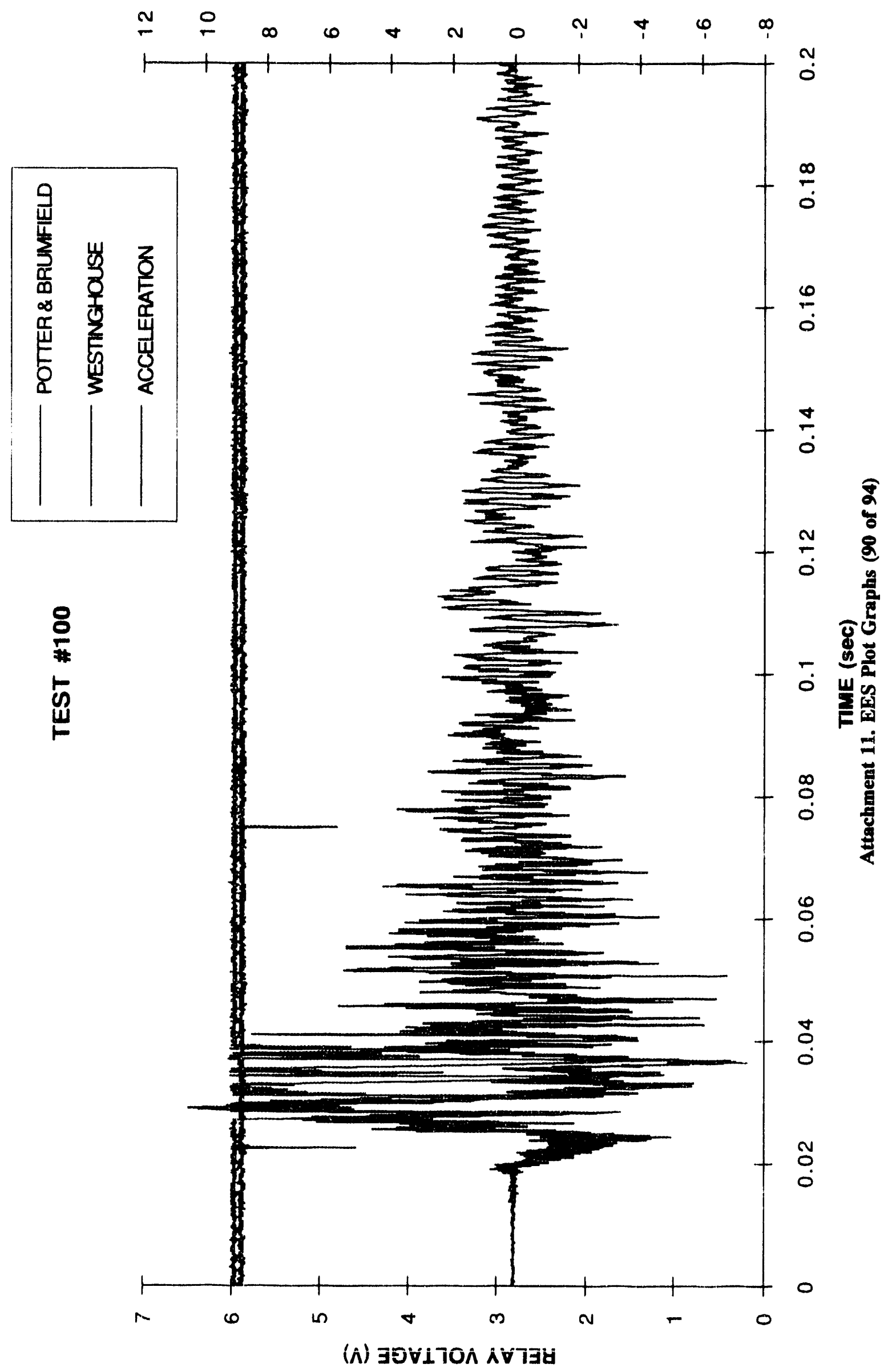


(6) NOI1 $\forall y \exists 7 \exists ว O \forall$

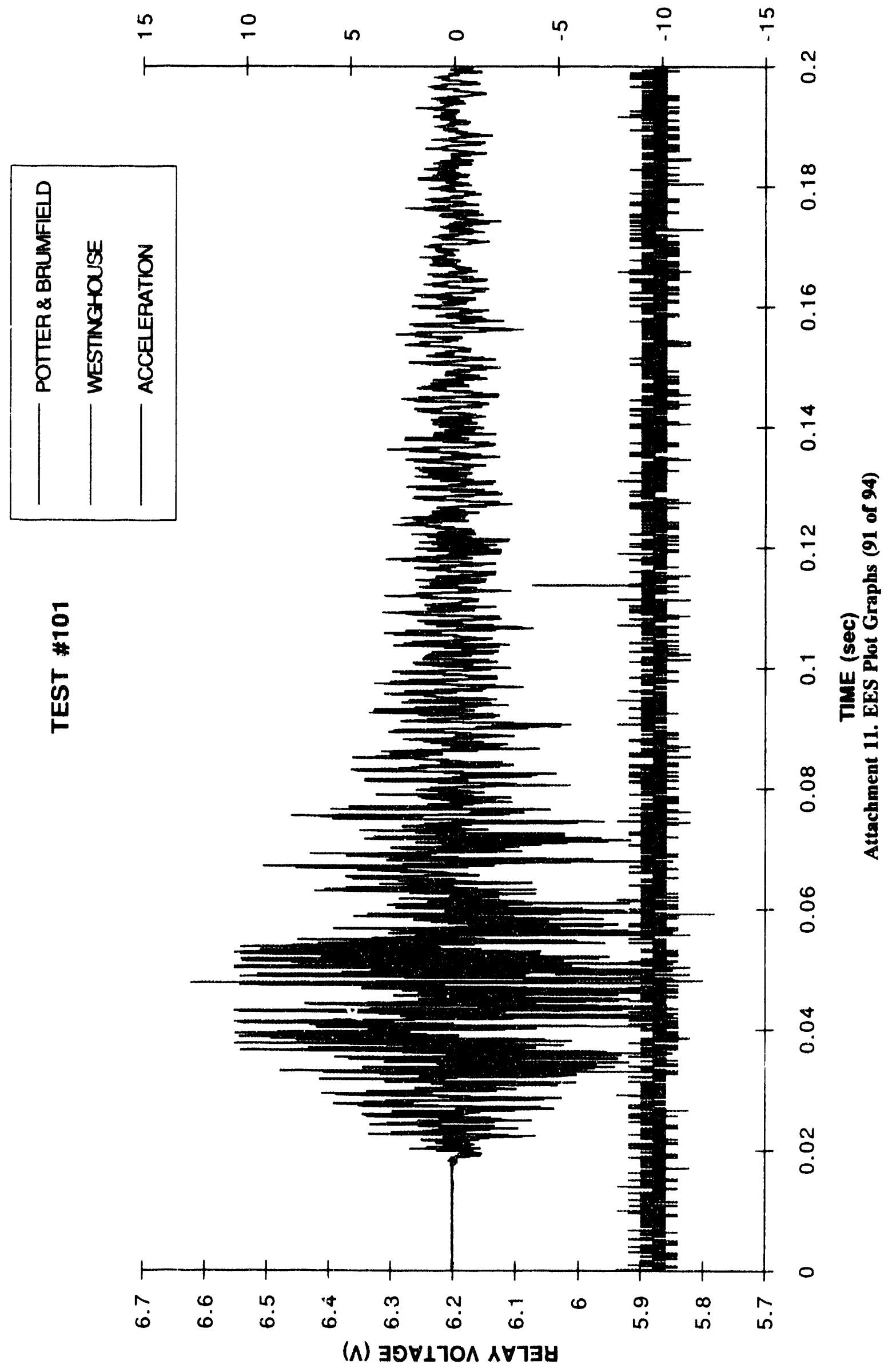


(6) NOIL $8497300 \forall$

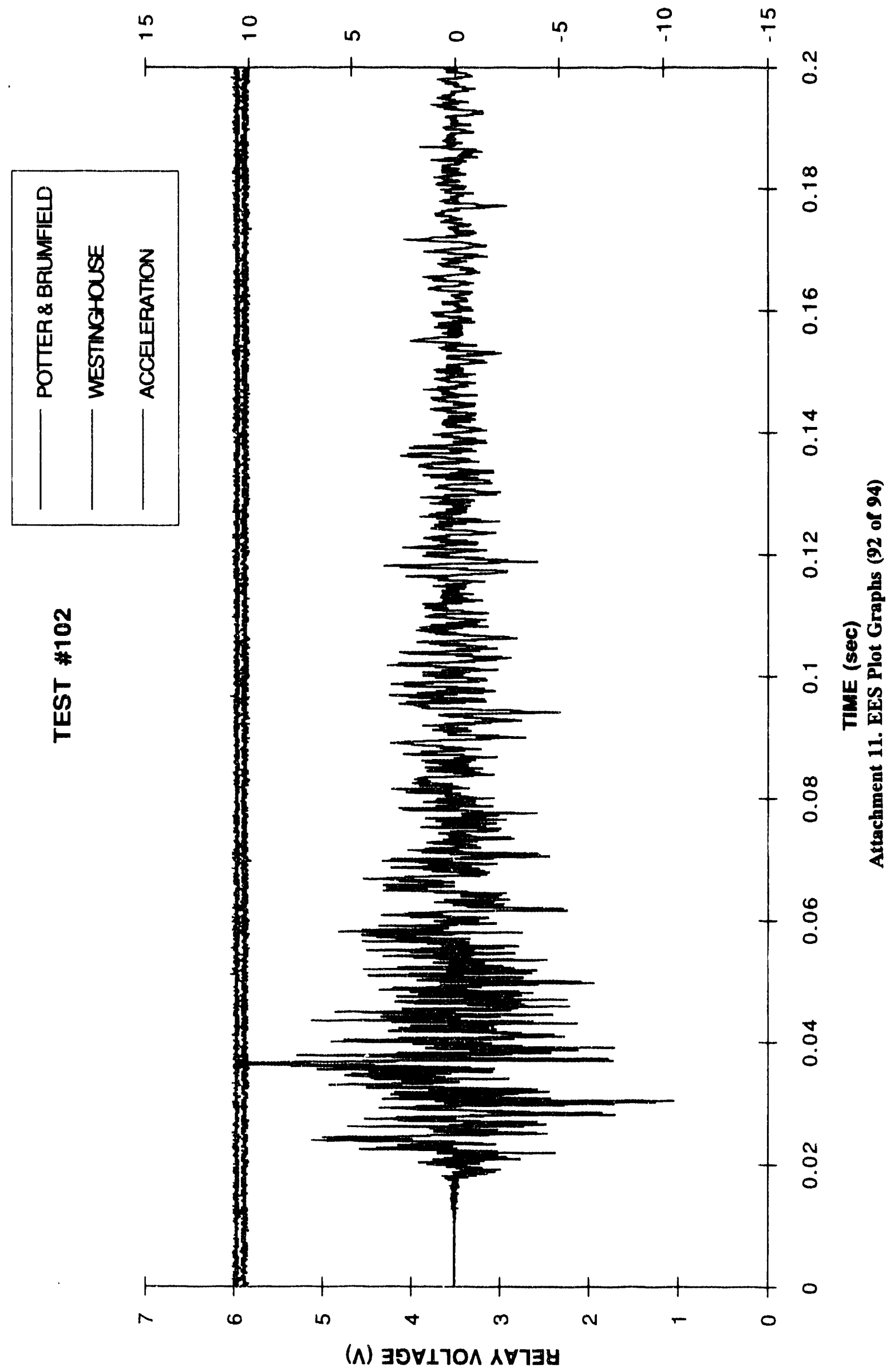




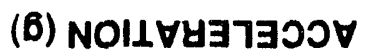

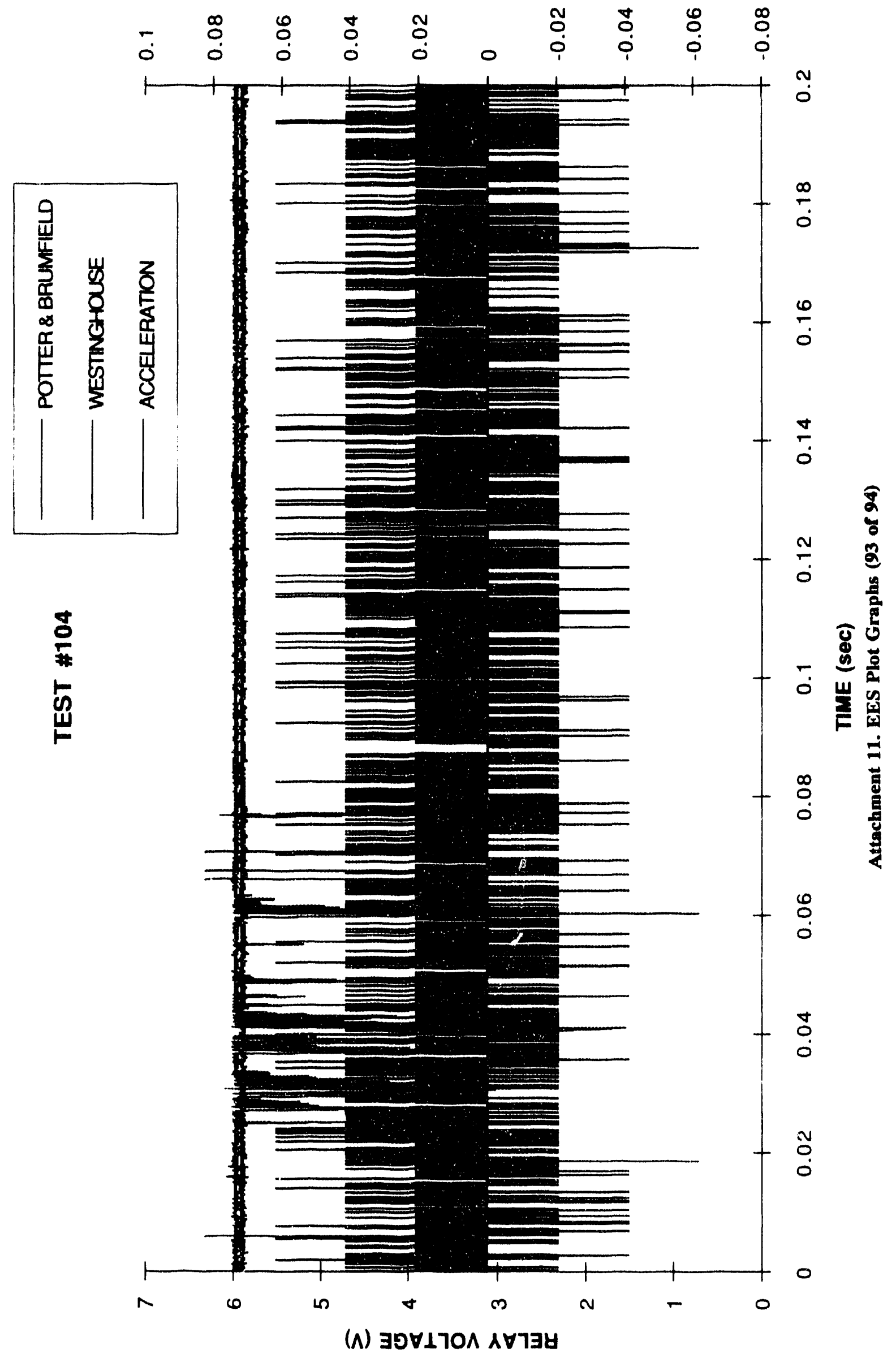




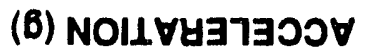

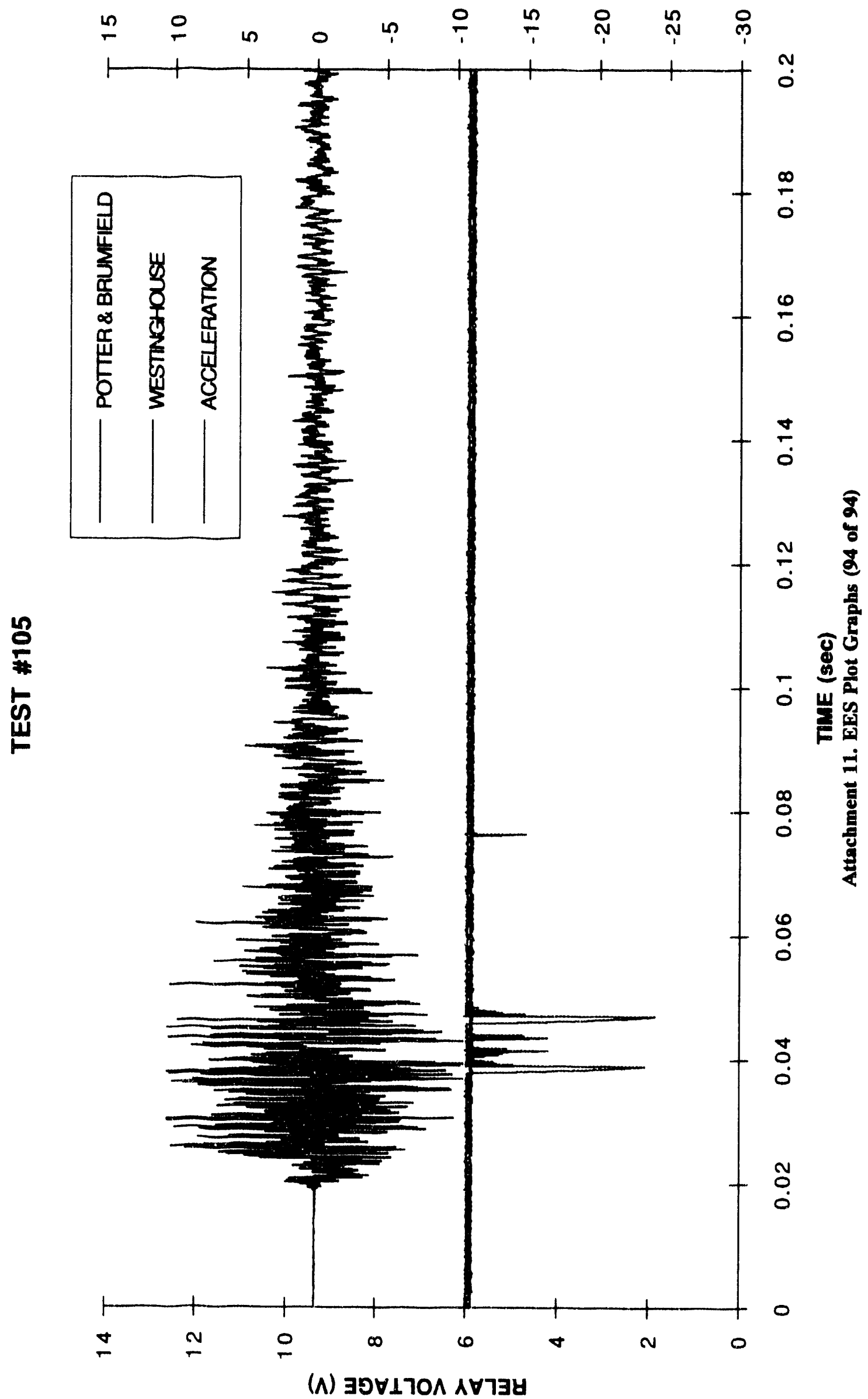



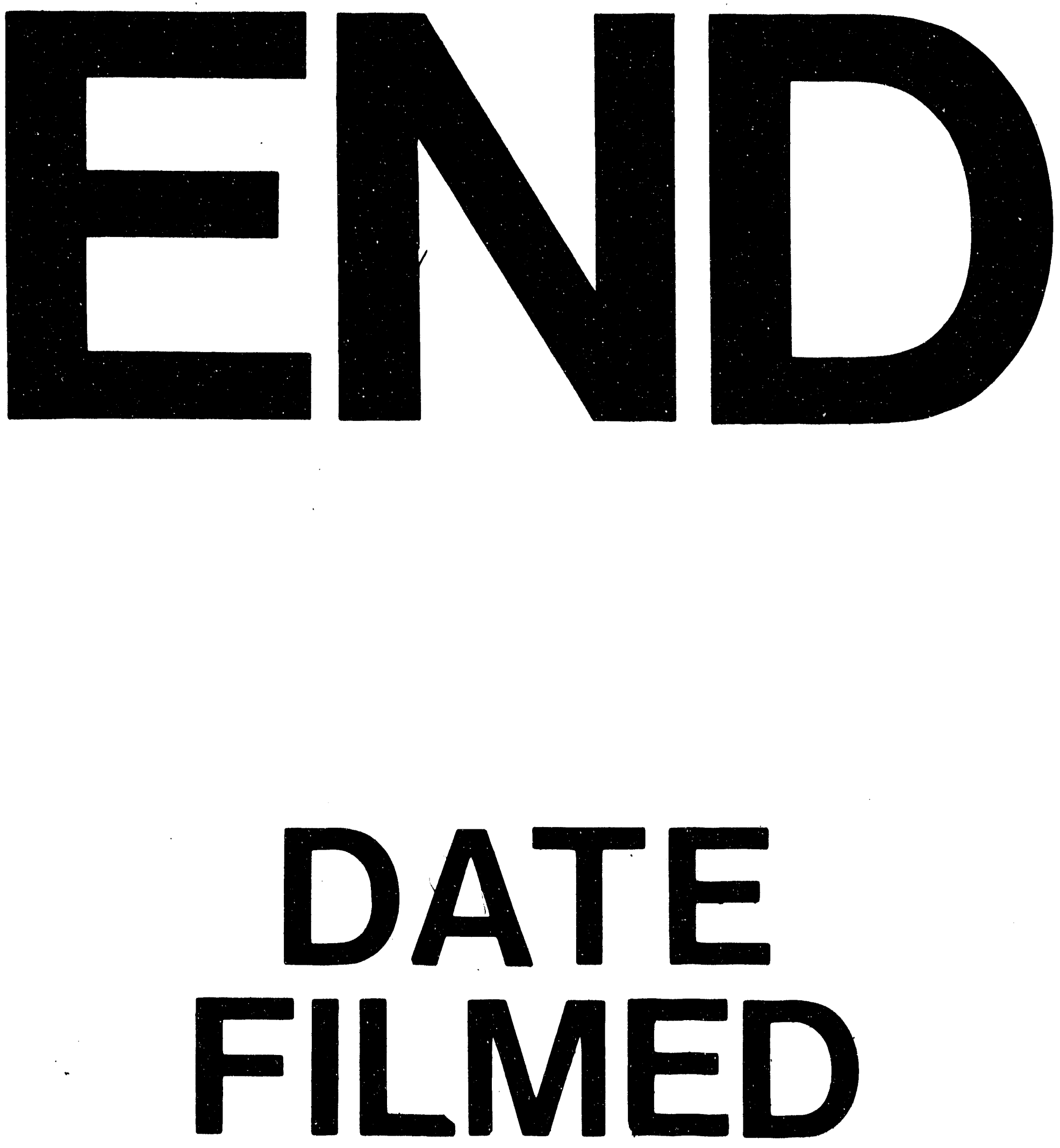

F

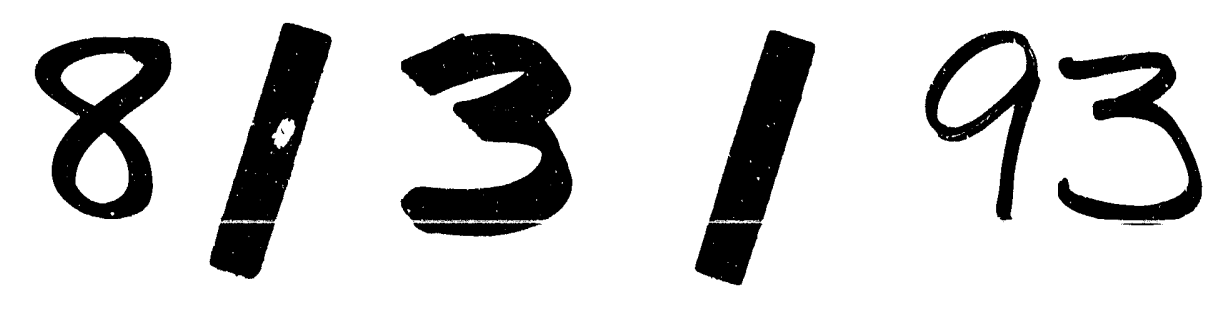


